FOR THE PEOPLE FOR EDVCATION FOR SCIENCE

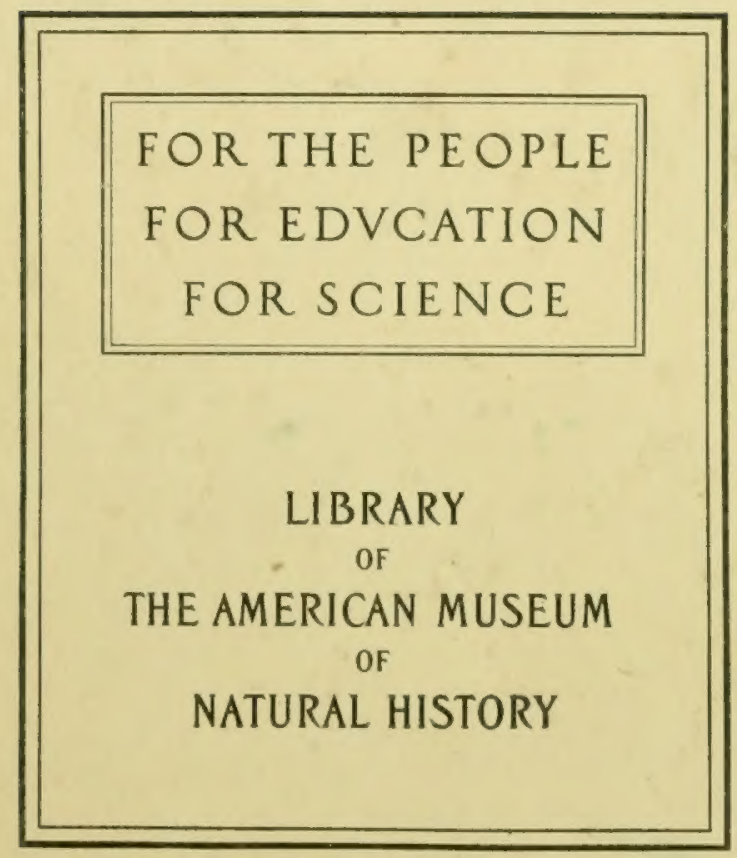




THE SNAKES OF SOUTH AFRICA 




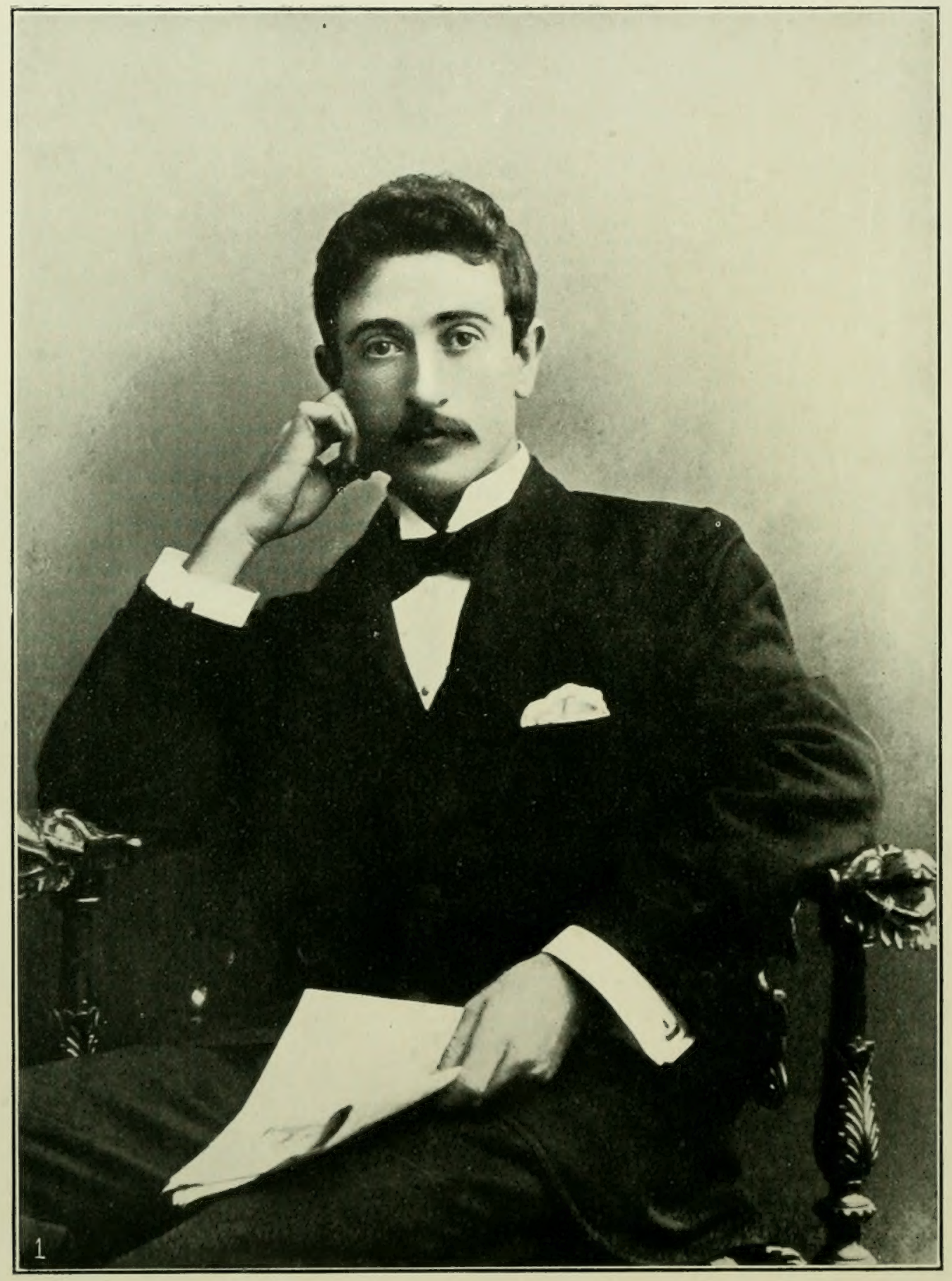

THE AUTHOR 


\section{THE SNAKES OF SOUTH AFRICA}

THEIR VENOM AND THE

T R E A T M E N T

OF SNAKE BITE

$59: 81(68)$

BY

F. W. FITZSIMONS, F.Z.S., F.R.M.S. ETC.

DIRECTOR, PORT ELIZABETH MUSEUM

NEW EDITION

T. MASKEW MILLER CAPE TOWN \& PRETORIA

LONGMANS, GREEN, AND CO.

39 PATERNOSTER ROW, LONDON

NEW YORK, BOMBAY, AND CALCUTTA

$$
\text { I } 912
$$




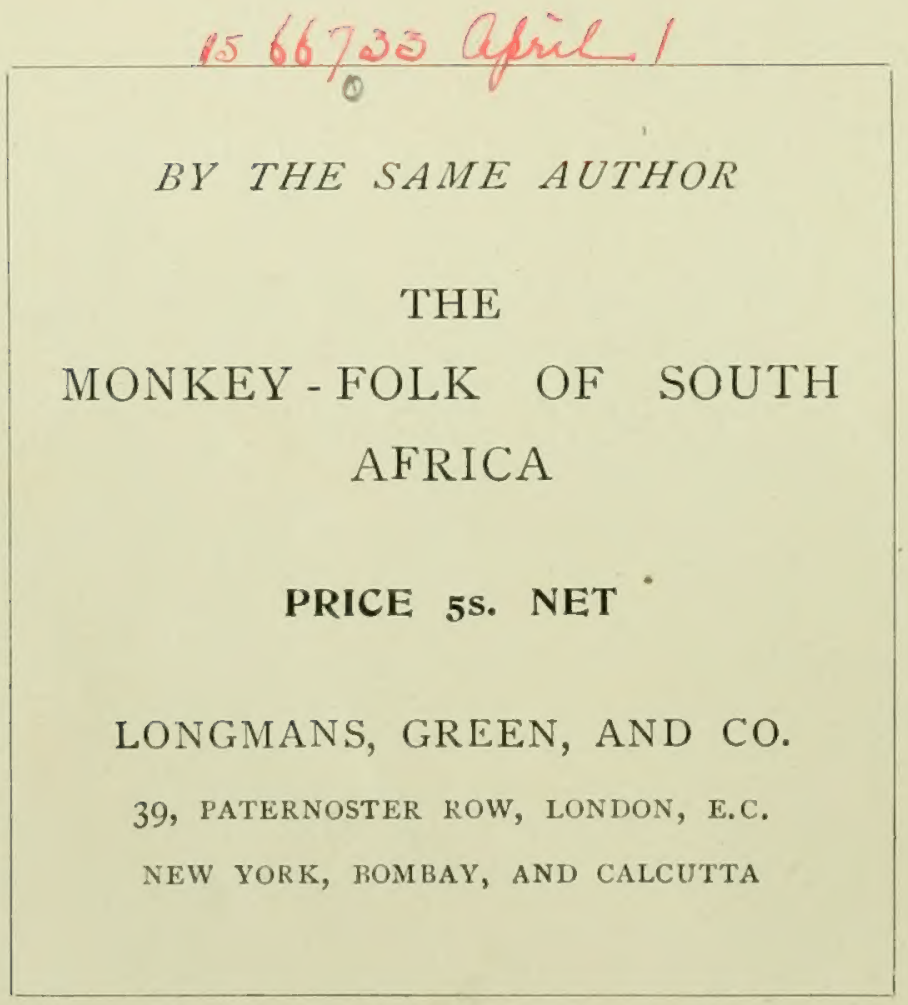

PRINTED BY WILLIAM CLOWES AND SONS, LIMITED LONDON AND BECCLES 


\section{PREFACE}

OUTSIDE the realm of science little is known about snakes, and still less of their venom. The most innocent snakes are confounded with the most venomous.

Beyond a few isolated contributions to various journals, there is no current literature on the snakes of South Africa, their venom, and the treatment of snake bite. The Kafir and Hottentot traditions and beliefs have been handed down and are accepted as facts by Colonists, hence erroneous ideas and beliefs prevail in regard to snakes, their venom, and the treatment of snake bite, and in consequence large numbers of useful lives are cut off annually-lives which, in the majority of cases, might have been saved. I have met many people who have been more or less invalided for life through the ignorant treatment applied for snake bite. A man of my acquaintance, in Rhodesia, was bitten on the hand by a venomous serpent. His friends immediately ligatured his arm in several places, poured two bottles of whisky down his throat, and then belaboured him unmercifully with sjamboks with the view of keeping him awake, the idea being that, if he were allowed to sink into a state of coma, he would die. The man was six months in hospital. His arm, owing to the long-continued application of the ligature, became gangrenous and had to be amputated. The lining membrane of his stomach was severely burned, and much of it irretrievably destroyed by the strong sprit, and to-day this man is minus his right arm, and is, moreover, an incurable dyspeptic.

Again, the scientist Fontana, nearly a hundred years ago, conclusively proved that the outward and inward use of ammonia, as well as injecting it direct into the veins, was utterly useless as a curative agent for snake bite. Yet, from that time to the present day, the belief in its antidotal power in cases of snake bite has been and is well-nigh universal. 
Here in South Africa the native population for generations past has had unquestioning faith in the antidotal effects of a substance known as zibiba. This belief is also commonly accepted among colonials. Yet this substance, when I subjected it to a careful series of experiments, was proved to be valueless as an antidote. In fact, it in no way even retarded a fatal issue.

If the results of these experiments had been contributed to a scientific publication only, this baseless belief would, perchance, not have been contradicted for many years.

The same argument holds good in regard to the Boomslang, which is a snake common all over South Africa, and which has been universally regarded as non-venomous, or only to so slight a degree as not in any way to be feared by man. If the results of the experiments which disproved this belief had been confined to a scientific journal or technical book, this popular belief would not have been dissipated.

I have not enlarged upon the experiments which I have conducted from time to time during many years past, except when calculated to serve a useful end. Many experiments were undertaken with a view of testing the accuracy or otherwise of assertions made in regard to the venom of snakes, its nature and effects.

The pioneers of investigation into the nature of snake venom were Doctors Fayrer, Brunton, and Rogers, in India; and Dr. Weir-Mitchell, in America. On the foundation laid down by these men, a number of scientists have been busily building.

There is a strong tendency among specialists in the various departments of zoology to create new species on altogether inadequate grounds. This is already leading to considerable confusion, and will result in greater chaos in the future. The slightest variation in a species seems sufficient for its separation into a sub-species or a new species, little or no effort being made to ascertain if the variation is constant.

In many lines of investigation I have found that the variations which have induced scientific men to create a new species are by no means constant. I will give one instance in point. The Simocephalus Genus of snake which was formerly represented by one species in South Africa was divided into two 
distinct species, because in one or two specimens certain head scales and the ventrals differed in shape and number. S. capensis is supposed to be distinguished by the "frontal being a little shorter than the parietals ; two postoculars ; ventrals 203-24I." Simocephalus nyasse is distinguished from the former by the "Frontal being much shorter than the perietals; a single postocular; ventrals I7I-I85."

I have found these characters are by no means constant. In some specimens the postoculars and frontal agree with $S$. capensis, while the number of ventrals agree with those of the other species, and visa versa. I have at this moment a specimen five feet two inches long before me, which has one postocular and 2 Io ventrals. The frontal is very much shorter than the parietals. It will then be noticed that while the number of ventrals indicate that it is $S$. capensis, the other characters point to it being $S$. nyassa.

This volume is the outcome of many years of practical study of the snakes of South Africa, in their haunts, in captivity, and a long series of experiments with their venom.

The majority of the illustrations are from direct photregraphs of living snakes, and specially prepared anatomical preparations.

If I should succeed in arousing an increased interest in this branch of Nature Study and in stimulating others to enlarge upon the knowledge collected, my object in writing this book will be fully attained.

Port Elizabeth Museum,

The Author. Jan., I9I2. 



\section{PREFATORY NOTE}

ONE of the great obstacles to a popular study of Natural History in a comparatively new country is the absence of books specially devoted to the forms of life one encounters. The naturalist in the older countries of Europe and in the United States, whether he be on land or by the sea, whether interested in birds, reptiles, fishes, shells or insects, has ready at hand popular works, beautifully illustrated, describing all the forms he is likely to collect. From these he readily attains the satisfaction of identifying his specimen, and then learns something of their habits and structure, and thereby becomes stimulated to further endeavour. In newer countries such knowledge, even if available, is in such a form as to be of assistance only to the specialist, not to the ordinary observer with but a general interest in the forms of life around him.

The reason for this is not far to seek. In the newer country nature students are few, pioneering work has to be done by them in the technical description of the many new forms encountered, or the trained investigator is obliged by force of circumstances or from a sense of duty to devote his abilities to the many pressing questions of practical and economic importance. The more human, cultural side of natural history comes with the maturity of a country, and flourishes only where some of its followers reach the stage of leisured reading.

The difference is strongly enforced when one endeavours to introduce the study of nature into schools. In the older countries a crowd of writers at once begin to adapt the facts of nature to the intelligence of the young and to provide the teacher with material arranged in suitable form. A school literature of natural history becomes available. In the newer countries the teacher is at once faced with the difficulty of an absence of the raw material of facts, and unless capable of supplying this from his own iraining and experience, can make no progress. Before 
much advance can be made the specialist student of Nature must have contributed his share.

It is considerations like the above which lead one to view with satisfaction the production of such a work as the present, deroted to the popularization of a group of animals familiar, unfortunately at times too familiar, to all in South Africa. For years the writer has made a special study of snakes, their habits and instincts, and has done much to popularize a rational interest in them and other groups of animals; indeed, it may truly be said that no one in South Africa has within recent years more successfully laboured to bring the facts of Nature in an attractive form before a people naturally responsive to them. It is much to be hoped that the book will succeed in stimulating a still wider and more intelligent interest in this special group of animals, and also give encouragement to the production of further works devoted to other groups These will then serve as so many means for introducing Nature knowledge to the rising generation in an attractive form, as well as for supplementing the experience already gained by those of more mature age.

Rhodes College, Grahamstown.

J. E. Duerden. Cape Colony. 


\section{NOTE.}

South Africa, in a zoological sense, is that portion of Africa south of the Zambesi and Cunene rivers. It is true that the boundary is a very artificial one, but it is convenient, and serves a good and useful purpose. Great numbers of the species of living creatures which inhabit various parts of South Africa also occur further north.

The distribution of each species of snake mentioned in this volume is given so far as it is at present known. We are constantly adding fresh localities to species of snakes. Because a snake is not recorded as occurring in any given place, it must not be assumed that it does not occur there. There are a great many portions of South Africa which remain well-nigh unexplored from a zoological point of view. Since the publication of the first edition of this volume, many new localities for snakes, and several new species, have been discovered. People who are resident in the wilder parts of South Africa can do much to further our knowledge of the distribution of South African snakes by placing collections of them in spirit and forwarding them to one of the public museums of the country. The Government permits all specimens for the museums in South Africa to be carried free by rail or post.

The nomenclature in this volume is according to the catalogue of snakes in the British Museum, compiled by that wellknown authority G. A. Boulenger.

It is also from this source I obtained the scientific descriptions of the Genera and Species which are, in the majority of cases, copied verbatim.

In giving the lengths of the various species of snakes, a general average of those measured has been taken. It is not claimed that the measurements given are the maximum lengths attainable by any of the South African snakes. Snakes of the same 
species differ materially in coloration and length in the different parts of South Africa, especially so where climatic and other conditions are largely dissimilar.

The first edition of this book was hurriedly written up from my notes, at a time when I was busy also with many departments of other work, and for that reason I crave the indulgence of critics for a necessarily immature product.

But this first edition has now been carefully revised, extensively altered, and enlarged, and the results of later experiments and experiences added, as well as a considerable number of illustrations of value.

The Author and Publisher wish to acknowledge gratefully their obligations to the following: The British Museum (Natural History), Authorities for the use of blocks from the British Museum, Catalogue of Snakes, also for Mr. Boulenger's classification of Snakes from the same source; Messrs. Blackie for the use of certain illustrations from their Physiology; Sir Ray Lankester and Messrs. Constable and Company, Ltd., London ; Messrs. F. W. Warne \& Co., for kindly allowing the use of illustrations from their "Royal Natural History"; Messrs. Funk \& Wagnall for diagrams; Messrs. Harmsworth; Prof. Seeley for his pictures "Dragons of the Air"; Messrs. Harmsworth, for illustrations from their "Natural History," and "Children's Encyclopædia." 


\section{CONTENTS.}

\section{CHAPTER I.}

PAGE

Classification and Evolution of Snakes .

- $I-I I$

CHAPTER II.

History, Distribution, and General Habits of Snakes . I2-49

\section{CHAPTER III.}

The Blind Burrowing Snakes (Typhlops and Glanconia). List of the South African species, habits, colouration, average length, and distribution. The South African Pythons, their life history, description, and various anecdotes . . . . . 50-79

\section{CHAPTER IV.}

The Aglypha, or Solid-toothed non-venomous snakes. List of the South African species, their habits, colouration, average length and distribution . . . . . . . . 80-II4

\section{CHAPTER V.}

Opisthoglypha or Back-fanged snakes, all of which are venomous. These snakes are in the transition stage of fang and poison gland development. List of the South African species, habits, colouration, average length and distribution

\section{CHAPTER VI.}

The Proteroglypha or Front-fanged typically venomous snakes of the Hydrophinæ and Elapinæ Sub-families, viz. the Sea Snakes, Cobras, Mambas, Coral Snakes, Garter Snakes, etc. List of the South African species, habits, colouration, average length and distribution

\section{CHAPTER VII.}

The Solenoglypha section of the Proteroglypha or Front-fanged venomous snakes, viz. the Adders and Vipers-Family Viperide. List of the South African species, their habits, colouration, average length and distribution 


\section{CHAPTER VIII.}

Snake Charmers. A Port Elizabeth Snake Catcher. Can snakes fascinate their prey? What really happens. Heroism of birds. Wrong conclusions. Captive snakes and birds. Paralyzed with fear. Hypnotism. Advice to Campers Out. Horse hair ropes. Snakes and their mates. Catching live snakes. How to collect and preserve snakes. Kafir superstitions. An exciting incident. Feeding snakes on live animals . . $\quad 246-282$

CHAPTER IX.

\section{Human Physiology.}

The brain and nervous system. The blood and how it is made. The science of health. A self-acting pump. Elixir of life. How we poison our blood. White corpuscles that eat up disease microbes. The Lymph and Lymphatics. How venom gets into the blood . . . . . . 283-308

\section{CHAPTER $\mathrm{X}$. \\ Alleged Snake Bite Cures.}

Results of experiments with a large number of so-called antidotes $30 y-34 \mathrm{I}$

\section{CHAPTER XI.}

Poison apparatus of snakes. Snake venom, its nature and effects $342-38$ I

\section{CHAPTER XII.}

The Scientific treatment of snake bite. Permanganate of Potash.

Results of Experiments. Serum Treatment . . . 382-437

CHAPTER XIII.

Latest Systematic List of South African Snakes for the use of Museum Curators and Scientific Students. By Dr. G. A. Boulenger, F.R.S., V.P.Z.S., of the British Museum . • 439-460

CHAPTER XIV.

Items of Snake Knowledge. Miscellancous Information . $4^{6 I-478}$ 


\section{ADDENDA.}

FIG.

A. Experiments at the Government Veterinary Research

Laboratories, Pretoria . . . . . . . $48 \mathrm{I}$

B. Venom of the Schaapsteker . . . . . . 484

C. More about Ringhals . . . . . . . . 488

D. A Boomslang Bite . . . . . . . . 490

E. The Isolation of Madagascar and Australia • • . 492

F. Potency of Mamba Venom . . . . . . . 494

G. Anaphylaxis . . . . . . . . . . 497

H. Intravenous versus Subcutaneous Injection of Serum · 500

I. The Saline Solution. An Emergency Measure • • 502

J. Injecting Ammonia for Snake Bite . . . . . 504

K. Why do Snakes' Fangs Differ in Length? Experiments . 505

L. Items of SNake KNowledge . . . . . . 510

\section{ILLUSTRATIONS IN ADDENDA.}
A. Python .
B. Boomslangs in cage at Port Elizabeth Museum
482
C. Schaapsteker's head and fangs
D. A handful of Schaapstekers
E. Homalosoma snake and young
485
- 488
F. Ringhals Cobra shamming death . . . . . . 495
G. Ringhals Cobra with hood expanded and contracted . . . 498
H. Ringhals Cobra rearing, showing side and back view . . 50r
I. Boomslang inflating its throat . . . . . 503
J. ". with body inflated . . . . . . 505
II. . and its eggs . . . . . . . 507
L. " showing close view of inflated neck and body . . 5II
M. Egg-eating snake and eggs . . . . . . . 5I4 
FIG.

N. Herald or Red-lipped snake after swallowing a large toad .

O. Ringhals Cobra with eggs

P. Feeding a Puff Adder with meat . . . . . . 5I7

Q. A remarkable Cape Cobra . . . . . . . 5 I8

R. A young Cape Cobra, showing dark throat patch . . . 5 I9

S. Claws and bones of the rudimentary hind legs of pythons . . 520

T. (I) Olive-black House snake . . . . . . . 52 I

T. (2) Ditto . . . . . . . . . . 522

U. Puff Adder in act of striking . . . . . . 523

V. Blind Burrowing snake . . . . . . 524

IW. Snipping off the fangs of a Puff Adder . . . . $\quad 525$

X. Skulls of snakes . . . . . . . . 526

Y. (I) Collecting venom from a Puff Adder . . . . . 527

Y. (2) ditto . . . . . . . 528

Y. (3) ditto . . . . . . . . 529

Y. (4) Feeding a Puff Adder . . . . . . . 530

Y. (5) A cannibal Puff Adder . . . . . . . 53 I

Z. Catching snakes on the veld . . . . . 532 


\section{THE}

\section{SNAKES OF SOUTH AFRICA.}

\section{CHAPTER I.}

\section{Classification.}

SNAKES belong to the great class of living creatures known as reptiles, which include all the living orders of crocodiles, turtles, tortoises, and lizards. The frog and salamander orders are, generally speaking, also reptiles, but owing to certain important differences in their anatomy they are separated into a class called Amphibia, from the Greek word Amphibios, which means "leading a double life," because these creatures live both on land and in water.

All living creatures are classified in to classes, orders, sub-orders, genera, and species, according to their anatomy. All creatures of the same species are practically identical, not only in their anatomy, but also in their colouration and habits. If a species, owing to various circumstances, such as a difference in food, climate, the presence or absence of enemies, etc., should become slightly modified in colouration or structure, we term it a variety, or sub-species. For instance, our well-known Bushbuck (Trage. laphus) has been divided into several sub-species, because it is found to differ slightly in colour and shape in the various districts of South Africa.

The Boomslangs, or Tree Snakes (Dispholidus), are in every case anatomically similar, but differ considerably in their colouration, even in the same districts. They are separated into six varieties, so in describing them we refer to them as variety $A$, variety $B$, and so on. 


\section{What Classification MEANS.}

To give a clearer idea of what we mean by classification, we will take the Boomslang or Tree Snake as an example. We will assume it is the first time I have seen or heard of a Boomslang. I know at a glance it belongs to the Oplitilia or snake order. I examine its teeth and discover it possesses a set of grooved teeth longer than the rest, set a good way back in the upper jaw, therefore I know it belongs to the division of snakes known as the Opisthoglypha, which means snakes with hind fangs. Then I count the number of the upper and lower teeth and note the shape and number of the shields on the head, and reckon the number of rows of scales round the body. After examining the shape of the head and body, its colouration, etc., I identify it and classify it as follows :-

ORDER: Ophidia.

Division: Opisthoglypha.

FAMILY: Colubrida.

Sub-FAMILY: Dipsadomorphine.

Genus: Dispholidus.

Species : Dispholidus typus.

Common name: Boomslang or Tree Snake.

Distribution: Tropical and South Africa.

When any new thing, whether a microbe or a large creature, is discovered, it is carefully examined and classified immediately. Without this system of classification it would be impossible to make any progress in science. In every department of human activity, classification is necessary. If you went into a museum and wanted to find a certain flesh-eating animal-a Leopard or a Mungoose, for instance-you would not look for it among the hoofed animals or the fishes. You would expect to find it among the group of creatures classified as Carnivora.

A synonym in natural history means a scientific name, as of a genus or a species, superseded or discarded, as by the law of priority.

When any new creature is discovered, it is given a scientific name, and recorded.

The latest recognized scientific name for the Boomslang is Dispholidus typus, but in 1832 it was known as Dispholidus lalandii; in I837, as Dendrophis colubrina; in I84I, as 
Bucephalus capensis ; in I849, as Dendrophis pseudodipsas ; and Dispholidus typus is the name by which it is now known. The others are synonyms.

\section{The Evolution of Birds.}

The birds of the present day do not seem to have anything in common with reptiles, and it would seem absurd to think they have evolved from such dissimilar creatures. However, it is generally believed that their remote ancestors were reptiles, because men of science have found the fossil remains of birds in various strata of rocks, which show them in the transition stages, half reptile and half bird. So close is the relationship between reptiles and birds that the late Professor Huxley says, "Birds can be aptly termed modified reptiles."

Snakes can therefore claim relationship with our beautiful feathered friends.

It would seem, that, many millions of years ago, some kinds of reptiles, owing doubtless to changes in their surroundings which made it difficult to procure a sufficiency of food, and being beset by enemies, were modified in their structure according to the great law which Darwin called the "Law of the Survival of the Fittest." As the long ages rolled past, these reptiles slowly but surely evolved into birds with feathers. Everything upon this earth seems to be subject to a great law of the Creator, which we term evolution. Even in the study of the science of Astronomy we find this great law at work. In everything upon this little speck we call Earth, as well as in the mighty Universe, it is quite apparent there is an intelligent, all-powerful Force or Will at the back, that great mysterious power-God the Creator. It is not for us to lay down dogmatically and ignorantly the law as to how the mighty Creator should or should not create what we see around us here, and in the heavens, by means of our physical senses.

\section{Evolution of Reptiles.}

Reptiles came into existence upon this earth long ages before the birds and mammals, which are both highly-evolved creatures, warm-blooded and possessing more highly specialized organs, 
nervous systems and brains than the reptiles. In the very early strata of sedimentary rocks, dating back millions of years ago, and known in science as the Ordovician System, we find the fossil remains of very low forms of backboneless creatures, such as worms, jelly-fish, molluscs, etc. Then, as we ascend into the strata of rocks known as the Silurian System, we find more highly-evolved creatures, such as fish without bony backbones,

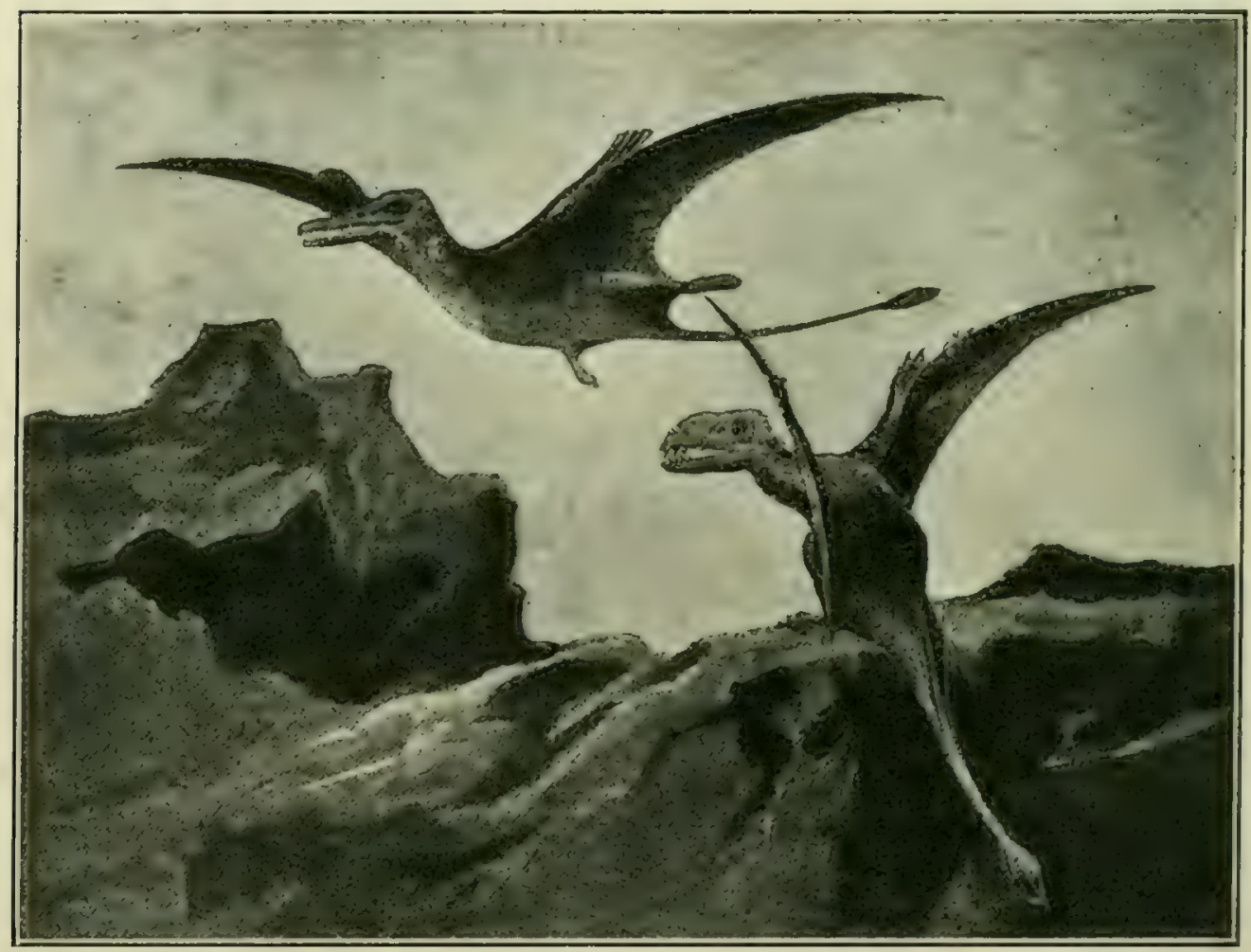

Fig. 1.-These are Flying Reptiles-the ancestors of birds. They lived millions of years ago. Their fossil remains have been found preserved in the oolitic rocks. Some of them measured I 8 feet across the expanded wings. (From "Extinct Animals" by Sir Ray Lankester. Messrs. Constable \& Co., London.)

or backbones composed of cartilaginous matter. These are known as the Silurian fishes, of which our present-day Shark Family is an example.

As we slowly ascend we find the fishes gradually becoming more highly developed or specialized; and when we reach what is known as the Devonian System, or, in other words, the time in the earth's history many millions of years ago when the old Red Sandstone was deposited as sediment and formed into hard rock, we discover the higher order of scaled fishes with real true backbones of hard bony matter. These were the first to evolve into what we term vertebrata, i.e. forms of life with backbones. 
Their ancestors were backboneless, but were slowly evolving a bony structure. We find, too, in the Silurian period already referred to that the creatures we call Silurian fish abounded, and that these fish were the link between the true mailed or scaled fishes with backbones and their more remote ancestors of the Ordovician Epoch.

Later we find some of the denizens of the ocean beginning to take to land and developing reptile characteristics, and throughout that vast period of time, known as the Carboniferous Period, when what is now coal was living vegetation upon the surface of the Earth, the reptiles were slowly but surely evolving from Amphibians to true reptiles of a higher order. When we come to the Mesozoic Period we find fossil remains in more or less profusion of great dragon-like reptiles, some of which were nearly a hundred feet long. These fossil remains have been put together, and are now to be seen in some of the great museums in Europe and America.

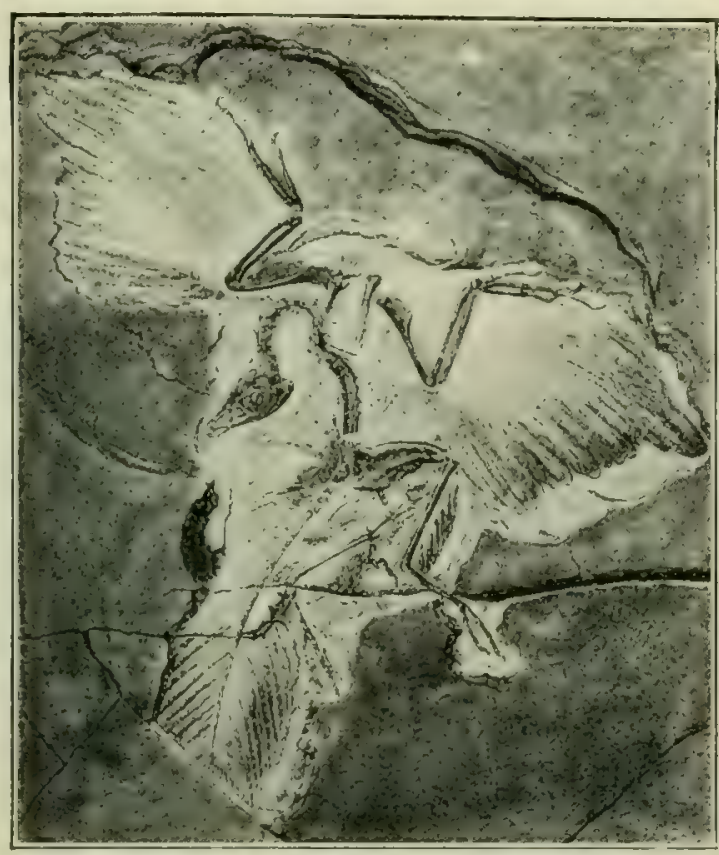

Fic. 2.-The fossil remains of a real bird known as the Lizard-tailed bird or Archaopieryx. It was found in the Solenhofen limestone of Bavaria. This strata of rock dates back to the Jurassic Period. This means that this bird lived on the surface of the world millions of years ago. This is a more recent creature than the Flying Reptiles, having doubtless evolved from them. The Archcopteryx was feathered. The backbone, however, does not terminate at the root of the tail like the birds of to-day, but extends the entire length, the feathers jutting out at the sides. From specimen in Berlin Museum.

As we ascend to the Mesozoic Period into the Tertiary Period, we find these great reptilian creatures showing signs of change and becoming more like true mammals in shape. During this Epoch we find the first fossil remains of true mammals, viz. the Ariinoitherium, Dinoceras, Tetrabelodon, Three-toed Horse, and others. Ascending higher into the most recent strata known as the Pliocene, we find the fossil remains of such animals as the Mastodon, Woolly Rhinoceros, Irish Deer, Giant Sloth, and Mammoth, the immediate descendants of which are now living upon 
the surface of our Earth. As the ages roll on many of the species of animals now living will in turn become extinct; some of their remains will be covered up and serve as evidence to future races of men. These creatures will, however, not be replaced by higher

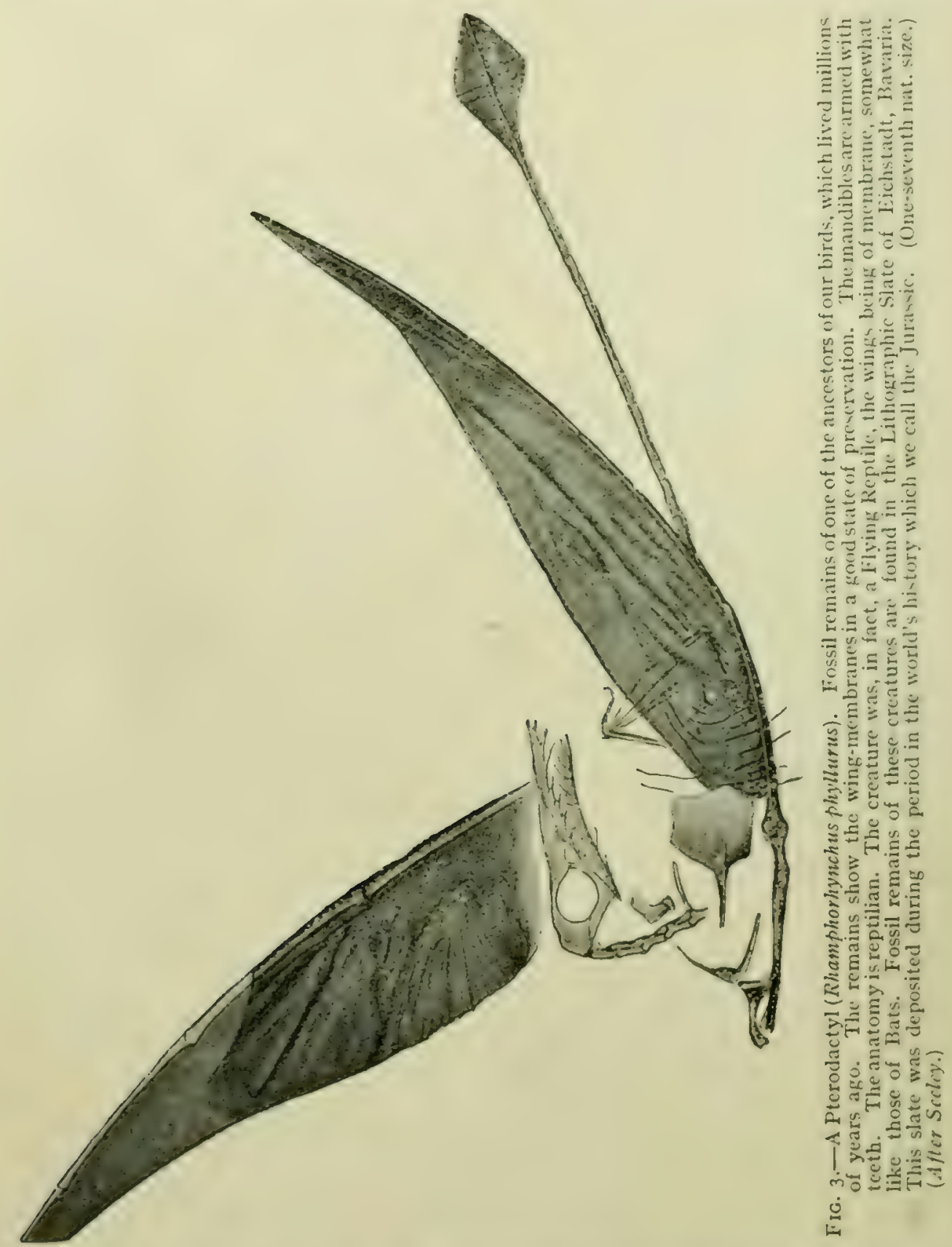

forms of their kind, for man will eventually overrun the whole of the habitable earth, and all of the large fauna will either become extinct or be domesticated for man's use or pleasure. 
EVOLUTION OF REPTILES.

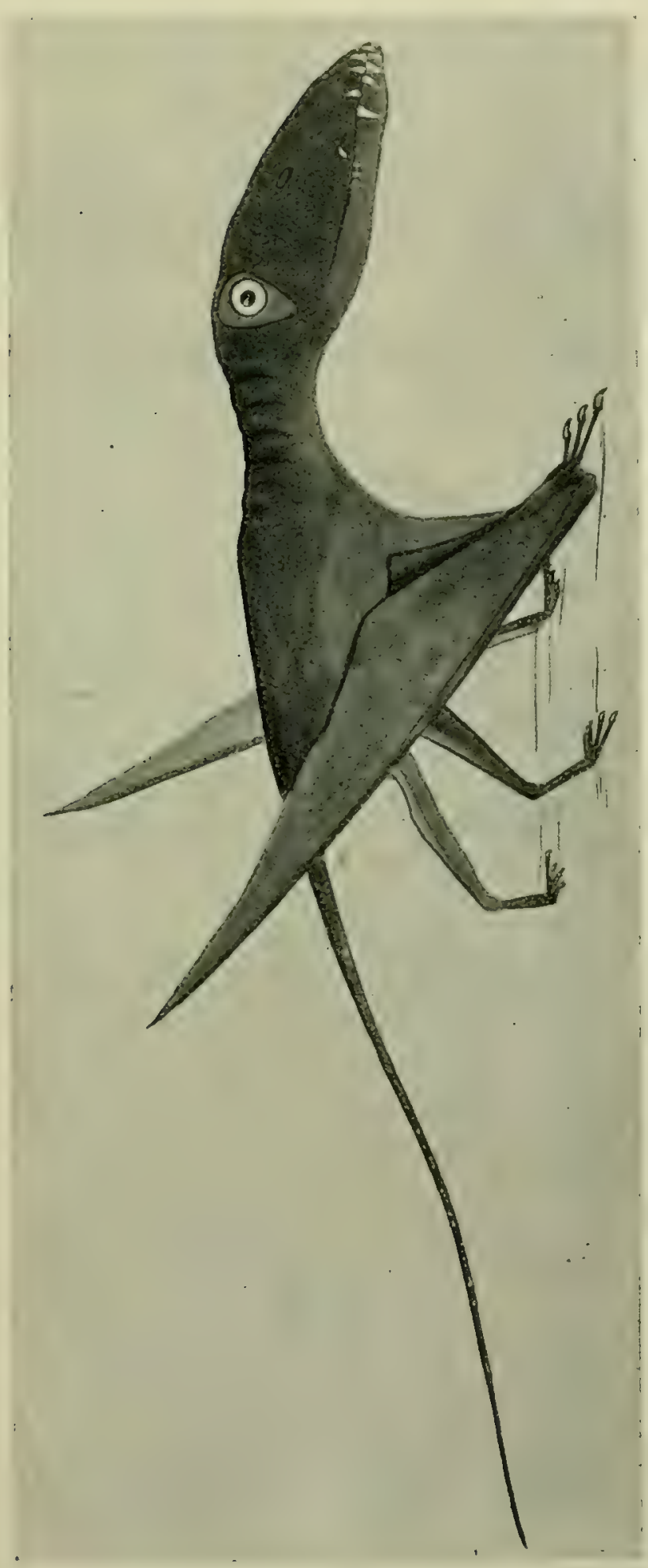

啳苛

寻色 $m$

ำ ํํำ

중

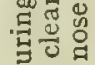

뭉

ह

\&

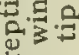

政

进

됸

$\therefore \stackrel{\circ}{\circ}$

잉

뭉.

도웛

in

은

ज峣

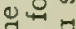

फ़्य

명형

สํำ

동

出出满

过

bo 류

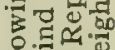

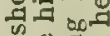

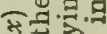

究。死嵌

눈

प्ठृ क

हुํํ

ชี त

政

tक्.

는

수을

\& 800

.

过

舟

过定

포 잉

$<$ वृ

|

迥 
8

THE SNAKES OF SOUTH AFRICA.

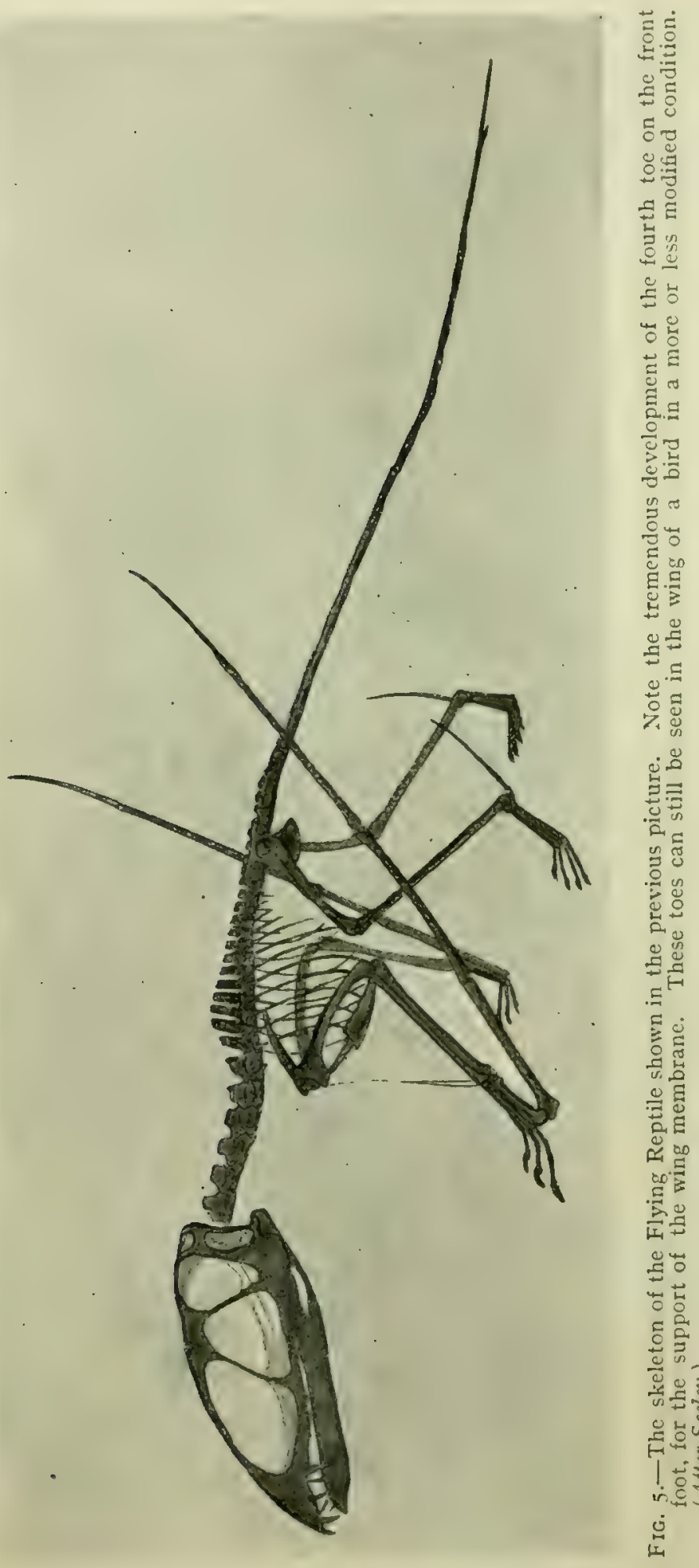


Relative Lengths of Epochs.

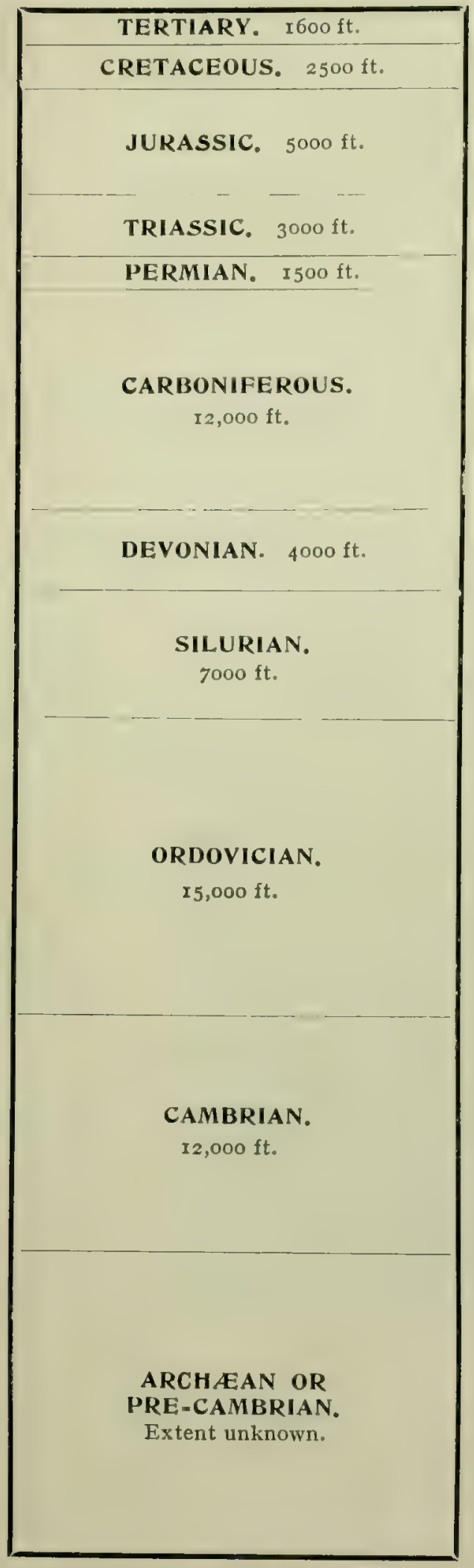

PLATE II. This diagram gives a rough jdea of the crust of the earth. The section named Pre-Cambrian is partly composed of the igneous fire-formed rocks. This is the base or bottom strata. Below this is whitehot liquid lava.

The Cambrian is stratified rock. It was formed after the earth was cool enough for the gases in the air to condense and fall as water on the earth. This water formed the oceans. Stratified, or in other words Sedimentary Rocks, are made by Sand, Silt, Ooze, etc., falling to the bottoms of oceans, lakes, and rivers. In this Cambrian formation we find the first forms of organic life, such as the very lowest types of ocean creatures There is no trace of vegetation, fish, reptile, bird, or animal life.

As we enter the Ordovician, we find fossil remains of Marine Scorpions, Crabs, and other Crustaceans, but no fish or land life.

Proceeding to the Silurian, we come across traces of higher forms of ocean life, such as the Silurian Fishes. As we emerge into the Devonian we discover fossil remains in abundance of the higher scaled fishes, with true backbones and hard skeletons. Still proceeding upward, we enter the great Carboniferous Period. It was during this Epoch that the surface of the land was covered with a vast growth of rapidly-growing vegetation of fern-like and mossy nature.

All vegetation grew with fungus-like rapidity, without any periods of rest, for there were no alternate hot and cold seasons then. The earth itself and the waters were warm and steaming; the air was charged with warm water vapour.

This vegetation lived, died, formed thick layers, and to-day we dig it up as coal and burn it. It represents so much stored-up heat, energy, and sunshine. This is how the all-wise Creator provided for our needs.

During the Carboniferous Period, the first land animals began to evolve in the shape of Amphibians, which developed later into true reptiles.

As we pass upward through the other layers to the Earth's surface, we find reptiles gradually evolving into warm - blooded animals, such as birds and mammals.

The most recent life upon our world is Man, the Masterpiece. He is the latest production, and the highest. To-day he is very lowly in comparison to what he will be in ages to come.

It must be clearly understood the various stratified rocks do not now lie evenly over one another all over the earth. They are more or less broken, tilted, cracked, and upheaved by the intrusion and pressure of molten rock from below, and the natural shrinkage due to the progressive cooling of the Earth's crust. 


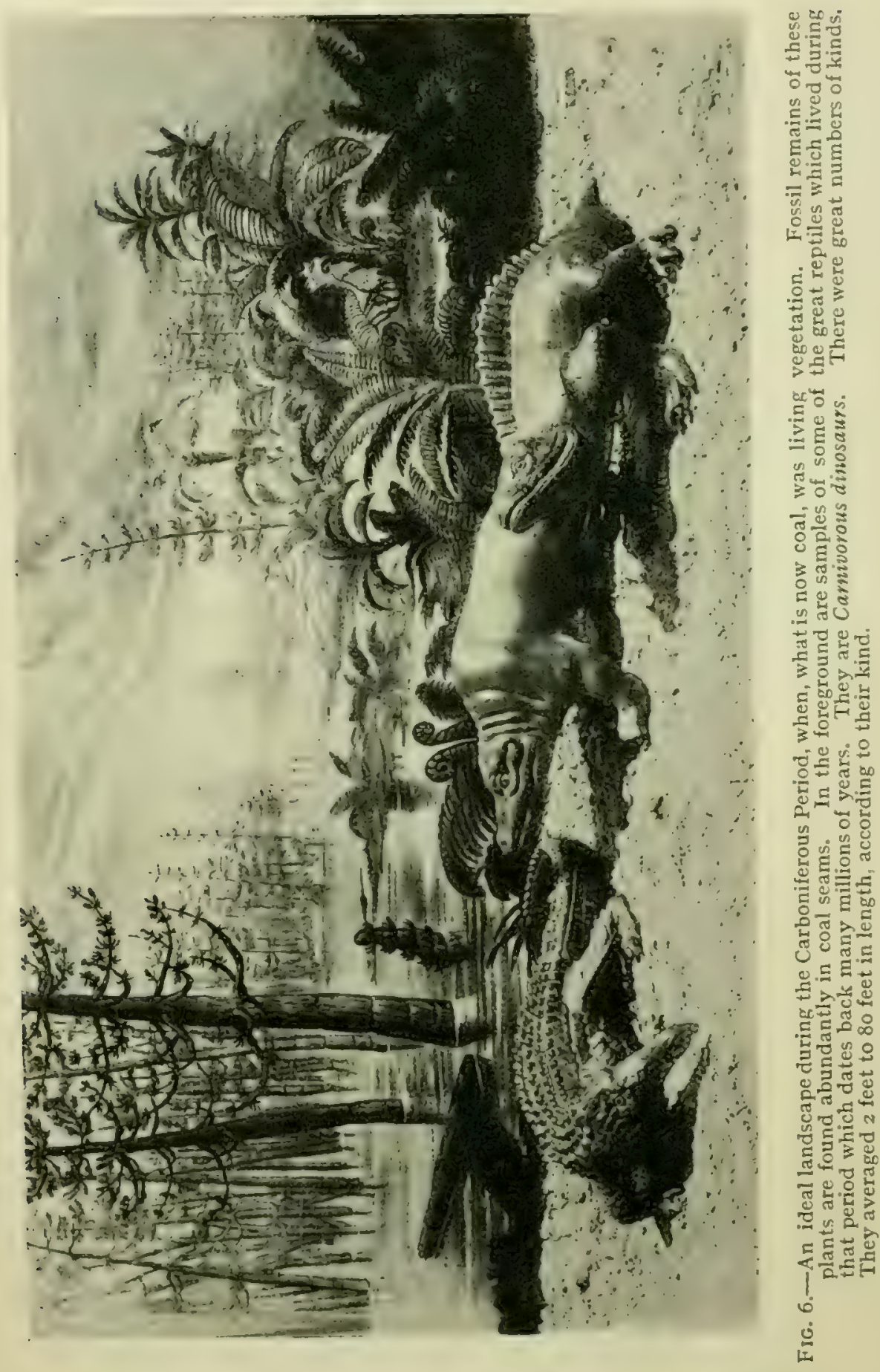

Reptiles Living and Extinct.

As far as we know, there have been nine great orders of reptiles, five of which are extinct, leaving only four orders still existing. 
(I) Crocodiles.

(2) Dinosaurs (extinct).

(3) Flying Dragons (extinct).

(4) Tortoises and Turtles.

(5) Pleisosaurians (extinct).

(6) Lizards and Snakes.

(7) Fish-lizards (extinct).

(8) Beaked Lizards or Tuateras.

(9) Mammal-like Reptiles (extinct).

The beaked Lizards or Tuateras are extinct, with the exception of one solitary species (Sphenodon punctatum) which inhabits New Zealand. These lizards grow to the length of two and a half feet, and can claim to be the last survivors of the race. 


\section{CHAPTER II.}

\section{History AND DistribUtion OF SNAKES.}

ACCORDING to the history of the stratified rocks of the Earth, and the countless number of fossil remains of animal and regetable life which are treasured up within their substance, men of science believe that living creatures existed upon this earth millions of years ago.

Fossil remains of snakes have been found in the later Cretaceous and early Tertiary periods in the world's history.

The fossil remains of a snake twelve feet long, of the Python family, was unearthed at Stepney. Remains of extinct specimens of Boa Constrictors twenty feet in length were found at Bracklesham. The backbones are perfect. They belong to the fossil genus Palaophis. In later deposits during the Tertiary Epoch, fossil remains of a venomous snake were discovered.

In the lower Tertiary deposits of North America, the fossil remains of great numbers of snakes have been found.

In the Western States of America the remains of different species of Boa Constrictors and other kinds of snakes have been found in the freshwater Eocene deposits.

Fossil snakes have also been found in the Tertiary deposits of India. Portions of the backbone and head of an extinct species of Python (Gigantophis garstini) have been dug up. From the size of the fossil remains it is estimated this species of Python attained a length of fifty to sixty feet, which is the largest serpent so far known.

The Cretaceous strata of rocks, when not pushed up by volcanic eruptions, etc., are at a distance of about 2600 feet below the Earth's surface. Their age can be roughly estimated at about two and a half millions of years. This means that it is over two millions of years ago since these rocks were deposited as mud and ooze, at the bottoms of rivers, lakes, and oceans. In the rock 
strata below the Cretaceous we find no traces of fossil snakes, so we naturally conclude snakes were evolved from reptiles with legs about this period, or Epoch, in the history of the Earth.

From Cretaceous times up to the present, snakes have evidently been on the increase, not only in numbers, but species judging by the comparatively few fossil snakes found. There are at present about $I_{500}$ species or kinds of snakes scattered over all the countries of the world, with the exception of New Zealand, where they have never been known to exist. Snakes are most abundant in the tropical and semi-tropical portions of the globe, in districts where forests and rank vegetation abound, for it is there they find an abundance of food and suitable shelter, as well as the necessary warmth to quicken their sluggish vital forces.

Extinct species of snakes of the Cobra family have been found in the Lower Miocene in Germany. Others of non-venomous species have also been discovered in the same formation. In Turkey and America fossil remains of snakes of the Crotaline sub-family have been unearthed.

\section{SNAKES AND LiZARDS.}

In outward appearance the limbless lizards resemble snakes in possessing tapering snake-like bodies, and being destitute of legs. Nobody would mistake a lizard with legs for a snake, but to those people who have not made a study of the anatomy of snakes and lizards, those lizards which are destitute of legs are invariably mistaken for snakes.

The general appearance of any ordinary snake is such that any one of average intelligence will immediately recognize it as a snake. There are, however, families of snakes known as the Typhlopiidee and Glauconiide, which are very worm-like in appearance, and might easily be mistaken for legless lizards or worms. In fact, the older naturalists classified them as lizards.

Snakes differ from lizards in the following ways :-

(I) The two parts of the lower jaw are attached in front by elastic ligaments, permitting the separation of the two halves of the lower jaw, for the purpose of permitting large prey to be swallowed. In the lizards these bones are solidly united in front. 
(2) The upper jaw and palate in the vast majority of snakes are more or less movable, which, with the distensible lower jaw, allows the snake to swallow comparatively large prey.

(3) The tongue can be completely withdrawn into a sheath in the mouth.

(4) The presence of additional articulations to the vertebre.

(5) No snakes possess movable eyelids. There is a fixed transparent scale over the eye.

(6) Snakes have no external opening to the ear.

\section{Eyes, Ears, and Tongues of Snakes.}

Snakes have no eyelids. The eye is protected in front by a transparent scale, in appearance like a watch-glass, which is firmly attached to the surrounding scales of the skin. The eye is thus protected from all external injury, unless, of course, this window pane gets broken. The eyes themselves are movable to a limited extent. Little glands secrete tears, which are for the purpose of lubricating the eyes, the fluid being drained off into the cavities of the nose by two little channels or ducts. Oddcoloured eyes are sometimes seen in snakes. This is particularly noticeable in the house snakes (Boodon).

The ears of snakes have no external opening, but beneath the skin is an intricate mechanism which registers the sound-vibrations and conveys them to the brain; and in spite of having no external ear openings, snakes have very fair hearing. They hear mainly by vibrations carried through some solid substance such as the ground. Sharp, high-keyed sounds have an exciting effect upon snakes. The tongue of a snake is black, except towards the root portion, which is flesh colour. It is bifid, which means forked. The tongue is exceedingly sensitive, and is used mainly as a feeler. It is quite innocent of any "stinging" powers. When at rest it is contracted, and withdrawn into a sheath in the centre of the lower jaw.

A day or two previous to the skin-shedding process, the eye scales become opaque, and the snake is temporarily blind, but can find its way about fairly well by means of its very sensitive tongue. I have satisfied myself of this on many occasions, by observing captive snakes. At these times when touched, snakes 

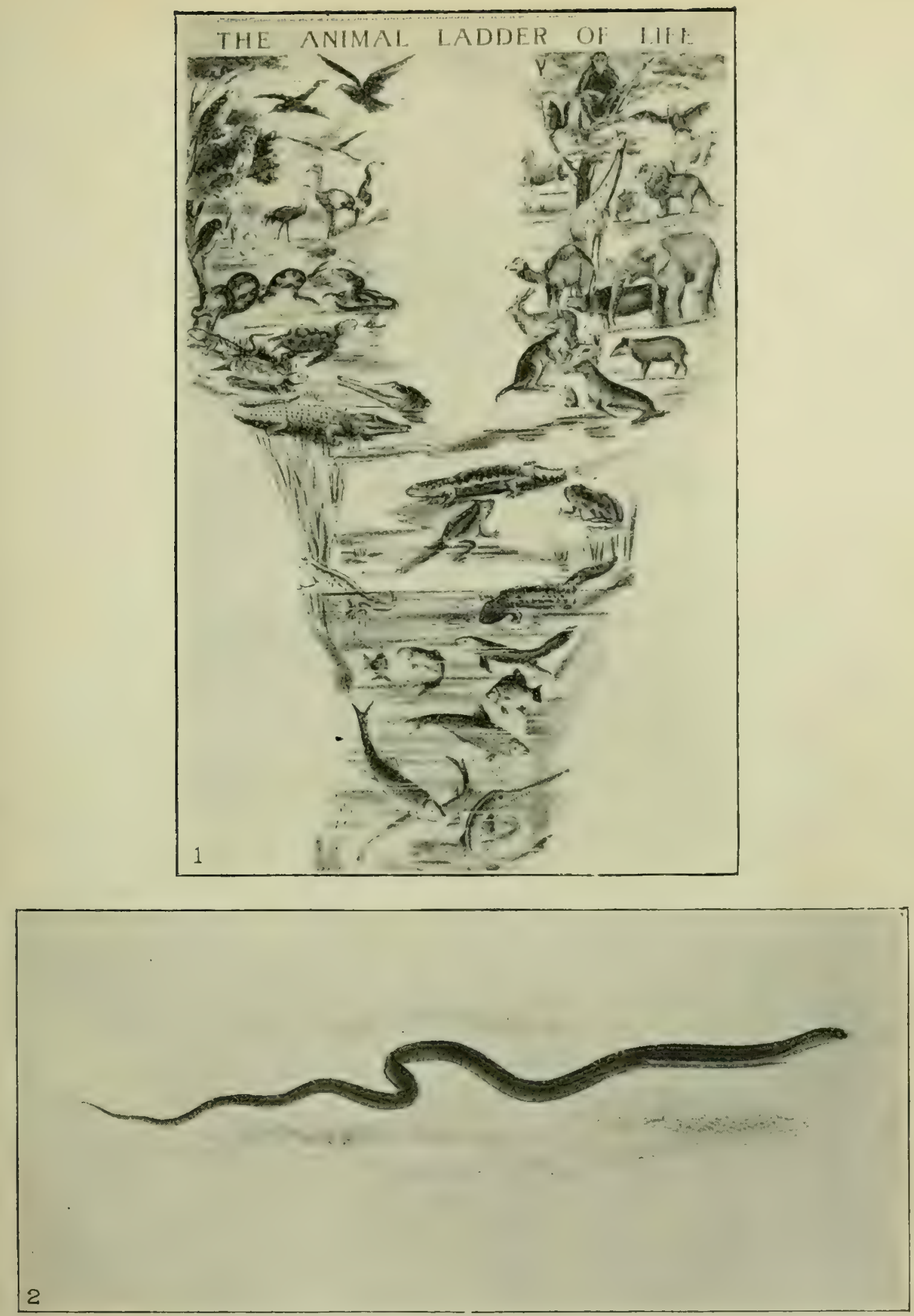

Frg. 7.- I. The Animal Ladder of Life, showing the gradual development of ocean life to Amphibians, reptiles, birds, and mammals (Children's Encyclopedia). When the creatures of the ocean began to take to land habits, it seems they divided into two great branches. One branch evolved the Mammals such as the Kangaroos, Antelopes, and Apes. Mammals are creatures which are warm-blooded and suckle their young. The other branch evolved on from Amphibians to Crocodiles, Turtles, Lizards, Snakes, and lastly birds.

2. This is a common South African Lizard, which has lost its legs. It has two tiny rudimentary front legs. The back legs have vanished. On dissection, the pelvis only is found. This lizard is in the intermediary stage of development between a lizard and a snake. There is another common South African Lizard (Acontias meleagris), which burrows in the ground. It has lost all vestiges of legs, but has a rudimentary pelvis, shoulder girdle, and movable eyelids, so it is still called a Lizard. 
lunge cut wildly with gaping jaws, but owing to their semi-blind condition their aim is not accurate.

When molested, a snake darts out and vibrates its tongue, evidently with the purpose of intimidating its enemy.

\section{Changing the Skin.}

Snakes change their skins several times a year before reaching the adult state. Adult snakes usually only change their skins once, sometimes twice during a season, sometimes only once in two seasons. At least, this is so in captivity, as I have had ample opportunity of ascertaining. The first skin-shedding process takes place a few days after birth.

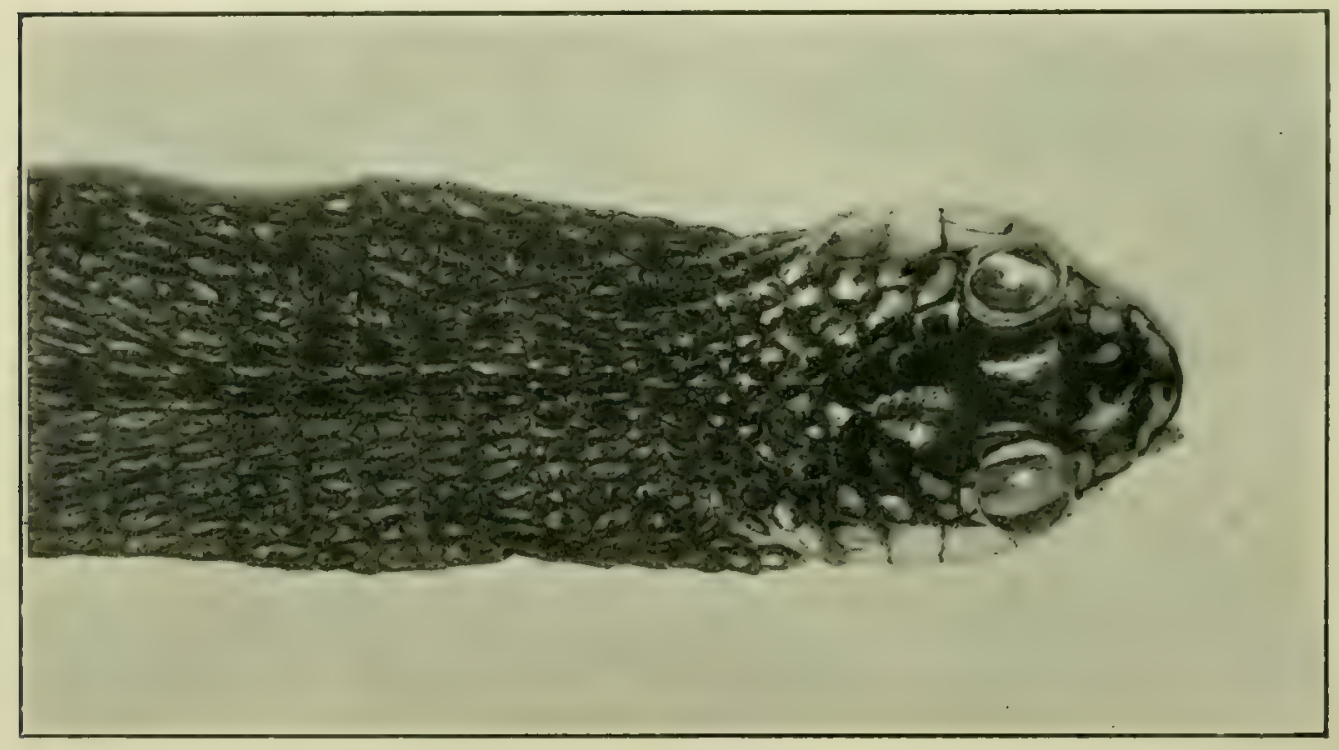

FIG. 8. Cast skin of head and neck of snake. Note inverted eye scales, like watch gilasses with concave side uppermost.

The shedding or casting of the old skin begins at the lips. The skin around the mouth curls up, and by pushing itself against twigs, crawling through tufts of grass, etc., the snake gradually draws itself right out of its slin. This comes off inside out, like a tight glove being pulled off the hand from the wrist portion.

The cast skin is often perfect, without a crack, tear, or loss of a single scale-even the transparent eye scales come away. The main reason why snakes cast their skins is to provide for increased growth. The skin of a snake does not grow with the growth of the body, as is the case with warm-blooded animals. So, when it 
begins to get too tight, it is discarded. In the case of adult snakes, it is thrown off when it gets shabby, dirty, and injured.

Naturally before the old skin is shed, a new skin has formed beneath, and the snake on emerging from its old covering looks clean, silky and bright, the markings and colours showing up to perfection. The new skin, for some hours, is thin, soft, and sensitive, particularly so immediately after the casting process. I tried once to assist a captive snake to shed its skin, and somehow pulled too fast or clumsily the skin it was casting, which resulted in the new skin beneath being badly torn, and exposing the flesh.

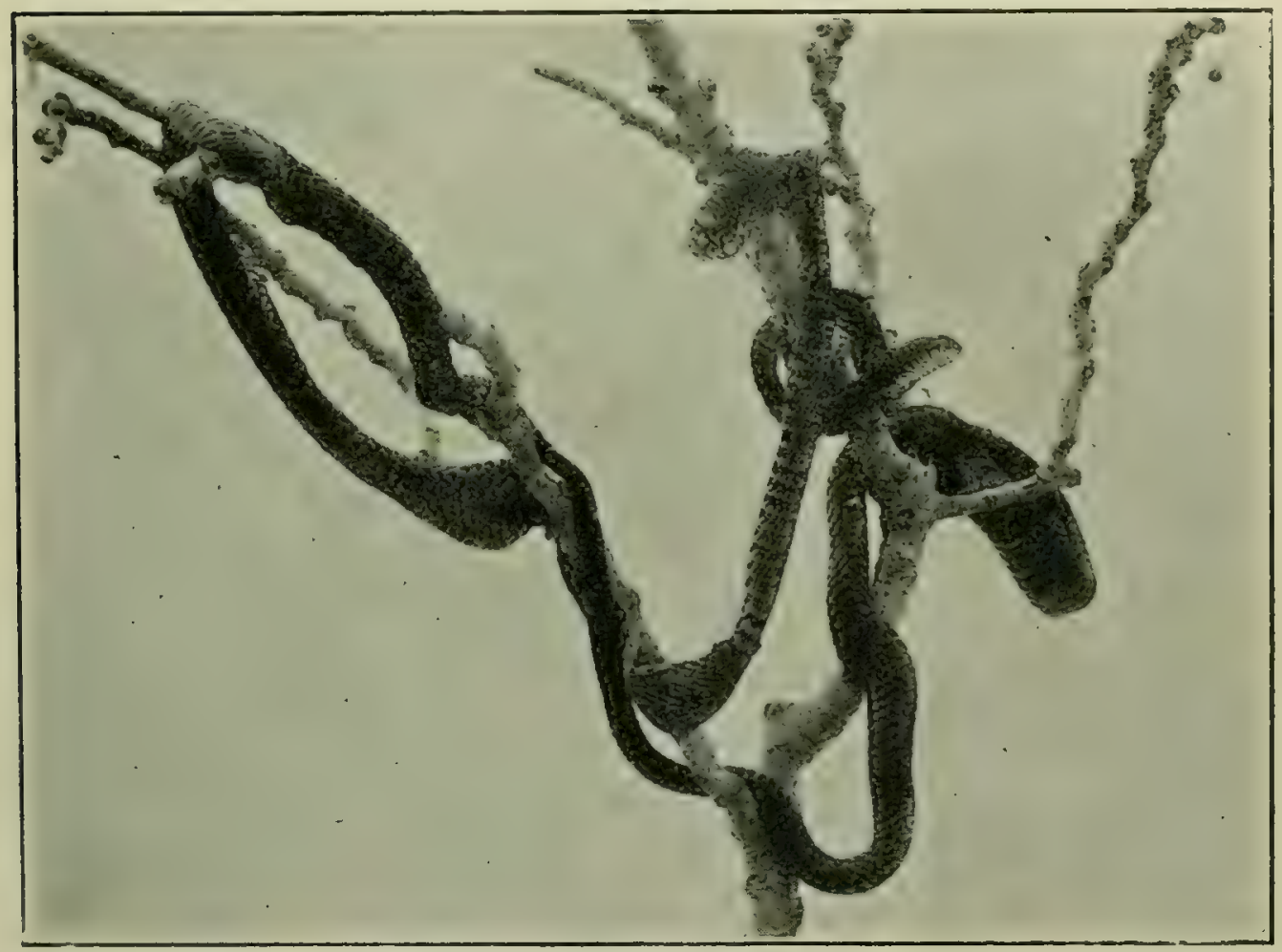

FIG. 9.-A Boomslang in the act of casting its skin amongst the branches of a tree. The snake's tail-end has not yet been withdrawn from the old skin.

The old skin, when being shed, is not actually loose. The operation of shedding the skin is similar to pasting down a strip of ribbon with a strong adhesive, and slowly peeling it off again before it is dry. The old skin of the snake adheres closely to the new one beneath, but seems to peel off very easily. Snakes in captivity should have tufts of grass, bundles of twigs, or loose stones in their cage to provide the necessary frictional resistance in the skin-casting process. 


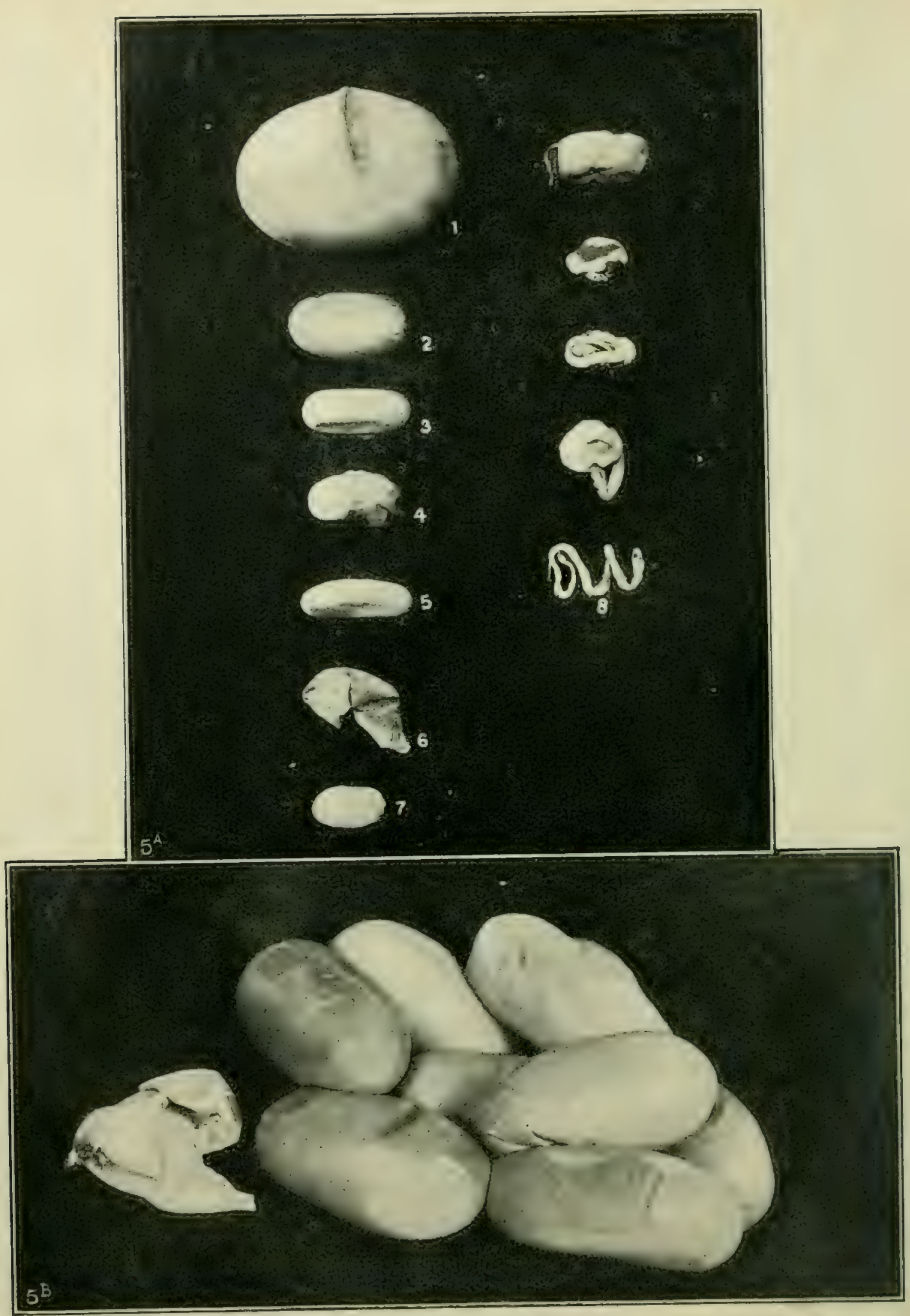

SNAKES' EGGS.

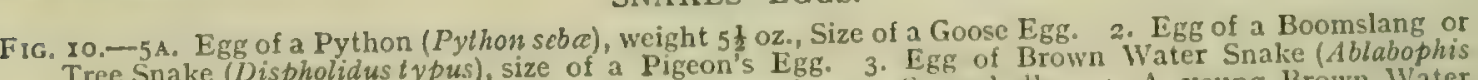
Tree Snake (Dispholidus typus), size of a the Boomslang. Same bulk. 4. A young Brown Water rululus). More elliptical than that or We Bater Snake (Chlorophis hoplogavicr). Same size and shape Snake, hatching out. 5. ".gh of Green Water Snake Chard and brittle, it is soft and tough. 7. Egg as No. 3. 6. The "shell " of a snake's cgg. It is not hard and britte, it is solt and the embryo of a suake. 5B. A pile of Snakes' Egrg, and the broken skin of another. These are the Ekrs and leathery. The contents

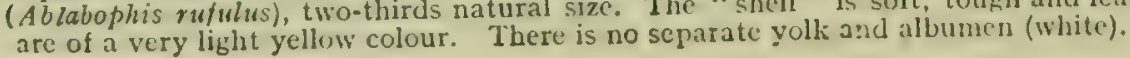




\section{Oviparous, Ovo-Viviparous and Viviparous.}

Some kinds of snakes lay eggs, and others give birth to young. Some species lay eggs which are quite fresh and are hatched or incubated outside the body, usually by the heat generated by their surroundings, such as decaying vegetation, manure, or the sun-heated ground. Certain snakes are believed to coil round their eggs and incubate them, but this is uncertain, except in the case of the Python. Those snakes which lay eggs which have not started incubating are known as oviparous snakes.

Some snakes lay eggs which have been more or less incubated before being laid. In certain cases the young are almost fully developed inside the eggs when they are laid. In others there are varying stages of development of the young. These are known as ovo-viviparous snakes, which means "producing eggs which are more or less incubated inside the parent's body."

There are yet other snakes which give birth to fully developed young. In these cases the eggs are developed full size within the parent's body, and they incubate there until

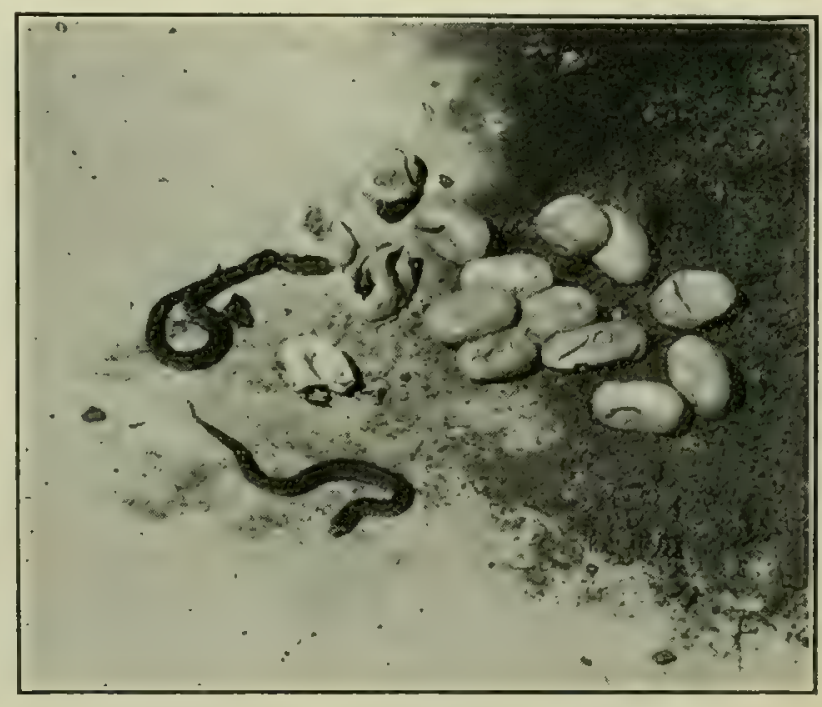

FIG. II.-Night or Demon Adders hatching out. Two are out, others are seen in the act of breaking the egg shells.

the young are completely developed. They are then born, each enveloped separately in a transparent membraneous bag, which their active struggling ruptures. Viviparous means giving birth to living young.

The temperature of a gravid snake is slightly increased, otherwise the embryos or foetal young would not develop satisfactorily. In the wild state the gravid female lies as often as possible in the sunshine. In captivity she invariably lies on the part of the floor where the sun happens to shine.

At the Port Elizabeth Museum the sun only shines for an 
hour or so daily into the cages, owing to their situation. In consequence the female puff adders frequently produce their young in an incomplete state of development. In others the embryo dies and the egg hardens, resulting in the death of the parent.

Practically speaking, then, snakes are oviparous and riviparous, that is, some lay eggs and others give birth to young.

\section{Sense of Smell and Breathing Apparatus.}

The sense of smell in snakes is very well developed, as will be seen on dissection of the apparatus of the nose. In the family of grass snakes this sense of smell is particularly good.

Snakes are thus enabled to find their prey and guard against their enemies by the senses of sight, touch, smell, and hearing.

Snakes breathe by means of lungs. The left lung is much smaller than the right one, and in most cases it is quite rudimentary, or entirely absent. In some snakes the right lung reaches from the neck fully two-thirds of the way down the body of the snake. The lung is a sort of long hollow tube or bag, with thin walls, in which are embedded the cells and blood vessels which take up the oxygen of the inspired air. Snakes, owing to their low temperature and slow blood circulation, do not require to breathe as frequently, or inhale such pure air as birds or mammals. The breathing is slow and quiet, except when the serpent is alarmed or enraged, when it will inhale a great volume of air and expel it forcibly, producing the characteristic hiss.

\section{Hissing.}

The hissing of a snake is caused by the long sac-like lung being inflated with air, which is forcibly expelled through the glottis and nostrils, causing that well-known hissing sound which warns us of the proximity of a snake.

The Puff Adder makes the loudest and most prolonged hiss of any South African snake. Hissing is the only sound snakes are capable of producing, except the American Rattle Snakes, which have a horny substance in loose sections or segments at the end of the tail, which, when shaken, emits a hollow kind of rattling noise. 
When alarmed, snakes hiss with the object of frightening off their enemies. If snakes were not able to make their presence known, they would be frequently trodden upon and injured by the various creatures of veld, forest, and mountain. For long ages the wild animals have, from bitter experience, learned instinctively to avoid snakes. The instinct has been so strongly developed that it is transmitted from parent to offspring. This instinct persists in a greater or lesser degree, even in domesticated animals whose ancestors, perhaps for scores of generations, have never seen a snake.

An animal will often manifest the wildest alarm at sight of a snake, or on hearing a snake hiss, although it has never before come in contact with one of these reptiles. This power of transmitting experiences is a wonderful provision of Nature, for if every living creature had to learn entirely by personal experience to avoid its enemies, and find out what kinds of foods were wholesome, or the reverse, a great number of species would rapidly become extinct. Venomous snakes invariably give a warning hiss, if suddenly and unexpectedly approached or trodden upon. If the latter should occur, they instinctively bite.

Nature has therefore evolved the power of hissing as a means of protection to the snake, and as a warning to other creatures that a reptile capable of inflicting serious mischief upon them is in dangerous proximity.

\section{Progression.}

Snakes progress or crawl about by means of their ribs and belly scales. The backbone of a snake is wonderfully constructed, and is capable of being twisted and curved in a great variety of ways without fear of dislocation. There are a great many joints to the backbone, often as many as three hundred. To each of these sections a pair of ribs are attached, one on each side. The heads of the ribs are loosely attached to the backbone sections, and they can thus be moved forwards and backwards with the greatest of ease. The extremities of the ribs are attached to the scales or horny shield-plates of the abdomen. When the snake crawls, the ribs along one side of its body move forward, the edges of the scales gripping the rough surfaces of the ground, tree, or whatever the snake may be crawling over. Then the ribs on the 
opposite side are brought parallel with the other set, dragging up the hinder part of the body, and propelling the upper or anterior part. All this is done so smoothly and equally that the snake crawls with the greatest ease, and moreover is exceedingly graceful in its movements. A snake cannot crawl upon a perfectly
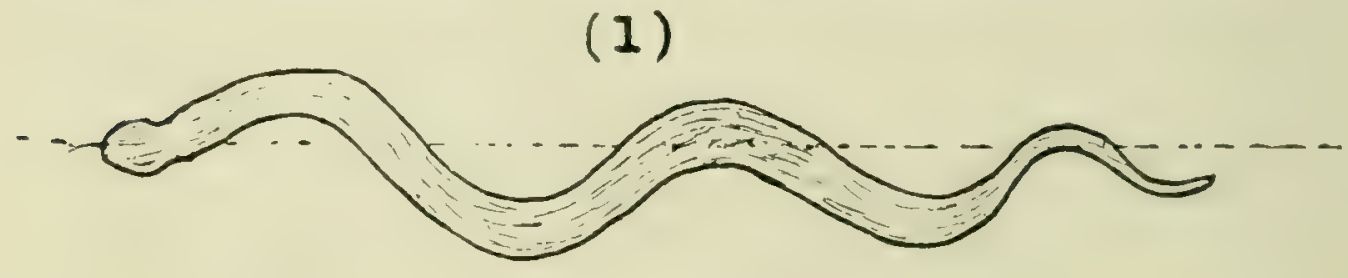

(2)

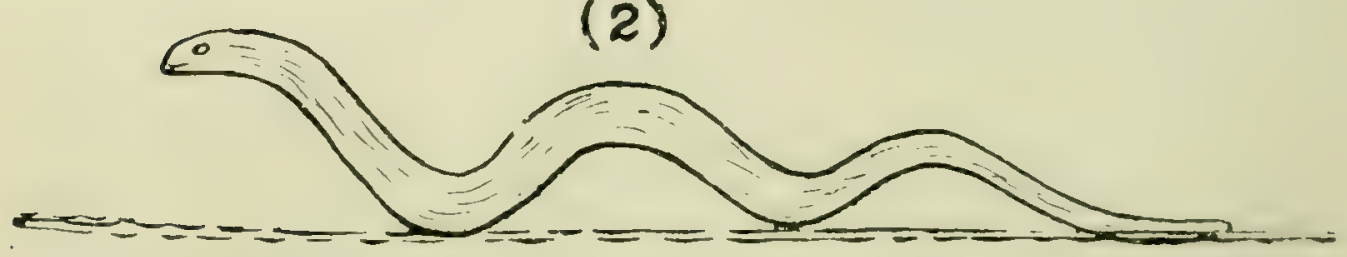

FIG. 12.-I. A snake crawls over the ground like this, propelled by its abdominal shiclds, the tios of which grip uneven surfaces.

2. The erroneously popular idea of how snakes progress over the ground.

smooth surface, such as a sheet of polished plate glass, and can only succeed in wriggling in a helpless sort of way. The scales of 'snakes partly overlap each other. The abdominal shields can be partially raised by certain muscular attachments.

\section{The TeEth.}

Snakes' teeth are recurved ; that is, they are curved inwards towards the throat. Non-venomous snakes, with the exception of the blind burrowing snakes, have two rows of small teeth in the upper jaw, and one row in the lower jaw. The teeth are not set in sockets in the jaw, but are fastened to the bone by cartilage. If, on examination, these teeth be found to be all solid, without any trace of grooving, then the snake is certain to be quite nonvenomous. But in a great number of snakes with two rows of upper teeth it will be found that one, two, and even three of the teeth in the outer row, usually about half-way back in the jaw, are longer than the rest, and more or less grooved. Such snakes should always be regarded as venomous to a greater or lesser degree. The Boomslang or Tree Snake (Dispholidus typus) is one 
of these latter, and it was shown, on experimentation, to be highly venomous.

The study of the fangs of snakes clearly shows the operation of the great law of Evolution.

\section{The Circulation of the Blood.}

The heart of a snake has three cavities-one ventricle and two auricles, not two of each, as is the case with all warm-blooded creatures. The heart pumps the blood through blood-vessels in the ordinary way. The blood corpuscles are both red and white, as is the case with the higher animals. The red corpuscles are elliptical, flattened, and bi-convex. The circulation of the blood is very sluggish, and its temperature is much below that of the mammal class of animals. Hence the reason they are termed "cold-blooded." Reptiles are all " cold-blooded," and mammals are without exception, "warm-blooded."

The circulation of the blood of snakes being very sluggish, they do not require nearly so much oxygen as do animals of the warm-blooded class such as mammals and birds, hence the reason they are able to live and thrive in air charged with carbonic acid, gas, and other gaseous impurities given off by decaying vegetation and stagnant water. Snakes, if entirely deprived of air, will continue to live, in many instances, for several hours. I have seen ordinary land snakes, such as the Puff Adder, sink themselves in a shallow pool and remain immovable at the bottom for nearly half an hour. I sat one day and watched a Python for one and a half hours lying coiled up at the bottom of a clear spring of water, without once raising its nostrils to the surface. If corked up in a bottle of water, a snake will die in one or two hours as a general rule. When swimming upon the surface of water, a snake inflates its lung, which makes it very buoyant. When swimming upon the surface they wriggle with a wave-like motion. I have watched snakes stretched out motionless upon water, apparently lying on it as lightly as a cork, sunning themselves in the hot rays of the midday sun. On being alarmed, they instantly sank out of sight without any apparent muscular effort. This is accomplished by expelling the air from the long, tube-like lung, whereupon the body sinks, being then denser than the water. 


\section{The Poison Fangs.}

In the typical venomous snakes, the outer row of upper teeth has vanished, with the exception of fangs, more or less large, and set in the front part of the upper jaw. These fangs are either deeply grooved or hollow, and are connected by a channel or duct with the poison glands, which secrete the venom. The poison glands, with but one or two exceptions, lie one on each side of the head, just below and back of the eyes. These glands are almond-shaped, and vary in size according to the species of snake. In the Puff Adder they are about the size of a small almond. The venom is secreted by the cells composing the gland, and is

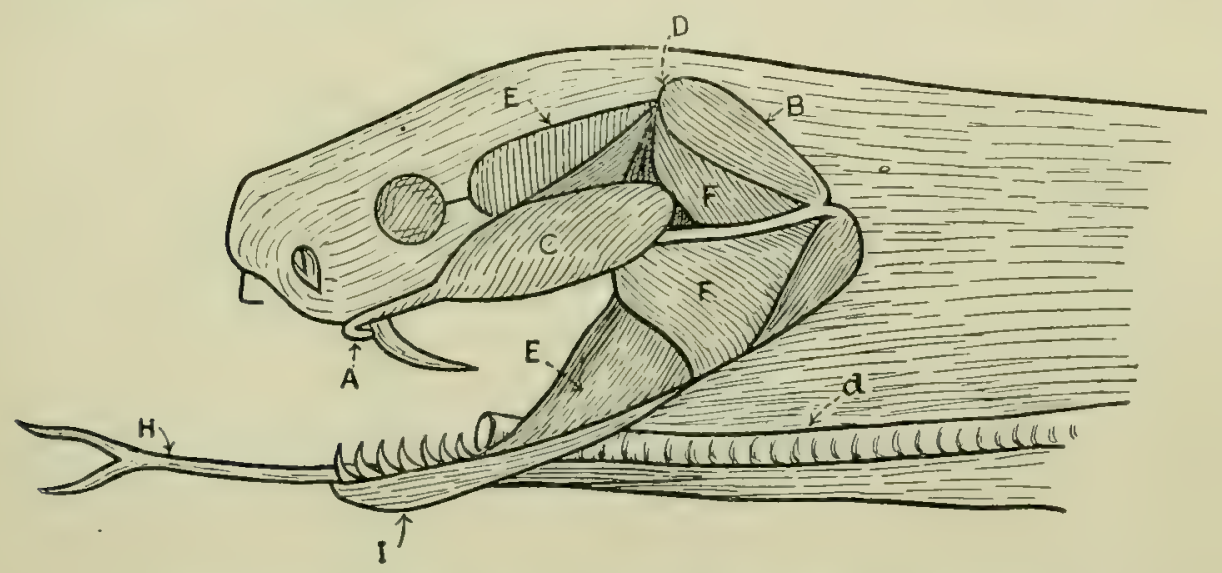

ANATOMY OF THE HEAD OF A VENOMOUS SNAKE.

FIG. 14-A. Duct from the poison gland, the end of which is bent upon itself and resting in the hole at the base of the fang into which the venom is squirted.

B. Digastric muscle which opens the jaw.

C. Poison gland.

D. Point of junction of the squamosal and quadrate.

E. Anterior temporal muscle.

F. Posterior temporal muscle.

H. The bifid tongue.

I. Lower jaw in which some solid re-curved teeth are set.

d. Trachea or windpipe.

expelled through the duct, down the grooved or hollow fangs into the punctures when the snake bites. The venom is driven out of the glands by the construction of certain muscle fibres which compress the glands violently.

\section{The Use of SNAKES.}

In hot countries, insects, reptiles, batrachians, and rodents swarm. The snakes are the natural enemies of these creatures, and act the part of Nature's agents in checking their too rapid 
increase. Owing to snakes not being so dependent on oxygen as the more highly-evolved creatures, they are able to exist where most birds of prey and carnivorous animals would die. They are, by virtue of their specially modified organism, able to penetrate into the morasses, jungles, swamps, and dense overgrown vegetation of the tropics where the smaller reptiles swarm in vast numbers. These latter reptiles reproduce their kind at a very rapid rate, and if not preyed upon by many enemies would rapidly become a plague.

Snakes are active agents in keeping down the numbers of these quick-breeding creatures, as well as those pests known as rats and mice. Owing to their long tapering bodies, snakes are enabled to penetrate into the innermost haunts of these destructive rodents and swallow parents and their young.

Snakes are frequently found in and about the dwellings of man, attracted thereto by the presence of rats and mice; and in the autumn they find some cosy place in the thatch, under a floor, down a hole, in a stack of timber, dung heap, or fodder, in order to hibernate during the winter months.

\section{ENEMIES.}

Snakes breed very rapidly, and in consequence they, too, have many natural enemies. Birds of prey and many of the smaller carnivorous animals feed upon their young, and frequently attack and devour grown snakes. Many species of snakes are cannibals, and do not hesitate to swallow their own young or those of others.

There are several species of mungoose, meercat and muishonds in South Africa, all of which readily devour snakes. None of them are, however, immune from snake venom. These little animals rely upon their quickness and activity in avoiding being bitten when attacking a venomous serpent. The nature of their hair is also a protection. I have frequently kept the different kinds of mungoose and meercats in captivity and introduced snakes into their cages. If the cage happened to be rather small, the animal would show much alarm, but when given a large roomy cage in which to operate, no fear was shown.

In the "Cambridge Natural History" volume on Reptiles, it 
is stated that "several well-known mammals and birds are immune by nature against snake venom, but most of them avoid being bitten. Some birds induce the snake to strike and bite frequently into their spread-out wings. Such more or less common creatures are the Mungoose, Hedgehog, Pig, Secretary Bird, Honey Buzzard, Stork, and probably other snake-eaters."

None of these creatures are immune to snake venom. If the venom is injected under their skins artificially, or naturally by a snake, they die just as rapidly as other animals. The hedgehog, owing to its spine-covered body, is not likely to be bitten when attacking a snake. Pigs are not actually immune. If a snake should drive its fangs into the thick layer of fat under the skin of a pig, there is little probability of its being absorbed, unless at such an exceedingly slow rate that the animal suffers little or no inconvenience. Pigs, which are allowed to range in a semiwild condition under natural conditions, develop a tough leathery hide, which the fangs of snakes cannot easily penetrate. I have found that if snake venom is injected into the tissues of a pig, among the capillary blood vessels and lymphatics, the venom is absorbed and produces characteristic symptoms of snake venom poisoning, as in other animals. The Secretary Bird, when attacking a snake, defends itself with its spread-out wings, which it holds in front of it like a shield. The instant the snake lunges at the quills, the bird throws the wings violently forward, casting the snake backwards with great violence. If the reptile should appear to be dazed, the bird at once seizes it by the neck in its powerful bill, and, with a severe nip, crushes the backbone, and thus incapacitates the snake. These birds often use their long stilt-like legs like arms, beating the snake to death with a quick succession of blows. The feet and legs of the Secretary Bird, as far up as the knee joint, are hard, brittle, horny, and so well-nigh impervious to the fangs of a snake.

Snake-eaters all owe their comparative immunity to death from snake-bite to their agility, methods of attack, and natura] defensive coverings.

\section{Duels WITH SNAKES.}

The following instance will illustrate how the Mungoose attacks and destroys snakes. The Mungoose (Herpestes pulverulentus) 
mancuvred around the snake, and the instant he saw his opportunity, made his spring, and with lightning-like rapidity seized the reptile in his jaws, crushed its vertebræ, and sprang away again. So quick were his movements, my eyes could hardly register the details. After eyeing the snake with his little, keen, black, wicked-looking eyes for a period, he was evidently satisfied the snake was incapable of further fight, as it evidently was, for it was apparent that its body was paralyzed by the injury to the backbone. He again leapt upon it, but this time retained his hold, and having mangled the head, chewed it from the body and swallowed it. Being then satisfied that the dangerous part of his foe was safely disposed of, he leisurely dined off the remainder of

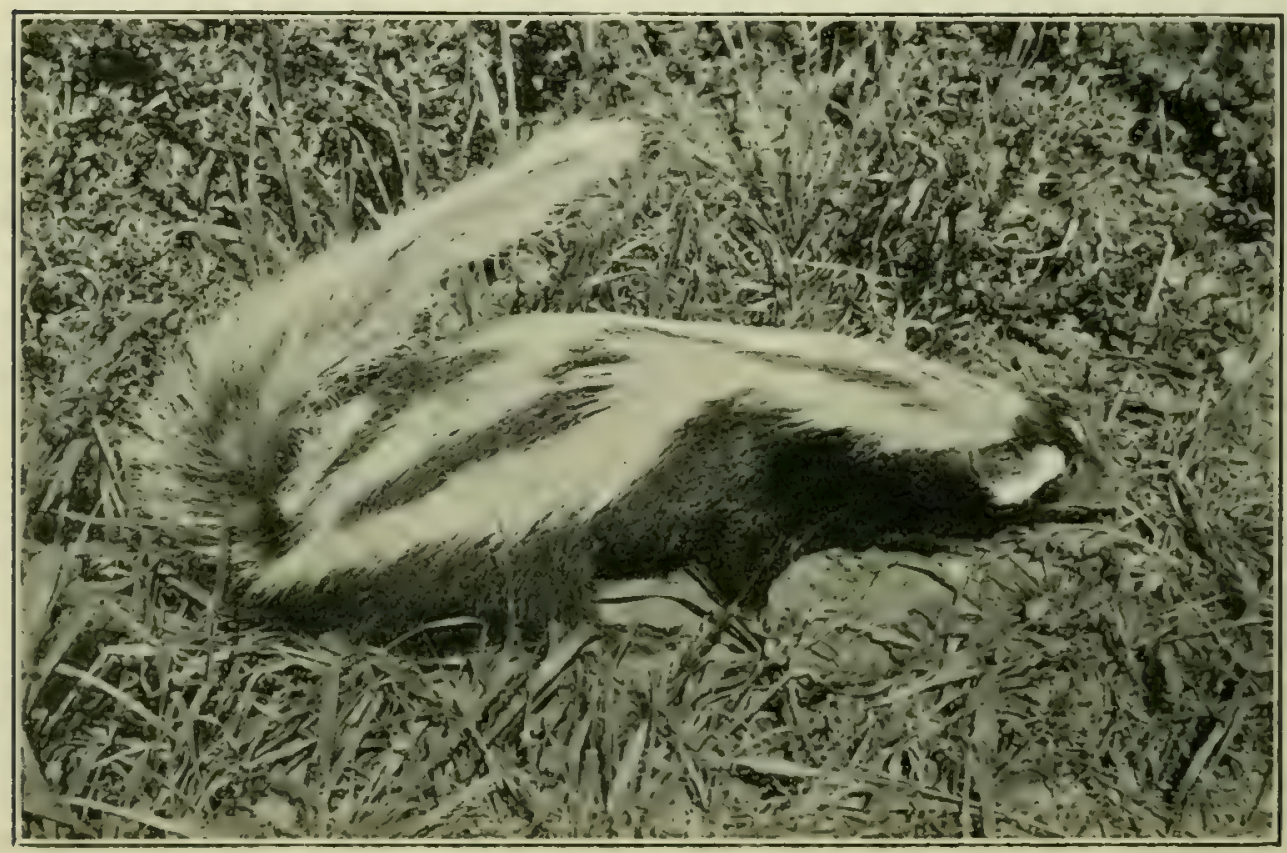

FIG. I5.-The Muishond or Stink Cat (Zorilla striata), who boldly attacks, kills and devours the most venomous of snakes.

the body. Removing the Mungoose, I replaced it with a hungry, Slender-tailed Meercat (Suricata tetradactyla), and introduced a large Puff Adder. The Meercat darted about nervously for a while, ran quickly forward, dodged the stroke of the snake, and seizing it by the neck, crushed the vertebræ. Then the Meercat deliberately nipped it in various parts down the spine, before starting to eat it, evidently with the intention of smashing the backbone and thus preventing the snake from wriggling about.

A Striped Muishond (Zorilla striata) was then experimented 


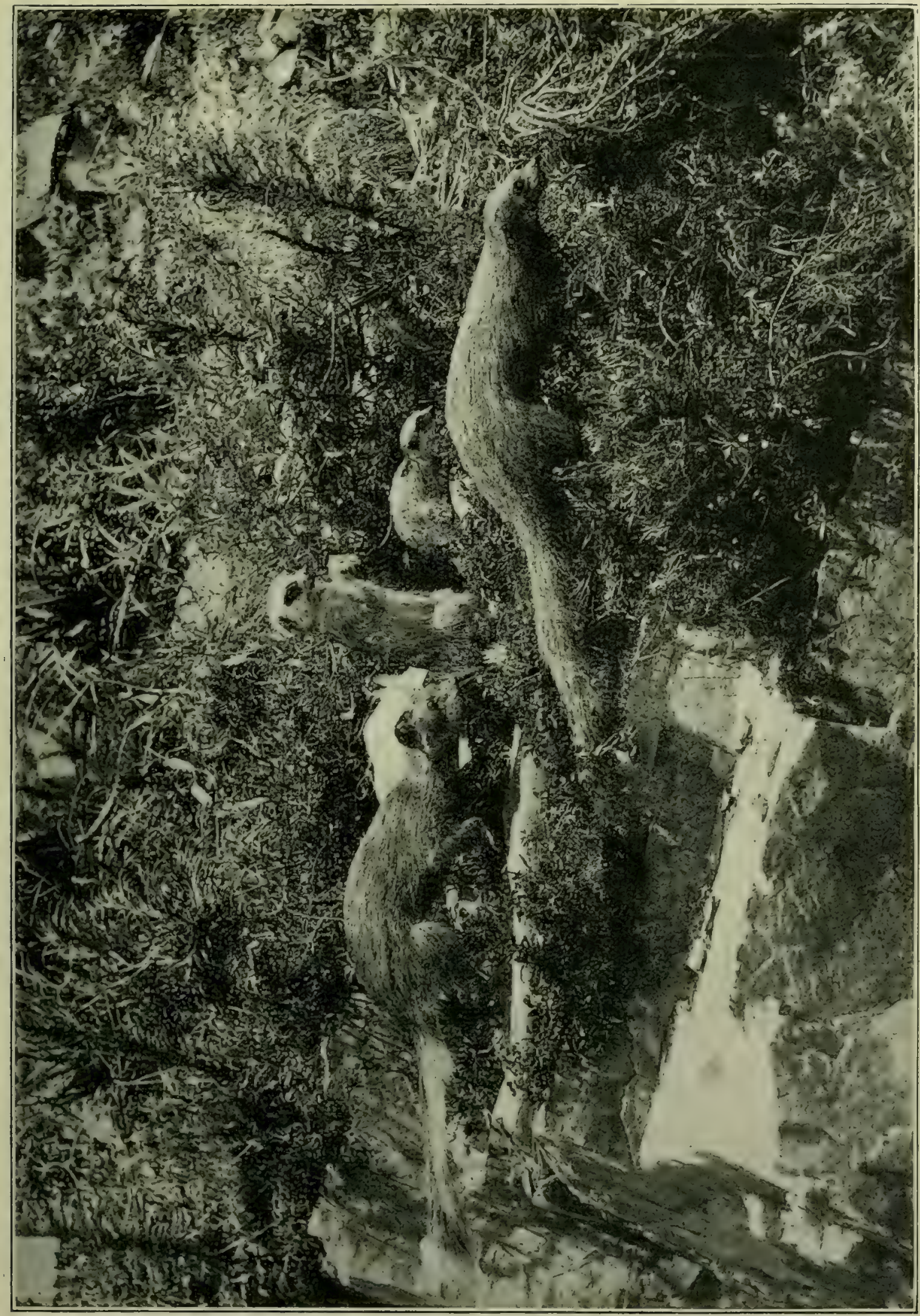

ANIMALS THAT EAT SNAKES.

FIG. 16. - These are a few of the natural enemies of South African Snakes. The two small animals in the centre are Meercats (Suricata tetradactyla). The. One on the left is the Bushy-tailed Meercat, called the Geel or Rooi Meercat by Colonists (Cynictis penicillata). The animal on the right is the Grey Mungoose or Pepper and Salt Cat (Herpestes pulverulentus). None of these animals are naturally immune to snake venom. They escape being bitten by their extreme activity, and the thick aature of their hair and under-fur. 
with. I placed a Cape Cobra in its cage. The Muishond instantly ran into a corner and faced the snake, which was on guard with raised body and hood expanded, ready to do battle with his foe. Suddenly the Muishond darted into another corner of the cage. Like a flash the snake swerved and again faced him. The Iuishond repeated the manouvre, but the snake was not to be flanked. He faced his foe every time. Finding these tactics of no avail, the Muishond began badgering the snake by snapping and snarling at him. At last the reptile, in a fury, lunged fiercely forward. His intended victim nimbly sprang aside, thus avoiding the blow, and before the snake could recover himself the Nuishond scized him by the back of the neck, and holding on tenaciously, inflicted serious damage by lacerating his victim's flesh. His endeavour was, evidently, to crush the snake's backbone, which he very soon did. He seemed to know quite well that the Cobra was now helpless, for he let go and rested a few moments. Then, seizing the reptile's head, he chewed it up and swallowed it, and then satisfied his appetite on a portion of the body.

Hearing a grunting noise near a mimosa tree, under which a friend and I had camped out for the night in the Natal bushveld, we took a small bull's-eye lantern, and proceeded cautiously to investigate. Presently a shrill, ear-splitting yell broke the stillness of the forest. Flashing the light of my lantern in the direction of the noise, there, within two yards of us, was a striped Muishond, with his paws firmly planted on an adult Black-necked Cobra (Naia nigricollis). The Muishond stood facing us menacingly, daring us to approach, and making the forest ring with his sharp penetrating yells, launched out at us at intervals. Thinking he had intimidated us sufficiently, he began, with a succession of low growls and snarls, to eat the still-living snake, eyeing us suspiciously with his lieen little eyes all the time.

After satisfying our curiosity, we retired and left the plucky little fellow to finish his well-earned meal in peace.

I have allowed Meercats (Suricata tetradactyla), Striped Muishonds (Zorilla striatc), Grey Mungooses (Herpestes pulverulentus), and the Large Grey Mungoose (Herpestes caffer) to be bitten by Puff Adders or Cape Cobras, or injected with their venom. In every instance these animals died of the usual symptoms of snake venom poisoning in from ten minutes to several hours 
in time, according to the size of the snake, its species, its condition, time of year, or quantity of venom artificially injected.

A Grey Mungoose, which I had in captivity, once fought and killed a Puff Adder. However, the snake, with a last expiring effort, lacerated the lip of its foe with one of its fangs. The Mungoose dropped the snake, retired to a corner, and after a short time began to mope. It died in seven hours. The reason that it lingered so long was because only a small quantity of venom had been discharged into the wound.

On another occasion a Puff Adder was introduced into the cage containing a Striped Muishond. The Muishond made a few feints, then darted at the snake before he could recover himself, aiming a terrific blow at the adder. Although the Muishond crushed the snake's head in its sharp teeth, immediately the reptile was released it struck out blindly and bit the Muishond on the skull. The latter retired to a corner and faced the snake, but died in forty-five minutes after.

The Rev. Father Bruno, of Kolbe, Cape Colony, informed me that he and some friends witnessed a fight between a Cape Cobra (Naia flava) and a Muishond. The latter circled round the snake, who stood with reared body and expanded hood, after the manner of all cobras when irritated. Eventually the snake seemed to get bewildered or tired with turning round so frequently and at such short intervals, for a cobra will never allow attack in the rear if he can avoid it. Lunging forward, he failed to recover himself in time, and the Muishond had him by the neck and quickly shattered his backbone with its sharp teeth. As in the former instance, it first ate the snake's head, and then dined off the body.

When in Natal I possessed an old Tom Cat, who was a mighty Nimrod. He scoured the neighbouring forest nightly. Whenever he made a capture of anything worth while, the old fellow, who was a great pet of mine, came scrambling in through my open bedroom window and, after laying his prize upon the floor, he would set up a musical crooning noise, like cats do when they call their kittens. He seemed quite pleased when I got out of bed, lit the lamp, and inspected his prize. Many a time I have obtained really good specimens for my collections in this way. Sometimes he would bring in snakes still writhing and wriggling. Just before dusk one evening, I was wandering round with old 
Tom at my heels, when a Puff Adder let out a hiss. Tom sprang forward and faced the snake. Knowing he was well able to take care of himself, and that he was by no means a tenderfoot, I moved back a few paces and watched. He started by making feints at the snake, which induced it to strike out furiously. Old Tom seemed to be a mass of the finest springs. The agile manner in which he sprang about and avoided the fierce forward lunges of the snake filled me with admiration for him. After about fifteen minutes the snake began to tire. Tom knew it too, full well, for he now began to grow bolder, and struck two or three severe blows with his forepaw. Once more the snake lunged with gaping jaws and erect fangs. Missing its aim, its head struck the earth with a thud. It was evidently spent, for it made no attempt to draw back in readiness for another lunge. Tom quickly finished it off by delivering a smashing blow with his forepaw, which seemed to daze the reptile, for it allowed the cat to seize it by the neck without showing further fight. Dragging the snake's body along, my plucky old hunter laid it at my feet, purring with evident pride.

A few months after this event, Tom came home one evening with a tremendously swollen head. He had evidently tackled a snake which proved more than a match for him. We did all we could for him, but he died within two hours.

\section{SNakes Eating Eggs.}

A story was published some years ago in a boys' journal, of a Cobra which disturbed a setting hen and swallowed five of her eggs. The Cobra was killed, the unbroken eggs removed from its interior, and replaced in the nest. Those eggs, in due time, hatched out into fine healthy chicks.

Unlike the generality of snake stories, this one happens to be true. I have the pleasure of knowing the gentleman who owned the hen and the eggs. He was farming in Bechuanaland, and had procured a setting of a specially good strain of Black Minorca eggs at considerable expense from Capetown. Observing the hen walking about the farmyard in an unusually excited condition and wondering why she did not return to her eggs, he got anxious, and went to the hen-house and peeped into the box containing the eggs. A large cobra, with a fierce hiss, made a ferocious lunge 
at his face. My friend, being young, active, and quick-witted, dodged the stroke. Summoning assistance, he returned to find the cobra making the most desperate efforts to disgorge several eggs, the shape of which could plainly be seen in the reptile's body. The eggs, however, were too smooth, slippery, and heavy for the disgorging mechanism of the snake to grip and expel, so the robber, perforce, was held captive, because the five eggs in its stomach weighted him effectually down. Rigging up a noose, my friend got it round the snake's head and carefully dragged it forth. An assistant seized the tail ; my friend placed the heel of his heavy boot on the reptile's head and smashed it. Then, taking out his penknife, he cut open the cobra's abdomen and recovered his property. Washing the slimy mucus off the eggs, they were replaced in the nest, and the hen was coaxed to return. These five eggs hatched out all right, and the chicks grew up into five fine Black Minorcas, one of which, for many years, was cock-in-chief of the farmyard fowls.

Snakes cannot suck eggs, but some snakes swallow eggs whole, the powerful digestive juices dissolving the egg-shell usually within twenty-four hours. Sometimes the remains of the shell are cast up, or perhaps it is completely dissolved or broken up very fine and passed with the excreta. The Boomslang (Dispholidus typus) I have frequently observed to swallow birds' eggs, which lodged in its stomach, the fragments of the shells of which, if at all hard, were cast up the following day. Pigeon's eggs frequently remained whole inside the snake for a couple of days.

There is, however, a species of true egg-eating snake which has been provided by Nature with a special set of enamel-tipped, tooth-like bony projections in the throat, for the purpose of sawing through egg-shells and releasing the contents, which are squeezed down the throat of the snake, the crushed shell being spat out afterwards.

\section{CONSTRICTION.}

Some of the slightly venomous and the majority of the nonvenomous snakes kill their prey by constriction. The snake, with unerring aim, makes a dart, seizes its prey by the head, usually the nose, and instantly coils around it, crushing its life out within a few minutes. Two coils, sometimes three or more, are thrown round the body of the prey. A well-known authority 
states that snakes never throw more than two coils round their prey. This is not true. The number of coils depend upon the size of the victim. The constricting power of snakes is very great. I have held Mole Snakes by the neck between my finger and thumb, allowing them to throw their coils round my wrist. Within five minutes the hand would grow cold and numb, the blood circulation having been almost entirely stopped by the pressure of the snake's constrictor muscles upon my wrist. The constricting power of the African Python is tremendous. I have seen a Duiker Buck squashed by a Python into a sausage-like shape within ten minutes.

So rapidly is the victim seized and constricted that the eye can barely follow the various movements. The snake remains quite motionless until the prey is within striking distance. Then, with a movement so rapid that the eyes can but distinguish a sort of blur, the serpent seizes its victim, and next instant its coils are doing their deadly work.

So swiftly and silently does a snake strike and constrict, that the nimble quick-witted rat and mouse, or the active bird are powerless to escape. I have frequently seen House Snakes seize mice which were leaping past them at top speed.

Hearing a squeak under the table when I was once having my evening meal, I looked to see what was the matter. A House Snake had seized and was constricting a mouse. For years I kept these House Snakes, which are quite non-venomous, in my house, not only because I was fond of harmless snakes, but because they were of practical use, for those snakes were better than any house cat in keeping down the mice. Finding my House Snakes too small to tackle big rats, I tamed a Mole Snake, and let him loose under the floor. Within a month the rats had evacuated the premises. After I was married, my snaky pets had to go, not because my wife objected, for she knows much about snakes and rather likes them, but because we could not manage to keep any servants. The servant class in Natal are kafirs as a rule, and all raw kafirs have a holy horror of snakes. It is of no use trying to convince them that any snakes are harmless. To them the bite of a snake is thought to be death for certain, unless some kafir "mooti" is taken.

One day we were feeding a captive Python. It was rather a bulky fellow, a little over sixteen feet in length. One man held 
it by the neck between his knees, which is a convenient way to force open the jaws and ram down the lumps of meat or dead rats. The second man held the snake near the tail-end, to prevent it wrapping itself round the person who was feeding it against its will. Somehow familiarity breeds contempt, or I suppose the man who was responsible for the tail of the python thought its fighting days were over. Anyway, he allowed it to get its tail free, whereupon in his attempts to recover it the snake managed to throw a coil right round the man's neck. Hearing a weird sort of gurgling sound, the fellow in front threw a glance over his shoulder, and saw his friend lying on the ground with his tongue hanging out of his mouth, the blood-vessels of his face swollen, and his eyes bulging almost out of their sockets. So tight was the Python's grip that great force had to be employed to remove the coil from the almost-strangled man's neck.

\section{Remarkable Expanding Power of Jaws.}

Snakes, with the exception of those of the burrowing and more or less worm-like kind, possess the power of expanding their jaws to a remarkable extent. The power varies a good deal, but seems to be possessed in about the same degree by most kinds of snakes. In all other vertebrate creatures the two portions of the jaw-bone are knit solidly together in front. On the contrary, these two parts in snakes' jaws are attached by strong but elastic ligaments. The skin of the head, neck, and body is elastic also, and the various bones composing the skull are loosely attached. The whole mechanism of the head, in fact, is of such a nature that expansion of all the parts is easy.

Snakes never chew their food. When about to swallow a comparatively large victim, the snake usually starts operations at the head. The jaws are lapped over the nose. By slow degrees the body of the victim is forced into the mouth by powerful forward movements of the snake's body muscles, assisted by the jaws, which grip the prey, and by means of the recurved teeth force it down into the throat. The whole swallowing process is a succession of gulps. Gaping its jaws to their utmost capacity, the snake pushes forward, taking a fresh grip and worrying the victim's body as far down as possible. Then there is a short rest, followed by another expansion of the jaws and the same 
contraction of the muscles of the head. Slowly, but surely, the prey is seen to vanish from sight. When the hindquarters have disappeared into the throat of the snake, the task is easy. The muscles of the body set up a series of contractions which force the creature down the gullet into the stomach tube. When it gets to the middle part of the snake where the real stomach is situated, the victim's body goes no further, until digested or disgorged. Sometimes a snake will seize a large rat, toad, or frog and begin by swallowing one of the hind legs. Finding that eventually he cannot make much progress, he rejects the swallowed leg and moves round to the head and begins again.

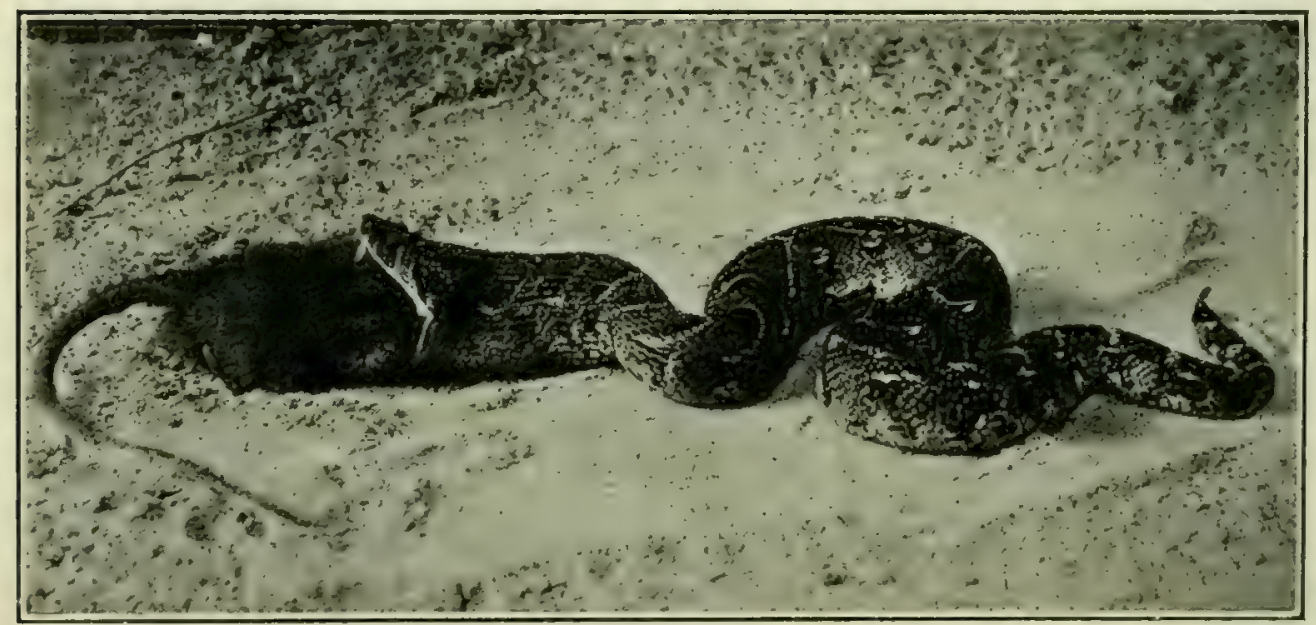

Fig. I7.-A Puff Adder swallowing a large Barn Rat. Note how the snake makes use of his fangs to help to get the body of his victim into his mouth.

I have seen a Puff Adder in captivity swallow three rats in succession. So powerful were its digestive juices that it completely digested them all. Boomslangs will, at times, swallow seven to a dozen frogs in rapid succession. When the prey is of small bulk, it is quickly swallowed. A Puff Adder takes from half an hour to a full hour, and sometimes longer, to swallow a large rat.

\section{Power of Disgorging Prey.}

It is popularly supposed that snakes cannot release their prey once it is well within their jaws, owing to the nature of their teeth, which are curved backwards. On the contrary, when alarmed or irritated, a snake invariably disgorges its prey, either 
during the swallowing process or after. A snake, when in the act of swallowing a bulky victim, is in a helpless state, for its jaws are distended enormously, and it is, moreover, unable to crawl away. Therefore it can neither defend itself nor effect its escape. So, if danger threatens, the victim is instantly disgorged. Snakes in poor condition often swallow prey so bulky that the gastric juices are unable to dispose of it, and the snake gets indigestion. Anyway, if the process of digestion is not proceeding satisfactorily, the victim is disgorged.

In captivity, when several snakes are kept in the same cage, it is a common occurrence for two of them to start swallowing a toad, frog, or rat from opposite ends. When their noses meet at the centre of the victim's body, one of the snakes usually reverses his swallowing mechanism and disgorges the portion he has succeeded in getting into his throat and mouth. Sometimes both stubbornly hold on. In this case the larger or more active snake laps his jaws over the other's head, and calmly and deliberately pushes him, as well as the object of dispute, down his throat. He then retires to a cosy corner, if he be not too bulky to move, and dozes for a week or two until his digestive juices have dissolved his huge meal.

I was lying hidden in a clump of thick bush one day, watching a big yellow Cobra swallowing a rat. I was not the only watcher, however, for it seemed a Mungoose had been carefully keeping the snake under observation, waiting until the reptile had the rat well within its jaws, when like a flash it sprang from the thicket upon the helpless snake, and with a vicious bite smashed the Cobra's backbone at the neck. Hearing me move, it vanished. I examined the snake and found the vertebræ of the neck quite broken, and the surrounding flesh mangled.

\section{Snakes' Climbing Powers.}

Most snakes are excellent climbers, although the majority of the species pass most of their lives upon the ground. The Cobras, Puff Adders, Night Adders, Schaapstekers, Herald Snakes, Water Snakes, and many other South African kinds climb trees with ease. In the snake cages at the Port Elizabeth Museum there are branches of trees fitted in, on which the snakes climb. The only snakes which never attempt to climb trees are the Burrowing 
Snakes and House Snakes. Mole Snakes in captivity never attempt to climb. Occasionally, in the wild condition, I have found them basking in the sun on the tops of creeper-clad shrubs.

The snake, whose natural home is in trees, such as the Mamba, Boomslang, and Bird Snake, glides with tremendous rapidity through the foliage, appearing barely to touch it in their rapid flight. In fact, they seem at times to glide through the branches, twigs, and leaves without touching them. These Tree Snakes move by gripping the twigs, bark, and branches with the sharp corners of their abdominal shields, which are, in turn, worked by means of the ribs and muscle attachments. The snake's body is twisted in and out, under and over the branches and twigs. Snakes never climb by coiling round a branch as is often depicted in pictures.

Puff Adders ascend trees occasionally, but only under exceptional circumstances. Sometimes during heavy rains their haunts get flooded, whereupon they climb up the nearest tree. Occasionally they make their home in a patch of dense bush, which may perhaps cover acres of land. Being unable to get to the beloved sunshine on the ground, they ascend the trees on warm sunny days and lie among the twigs at the tops and bask in the warm rays. Puff Adders frequently do this in the forest belt known as the "Dene," Port Elizabeth. This forest is very dense. The trees were planted by Government with the object of fixing the drifting sand which threatened to cover up the southern portion of Port Elizabeth.

Pythons are expert climbers, although they are usually of such huge bulk. They follow the arboreal Vervet and Samango monkeys to their leafy lairs and levy toll upon them in the evening by lying motionless among the leafy twigs and darting out with gaping jaws, like an arrow from a bow, when the monkeys are passing on their way to bed.

\section{SNAKES' FOOD.}

Snakes prey upon many kinds of living creatures, chief among which are rats, mice, birds and their eggs, toads, frogs, lizards, insects and their larvae. Many kinds of snakes eat their young, and other species of snakes, when opportunity offers. Pythons, of course, being so large, prey mostly upon Monkeys, 

Cane Rats, Hares, and Dassies, as well as the smaller antelopes and the larger birds.

Each species of snake has its own favourite food. The Puff Adder and Cobra prefer toads, rats, mice, and lizards; Water Snakes like fish and frogs; Tree Snakes prefer birds, birds' eggs and their young, chameleons and other tree lizards. Ringhals are partial to toads; Schaapstekers to lizards; House Snakes to young rats and mice; Egg-eating Snakes to fresh eggs; Mcile Snakes like rats and moles.

Snakes, in the wild state, probably never eat any creature which they might find already dead. They hunt living prey. In captivity they can occasionally be induced to eat dead animals and reptiles, but not often. After the snake has become fairly tame and used to its surroundings, it will sometimes seize and swallow a dead creature which is dangled in front of its nose, or gently laid there. Sometimes we suspend the dead bodies of birds, rats, mice, frogs, or toads, by a fine silken thread from the top of the snake-cage. The slightest vibration causes the bodies to twist and turn. In this way the snakes are deceived into the belief that the creatures are alive, whereupon they seize and devour them. Snakes can easily be tamed and taught to take food from the fingers. Several of the live snakes at the Port Elizabeth Museum are fed by an assistant in this manner. A friend of mine had a tame Boomslang which took chameleons and frogs from his fingers. It was so tame that he allowed it out of its cage. It delighted to explore the room. If a stranger entered, or there happened to be any other cause for alarm, it instantly sought refuge in its cage. When my friend held a chameleon up in front of the cage, the Boomslang would work itself up into a tremendous state of excitement. When the door was opened, it darted out like a flash, threw a coil or two of its tail round my friend's neck and arm, and gently took the chameleon into its mouth and proceeded forthwith to swallow it.

In those days we considered Boomslangs to be practically harmless, and in consequence handled them freely. However, our safety lay in our habit of always being gentle in handling snakes. It is the only way to tame them. Eren the sluggish and surly Puff Adder can be tamed by frequent handling, but I always prefer to remove his supply of poison fangs, of which he 
has several duplicate sets in each jaw, previous to starting Puff Adder or Cobra taming experiments.

\section{Adaptation to Surroundings.}

Adaptation of habits and colouration to surroundings is possessed in greater or lesser degree by all living creatures. This provision of Nature operates in two ways. It serves as a protection against enemies. On the other hand, it is of immense service to flesh-eating animals in capturing their prey. The tree-climbing snakes are so alike in colouration to the branches and foliage that they have little difficulty in getting within striking distance of birds. I have seen Tree-snakes remain perfectly rigid, twisting their bodies to represent tree branches, and have watched birds hop right up to them, and even perch upon their bodies, mistaking them for twigs. A bird once within striking distance of a Tree Snake has very little chance of escape, so rapid are the snake's movements. I have seen Boomslangs and Green Mambas make off into small trees scantily clothed with leaves and instantly vanish from sight. On close inspection, they would be found to be entwined among the branches, rigid and still, relying upon the blending of their colouration with their surroundings to escape detection.

The colour of nearly all snakes blends with their surroundings. A Puff Adder, for instance, lying upon the leaf and twig-strewn earth is practically invisible to any one not specially on the lookout for it.

In the various parts of South Africa snakes of the same species vary more or less in colour to suit the nature of their surroundings. The natural habitat of the Boomslang is in trees and shrubs. Its body is, therefore, specially evolved for climbing and rapid gliding movements through dense foliage. In the Eastern Province of the Cape Colony I have frequently seen and captured Boomslangs of a chocolate-brown colour on the ground. When alarmed they invariably glide off and seek refuge down holes, among refuse, or shrubs. I have not yet discovered them in trees.

Mr. James Williams, the man who captures snakes for me, tells me that he nearly always finds these chocolate-coloured 
Boomslangs on the ground. Occasionally he has found them in shrubs, but their usual habit is to hunt for their prey, which consists mainly of lizards, lying on the ground.

These chocolate Boomslangs are of the same species as the others. They vary only in colouration, induced by their altered habits. Green, or greenish-yellow, banded with black, being conspicuous upon the brown earth, dead leaves, and stones, wise Nature has adapted them to their surroundings by changing the colour of their skins. This adaptation of colouration of the various creatures to their surroundings is wonderful and mysterious. It is most certainly not induced by any thoughtpower, or desire in the snake's brain. It is abundantly evident there is a protecting force or Law at work which operates without any conscious desire or wish on the part of the creatures whom it seeks to benefit, by making them as inconspicuous as possible to their enemies and their intended prey. This great Natural Law is quite impartial, as are all the Law's of God. It makes the colour of one creature blend so perfectly with its surroundings as to enable it to steal upon its intended victim unawares, but it also seeks in a similar manner to render the intended prey as inconspicuous as possible. This is one of the methods by which Nature forces all living creatures to exert themselves mentally and physically. It is only by mental and physical activity that the evolution of life proceeds.

\section{Fresh-WATER SNAKES.}

The Fresh-water Snakes haunt the vicinity of rivers, pools, and marshes, swimming and diving with the greatest ease and grace. They live mostly upon aquatic creatures such as tadpoles, frogs, and fish. Specimens kept in captivity readily seize and eat small live fish placed in their water-pan. These snakes do not live habitually in the water. In fact, they only enter the water in search of prey. If a frog or fish be seized in the water, the snake will swim to land with it. I have seen Green Water Snakes carry frogs several yards up a sloping bank. The snake holds its prey in its jaws and raises the head and fore part of the body off the ground when thus employed. 


\section{SALT-WATER SNAKES.}

These snakes inhabit the ocean, and feed upon fish and other marine creatures. They are all very venomous. These Saltwater Snakes are distinguished from all other snakes in having a keel-like tail, flattened at the sides, which they use as a propeller. They possess no fins and are true snakes, and therefore real sea serpents. As far as is known, they are all viviparous. The gravid female visits the shallow waters of rocky coasts and gives birth to her young in the rock pools. Sea snakes are usually brilliantly coloured. They are seldom found in mid-ocean.

\section{Migration.}

Snakes do not migrate from one locality to another, unless forced by hunger or a change in their surroundings, such as an unusually heavy rainfall, rendering the ground more or less marshy, or the slow change brought about by the prolonged droughts which occur from time to time in various districts. They always remain in the same locality as long as food is procurable. Most species have some favourite spot to which they retire when desiring to rest, or to escape from their enemies.

\section{Hibernation.}

Snakes usually hibernate during the colder months of each year. They do this for two good reasons. Food is scarce during the winter months. Snakes are largely dependent for their vitality on the temperature of the surrounding air, their bodies being unable to accommodate themselves to rapid changes of temperature owing to the very slow circulation of their blood and consequent low normal temperature. In the tropics and in favourable situations in temperate climates, snakes often remain active all the year round. In certain localities in South Africa several species of snakes do not hibernate. Others hibernate only when the days are very chilly, but if a warm breeze should blow, and the temperature of the air rises a few degrees, they will often issue out of their lurking places to bask in the sunshine. I have examined snakes quite stiff and rigid, and apparently dead 
with the cold, but on the application of heat they soon regained all their vigour and vitality.

The live snakes in the Port Elizabeth Museum cages are most active when the air is warm, and grow torpid in proportion to the lowering of the temperature of the air. When their cages are artificially heated they immediately revive.

If a snake should find a cosy retreat, and provided there is sufficient sustenance in the neighbourhood, he will make that spot his headquarters, from which he will issue forth when hungry and scour the neighbourhood in search of food; or else bask in the warm sunshine ready to beat a retreat on the least sign of danger. When the leaves begin to fall and the air grows chilly, a drowsy feeling begins to pervade his body which warns him it is time to seek out a cosy shelter for his long sleep. So he crawls into the innermost recesses of his lair, or seeks out a better one. Coiling himself up, he sinks into a condition of torpor.

Most species of reptiles have the power of suspending animation and lying in a death-like trance through the winter months, when the food on which they live is either very scarce or quite unobtainable. When animation is more or less suspended, an exceedingly small quantity of food-material is used up to keep the creature alive; whereas if it were active all the winter, it would require an abundant supply. This would mean that most species of reptiles would die of starvation. Those which had found enough food to tide them over till the summer season would not be in sufficient numbers to keep down the armies of living creatures which constitute the diet of reptiles. Thus would the balance of Nature be upset.

\section{Parasites on Snakes.}

Snakes are frequently infested with parasites. Ticks often fasten themselves upon the skin between the scales.

There once occurred an unusual mortality amongst the collection of live snakes in the Port Elizabeth Museum, which are kept in a long row of cages each four feet square and the same height, with plate-glass on the four sides. Noticing minute parasites upon one of the dead snakes, I made a microscopical examination of them, and found they were a species of lice somewhat smaller 
than fowl lice. On close observation of the living snakes I discovered they were all swarming with these tiny vermin, which harboured under and between the scales. I immediately caused the snakes to be thoroughly oiled all over, and the cages washed out with disinfectant. We were never again troubled with lice. The parasites had doubtless been introduced by a snake which had, in the wild state, been infested with them.

\section{The Habits of SNakes.}

When we study the habits of various creatures, we find that their customs are regulated by their food supply, the necessity for avoiding enemies and climatic conditions.

Snakes come forth in search of their prey, both during the daytime and at night. During the heat of the day they issue from their various retreats to bask in the sun's warm rays, for their blood is cold, and they love the heat. It means life and vitality to them. Tree Snakes hunt mostly during the daytime, both among the foliage and upon the ground, for their food. The Cobra, Puff Adder, Ringhals, and various other snakes, whose chief diet consists of toads, rats, and mice, usually issue forth toward sundown, and actively scour the neighbourhood, knowing that the creatures on which they prey are in the habit of going out about that time and during the evening. When the temperature of the air is fairly warm, snakes may be seen at any hour of the day or night. As a rule, they do not wander much on dark nights, but in the warm moonlight they are invariably out looking for food.

Snakes strongly dislike cold and wet, and on the approach of rain, or if the temperature of the air falls, they hasten away to their snug retreats, and await the return of bright and warm weather.

Beetles, slugs, and other insects, which constitute the chief food of toads, invariably go out about sundown to feed upon other insects or vegetation. The toads, knowing this, come out from their lairs at these times. The crafty Cobra, knowing he is most likely to find a good fat toad for his supper about sundown, also comes forth and spies around. Because the vegetation is damp and succulent after sunset, the insect prefers to eat it at that time. The toad comes out and eats its prey, and the 
Cobra comes along and swallows the toad. Lastly, man follows and captures or kills the Cobra.

The habits of the same species of snakes differ in accordance with their environment. In some loralities snakes are never seen at night, because the air is invariably cold after sundown. In other localities it is just the reverse.

Finding themselves under strange and abnormal conditions when placed in cages, most snakes refuse to eat, although they will regularly drink water and actively crawl around. I have never succeeded in keeping Schaapstekers, Grass Snakes, or Sand Snakes alive for more than six months in ordinary cages indoors, or in other situations where there was a lack of sunshine.

It is only occasionally that Boomslangs will take food. The majority take no notice if chameleons, lizards, or nests containing fresh pigeons' and other birds' eggs are placed in their cages. Puff Adders will eat a rat on occasion. As likely as not it will be disgorged the following day. Frequently they strike and kill the rats, but take no further notice of them. Mole Snakes invariably refuse all food. House Snakes, Green Water Snakes, Brown Water Snakes, and Night Adders eat freely in captivity. The House Snakes eat mice; the other three species prefer frogs.

Snakes, if kept in an enclosure twelve or more feet square, out in the open air, with suitable cosy corners, nooks, and crannies provided, and plenty of fresh water, will live, thrive, and breed. In such a large enclosure many species of snakes may be kept together. It is true they sometimes swallow each other, but that is not of much consequence if they are of common species, for they can easily be replaced. The only really aggressive snakes are the Cobras, especially those species which grow to a large size, such, for instance, as the Cape Cobra (Naia flava). These big fellows are bold, active, and aggressive, and often deliberately attack other snakes. However, after being a few months in captivity, they calm down, and will not interfere, as a rule, with other species of snakes, except the smaller kinds, which they attack, overcome, and swallow when hungry.

The only drawback I have found in keeping a large number of different species of snakes in one large enclosure is that if one should seize and begin to swallow a toad, etc., another will often 
come along and start operations at the opposite end of the victim, and thus in many cases one snake is swallowed by another.

Of course, it is not desirable to keep the bulky Python with the other kinds of snakes. He is an inoffensive fellow, but his huge bulk, which he cannot help dragging along with him, is apt to injure snakes over which he might happen to crawl. Also he has a habit of poking about and endeavouring to thrust himself out of sight into small holes and crannies, and in this way he makes chaos of the little interior arrangements of the enclosure designed for the convenience of the smaller reptiles.

A snake-house should be so situated as to be well sheltered from wind and rain, and so arranged that the sun may at all times of the day, from sunrise to sunset, shine into some portion of it. Great care should be taken that the snakes have cool places into which to retire when the sun is very hot and the atmosphere rises to blood heat. Free access to air must be given, so that the snake-house may not get unduly heated.

I once lost a large collection of snakes by allowing the air to get too hot inside the snake-house. The sun heated the glass and wooden partitions, which naturally had the effect of raising the temperature of the air considerably. Every snake perished with the heat, although they were not subjected to direct sunshine. Testing the degree of heat with a thermometer, I found the air registered a hundred and six degrees Fahr.

If you hold the belief that snakes are very tenacious of life, abandon that belief, for they are not. When mangled they may twist, writhe, and squirm for many hours, but nevertheless a snake is very easily killed. A slight injury will cause death, not necessarily at once, but perhaps a week or a month later. At the Port Elizabeth Museum I used to wonder why we had such a great mortality amongst our live snakes which were sent us by kind friends in various parts of the country. On skinning them my assistant discovered various discolourations, showing that they had been struck or otherwise knocked about when being captured. At first I used to dissect out the fangs, and sometimes the maxillary bone on which they are fixed. I found that in the majority of cases abscesses formed which caused the snake to cease eating. When fed artificially the mouth invariably bled, the abscesses grew worse, and the snakes pined and died. 

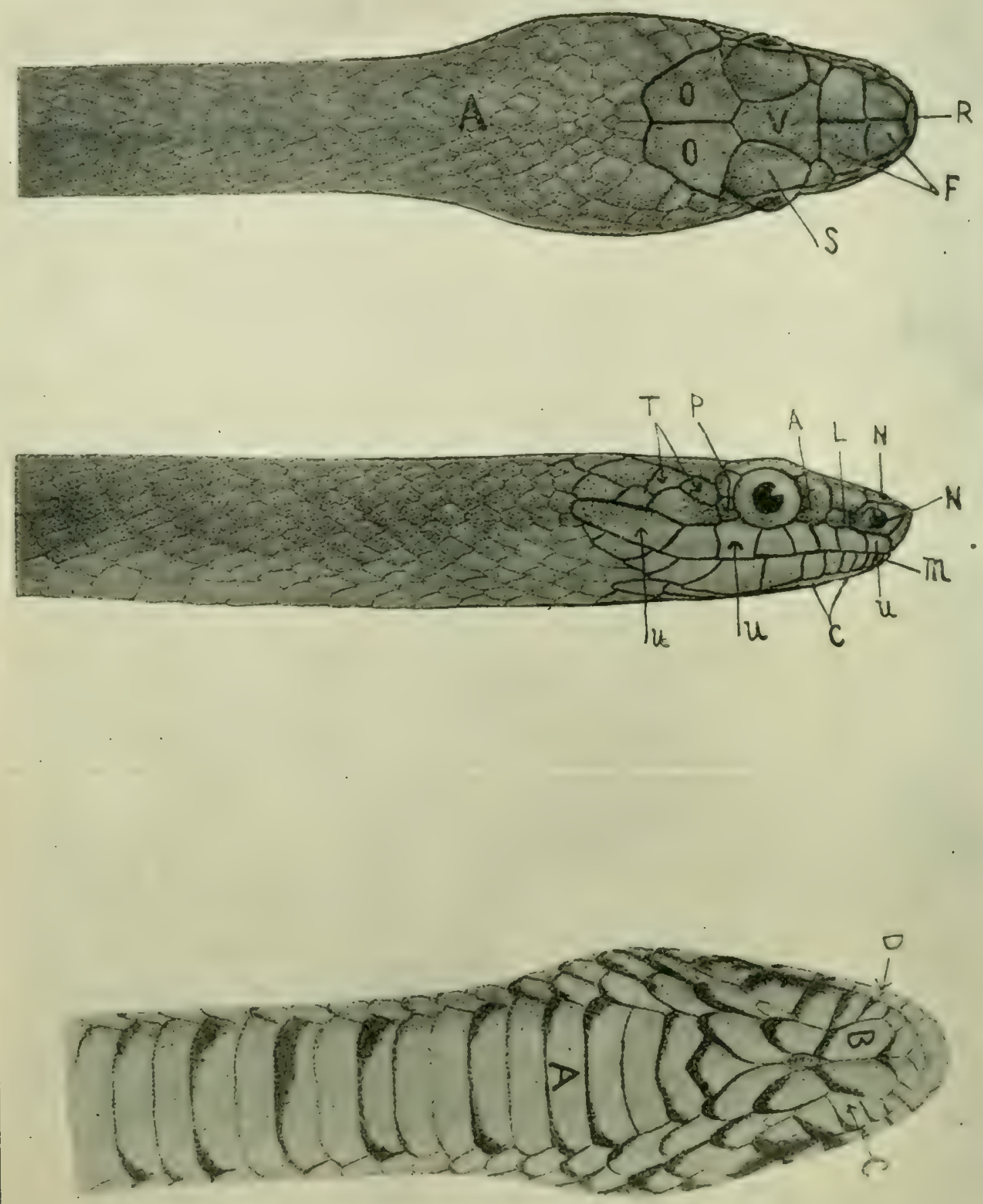

STUDY PLATE FOR SCIENTIFIC STUDENTS.

F1G. 19.-I. (A.) The scales of the back. O.O. Parictal shields. V. Interparietal shicld. F. Anterior and posterior frontal shields. S. Supraocular shield. R. Rostral shield. P. Postocular shicld. U.U. Upper 2. N.N. Nasal shield. L. Loreal shield. A. Preocular shield. P. Postocular shields. labial shields. T. Temporal shields. M. Mental or median lower labial. C. Chin shields.

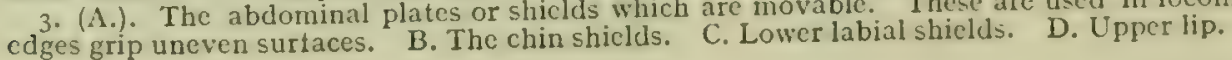


In some experiments which I conducted with a view of ascertaining if certain species of snakes were immune to Puff Adder venom, I allowed the adder to bite them, either in the neck or somewhere about the abdomen. In nearly all cases the bitten snakes died a week or so later. However, I subsequently discovered that the deaths were caused not by the venom, but by the actual mechanical injury caused to the internal parts of the bitten snakes, by the large fangs of the Puff Adders.

\section{IDENTIFICATION OF SNAKES.}

In the identification of the species of snakes the colouration is a most uncertain guide. The systematic Zoologist examines the dentition to ascertain to what division the specimen belongs. There are three main divisions, viz. the AGLYPHA, or solid-toothed non-venomous snakes; the OPISTHOGLYPHA, or hindfanged, more or less poisonous snakes; and the PROTEROGLYPHA, or front-fanged, typically venomous snakes.

After finding out what family, sub-family, and genus the specimen is a member by means of the general formation of the body, scales, and shields, the zoologist identifies the species by examining the shields on the head and abdomen. The number and shape of the head and abdominal shields differ in the various species of snakes. Sometimes they merely slightly differ in a species. In these cases we term it a sub-species, if the difference is observed to be constant.

If you compare the head shields of two different species of snakes, you will notice they differ in shape. If the abdominal (ventral) shields are counted they will differ in number. So also will those from the vent to the end of the tail (sub-caudals). In some species of snakes the shield

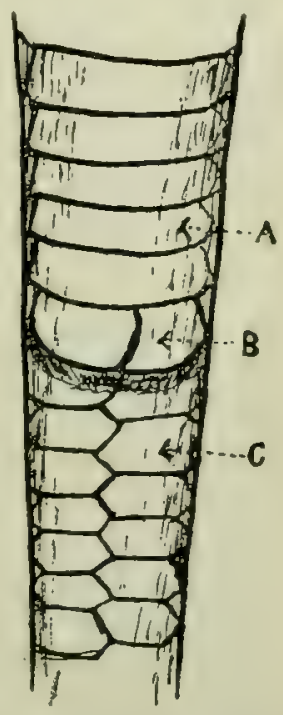

FIG. 20.-A. Ventrals or abdominal shields. They extend from throat to vent.

B. Anal shield. In some snakes this shield, which covers the vent is divided. In others it is entire.

C. $S u b-c a u d a l$ These shields in some snakes are in two rows; in others in a single row. (anal) over the vent is divided. In others it is entire. So also with the sub-caudals. In some snakes they are in one row, and in others they are in two rows. Their number also differ with the species. 


\section{CHAPTER III.}

The Blind Burrowing Snakes.

(Blind Delgend Slang.)

FAMily I.-TyPhLOPIDE.

THESE snakes are small and worm-like in appearance, with cylindrical bodies and blunt tails. They are covered with tiny closely-fitting scales, and their eyes are more or less rudimentary. They burrow in the ground, especially in soft loamy and sandy soils, and feed upon small lizards, ants, larvæ, worms, beetles and other insects. They are usually found under stones, loose soil, and decaying leaves and wood. Occasionally, after a shower of rain, they appear above ground in search of insects, which issue forth from their retreats at this time. The jaws of this family of snakes are not capable of much distension, as is the case with the more highly evolved or specialized snakes, consequently they cannot swallow large prey. Their upper jaws are armed with small, sharp teeth, but the lower jaws are toothless. They are all quite non-venomous and can be safely handled. They make nice pets, and soon grow very tame, and thrive if kept in a box containing sand in which they may burrow, and supplied with water and insects, especially ants and their larvæ. If the cage be placed out in the sun they come up to the surface to bask, their bodies glittering like burnished metal.

All the different species lay eggs, which are large in proportion to the size of the snake. This family of snakes, and the following family (Glanconida) constitute the link between the more highlyspecialized snakes and lizards from which snakes have evolved. There are over roo species or kinds of Typhlops snakes inhabiting various parts of the world, ten of which live in South Africa, south of the Zambesi. These Burrowing Snakes still possess rudiments 
of a pelvis, which indicates that their remote ancestors had legs. Those ancestors, in fact, were lizards. The fact that these snakes have blunt tails and the vent situated almost at the end, has given rise to the popular belief in "Two-headed" Snakes. When examined casually they certainly have the appearance of possessing a head at opposite ends of the body.

\section{GENUS TYPHLOPS.}

A single Gemus in South Africa.

KEY TO THE SPECIES.

I. TYPHLOPS VERTICALIS, - Snout rounded; 22 or 24 scales round the body. Preocular much narrower than the ocular, in contact with the second and third labials; diameter of body 42 to 45 times in total length.

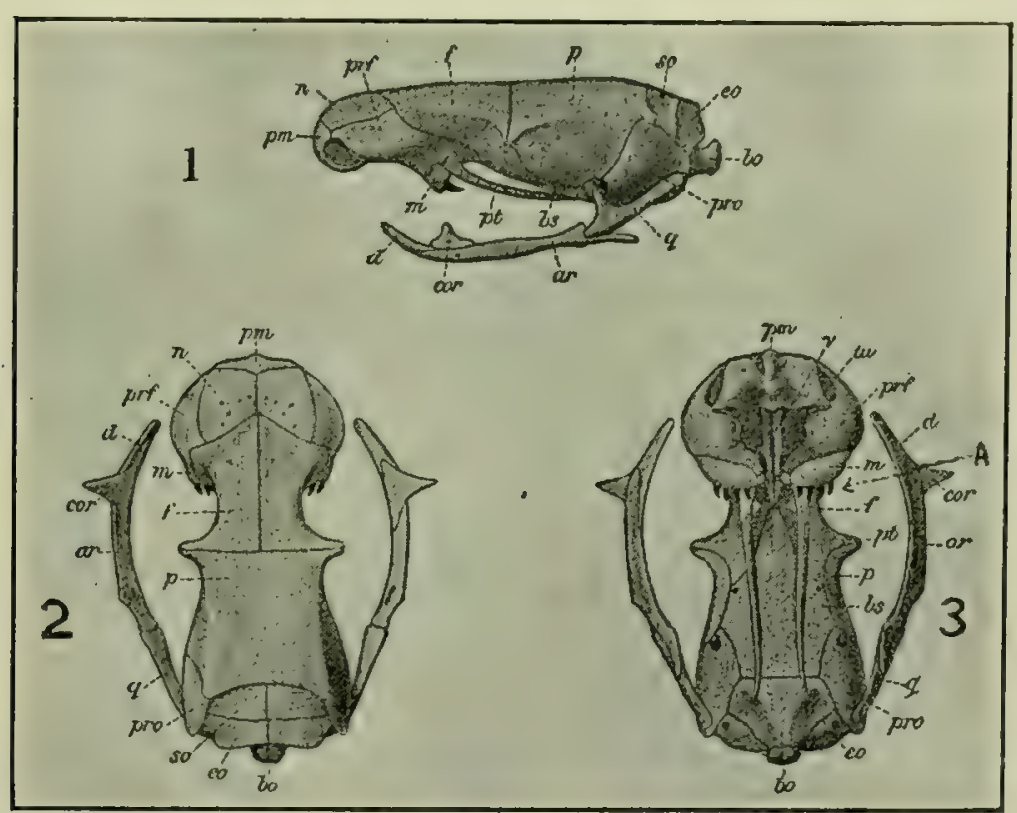

SKULLS OF TYPHLOPS OR BLIND BURROWING SNAKES.

FIG. 2I.-(I) Side view showing situation of teeth. (2) Skull viewed from above. (3) Skull showing roof of the mouth and row of teeth. These are the only teeth a Typhlops Snake has. (Brit. Mus. Cat. Snakes.)

2. Typhlops Fornasinir.-Snout rounded; 22 or 24 scales round the body. Preocular a little narrower than the ocular, in contact with the second labial only ; diameter of body 23 to 30 times in total length.

3. TyPhLOPS MOSSAMBICUS.--Snout with obtusely angular, not trenchant, 
horizontal edge; 24 scales round the body. Preocular in contact with the second and third labials; diameter of body 30 times in total length.

4. TyPhlops ANCHIETE.- Snout with obtusely angular, not trenchant, horizontal edge; 30 or 32 scales round the body. Preocular in contact with the second labial only; diameter of body 24 times in total length; eye not distinguishable.

5. TYPHLOPS BIBRONII.-Snout with obtusely angular, but not trenchant, horizontal edge; 30 to 34 scales round the body. Preocular in contact with the second labial (rarely second and third) ; diameter of body 28 to 36 times in total length ; eye distinct.

6. Typhlops Delalandi.--Snout not hooked (in profile). Snout with sharp, trenchant, horizontal edge; 28 to 30 scales round the body ; diameter of body 35 to 50 times in total length.

7. Typhlops mucroso.--Snout not hooked (in profile). Snout with sharp, trenchant, horizontal edge ; 30 to 38 scales round the body : diameter of body 25 to 35 times in total length.

8. TYPHLOPS DINGA.-Snout with sharp, trenchant, horizontal edge. Snout not hooked (in profile); 34 to 4 o scales round the body; diameter of body 42 to 46 times in total length.

9. TyPhlops schlegeli. - Snout with sharp, trenchant, horizontal edge. Snout not hooked (in profile); 40 to 44 scales round the body; diameter of body 25 to 30 times in total length.

IO. TyPhlops Schinzi, - Snout hooked. Snout with sharp, trenchant, horizontal edge; 24 to 26 scales round the body; diameter of body 45 to 57 in total length.

\section{TYPHLOPS.}

\section{Ten Species in South Africa.}

1. Typhlors verticalis. The Yellow-brown Blind Snake. Geel-bruin Slang.

Synonym-Onychocephalus verticalis.

Colour-uniform brownish-yellow.

Average length-6 to 8 inches.

Distribution-Western Province of Cape Colony.

2. Typulops ForNASINII. East African Blind Snake.

Colour-bluish or greyish. Anal region yellowish.

Average length -6 to 8 inches.

Distribution-Delagoa Bay; Portuguese East Africa.

3. Typhlops mossambicus. Mossambique Blind Snake.

Synonym-Onychocephahis mossambicus.

Colour-Dark brown; lower surface of head and anal region ycllowish. Average length - 6 to 7 inches.

Distribution-Zululand; Northwards to Portuguese Vast Africa.

4. Typhlops anchietre. Anchieta's Blind Snake.

Colour-Pale yellow, with greyish-brown blotches.

Average length -6 inches.

Distribution-Transvaal; Angola.

5. TYPHLOPS BIBRONII. Variously known as the Blind Snake; Twoheaded Snake; Ground Snake; Aard Slang; 'lweekop Slang. Synonym-Onychocephalus bibronii. 


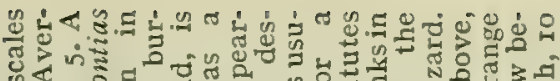

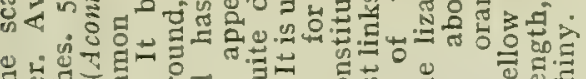

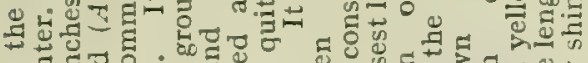

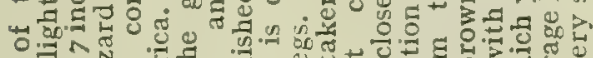

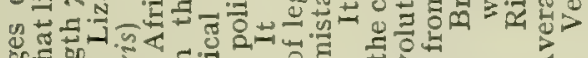

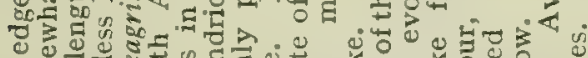

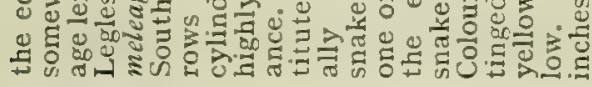
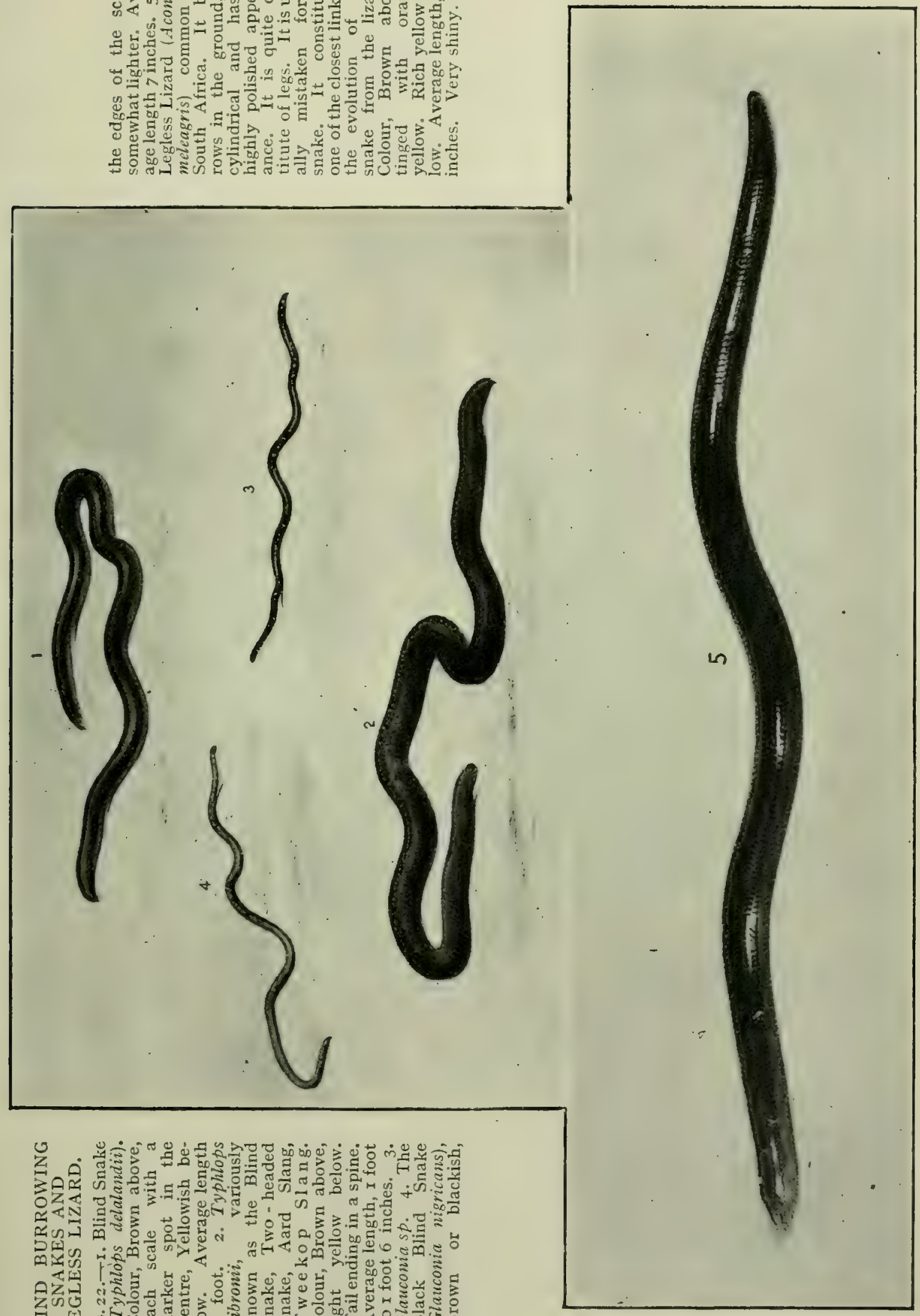

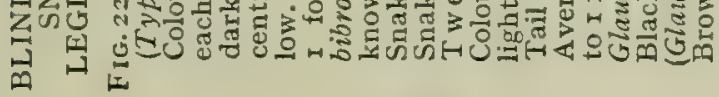


Colour-Brown above; yellow on the underparts.

Average length - I foot to $x$ foot 6 inches,

Distribution-Common throughout South Africa. Not recorded north of the Zambesi.

6. Typhlops delatandir. Delalandi's Blind Snake.

Colour-Pale brown above each scale, with a darker central spot;

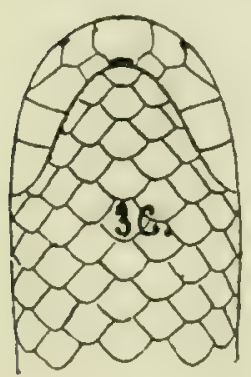

3c.

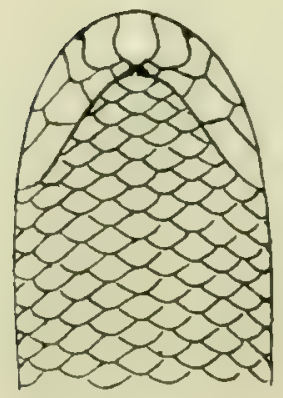

5 c.

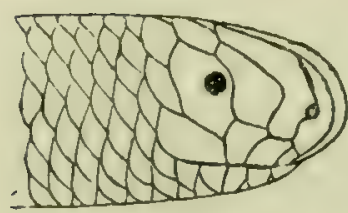

$5 b$.
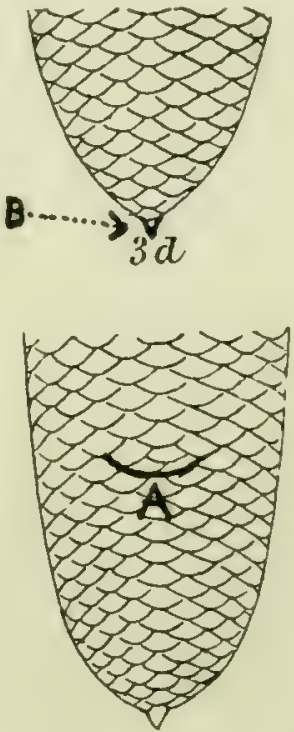

$5 d$

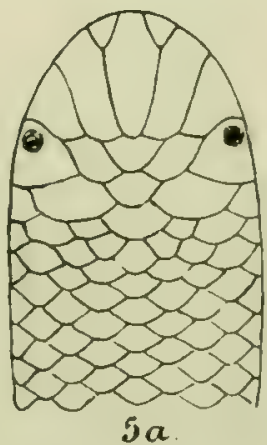

$5 a$ yellowish on the underparts.

Average length-I foot.

Distribution-Occurs all over South Africa. Not recorded north of the Zambesi.

7. Typhlops mucroso. The Vari. able Blind Snake.

Synonym - Onychocephalus mucroso.

Colour-Upper parts variable in colour; lower parts uniform yellowish.

Average length - I foot to I foot 6 inches.

Distribution - Transvaal; Delagoa Bay; Rhodesia ; Zambesi Regions; North to East and Central Africa.

8. TYPhLOPS DINGA. The Rustyred Blind Snake.

Synonym - Onychocephalus dinga.

Colour-Rusty red above, with confluent black spots.

Average length -2 feet to 2 feet 6 inches.

Distribution - Southern Rhodesia; Portuguese East Africa.

9. Typhlops SchlegeliI. Schlegel's Blind Snake.

Synonym - Onychocephalus schlegelii.

Colour-Uniform olive - brown above, or parti - coloured yellow and olive-brown, the latter colour forming irregular blotches; lower parts uniform yellow.

Average length -1 foot 6 inches to 2 feet.

3d. Tail, showing the spine at the tip $B$.

5a. Head viewed from above.

5b. Head viewed from the side.

5 c. Head vicwed from below.

5d. Tail showing spine at end.

Vent is at part marked A. Eyes are covered by scales. (From Brit. Mus. Cat. Snakes.)

Distribution-Sonthern Rhodesia; Portuguese Fast Africa; Central Africa.

ro. Typhlops schinzi. Black-spotted Blind Snake.

Colour-Yellowish above, with small black spots.

Average length -8 inches.

Distribution-Northern parts of Cape Colony: Little Namaqualand. 


\section{FAMily II. GLAUCONIDÆ.}

These snakes are very similar in general structure to the former family (Typhlopida), and their habits are more or less alike. They are placed in a separate family because they are anatomically somewhat different, viz. they have teeth in the lower jaw only, the upper jaw being quite toothless. They possess fourteen rows of scales round the body. The typhlops snakes, on the contrary, have teeth in the upper jaw, but none in the lower jaw, and they have at least eighteen rows of scales round their bodies. The Glanconida snakes are blunt-tailed like the former family, and are, like their cousins, often popularly termed "Two-

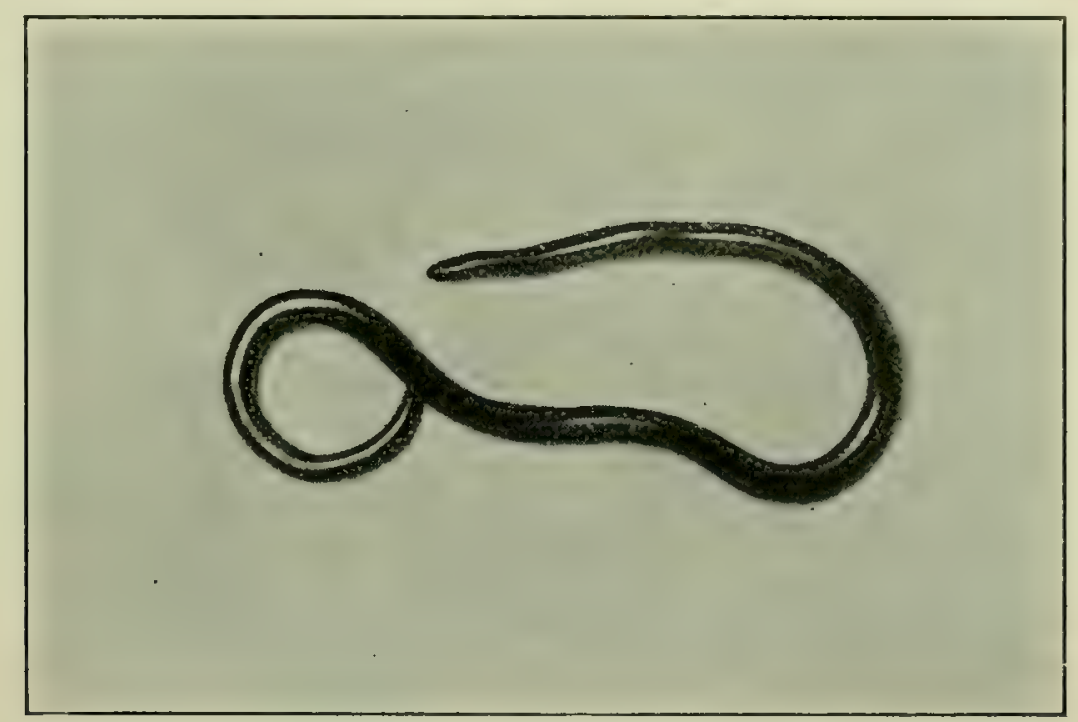

FIG. 24.-A life-size Glauconia or Blind Burrowing Snake (Glauconia nigricans).

headed Snakes." People have occasionally brought snakes to me, and were in a very excited state, claiming to have discovered a snake with a head at each end of the body. In all cases they turned out to be Blind Burrowing Snakes. Like the former family, the Glauconida are all quite non-venomous, and make most interesting pets. These Burrowing Snakes are very useful in the economy of Nature in keeping down the too rapid increase of insect life.

There are about thirty species of these snakes, six species of which are known to inhabit South Africa. 


\section{Genus GLAUCONiA.}

\section{A single Genus in South Africa.}

KEY TO THE SPECIES.

I. Giauconia nigricans.-Supraocular present. Rostral separated from the supraocular by the upper part of the nasal; diameter of body 40 to 60 times in total length.

2. Glauconia conjuncta. - Supraocular present. Rostral in contact with the supraocular; Rostral not more than twice the width of the nasal, extending to, or slightly beyond a line connecting the posterior borders of the eyes. Diameter of body 47 to 60 times in total length.

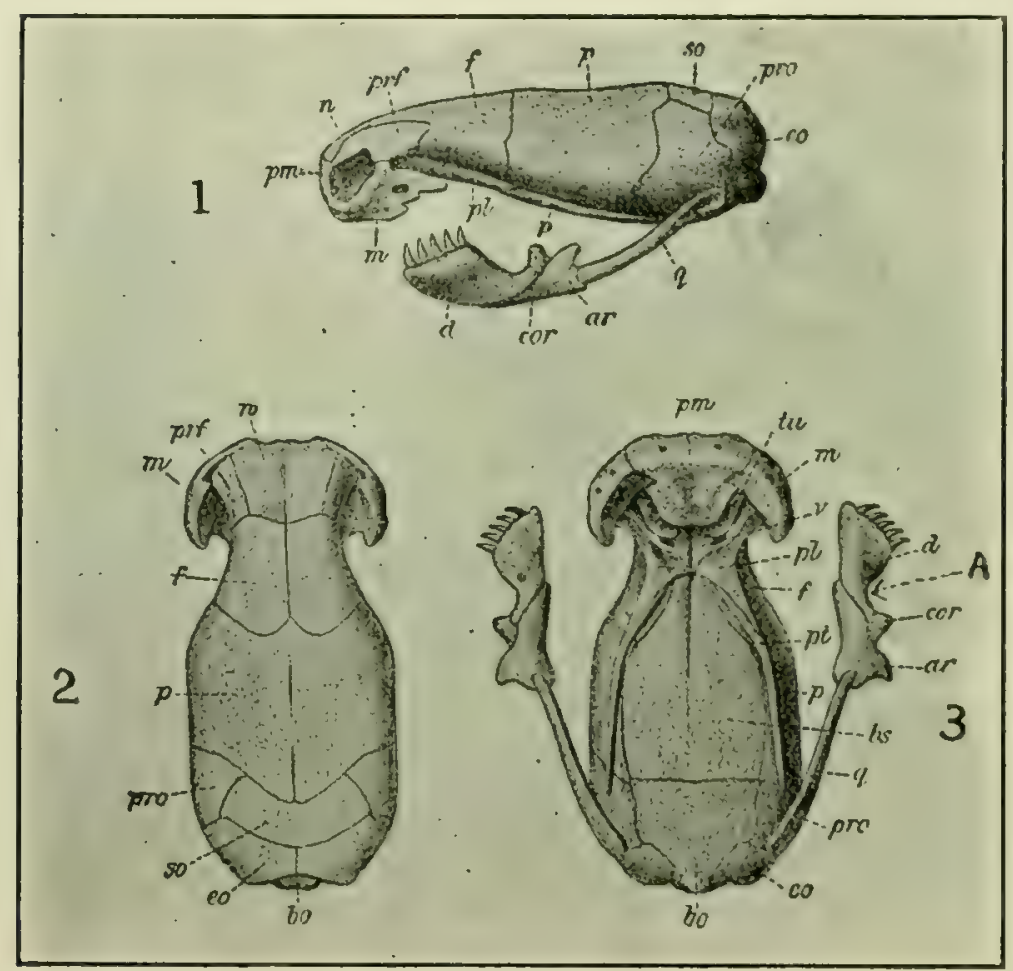

SKULLS OF GLAUCONIA SNAKES.

FIG. 25.-I. Side view showing the teeth in the lower jaw. There are none in the upper jaw.

2. Skull seen from above.

3. Skull seen from below showing toothless palate. A. Lower jaw. (Brit. Mus. Cat. Srakes.)

3. Glauconia GRACILIOR.-Differs from the former in having the diameter of the body 90 to I Io times in total length. Body very slender.

4. Glauconia scutifrons.-Supraocular present. Rostral, very large, at least twice as broad as the nasal and extending beyond a line connecting the posterior border of the eyes; diameter of body 50 to 80 times in total length. Snout rounded.

5. Glauconia distanti.-Supraocular present. Snout with preoral part concave, appearing slightly hooked in profile.

6. Glauconia LAmialis.-No supraocular. In all the other species the supraocular is present. 


\section{GLAUCONIA.}

\section{Six Species in South Africa.}

1. Glauconia nigricans. Black Blind Snake. Zwart Blind Slang.

Synonyms-Typhlops nigricans: Stenostoma nigricans.

Colour-Brown or blackish, with scales edged with lighter.

Average length -6 inches.

Distribution-Both provinces of Cape Colony; Natal; O. R. C., Transvaal.

2. Glauconia conjuncta. The Intermediate Blind Snake.

Synonyms-Stenostoma conjunctum; Stenostoma nigricans : Stenostoma groutii. This species connects $G$. nigricans with $G$. scutifrons.

Average length -6 inches.

Distribution-Both provinces of Cape Colony ; O. R. C.; Basutoland ;

Natal; Zululand; Transvaal; Northwards to East Africa.

3. Glauconia gracilior. The Slender Blind Snake.

Colour-Uniform brownish-black.

Average length -8 inches.

Distribution-Western Province, Cape Colony.

4. Glauconia scutifrons.

Synonyms-Stenostoma scutifrons; Glauconia latifrons.

Colour-Brown or blackish above; whitish beneath.

Average length -6 to 8 inches.

Distribution-Eastern Province of Cape Colony; Natal; Zululand:

O.R.C.; Transvaal; Southern Rhodesia; Northwards to Angola.

5. Glauconia distanti. Distant's Blind Snake.

Colour-Uniform blackish, the borders of the scales lighter.

Average length -5 to 6 inches.

Distribution-Transvaal; Bechuanaland; Southern Rhodesia.

6. Glauconia labialis.

Distribution-German South West Africa.

\section{The Python or Rock Snake (Python Sebex).}

\section{Family iII. Boide. Genus Python.}

The Python belongs to a family of snakes known as the Boida. There are nine species or kinds of Pythons, three in Africa and the rest in the Malay Archipelago, India and Australasia. Belonging to the same family is another sub-family of snakes called Boas, chief among which is the terrible Anaconda of Amercia, which is stated to attain a length of thirty-six feet. None of these Boa-constrictors inhabit Africa.

\section{The African Python.}

The South African Python, also known as the Natal Rock Snake (Python sebce), is common in the Southern portion of Africa, mostly towards the East side. In West Africa it is replaced by 
another species known as the West African Python (Python rewius), and in South W'est Africa by Anchieta's Python (Python anchicte). The Rock Snake or Python is fairly common in Rhodesia, Natal, Zululand and Eastern Transvaal. I have also obtained specimens from Bechuanaland.

The statements in regard to the length attained by these

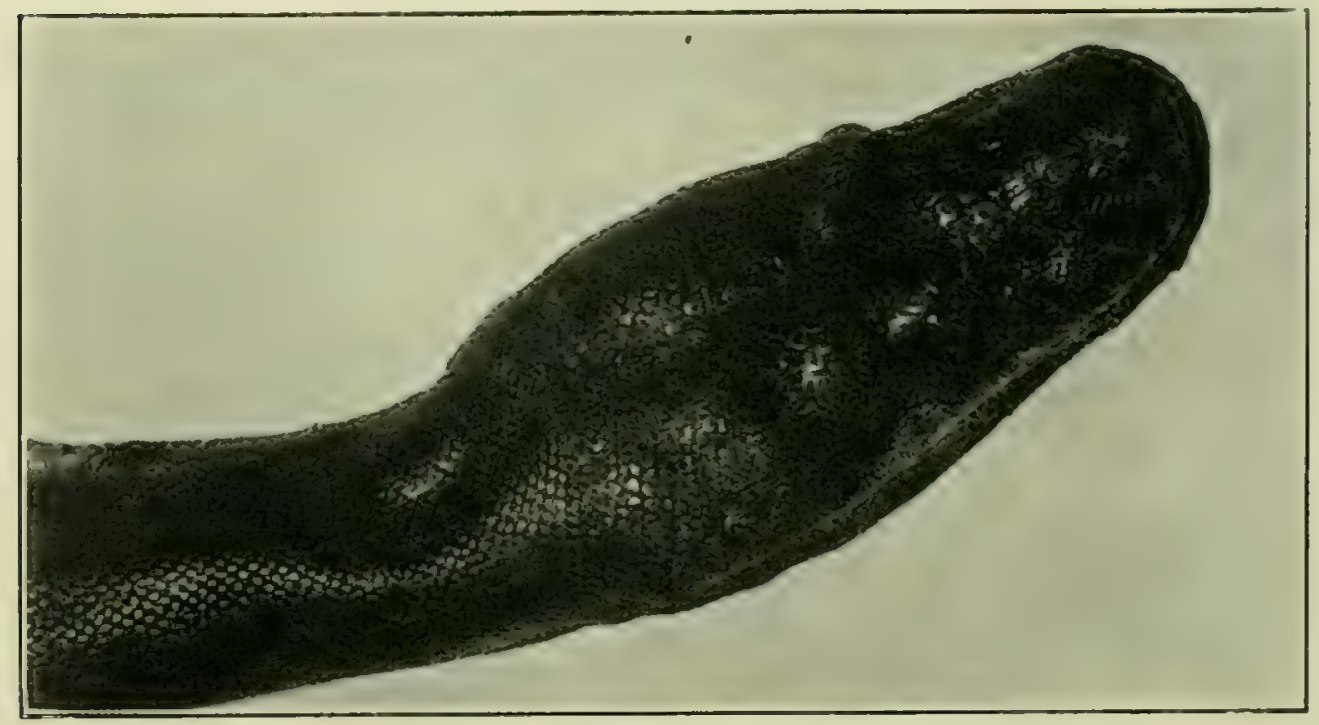

FIG. 26.-Head and neck of a South African Python (Python scbe).

Pythons is very conflicting. Sir Andrew Smith, in his " Zoology of South Africa," mentions one twenty-five feet long, which he personally examined and measured. I have examined a considerable number, and the longest was twenty feet. The average length seems to be about sixteen feet, the circumference at the thickest part being about eighteen inches.

I. Python Seber. The South African Python, also known as the Natal Rock Snake.

Synonyms-Coluber seba: Hortulia natalensis.

Colour-Pale brown above, with dark brown, black-edged, more or less sinuous cross bars which are usually connected by a continuous, or interrupted dark stripe running along each side of the back; sides with large spots, and finely dotted with black; a large triangular dark brown blotch occupying the top of the head, bordered on each side by a light stripe, beginning at the end of the snout above the nostril, and passing above the eye. A dark stripe on each side of the head, and a dark sub-triangular blotch below the eye; upper surface of tail with a light stripe between two black ones. Belly spotted and dotted with dark brown.

Average length -16 feet. Said to attain a length of 25 feet.

Distribution-Natal; Zululand; Eastern Transvaal; Eastern portion of Bechuanaland; Southern Rhodesia; Portuguese East Africa; Tropical Africa. 


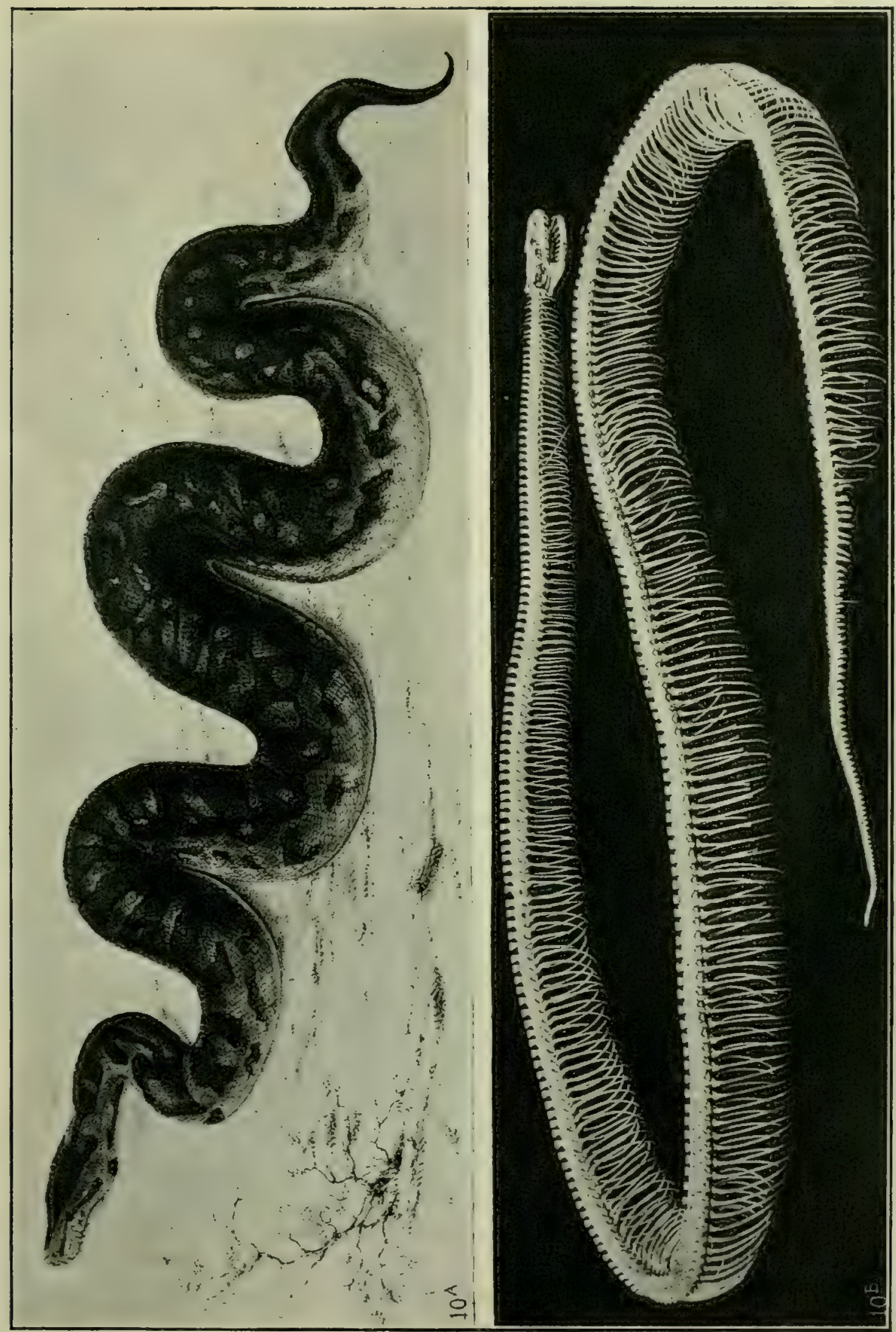

A PYTHON AND ITS SKELETON.

Frg. 27.-The African Python or Natal Rock Snake. (After Smith.) These snakes attain a length of 20 feet and over. Colour, light brown, with irregular cross bands and squares of dark brown. Yellowish beneath, usually spotted and dotted with dark brown. 2. The complete skeleton of a South African Python (Python sebce) I6 feet in length. This skeleton was prepared at the Port Elizabeth Museum, and is on exhibition there. It is bored and wired throughout. Note the huge number of ribs, and sections of the backbone. 


\section{Their Haunts and Diet.}

Pythons frequent moist rocky valleys, plantation and bushcovered lands, and are rarely found far from water. Their principal diet is birds, mammals, such as Dassies, Hares, Cane Rats, the smaller antelopes, monkeys, etc.

Along the coastal districts of Natal there are extensive sugarcane plantations, where these Pythons delight to dwell, as there is abundance of food in the shape of Cane Rats, otherwise known as Ground Pigs (Thryonomys swindercniamus). These Cane Rats attain the size of full-grown Dassies or Rock Rabbits. They are not real rats. Their nearest relation is the porcupine. These Cane Rats are very destructive to the sugar-cane, so the planter regards the Python as his best and most useful ally.

When seeking food the Python usually lies in ambush in some place where animals are likely to pass. When the intended victim is within striking distance, the snake lunges forward, seizes its startled victim in its jaws, which are armed with fairly large re-curved teeth. Then with lightning-like rapidity its body is thrown around the terrified, struggling animal, which is rapidly crushed to death.

\section{Swallowing the Prey.}

The snake begins at the head and swallows the body, after the manner of other snakes, as previously explained. If the captured animal be large, the snake crushes it so effectually that it is converted into a sausage-shaped mass, which naturally makes the swallowing process ever so much easier.

During deglutition the salivary glands are very active, and an abundance of saliva is excreted which enables the snake to swallow the prey with comparative ease. The snake does not, however, smear its victim with saliva before starting to swallow it. The saliva only comes in contact with the portion of the prey which is within the mouth. Sometimes a little escapes from the sides of the mouth. Snakes never "slime" their prey previous to swallowing it.

The popular belief that snakes cover their prey with a slimy secretion previous to proceeding to swallow it, is incorrect. What evidently gave rise to this belief, is the custom of snakes to disgorge their prey if irritated or alarmed. Naturally the 
cast-up body of the victim is covered with a slimy secretion with which it became covered during the swallowing process, and while in the digestive tract.

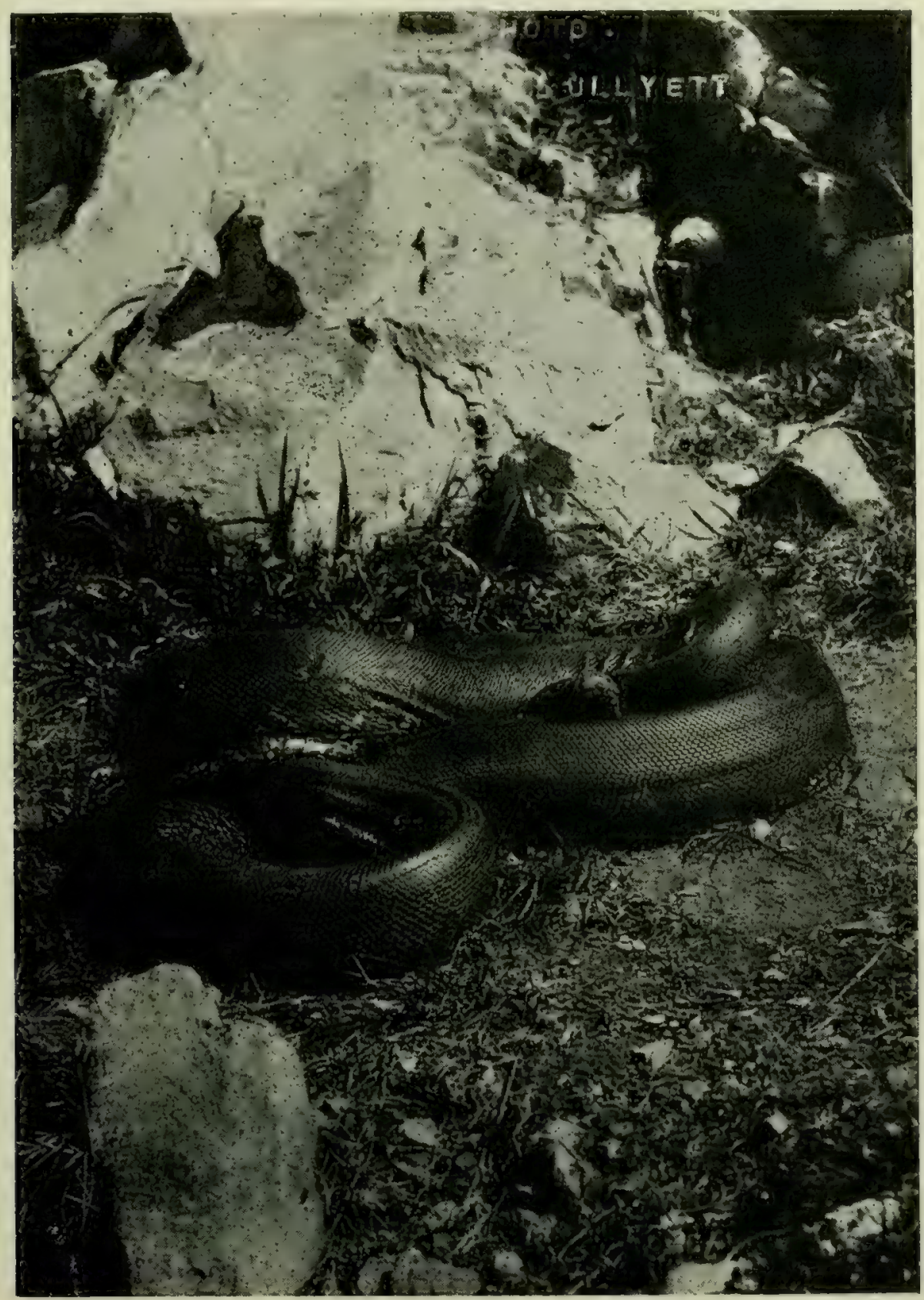

FIG. 28.-A South African (Python scba) I7 feet in length, basking in the sun. Photographed in its native habitat.

A large Python can swallow an animal the size of a full-grown Duiker Buck (Cephalophus grimmi). When out hunting one day in Natal with a friend, we came across a huge Python in a small 
cave at the foot of a krantz. After killing it, we dragged its body out into the light, and discovered that a pair of Duiker Buck horns were sticking fully an inch and a half through its ribs and skin. It had evidently swallowed the buck, horns and all, and the latter worked their way through the skin. The Python would probably not have died through the injury. These reptiles have such powerful digestive juices that the whole body, bones and all, of the buck, would have been digested, and the horns would eventually have dropped out. On a second occasion I was present when a Python was killed, with the horns of a Duiker Ram sticking out of its skin. In this case the skull had evidently been dissolved by the snake's gastric juices, for the horns came away very easily when pulled, leaving two small round holes in the snake's side, which doubtless would have healed in a very short time.

One day when lying under the shade of a big forest tree near Table Nountain, in Natal, I heard the terrified cries of an animal. On emerging from the bush, I saw a Python with a Duiker Buck in its deadly folds. Having no gun, I converted the branch of a tree into a cudgel, and rushed up the incline at the snake. However, on seeing me approaching, it quickly disengaged its jaws, unwound its coils, and made off amongst the bush-covered rocks, leaving the buck in a dying state upon the ground.

On another occasion my Fox Terriers gave tongue. Climbing over rocks and stubbly bush in the direction of the sound, I saw a Python of average size with head and neck distended enormously. On seeing me it made desperate efforts to disgorge, but its jaw's were so dreadfully stretched that it was seemingly powerless to reverse its mechanism. I rapidly tied one end of a stout cord round the snake's middle, and the other end to a tree, and ran back to get a strong linen bag from a satchel, which hung from my saddle. Returning, I found the Python had succeeded in disgorging its prey, which was a half-grown Duiker. The reptile was worked up into a great state of excitement by the badgering of the terriers, and his inability to escape. Holding out the spread-out bag, the Python lunged forward and seized it. The snake's recurved teeth got entangled in the material, and without a moment's delay I enveloped its head, and then seized it by the neck. Wrapping the bag round its head, I tied it with a cord. I sat down and waited patiently until the Python had expended 
its strength in blindly tumbling and rolling around. At last it ceased to fight. It felt it was vanquished. I advanced and carefully removed the bag which was blindfolding it. Opening the mouth of it, I thrust in its head. Instantly it began to crawl forward, thus aiding me in bagging it.

Slinging the bag over my shoulder, I staggered off with nearly a hundredweight of Python.

My pony was an old trusty friend and companion of countless excursions, and was used to the sensation of various kinds of wriggling things on his back, so he did not mind when I strapped my load to the saddle and led him along to my Dutch friend's farm, five miles distant.

\section{Pythons on THE WATch.}

The favourite haunt of the Python is the rocky, wooded valleys, in the vicinity of water. They love water, and delight to wallow in it, often lying submerged for hours, with only the nostrils above the surface.

They are excellent climbers, twisting in and out amongst the branches. The popular idea is that snakes climb by twisting their bodies in spiral fashion round the branches after the manner of a rope being twisted, strand above strand round the trunk of a tree. This is not so. No snake ever climbs in this manner. These huge Pythons often lie along the branches of trees with their stony-looking, unwinking eyes fixed upon the ground below. If something good to eat comes along, the snake simply drops upon it, the end of the tail gripping tight to the branch, or to a twig. When the animal is large and strong, the Python prefers some leverage for its tail in the shape of a shrub, branch, tuft of grass, or a projection of rock, to give its body muscles more power to act. As a rule, however, these snakes just envelop their prey with their folds, and then proceed to squeeze the life out of it.

\section{Capturing a Python.}

Pythons are not venomous; they are destitute of poison fangs or poison glands.

The teeth of Pythons are all quite solid, without any signs of 
grooving. They are re-curved, which means they are curved backwards. These teeth are capable of inflicting a nasty wound. I was trying to capture a Python one day amongst some rocks

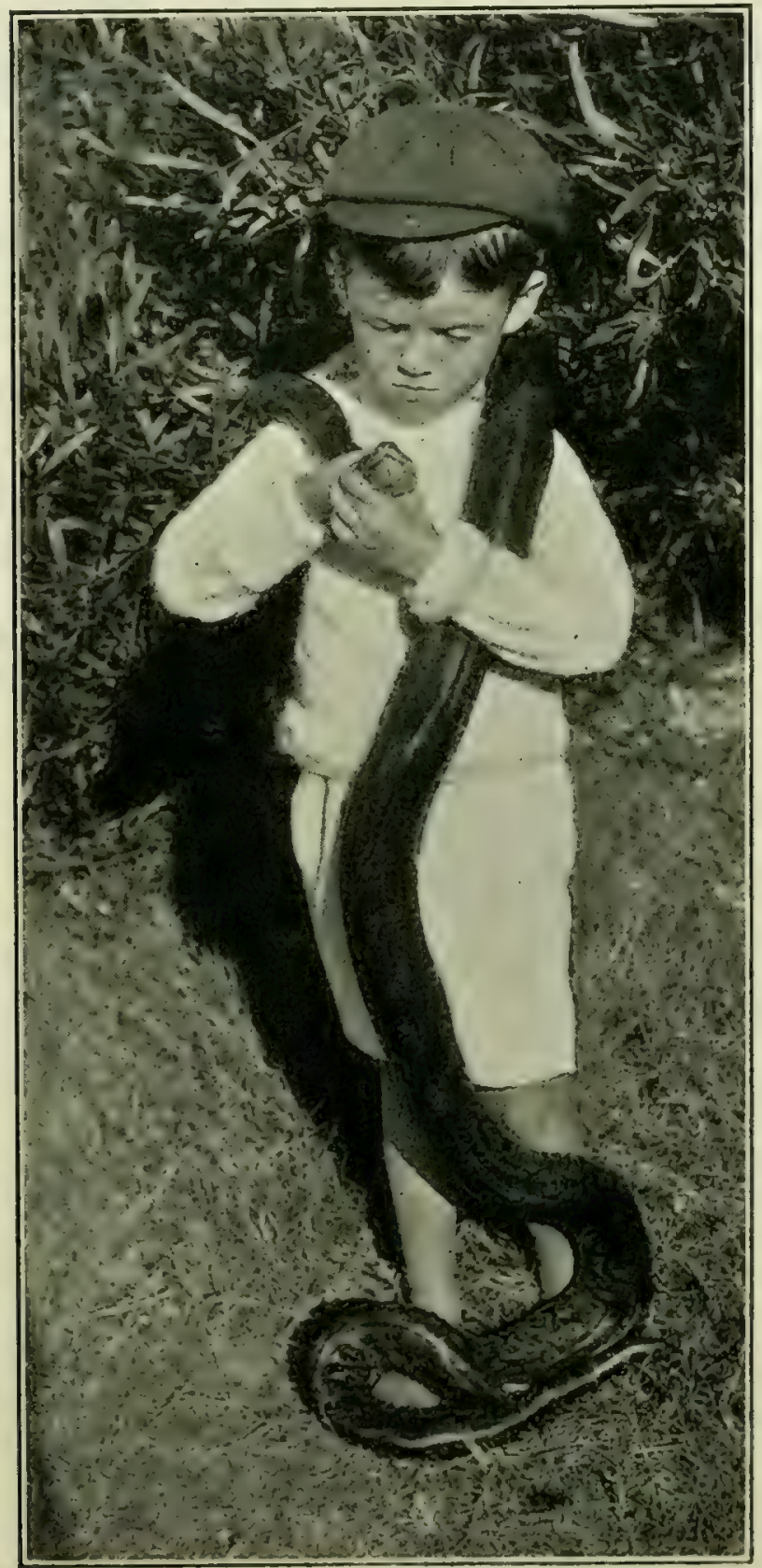

FIG. 29.-Desmond FitzSimons, aged five years, holding a young Python which his daddy had just captured on some adjoining rocks. in one of those beautiful tropical- looking valleys, so abundant in Natal. I got it cornered, and tried to get a noose over its head. In desperation, I suppose, it made a fierce lunge and seized my left hand in his great jaws and held as tight as a steel rat trap. I yelled out to my companion, but he was away in the bush somewhere. Fearing the Python would want to take the liberty of embracing me, I dragged my hand ont of its mouth, the hand, of course, being minus most of its epidermis. You want to know what I did then? Well, I bolted down the rocks. After my friend had bandaged my hand, we crawled up again and shot the Python, and retrieved my gun, satchel, and hat.

Pythons become very tame and docile in captivity. For many years past I have kept them in cages. I had one big fellow eighteen feet long, and so tame did he 
become that one day I coiled him round a lady's neck and waist, and photographed her with the python.

\section{A Sensation.}

This Python escaped one night, and I solemnly warned a relative to keep the fact a dead secret. She confided the fact to a neighbour, binding her to strict secrecy, but of course that secret was known in a very short while over the whole neighbourhood. Anyhow, for a month or two nobody would venture out of doors in that suburb after dark. Whenever little Tommy or Mary were a little late in coming home from school, their mothers were in horrible suspense lest the Python had interviewed them en route. Whenever any domestic animals were missing, of course the Python got the blame. Why, they even blamed it for doing away with a man. It seems Mr. — suddenly disappeared from his home, and no trace of him could be found, and the poor old Python was blamed, but I knew that man had a shrew of a wife, with a dreadful temper, who preferred gossip to looking after her domestic affairs, so I guessed the reason of his disappearance.

\section{They Hankered after his Gall.}

The Kafirs believe that the gall of a man who has killed a Python will confer on the person who swallows it wonderful vigour, courage and longevity.

Prior to the advent of Europeans into South Africa, and the introduction of their irksome laws, the kafir who was known to have killed a Python stood little or no chance of living to an old age. The Chief of the tribe coveted his gall. So did others, but they lay low, for they well knew that to thwart the desires of the Chief meant retaliation, swift, sure, and cruel, upon themselves.

Now, when any of the old-time powerful native chiefs coveted anything, he got it by fair means or foul, if it were at all procurable. Summoning the Witch-doctor he declared, with many groans, exclamations, and lamentations that he felt ill, frightfully ill, and raising his voice aloud, proclaimed that he had been bewitched. 
Then in a whisper to the Witch-doctor he named the man whose gall he coveted, adding that he was the fellow who had killed a Python. The cunning and unscrupulous Witch-doctor instantly took the hint. Going forth, she proclaimed in exaggerated and excited language, and with wild gestures, that the Chief had been bewitched. The men of the tribe were, in due time, summoned, and commanded to sit in a circle. The apparently sick chief or

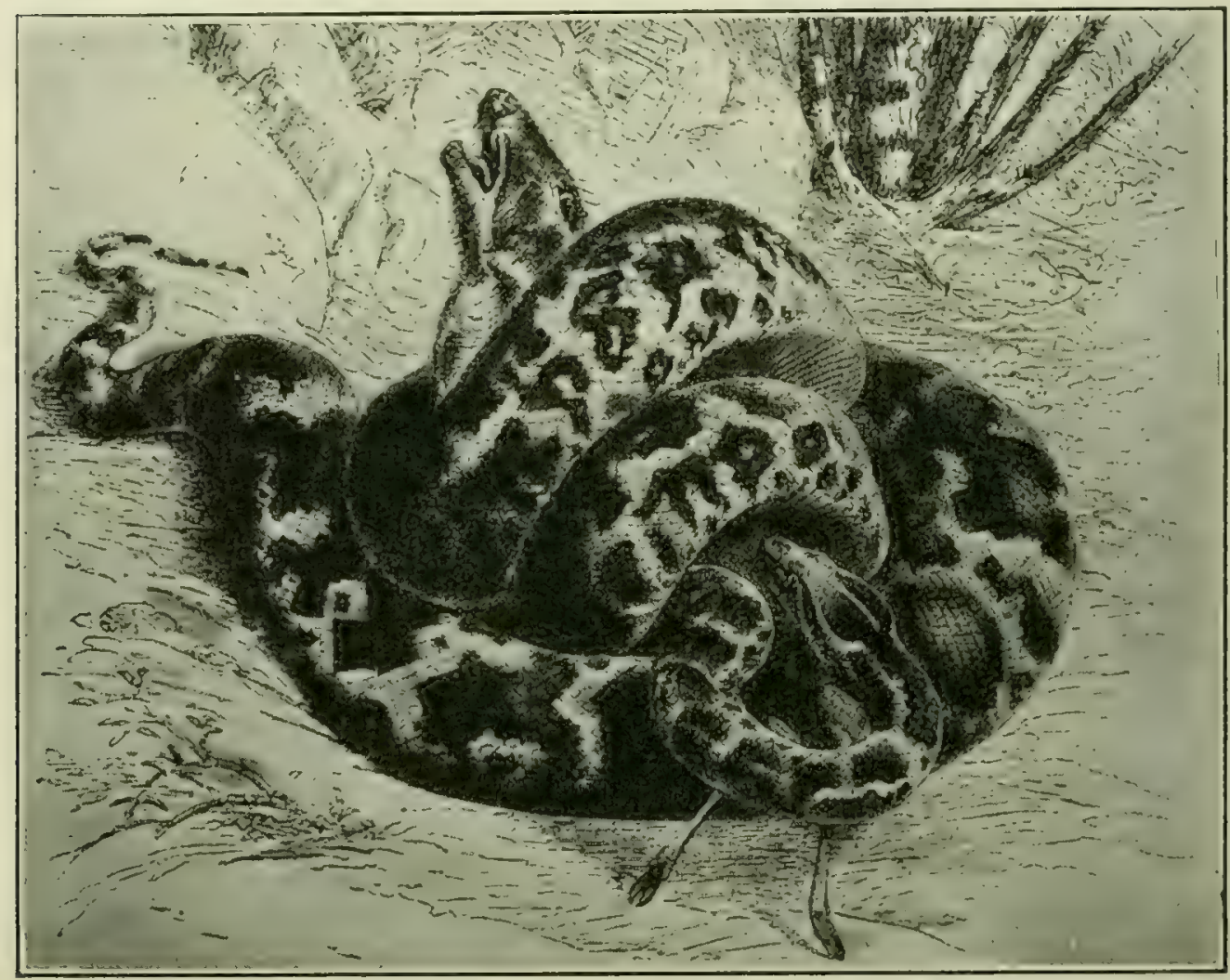

FIG. 30.-An Indian Python constricting an antelope. The squeezing power of a large Python is enormous. The ribs of the victim are crushed and the body elongated. It is then swallowed head first. (From IVarne's Roval Natural History.)

king is brought forth and laid upon a mat, supported and attended by a bevy of his wives.

Then the serious part of the business begins. The Witchdoctor, with horrible yells and mutterings, bounds into the circle. A weird and repulsive-looking object she generally is. She is not necessarily old and shrivelled. On the contrary, those I have seen were usually stalwart women of unusual height, with a commanding, bold aspect.

The face is smeared with daubs of white, and other paints. Strings of the claws of birds, bones of human beings and animals, 


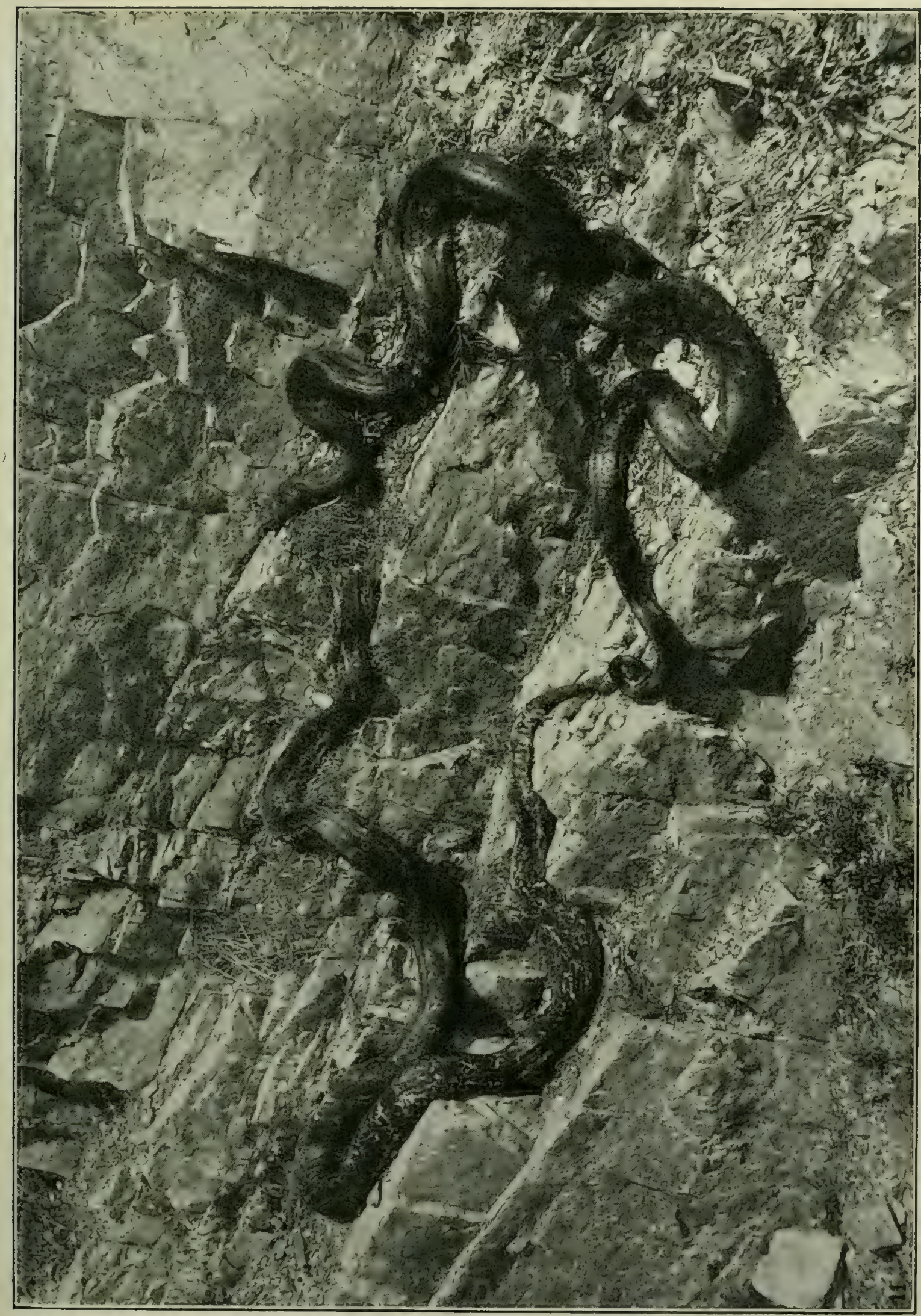

FIG. 3I.-Two South African Pythons on the rocks in their native habitat. These were photographed as they were trying to escape up the rocks. One is 14 feet, the other is feet 6 inches in length. They fought savagely when we tried to capture them. 
bits of medicinal bark, and small bladders filled with various substances are suspended round her neck and waist; her wool is long, unkempt, and adorned with many blown-out gall bladders of animals. Sometimes her whole person is decorated with a miscellaneous array of gruesome-looking things.

Crouching down, she crawls around, sniffing each man. Then, working herself into a kind of frenzy, her features become distorted, she writhes, twists, mutters, yells. In fact she does everything in her power to inspire awe, reverence, and deadly fear in the minds of the onlookers, each of whom is already in an abject state of terror, lest he should be the victim of her attentions. Eventually, with a succession of yells, she leaps high into the air, and with her wand, points to one of the men in the circle. Those in his vicinity instantly shrink away, in horror, from him. The hitherto terrified savages, now become ferocious and demoniacal, and gather around the victim, uttering the most appalling threats. However, the Witch-doctor knows her business. She wants the man's gall for the Chief; so, commanding the men to retire, she consults the Chief. Announcing that he has given instructions as to the disposal of the man, he is dragged off and done to death in a horribly brutal and agonizing manner.

In due time the dead man's gall is privately conveyed to the Chief by the Prophetess, who then receives an ample reward. These "smelling out " cases were of frequent occurrence in olden times. If any of the Chief's cattle should sicken and die, if any one should get ill from any cause, if misfortune in any shape or form should visit the tribe, this gruesome " smelling out " business was usually resorted to in order to unmask the wizard with the evil eye, who by his bewitching powers had caused the trouble. If the good folk in the Mother Country knew the conditions under which the natives of South Africa lived before the advent of the Dutch and the British, they would have less to say about. the "poor, ill-treated, down-trodden, sweated blacks." A former Chief Magistrate of East Griqualand writes me as follows: When I came to Tembuland in 1876 there was living here a white man named King, who was married to a native woman. This man had killed a very large Python in the Dwesa forest. On information received from his wife through her relatives, he was assured that the chief Kuli was secretly laying plans to do him to death and secure his gall, so he precipitately fled. In those days a refugee 
from a neighbouring tribe was as securely protected as such people were in the old Highland clans.

The Python is the most popular "familiar" of the Kafir Witch. On this ground alone the average Kafir would never dream of interfering with it.

These "Witch-doctors" may be of either sex. Colonists usually make no distinction in the name.

\section{An Exciting Adventure.}

I was staying at the farm of a Boer friend, and one morning accompanied him down to his rabbit hutches to help feed the rabbits; and in one of those hutches we found a sixteen-feet Python asleep, with a big Belgian hare inside of it. It had squeezed itself between the iron bars, swallowed the rabbit, and finding it could not get out, made itself comfortable and dozed off. We shoved it into a sack, and I rode a twenty-mile journey home, with it strapped to the front of the saddle. On the way it got alarmed, and began to struggle. My pony turned his head, sniffed the sack, and next instant shot across the hillside at break-neck speed. The sack got loose and fell. However, when my frisky pony had worked off his surplus energy, I returned, packed up my sackful of Python, and wended my weary way homeward. My troubles were not over, for on arrival home late in the night I told my native groom to take off the sack and put it on the ground and stable the pony. Presently I heard a most awful yell, and rushing out, was just in time to see my Python making off into the darkness, and the Kafir lying on his back bawling at the top of his voice in Zulu for his mother and his father, as is their custom when frightened, or in pain. It seems the silly fellow, in removing the sack from the saddle, went and undid the cord binding up the mouth of the sack. At least, that was his explanation. The real fact was he thought there was some buck meat inside the sack, and wanted to make sure, so as to be prepared to beg some when I came out again to see if my horse had been rubbed down and properly fed, as was my custom. I never saw that Python again, but somehow the news got about, and I was voted a pest and a nuisance, and people talked of petitioning Government to remove me from the neighbourhood. 


\section{PYTHON'S EGGS.}

In the wild state, when the female Python desires to lay her eggs, she selects some secluded spot amongst tangled brushwood down an Aard-rark hole, or in one of the innermost crevices of a rugged krantz. She lays her eggs in a heap, coils her body

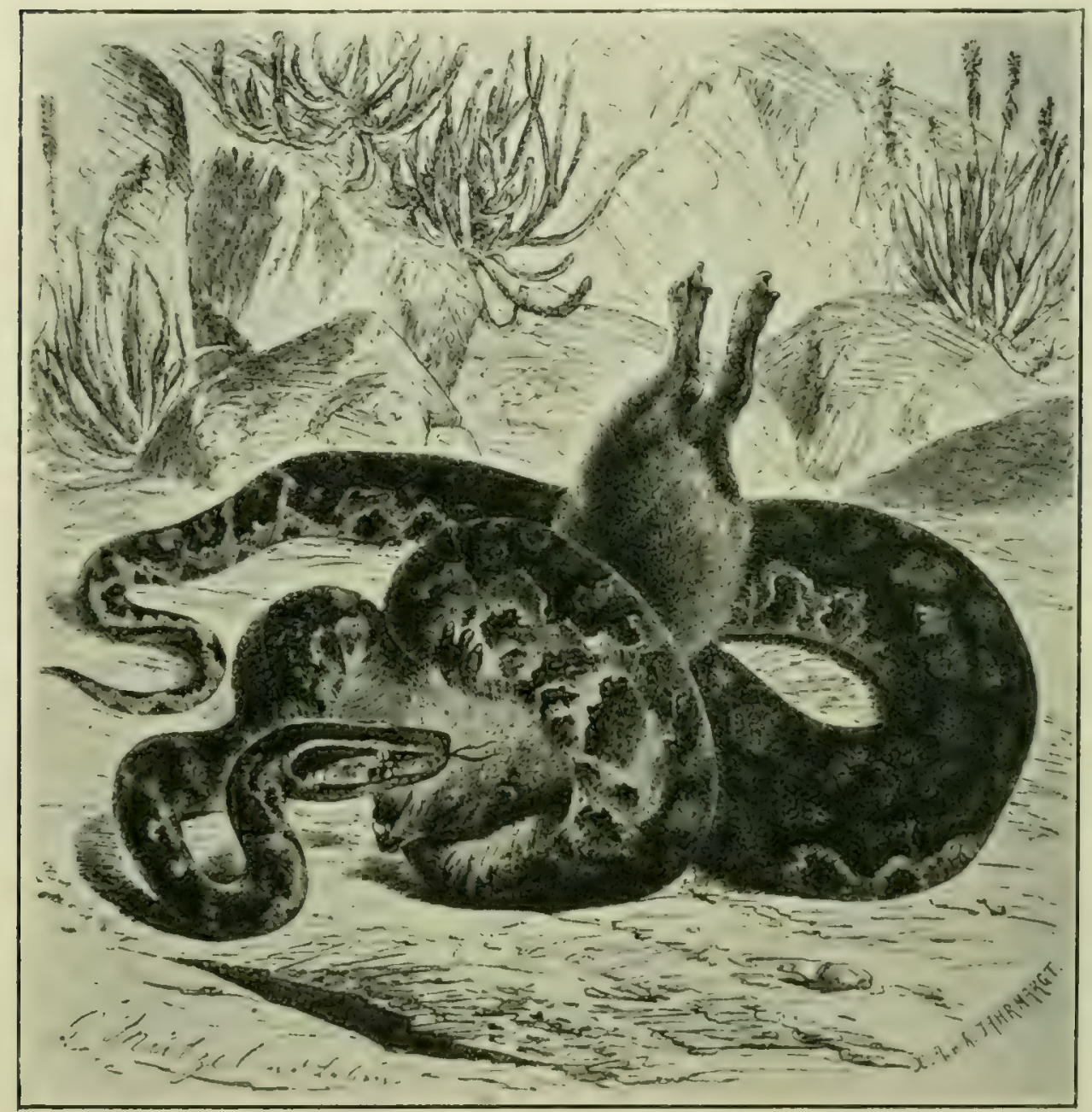

FIG. 32.-A South African Python about to swallow a IRlip Dassie (Procavia capensis), which it has captured and constricted. (From Warme's Royal Natural History.)

around them, fold above fold, with her head on top, completely concealing the eggs. During the incubation period, the snake's temperature rises, which seems to be a provision of Nature for the hatching of the eggs. I am by no means sure whether the eggs would not hatch just as well, if laid in some warm, moist place, and left to incubate by themselves, as is the case with most other egg-laying snakes One reason which undoubtedly prompts 
the female Python to coil around her eggs is to protect them from being eaten by wild animals, such as mungooses, rats, and mice, and by Nilotic Monitor Lizards, otherwise known as "Leguans," or "Iguanas."

One blazing hot summer day in Natal, we came across a Python basking in the sun. On seeing us approach it vanished down a hole, which proved to be that of an ant-eater, otherwise known as an Aard-vark (Oryctcropus afer), which is an animal as big as an adult pig. We filled the entrance with boulders, and wandered away. Returning anon with some muscular Zulus, we dug vigorously for a couple of hours or so. Eventually we came across the snake coiled up in front of a pile of eggs at the end of the hole, in the lair formerly occupied by the Aard-vark. We captured the mother Python alive, and counted the eggs, which numbered forty-eight. Breaking open two we found them to be partly hatched. There were indications which showed the Python had been lying coiled up in front of its eggs for some time.

We kept a large Python in captivity in the Port Elizabeth Museum, during the month of November, and it laid a batch of forty-four eggs. These eggs were elliptical and about the size of those of a goose, and contained a yellowish substance similar to the yolk of fowls' eggs, but lighter in colour. They weighed $5 \frac{1}{2}$ ounces. The " shell " was not hard and brittle like the shells of birds' eggs. It was soft and leathery in texture, and creamy-white in colour.

When the young Pythons hatch out, the mother takes no apparent heed of them, and moves off, her maternal duties being ended. The young scatter in different directions, their instinct impelling them to seek for food, which at this time consists of small fry in the shape of mice, rats, birds, lizards, frogs, etc.

\section{An Adventure.}

One day, when meandering wearily along with a gun under my arm amongst the rugged, rocky, shrub-covered mountains in Natal, I kicked my toe against something soft and tumbled over on to it, when, to my horror, that big soft mass began to wriggle and uncoil, and for a moment or two I saw nothing but a succession of huge coils. Then those coils resolved themselves into the form of a great Python about twenty feet long. He made off 
into the bush as fast as his ribs and scales would propel him, evidently as much terrified as I was. When I was able to collect my thoughts I looked around for my gun and hat, and wandered off, calculating whether the Python could have managed to swallow me whole.

\section{The Python and the Cock.}

Sitting on the stoep of a Dutch farmhouse listening to the tales of a tough old Boer hunter, a rooster suddenly began to cry out in evident distress, down amongst the foliage in the garden. We made off in the direction of the sound, and there in a shady glade was a tremendous Python doing his mightiest to constrict the fowl. The rooster's head was sticking out in one direction, his tail in another, and his legs and wings were north, south, east and west. The Python had him enveloped in his great coils, but the fowl's body was so comparatively small, and the Python so large, that he somehow could not get a sufficient grip to squash the rooster, and in the meantime the cock was crying out for aid, assisted by his wives, who kept at a safe distance and cackled.

We darted back to the house, procured a mealie sack, and from three points of the compass stalked the Python like stealthy Red Indians. A signal was given, and we simultaneously rushed in and assaulted him. In his bewilderment he raised his head to take in the situation. Before he could decide how to act, the Dutchman clapped the mouth of the sack over the Python's head; his son and I threw ourselves on the huge body, and after about fifteen minutes' tumbling and rolling around, we managed to get him safely lodged inside the sack, which he almost filled. We kept this Python alive in a cage in the grounds of the Natal Museum for a long time.

\section{Buck-Hunting InCident.}

At the big buck hunts in Natal, it is the practice to gather together from fifty to a hundred kraal natives, with their dogs. These natives would spread themselves out crescent-fashion and enter the dense bush, and we fellows with the guns would go away. 
ahead and keep on the qui vive for any bucks that broke cover. At such hunts, Pythons are frequently killed. The dogs locate them in the bush, and bring them to bay. At one of these hunts a big torpid-looking fellow broke away and came crawling sluggishly over the rocks. We killed him, whereupon two or three of the natives became very officious in volunteering their

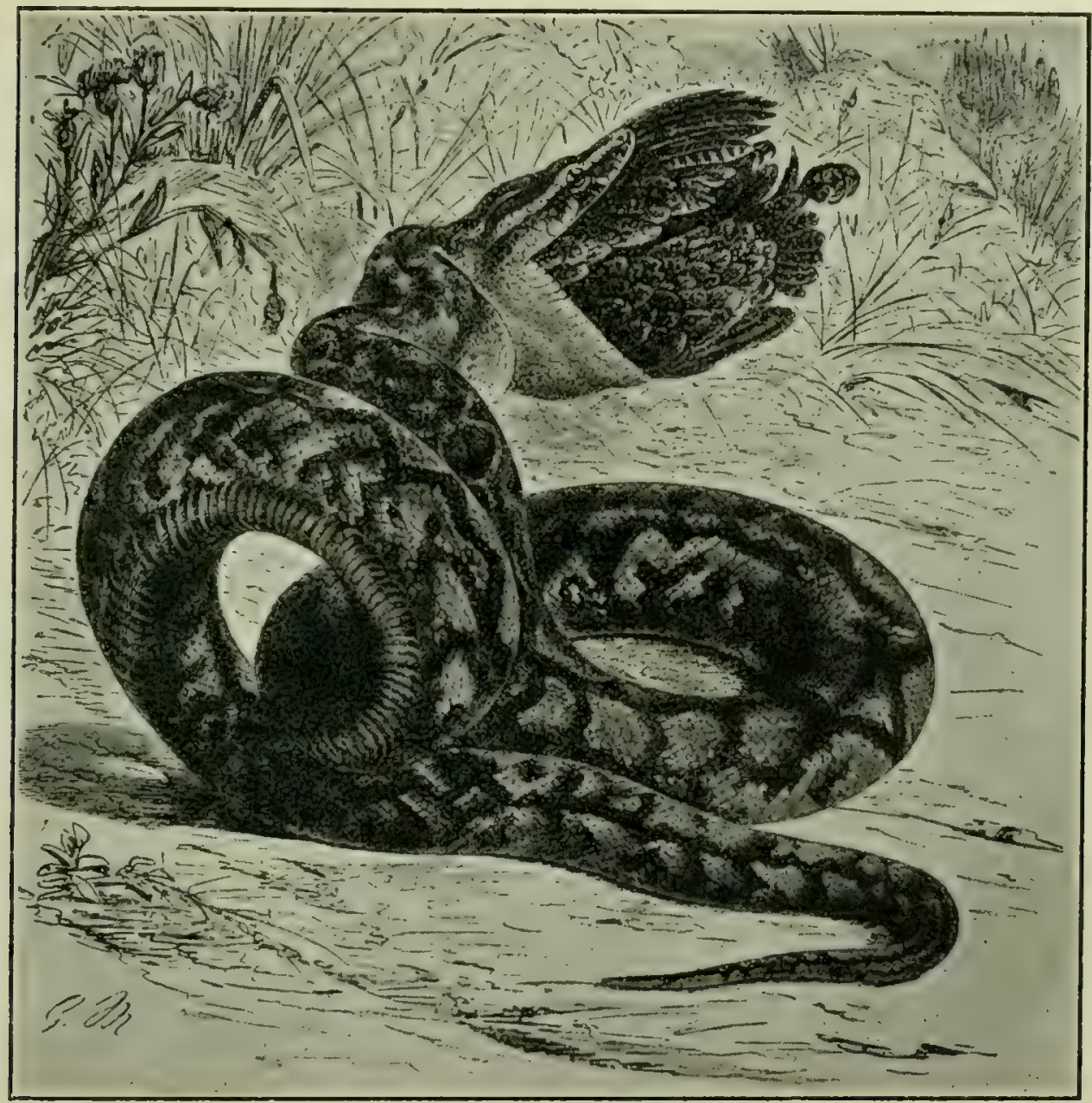

Fig. 33. - An African Python swallowing a bird. (From Warme's Royal Natural History.)

services in skinning him for me without the usual fee, so I willingly agreed. When they were taking the skin off, one of them pulled the remains of a Duiker Buck from the snake's interior. It was a pulpy shapeless mass, covered all over with slime. The Kafir laid it carefully aside. I inquired: "What are you going to do with that?" "Eat it, boss." "What! eat that slimy thing -ugh!" "Yes, boss, why not? It's good meat. We will wash it in the stream and skin it, and have a feast to-night." 


\section{A Crafty Python.}

I was fortunate enough once to witness a most remarkable occurrence. I was lying concealed in the midst of some tangled scrub near a still pool in a densely wooded valley, studying the habits of various species of birds, and all was as silent as the grave, with the exception of the occasional twittering and calls of birds. Suddenly a Red Natal Duiker Buck (Cephalophus natalcnsis) emerged from amidst the leafy shrubs, right opposite to where I lay. It cautiously and timidly looked around to make sure all was safe, stooped and began drinking. Suddenly the water was lashed into foam. Considerably startled, I rushed to the edge of the pool, and there at the other side was a Python in the shallow water with the buck in its coils. The struggle was fearful, but it ended in the snake smothering the antelope. When the victim ceased to resist, the snake laboriously dragged it to the shore, and after resting awhile, constricted it afresh, evidently to elongate the body to make the swallowing process as easy as possible, and then began eating at the head. After the head, neck and shoulders had disappeared down the snake's throat, I carefully crept round through the bush, and pouncing upon the Python, smashed its head and backbone with a quick succession of blows from a stout stick.

The Python had evidently submerged itself in the water, and was effectually concealed from view by the various water plants. On the approach of the buck it had silently sunk its head under the level of the surface of the water, and when the buck bent its neck to drink, those cruel re-curved teeth had seized it, and next instant the victim was in the deadly coils of the serpent. We ate some of the buck at our camp that night, and a leopard sneaked off the rest. However, we got even with it next day, for we traced it to its lair with the aid of our fox-terrier dogs, killed it, and took its hide off as a trophy.

\section{Pythons Swallowing People.}

I have read and heard may travellers' tales about Pythons swallowing people, but I have never known of a case which was thoroughly authenticated. I have been told scores of times by 
natives, prospectors and hunters of instances, but I always took them cum grano salis.

One instance, however, came within my experience which might have resulted in a Jonah-like performance. A plucky little Kafir boy, of twelve years, attacked a Python with his kerrie. In endeavouring to deal it a blow on the head, it got a grip of his leg with its tail, and was instantly round his body. His cries brought us to the spot. We unwound the Python, and beyond a dreadful fright, the boy was little the worse, except for a bite on the shoulder. The snake was only twelve feet in length. If it had been larger it would have, doubtless, crushed the boy's ribs before our arrival.

Pythons will show fight when wounded or cornered, and at these times it is distinctly dangerous for a man, if alone, to tackle them.

A friend of mine wounded a Python, and in his excitement rushed forward to despatch it, but it came at him with gaping mouth. He involuntarily put up his hands to save his face. The Python seized his hand, and in his terror, my friend dragged back with all his might, and, before we could release him, the sharp re-curved teeth lacerated his hand dreadfully. The wounds eventually healed all right.

\section{Feeding a Python.}

Pythons in captivity as a general rule refuse to eat, and consequently they have to be fed artificially. At various times we have had live Pythons at the Port Elizabeth Museum, but in no single instance have we ever succeeded in inducing them to eat. At the Natal Government Museum we also kept Pythons, but were obliged to feed them artificially. I kept them for years at my residence, with like results. However, I have found lately they will if kept cosy and warm, often seize and swallow young chickens and forwls. Then after some time they will readily seize, constrict, and devour rabbits, guinea pigs and rats. None of these creatures show the slightest alarm at the presence of a Python in the same cage. When captured and constricted death is rapid and painless. At the Port Elizabeth Museum it was our practice to feed them once a fortnight. The Python was carried outside. One man seized its tail, another the middle part of 
its body, and a third held it by the neck, opened its mouth and gently pushed lumps of raw meat down its gullet with the aid of a smooth, rounded stick. The second man meanwhile worked

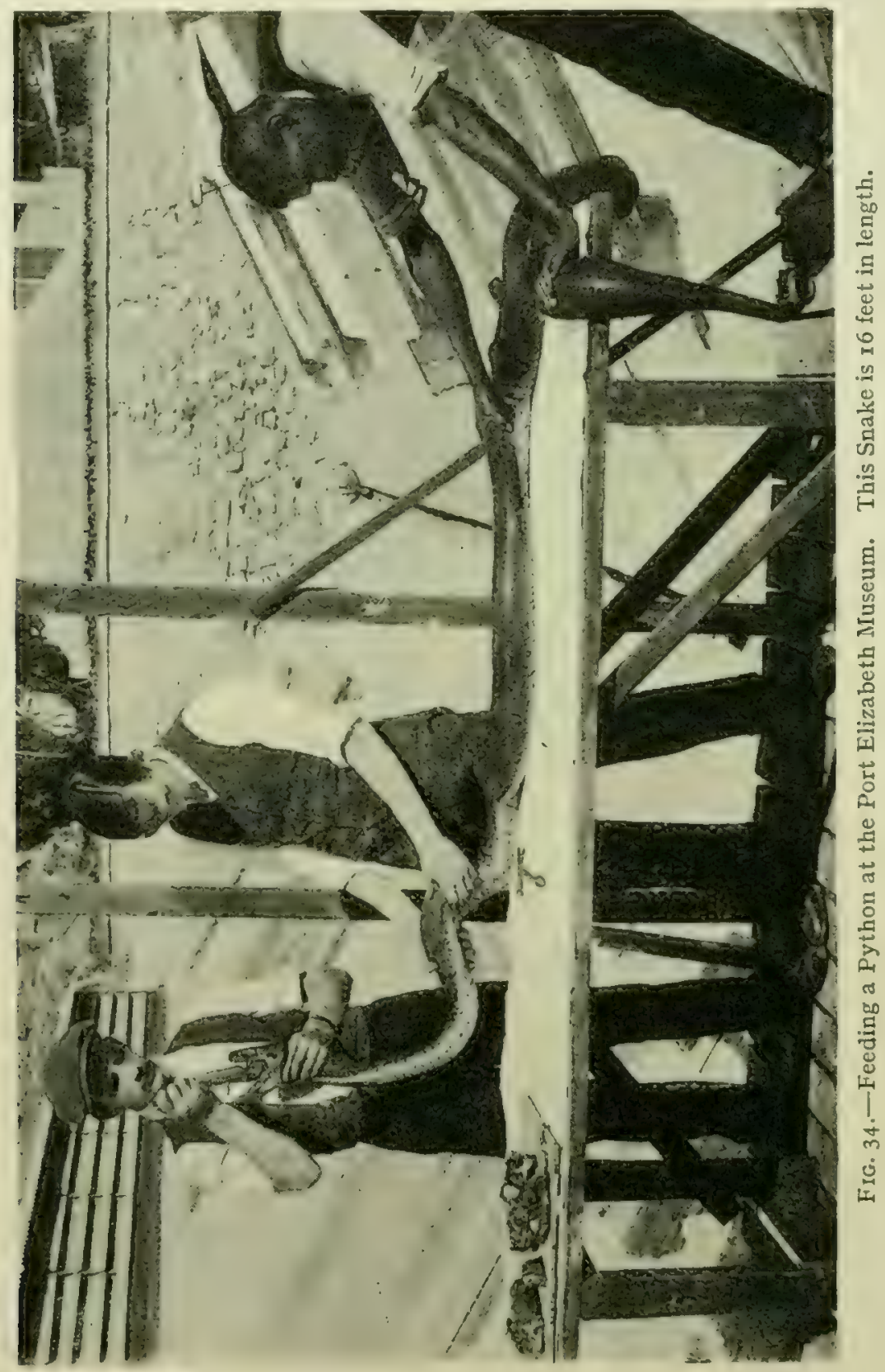

the meat down to the middle part of the snake. After about ten pounds of beef had been lodged in the snake's stomach, a ligature was applied above the meat-that is, between the meat and the snake's mouth. This was to prevent the snake disgorging the 
food, as it would otherwise have done every time. The snake was then placed out in the warm sunshine for half a day, the ligature was removed, and it was then put back into its cage again until next feeding time.

\section{Crockery-Smashing Python.}

When out hunting one day in Natal we captured a Python, about seventeen or eighteen feet long. My Dutch friend brought it in next day to me in a mealie sack. He dumped it down in my chemical room at the Museum, the walls of which were covered with shelves on which hundreds of jars of specimens in spirits, and lots of empty glass jars, were stored. We could not get a cage ready that day for the Python, so, thinking he would be safe in the sack till the following day, I locked him up and went home.

\section{What The Python did.}

You want to know what the Python did? Why, he somehow or other got out of the sack during the night, and explored every inch of each shelf in the room, seeking some hole through which to escape. Finding none, he coiled himself up in a ball on the topmost shelf and went to sleep. He left an odd bottle here and there on the shelves, thinking I might need a few, but all the rest had been pitched in a heap on the floor. We let him sleep for half a day, until we had sorted out all the specimens from the heaps of broken glass which half filled a cart, then we tackled him. We thought we were going to have quite an exciting time, but we were woefully disappointed, for the Python was as drunk as a mediæval fiddler. What! a Python drunk? How did he get drunk? Why, quite easily. Those bottles he knocked down from the shelves were full of methylated spirit, and the concentrated fumes of alcohol in that closed-up room got into his blood through absorption from the air breathed by him. When he got sober he found himself imprisoned in a wire cage, where he was forced to do a year's solitary confinement. Then he escaped, and a newspaper reporter finding it out, he reported in the leading daily paper a marrow-freezing account of how Pythons swallow people as easily as we dispose of oysters. 


\section{Fasting Powers.}

Pythons have been known to fast for at least two years. I have kept Pythons in captivity which lived from six months to a year and a half without food. I did not purposely starye them. I offered them their natural food from time to time, but never succeeded in inducing them to eat. I dare say those I kept would have lived much longer, but I did not care to see the creatures starve to death, so began feeding them artificially. I must admit, however, that after a year and a half of starvation, they did not appear to be much emaciated. Although snakes will fast a long time, they will die, as a rule, after a few months if deprived of water, except during the winter months, when they will frequently coil up in a warm corner of their cage and lie dormant for three or four months.

\section{Rudiments OF LEgs.}

Most Pythons still retain traces of the legs their remote

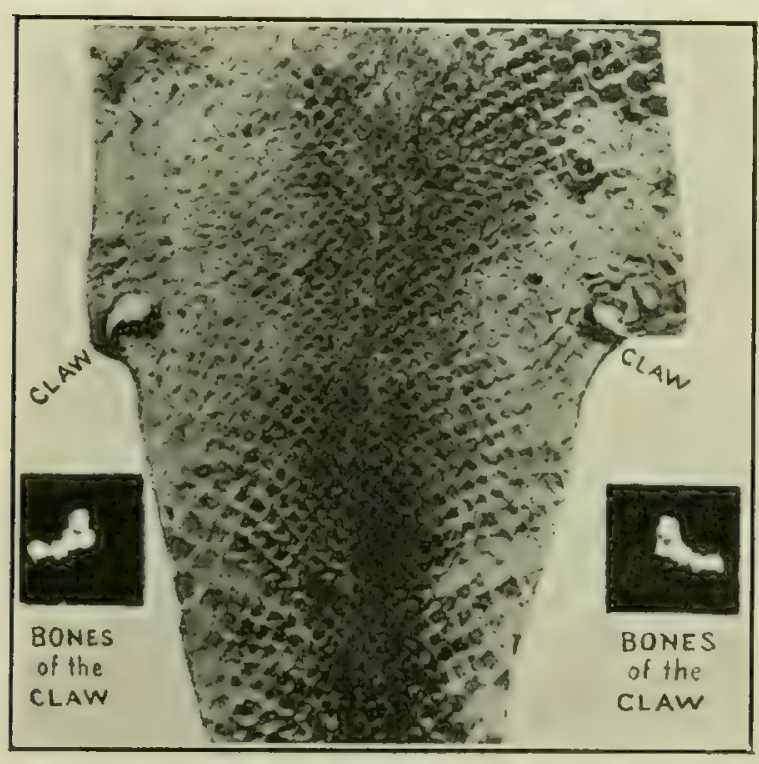

Fic. 35.-Part of the flattened skin of a South African Python showing the claws and bones which indicate that the remote ancestors of Pythons possessed legs. (From British Museum Guide. Reptiles.) ancestors possessed, but gradually lost, because they did not use them sufficiently. On examination, two horny spurs will be found near the vent, which are the external rudiments of hind legs. Internally a portion of the pelvis bone still remains. Pythons are doubtless the descendants of huge prehistoric lizard-like creatures which lived upon the surface of the earth millions of years ago.

\section{STUPID INDIFFERENCE.}

Once I had a Python in captivity, and the perrerse thing would not eat. I introduced a big barn rat into its cage. The 
rat showed no fear of the snake. I allowed it to remain for a couple of weeks, feeding it regularly. The rodent invariably sought refuge within the Python's coils when alarmed; and at other times would sit on top of the coiled-up Python, and busy itself cleaning its whiskers. One morning I was astonished to observe that the flesh had been eaten for several inches along the back of the snake near the tail, exposing many sections of the backbone. The rat had evidently dined off the Python during the night, and the beast had seemingly not resented the liberty, for the rat was sitting in a corner with an expression of contentment upon his cunning visage. Now, although the Python had not tasted food for fourteen months, this extensive wound healed up completely.

\section{Pythons in Cape Colony.}

Pythons could not have been very common in Cape Colony, at least in fairly recent geological times, as most parts are not particularly favourable to their existence. The old Hottentots and Bushmen, however, when questioned, declare that they existed when they were boys, in the warm, moist regions of the Colony. However, they are now supposed to be extinct within the borders of the Cape Colony. It is possible, however, that there may be a few individuals left. They seem to be fairly plentiful in the neighbourhood of Palapye Road, in Bechuanaland, as Mr. Paul Jousse has sent me several from that locality.

\section{Python SteAK.}

Snakes are really good wholesome food, and Python steak grilled in the red glowing wood fire of the hunter's camp is not to be despised. One day when hunting, we killed a Python, and two of our men, who were a mixture of several breeds - the Hottentot element predominating-after skinning the reptile, carried the carcase off to camp. When we arrived many hours later, gameless and famishing with hunger, our men were all squatting round a fire, each one with a lump of Python flesh impaled upon the sharpened point of a freshly-cut stick, and holding the meat in the fire. It smelt so savoury that I set the example and ate a piece, and liked it so much that I tried another piece, for it was really nice, tender and juicy. 


\section{CHAPTER IV.}

Division Aglypha. The Solid-Toothed Snakes.

FAMILY IV. COLUBRIN在.

Sub-Family I. Colubrinæ.

THERE are about IOoo species or kinds included in this subfamily of snakes, scattered over the various temperate and tropical regions of the world. Of this great number only twentyeight species inhabit South Africa. All of this sub-family are known as the Aglypha, because their teeth are quite solid, showing no traces of grooving. They are consequently all non-venomous, and should not be interfered with, for they do an immense amount of service in ridding the country of rats, mice, and noxious insects. Some species are oviparous, that is, they lay eggs. Others are viviparous, which means they give birth to young.

After reading this book and carefully studying the pictures showing the heads and teeth of the three typical kinds of snakes, viz. the solid-toothed non-venomous snakes; the back-fanged more or less venomous snakes; and the front-fanged, typicallyvenomous snakes, it should be quite easy for any student, by means of a strong magnifying glass, or low power microscope, to identify a snake of any of these three divisions. If grooved or hollow fangs are found in the front of the top jaw, then the snake is one of the typical venomous kind. If there are two or three grooved fangs at the posterior end of the upper row of teeth, the snake belongs to the back-fanged kind, which are all more or less poisonous. All those snakes possessing solid teeth, without any pronounced grooving, are as harmless as lizards, as far as venomous properties are concerned. 


\section{SUB-FAMILY COLUBRINÆ.}

\section{SYNOPSIS OF THE SOUTH AFRICAN GENERA.}

This sub-family are without grooved fangs in the upper jaw. Their teeth are quite solid. No trace of poison glands.

I. Genus Tropidonotus.--Scales smooth in I9 rows. Pupil round; posterior maxillary teeth longest; internasal not entering the nostril ; snout rounded.

2. Genus Pseudaspis. - Scales smooth in 27 to 31 rows; internasal entering the nostril; snout with vertical sides, more or less prominent. Pupil round. Posterior maxillary teeth longest.

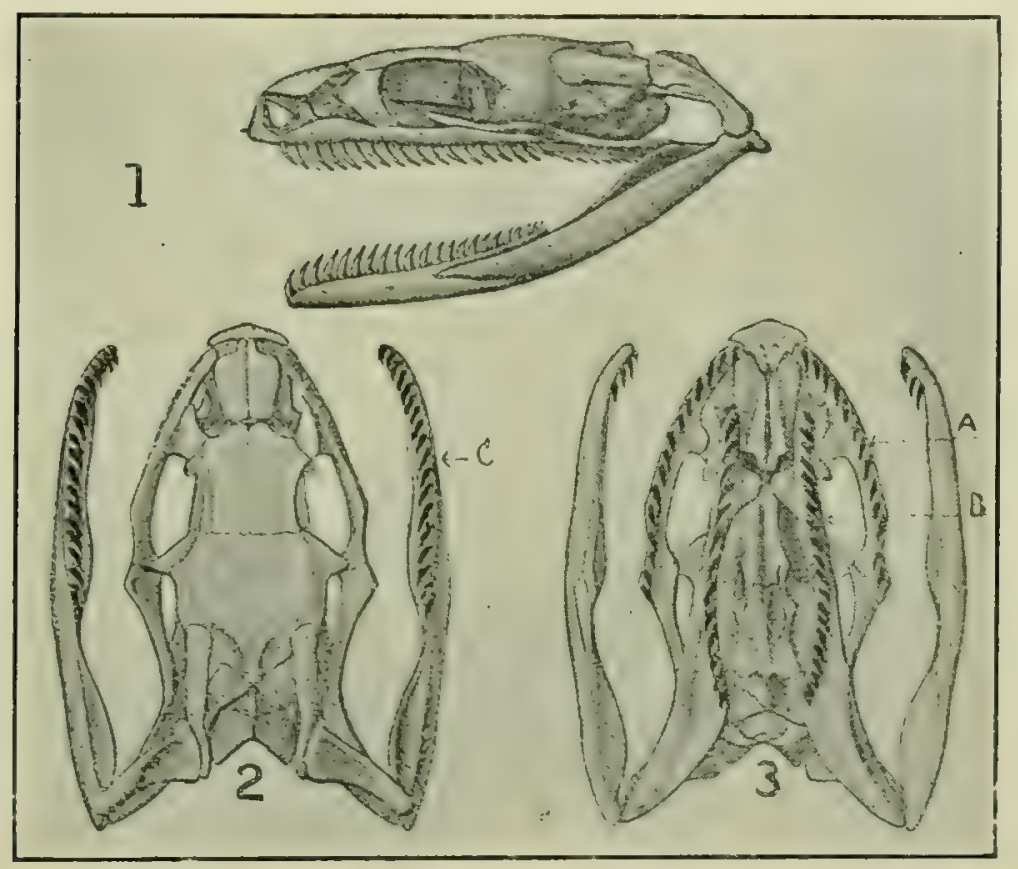

FiG. 36.-Skull and teeth of a typical snake of the non-venomous division (Aglypha).

I. Skull showing the teeth in both jaws, all of which are without grooves.

2. Top of the skull and lower jaw (C).

3. View of roof of mouth showing the two rows of upper teeth.

(A.) Maxillary teeth. (B.) Palatine teeth. (Brit. Mus. Cat. Snakes.)

3. Genus Ablabophis.-Scales smooth, in i9 rows; Pupil vertically elliptic; anal entire. Frontal at least once and a half as long as broad; maxillary teeth equal.

4. Genus LAmprophis.-Scales smooth, in I9 to 23 rows; frontal broad and short; posterior maxillary teeth shortest; Pupil vertically elliptic or sub-elliptic. Anal entire.

5. Genus Boodon.- - Scales smooth in 23 to 33 rows, with apical pits ; anterior maxillary teeth strongly enlarged. Vertically elliptic pupil. $r 8$ to 24 maxillary teeth.

6. Genus Lycophidium.-Scales smooth, with apical pits in I5 or 17 rows. Tail short (sub-caudals not more than 50 pairs). Pupil vertically elliptic ; rostral small ; anterior maxillary teeth longest. 
7. Genus Prosymna.-Scales smooth, in 15 or 17 rows. Pupil vertically elliptic; rostral very large, with angular horizontal edge; posterior maxillary teeth strongly enlarged. Maxillary bone short with 7 or 8 teeth.

8. Genus Homalosoma.-Scales smooth in 15 rows. Pupil round; rostral small; nasal single; anterior maxillary teeth longest. Maxillary short, with Io to 12 teeth. Tail short, sub-caudals in two rows.

9. Genus Chlorophis.- Scales smooth with apical pits in 15 rows. Tail long (sub-caudals more than 80 pairs) ; pupil round ; posterior maxillary teeth longest. Sub-caudals not keeled, and in 2 rows.

Io. Genus Philothamnus.-Scales smooth with apical pits, in 13 or 15 rows, disposed obliquely, at least on the anterior part of the body. Sub-caudals keeled and notched, like the ventrals. Tail long.

I I. Genus Simocephalus.-Scales keeled, without pits, in 15 or 17 rows; those of the vertebral row enlarged and bi-carinate; anterior maxillary teeth longest. Pupil vertically elliptic.

I2. Genus Dasypeltis.-Scales in 23 to 27 rows, laterals very oblique, and with serrated keels; teeth very small and few. Pupil vertically elliptic.

\section{GENUS TROPIDONOTUS.}

\section{Two Species in South Africa.}

\section{KEY TO THE SPECIES.}

Ventrals I62-I80; anal entire .. . . . . Tropidonotus lavissimus. Ventrals I3I-I49; anal divided .. . . Tropidonotus olivaceous.

I. Tropidonotus Levissimus. Watermeyer's Black Snake.

Synonyms-Natrix lavissimus; Grayia lubrica.

Colour-Dark shining black above, a narrow yellow line on either side of the head behind the eye; below, yellow, with a narrow illdefined dark line running the whole length of the body along the centre of the ventrals. The two outer rows of scales spotted and blotched with black.

Average length-3 feet.

Distribution-Eastern Province, Cape Colony; Natal.

2. Tropidonotus olivaceous. Banded Olive Snake. Olyfen Slang. Synonym-Coronella olivacea.

Colour-Olive or brown above, with a more or less distinct darker vertebral band 4 or 5 scales wide, bordered on each side by a series of whitish dots; flanks and ends of ventrals olive; upper lip yellowish, the sutures between the shields black; ventrals yellowish, sometimes edged with olive.

Average length -2 feet.

Distribution-Southern Rhodesia; North to Tropical Africa.

\section{GENUS ABLABOPHIS.}

\section{One Species in South Africa.}

Scales smooth with apical pits, in I9 rows. Frontal at least once and a half as long as broad; maxillary teeth equal .. .. .. Ablabophis rufulus. 
1. Ablabophis Rufulus. Olive-brown Water Snake. Olyfen-Bruin Water Slang.

Synonym-Coronella rufula.

Colour-Uniform dark olive-brown or blackish above; upper lip and lower parts, light pink.

Average length -2 feet, to 2 feet 6 inches.

Distribution-Occurs all over South Africa. Has not been recorded north of the Zambesi.

\section{Genus LAMPROPHIS.}

Four Species in this genus, all of which inhabit South Africa.

KEY TO THE SPECIES.

Scales in 23 rows. Internasals a little shorter than the prefrontals; loreal a little longer than deep $\quad . \quad \ldots \quad$.. . . . Scales in 23 rows. Internasals much shorter than the prefrontals; loreal at least nearly twice as long as deep ... ... ...

Lamprophis aurora.

Scales in 23 rows. Internasals longer than the prefrontals; loreal as long as deep, or a little longer than deep .. .. . . .. Lamprophis fiskii.

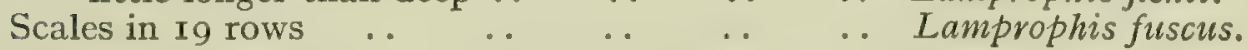

I. LAMPROPHIS AURORA. The Night Snake; Nacht Slang.

Synonym-Coluber aurora.

Colour-Olive or pale brown above, uniform or speckled with black; the scales of the vertebral series bright yellow or orange; lower parts white.

Average length -2 feet.

Distribution-Both provinces of Cape Colony; O. R. C., Transvaal.

2. LAMPROPHIS inornatus. The Brown Snake. Bruin Slang.

Colour-Uniform brown above; brownish white below.

Average length - I foot 6 inches.

Distribution-Both Provinces of Cape Colony.

3. LAmprophis FiskiI. Fisk's Snake.

Colour-Lemon yellow on the five median rows of scales, with large blackish-brown spots forming a single series anteriorly, a double alternating series posteriorly. Head lemon yellow above, with symmetrical blackish-brown markings, viz. an oblique band on each side of the occiput, a horseshoe-shaped band passing through the eyes and across the snout, and a bar across the frontal. Lateral scales of body and tail brown in the centre and yellowish-white on the borders. Upper lip and lower parts white.

Average length $-\mathrm{I}$ foot 6 inches.

Distribution-Western Province of Cape Colony.

4. Lamprophis Fuscus. The Yellow-lipped Snake. Geel-lip Slang.

Colour-Uniform brown above; upper lip, two outer rows of scales and lower parts yellowish.

Average length -2 feet.

Distribution-Western Province of Cape Colony. 
Genus BOODON.

Four Species in South Africa.

KEY TO THE SPECIES.

Scales in 23 or 25 rows. Three labials entering the eye. Two postoculars ; preocular not extending to upper surface of head; ventrals I 75-rg6

Boodon infernalis.

Scales in 23 or 25 rows. Three postoculars; preocular extending to upper surface of head; ventrals I96-210 … … …

Scales in 27 to 33 rows. Ventrals 192-237. Two (rarely three) labials entering the eye; two pairs of chin shields in contact with each other ..

Scales in 27 to 33 rows. Three labials entering the eye; only one pair of chin shields meeting on the median line .. $\quad . . \quad \ldots \quad \ldots \quad \ldots \quad \ldots$ Boodon mentalis.

r. Boodon INFERnalis. Olive-brown House Snake. Zwart Huis Slang. Colour-Olive-brown above ; lower parts whitish.

Average length -2 feet 6 inches.

Distribution-Both provinces of Cape Colony; Natal; O. R. C., Transvaal; Southern Rhodesia ; East Africa.

2. Boodon guttatus. Spotted House Snake. Stippel Huis Slang. Synonyms-Lycodon guttatus; Alopecion annulifer.

Colour-Yellowish-brown above, with several rows of reddish-brown spots with umber-brown borders, the two rows of spots along the middle of the back almost circular, and largest; a dark brown blotch on each side of the back of the head, and a pair of dark longitudinal streaks on the nape; under-parts pale yellow.

Average length - I foot 6 inches.

Distribution-Both provinces of Cape Colony.

3. Boodon lineatus. Brown House Snake. Bruin Huis Slang.

Synonyms-Lycodon geometricus: Boodon geometricus.

Colour-Reddish brown above, uniform or variegated with yellowish, with or without a yellow lateral streak; side of head light, the brown of the upper surface ending in a point on the snout, with a dark brown lateral streak passing through the eye, and dark spots on the labials; or head dark brown, with two more or less distinct light lines on each side. Lower parts yellowish.

Average length -2 feet 6 inches.

Distribution-Common all over South Africa ; Extends north to Tropical Africa.

4. Boodon mentalis. Striped House Snake. Streep Huis Slang.

Colour-Pale brownish above; two yellow lines on each side of the head; lower parts white.

Average length-I foot 6 inches.

Distribution-Damaraland.

Ventrals $164-208$

Ventrals $146-156$

\section{GENUS LYCOPHIDIUM.}

Two Species in South Africa.

KEY TO THE SPECIES.

. $\quad$. $\quad \ldots \quad$.. Lycophidium capense.

. $\quad$. $\quad \ldots \quad \quad \ldots \quad$ Lycophidium semiannulis. 
I. Lycophidium CAPENSE. Cape Wolf Snake, Kaapsche Wolf Slang. Synonyms-Lycodon capensis : Lycophidion horstockii.

Colour-Brown, purplish or olive above; sides of head speckled or vermiculate with whitish.

Varieties-

A. Brown or dark purple above, the lateral scales tipped with whitish ; lower parts whitish.

B. Dark purplish brown above and below, lateral scales and ventrals with a whitish edge; throat white (Port Elizabeth).

C. Dark grey above, the scales edged with blackish; two series of black spots along the back, the anterior confluent into crossbars; throat white; ventrals and sub-caudals blackish-brown, edged with whitish. Average length-I foot 6 inches.

Distribution-Eastern Province of Cape Colony; O. R. C., Transvaal ; Southern Rhodesia; Natal; Zululand; Delagoa Bay, and northwards to Tropical Africa. (Moist; damp localities among dead leaves, and under decaying logs.)

2. Lycophidium SEMiannulis. Northern Wolf Snake.

Colour-Greyish blue or purplish above, with irregular black crossbars; snout and sides of head yellowish, speckled with black; blackish-brown beneath, the shields edged with yellowish.

Average length $-\mathrm{r}$ foot.

Distribution-Zululand; Portuguese East Africa.

GENuS SIMOCEPHALUS.

Two Species in South Africa. KEY TO THE SPECIES.

Frontal a little shorter than the parietals; two

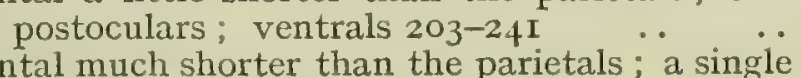

Simocaphalus capensis. postocular; ventrals I7I-I85 .. .. Simocephalus nyasse.

I. Simocephalus CAPENSIS. Three-cornered or File Snake. Driekant Vijlslang.

Synonym-Heterolepis capensis.

Colour-Brown above, upper lip, middle of vertebral scales yellowish; yellowish or white beneath. Two rows of blackish blotches the whole length of the body at ends of abdominal shields present in adults.

Average length -4 feet.

Distribution-Natal; Southern Rhodesia; Delagoa Bay; Portuguese East Africa; Central Africa.

2. Simocephalus Nyasse. Northern Three-cornered or File Snake. Noordelijke Driekant Vijlslang.

Colour-Blackish-brown above, paler brown below, the chin and the lateral ventral keel yellowish.

Average length -4 feet. Attains a length of 5 feet.

Distribution-Natal; Transvaal; Delagoa Bay; Portuguese East Africa; Central Africa.

GENUS PSEUDASPIS.

Genus is represented by one Species only.

KEY TO THE SPECIES.

Scales smooth in 27 to 31 rows. Internasal entering the nostril; snout with vertical sides, more or less prominent

Pseudaspis cana. 
I. Pseudaspis Cana. Mole Snake. Zwart Slang; Lui Slang; Molslang. Synonyms-Coluber canc; Coronella cana; Coronella phocarum; Duberria cana: Cadmus cuneiformis.

Colour-The young are pale brown above, with dark brown whiteedged spots forming four longitudinal series; sometimes a darker vertebral line; lower parts yellowish or purplish brown, uniform or spotted with black.

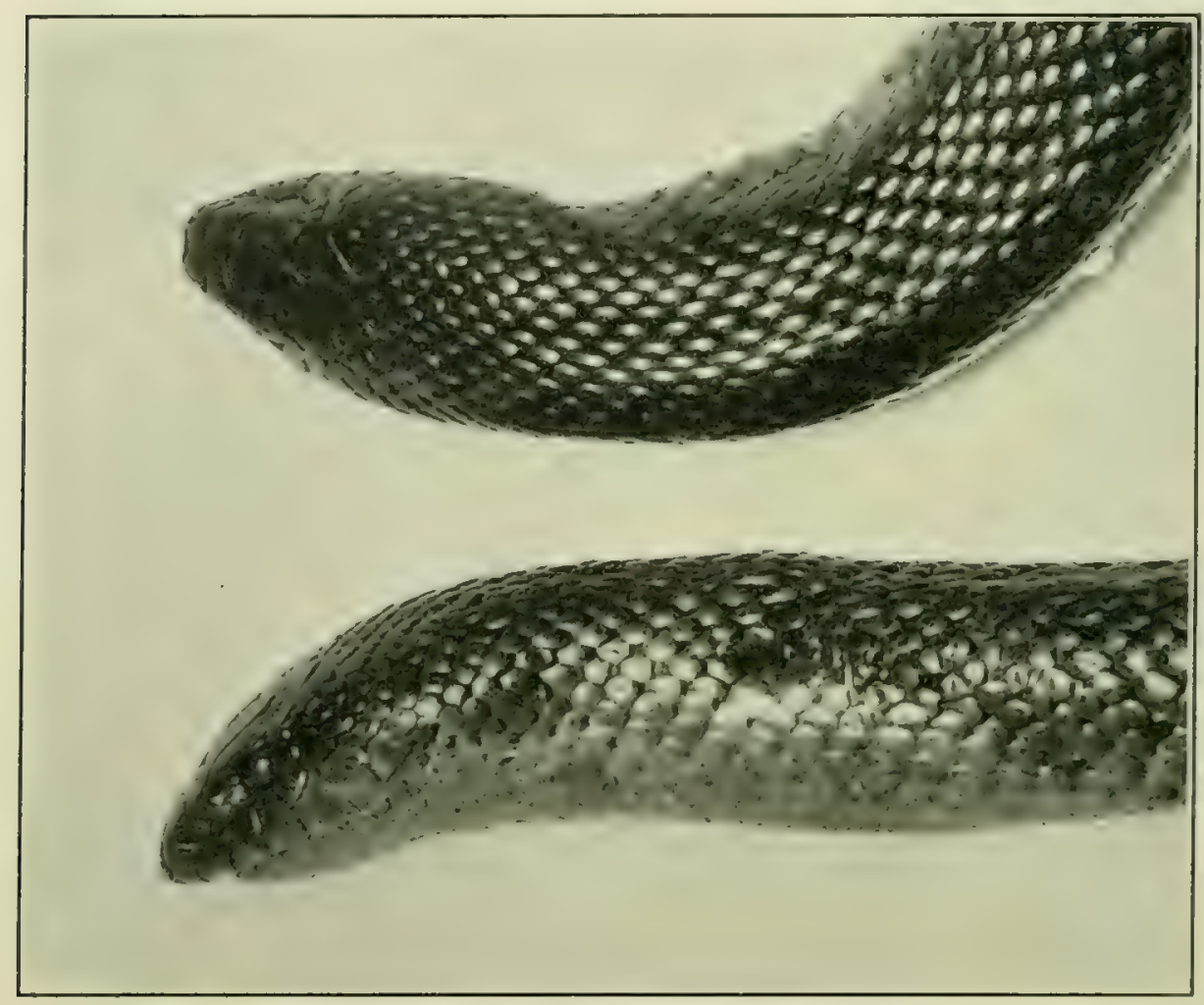

FIG. 37.-Head and neck of the harmless Mole Snake (Pscudaspis cana).

(From Harmsworth's Natural Hislory.)

Aduits are very variable in colour, brown or reddish, with more or less distinct spots; often uniform dark brown or shiny black.

Average length -4 feet. These snakes sometimes attain a length of over 7 feet.

Distribution-All over South Africa; North to Angola and British East Africa.

\section{GeNuS CHLOROPHIS.}

Four Species in South Africa.

KEY TO THE SPECIES.

Ventrals without keels. Two labials entering the eye; sub-caudals $85-107 \quad \ldots \quad \ldots \ldots$

Chlorophis hoplogaster.

Ventrals with distinct lateral keels. Two labials entering the eye; a single anterior temporal; sub-caudals $77-\mathrm{I}_{4}$

\section{Chlorophis neglectus.}


Ventrals with distinct lateral keels. Two labials entering the eye; usually two superposed anterior temporals; sub-caudals I I $4-\mathrm{I} 4 \mathrm{O} \ldots$

Ventrals with distinct lateral keels. Three labials entering the eye; sub-caudals $94^{-\mathrm{I} 33}$..

Chlorophis natalensis.

Chlorophis irregularis.

I. Chlorophis hoplogaster. Green Water Snake. Groen Water Slang.

Synonyms-Ahatulla hopolgaster; Chlorophis oldhami: Pithothammes hoplogaster.

Colour-Uniform bright green, sometimes with an olive tinge above greenish-yellow on the underparts.

Average length -3 feet.

Distribution-Cape Colony; O. R. C., Transvaal; Natal; Zululand; Rhodesia; East and Central Africa.

2. Chlorophis Neglectus. East African Green Snake.

Synonyms-Pithothammus neglectus; Ahatulla neglecta.

Colour-Green above; greenish-yellow beneath. Some specimens have purplish-brown blotches on the anterior part of the body.

Average length -3 feet.

Distribution-Southern Rhodesia; East Africa; British Central; Africa.

3. Chlorophis Natalensis. Natal Green Snake. Natalsche Groen Slang.

Synonyms-Dendrophis natalensis; Philothamnus natalensis.

Colour-Olive-green above, usually some of the scales with a white spot on the outer border, and the skin between the scales black; greenish white below.

Average length -3 feet.

Distribution-Generally distributed over South Africa; North to Central Africa.

4. Chlorophis irregularis. Northern Green Snake. Noordelijke Groen Slang.

Synonyms-Coluber irregularis : Philothamnus irregularis : Philothamnus guentheri.

Colour-Green or olive above, scales often with a white spot at the base, with or without a black upper border; skin between the scales black; sometimes with black spots or irregular cross-bands on the anterior part of the body; greenish-yellow below.

Average length -3 feet.

Distribution-Southern Rhodesia; North to Tropical Africa.

\section{GENUS PHILOTHAMNUS.}

\section{A single Species in South Africa. \\ KEY TO THE SPECIES.}

Scales in 15 rows. Ventrals $169-207$, anal divided. Sub-caudals keeled and

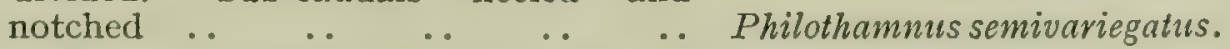

I. Philothamnus semivariegatus. Bush Snake. Bosch Slang. Synonyms-Philothamnus punctatus ; Dendrophis semivariegatus; Abetulla bocagii : Leptophis punctatus.

Colour-Green or olive above, with or without black spots or cross-bars; greenish-yellow below. 
A. Irregular black cross bars; some of the scales with a whitish spot.

B. No black spots or bars; some of the scales with a whitish spot.

C. With black spots, at least on the anterior part of the back.

D. Spots and bars absent or very indistinct.

Average length -3 or 4 feet.

Distribution-Delagoa Bay; Portuguese East Africa.

\section{GENUS PROSYMNA.}

Five Species in South Africa.

KEY TO THE SPECIES.

Scales smooth in $\mathbf{I} 5$ rows. Internasal paired; two superposed anterior temporals .. ..

Scales smooth in $I_{5}$ rows. Internasal single; a single anterior temporal. Width of the frontal not half the width of the head; ventrals 167 ; sub-caudals 50 .. $\quad . \quad \ldots \quad \ldots \quad \ldots \quad \ldots$ Prosymna frontalis.

Scales smooth in I5 rows. Ventrals $\mathrm{I}_{3} \mathbf{I}-\mathbf{1 5 3}$; sub-caudals 19-34 .. ... . . . . Prosymna ambigua.

Scales smooth in 5 rows. Width of the frontal more than half the width of the head; ventrals I69-I85; sub-caudals 38-49 .. . . . Prosymna bergeri.

Scales keeled in I7 rows; a single internasal .. Prosymna jani.

I. Prosyma sundevalliI. Coppery Snake. Koperachtig Slang. Synonyms-Temnorhynchus sundevallii: Rhinostoma cupreum: Temnorhynchus frontalis.

Colour-Pale brown above, each scale edged with darker; head yellowish, with a more or less distinct brown band between the eyes and a large dark brown crescentric blotch bordering the parietals posteriorly; two rows of small brown spots along the back; uniform whitish inferiorly.

Average length $-\mathrm{r}$ foot.

Distribution-Both provinces of Cape Colony; Natal; Orange River Colony: Transvaal.

2. Prosyma frontalis. Northern Coppery Snake.

Synonym-Temnorhynchus frontalis.

Colour-Very similar to the former.

Average length $-I$ foot.

Distribution-German South West Africa; Angola.

3. Prosyma ambigua. Grey-Spotted Coppery Snake.

Synonym-Ligonirostra stuhlmanni.

Colour-Blackish above, each scale usually greyish in the centre; lower parts whitish or brown.

Average length-I foot.

Distribution-Zululand; German South-West Africa; Southern Rhodesia; Angola; East Africa.

4. Prosyma bergeri. West African Coppery Snake.

Average length $-\mathrm{I}$ foot.

Distribution-German South-West Africa.

5. Prosyma Jani. Black-headed Coppery Snake.

Colour-Pale reddish-brown above; the greater part of the upper surface of the head and nape black, leaving a pale sponton, each supraocular and a cordiform one on the middle of the nape; a black cross bar on the neck, followed by a double series of black 


$$
98
$$


spots along the anterior two-thirds of the back; yellowish-iwhite below.

Average length-I foot.

Distribution-Zululand; Portuguese East Africa.

\section{HOMALOSOMA.}

Two Species in South Africa.

KEY TO THE SPECIES.

Ventral II5-I44 . $\quad \ldots \quad \ldots \quad \ldots \quad \ldots \quad \ldots$ Homalosoma lutrix.

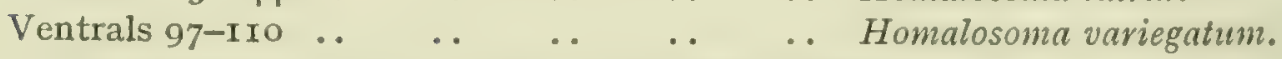

I. Homalosoma lutrix. The Homalosoma Snake.

Synonyms-Coluber lutrix: Homalosoma shiranum.

Colour-Colouration very variable; under-parts and lower surface of tail uniform yellowish in the middle, and greyish on the sides, usually with a regular lateral series of black dots.

The following is the description of the various varieties:-

A. Pale Brown or yellowish above, with a vertebral series of black dots: greyish olive or plumbeous on the sides, which are limited above by a series of black dots; lateral ventral dots large.

B. Reddish brown above, blackish olive on the sides, greyish towards the belly; a fine black vertebral line; lateral ventral dots large.

C. Like the preceding, but the vertebral line and the ventral dots indistinct.

D. Uniform olive brown above, passing to greyish on the sides; the lateral ventral dots very small.

E. Reddish brown or brick red above, grey on the sides; lateral ventral dots well marked. (Eastern Prov. C. C.)

Average length- $\mathrm{I}$ foot.

Distribution-Western and Eastern Provinces of Cape Colony; Natal; 1..... O. R., C.; Transvaal; Rhodesia; North to East and Central Africa.

2. Homalosoma variegatum. The Variegated Snake, Bont Slang.

Colour-The colour varies.

A. Dark brown above, with irregular lichen-like, brownish-white variegation.

B. Olive-brown above, with three series of dark brown spots. Underparts in both varieties reticulated black and whitish.

Average length - I foot.

Distribution-Zululand; Delagoa Bay; Portuguese East Africa.

SUB-FAMILY RHACHIODONTINA.

GENUS DASYPELTIS.

A single Genus in South Africa.

Scales in 23 to 27 rows, laterals very oblique and with scrrated kecls; teeth rudimentary.

DASyPeltis Scabra. The Egg-eating Snake or Eier Vreter, or Eier Slang. Synonyms-Coluber scaber: Anodon typus; Rachiodon scaber: Tropidonotus scaber. Dasypeltis inornata. 
Colour-The colouration varies considerably according to the locality of the species-

A. Vertebral spots elongate and more or less confluent into a zig-zag vertebral band; a black stripe along upper surface of tail; under-parts spotted with blackish.

B. A dorsal series of large squarish or rhomboidal dark spots, separated by light intervals, alternating with a lateral series of spots or cross bars; under-parts spotted or dotted only at the sides.

C. Pale reddish-brown above with the markings very much effaced. Intermediate between $B$. and $F$.

D. Dorsal markings as in B. but ventrals edged with blackish.

E. Dorsal spots confluent with lateral ones, forming cross bands; belly unspotted.

F. No spots or markings of any kind (Natal).

Average length -3 feet.

Distribution-Generally distributed over South Africa; ranges as far north as Sennar and Sierra Leone.

\section{Olive-Brown Water Snake.}

\section{(Ablabophis rufulus.)}

This well-known snake is common in suitable localities all over South Africa. It is invariably found in the neighbourhood

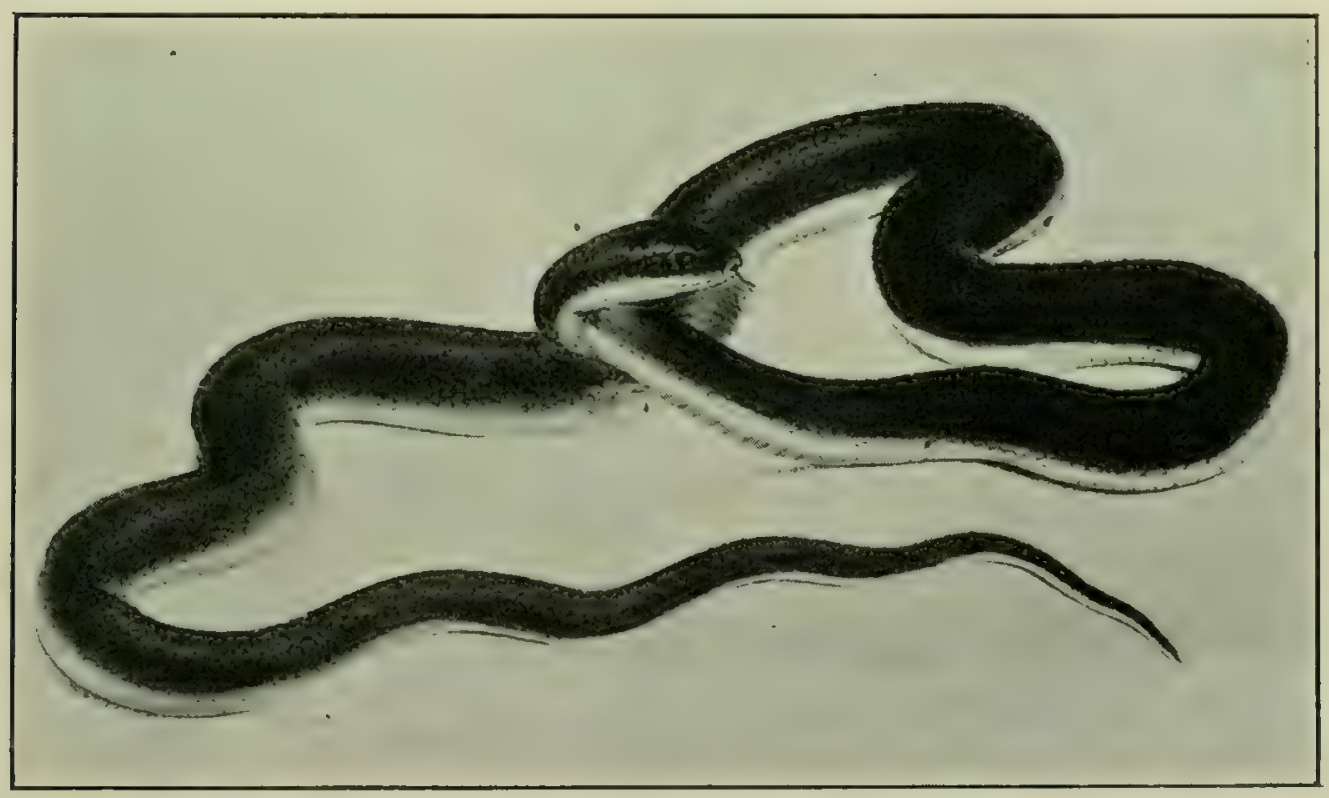

FIG. 39.-An Olive-brown Water Snake. (After Simith.)

of swamps, vleis, and the banks of river and pools. It is an expert swimmer and diver, as well as climber. In captivity it prefers frogs to any other food, showing great expertness in their capture. I have, on several occasions, observed these Olive Water Snakes chase frogs into the water and dive down and secure them at the 
bottom of the pond. In captivity they will seize and devour live fish. In the neighbourhood of Port Elizabeth they are common. We have a dozen or more at the Port Elizabeth Museum which thrive well on their diet of frogs. They attain an average length of about 2 feet. The under-parts are of a beautiful light pink tint, which rapidly fades to a yellowish hue when a specimen is placed in alcohol.

These snakes when constricting their prey will often throw as many as five coils round it.

\section{The Green Water Snakes.}

There are four species of Green Water Snakes, or Groen Water Slangs, as the Dutch call them. Two species are common in the southern parts of South Africa, and the other two in the northern parts near the Zambesi. In Natal these Green Water Snakes are frequently mistaken for Green Mambas, for although partial to water they are in reality Tree Snakes living largely in the foliage of trees, since they are expert climbers. These Water Snakes have long tapering bodies and large eyes. They frequent marshes, ponds, rivers and damp localities in search of frogs, which are their favourite food. They swim and dive with the greatest ease, and cause much alarm to bathers by popping up almost under their noses. They are perfectly harmless, being quite destitute of poison glands or poison fangs. If one of these snakes should capture a frog or fish in the water it swims ashore, and holding its head some inches above the ground, glides up the bank, and, finding a suitable place, swallows its prey. The Green Water Snakes are equally expert at swimming, diving, climbing and travelling on the ground.

I kept some Green Water Snakes and Boomslangs in the same cage. One day one of the latter swallowed a Water Snake. After about twenty minutes I forced the Boomslang to disgorge its victim. When thrown up, the Water Snake was none the worse, and instantly glided off and almost immediately afterwards caught a frog and swallowed it.

\section{The House SNakes.}

There are four species of snakes known as House Snakes, classed under the genus Boodon. The Olive-Black House Snake, and 
the Brown House Snake, are the two best known. They are called House Snakes because they are so frequently found in and about the dwellings of man, attracted thereto by the presence of mice and young rats on which they feed. In return for this great service men ignorantly kill them at sight, although they are as harmless as any innocent lizard. These snakes are simply invaluable about farmhouses, and are much more serviceable than cats, for they can follow the destructive little rodents right down to their secret hiding-places. House snakes are quite harmless, and it would be well for all farmers to learn to identify them with a view of protecting and shielding them from harm. In the House Snake the farmer has a very valuable ally against his enemies the rats and mice.

Late one night at a certain dwelling in Port Elizabeth, close to my house, there was a great commotion. It seems three of the inmates returned about midnight from a party. Arriving on the landing half-way up, they saw the form of a snake by the light cast by the candle.

Holding a consultation, the three retired below to seek

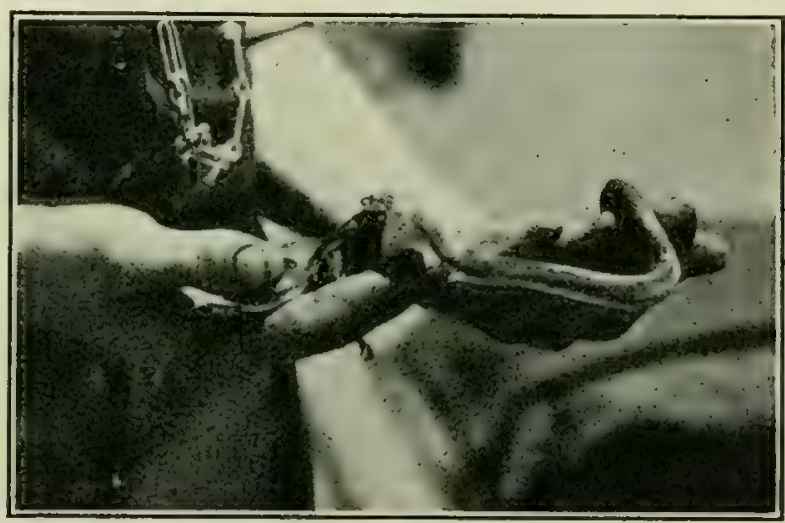

F1G. 40.-A tame Brown House Snake swallowing a young dead rat.

weapons. Meanwhile the landlady, hearing the unusual commotion, sallied forth, accompanied by her two daughters. Cautiously peering down the stairs, they descended step by step. Without previous warning, a loud hiss struck upon the strained ears of the ladies. The form of a snake rapidly vanishing from view behind a pedestal, caused such a succession of shrieks that I bounded out of bed, hurried on a dressing-gown and rushed out of my house to the rescue, fully believing some burglars were committing murder. I did not knock. I just went in. Cautiously stealing up the stairs were three young men armed with weapons. I was much relieved to learn the trouble was only a snake.

By the time it was killed there was many a dent in the hat 
stand in the hall, and sundry ugly cuts in the wallpaper caused by the wild blows aimed at the reptile.

Hauling the mangled body out in triumph, one of the fellow's declared he would take it to the museum the following day. I quietly assured them it was only a common Brown House Snake, that it was perfectly harmless, as harmless as a lizard, and that it was evidently intent upon catching mischievous, thieving mice.

House snakes soon become quite tame, if gently handled at frequent intervals. Those in our cages are taken out, and while being held in the hand, they take dead mice from the fingers, and swallow them.

One evening when walking in St. George's Park, at Port Elizabeth, I attempted to capture a snake, which I noticed on the path. In the darkness I bungled, and the reptile bit my hand. I felt the sting of its teeth. Being too dark to identify the species, I seized it firmly and hurried off to the nearest electric light. I was much relieved to find that, instead of a Night Adder, it was a harmless Brown House Snake. Now, if I had known nothing about snakes I should probably have rushed off for help in a great state of alarm and nervous dread, and doubtless have been dosed with some popular snake bite remedy, and ever afterwards advocated it as a cure for snake bite.

\section{Much Ado About Nothing.}

The following appeared in a certain Cape Colony newspaper, and was telegraphed all over the country:-

"Our Louwsburg correspondent writes:-An extraordinary affair occurred last night, when the inmates of the local gaolsituated four miles away-were thrown into commotion by the entrance of a snake into one of the two cells which a paternal Government has provided for the accommodation of prisoners and witnesses alike. About II p.m. one of the prisoners heard a rustling noise near him, and, thinking it was a mouse, put out his hand to drive it away. His fingers came into contact with the body of a snake, and immediately he was bitten on the hand. The shouts of the prisoners brought out the warders, but when they entered the cell the snake had already retired into its hole. The bitten man was suffering severely, and a messenger was 


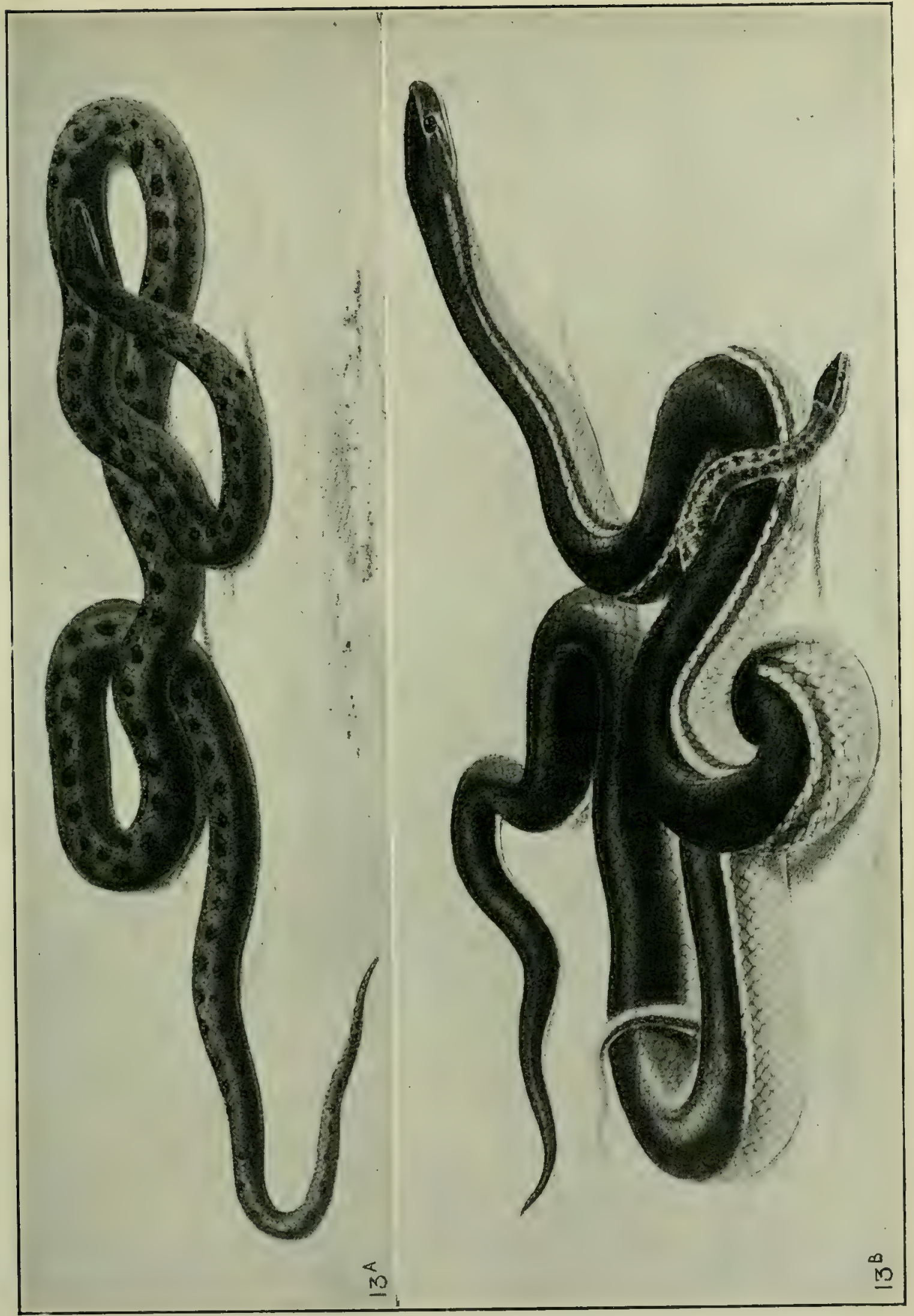

HARMLESS HOUSE SNAKES. (After Smith.)

FIG. 4I.-Spotted House Snake. Stippel Huis Slang. (Boodon guttatus.) Average length I $\mathrm{ft}$. Colour: Yellowish-brown above, with several rows of reddish-brown spots, two rows of spots along middle of back almost circular. A dark brown blotch on each side of back of head, and pair of dark longitudinal streaks on nape. Under-parts pale yellow. (Brit. Mus. Cat.Snakes.) Distribution: Cape Colony. 2. Brown streaks on nape. Under-parts pale yellow. (Boon lineatus), and young specimen of same. Bruin Huis Slang. Average length $2 \mathrm{ft}$. Colour: Brown above, uniform, or variegated with yellowish, lateral streak passing through eye. Head dark brown with two more or less distinct lines on sides. Lower parts yellowish. (Brit. Mus. Cat.Snakes.) Distribution: All over South Africa, N. to Cent. Africa. 
immediately despatched for the District Surgeon. Fortunately, the snake was not of a kind whose venom acts promptly, for the messenger had to ride four miles, and the doctor four miles ere medical assistance could be rendered to the sufferer. Dr. Wildish took with him the anti-venom discovery of the Pasteur Institute, and its effects have so far been successful." Subsequently, water was poured down the hole where the snake was seen to disappear, and behold! out crawled a half-drowned, harmless Brown House Snake.

\section{Three-Cornered or File Snakes.}

These snakes, although found in most parts of South Africa, seem to be rather rare everywhere. Although large and formidable-looking, they are perfectly harmless. Their average length is three to five feet. They are not easily mistaken for any other genus of snake owing to their peculiar vertebral or backbone scales, which, at first sight, gives these snakes a triangular appearance. The row of scales along the backbone are bicarinate, which means double-keeled. These scales have a groove longitudinally down the centre. The colour of the skin in the groove is yellow, forming a long line from the head to the tail of the snake. These backbone scales are rounded and larger than those on the rest of the body. The colour of the upper parts is usually brown. The edges of the abdominal shields and lower half of last row of body scales are blotched, forming two rows extending the whole length of the body. The head is blackish in colour. Two species are officially recognized in South Africa, viz. Simocephalus capensis and Simocephalus nyassa. The reason for separating them into two species was because $S$. capensis was supposed to have two postocular shields and 203-24I ventrals, and S. nyassa only a single postocular and I7I-I85 ventrals. However, I do not agree with the separation of Simocephalus into two species. I have examined several specimens and find that the above characters which are supposed to distinguish them, are not constant. In some there are two postocular shields and I7o to I80 ventrals. In others a single postocular and 203 to 240 ventrals, thus proving that these characters cannot be relied upon. I have found the same thing to hold good with other 


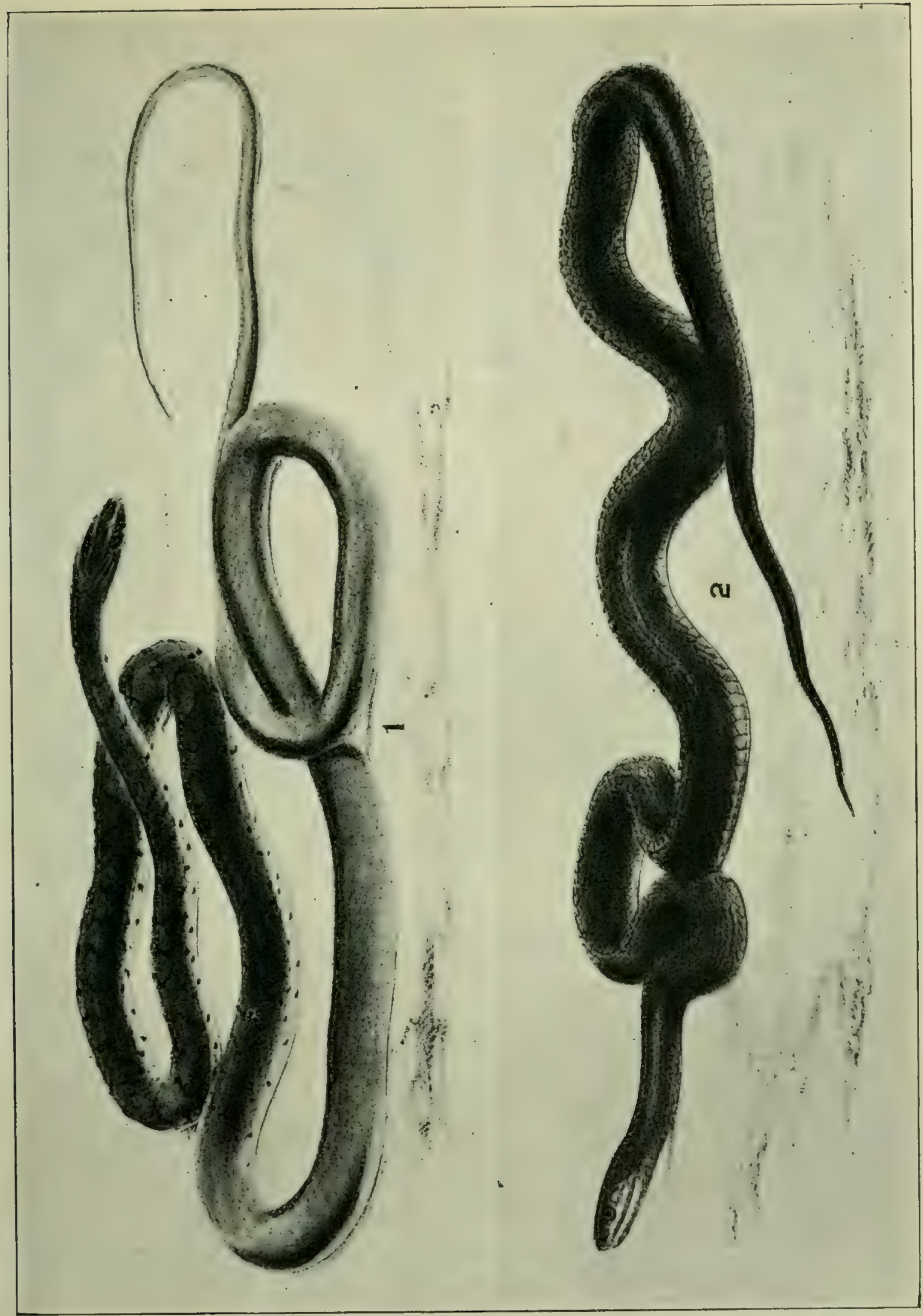

1. THE BUSH SNAKE. 2. THREE-CORNERED OR FILE SNAKE. (After Smith.)

FIc. 42-Bush Snake or Bosch Slang (Philothammus semivariegatus). Average length 3-4 feet. Large eye, slender shape, tapering tail. Colour varies in different specimens. The variations are: (a) Colour above, gren or olive with irregular black cross bars; some scales with whitish spot. Greenishyellow below. (b) No black spots or bars; some scales with whitish spot. Ground colour green above, yellow below. (b) No black Wpots or back spots, at least on anterior part of back. (d) Spots and bars and yellowish below. (c) With black spots, at least on ant. The prevailing colour is always green or absent, or very indistinct.- (Breen, and yellowish below. 2. Three-cornered Snake or Vijlslang (Simociphalus capensis). olive green, and yellowish below. ${ }^{2 .}$. Threc-cornered length $3 \mathrm{ft}$. Colour: Dark brown above, with olive shade. Upper lip and scales along top of backbone yellowish. Light yellow below. 
species of snakes. This constant creation of new species in Zoology is being carried to an extreme and will doubtless create endless confusion and labour in the future, if continued. In the case in point the difference is merely a matter of variation which is by no means constant. Naturally, if a large series should be examined, and if the difference should be seen to be constant, then there is justification for the creation of a new species, not otherwise.

The generic name Simocephalus has been previously used for a genus of Cruslaceans, and will require to be altered.

\section{The Mole Snake.}

Also known as the Zwart Slang, Lui Slang, Mol Slang.

\section{(Psendaspis cana.)}

The Mole Snake is widely distributed over South Africa. It varies considerably in colour. Some specimens are shiny black, others brick red, or brown spotted with black. The Mole Snakes and House Snakes can be regarded as typical examples of nonvenomous snakes. Young Mole Snakes are brown, with irregular black markings. Many of these about two feet long are lightbrown with wavy black markings on the back, and are also spotted and blotched with white. Adults are usually found most abundantly about the haunts of moles, mole-rats, field-rats and vlei otomys, in sandy soil, sparsely covered with scrubby bush. The young haunt stony hillocks, and rough, rock-strewn ground, in pursuit of lizards, on which they mostly feed. In captivity, Mole Snakes usually refuse all food. Occasionally I have induced them to eat, and have observed them constrict and swallow moles and rats.

Mole Snakes, when surprised, will show fight, boldly facing the intruder and making desperate lunges in his direction, with gaping mouth and slightly raised body. This habit of raising the fore part of the body and head, and general outward similarity to the Cape Cobra, causes them to be mistaken usually for the latter. Apart from the difference in the formation of the teeth and scales, Mole Snakes can easily be distinguished from cobras. Their heads are narrow, and join the body without any narrowing at the neck region. Their bodies are nicely rounded (cylindrical), 


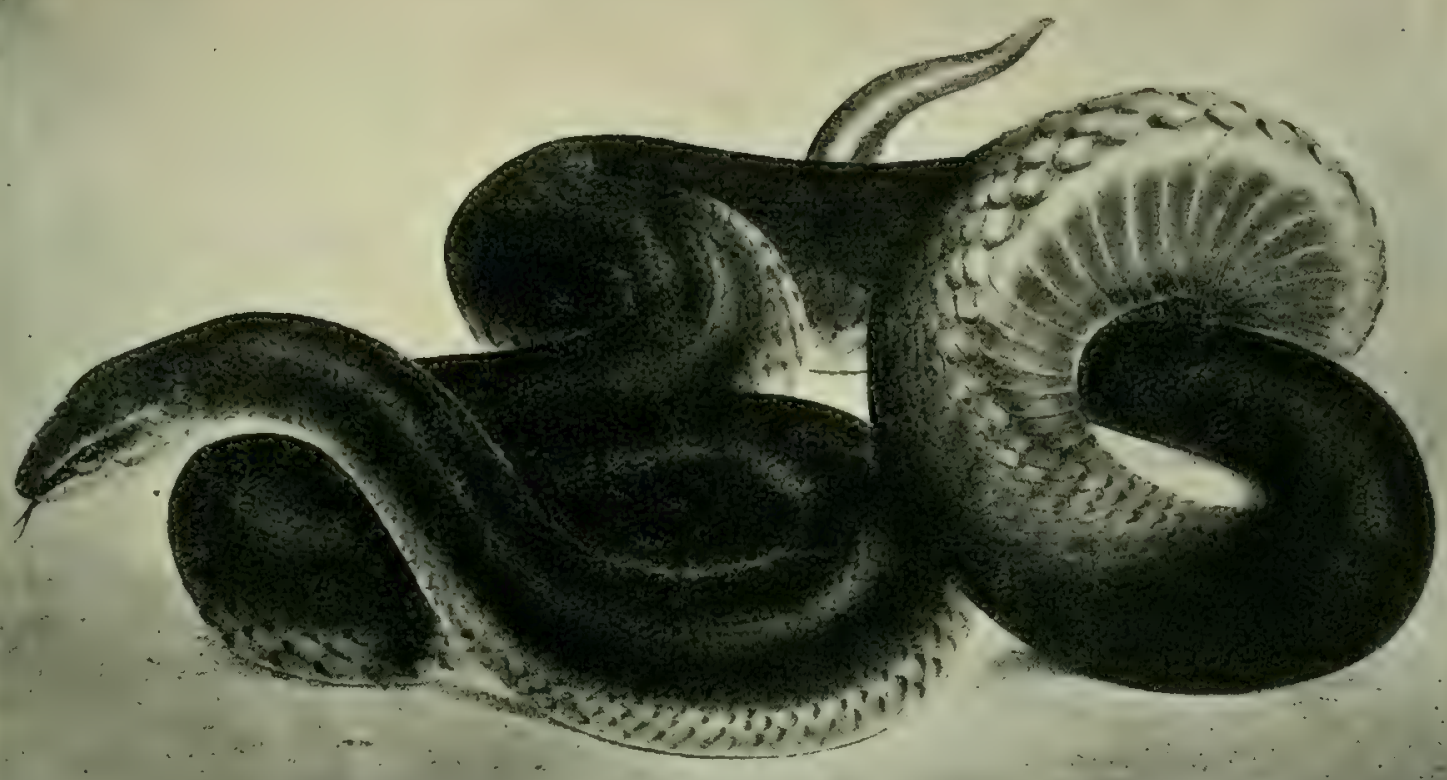

$12^{A}$

$12 \mathrm{~B}$
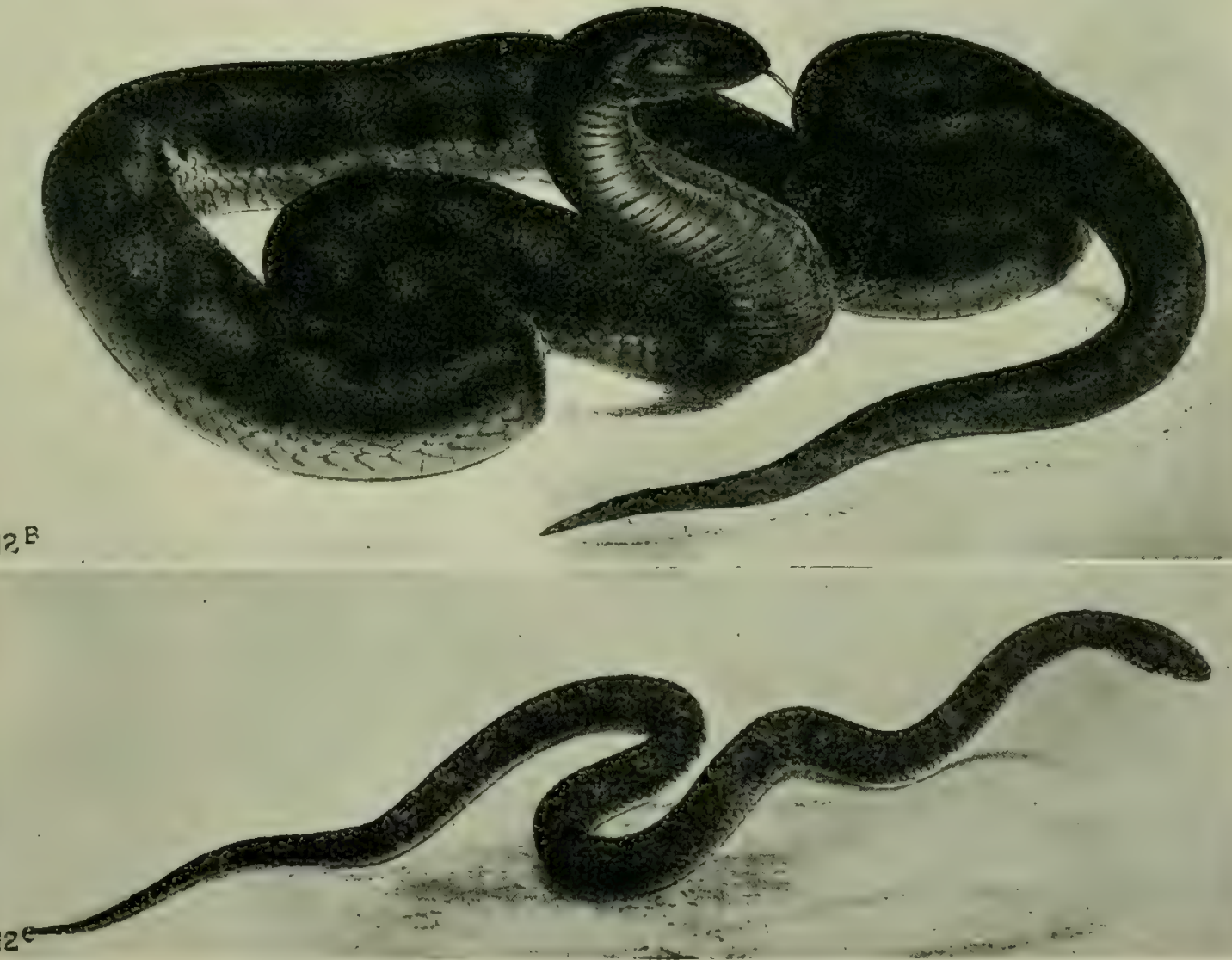

MOLE SNAKES. (After Smith.)

Fig. 43. -The Mole Snake (Pseudaspis cana), also known as the Zwart Slang and Lui Slang. Average length 3 to 4 feet. Mole Snakes vary remarkably in colouration. This illustration shows the black variety, the brown spotted variety, and the young. There are six pronounced varieties of colouration which are as follows : I. Glossy black, shading into purple on the under parts. No trace of spots or markings. (Zwart Slang.) 2. Brown, covered with blackish, irregular, more or less rounded markings. Under-parts yellowish. 3. Uniform dark brown. Lighter on the under-parts. No trace of markings. 4. Brick red in colour, covered with more or less rounded blackish markings. Under-parts yellowish. 5. Half-grown young. Sometimes like No. 2 and No. 3. I have examined specimens from Eastern Province of Cape Colony which are light brown, with a succession of lateral markings from the tip of the tail to the head. These are made up of alternate black and white spots. The spots over the backbone are the largest, and form a continuous line of black, running lengthwise. 6. Young, from birth to 3 months of age. Brown, with wavy cross-markings of blackish. These markings are edged with white, and the whole form four longitudinal series. 
and not flattened like those of the cobras. They possess no porrer of elevating the skin of the neck in the form of the well-known "hood" of the cobra. If any snake expands a hood, and at the same time raises its head and the fore part of its body above the ground, you may rest assured it is one of the venomous cobra family.

\section{Mole Snakes are Harmless.}

The Mole Snake is quite non-venomous. It always kills its prey by constriction. The power which it can exert is very great. I have frequently held Mole Snakes between my finger and thumb, and allowed them to coil round my wrist. In a few minutes the blood circulation was arrested, and the hand grew cold and numb, so great was the power of constriction exerted by the snake.

In captivity Mole Snakes rarely climb. They only seemed to do so when exploring their place of confinement, just after being placed therein. After a day or two they never attempt to climb the branches in the cage, and most of the time lie buried in the sand with the head protruding, which they instantly withdraw if disturbed. In the wild state I have occasionally found them high up above ground in thick creepers, such, for instance, as the honeysuckle, grenadilla, and creeper-covered bushes. It is a common sight to see Mole Snakes basking in the sun near rat or mole holes, into which they instantly retire if disturbed.

The Mole Snake is viviparous, giving birth to a great number of young, usually from thirty to forty-five.

We procured one which measured seven feet three inches, and it gave birth to eighty-four young, which is the maximum number ever recorded. This specimen was, however, much larger than the average of Mole Snakes, which are usually from three to four feet in length.

It is a grave mistake to kill Mole Snakes, for they are as harmless as lizards, and are the farmer's great allies, aiding him most efficiently in killing off those pests the rats, mice, and mole rats. They eat the useful little insect-eating mole, but that is a small matter in comparison to the great amount of good they accomplish. 


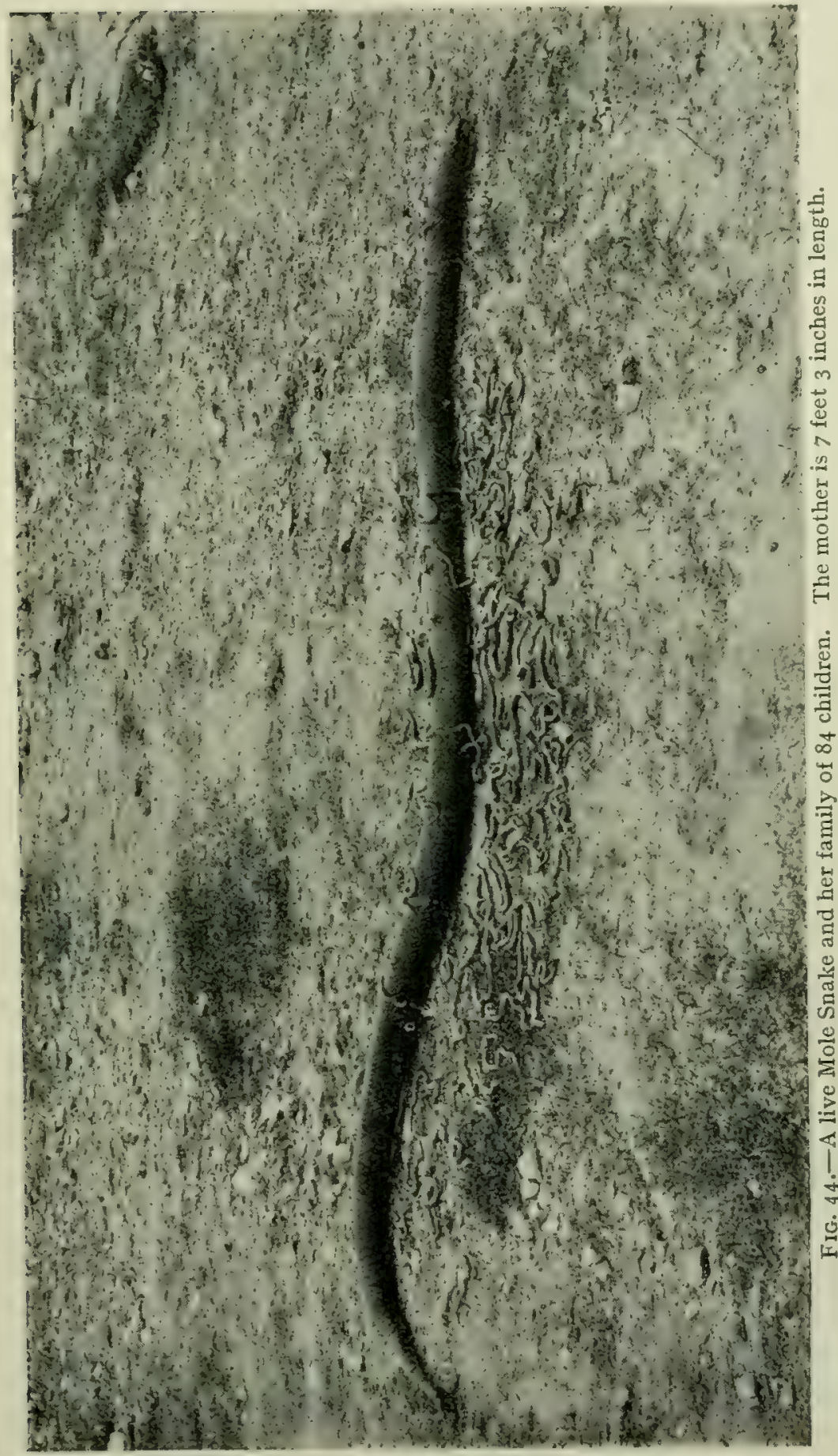




\section{HaRMLESS SNAKES.}

It is unnecessary to notice in detail each of the Solid-toothed Snakes, the names of which are given above. They are, one and all, perfectly non-renomous, possessing no restiges of poison glands, and their teeth show no signs of grooving.

It is very desirable that the general public should become acquainted with the different species of snakes in order that the present indiscriminate slaughter of these innocent and exceedingly useful reptiles should be checked. Through lack of knowledge of the habits and ways of these creatures of the earth, a bitter warfare has been waged against them, and great numbers of species of exceedingly useful reptiles have been, and are being, exterminated.

The Egg-eating Snakes.

Sub-FAmily II. RAChiodontine.

The EgG-eating Snake or Eier Vreter.

(Dasypeltis scabra.)

The Egg-eating Snake is truly a remarkable creature, and serves to bring forcibly home to us the wonderful and aweinspiring workings of Nature. In the study of Nature we see the operation of a mighty All-Wise Intelligence. It reveals to us the fact that there are great and mighty forces at work which we call Laws, and through the operation of these great forces or Laws, the Creator works. The student of Nature sees the results of the operation of this mighty Power or Intelligence in everything. In the Egg-eating Snake we have a living example of how Nature takes away that which is no longer required, or which through neglect or indolence is not used. We also see how wonderfully she provides for the altered habits and environment of the creatures of the Earth.

The only species which represents this sub-family of Colubrine snakes is the Egg-eating Snake of Africa. It is different from all other snakes in having only five very rudimentary teeth in the upper jaw, and four in the lower jaw, situated about the centre part of the mouth. In fact, practically speaking, its jaws are 

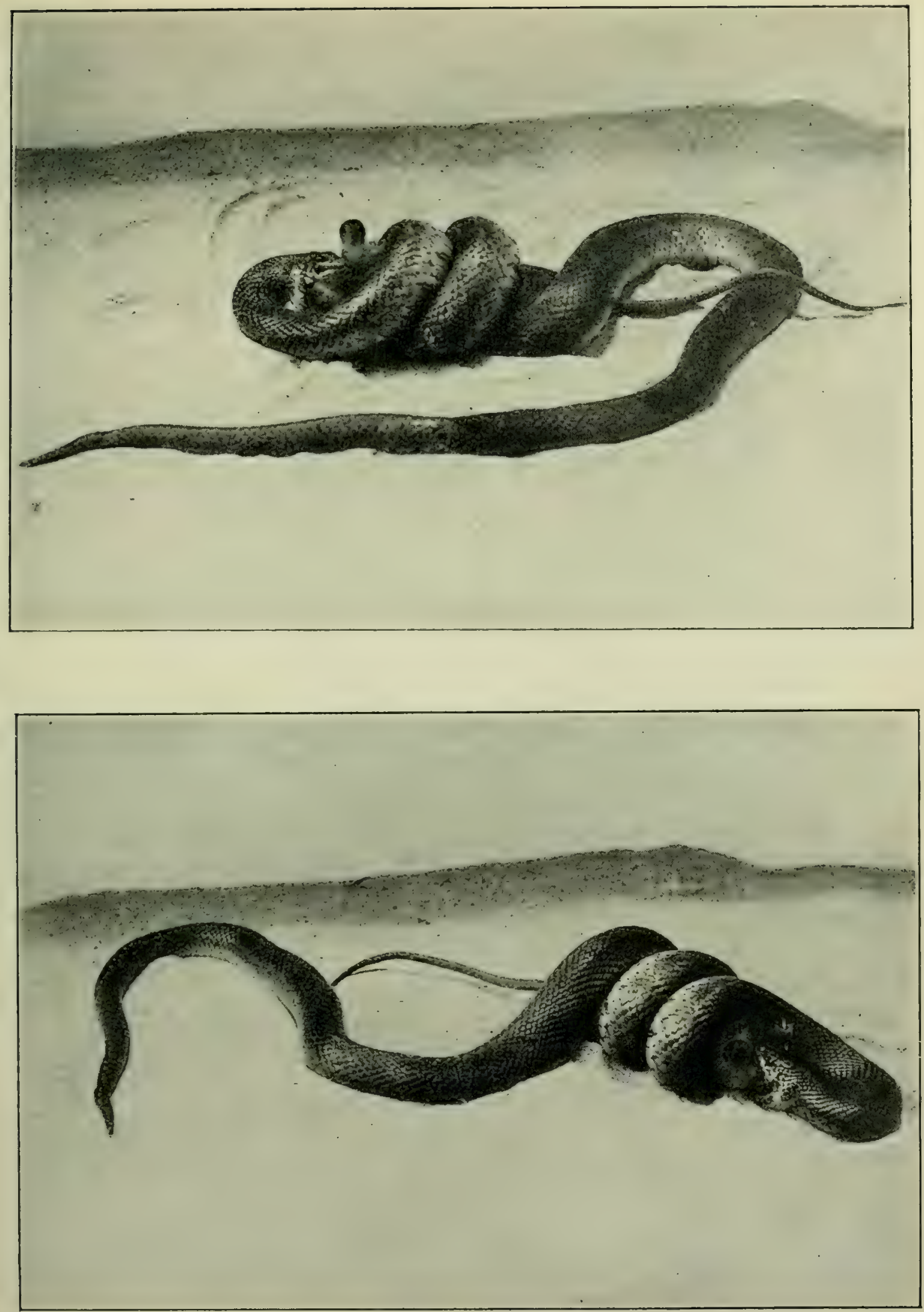

MOLE SNAKES CONSTRICTING RATS.

Fig. 45.-The snake seizes the rat by the nose, whenever possible, and throws a couple or three coils round its body. So powerfully does it constrict, that the rat is unable to breathe, and dies rapidly. The snake, after constricting its prey in the manner seen in the picture, lies perfectly quiet for a few minutes, and then proceeds to swallow the victim whole. The coils are, at this time, somewhat loosened, but remain in a position ready for instant contraction, should the prey show any signs of life. It is stated in certain scientific books that snakes only throw two coils round their prey; this is not so, at least with South African constricting snakes. The number of coils depends upon the size of the victim. I have seen as many as five coils thrown round the prey. [Photograph taken from life at the Port Elizabeth Museum.] 
toothless. The Egg-eating Snakes vary a great deal in colouration, according to the district in which they are found. On account of such differences, they have been divided into six varieties. Four out of the six varieties are found south of the Zambesi, the other two occurring in Central and Northern Africa. The sub-family name applied to the Egg-eating Snake is Rachiodontina, which means having enamel-tipped tooth-like projections in the spine, penetrating the gullet. These snakes are found in all parts of South Africa, but are nowhere common. Their average length is three feet.

\section{Evolution of the EgG-Breaking Mechanism.}

In proportion to the degree in which this species of snake took to feeding upon eggs, its teeth dwindled in size and number, and to-day it only possesses a few, which are quite rudimentary, and cannot be detected unless the snake's jaws be dissected. In the act of swallowing eggs, teeth were of no use to the snake; in fact, they were a distinct hindrance, so Nature took them away, and specially provided for the altered habits of this creature in a most wonderful and unique manner. It reads almost like a fairy tale, but it is nevertheless true that the Egg-eater actually has teeth in its backbone. For all practical purposes they are teeth, but in a strict scientific sense they are little bony projections jutting out from the backbone of the neck. They project forwards, and downwards into the gullet, and are tipped with enamel. There are about thirty altogether. The smaller "teeth" start from the base of the skull, and in full-sized snakes continue for two and a half to three inches down the backbone, terminating in six or seven others a little more prominent, and more freely coated with enamel. These larger "teeth" are for the purpose of sawing through strong hard shells which the smaller teeth cannot negotiate. Below these, there are seven bony projections almost a quarter of an inch long. These are not tipped with enamel. They, like the others, project into the gullet, pointing at an angle towards the mouth. When the snake swallows an egg, it, by means of these projections, keeps the egg in position until it is sawn through by the other teeth. They are also used as an aid in helping the snake to cast out the crumpled egg-shell, and ensuring that no pieces 


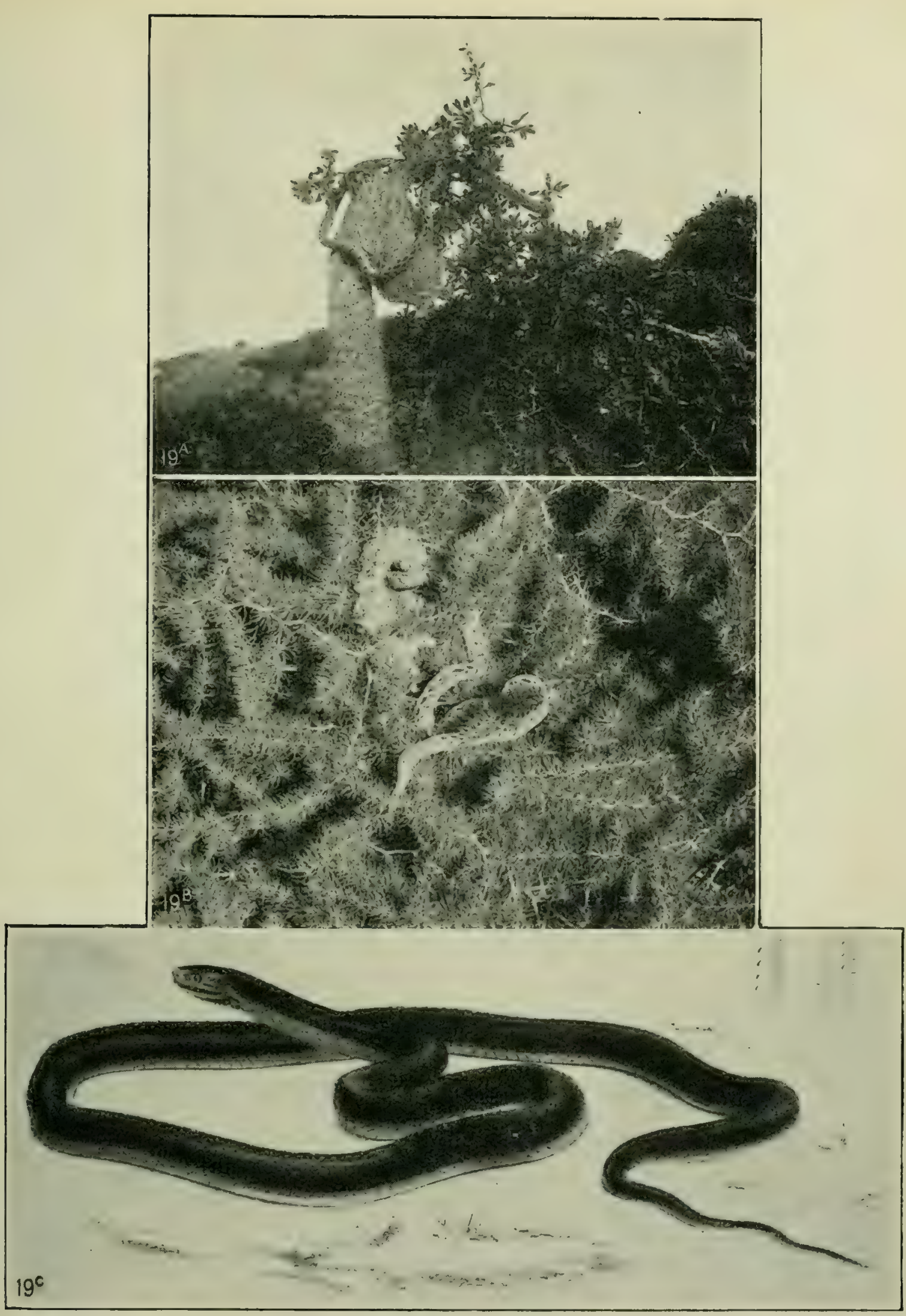

EGG-EATER AT WORK.

Fig. 46.-An Egg-eater doing his best to find a way into a Weaver bird's nest. This is the nest of Smith's Weaver Bird (Sitagra capensis) which youngsters know as a Bottle Fink. This crafty Fink builds its nest at the extreme end of a branch, so that its enemies, the wild cats and snakes, may not be able to reach it. As an additional security, it makes a long tube to the nest so that, even if a cunning serpent should reach its home, as was the case in this instance, it could not get inside, because if it tried to climb down the tube, it would fall off to the ground. The second picture shows an Egg-eater robbing the nest of a Warbler in an "Evergreen" bush, his head and neck are inside the nest. The third picture shows an Egg-eater, from Natal. This specimen is 2 feet 10 inches long. Its upper parts are of a dull reddish-brown colour, with a slight tinge of olive. The under-parts are light yellow. This is one of the varieties of Dasypcltis scabra. In the corner of the picture is seen a portion of the backbone, and also a section of the gullet, showing a few of the gular teeth protruding. 
should slip down into the stomach. There is no other species of snake in the world which possesses these wonderful backbone or gular teeth.

\section{Egg-Swallowing Process.}

The expanding elastic-like power of the Egg-eater's lower jaw and skin of the throat is really immense, as will be noticed in the illustration. The snake seizes the egg at one end and proceeds to swallow it by a succession of slow and deliberate gulps, accompanied by a pushing-forward movement of the body. In fact, the snake's mouth seems just to spread slowly over the egg, so smoothly and evenly does the process act. When the egg has been worked down into the throat, the snake raises its head and neck an inch or two above the ground, and by working its backbone backwards and forwards, saws the egg-shell right through longitudinally, just as a person would do with a very fine fret-saw. Then the neck-muscles are put into operation, and the snake moves its neck from side to side, constricting the egg until all the contents have been squeezed out and down the gullet. Then raising its head a little higher, the Egg-eater spits out the crumpled shell.

An Egg-eating Snake with a head the breadth of a man's forefinger can swallow a bantam's egg. The largest varieties can manage an ordinary domestic forvl's egg.

\section{EGG-Eaters in Captivity.}

Egg-eating snakes are interesting reptiles to keep in captivity. Unlike most other snakes; they are not only quite nonvenomous, but, having no teeth, other than a few rudimentary ones in the mouth, they are unable even to scratch the skin. Knowing this, they never attempt to bite when handled, even when first captured, as do many non-venomous snakes.

No species of snake is more interesting to observe and study than the Egg-eater in captivity. He is different from the usual snake, as he has a gentle, innocent look about him. After being in captivity for a month or two, and gently handled at intervals, he seems to become affectionate with whoever fondles him. However, I fear a snake's tiny spot of a brain is not sufficiently evolved to 
be capable of disinterested affection. The reason why snakes grow to like being handled and carried about in a person's pocket, is because of the warmth, which is exceedingly pleasurable to them. The normal temperature of a snake is many degrees below that of our bodies. Moreover, their temperature largely depends on that of the atmosphere with which they are surrounded. They generate heat so slowly within themselves that, unlike us, their vital organs are quite unable to adapt themselves to a sudden rise or fall of the temperature of the air.

So, when held in the hand, the warmth of our skin imparts an enjoyable and pleasant feeling to a snake; therefore, if gently handled, snakes soon lose all nervousness and fear, and will lie contentedly in the hand, or make explorations up the sleeves, down the back, and all around the body, popping out occasionally to take their bearings.

This reminds me of an amusing incident. One of my Eggeaters was a special favourite, because he was so tame that he took eggs from my fingers, and when I allowed him to wander about my person he always seemed reluctant to be taken back to his cage. He was real company for me in my study. It made me less lonely to feel him crawling up my trouser leg, exploring my back, diving down my neck, or suddenly popping out of my sleeve to see what I was up to. My aunt had a standing grievance against me, because I so rarely put in an appearance in the drawing-room when she had visitors.

Once she was having some special friends in the evening to see her, so I promised I would join the party. Taking a walk around the grounds, to see if my Zulu servant had fed my small menagerie of domesticated wild animals, and after taking down a pet Python which I allowed to crawl up a tree in the yard to bask in the warm sunshine and dream dreams all day long of his former free, wild life in the rocky forest-clad, moist valleys of the Eastern Transvaal, I meandered in to my study, took out my Egg-eater snake, and, after fondling him for a few minutes, pushed him into my pocket to get warm. I was startled presently by the voice of my aunt at the door complaining of my unsociable and selfish conduct. With many regrets, I hurried after her, and was soon absorbed in conversation with her friends, or rather answering 


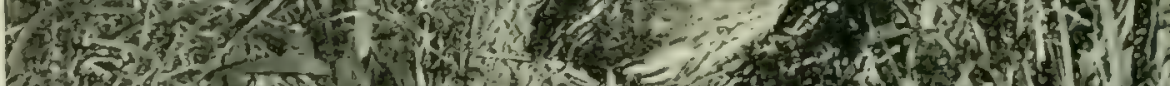

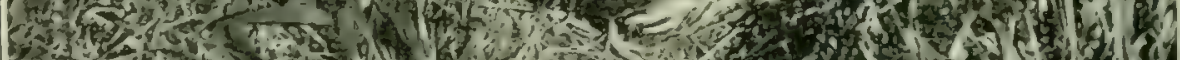

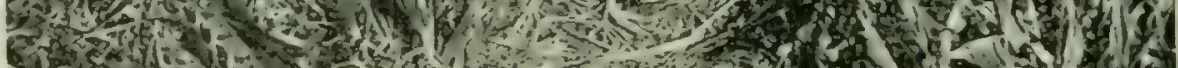
S. 0 . 1.

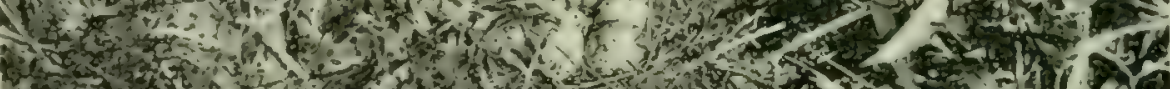

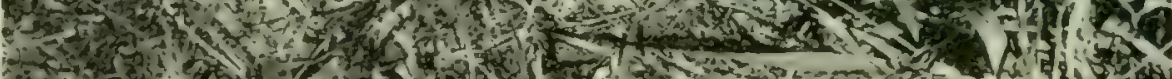
3.t.

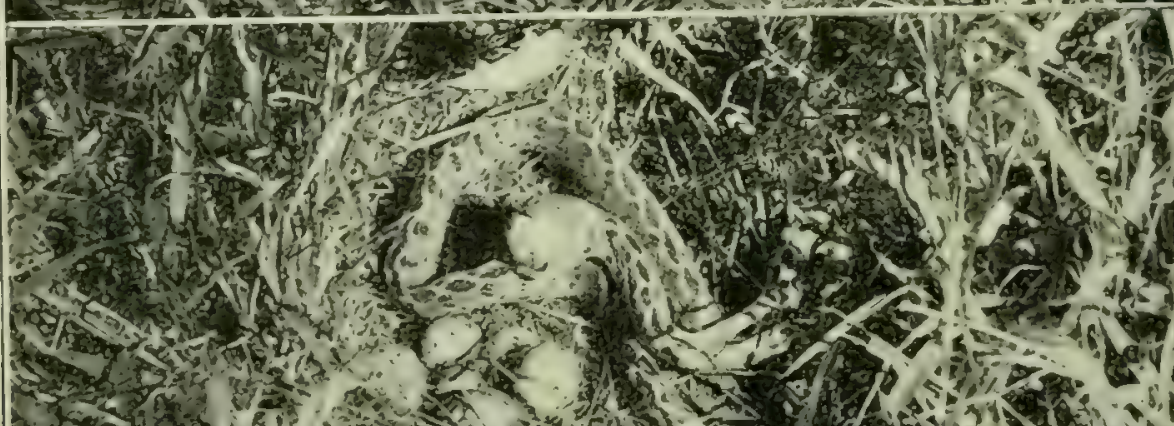

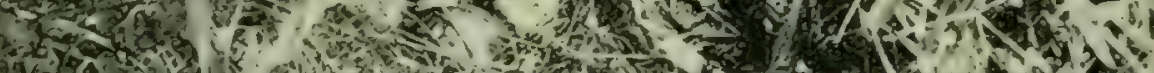

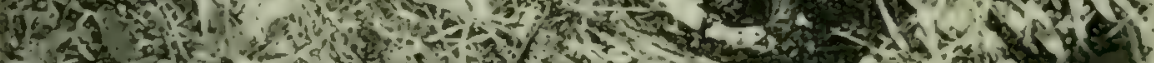

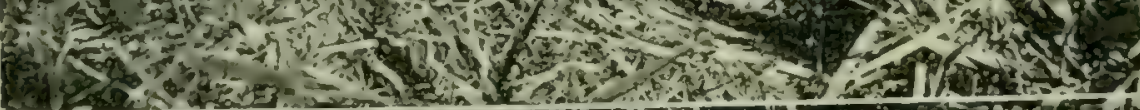

- 1 - 1 -

(i)

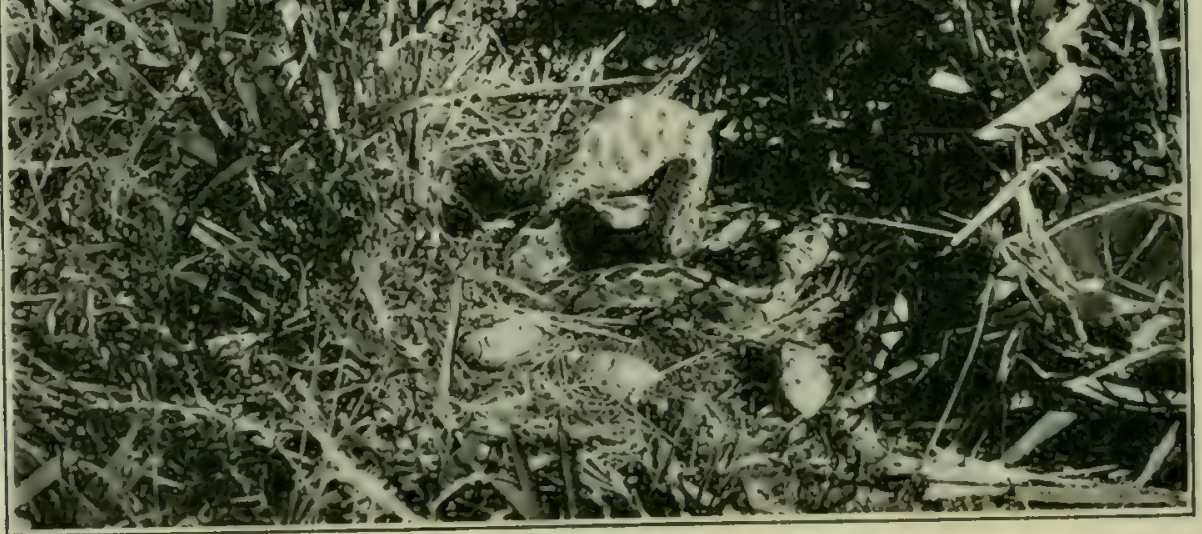

AN EGG-EATER ROBBING A NEST

Fig. 47. - This plate illustrates a very pathetic incident. (I) Shows a Cape Quail on its inate kerping it company. (2) Sheors the approach of an Egg-eating snake. The quail is seen reluctantly retiring before this forminble encmy. The snake proceeds to make a meal of the eggs. 


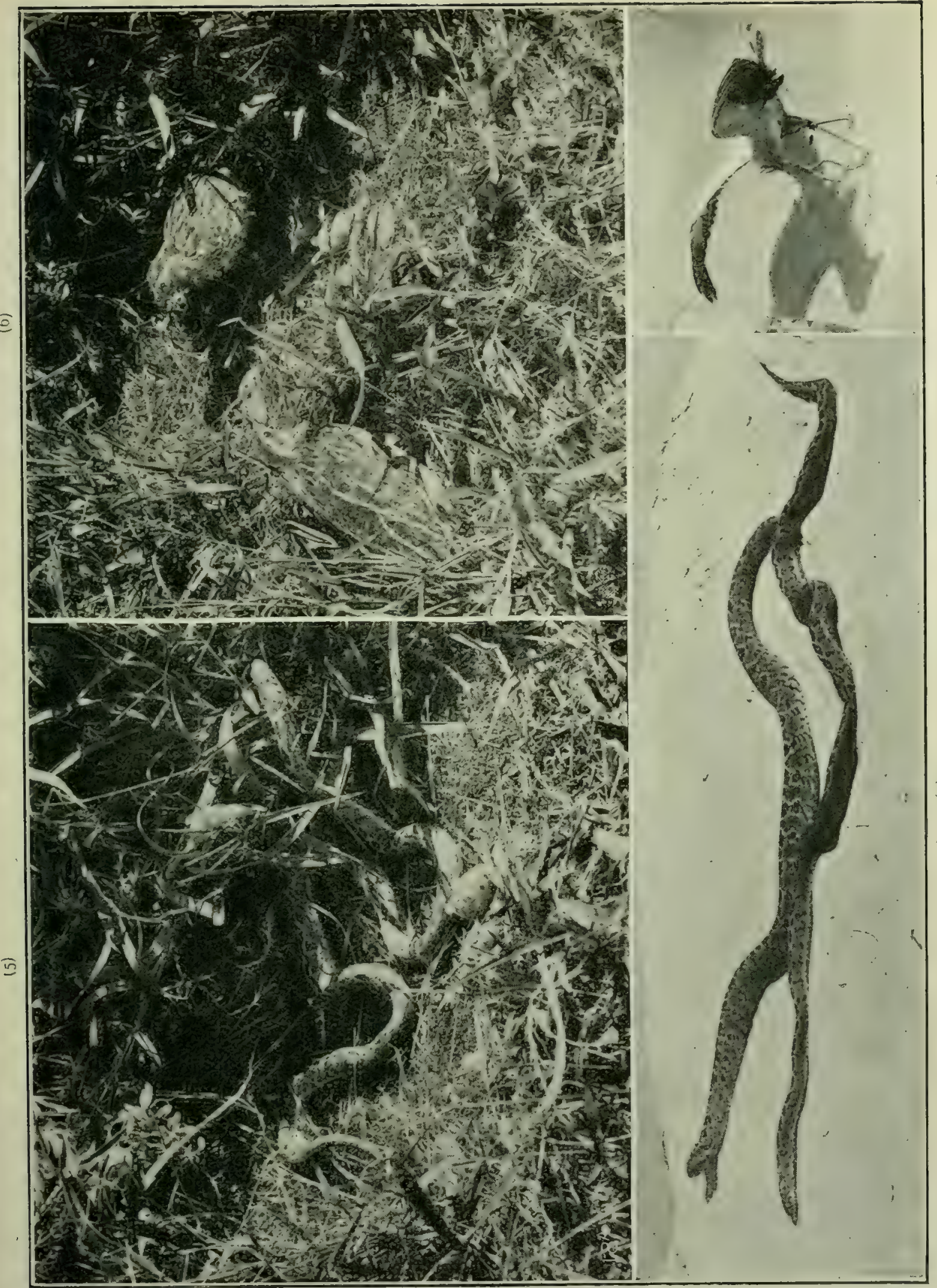

THE ROBBER ESCAPING. THE QUAIL'S GRIEF.

Fig. 48. -Continued.-(5) Having eaten the eggs, the wily serpent retires to the foliage. (6) The mother and father quails return to find crumpled up egg shells. In illustration ( 77 , the Cape Colony variety of the Egg-eater is shown, in comparison with the Night or Demon Adder (Causus rhombeatus). The top easily be distinguished. His body is not so flat or broad as that of the Night Adder. It tapers more, the black markings are different in shape, the scales are rough, and the iris of his eye is white, whereas that of the Night Adder is black. Why! The easiest way to find out is to open the mouth and feel with your finger inside. If no teeth, it is a harmless Egg-eater. If a couple of fangs should stab you, then it is a venomous snake. This bird's-nest robbing Egg-eater met with a violent end. One day he got out of his cage, and a tame Secretary Bird gobbled him like a worm (8). 


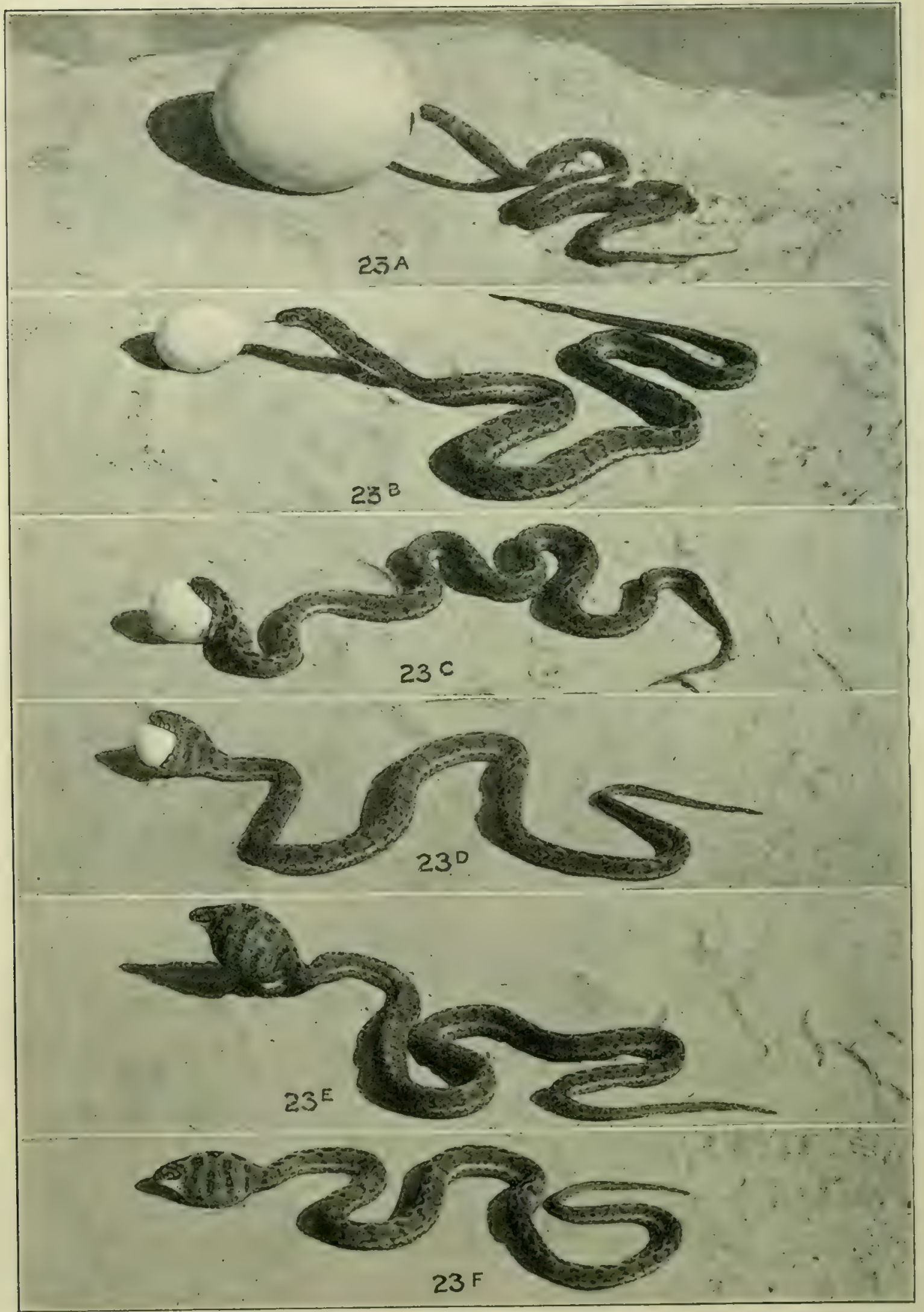

AN EGG-EATING SNAKE DINING.

FIG. 49.--Here we have a wonderful picture taken from life, the only known one of the kind in the world. This is an Egg-eating Snake (Dasypeltis scabra) in the Port Elizabeth Mluseum. We placed an ostrich che befe it, but it realızed it was uscless attempting to swallow it. We then (23 B) put a fresh fowl's egg before it, and it at once proceeded to swallow it. $23 \mathrm{C}$ shows it getting the end into its mouth. In $23 \mathrm{D}$ the egg is well on the road. Now cones the wonderful part, for, in the next picture, we see the snake busy sawing the shell with those marvellous "teeth" mentioned in the text. In $23 \mathrm{~F}$ the shell is collapsing and the reptile is working its neck-muscles from side toside to crumple up the slell in as sinall a space as possible, and at the same time squeczing the contents down its throat. 


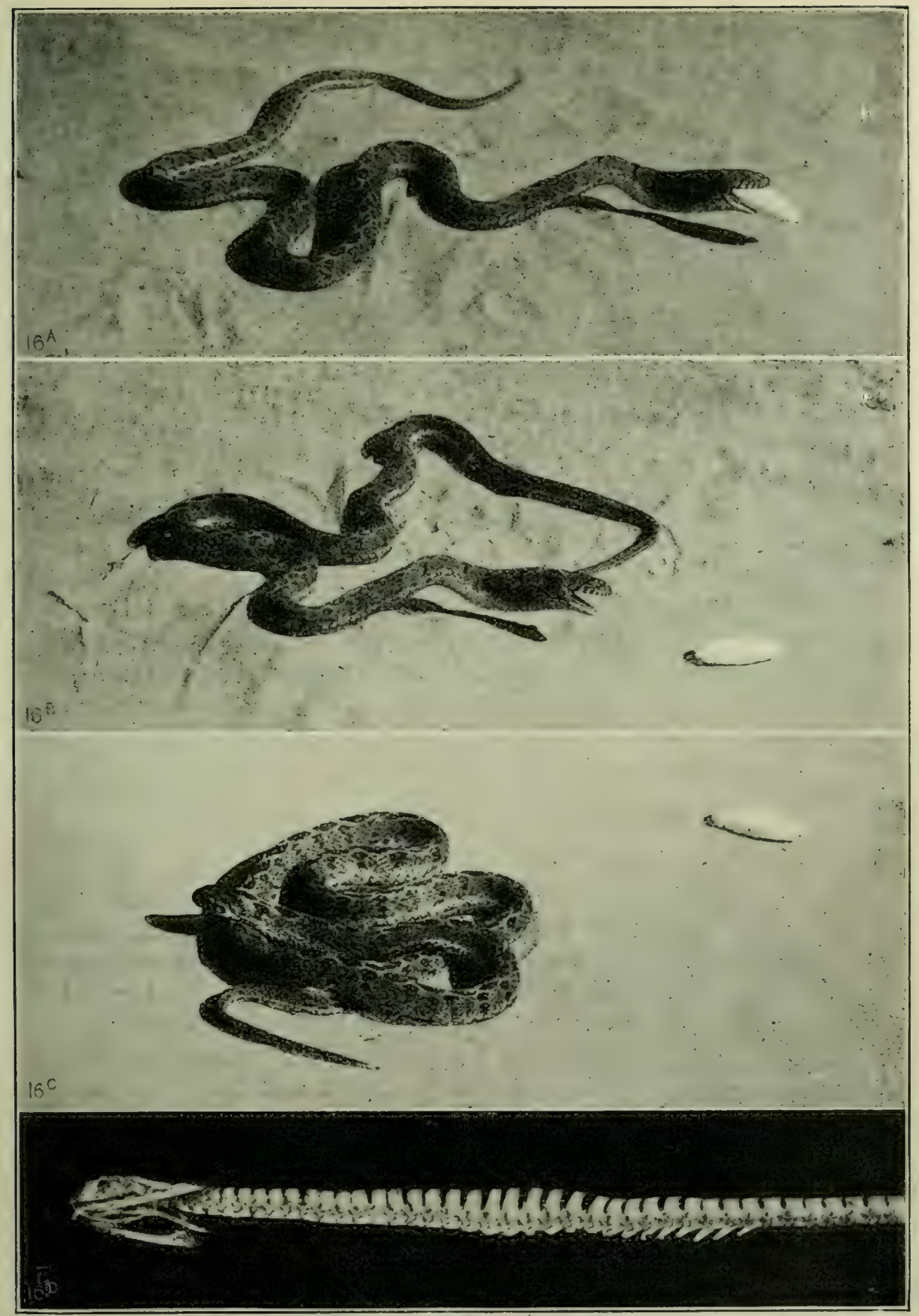

THE SNAKE CASTS UP THE SHELL.

Fig. 50.-Continusd. Behold him casting up the crumpled egg-shell. In I6C (figure three) we see him coiling himself up for a nap after his meal. The last picture shows the skull, and part of the back-bone of an Egg-eater. The sharp enamel-tipped sawing apparatus, in appearance like a long row of teeth, is seen on the lower portion of the backbone. There is one on each section of the backbone. They protrude into the top portion of the gullet. The rather long projections at the opposite end to the skull are not enamel-tipped. They hold the egg in position whilst the sawing operation is in progress. 
the variety of questions asked me, and listening to some wonderful snake stories which I was assured were perfectly true.

Just when an old lady was in the middle of a thrilling tale about a dreadfully venomous snake darting at her with open mouth and long forked tongue, I was startled to observe her face take a dismal hue. Her eyes were fixed in a glassy stare, and her jaw hung limp. Starting from my seat, I prepared to advance to her aid, when with a scream she lurched backwards. I glanced hastily around, and was about to summon the other ladies to come and help, when my words were checked by observing them rush with gestures of terror out of the room.

Just then my aunt threw light upon the bewildering affair by ordering me to leave the room instantly, and take away my loathsome snakes. Then it all came like a flood of light into my mind. It seems as I was listening intently to the old lady talking, that Egg-eater, which I had forgotten all about, suddenly popped his head and a few inches of his body out into the full glare of light, from under the neck portion of my coat. That explained the whole mystery.

I retired again to my studies abashed.

\section{EgG-eaters are Crafty Snakes.}

The Egg-eater is not altogether a fool. You cannot trick him about things which his ancestors for untold generations have learned from experience and transmitted to him in the form of a remarkably acute sense of smell, which is very necessary for him in his profession of an egg-eater. Being short of fresh pigeons' eggs once, I went to my cabinet and took the clean blown shells of a few doves' eggs. Beating up the contents of a fresh fowl's egg, I syringed it into the empty shells, and carefully pasted tiny bits of tissue paper over the holes. Placing these in the Egg-eaters cage, I watched, expecting the snakes to swallow them as they always did the other eggs. First one Egg-eater advanced. Touching each egg gently in turn, with the tip of his nose or the point of his forked tongue, he crawled away in disgust. Another and yet another eagerly ardvanced, repeating the performance and duly retired. I began to get 
interested. Leaving the eggs, I returned in a few hours' time to find them still there. For two whole weeks these eggs remained in the cage untouched, although I refrained from giving the snakes any others. Then, procuring some fresh pigeons' eggs I put them into the cage. The snakes approached, touched them with their noses or tongue and instantly began to swallow them. I tried this experiment a-second time with the same result. Frequently I have noticed that the snakes would eat some of the eggs given them, but reject the others. On breaking the latter open I always found them either addled, or with a more or less developed young bird inside. I could never induce an Egg-eater to swallow an egg, other than a fresh one.

The Egg-eater is an expert climber, and his sense of smell being acute he is able to discover birds' nests with the greatest facility. It seems that he possesses a peculiar kind of smellsense which enables him to detect the proximity of eggs. The odour given out by eggs evidently has an affinity for his sensitive nerves of smell. If an old, empty bird's nest be placed in the cage of an Egg-eater he takes no notice of it, unless perhaps occasionally for the purpose of utilizing it as a cosy bed. However, if fresh eggs be placed within it, he instantly detects their presence, although hidden from sight.

If the Egg-eater had to depend entirely upon his senses of sight and hearing, he would procure but a lean living, for birds' nests, as a general rule, are effectually concealed from view. Having a toothless mouth and a special set of egg-sawing tools in his gullet, this snake is able to subsist mainly, if not entirely, on birds' eggs. It is probable, however, he will swallow the young of birds, as well as various soft-bodied creatures, such as lizards, worms, and various larve. But I have not ascertained for certain if he eats the living young of birds, for, somehow, I could never harden myself sufficiently to rob innocent parent birds of their young, and allow these little creatures to be swallowed or otherwise perish miserably, for, having studied their ways and habits in their native homes, I have grown to love birds.

Most Egg-eaters are light brown, spotted and lined with black, and are, in consequence, frequently mistaken for Night Adders (Causus rhombeatus). In Natal and along the East Coast, the colour is invariably a uniform pale reddish, or olive-brown above, 
with no black spots or markings. This sub-species is known as Dasypeltis inomata.

This variety of colouration in the same species of snake in the different parts of South Africa, leads to considerable confusion in the public mind. If any one is in doubt about the identity of an Egg-eater, open its mouth, and if no teeth are present, then he may be certain it is a true Egg-eating snake, and quite harmless. 


\section{CHAPTER V.}

\section{Division OpISTHOGLYPHA.}

(The Back-fanged Snakes.)

\section{Sub-family III. Dipsadomorphinae.}

THIs third sub-family of the Colubrines belongs to a division or series of snakes known as the Opisthoglypha, which means a class of snakes with the posterior (back) maxillary teeth grooved. There are about 300 species of them to be found in the temperate and tropical parts of the world, with the exception of New Zealand.

This family of snakes possesses one or more pairs of grooved teeth situated in the upper jaws, midway between the front and base of the jaws. They are set in the posterior or back maxillary bone, which is more or less movable. Above these grooved teeth there are glands which secrete a venom sufficiently strong to paralyze prey preparatory to swallowing it. Owing to the more or less rudimentary appearance of these glands, and the absence of ducts, etc., as in the typical venomous snakes, it has been assumed by naturalists that all this sub-family of snakes are practically non-venomous as far as man is concerned, the fluid secreted not being thought of sufficient quantity or quality to affect animal life seriously, other than the small creatures on which these snakes prey.

This belief has recently been shown to be erroneous, - at least, in the case of two of these Back-fanged Snakes, viz., the Boomslang (Dispholidus typus) and Schaapsteker (Trimerorhinus rhombeatus) of South Africa, an account of which is given later on.

The Back-fanged Snakes should all be regarded as venomous to a greater or lesser degree, and liberties should therefore not be taken with them. 
These snakes stand midway between the harmless solidtoothed (Aslypha) and the typically-renomous snakes which, without exception, have the fangs placed in the front of the jaw, and properly connected up with poison glands and ducts.

The Opisthoglypha snakes have grooved fangs, which are situated so far back in the jaw that wounds cannot readily be inflicted with them.

I have always found that these Back-fanged Snakes will never attempt to bite unless in self-defence. I have frequently handled most of the South African species, including the now dreaded Boomslang, and they never showed any disposition to bite. When kept in captivity for six months or more, and habituated to the presence of human beings, they can be picked up and caressed, and show little or no fear. However, when attempting to capture them in the wild state they show fight, and will bite if opportunity offers. Some of these Back-fanged Snakes are arboreal, others terrestrial, although all are fairly good climbers.

There are twenty-six species or kinds of this Back-fanged family of snakes in South Africa, south of the Zambesi and Cunene Rivers.

\section{SUB-FAMILY DIPSADOMORPHINAE.}

\section{SYNOPSIS OF THE SOUTH AFRICAN GENERA.}

This sub-family of the Colubrine Snakes have grooved fangs at the posterior end of the upper jaw. They are, without exception, more or less venomous.

Genus Pythonodipsas.-Maxillary teeth $I 3$, third to sixth longest, followed after a very short interspace, by a large grooved fang; second to fifth mandibular teeth strongly enlarged, fang-like. Head distinct from neck; eye moderate with vertically elliptic pupil; nostril directed upward, pierced between a nasal and a supranasal; parietals broken up into small shields. Body cylindrical; scales smooth or very obtusely keeled, with apical pits in 21 rows; ventrals rounded. 'Tail moderate; sub-caudals single.

GENUS TARBOPHS,-Maxillary teeth Io to I2, anterior longest gradually decreasing in size posteriorly, and followed after an interspace by a pair of enlarged, grooved fangs situated below the posterior border of the eye; anterior mandibular teeth strongly enlarged. Head distinct from neck; eye moderate with vertically elliptic pupil. Body cylindrical or slightly compressed; scales smooth, oblique, with apical pits, in 19 to 23 rows; ventrals rounded. Tail moderate; sub-caudals in two rows. 
Genus Leptodira.-Maxillary teeth $\mathrm{I}_{5}$ to I8, gradually and feebly increasing in length, followed after an interspace by a pair of enlarged grooved teeth situated just behind the vertical of the posterior border of the eye; mandibular teeth, anterior slightly enlarged. Head distinct from neck; eye large with vertically elliptic pupil; posterior nasal concave. Body cylindrical or moderately compressed; scales smooth or faintly keeled, with apical pits in $I 7$ to 25 rows; ventrals rounded; sub-caudals in two rows.

Genus Chamerortus.-Maxillary teeth I2, gradually and feebly increasing in length, followed after a short interspace, by a large grooved fang situated below the posterior border of the eye; mandibular teeth sub-equal. Head distinct from neck; eye large with vertically elliptic pupil ; posterior nasal concave; loreal entering the eye. Body compressed; scales smooth with apical pits, in $I 7$ rows; ventrals obtusely angulate laterally. Tail long; sub-caudals in two rows.

Genus Amplorhinus.-Maxillary teeth 12 or 13 , gradually increasing in size, followed by an enlarged, grooved tooth: mandibular teeth sub-equal. Head distinct from neck; eye moderate with round pupil; nasal semi-divided. Body cylindrical; scales smooth or feebly keeled, with apical pits, in 17 rows; ventrals rounded. Tail moderate; sub-caudals in two rows.

Genus Trimerorhinus. - Maxillary teeth ro to I2, sub-equal, followed after an interspace by a pair of enlarged, grooved fangs, situated below the posterior border of the eye; anterior mandibular teeth strongly enlarged. Head distinct from neck; eye moderate, with round pupil; nostril crescentric, between two nasals and the internasal. Body cylindrical; scales smooth, with apical pits, in I 7 rows; ventrals rounded. Tail moderate; sub-caudals in two rows.

Genus Rhamphiophis.-Maxillary short, with 6 to 9 teeth gradually increasing in length and followed, after an interspace, by a pair of very large grooved fangs situated below the eye; anterior mandibular teeth longest. Head distinct from neck, with projecting snout; rostral large, hollowed out beneath; eye moderate with round pupil; nostril crescentric in a divided or a semi-divided nasal. Body cylindrical; scales smooth, with apical pits, in 17 or 19 rows. Ventrals rounded. Subcaudals in two rows.

Genus Psammophis.-Maxillary teeth Io to 13 , one or two in the middle much enlarged, fang-like, preceded and followed by an interspace, the last two, large and grooved and situated below the posterior of the eye; anterior mandibular teeth very strongly enlarged. Head distinct from neck, with angular canthus rostralis; eye moderate or large, with round pupil; frontal narrow. Body cylindrical; scales smooth, more or less oblique, with apical pits, in II to Ig rows; ventrals rounded. Tail long: sub-caudals in two rows.

Genus Disprolidus.-Maxillary short, widening behind, where it articulates with the forked ectopterygoid; teeth small, 7 or 8, followed by three large grooved fangs situated below the eye; mandibular teeth sub-equal. Head distinct from neck, with distinct canthus rostalis. Eye very large with round pupil; nasal entire. Body slightly compressed; scales very narrow, oblique, more or less strongly keeled, with apical pits, in I9 
or 2 I rows; ventrals rounded or obtusely angulate laterally. Tail long; sub-caudals in two rows.

GENUS THELOTORNIS.-Maxillary teeth I6 or $\mathbf{1 7}$, gradually increasing in length, followed after a short interspace by two or three enlarged grooved teeth situated below the posterior border of the eye; anterior mandibular teeth strongly enlarged. Head distinct from neck. Eye large, with horizontal pupil; nasal entire. Body cylindrical, very slender. Scales narrow, very oblique, feebly keeled, with apical pits, in I9 rows; ventrals rounded. Tail long; sub-caudals in two rows.

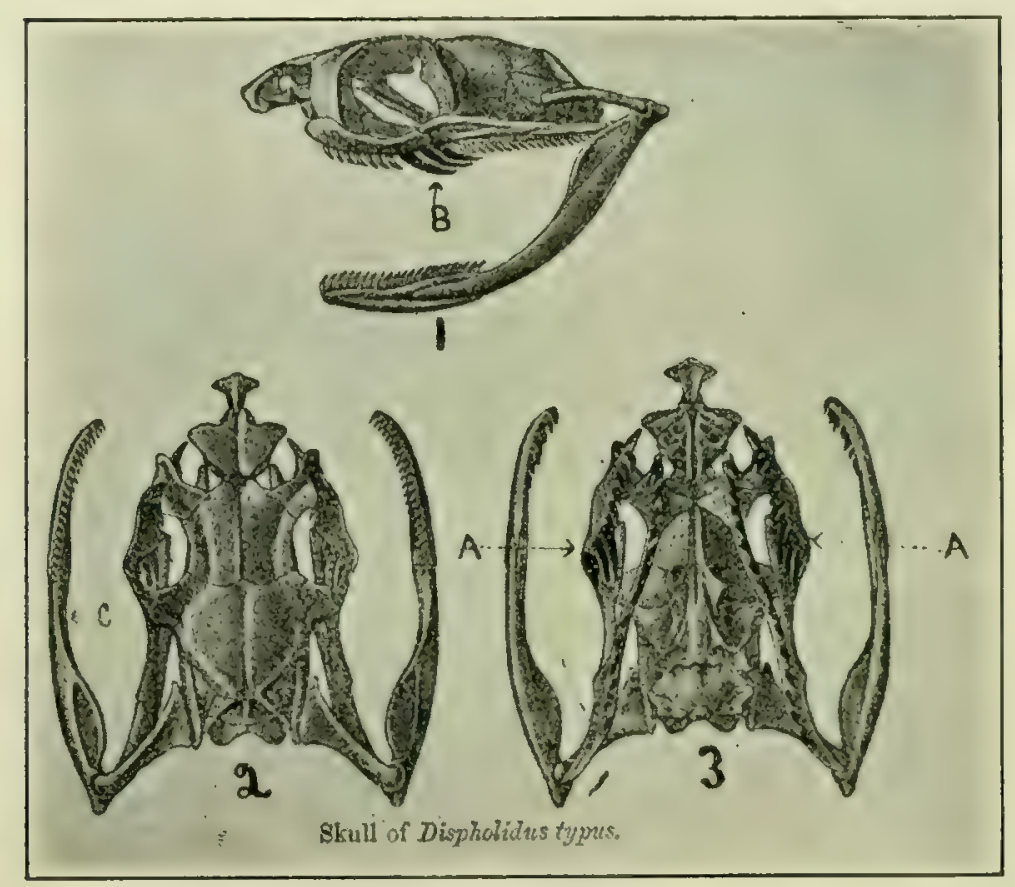

(Brit. Mus. Cat. Snakes.)

FIG. 51.-Skull of typical Back-fanged Snake.

I. Side view showing the position of the fangs (B).

2. Top of head and lower jaw (C).

3. Roof of the mouth (A). Showing position of the fangs at posterior end of outer row of upper teeth.

The inner row of teeth are the palatines.

Genus Amblyodipsas.-Maxillary very short, with 5 teeth gradually increasing in size, and followed, after an interspace, by a large grooved fang situated below the eye; mandibular teeth decreasing in size posteriorly. Head small, not distinct from neck; eye minute, with round pupil; nostril in a single very small nasal; no internasals; no loreal; no preocular; no anterior temporal. Body cylindrical. Scales smooth, without pits, in I5 rows; ventrals rounded. Tail very short, obtuse; subcaudals in two rows.

Genus Calamelaps.-Maxillary very short, with 3 or 4 teeth gradually increasing in size and followed, after an interspace, by a large grooved fang situated below the eye, anterior mandibular teeth enlarged. Head small, not distinct from neck; 
eye minute, with round pupil; nostril in a divided or semidivided nasal; no loreal; no preocular; no anterior temporal. Body cylindrical. Scales smooth, without pits, in I 7 or I9 rows. Ventrals rounded. Tail very short, obtuse; subcaudals in two rows.

Genus Macrelaps.-Maxillary short, with 4 moderately large teeth, followed by a very large grooved fang situated below the eye ; anterior mandibular teeth enlarged, third to fifth longest. Head small, not distinct from neck; eye minute with round pupil; nasal divided; no loreal; no preocular; prefrontal entering the eye. Body cylindrical; scales smooth, without pits, in 25 or 27 rows; ventrals rounded. Tail short; sub-caudals single.

Genus Aparallactus.-Maxillary short, with 6 to 9 small teeth followed by a large grooved fang situated below the eye; anterior mandibular teeth longest. Head small not distinct from neck; eye small, with round pupil; nasal entire or divided no loreal. Body cylindrical; scales smooth, without pits, in I 5 rows; ventrals rounded. Tail moderate or short; subcaudals single.

\section{GENUS PYTHONODIPSAS.}

This Genus is represented by a single Species.

(For Scientific Description, see Synopsis of Genera of the Dipsadomorphina.)

I. Pythonodipsas Carinata.-Keeled Snake: Driekant Slang. (Kiel Slang.)

Colour-Sand-coloured or pale buff above, with a double.alternating series of square grey spots, a few of which may coalesce to form transverse bars; lips with vertical grey bars; lower parts white.

Average length-Two feet.

Distribution-Damaraland; Zambesi Regions.

GENUS TARBOPHIS.

A single Species in South Africa.

KEY TO THE SPECIES.

Scales in 19 rows ; anal divided. Three labials entering the eye. Ventrals 206-242 .. Tarbophis semianmulatus.

I. Tarbophis semiannulatus. Tiger Snake. Tijger Slang. (Tier Slang.) Synonyms-Télescopus semianmulatus.

Colour-Yellowish or pale brown above, with 24 to 34 dark brown or blackish transverse rhomboidal spots or cross-bars on the body; head without any spots or markings; yellowish-white beneath.

Average length -2 feet 6 inches.

Distribution-Natal ; Basutoland ; Orange River Colony ; Transvaal ; Delagoa Bay; Portuguese East Africa; Central and East Africa. 


\author{
Genus LEPTODIRA. \\ A single Species in South Africa.
}

KEI TO THE SPECIES.

Anal entire; scales in Ig (exceptionally I7) rows;

ventrals $144-180$; sub-caudals $32-54$.. Leptodiva hotambaia.

I. Leptodira hotambera. The Herald or Red-lipped Snake. Roodelip Slang. (Rooi-lip Slang.)

Colour-Brown, olive or blackish above, uniform or with whitish dots, like fly's eggs, more apparent when skin is stretched. A black band on the temple, usually connected with its fellow across the occiput; upper lip bright red, or orange red; underparts whitish.

Average length -2 feet.

Distribution-General all over South Africa; North through Tropical Africa to Senegambia and Nubia.

\title{
GENUS CHAMATORTUS.
}

This Genus is represented by only one Species.

(For scientific description see the Synopsis of Genera of the Dipsadomorphina.

I. Chametortus aulicus. The Cross-barred Snake.

Colour-Brown above, the back with numerous whitish, dark-edged cross-bars, the sides spotted with whitish; head whitish, spotted and marbled with brown, and with a brown streak on each side passing through the eye; labials edged with brown; beneath white.

Average leng th -2 feet 6 inches.

Distribution-Transvaal ; Southern Rhodesia ; Portuguese East Africa; East and Central Africa.

\section{GENUS AMPLORHINUS. \\ A single Species in South Africa. \\ IEY TO THE: SPECIES.}

Scales in $I 7$ rows, feebly keeled on the posterior part of the back and at the base of the tail. Ventrals I33-149; anal entire: sub-caudals 6o-86. Rostral moderate; nostril in single semidivided nasal .. .. .. .. Amplorhinus multimaculatus.

I. Amplorhinus Multimaculatus. Cape Many-spotted Snake. Faapsche Stippel Slang.

Colour-Olive or brown above, with two more or less distinct yellowish stripes and longitudinal rows of black spots; bluish-grey or olive beneath. Some specimens uniform bright green above, and lighter green beneath.

Average length-I foot 6 inches.

Distribution-Cape Colony; Transvaal (High veld). 
Genus TRIMERORHINUS.

Two Species in South Africa.

KEY TO THE SPECIES.

Eye as long as its distance from the nostril .. Trimerorhinus rhombeatus: Eye shorter than its distance from the nostril Trimerorhinus tritceniatus.

I. Trimerorhinus RHombeatus. Rhombic or Spotted Schaapsteker. Bont Schaapsteker.

Synonyms-Coluber rhombeatus: Psammophis longementalis.

Colour-Colouration variable. Greyish, yellowish or pale olive-brown above, with brown black-edged markings which may form three or four longitudinal series of round or rhomboidal spots, or be partially or entirely confluent into three undulous or straight longitudinal bands; a yellow vertebral line sometimes present; a dark band on each side of the head passing through the eve, widening behind and often joining its fellow on the occiput, sometimes broken up into spots; upper lip yellowishwhite, uniform or with black spots; tail with three dark stripes ; lower parts white, dotted or spotted with bluish grey or black.

Average length -2 feet to 2 feet 6 inches. Attains a length of 3 feet.

Distribution-Both provinces of Cape Colony ; Orange River Colony; Transvaal; German South West Africa; Southern Rhodesia; Angola.

2. Trimerorhinus triteniatus. "Striped Schaapsteker; Streep or Gestreepte Schaapsteker.

Synonym-Rhagerrhis tritaniatus.

Colour-Greyish or pale brown above, with two or three dark brown, black-edged bands originating on the head and extending to the end of the tail, the outer passing through the eye, the vertehral sometimes rather indistinct or absent; a fine yellowish line sometimes divides the vertebral band; the sides below the bands white with a pale brown or red streak running along the outer row of scales; upper lip and lower parts white.

Average length -2 feet 6 inches.

Distribution-Occurs all over South Africa; Common near Port Elizabeth; North to the Equator.

\section{GENus RHAMPHIOPHIS.}

$A$ single Species in South Africa.

KEY TO THE. SPECIES.

Snout short, pointed. Scales in I7 rows.

Ventrals I55-r68. Anal divided.

Sub-caudals $3 \mathbf{I}-40$. Rostral large .. Rhamphiophis multimaculatus.

I. Rhamphiopins multimaculatus. Damaraland Many-spotted Snake. Stippel Slang.

Synonym-Coronella multimaculatus; Dipsida multimaculata; Rhagerrhis multimaculata.

Colour-Pale buff or sandy grey above, with three or five series of regular brown spots, the vertebrals broader than long; a $\Lambda^{\text {- }}$ shaped brown marking on the occiput; an oblique brown streak behind the eyc; lower parts white.

Average length-I foot 6 inches to 2 feet.

Distribution-Northern parts of Cape Colony; Orange River Colony; German South West Africa. 
Genus PSAMMOPHIS.

Ten Species in South Africa.

KEY OF THE SPECIES.

Scales in 17 rows ; ventrals I 54-I98. Anal

entire; two preoculars; sub-caudals

8I-IOH .. .. .. .. .. Psammophis notostichus

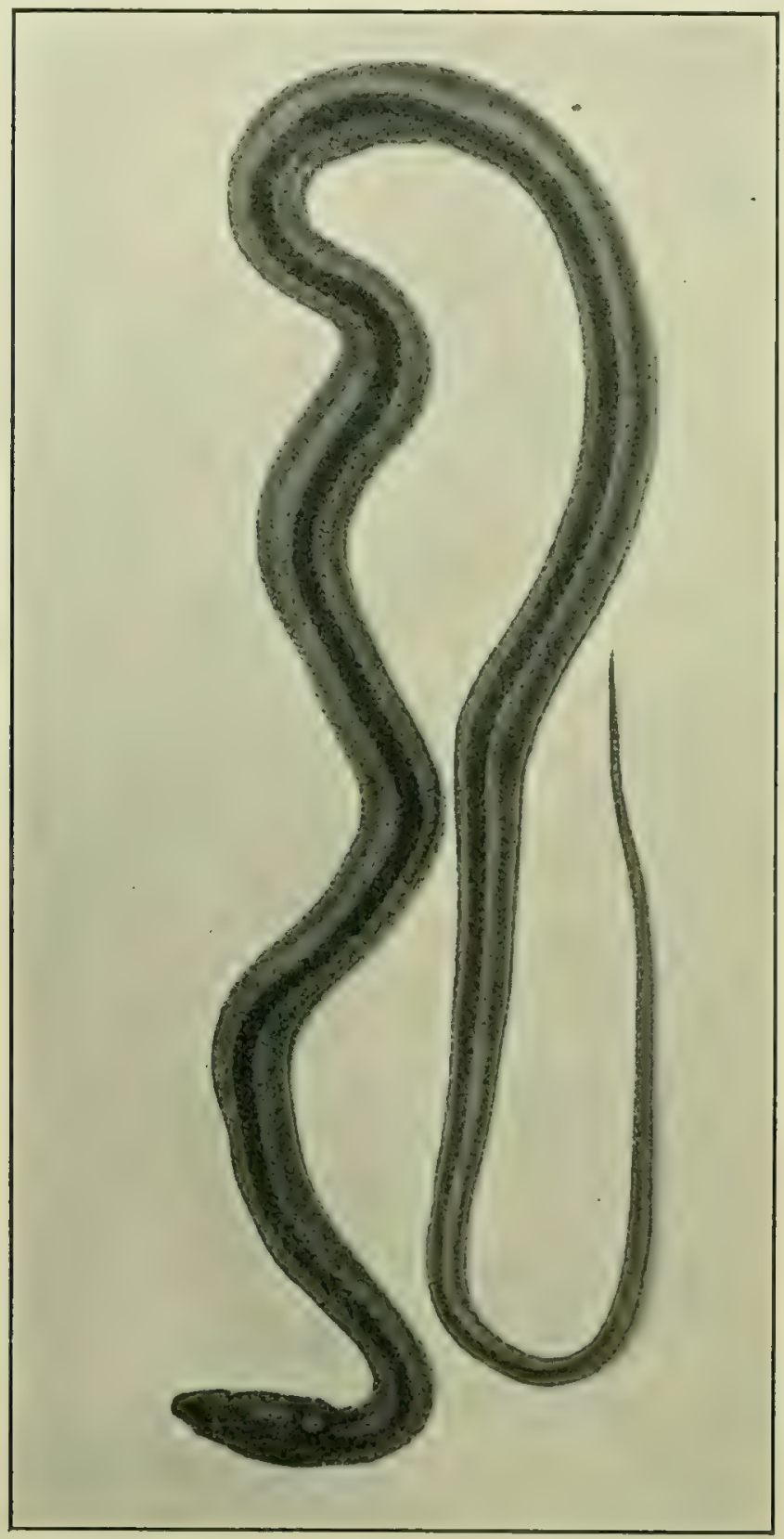

空

悹

3

ॠ

है

$\square 0$

표

त्

동

उ.

넝 용

है वृ

in क्षै है

उ 0.

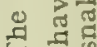

जी

in

ن.

जि द्व

हूँ

常

$\nsubseteq$

$\pm$

$\ddot{\circ}$

过

ตี

$\stackrel{1}{1}$

Scales in 17 rows; Ventrals 154-198. Anal divided (rarely entire). Preocular extensively in contact with the frontal; forehead concave; two labials entering the eye 
Scales in I7 rows; Ventrals I54-I98. Preocular narrowly in contact with or separated from the frontal. Two preoculars; rostral considerably broader than deep, 8 upper labials, 3 entering the eye $\quad . \quad \ldots$..

Scales in I7 rows; Ventrals I54-I98. 9 upper labials, 2 entering the eye ..

Psammophis transvaaliensis.

Psammophis trigrammus.

Scales in 17 rows; ventrals I 54-198..9 upper labials, 3 entering the eye. Snout nearly twice as long as broad; anal divided ; sub-caudals I09-127..

Scales in 17 rows; Ventrals I54-198. A single preocular; rostral as deep as broad or slightly broader than deep; two labials entering the eye. Frontal, in the middle, narrower than the supraocular; sub-caudals 9o-II6 ..

Scales in I7 rows; Ventrals I54-I98. Frontal in the middle nearly as broad as the supraocular; sub-caudals $64-95$

Scales in 15 rows. Preocular extensively in contact with the frontal; Ventrals I65-I77 . . . . .

Scales in 15 rows. Preocular not reaching the frontal; Ventrals I36-I55 .. Psammophis crucifer.

Scales in I3 rows. Ventrals I4I-I55 .. Psammophis angolensis.

I. Psammophis notostictus. Dapple-backed Sand Snake. Appel Bont Zand Slang.

Colour-Pale brown or olive above, with a pair of more or less distinct lighter stripes, and with or without small black spots; each vertebral scale often yellow in its posterior half; head with dark spots but no longitudinal streaks; upper labials and usually pre- and postoculars yellowish white; anterior labials often spotted with black; lower parts and whole or part of outer row of scales yellowish white, or olive with lateral yellowish stripe; anterior ventrals often with small black spots.

Average length -2 feet 6 inches to 3 feet.

Distribution-Both provinces of Cape Colony; Orange River Colony ; Basutoland; German South West Africa; Angola and Lower Congo.

2. Psammophis furcatus. Fork-marked Sand or Grass Snake; Whip Snake; Vurk-merk Zand Slang. (Vurk-gemerkde.)

Synonym-Psammophis monoliger.

Colour-Brown above, the scales edged with darker, a narrow yellow vertebral line bifurcating on the occiput, its branches extending to the anterior border of the frontal shield; a broader yellow streak on each side, from the eye to the end of the tail ; upper lip, lower half of the outer row of scales, and lower parts yellowish white with or without an interrupted blackish line on each side of the ventrals.

Average length -3 feet.

Distribution-Both provinces of Cape Colony; Orange River Colony ; Transvaal; Southern Rhodesia; German South West Africa; North to Angola and Lower Congo. 
3. Psammophis Transvadiensis. Gough's Sand Snake.

Colour-The seven middle rows of scales dark brown, tipped or edged with black. The top third of the row of scales fifth from middle of back, black; lower two-thirds of fifth row and upper twothirds of sixth row, cream-coloured; outer third of this row black. The seventh and eighth rows dark brown, almost black at the tips. Upper half of outer row black; lower cream.

A black line along each side of the ventrals, the space between the black lines yellow. Lips and chin cream, with black dots and markings; a black line runs along the upper edge of the labials, across the rostral. Upper surface of head light brown with darker black-edged markings, a lighter transverse band on the nape. The yellow lateral stripes originate at a short distance from the head, the portion of the neck anterior to them with indistinct cross bars.

Average length -2 feet 6 inches.

Distribution-Transvaal.

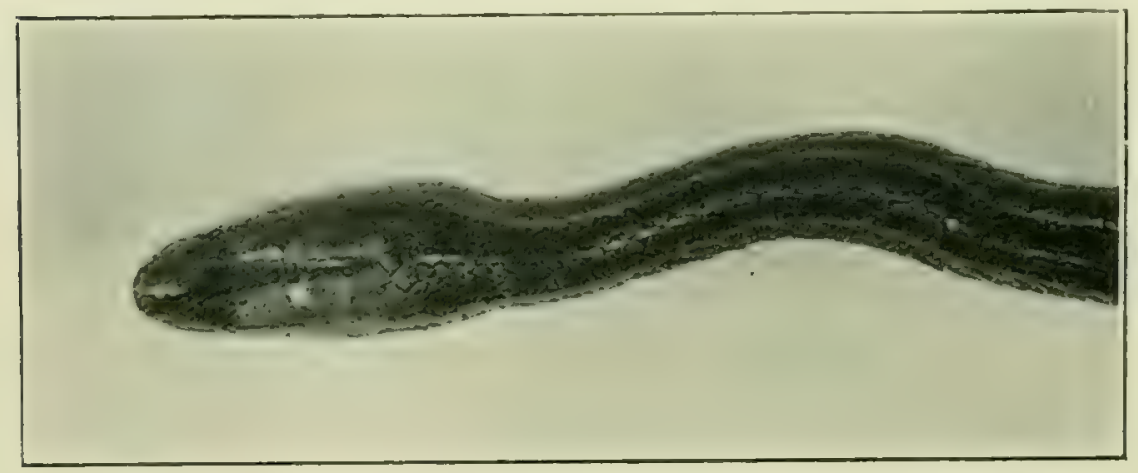

Fic. 53.-Head and neck of a Sand Snake, also known as a Whip Snake (Psammophis furcalus).

4. Psammophis trigrammus. Namaqualand Sand Snake.

Colour-Pale olive above, yellowish posteriorly, the scales on the vertebral line black-edged, forming a stripe posteriorly; a rather indistinct dark lateral stripe running along the outer row of scales; upper lip, pre-and postoculars yellowish white; lower parts and lower half of outer row of scales yellowish white, the ventrals clouded with olive in the middle.

Average length -3 to 4 feet.

Distribution-Namaqualand.

5. Psammophis bocagir. Bocage's Sand Snake.

Colour-A broad, reddish-brown black-edged vertebral band seven scales broad separated from the sides, which are grey or reddish brown, by a yellow streak; a black line along the middle of the outer row of scales; head with rather indistinct yellow, black-cdged cross-bars; a black line along the upper border of the labials, which are dotted with black; lower half of outer row of scales and lower parts pale yellow, with a black line on each side.

Average length -3 feet.

Distribution-Southern Rhodesia; Angola. 
6. Psamophis sibilans. Hissing Sand Snake; Blaas Zand Slang. Synonyms-Coluber sibilans: Psammophis thomasi.

Colour-Colour very variable.

A. Olive or brown above, the scales mostly black-edged; a more or less distinct narrow yellow vertebral line and a broader yellow streak along each side of the back; head with yellow, black-edged longitudinal streaks in front, and transverse ones behind, which markings, however, may become very indistinct in the adult; upper lip yellowish white, uniform or with a few brown or black dots on the anterior shields ; lower parts including the lower half of outer row of scales yellowish white, uniform or with a faint brown lateral line.

B. As in $\mathrm{A}$, but no trace of a light vertebral line.

C. Uniform brown or greyish-olive above, the markings on the head very indistinct; upper lip and lower parts, including lower third of outer row of scales, uniform yellowish white.

D. Brown or olive above, with lateral streaks and head markings as in A. Vertebral line absent or reduced to a series of yellow dots, one on each scale; upper lip with brown or black dots; lower parts including lower half of outer row of scales, white, with a continuous or interrupted black longitudinal line on each side of the belly.

$\mathrm{E}$. Uniform brown or olive above, with more or less distinct traces of the markings on the head; upper lip yellowish, with brown or blackish dots; lower parts including lower third or lower half of outer row of scales, yellowish, with a brown or black line on each side of the belly.

F. Olive above, which colour extends down to the ends of the ventrals, uniform or dotted with blackish, or with most of the scales black-edged; sometimes in the young with traces of light longitudinal stripes; upper lip yellowish, spotted or speckled with black; belly yellowish or pale olive, uniform or dotted with black on the sides, the dots sometimes confluent into longitudinal lines.

Average length - 4 feet. Some specimens attain a length of over 5 feet.

Distribution-Both provinces of Cape Colony; Natal; Zululand; Transvaal; Southern Rhodesia; North through Tropical Africa to Egypt.

7. Psammophis BRevriostris. Short-snouted Sand Snake. Kort-snoet Zand Slang.

Synonym-Psammophis sibilans.

Colour-Brown or dark olive on the back ( 7 rows of scales), pale olive on the sides down to the ventrals, the two shades separated by a more or less distinct lighter streak; a yellowish black-edged spot usually present on each vertebral scale; head uniform olive brown in the adult, in the young with a yellowish streak along the frontal, and yellowish cross-bars behind; yellowish white beneath, with a series of olive or blackish dots or short streaks along each side.

Average length -4 feet. Some specimens attain a length of over 5 feet.

Distribution-Both provinces of Cape Colony; Natal; Zululand; Transvaal ; Angola.

8. Psammophis JALlæ. Sand Snake.

Distribution-Southern Rhodesia. 
9. Psammophis crucifer. Crossed Grass Snake. Kruis Gras Slang. Synonym-Coluber crucifer.

Colour-Pale olive or brownish above, with a black-edged dark vertebral band, three scales wide which extends to the head, giving off one or two transverse bars on the nape, and enclosing a light spot or streak on the suture between the parietal shields; sides of head with large dark blotches, the pre- and postoculars yellowish; a more or less distinct band along each side of the body, with a white streak below it on the lower half of the outer row of scales and the outer ends of the ventrals; lower parts yellow or reddish orange, uniform or finely speckled with blackish with a dark streak or series of small spots on each side.

Average length -2 feet.

Distribution - Both provinces of Cape Colony; Basutoland; Natal ; Zululand; Orange River Colony ; Transvaal.

IO. PSAMmophis ANGolensis.

Synonyms-Amphiophis angolensis; Coluber crucifer: Ablabes homeyeri: Dromophis angolensis.

Colour-Pale olive above, with a dark olive or blackish vertebral stripe three scales wide, finely edged with black and yellow; head dark olive in front; blackish behind, with three yellow transverse lines, the first behind the eyes, the third behind the parietal shields; two black cross-bands may be present on the nape of the neck, separated by a yellowish interspace; labials and preoculars yellowish white; one or two more or less distinct dark lines or series of dots along each side; lower parts whitish.

Average length -2 feet.

Distribution-Orange River Colony; Angola; East and Central Africa.

\section{GENUS THELOTORNIS.}

\section{This Genus is represented by one Species.}

\section{KEY TO THE SPECIES.}

Scales in 19 rows, feebly keeled. Ventrals I47-I8I. Anal divided. Sub-caudals I 7-1 7o. Pupil horizontal; eye large; body slender. Tail very long and slender.

I. Thelotornis kirtlandix. Bird Snake; Vogelvreter Slang. Synonym-Leptophis kirtlandii.

Colour-Greyish or pinkish-brown above, uniform or with more or less distinct darker and lighter spots and cross bands; head green above, with or without some patches of pinkish, speckled with black and a pinkish black-dotted streak on each side of the head, passing through the eye; upper lip cream-colour or pink, uniform or spotted with black; one or several black blotches on each side of the neck; greyish or pinkish beneath, speckled or striated with brown.

There are two varieties, which are coloured as follows:-

A. Head uniform green above and on the sides; black blotches usually forming cross bands on the neck.

B. Head with black dots above and on the sides; no cross bands on the neck.

Average length -4 feet.

Distribution-All over South Africa in forest clad parts, excepting Cape Colony; Northwards to East and Tropical Africa. 


\section{GeNuS DISPHOLIDUS.}

This Genus is represented by one Species.

KEY TO THE SPECIES.

Scales keeled in 19 or $2 \mathrm{I}$ rows. Eye very large. See synopsis of genera of Dipsadomorphinæ .. . . Dispholidus typus

I. Dispholidus typus. Tree Snake or Boomslang.

Synonyms-Bucephalus typus; Dispholidus lalandii; Bucephalus capensis: Dendrophis pseudodipsas.

Colour-The colour is variable. The colourations of the various varieties are as follows :-

A. Brown above, upper lip and lower parts yellowish or greyish; young with darker and lighter spots, and the belly speckled with brown.

B. Olive-brown above, yellowish beneath, scales and shields edged with blackish.

C. Green above, uniform, or scales narrowly edged with black.

D. Green or olive above, all the scales and shields edged with black; head often much spotted with black.

E. Black above, each scale with a yellowish or greenish spot; head spotted or marked with black; ventrals and sub-caudals yellowish edged with black.

F. Uniform black above, blackish grey beneath.

G. Brownish-black above. Light yellow beneath. The abdominal shields blotched with dark brown on their sides, and edged with a narrow line of brown.

Average length -4 to 5 feet. Some specimens attain a length of over 6 feet.

Distribution-Common all over South Africa in bush-clad localities; North to Tropical Africa.

\section{GeNuS AMBLYODIPSAS.}

This Genus is represented by one Species.

\section{KEY TO THE SPECIES.}

Scales in 15 rows. No internasals; sub-caudals in two rows; head small, not distinct from neck. Refer to synopsis of the genera of the sub-family Dipsadomorphinæ.

I. Amblyodipsas microphthalma. The White-lipped Snake.

Synonym-Calamaria microphthalma.

Colour-Dark brown above; upper lip, two outer rows of scales, outer ends of ventrals, and lower surface of head and tail white; a dark brown stripe along the middle of the belly.

Average length $-I$ foot 6 inches.

Distribution-Zululand; Portuguese East Africa.

\section{Genus CALAMELAPS. \\ Two Species in South Africa. \\ KEY TO THE SPECIES.}

Scales in $\mathrm{I} 9$ rows; ventrals $\mathrm{I} 6 \mathrm{I}-\mathrm{I} 74 \ldots \ldots$ Calamelaps warreni. Scales in 17 rows; ventrals $133-134 \ldots \ldots$ Calamelaps concolor. 
I. Calamelaps WARRENi. WVarren's Snake (recently discovered). Colour-Uniform plumbeous grey.

Average length-I foot.

Distribution-Zululand.

2. Calamelaps concolor. Purple-glossed Snake.

Synonyms-Choristodon concolor; Calamelaps mironi.

Colour-Greenish black above, with a purple gloss; pale blackish purple beneath, the shickls margined behind with livid white.

Average length $-\mathrm{r}$ foot.

Distribution-Natal, Caffraria.

\section{GENUS MACRELAPS.}

There is only one Species in this Genus.

KEY TO THE SPECIES.

Scales in 25 or 27 rows ; no preocular. Refer to synopsis of the genera of the sub-family Dipsadomorphinx.

I. Macrelaps microlepidotus. Natal Black Snake. Zwart Slang. Synonym-Uriechis microlepidotus.

Colour-Uniform black.

Average length -2 feet 6 inches.

Distribution-Eastern parts of Cape Colony; Natal.

\section{GENUS APARALLACTUS.}

Two Species in South Africa.

KEY TO THE SPECIES.

Nasal divided; ventrals I53-I80 .. . . Aparallactus guentheri.

Nasal entire; ventrals I38-I66 .. .. Aparallactus capensis.

I. Aparallactus guentheri. Guenther's Snake.

Synonym-Uriechis capensis.

Colour-Blackish brown above, a little lighter beneath; chin and throat yollowish white; a deep llack collar, edged with ycllowish white in front and behind, narrowly interrupted on the throat.

Average length - I foot.

Distribution-Southern Rhodesia; Angola; Iast and Central Africa.

2. Aparallactus Capensis. Black-headed Snake. Zwart-kop Slang. Synonyms-Elapomorphus capensis; Uriechis capensis.

Colour-Yellow or pale reddish brown above, with or without a blackish vertebral line, yellowish white beneath; upper, surface of head and nape black, with or without a yellowish cross-bar behind the parietal shields, the black of the nape descending to the sides of the neck; sides of head yellowish, the shiclds bordering the eye, black.

Average length - I foot.

Distribution-Eastern parts of Cape Colony; Orange River Colony; Basutoland; Zululand; Transvaal; Southern Rhodesia; East Africa. 


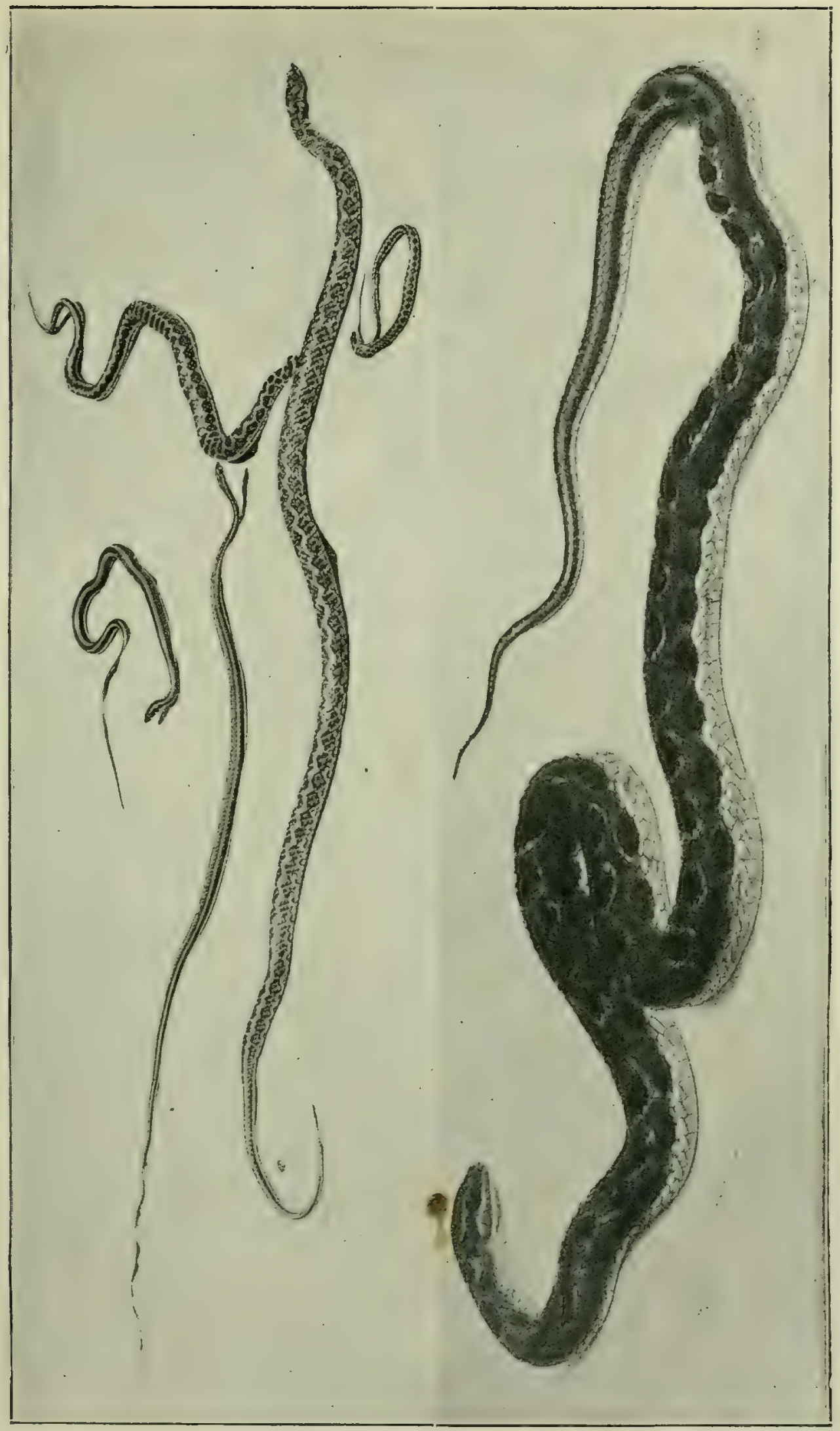

FIG. 54.-(36 A.) The coiled snake top right of picture is a Striped Schaapsteker (Streep or Gestreepte Schaapsteker). Average length 2 feet. Grey or pale brown colour above, two or three dark brown black-edged bands on head extending to tail, the outer passing through eye. Often a fine yellowish line running along backbone. Upper lip and lower parts white. Thin snake in centre, a Grass or Sand Snake, or Whip Snake. Average length 3 feet. Tail brittle, easily breaks. The two larger snakes and small one are Spotted Schaapstekers. (36) Spotted Schaapsteker. Average length 2 feet. Greyish or pale olive colour above, black-edged or brown markings. Tail has three dark stripes. 
The Schatestekers, Grass Sxakes, and Sand Sxaies.

The Schaapstekers, or Sheepstickers, are well known to all South African colonists. Their farourite haunts are the grassy stunted-shrub-covered districts, dry plains and veld. On the Karroo they are common. They are frequently found on the grazing grounds and about the sheep kraals, drawn thither by the lizards, beetles, larvæ, and other living creatures which accumulate in and about the excrement of sheep and cattle. Now and again a villainous Cobra, or Ringhals, gets irritated at the presence of sheep grazing on his hunting grounds, and bites one or two. The cobra is a crafty fellow, and can take good care of himself. After doing all the damage he can amongst the sheep, he retires discreetly to his hole, or into the tangled bush. The farmer, or his herdsman, comes along, finds the dying sheep, and seeing Schaapstekers about, immediately concludes they are the guilty parties, hence the name Schaapsteker, which means "sheepsticker."

They are delicate snakes, and do not thrive well in captivity, unless the conditions under which they are kept are such as they were accustomed to in the wild state.

The Schaapstekers, Grass Snakes, and Sand Snakes will rarely attempt to bite unless roughly handled or trodden upon. Moreover, being Back-fanged Snakes, their bite is not much to be feared, unless they take a full mouthful of bare flesh, and are allowed to retain their hold for a few seconds in order to worry the flesh. A bite from any of these Back-fanged Snakes through the sleeve or trouser would, in most instances, not develop any poisonous symptoms at all. Even if a barefooted person should tread upon a Schaapsteker, and it bit him, the chances are that he would only be slightly poisoned, for the first instinct of a bitten person is to jump aside, or instantly shake the snake off; so, it is apparent that in most cases of bites by ordinary Back-fanged Snakes, there is little real risk.

IIy snake collector, Mr. James Wrilliams, has such a contempt for them that he sometimes brings me a pocket-full, and pulls them out with his bare hand, one by one. Now and then he is bitten. He instantly sucks the wound, and malies a couple of slight cuts over the punctures and rubs in a few permanganate crystals. Sometimes he feels a slight headache for an hour 
THE SCHAAPSTEKERS, GRASS SNAKES, ETC. I31

afterwards, but no alarming poisonous symptoms have so far manifested themselves.

I have experimented with the Spotted or Rhombic Schaapsteker, and find that a full bite on the bared thigh of a rat will cause death in two hours. Fowls bitten by full-sized Schaap-

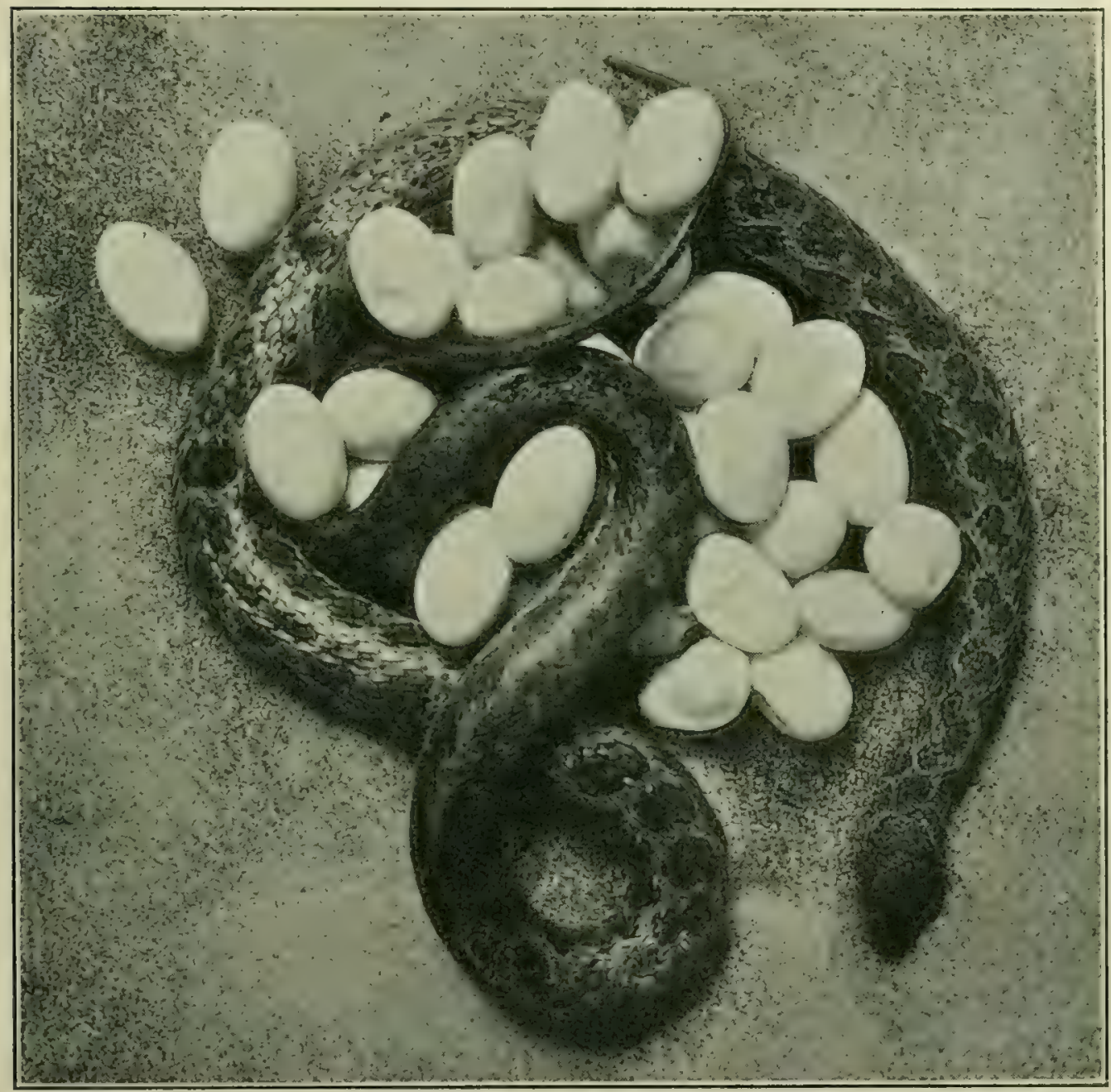

FIG. 55.-A Rhombic or Spotted Schaapsteker (T. rhombeatus) photographed from above just after laying a batch of eggs in the Port Elizabeth Museum.

stekers died in from seven to ten hours. For the first couple of hours the forwls seemed none the worse. Then drowsiness slowly set in, which was progressive, terminating in paralysis and death. Post-mortem examinations showed all the organs to be apparently normal. There was no sign of hæmorrhage anywhere. It was evident death was due to paralysis of the nerve centres. 
The Back-fanged Snakes, known as the Grass Snakes and Sand snakes (Psummphis), are, if anything, less renomous than the above-named Schaapsteker. Half-sized specimens when allowed to bite fowls, produced only slightly poisonous effects. When full-sized specimens were allowed to bite fully and worry the flesh for a few seconds, the forwls died, usually in from eight to twelve hours. After going to press I conducted another series of experiments with the venom of the Schaapsteker; the results of which are seen in the Addenda at the end of this book.

\section{A Battle-and the Result.}

One day I introduced a Lineated Schaapsteker Snake, two feet three inches long, into a case containing an Olire-black House Snake, which was two feet five inches in length. The latter began to investigate the intruder with lis black-forked tongue, which he vibrated incessantly. He was evidently working himself up into an excited condition. Presently he made a lightning-like srab, and instantly lapped his jaws over the head of the Schaapsteker. He gripped tenaciously, but made no attempt at constriction. The victim, realizing his danger, coiled, lashed, and struggled mightily. After tumbling over and over, and tying and untying themselves in a series of knots, the Schaapsteker began to weaken. The House Snake still kept the same grip. His jaws had not shifted in the least. He made no attempt to get the head of his victim further into his mouth.

After holding on thus for over an hour, he proceeded slowly to swallow the, now limp, Schaapsteker. I timed him, and found he took four and a half hours before the end of his victim's tail disappeared down his throat. Then he yawned half a dozen times. Opening the cage door, I lifted him carefully out and placed him in cotton wool in a cosy little box, and left him to his slumbers, for he was now torpid and helpless. I peeped in at him every day, but, beyond raising his head and sticking ont his tongue at me, he made no attempt to move. In five day's time he began to revive, and mored around at times; but he harl not ret completed the digestion of his rictim, for, on feeling his ribs, I could detect the remains of the Schaapsteker in his digestive tract. However, in seven days' time the Schaapsteker had 


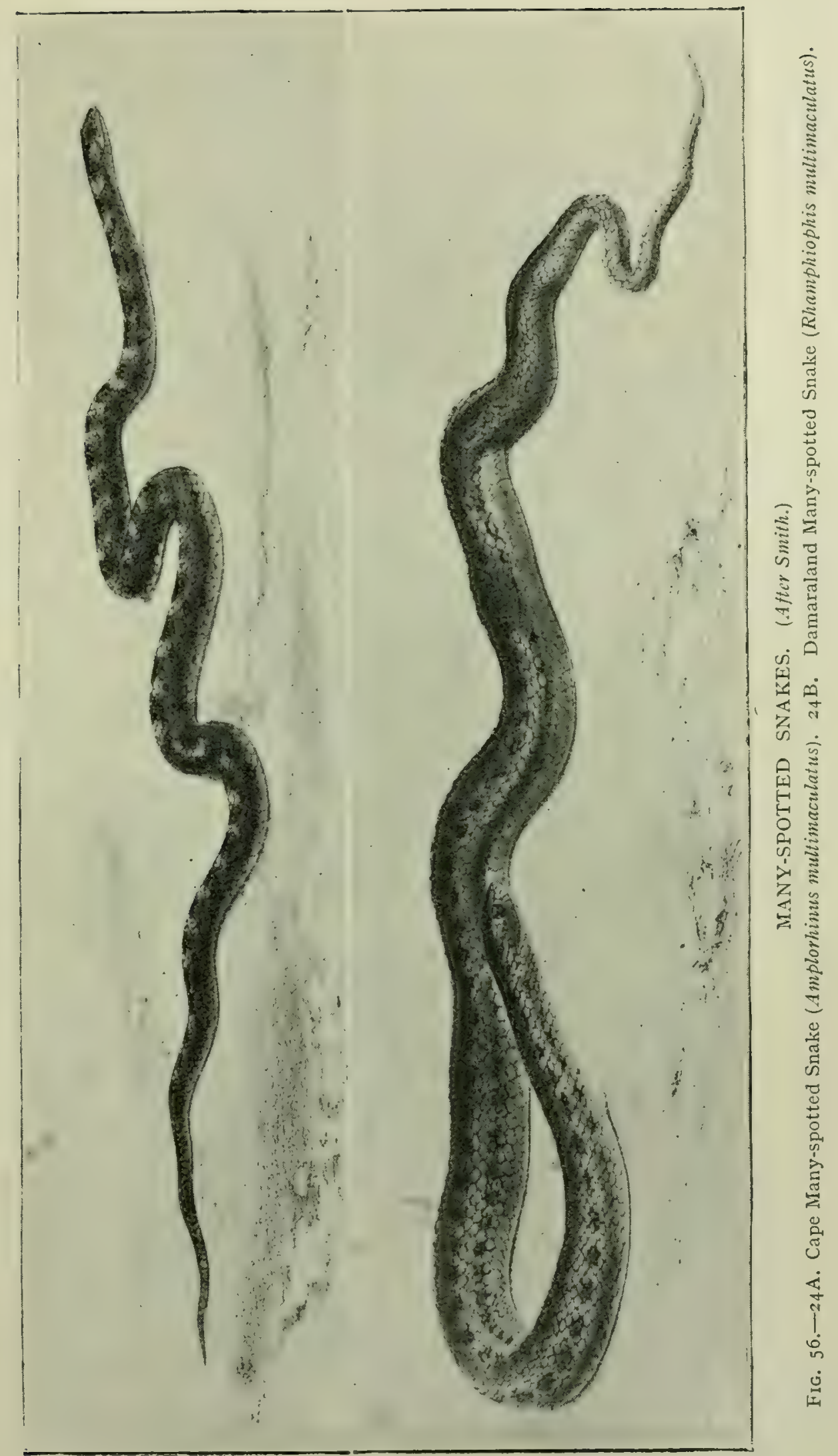


been completely digested, and the now plump and sleek House Snake became as active as ever.

\section{The Red-Lipped or Herald Snate. Roode-Lip Slang. (Leptodira hotambceia.)}

This is one of the best-known and most wide-spread snakes in Africa. It is found from the Cape, right away through the continent to the northern states of Africa.

It is known in the Eastern Province of the Cape Colony as the Herald Snake, being named such by Mr. J. II. Leslie, who was the first to discover it in these parts. It was named in honour of the Eastern Province Herald.

The Herald Snake haunts gardens in the vicinity of houses, taking refuge under pieces of timber, old tubs, rubbish, etc. It usually ventures out about sundown, and may frequently be seen on garden paths and public roads on moonlight nights. If attempts be made at capture, it will bite fiercely. If trodden upon it will instantly bite. Its fangs, however, are set far back in the jaw, and are comparatively small, so it is seldom any serious harm results from a bite. The food of these snakes consists of mice, small garden toads, lizards and insects. The average length of the Herald Snake is about two feet. It is olive-brown in colour, sometimes uniform, but usually the upper parts are flecked with tiny white dots, in appearance like flies' eggs. These are very apparent when the skin is distended. The under-parts are whitish. Two broad bands of shiny purplishblack run from the snout to the base of the head, where they join. The upper lip is a bright coral red or orange red. No other South African snake has these red streaks along the upper lips, and they consequently serve as a sure means of identification.

It is one of the back-fanged snakes, with the venom glands in the transition stage. I have experimented on fowls and rabbits, both by forcing it to bite them, and also by pounding the glands in water and injecting them under the skin. The animals, in all cases, showed signs of poisoning to a greater or lesser degree, according to the size of the snake and the season. The bitten animals invariably recovered after appearing more or less lethargic for a day or two. 
In some recent experiments with a large freshly caught Herald Snake, some of the bitten fowls died about twelve
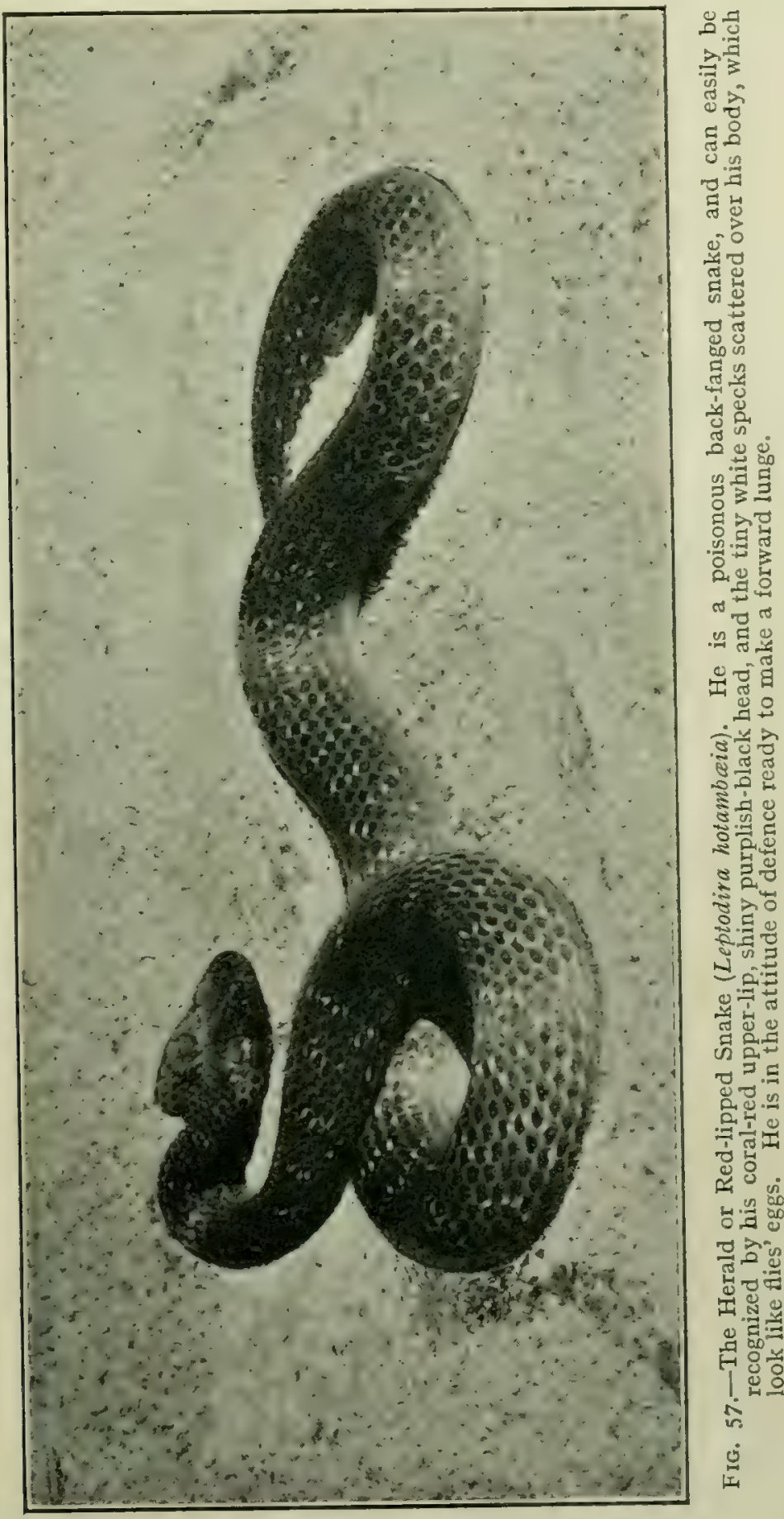

hours after the snake was allowed to obtain a full grip and press its fangs well home for about twenty seconds. A monkey which 
was bitten moped for a day and a half, but recovered eventually.

When allowed to bite through ordinary trouser cloth, and if not permitted to hang on, the fangs of Herald Snakes and Schaapstekers in most instances failed to penetrate the flesh. It is not because the fangs are not sufficiently long. The reason is that with back-fanged snakes the poison fangs are at the back of the upper jaw. It is, therefore, necessary for the snake to ensure a mouthful before he can succeed in driving the fangs fully home.

Persons must never take liberties with any of these backfanged snakes. Under ordinary conditions the momentary bite of most of this family of serpents is not likely to have very serious results, especially so if the punctures be scarified and rubbed with permanganate of potash. It must be remembered, however, that if allowed to bite and hold on, they will work sufficient venom into the flesh to cause serious symptoms of poisoning, and often death results.

Although the venom of a snake may not be in sufficient quantity to destroy life by its direct action upon nerve centres or blood, it is quite likely that it may be the indirect cause of death by setting up a state of sepsis, or ordinary blood-poisoning. Those addicted more or less to the habit of drinking alcoholic liquor are strongly predisposed to contract blood-poisoning, and die as the result of the injection of even a fractional dose of snake venom into their blood.

\section{The Boomslang or Tree Snake.}

\section{(Dispholidus typus.)}

\section{A CANNibal.}

This is the snake which recent events have made famous in South Africa. Recently, one bit an assistant in our Museum, with nearly deadly effect; then another in our collection of living snakes deliberately swallowed another of its own species, almost as big as itself. These incidents caused heated discussions everywhere, as, in the first place, the Boomslang has been regarded as a non-venomous snake, and, secondly, it has hitherto been believed that when snakes swallow each other it 
is of the nature of an accident-as, for instance, when two snakes seize and attempt to swallow a frog, rat, or other prey, neither caring to let go, the bigger snake naturally engulphs the smaller. In the case of the Boomslang referred to, the act was deliberate in every sense of the word.

Some live frogs were introduced into the cage containing five of these tree-snakes, one of which managed, by superior agility,

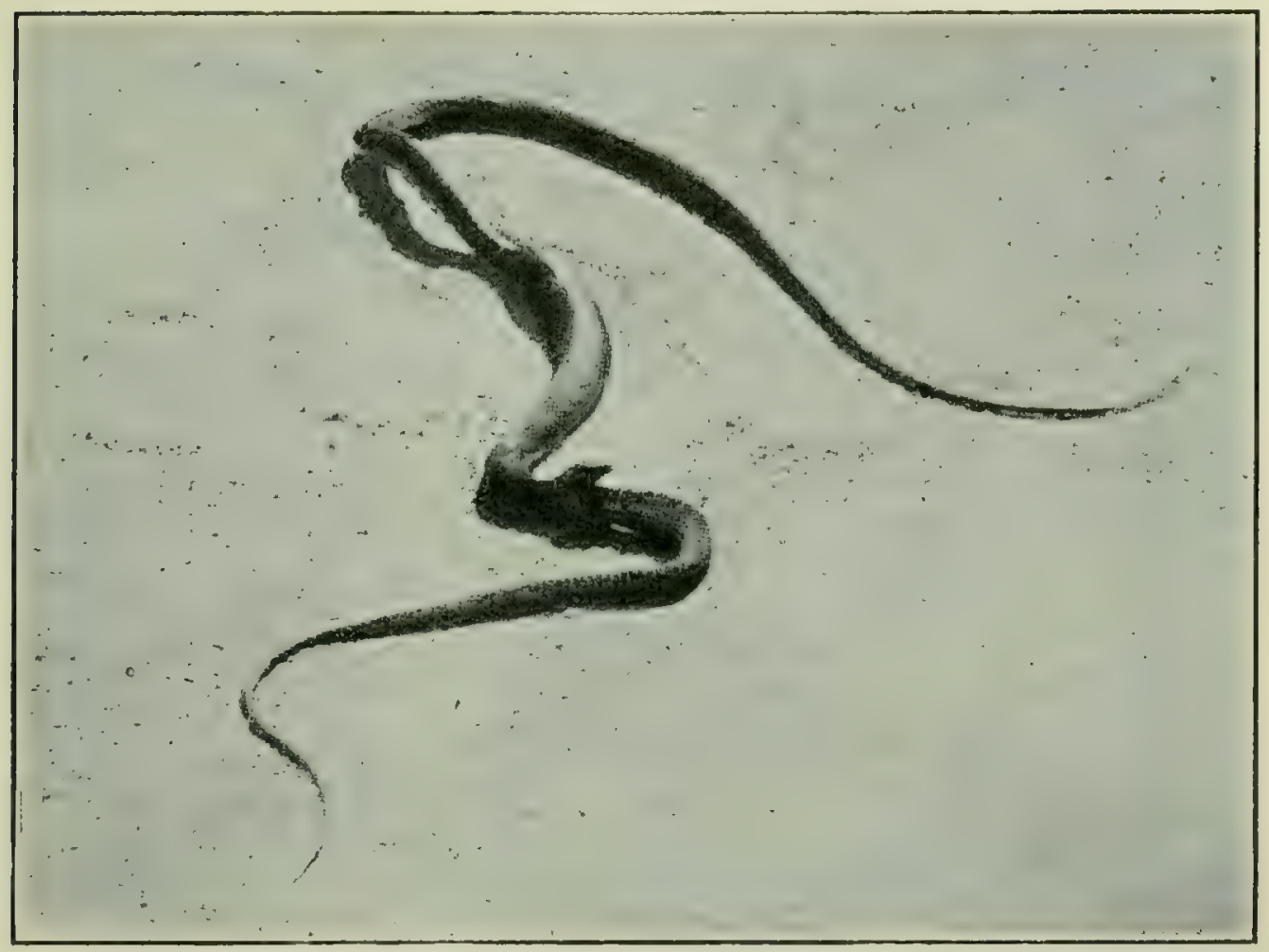

FIG. 58.-A Cannibal Boomslang. Photographed from life at the Port Elizabeth Museum. $\mathrm{He}$ is in the act of taking another mouthful of his victim.

to capture and swallow several of the frogs, much to the annoyance of one of its fellows. The latter worked itself into a state of great excitement, and attacked its companion viciously, seizing it in various parts of the body. Eventually it gripped the other firmly by the neck and gradually worked its head forwards until it reached the other's jaws, whereupon it began deliberately to stvallow it with a succession of spasmodic gulps, accompanied by heaving, forward movements.

After a lapse of twenty minutes it had swallowed one-half of the struggling, writhing victim. I then had it removed and photographed, and, during the process, so intent was it upon the work 
it had in hand, that the swallowing process went merrily on, and the photograph shows it in the act of raising its jaw in order to take another mouthful. Being desirous of preserving these specimens as evidence of the occurrence, I removed a little tobacco-juice with a feather from a dirty pipe and passed the feather between the jaws of the Boumslang.

Almost instantly a curious vibratory thrill passed through the snake from head to tail, the muscles relaxed, and the snake lay a lifeless mass within two minutes of the introduction of the tobacco-juice, demonstrating the rapid prussic-acid-like action of this poison upon the vital functions.

This Boomslang was of the striped, black and yellowish-green variety, measuring four feet nine inches, whilst the victim was the brown variety three feet eleven inches long.

\section{What Naturalists Say.}

The Boomslang is placed in the British Nuseum Catalogue of Snakes by G. A. Boulenger in the family Colubrince, series opisthoglypha, sub-family Dipsadomorphince. The definition of the Opisthoglypha is "a division of snakes with one or more of the posterior maxillary teeth grooved." Most, if not all, are regarded as poisonous to a slight degree, sufficiently so only for paralyzing their prey before deglutition.

Now, this is a very important point to bear in mind, viz., one of the Opisthoglypha has been classified in many text-books of science as practically a non-venomous snake, or one not at all dangerous to man. It is my present intention to prove the opposite.

Sir Andrew Smith, in his "Zoology of South Africa," remarks : "As this snake, in our opinion, is not provided with a poisonous fluid to instil into wounds which these fangs may inflict, they must consequently be intended for a purpose different to those which exist in poisonous reptiles. Their use seems to offer obstacles to the retrogression (retention) of living animals, such as birds, etc., while they are only partly within the mouth; and from the circumstances of these fangs being directed backward and not admitting of being raised so as to form an angle with the edge of the jaw, they are well fitted to act as powerful holders when once they penetrate the skin and soft parts of the prey 
which their possessors may be in the act of swallowing. Without such fangs escapes would be common ; with such they are rare."

He goes on further to say: "The natives of South Africa regard the Boomslang as poisonous, but in their opinion we cannot concur, as we have not been able to discover the existence of any glands manifestly organized for the secretion of poison. The fangs are enclosed in a soft, pulpy sheath, the inner surface of which is commonly coated with a thin glairy secretion. This secretion may possibly have something acrid and irritating in its qualities, which may, when it enters a wound, occasion pain and even swelling, but nothing of greater importance."

This belief is held by naturalists to the present day, viz., that the back-fanged division of snakes possessed these posterior fangs only for the purpose of aiding them in retaining their struggling prey, and as an extra aid in the swallowing process. Sir Andrew Smith's explanation that the sticky fluid observed in the fang capsules was merely capable of exerting a paralyzing influence upon such creatures as small birds and lizards has up to now been the opinion of zoologists.

Naturally, I accepted this generally current belief, and, in consequence, I and my assistants freely handled these snakes, taking no precautions against being bitten, deeming such to be superfluous until, "like a bolt from the blue," Mr. James Williams, my assistant, was bitten, and came within a hair'sbreadth of losing his life.

\section{No Ordinary Venom Glands.}

I carefully dissected the heads of several Boomslangs. In every case I discovered a small gland on each side of the head, lying immediately behind and above the grooved fangs. It could clearly be seen that it had a connection with the cavity at the root of the grooved fangs, and that it was the gland which secreted the sticky fluid in the sheath enveloping them.

The next step was to ascertain if the organ was really a gland capable of secreting any fluid, whether venomous or not. Dr. Robertson, of the Veterinary Institute at Grahamstown, made a microscopical examination of its structure, and reported it to be undoubtedly glandular and capable of secreting. Subsequent experiments by myself bear out this opinion, and, 
moreover, under the microscope, a sticky, colourless fluid, identical with that found in the sheath, was observed in the structure of the glands, and was pressed out upon the microscopical slide with the tip of a lancet. Small pieces of these glands were cut up and inserted under the skin of rabbits, and slight pressure applied for an instant. Within fifteen minutes the rabbits were dead.

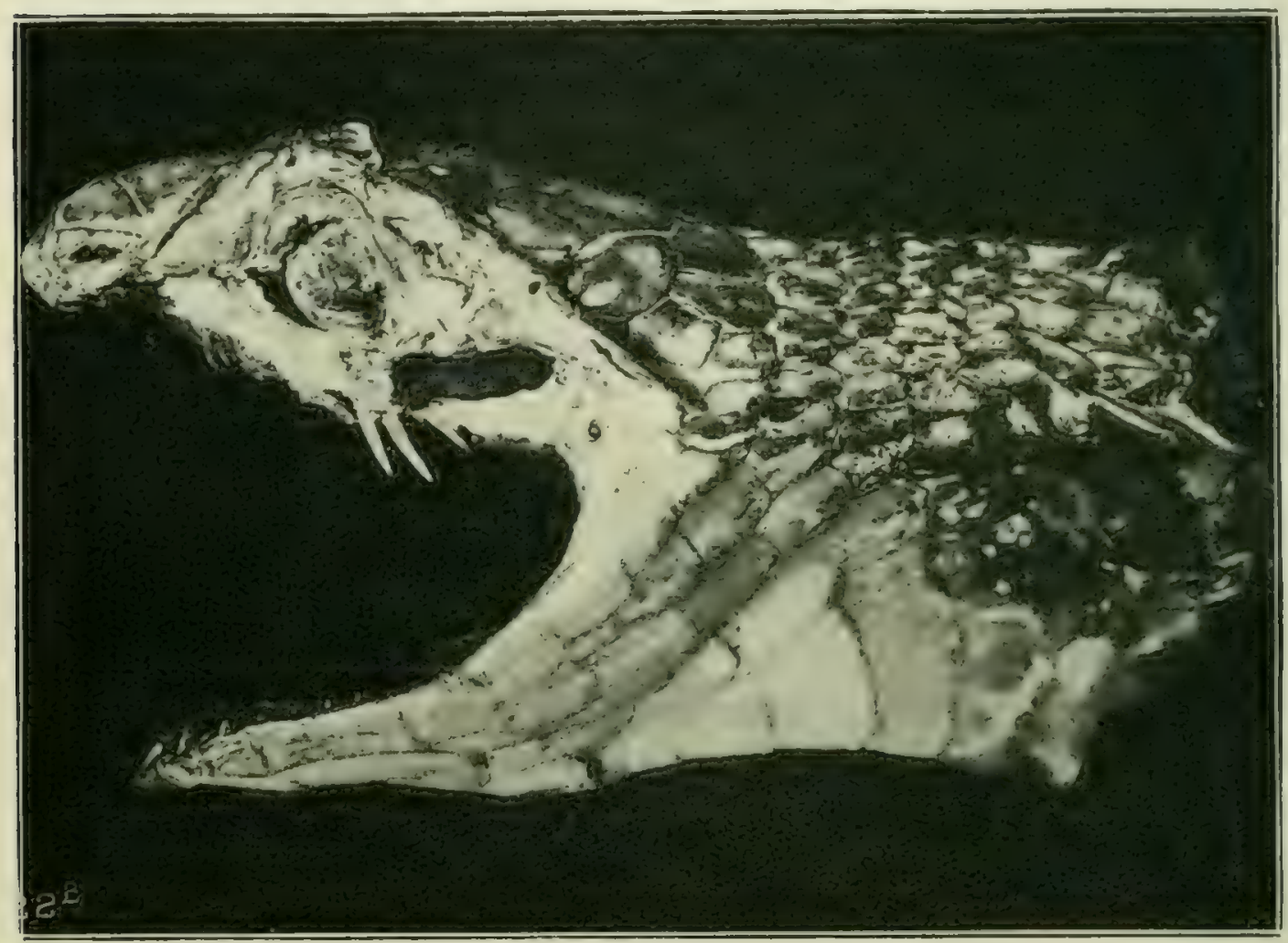

FiG. 59.-Life-sized head of a Boomslang, showing the situation of the fangs. The gland lies above and behind. It is coloured black. The venom oozes from its base through a hole in the jawbone into the fang capsule or sheath, and is forced down the grooves in the fangs.

This is a type of the Back-fanged Division of Snakes.

One was stricken with complete paralysis within five minutes of the insertion of the fragment of gland.

\section{Boomslangs are Highly Venomous.}

These and other experiments, mentioned in detail a few pages further on, conclusively prove these glands to be capable of secreting a very virulent venom, and that the glands produce the glairy sticky fluid within the sheaths enveloping the fangs. The 
poison-glands are comparatively small - a fifth the size of those of a Puff Adder. That they secret a venom, potent and virulent, in proportion to their size, does not admit of a doubt. Sir Andrew Smith claims that the fangs are simply used for the retention of the prey, such as birds, which would otherwise escape. This is partly, but not wholly so. When a Boomslang seizes a live bird, it grips with great tenacity. The bird struggles frantically for a minute or two, and is then overcome by the potent action of the venom injected through the snake's grooved fangs. It then leisurely proceeds to swallow the bird, feathers and all. Boomslangs never constrict their prey.

\section{A Man Bitten.}

During November, I907, we had occasion to transfer our collection of live snakes to their new apartments, and Mr. Williams was carrying a large variegated Boomslang when it suddenly buried its teeth in the muscles of his bared forearm, just below the elbowjoint. It gripped with great power, and held on firmly. We disengaged its jaws, and I suggested treating the wound, but he would not hear of such a thing, and believing, as I did at the time, that it was practically

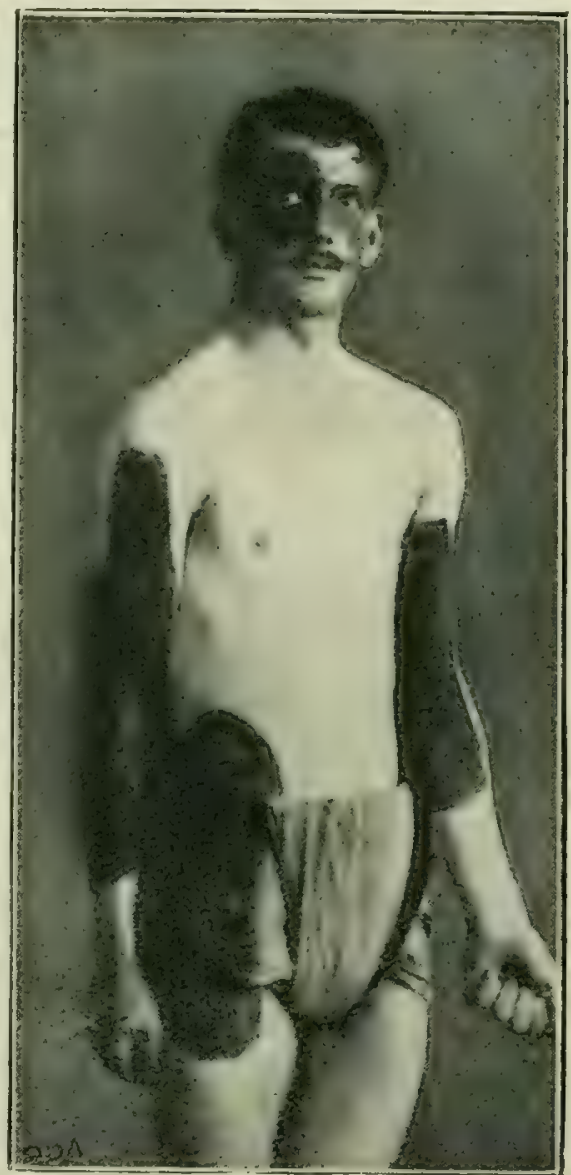

FIG. 6o-This is Mr. James Williams, who was bitten by a Boomslang, referred to in the text. The parts, coloured black, were the portions of his body where the blood flowed out through the walls of theiblood vessels, and accumu. lated in the tissues, causing dark purple patches, which were very much swollen and inflamed. The right eye and the surrounding tissues were immensely swollen, disfiguring Williams' face almost beyond recognition. In fact, the man presented a terrible and never-tobe-forgotten sight. Blood oozed from his mouth and nose. Hæmorrhage also took place in his stomach and bowels. His recovery was little short of miraculous. It was evidently due to his vigorous constitution, the result of very abstemious habits.

a non-poisonous snake, I did not insist. The wound smarted a little, and he went on working. Within an hour a throbbing headache had manifested itself, accompanied by oozing of 
blood from the mucous membranes of the mouth, followed by vomiting.

Meanwhile the wound was slowly oozing blood, and the muscles in the vicinity were somewhat swollen. He was then taken to Dr. Bruce, who declared him to be suffering unmistakably from the effects of virulent poison, which was seriously affecting the blood and mucous membranes. During the night Williams' condition gradually became more alarming, and he was taken to the Provincial Hospital the following day in a state of utter collapse. He steadily grew worse, and blood oozed continuously from all the nucous surfaces, viz. the mouth, nose, stomach, bladder, and bowels. Then the blood began to accumulate in the tissues, and caused large blackish-purplish swollen patches under the slin. One eye and its surrounding tissues, both forearms for two-thirds their length, a portion of the abdomen, hip, and thigh, were all charged with extravasated blood, presenting a dreadful sight. Other parts, including portions of the back, left eye, and cheek, were slightly discoloured.

The venom of the Boomslang evidently contains a poison which acts upon the endothelial cells lining the capillaries. This action is particularly characteristic of the poison of the Crotaline (Rattlesnakes), and is most marked after poisoning by the South American vipers of the genus Lachesis, and S. African adders.

Flexner has given the name "hremorrhagins" to the constituents of poisons possessing this action, and regards them as special cytolisins for endothelial cells.

\section{Between Life and DeAth.}

Williams rapidly grew worse after the second day in hospital, severe abdominal pains setting in and inability to retain even water in the stomach. From this time he rapidly grew worse, and on the evening of the third day after being bitten I went to the hospital, accompanied by Mr. William Armstrong, J.P., who took what he believed to be his dying deposition, the doctor declaring him to be in an extremely critical condition, which might result in death before the morning. He lingered on in 
this state, bordering between life and death, till about the sixth day, when a slow improvement began to manifest itself. From this time onward his condition rapidly improved, and in three weeks he was discharged from the hospital still in a weak, debilitated state, and although he gradually regained strength, he had relapses of slight bleeding from the mucous membranes of

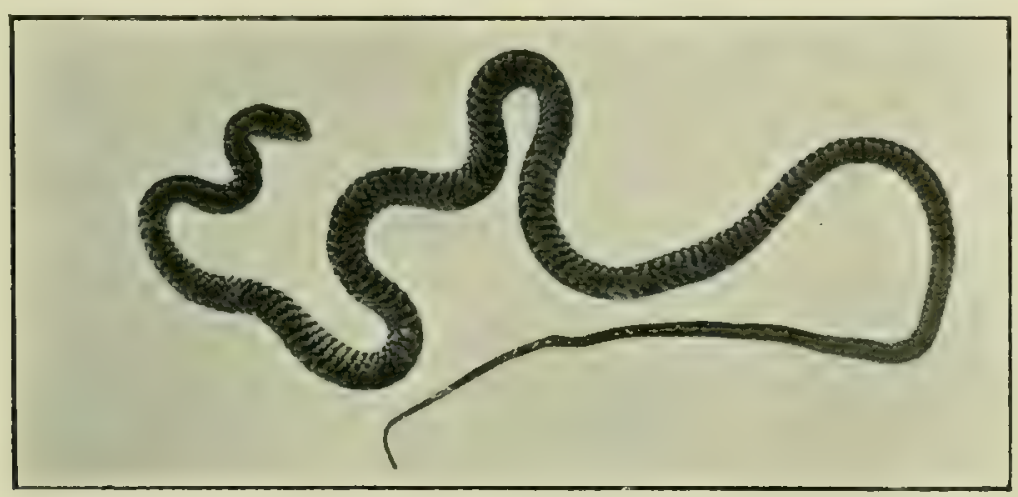

FIG. 6I.-The Boomslang which bit Williams. It died about six months afterwards, and is now pickled in a tank of spirit.

the mouth, and one eye was occasionally affected. Even three months after the accident, slight discolouration in the tissues surrounding one of his eyes showed itself for a few days. Apart from this, he has otherwise entirely recovered his health and strength, thanks to the skilful treatment in the first instance by Dr. Bruce, followed by the effective treatment whilst in hospital under the care of Drs. Pottinger and Wallace.

\section{ANOTHER Instance.}

Some years ago a local gentleman was bitten by a Boomslang, and died a few days later, but the general belief was, and is, that he died of blood-poisoning consequent upon pricking and irritating the wound with some foreign substance. A well-known gentleman, who saw him shortly after being bitten, says: "I questioned him as to whether he had experienced any effects from the bite, and he certainly gave me to understand that he had not, and attributed the whole trouble to the rash use of a needle, and making too deep a puncture with it. He told me that he felt 
quite well as far as his health was concerned, and I was surprised to hear a few days afterwards that his death was attributed to the bite of the Boomslang; I had always been under the impression it was a case of ordinary blood-poisoning."

I have made very careful inquiry into this case, and it seems the gentleman at first showed no very apparent signs of constitutional disturbance, but subsequently symptoms set in very similar to those exhibited by Williams, viz. oozing of blood from the gums and extravasation of blood into the tissues on various parts of the body, then death. This would seem to indicate that in this case there was a smaller dose of venom discharged into the wounds than was the case with Williams, which took a longer period to manifest its effects. Medical men who saw the gentleman before he died declare his symptoms were by no means those of ordinary blood-poisoning. The medical man who attended him informs me there is no doubt at all about the fact that he died of the effects of the venom of the snake which bit him.

I closely cross-questioned Williams, and he admitted that within half an hour of being bitten he felt a curious, restless, dizzy, and languid feeling, but refused at the time to own it, thinking it to be due to some other cause, and beliering so fully that a Boomslang was perfectly harmless. However, in Williams' case the symptoms were such as to leare no possibility of a doubt that he suffered directly and unmistakably from some extremely potent venom, and local medical opinion was unanimous on this latter point.

\section{The EXPERIMENTS.}

It now became imperative to demonstrate whether Boomslangs were really venomous or not, as this individual case of Williams would not by any means be accepted by scientific men as proof positive. Naturalists and others handle these snakes and make pets of them under the belief that they are non-venomous, and, moreover, in the public interest this question had to be decided for all time, especially so as the Bormslang is one of the commonest of South African snakes.

The following are the results of the experiments :-

A large brown female Boomslang was held by the neck and induced to bite the bared thighs of three fowls in quick 
succession. The first fowl died in thirteen minutes, the second in fifteen minutes, the third in three hours and four minutes.

A variegated male Boomslang bit the bared thighs of two fowls within the space of one minute. The first fowl died in nine minutes, the second in forty-five minutes.

A fowl bitten slightly lived two days and died, the wound oozing blood, and the mucous membranes of the mouth being inflamed and congested.

A variegated (greenish-yellow and black) Boomslang bit a fowl on the thigh. I killed the snake and injected some of its blood into the victim. No curative effect followed. The fowl died in twelve minutes.

A brown Boomslang bit a fowl on the thigh. I killed the snake and injected contents of its gall into the fowl, which died in eleven hours.

Another fowl was bitten and injected with the serum of the blood of the snake that bit it. No curative effect; it died in fourteen minutes.

A brown female Boomslang bit a duck on the thigh. Progressive exhaustion; slight oozing of blood in mouth; rapid heart's action; paralysis; death in seventeen minutes.

A second duck was bitten by the same snake immediately after the first one. Same symptoms; died in thirty-five minutes.

A variegated Boomslang bit a duck on the neck. Within three minutes it fell on its back completely paralysed; it remained still for another five minutes; struggled feebly when touched. Died in nineteen minutes.

A variegated Boomslang bit a large cock fowl on the comb. Blood oozed from the cock's nostrils one minute after being bitten. It began to mope, then suddenly sprang four feet straight up into the air and fell a dead mass, three minutes after being bitten.

The glands of a variegated Boomslang were rubbed up with a little water and injected with a hypodermic syringe into a vein in a live and active Cape Jackal. The animal died before the needle could be withdrawn. It perished as quickly as if shot through the head with a bullet. The venom, being injected into a vein, reached the heart almost immediately, and instantly paralysed its action. 


\section{Conclusively Proved.}

These experiments were repeated over and over again with all varieties and both sexes of Boomslangs. In all cases death occurred within twenty minutes of the first bite; the fowls and ducks which were subjected to the second bite from the same snake usually lived from fifteen minutes to two hours; not a single fowl recovered.

The fowls and ducks seemed to suffer little or no pain beyond irritation at the seat of puncture for a minute or two. Within two or three minutes they showed unmistakable signs of collapse and with a spasmodic jerk or two would suddenly expire.

A few higher animals of greater vital tenacity were also experimented with, and the characteristic slow oozing of blood from the fang-punctures and mucous surfaces was noticeable, as was the case with Williams. The animals in every case gradually grew worse, and after about twelve hours were chloroformed, it being evident they were slowly sinking under the potent effects of that subtle, death-dealing venom.

\section{Experiments to Save Human Life.}

Some folks will regard these experiments as cruel, but they were conducted in order that human life might be saved, for in no other way could I have rapidly and conclusively demonstrated to the public that the Boomslang is not only venomous, but exceedingly so. I can go further, and claim that the venom of the Boomslang is equal in its death-dealing power to that of the dreaded Cobra (Naia flava) and Ringhals (Sepedon hamachates). I forced these snakes (Cobra and Ringhals) to bite several fowls by baring the thigh and holding the snakes' heads between finger and thumb close up against the flesh.

In all cases I made the snake give a second bite to make absolutely sure a lethal dose had been injected. The fowls all died in from five to twenty minutes - the average being fifteen minutes. In most cases fowls bitten twice on the bared thigh by Puff-Adders (Bitis arictuns) survived from four up to twelve hours, some recovering completely. The majority bitten by NightAdders (Causus rhombeatus) were very sick for a couple of days, then recovered, one or two dying after twelve hours. 
It will be seen by the results of the above experiments that the bite of the Boomslang destroys the life of a fowl just as rapidly as that of the Cobra, and that the venom of the Puff-Adder is in comparison very slow in its action and not so virulent.

\section{How Boomslangs Bite.}

There are two reasons why the Boomslang does not always inflict a venomous bite. The fangs are grooved and comparatively small, and if the bite is delivered through clothing the venom is absorbed by the material, and the fangs barely scratch the flesh. Secondly, the fangs are set half-way back in the upper jaw, and are three in number on each side, exactly under the eyes, and naturally, unless the Boomslang's grip be full and complete, these fangs do not penetrate the flesh. During my experiments, I observed that the Boomslang in every case took as good a grip as possible on the animal, then almost instantly, with a heaving, forward movement and disengagement of the teeth of the upper jaw from the victim's flesh, it would take a fresh and more secure hold, the upper jaws in which the fangs are set being capable of being pushed downwards, exposing the fangs and forcing their points forward; the jaw then closes with a snap, and the snake worries the flesh, with the evident intention of forcing the venom into the punctures, as well as enlarging them for the freer ingress of the poison.

A medical correspondent from Barkly, Eastern Province of Cape Colony, wrote me that a short time ago he lost a favourite. dog from a bite by a Boomslang. The dog attacked the reptile, which bit its foe on the leg. The dog died a few hours after being bitten.

A stock farmer at the Vaal River told me that one of his oxen was bitten on the lip by a large Boomslang. The ox was eating the foliage of a tree, and had evidently disturbed the snake. The herd-boy saw the affair, and called the farmer, who was at his waggon, a little distance away. He says he saw and shot the snake, which was a variegated variety of Boomslang. He applied what is known as "Jesse Shaiv's" cure, but the ox died threequarters of an hour after.

Since the publication of the first edition of this book I have 
received sereral accounts from well-known farmers, and two by medical men, of natives being bitten by Boomslangs which, with the exception of two of the cases, terminated in death.

An instance was related to me by a gentleman who is a keen naturalist. He says he was quite unaware that the Boomslang was venomous. In fact, he was inclined still to be sceptical, owing to an experience which he had with this species of snake. Being anxious to capture one alive, one day he pursued a large Boomslang of the variegated variety, which escaped up a small tree. There being no other trees near, the snake ascended to the top, and, on his approach, showed fight. In attempting to seize it, the reptile bit him severely on the forefinger. Grasping the snake by the neck, he quickly unhooked its small recurved teeth, which were embedded in his skin. No symptoms of poisoning set in, although his finger bled a little from the various punctures. He regarded this as proof that the Boomslang was non-venomous. The fact of the case was, the snake, in its haste, merely gripped the finger of the man with the front portion of its jaws, and did not succeed in getting its fangs into a suitable position to drive home before it was dragged off the flesh.

\section{Boomslangs and Their Habits.}

The word "Boomslang" is Dutch, and means Tree Snake. Boom $=$ tree, and Slang $=$ snake .

Boomslangs vary considerably in colouration, as will be noticed on reference to the description of the colouration of this species of snake given at the beginning of this chapter, in the list of the snakes of the back-fanged division.

The round and long tapering body of the Boomslang is specially adapted for gliding swiftly and silently through the foliage of trees. Like other snakes, Boomslangs tend to vary in colouration according to their environment and habits. In districts more or less bare of forests and wooded kloofs, Boomslangs are gradually taking to a terrestrial mode of life. Not being able to gain sufficient food in the trees and shrubs, they are compelled to take to the ground and hunt frogs, lizards, ground birds, and various other creatures. In consequence of this modification of environment and habits, their colour undergoes a 
change, eventually developing into uniform chocolate or light purplish brown, which is eminently suitable, blending perfectly

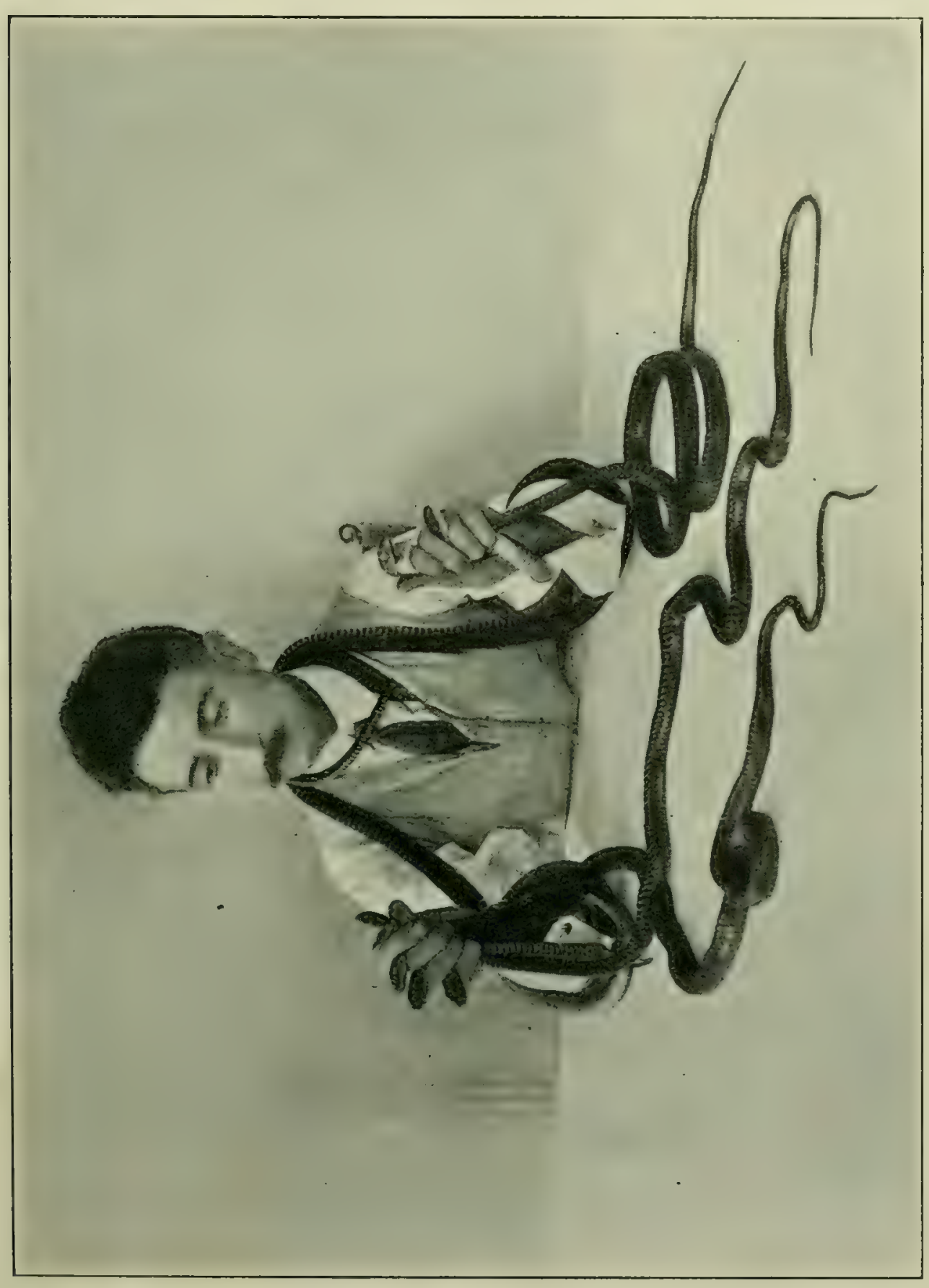

with the earth, dead leaves, branches, stones, etc., over and through which they hunt their prey. When the skin of a brown variety of Boomslang is distended, most of the scales are seen to 
be tipped with bluish white, which has a very beautiful appearance. These spots are, however, not always present.

The favourite food of the Boomslang consists of chameleons, birds and their fallow young, and eggs. The latter are swallowed whole, the powerful gastric juices of the snake dissolving the shell.

My captive Boomslangs often swallowed pigeons' eggs, which remained in their stomachs intact, sometimes for twelve to twenty-four hours. In one instance a snake swallowed two pigeons' eggs, which remained unbroken in its stomach for three weeks. The reptile, being in poor condition at the time, its gastric fluid was evidently too weak to dissolve the shell. When the eggs were removed after the death of the snake, I noticed the shell had been somewhat roughened by the action of the acid fluids of the snake's stomach.

Chameleons, other tree lizards, caterpillars, and various larvæ are sought after and eaten by Boomslangs. So closely does the colour of these reptiles' skins blend with the foliage, that I have known birds to hop upon their bodies, mistaking them for branches. These snakes can imitate the branches of a tree to perfection. The body is contorted and twisted amongst the leaves, and is perfectly rigid. For hours a Boomslang will lie amongst the leaves and twigs, its large unwinking eyes keenly on the alert. If an unwary bird should approach within striking distance, the forepart of the snake's body is shot out as swiftly. as a stone from a catapult, and next instant the bird, struggling, is in its jaws. In a minute or two the victim ceases to move, for the deadly venom has paralysed its nerve centres. Then the snake assumes a comfortable position, and swallows its prey.

When a Boomslang is seen by birds in the vicinity of their nests, they become intensely alarmed and excited, flying rapidly to and fro, hopping from twig to twig, fluttering their wings and making various other excited demonstrations. Hearing the noise, other birds come along and join in the effort to scare away the intruder. The snake is in no way alarmed. It remains as still as a statue, its head drawn back and its body at an angle suitable for a rapid and long forward thrust. Presently one of the birds, in wild excitement, approaches within striking distance. Instantly, with unerring aim, its body is launched forth and a bird loses its life. 
Once a Boomslang seizes its prey, it is loth to let go. Holding on, it makes no effort to swallow or constrict its victim. It

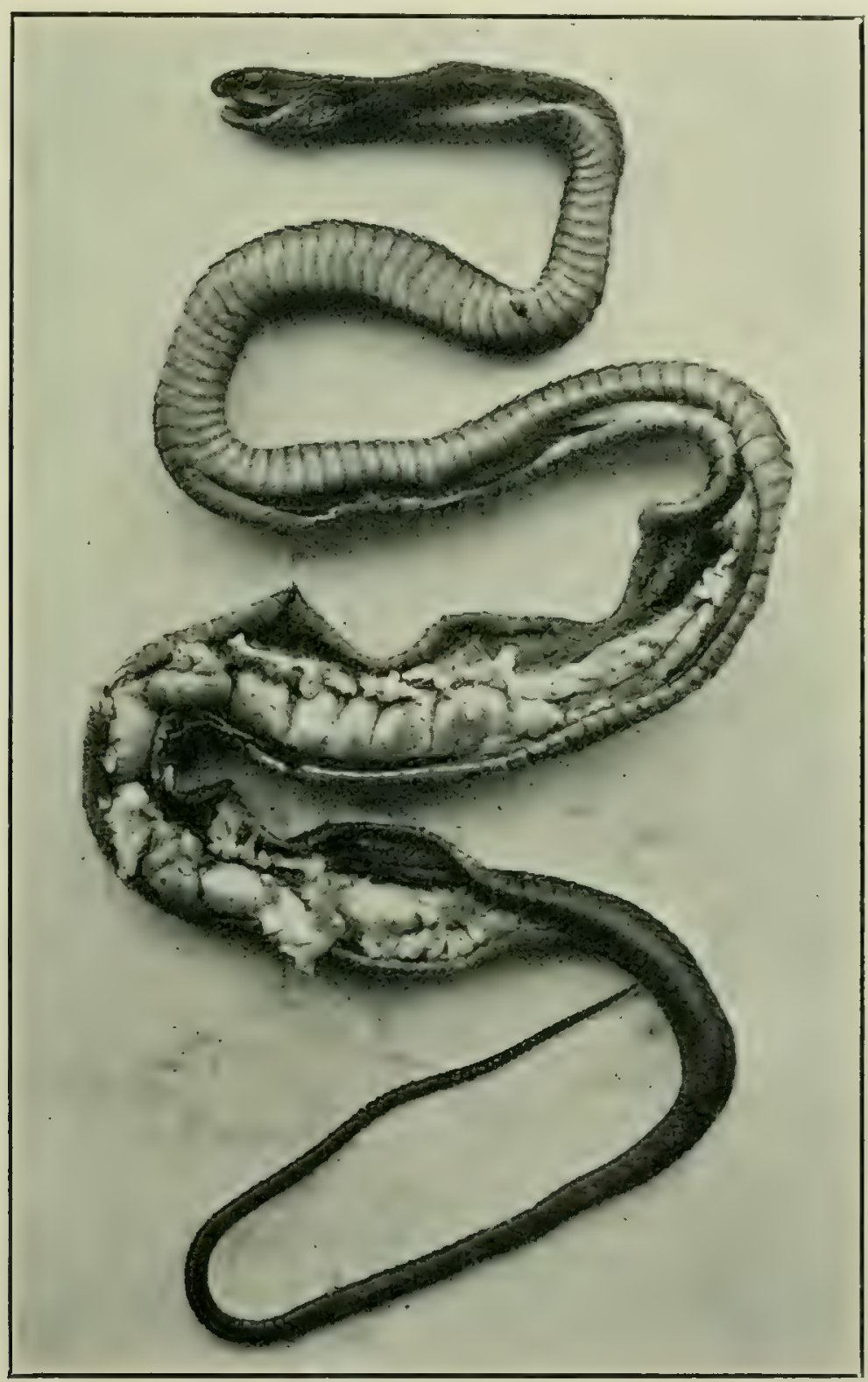

FIG. 63.-A brown variety of Boomslang dissected to show how the eggs lie. These eggs are fully developed, and were being laid when the snake was killed to obtain this picture. The shapelesslooking white substance about the eggs is fatty tissue.

knows only too well the power of the fluid which is distilled by the glands in its head. It is well aware that the venom will rapidly reduce the struggling prey to a limp, dead mass, easy to swallow: 
Boomslangs are timid creatures, and will on the slightest alarm make off into the dense bush. They are fond of descending to the ground and sunning themselves on some dry exposed bank or patch of ground. The variegated variety of Boomslang, when alarmed, instantly glides up a tree or into the tangled bush. On the contrary, the brown variety usually has a hole in a bank, or a crevice amongst rocks, a pile of dead brushwood, or some such shelter into which to retire.

One day I was riding over the veld, when a Boomslang of the yellowish-green and black variety darted across my path and took shelter in a small thorn tree about five feet in height, sparsely covered with narrow, feather-like leaves. I could see through the small tree quite easily, for it was only about three or four feet in diameter. I walked round and round the bush, and examined it up and down for some minutes without seeing a trace of the snake. Then, starting at the bottom, I searched every twig systematically with my eyes, and followed each branch to its end. Eventually, half-way up the tree, I saw the snake. Its body was contorted and twisted at exactly the angles at which the branches and twigs jutted out. The yellowgreen of the skin blended perfectly with the leaves, the effect being considerably heightened by its black, uneven cross markings. Approaching within two feet, I eyed it for a time, and not once during that time did it make the slightest movement. When I attempted to capture it by putting a bit of string with a noose at the end round its neck, it got angry, and sought to intimidate me by puffing out the throat, making its head look twice or more its natural size.

After being captured and kept for some hours in a dark bag, most Boomslangs will permit themselves to be freely handled without showing any disposition to bite. However, if one should suddenly touch your face or bare hand or arm with its nose, it instantly bites, and holds on till you forcibly remove it. If handled carefully and gently, they will rarely bite.

The sex of a Boomslang cannot be determined by the colour with any degree of certainty. I used to think that the female of the yellowish-green variety was not so yellowish as the male, but rerently I have examined a large series of them, and find them all to be males. All the chocolate coloured ones so far examined have been females. 
In captivity, Boomslangs will readily eat frogs. Toads

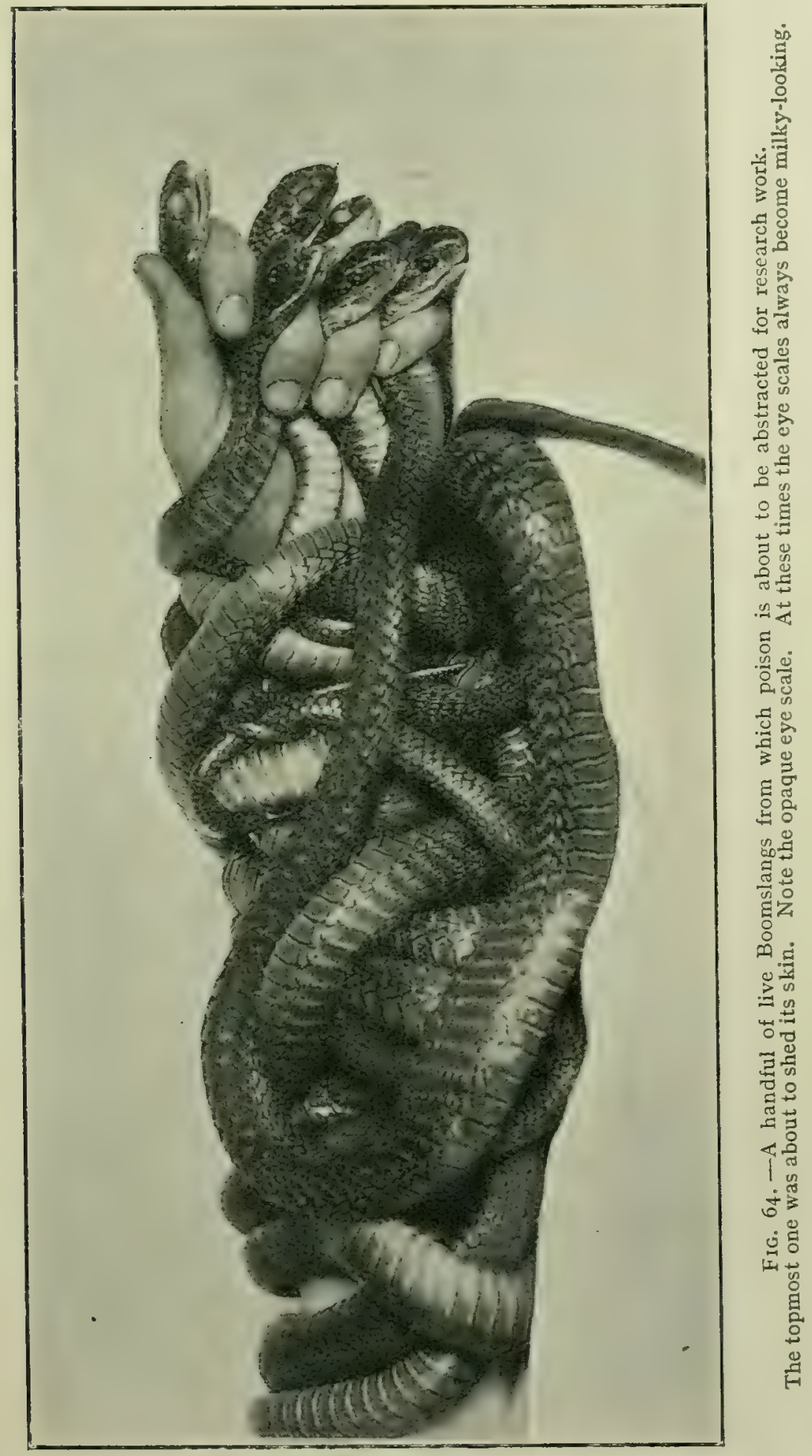

they will not touch. Many refuse all food, and have to be fed 
artificially by syringing the beaten-up contents of fowls' eges down their throats and then putting them gently down, else they will vomit the food. The best way is to hold the snake in your hand for five minutes or so after feeding it, and then lay it very gently down in a warm cage.

Dead frogs and bits of raw meat may be pushed gently into the snake's throat and worked down with the fingers.

Boomslangs descend to the ground to lay their eggs, which are usually placed under a thick layer of fermenting leaves or vegetable mould under tangled bushes. At other times the eggs may be laid in a Starling's nest in a hole in a bank, or among the tangled roots of a forest tree. Warmth and moisture are necessary for the incubation of the eggs. On hatching out, the young Boomslangs almost immediately take to an arboreal life, and lead an existence entirely independent of their parent.

The Boomslangs which are green, or variegated green and black, are strictly arboreal. The brown varieties are more or less terrestrial in their habits. For some considerable time I had a Boomslang alive which was intermediary between the variegated green and the dark-brown varieties. This specimen was blackish above, through which traces of greenish-yellow were visible in places. The "blackishness" on the back shaded off on the sides and abdomen to yellowish green. The specimen was a female, and laid thirteen eggs during the month of October.

On several occasions brown Boomslangs have laid batches of eggs varying in number from a dozen to twenty-three, containing a yellowish fluid, with no sign of incubation having already begun. The eggs are laid during midsummer, usually October, November, and December. On many occasions I have noticed the Boomslangs, which I have kept in captivity, swallow domestic pigeons' eggs whole. These eggs are not crushed in the throat, as is the case with the Egro-eating Snake (Dasypeltis). They lodge in the stomach and remain there until the gastric juices dissolve the shell and release the contents, which sometimes takes several days.

\section{CONCLUSIONS.}

The Boomslang is a member of the Opisthoglypha or Hindfanger snakes, which have hitherto been regarded by some 
authors as non-vénomous, and others as only very slightly venomous. Now, the fact of the Boomslang having been proved to be very highly venomous shows that at least one of this class of Hind-fanged snakes possesses highly-specialised venom capable of destroying human life, therefore it is reasonable to assume a good many of the others would be found, on investigation, to be equally venomous. Until each individual snake of this class has been carefully experimented with, it would be unwise to lead the public to infer they were either harmless, or only venomous to a very slight degree. This opens up a wide field for experimental work, for there are over three hundred species of the Back-fanged Division of Snakes in the various snake-infested countries.

NoтE.--Further information and illustrations about Boomslangs will be found in the Addenda at the end of this book. 


\section{CHAPTER VI.}

\section{Sub-Family IV.-Hydrophinæ. \\ Division III.-Proteroglypha.}

THE Sea Serpents belong to the division of snakes known as the Proteroglypha, so called because they have fangs in the front part of the upper jaw. These fangs, which are set in the anterior maxillary bone, are deeply channelled or grooved, the sides of the channels showing a tendency to unite and form a complete perforated or hollow tooth similar to the hollow fangs of the Viper family. These are the typical poison fangs. Independent

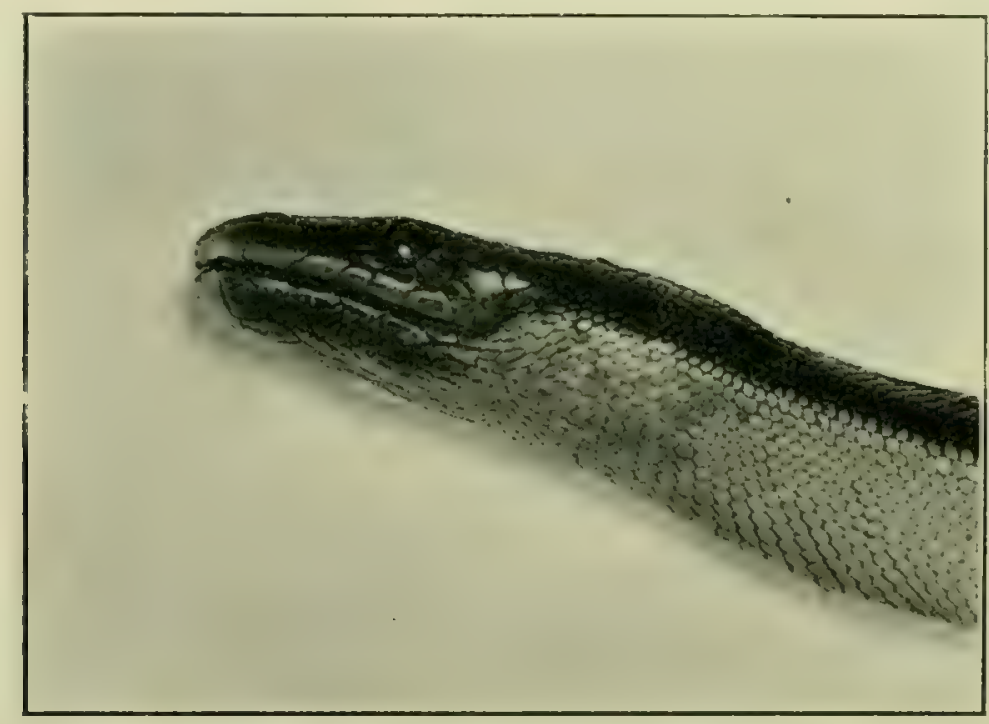

Fig. 65.-Head and neck of the poisonous Black and Yellow Sea Snake of the African Coast (Hydrus platurus).

of the fangs there is a set of small solid teeth, also set in the front part of the upper jaw.

The sub-family Hydrophinæ are all Sea Snakes. There are about fifty-five species or kinds known.

All are highly venomous, except one single species (Distiva 
semperi), which is only found in a fresh-water lake at Luzon, in the Philippines.

The Sea Snakes can be distinguished from all other snakes by the flattened oar-like tail, which is used as a rudder and propeller, for they have no fins.

Sea Snakes shed their skins very frequently, but the old skin

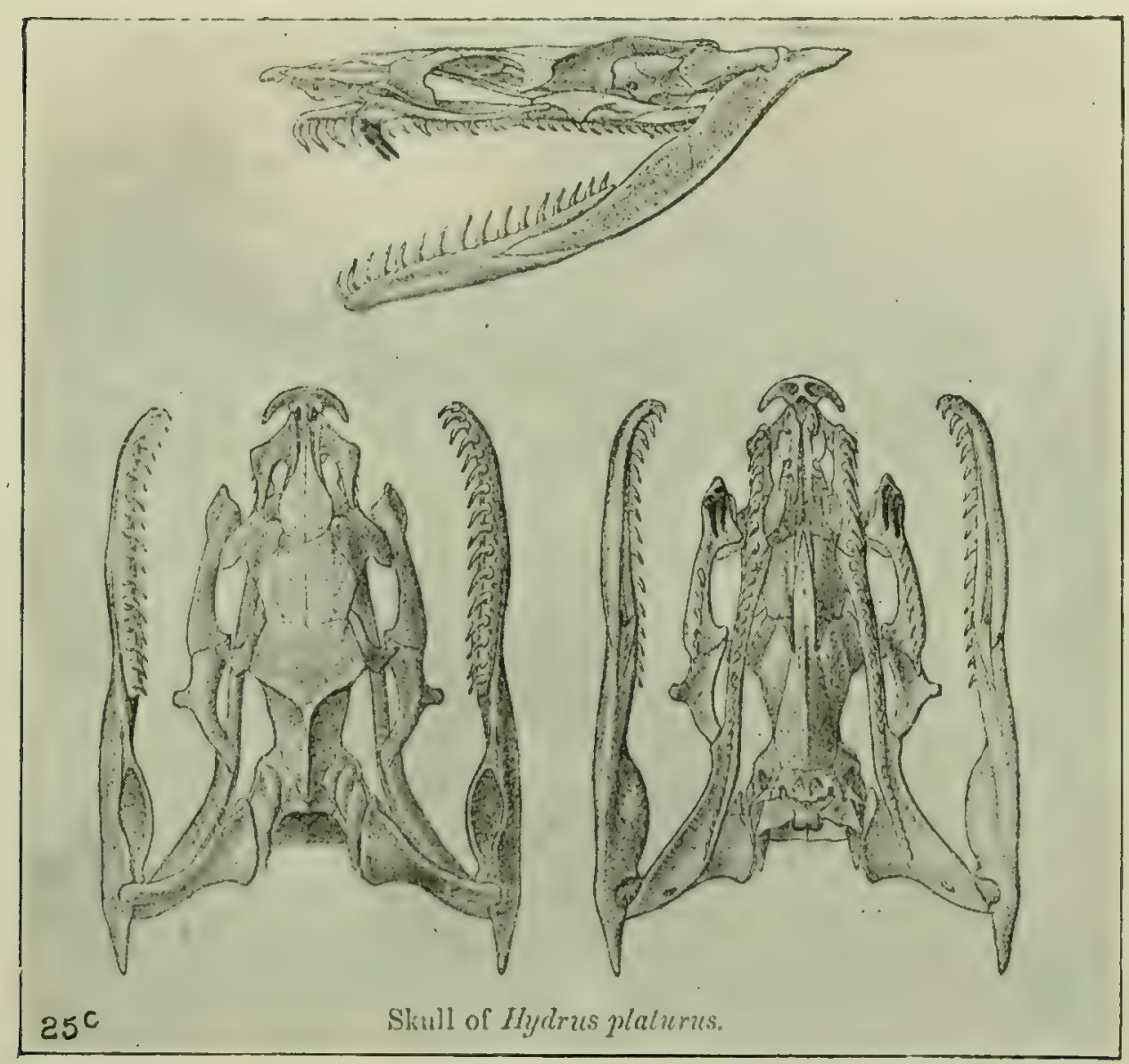

FIG. 66.-Skulls and poison fangs of Black and Yellow Sea Snakes (Hydrus platurus). There are two fangs in each jaw (Brit. Mus. Cat. Snakes.)

peels off in pieces, and does not come away entire, as is the case with their terrestrial cousins.

\section{Habits of Sea Snakes.}

Although living in the water, they breathe air. Their nostrils are situated on the top of the snout. Most species are brilliantly and beautifully coloured. Their food is fish and other marine creatures. Although most species are helpless, and perish if cast 
up on shore, there are some which make frequent inland excursions, sometimes to considerable distances over the land, usually at night, when the vegetation is moist. Sea Snakes are most abundant in the Tropical portions of the Indian Ocean and Western Pacific. Some species congregate in great shoals, and swarm in the cracks and crannies of ocean rocks which are submerged at high tide. If poked with a stick they bite riciously, after the manner of venomous land snakes.

\section{SUB-FAMILY HYDROPHINAE.}

The various Genera and Species of Sea Snakes belong to the above sub-family. They are all very venomous, possessing grooved fangs at the anterior end of the upper jaw.

\section{GENUS HYDRUS.}

This Genus is represented by only one Species.

\section{KEY TO THE SPECIES.}

Rostral as deep as broad or a little broader than deep; frontal large, at least as long as the snout or the parietals, one or two pre- and two or three postoculars; one or two suboculars sometimes present ; temporals small and numerous; seven or eight upper labials, second in contact with the prefrontal, fourth, fifth; or fourth and fifth usually entering the eye; chin shields small and indistinct; 45 to 47 scales round the body, smooth in the female and young; laterals and ventrals rough, with one, two, or three small tubercles in the male.

I. Hydrus Platurus. Black and Yellow Sea Snake.

Synonyms-Anguis platurus; Hydrus bicolor: Pelamus bicolor: Pelamus platurus.

Colour-Markings very variable.

A. Yellow, with brown, black-edged cross bands; black bars between the cross bands, on the sides of the belly.

B. Anterior third of the body with a black dorsal stripe; further back a series of transverse dorsal rhombs on the back, and black spots on the sides and belly.

C. Dorsal region black; sides and belly yellow, with a lateral series of black spots which may be partly confluent into a stripe; tail with dorsal and lateral spots.

D. Dorsal region black, ventral region brown, the two separated by a yellow lateral stripe; tail spotted as in the preceding.

E. Black above; sides of belly yellow; the two colours do not blend. There is a distinct line of demarcation. Tail spotted as in the preceding.

F. Yellow, with a black vertebral stripe, broken up into spots posteriorly; no lateral spots on the body or tail.

$\mathrm{G}$. Yellow, with a vertebral band and spots on the tail pale brown or olive.

Average length -2 feet.

Distribution-Coast of South Africa; Indian Ocean and Tropical Pacific. 


\section{- Black and Yellow Sea Snake. \\ (Hydrus platurus.)}

The only species of Sea Snake which inhabits the ocean about the coasts of South Africa is the Black and Yellow species. It is often seen in the shallow pools amongst the rocks on the seashore, left stranded there by the out-going tide. It is very necessary that the general public should become acquainted with the appearance of this snake, as many fatalities have occurred

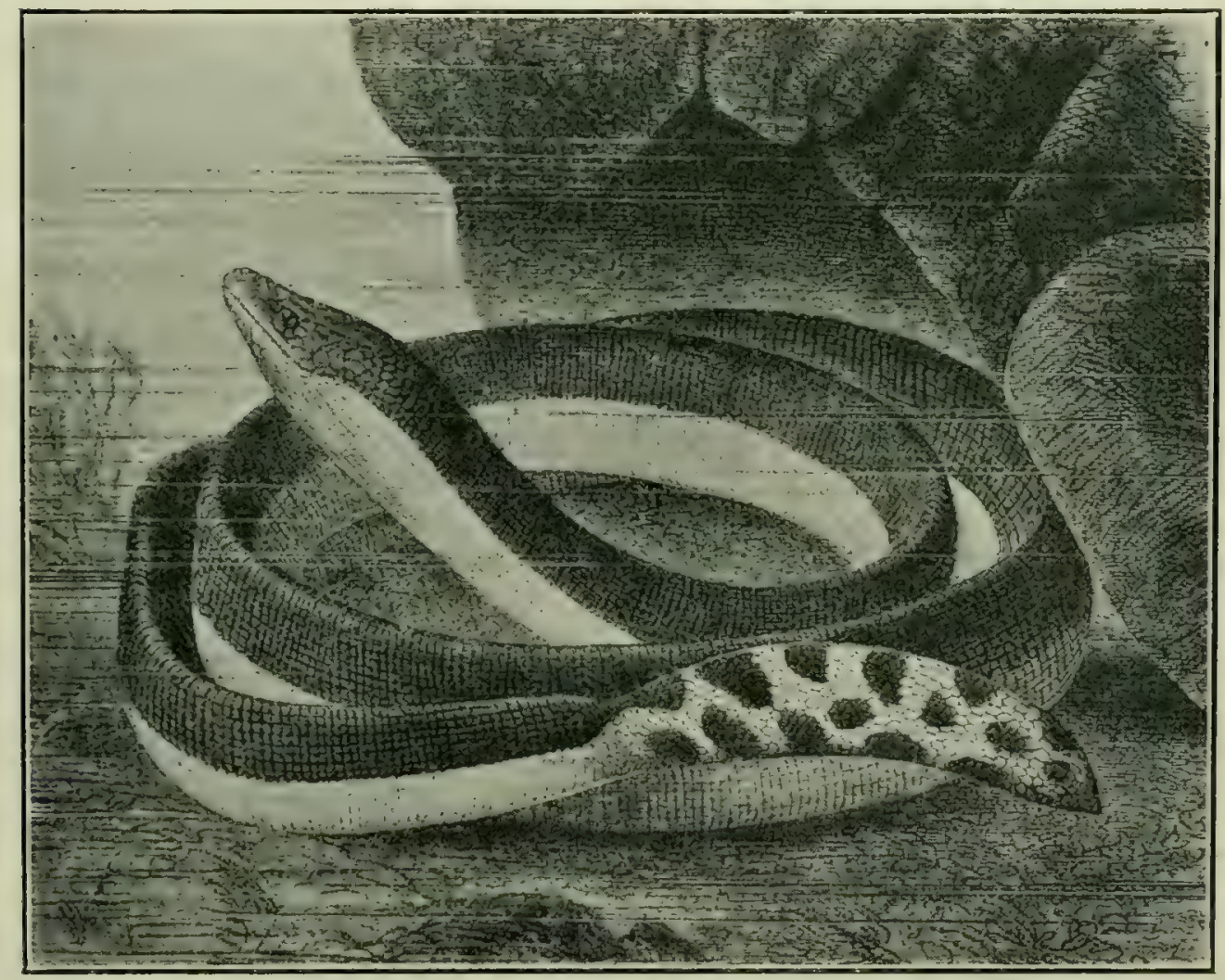

F1G. 67.- The Black and Yellow Sea Snake (Hydrus platurus) which lives in the ocean, and is often left stranded in the rock pools along the South African Coast. It is highly venomous. (Royal Natural History.)

by people mistaking it for an eel and catching hold of it. A naval officer was thus bitten recently, and lost his life. He died four hours after the bite. Another instance is recorded of a sailor being bitten and dying in two and a half hours after. A coloured man once brought me one in a tin containing sea water. $\mathrm{He}$ said he had caught it in a small pool on the beach. He foolishly pulled it out of the tin, remarking what a fine eel it was. Before 
I could warn him it had bitten his hand, but I instantly ligatured his arm, scarified the wound, rubbed in permanganate of potash, and injected serum. He recovered.

This species of Sea Snake is black above, and bright yellow beneath, the two colours being distinctly separated-the line of demarcation being very pronounced. Some specimens have a profusion of black spots over the abdomen, and the tail is mottled whitish and black. The average length is two feet to two feet six inches.

The poison apparatus of all the Sea Serpents is highly specialized, like that of the Cobra.

I have frequently found these snakes cast upon the shore of Algoa Bay, or in pools left amongst the rocks by the outgoing tide. They have also been recorded from Durban Bay, Simonstown, False Bay, and Table Bay. I have several times tried to keep these snakes alive in an aquarium, but they always died after a few days. I have no doubt, however, that they would live and thrive in a properly constructed aquarium if the water was kept at about the temperature they are accustomed to. Hydrus platurus is divided into seven varieties, owing to the differences in colouration in the different localities it inlabits. The one marked Variety E, is the kind we find at Algoa Bay.

The Proteroglypha or Front-Fanged Snakes.

COBRAS, MAMBAS, CORAL SNAKES, GARTER SNAKES, ETC.

\section{Sub-Family-Elapinæ.}

This important sub-family of Colubrine snakes include the most dreaded of all snakes, viz., the Cobras and Mambas.

There are about one hundred and forty species known, which are scattered over the Southern part of North America, Central and South America, Africa and Southern Asia to Australia. These highly-venomous snakes belong to the division known as the Proteroglypha, having fangs set in the front part of the upper jaw, in the bones known as the anterior maxillary bones. The fangs are usually deeply grooved or channelled. In some cases the sides of the grooves show a tendency to unite and form 


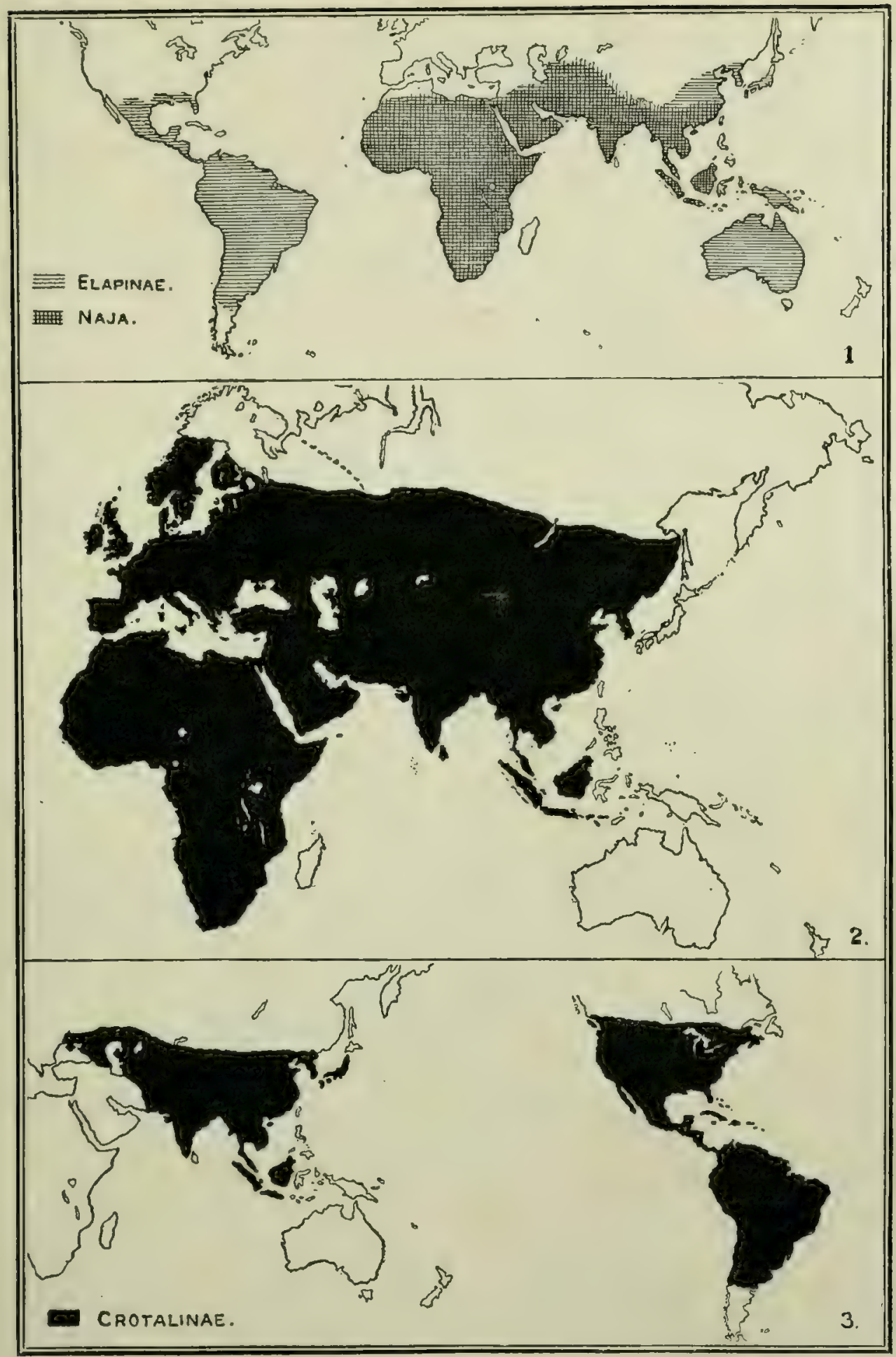

MAPS SHOWING THE DISTRIBUTION OF TYPICAL VENOMOUS SNAKES.

FIG. 68.- - Distribution of the Colubrine family of snakes, viz. Africa, Southern Asia, to Australia, Central and South America. The true Cobras (Naja or Naia) inhabit Africa, Southern Asia and the Malay Archipelago only.

2. The parts coloured black show the distribution of the Viper, otherwise known as the Adder family of snakes. This does not include the sub-family of Pit Vipers known as Crotalince.

3. The parts coloured black show the distribution of the Pit Vipers to which the Rattlesnakes belong (Crotalina).

New Zealand is the only country in the semi-tropical regions in which snakes do not occur. There are snakes in Madagascar of the Aglypha and Dipsadomorphine kinds, but no Proteroglypha or front-fanged snakes. 
hollow fangs. In some, this union of the two edges of the channel is well advanced, having firmly united in places. These snakes all possess a highly-specialized poison apparatus.

Most species of the Elapinze are viviparous.

There are fourteen species or kinds of snakes belonging to the above sub-family which inhabit South Africa south of the Zambesi.

\section{SYNOPSIS OF THE GENERA.}

GENUS NAIA.-Maxillary extending beyond the palatine, with a pair of large grooved poison-fangs, and one to three small faintly-grooved teeth near its posterior extremity; mandibular teeth, anterior the longest; head not, or but slightly, distinct from the neck; eve moderate or rather large, with round pupil ; nostril between two nasals and the internasal; no loreal. Body cylindrical; scales smooth without pits, disposed obliquely in 15 to 25 rows (or more on the neck); ventrals rounded. Tail moderate; sub-caudals all or greater part in two rows.

Genus Sepedon.-Maxillary extending forwards beyond the palatine, with a pair of large grooved poison fangs; no other maxillary teeth; mandibular teeth, anterior longest. Head not distinct from neck; canthus rostralis distinct; eye moderate with round pupil; nostril between two nasals and the internasal; no loreal. Body slightly flattened; scales oblique, keeled, without pits, in I9 rows; ventrals rounded. Tail moderate; sub-caudals in two rows.

Genus Aspidelaps.-Maxillary extending forwards beyond the palatine, with a pair of large, grooved poison fangs; no other maxillary teeth; mandibular teeth, anterior longest. Head slightly distinct from neck; eye moderate with round or vertically elliptic pupil; rostral shield very large, detached on the sides; nostril between two or three nasals, and the internasal; no loreal. Body cylindrical; scales oblique, smooth or keeled, without pits, in I9 to 23 rows; ventrals rounded. 'Tail short; obtuse. Sub-caudals in two rows.

Genus Elapechis.-Maxillary bone extending forwards as far as the palatine, with a pair of large grooved poison fangs, followed by two to four small teeth; mandibular teeth anterior longest. Head not distinct from neck; eye small with round pupil; nostril between two nasals; no loreal. Body cylindrical ; scales oblique, smooth, without pits, in I 3 to I 5 rows. Ventrals rounded. Tail very short; sub-caudals all or most in two rows.

Genus Homorelaps.-Maxillary extending forwards beyond the palatine, with a pair of large poison fangs, pterygoids toothless; mandibular teeth few, sub-equal. Head small, not distinct from neck; eye very small with round pupil; nostril in a single nasal; no loreal. Body cylindrical; scales smooth without pits, in I5 rows; ventrals rounded. Tail short; sub-caudals in two rows. No postfrontal bone; prefrontals widely separated from each other and in contact with the parietals, excluding the frontals from the orbital periphery. 


\section{PROTEROGLYPHA OR FRONT-FANGED SNAKES. I63}

GeNus DendRaspis.-Maxillary bone curved upwards, with a strong posterior process directed backwards and outwards; a pair of large poison fangs, not fissured, not followed by other teeth: a large fang-like mandibular tooth, followed by a considerable toothless space. Head narrow, elongate; eye moderate, with round pupil; nostril between two shields; no loreal. Body slightly compressed; scales smooth, narrow, very oblique, without pits, in 13 to 23 rows; ventrals rounded. Tail long; sub-caudals in two rows.

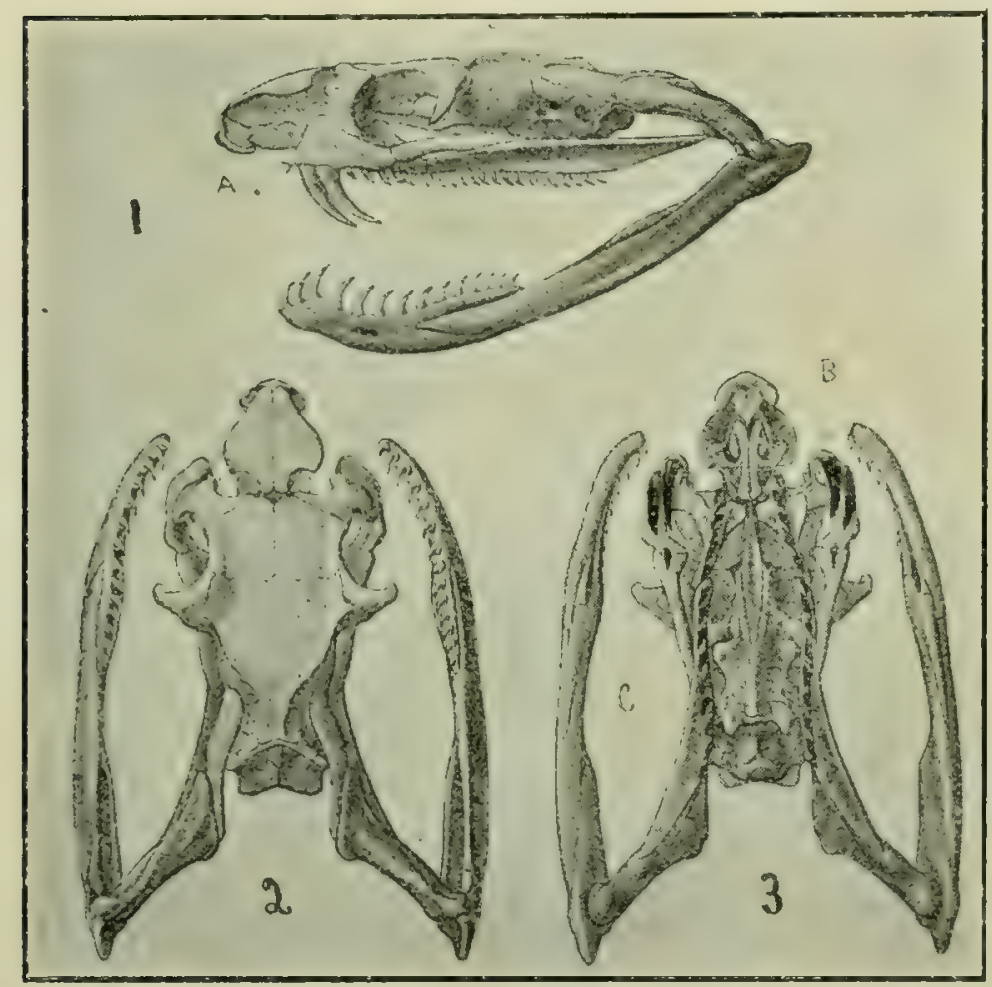

FIG. 69.-Skulls of typical snakes of the Front-fanged Elapinæ sub-family.

I. Side view showing the fangs and rows of harmless teeth.

A. Anterior maxillary bone to which the fangs are attached.

2. Back of skull and lower jaws.

3. Roof of mouth.

B. Poison fangs.

C. Lower jaw." (Brit. Mus. Cat. Snakes.)

\section{Genus NAIA. (Typical Cobras.)}

\section{Four Species in South Africa.}

KEY TO THE SPECIES.

Sub-oculars separate the eye from the upper labials. $2 \mathrm{I}$ or 23 scales across neck, I9 or 2 I across middle of body $\quad \cdots \quad \cdots \quad \cdots \quad \cdots \quad \cdots$ I 7 scales across neck, as well as across body .. Naia anchiete. 
Third, or third and fourth upper labials entering the eye. Sixth upper labial largest, and in contact with postoculars; 23 scales across neck .. ..

Third, or third and fourth upper labials entering the eye. Third upper labial deepest, sixth not in contact with postoculars; 23 to 29 scales across neck . . . . . . . . . . .

Naia flava.

Naia nigricollis.

I. NaIA hale. Egyptian or Banded Cobra. Koper Kapell.

Synonyms-Coluber haie; Cerastes candidus; Naja haje.

Colour-Yellowish or olive to dark brown or black above, uniform or with darker or lighter spots; lower parts yellowish, with a brown or black band on the neck, or dark brown to blackish; head sometimes blackish.

Colouration varies as follows:-

A. Brown above, yellowish beneath, with or without brown spots.

B. Dark brown above, with yellowish spots; dark brown beneath.

C. Blackish brown above and beneath.

Average length -5 feet.

Distribution-Natal ; Zululand; Transvaal; Rhodesia; Delagoa Bay ; Northwards to Palestine.

2. Naia anchiete. Anchietas' Cobra; Anchietas' Kapell.

Colour-Brown to blackish above; end of snout and sides of hearl yellow; yellow or pale brownish beneath, with or without brown spots, and with a brown or black cross-band under the neck.

Average length -5 feet; attains a length of seven feet.

Distribution-North West Rhodesia; German South West Africa; Angola.

3. Naia Flava. Cape Cobra; Geel Kapell; Bruin Kapell; Spoeg Kapell (Spuug).

Synonyms-Vipera flava: Naja nivea; Naja nigra.

Colour-Colour variable. There are five distinct varieties :-

(I) Uniform gamboge yellow usually with a few scales coloured reddish-brown.

(2) Reddish-brown and yellow, the former predominating.

(3) Very dark umber approaching to black. A few scales coloured yellow.

(4) Light olive brown with a tinge of dull yellow. Some are dun colour with a shade of olive yellow.

(5) Shiny purplish-black. For fuller description see account of Cape Cobra.

Average length -5 feet; attains a length of nearly 7 feet.

Distribution-Whole of Cape Colony; German South West Africa. Black varicty does not occur in Eastern parts of Cape Colony.

4. NAIA Nigricollis. Black-necked Cobra; Zwart-nek Kapell.

Synonym-Vipera haje.

Colour-Colour variable, as follows:-

A. Brown or olive above, some or all of the scales black-edged, the skin between the scales black; yellowish beneath, the ventrals speckled or edged with brown or blackish; lower surface of neck with black cross bars. (Mossambique variely.)

B. Uniform brown above, yellowish beneath; lower surface of neck brown in the adult; young with a broad black ring round the neck. 


\section{PROTEROGLYPHA OR FRONT-FANGED SNAKES. I65}

C. Dark olive to black above ; lower surface of head and neck black ; sub-caudals and posterior ventrals black, the remainder black and yellow.

Average length -5 to 6 feet; attains a length of over 7 feet.

Distribution-All over South Africa, excepting the Southern parts of Cape Colony; Northwards to Senegambia and Upper Egypt.

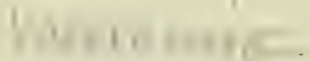 \\ GENUS SEPEDON: - he: $\because 1: \ldots$}

This Genus is represented by one Species.

Scales strongly keeled, without pits, in I9 rows; ventrals II6-I50; anal entire. Sub-caudals

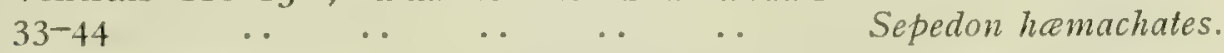

r. Sepedon hamachates. The Ringhals or Spitting Snake. Ringhals Slang.

Synonyms-Coluber hamachates; Vipera hamachates: Naja hamachaetes; Aspidelaps hamachates.

Colour-Black above, spotted, variegated or irregularly barred with pale brown or yellowish-white; or brown spotted with black; black beneath, usually with one or two whitish cross bands on the neck.

A. Jet black above and below, with a white cross band on the throat. Sometimes the white band is entirely absent, or else only slightly developed.

Average length -2 feet 6 inches to 3 feet.

Distribution-Cape Colony; Natal; Zululand; Orange River Colony ; Basutoland; German South-West Africa; not recorded from Rhodesia or north of Zambesi.

\section{GENuS ASPIDELAPS.}

\section{Two Species in South Africa.}

\section{KEY TO THE SPECIES.}

Internasals in contact behind the rostral; third and fourth upper labials entering the eye; scales all smooth; ventrals I $_{4} 6-\mathrm{I} 76$. .

Internasals separated by the rostral; fourth upper labial entering the eye; scales on posterior part of body keeled; ventrals

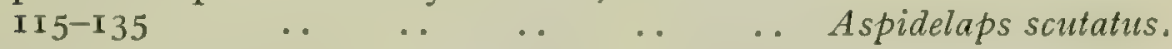

I. Aspidelaps LUBricus. Coral Snake. Koraal Slang.

Synonyms-Natrix lubrica; Coluber latonia; Elaps lubricus; Naja lubrica.

Colour-Orange or red with black annuli, which are slightly angular on the back; a black bar below the eye; sometimes a black cross bar between the eyes, and an oblique band on the temple; upper surface of head sometimes entirely black.

Average length $-I$ foot 6 inches to 2 feet.

Distribution-Both provinces of Cape Colony; Orange River Colony; German South-West Africa; Rhodesia; Zambesi Regions. 
2. Aspidelaps scutatus. Shield Snake. Schild Slang.

Synonyms-Cyrtopsis scutatus; Naia fula-fula.

Colour-Pale greyish-brown above, with transverse dark spots or cross bands; head and about two inches of the neck black; chin and throat white, separated by black irregular blotches; underparts whitish.

Average length - I foot 6 inches to 2 feet.

Distribution-Natal; Orange Free State; Transvaal; Delagoa Bay ; Southern Rhodesia; Portuguese East Africa.

\section{GENUS ELAPECHIS.}

Three Species in South Africa.

\section{KEY TO THE SPECIES.}

Portion of rostral visible from above, not half as long as its distance from the frontal, which shield is a little shorter than the parietals; diameter of eye less than its distance from the nostril in the adult. Scales in 13 rows. Snout broadly rounded .. Elapechis guentheri.

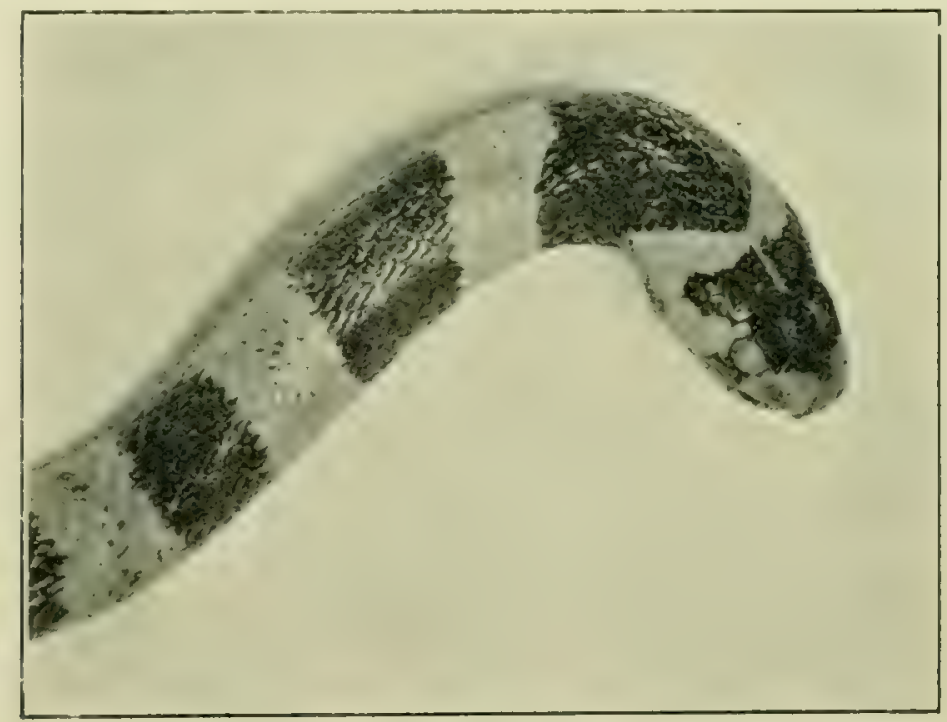

Fig. 70.-Head and neck of the Coral Snake (Aspidclaps lubricus). Colour, cural-red or ornage-red, banded with black. A rather large shield curving back from the nose.

Scales in 13 rows. Portion of rostral visible from above, at least half as long as its distance from the frontal, which shield is much shorter than the parietals; diameter of eye less than its distance from the nostril in the adult $\quad \ldots \quad$. $\quad \cdots \quad \ldots \quad \ldots \quad \ldots$ Elapechis sundevallii.

Snout obtusely pointed. Portion of rostral visible from above, at least half as long as its distance from the frontal, which shield is much shorter than the parietals; diameter of eye equal to its distance from the nostril

Elapechis decosteri. 


\section{PROTEROGLYPHA OR FRONT-FANGED SNAKES. I67}

I. Elapechis guentheri. Guenther's Garter Snake. Kousband Slang (Kouseband Slang). Synonyms-Elapsoidea guentheri ; Elapsoidea semiannulata.

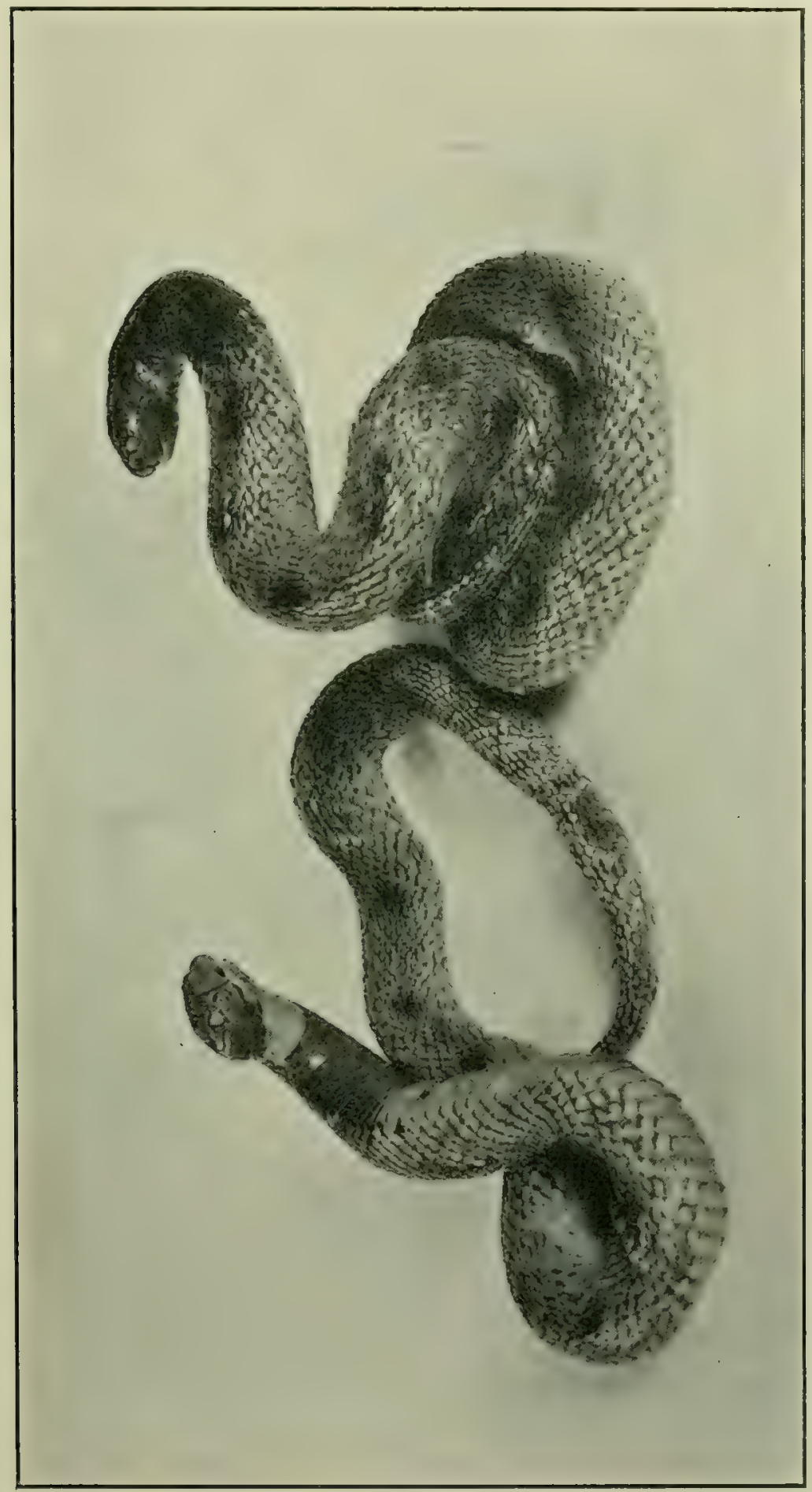

$$
\begin{aligned}
& \text { 몽 }
\end{aligned}
$$

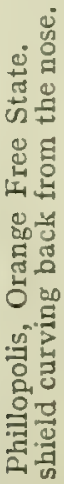

$$
\begin{aligned}
& \text { 遠点 }
\end{aligned}
$$

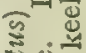

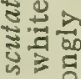

$$
\begin{aligned}
& \text { 要焉 } \\
& \text { 혼 } \\
& \text { ( } \\
& \text { 도에 } \\
& \text { 을 }
\end{aligned}
$$

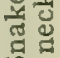

$$
\begin{aligned}
& \text { 글 } \\
& \text { के } \\
& \text { | }
\end{aligned}
$$

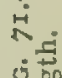

$$
\begin{aligned}
& \text { 空昙 } \\
& \text { ( } \\
& \Xi
\end{aligned}
$$

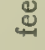

$$
\begin{aligned}
& \text { 롱 } \\
& \text {. } \\
& \text { 离 }
\end{aligned}
$$

Colour-White or greyish above, with black white-edged cross bands, or blackish with whitish cross bars or lines formed by the edges 
of some of the scales; lower parts dirty white or brownish, grey, or blackish.

Average length-I 5 inches.

Distribution-Transval ; Northwards to Tropical Africa.

2. Elapechis sundevalliI. Sundevall's Garter Snake. Kousband Slang. Synonyms-Elaps sunderwallii; Elapsoidea sundevallii.

Colour-Reddish brown above with yellow cross bands, the scales on which are edged with reddish-brown; upper lip, outer row of scales, and lower parts yellow.

Average length-I foot 6 inches.

Distribution-Griqualand; Basutoland; Natal.

3. Elapechis Decosteri. De Costa's Garter Snake. Kousband Slang. Synonym-Elapsoidea decosteri.

Colour-Dark grey above, each scale edged with black; outer row of scales and lower parts white.

Average length- $\mathrm{I}_{4}$ inches.

Distribution-Zululand; Vryheid District; Delagoa Bay; Portuguese East Africa.

\section{Genus HOMORELAPS.}

Two Species in Sonth Africa.

KEY TO THE SPECIES.

Ventrals $160-2 I 5 \quad \ldots \quad \ldots \quad \ldots \quad \ldots \quad \ldots \quad \ldots$ Homorelaps lacteus.

Ventrals $2 I 9-244 \quad \ldots \quad \ldots \quad \ldots \quad \ldots \quad \ldots \quad \ldots$ Homolaps dorsalis.

I. Homorelaps Lacteus. Southern Garter Snake; Kousband Slang.

Synonyms-Coluber lacteus: Cerastes lacteus; Elaps lacteus; Vipera lactea: Elaps hygea: Aspidelaps lacteus.

Colour-Colouration variable, but vertebral line constantly bright red, yellow, or orange, even if crossed by black annuli; head black, with yellow or orange markings, sometimes with two yellow dots close together behind the frontal shield.

A. Yellowish-white with more or less regular black bars or annuli; belly black, or with a continuous or interrupted black stripe.

B. As in the preceding, but ventrals uniform white.

C. Black, with small round yellow spots forming various markings; a series of large orange spots along the spine more or less confluent into a band : ventrals black at the base, yellow behind.

D. Black, each scale with a yellow dot; an orange or citrine vertebral stripe; ventrals black at the base, yellow behind.

Average length $-\mathrm{I}$ foot 4 inches.

Distribution-Both provinces of Cape Colony; Natal; Griqualand; Orange River Colony; Transvaal.

2. Homorelaps Dorsalis. Striped Garter Snake. Streep Kousband Slang.

Synonym-Elaps dorsalis: Pcecilophis dorsalis.

Colour-Black above with a yellow vertebral stripe extending to the tip of the snout; lower paris and three outer rows of scales white.

Average length-I foot.

Distribution-Eastern Province of Cape Colony ; Orange River Colony ; Vryheid District; Natal; Transvaal. 
PROTEROGLYPHA OR FRONT-FANGED SNAKES. I69

GENUS DENDRASPIS.

Two Species in South Africa.

KEY TO THE SPECIES.

Scales in 19 to 23 rows in the middle of the body ;

8 upper labials; upper anterior temporal

not longer than the lower .. .. . . Dendraspis angusticeps.

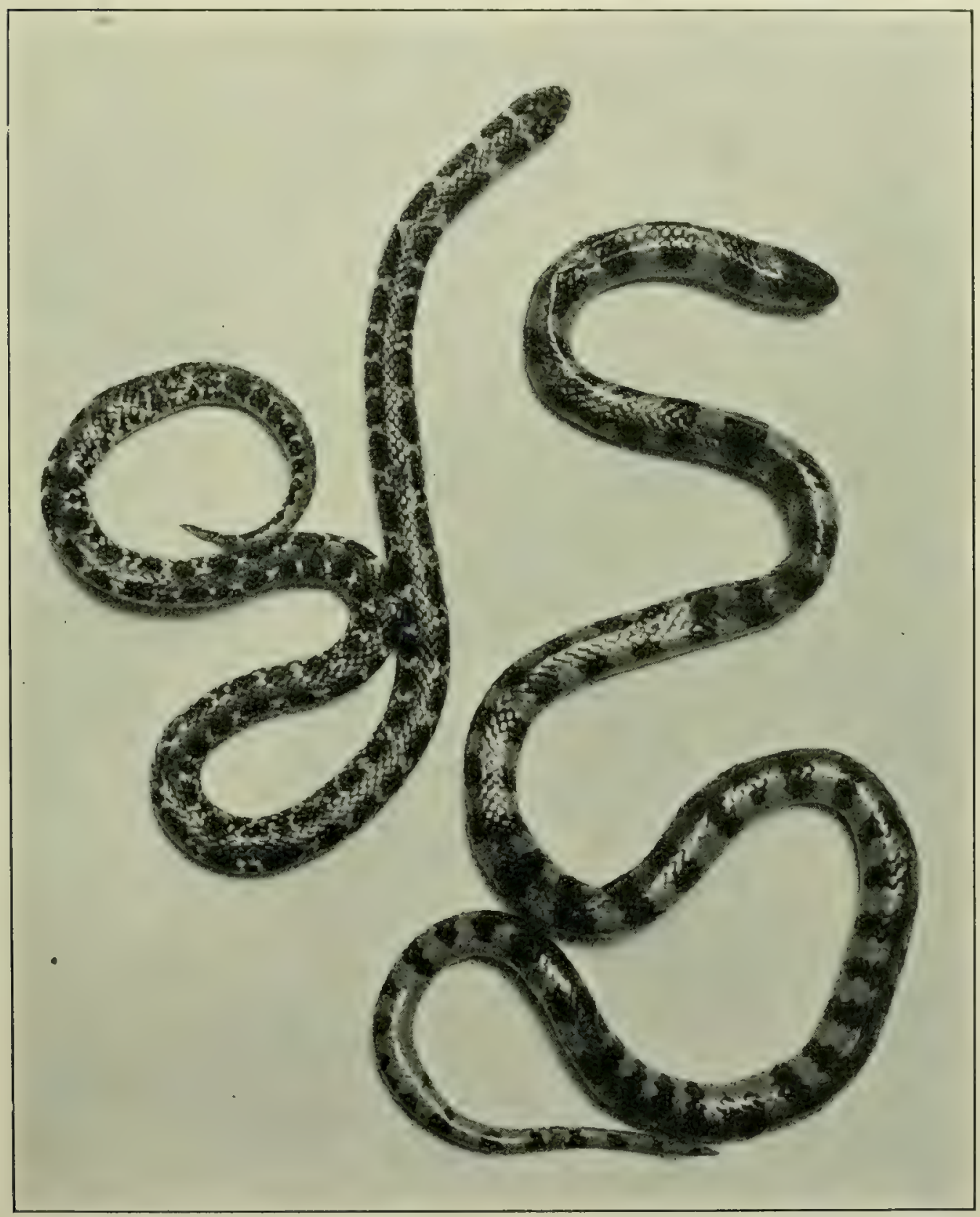

FIG. 72. - These are Southern Garter Snakes (Homorelaps lacteus). They vary more or less in their markings, but the orange or coral-red line down the middle of the lack is always present. Average length, one foot. 
Scales in 25 rows. 9 upper labials; upper anterior temporal twice as long as the lower .. $\quad . . \quad \ldots . \quad \ldots \quad \ldots \quad \ldots$ Dendraspis mamba.

I. Dendraspis angusticeps. Mamba or Tree Cobra.

Synonyms-Naja angusticeps; Chlorochis angusticeps; Dendraspis intermedius; Dinophis angusticeps.

Colour-Green, olive or blackish, uniform or some of the scales edged with black; yellowish or pale green beneath; caudal scales and shields not black-edged.

A. Uniform dark olive or blackish above. Yellowish-white beneath.

B. Uniform leaf-green above, shading into lighter green below. Some specimens are bright greenish-blue.

Average length-6 to 9 feet. Attains a length of 13 feet.

Distribution-Natal; Zululand; Transvaal; Southern Rhodesia ; East and Central Africa.

2. DeNDRAspis Mamba. Gough's Mamba.

Colour-Dark olive-green above, bluish-green below, skin between the scales very dark purple.

Distribution-Transvaal.

The Cape Cobra (Naia flava).

Also known as the Geel Slang, Bruin Slang, Spoeg Slang.

The Cape Cobra is common all over the Cape Colony. Farther north in Natal, Transvaal, and more northern parts of South Africa, the Banded or Egyptian Cobra, Black-necked Cobra, and Anchieta's Cobra take its place.

The Cape Cobra is universally feared, and well it miglıt be, for it is a highly venomous, bold and courageous snake. When molested it instantly faces its foe, with body reared and hood expanded. If tormented it works itself up into a furious rage, and will not hesitate to attack its aggressor. During the pairing season the male is particularly aggressive, and will boldly face and often chase any one intruding into its haunts. As a general rule, when molested, the Cobra will rear in a threatening manner, and, seizing its opportunity, glides off amongst the grass, undergrowth, or into crevices or holes. If chased it will always rear and face its enemy whenever he gets within a few yards of it.

A friend once ventured into a kloof in search of wild flowers. He was suddenly confronted by a large yellow variety of Cape Cobra. He lost his nerve and ran. The Cobra followed, and he, not being able to make much progress in the tangled bush, was overtaken and bitten. We saw him staggering towards the 
homestead like a drunken man. When we reached him he collapsed, and died an hour afterwards.

\section{DANGerous Reptiles.}

To be bitten by a Cobra is a common occurrence in South Africa, and many deaths result. The unshod and bare-legged natives are the principal sufferers. Cobras are frequently found in and about farmsteads. Many farm-houses and outbuildings are roofed with straw, the walls being made of "wattle and daub," viz. two rows or walls of twigs entwined or interlaced, with a space between. These are plastered over with mud. Cobras frequently take up their quarters in the thatch, in the hollow spaces in the walls, and down rat holes, and in the crevices of the stone walls of the cattle kraals. The abundance of rats and mice about farmsteads attract the Cobras.

\section{FAtAlities.}

Many instances are on record of Cobras actually getting into bed with the sleeper, attracted there by the warmth; and many are the cases of people being bitten in this way.

Two European children were recently bitten by a Cobra, both of whom died. It was a very sad case. They were spending their holidays with a relative in the country. One night a Cobra crept into their bed. One of the children evidently moved in his sleep, whereupon the Cobra instantly bit him on the face. The terrified boy sat up and screamed, and before his little brother could realize what had happened, he too was bitten. The uncle and aunt, hearing the cries, rushed to the room. One of the children, a sturdy, manly little fellow, recovering his presence of mind, cried to his relatives not to come into the room, but to get a light and a stick, for there was a snake inside. A candle and weapons were hastily secured, and there, right in the middle of the room, was a large Cobra, reared and ready to strike. Both the children died before morning.

Dogs and monkeys, if bitten by an adult Cape Cobra, will usually die within an hour. A Vervet Monkey which was bitten on the forearm died in seven minutes. Some venom injected 
direct into a vein killed another monkey instantly. The monkey was dead before the syringe needle could be withdrawn.

\section{Chasing a Cobra.}

One day I came across an adult Cobra in the bush. I followed it up through the tangled undergrowth, but every time I got within striking distance it veered round and showed fight. Finally I got in a blow, but it evidently only slightly wounded it, for it instantly swerved, and with extended hood made a quick dash at me. I aimed a wild random blow which missed, and next instant it was upon me. I felt a thud against my leather gaiter, and before it could strike again I smashed it. Examining my legging, I found the fangs had scored the leather, but had not penetrated it. The spot where it struck was bespattered with venom.

\section{A Terrifying Experience.}

Cobras frequently climb trees in search of birds' eggs and their young.

A friend, who, like myself, was studying native birds and accumulating data about the colour, sizes, etc., of their eggs, was out with me on an expedition. Spying a Sparrow Hawk's nest in the topmost branches of a great tree, he climbed up to see if there were eggs in it. Reaching the nest he peered over its edge, when, to his horror, a Cobra reared from the nest, and with a fierce hiss lunged at his face. In his endeavour to avoid the blow he lost his hold and came crashing down through the branches to the ground, and lay stumned and bleeding. However, he got off very lightly with a broken arm and a multitude of cuts and abrasions. For many nights afterwards he would start up in his sleep with a terrifying cry and a blanched face. The sudden apparition of the Cobra had evidently made a strons mental impression which was slow to wear off.

\section{Cobras vary in Colour.}

Cape Cobras vary considerably in colour; causing much -confusion in the public mind. Although so diverse in colouration 
they are all of the one species. In the Western Province of the Cape Colnny we find the black variety. In the Eastern Province four varieties occur, the two commonest being the yellow and the brown.

\section{VARIETY A.}

\section{Yellow Cobra. Geel Kapell.}

Bright yellow, sometimes tinged with reddish. In some of the individuals a few of the scales are rich umber brown, giving the reptile a speckled appearance. Some adult specimens which

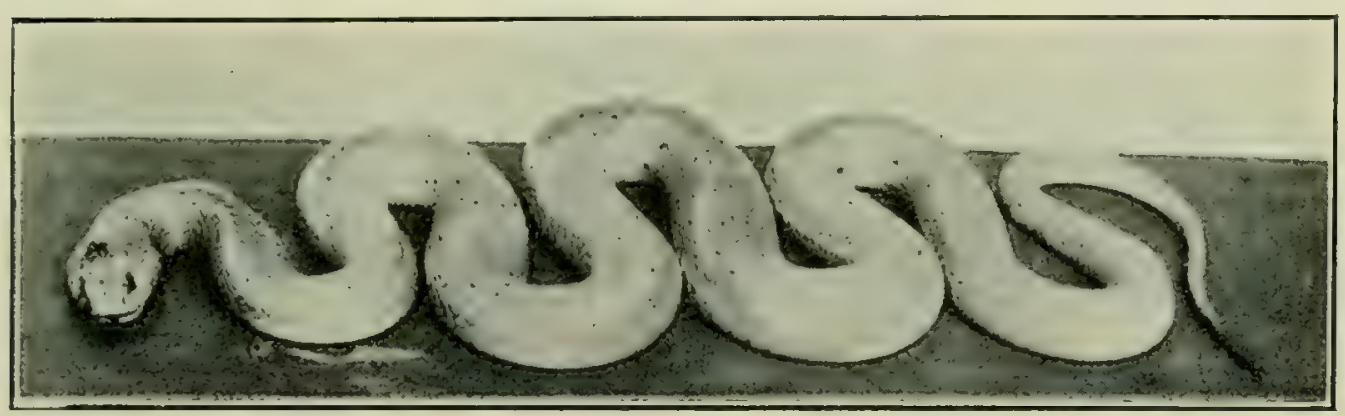

Fig. 73.-A Yellow Cape Cobra. (Photo by W. C. Scully.)

I have examined and measured, were over six feet in length, and bright yellow, without any darker markings.

In young specimens there is a rich shiny chestnut or umberbrown patch, sometimes divided, on the throat. This either becomes very indistinct or fades from view when the snake reaches maturity, although I have found if the scales be removed, it is still clearly visible beneath. When kept long in captivity the Yellow Cohra invariably becomes much darker, and more like the Brown variety. The eyes are reddish brown. An excellent illustration of a young yellow variety of cobra will be found in the Addenda.

\section{VARIETY B.}

Brown Cobra. Bruin Kapell.

Bright umber-brown, changing to duller brown. Some individuals are mottled with lighter tints of a gamboge-yellow colour. In captivity the colour usually fades to uniform reddish brown, and the shiny gloss is not so apparent. 


\section{VARIETY C.}

Light olive brown, with a yellowish tinge. Skin between the scales light yellow. A few odd scales a rich umber brown. (This variety is uncommon.)

\section{VARIETY D.}

\section{Black Cobra. Spuug Kapell.}

Shiny purplish black. The livid purplish tinge is most pronounced on the under parts. This variety possesses the power of "spitting" in a similar manner to the Ringhals, but in a much lesser degree. I have never personally seen them "spit," but the evidence seems to be so strong on the point that it is reasonable to conclude they do. I have tried many scores of times to get the two other varieties to "spit," but have never succeeded.

\section{VARIETY E.}

Dark mahogany with a blackish tinge. Speckled sparingly with yellow. (This variety is uncommon.)

\section{THE COBRA'S HOOD.}

The Cobra does not expand its hood by puffing out the skin with air, as most people believe. In the region of the neck, the ribs are elongated, lengthening to their maximum length, then gradually shortening, forming a sort of crescent on each side of the neck. The skin of the neck is loose and flabby. When the snake is at rest the ribs are depressed, the skin falls into folds, and no hood is visible. If the reptile be irritated or alarmed, the head and fore portion of the body is reared, the ribs in the neck-region are raised, which in turn elevate and spread the skin, and we see the "hood." It is evidently intended by Nature to aid the Cobra in frightening off its enemies. With hood expanded and bright glistening eyes and skin, rearing amongst the stubble and ready to strike, the Cobra is truly a terrifying sight.

The Cobras, which include the Ringhals, are the only South 


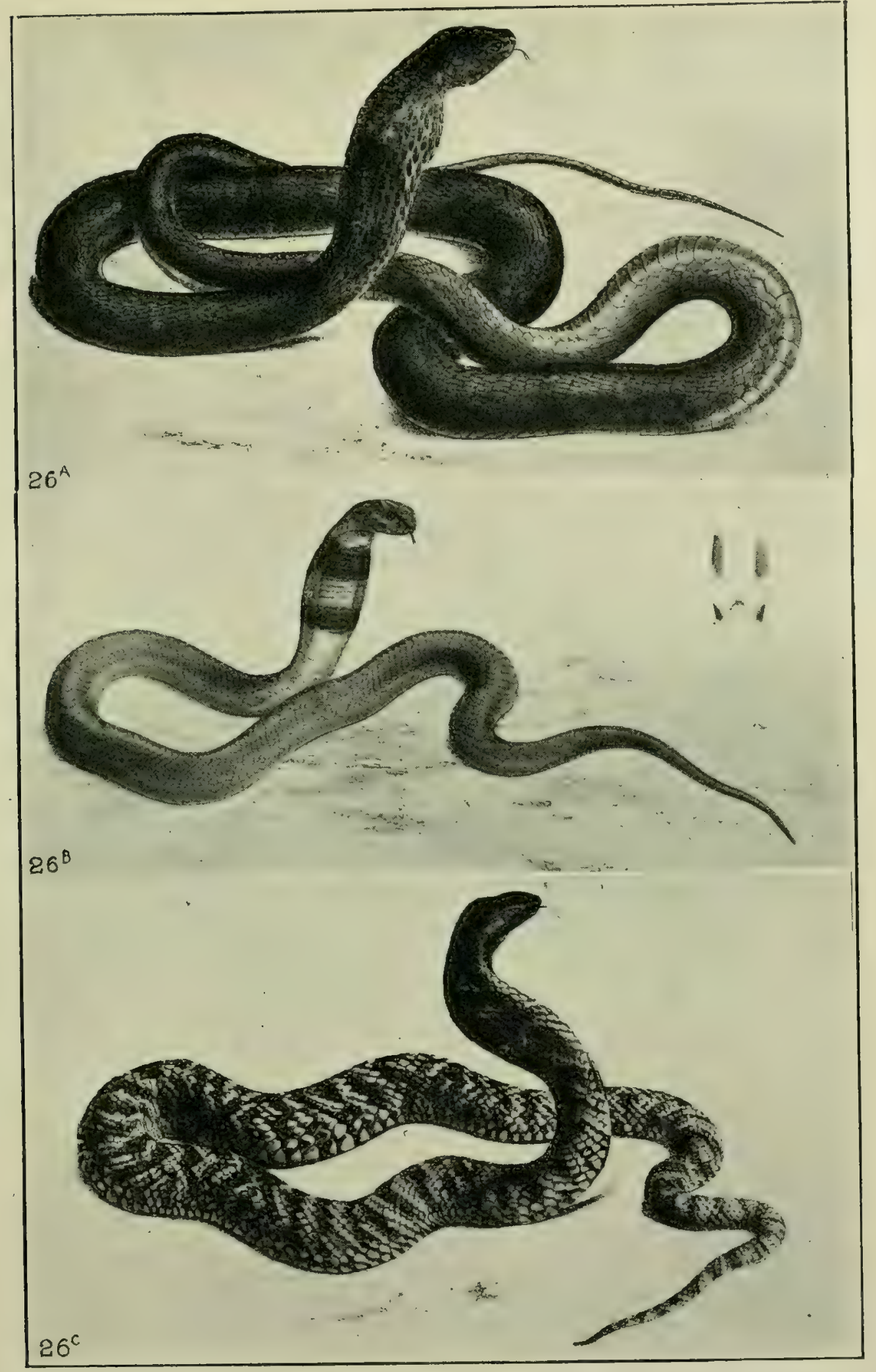

CAPE COBRAS AND RINGHALS. (After Smith.)

FIG. 74.-(26A) Black variety of Cape Cobra or Zwart Kapell (Naia flava). (26B) Young Cape Cobra showing dark brown throat patches which fade when snake reaches adult stage. Usually only one throat patch with rich umber colour is present. (26c) Stage. Ringhals or Spitting Snake (Sepedon hemachates). Black in colour, crossed Typical Ringhals or Spitting Snake (Sepedoni hemachates). Black in tossy purplish black. Eye black and very brilliant. Some specimens are black. 
African snakes which expand a "hood." If a snake is seen rearing the fore part of its body perpendicularly above the ground, and expanding the skin of its neck in the well-known manner of Cobras, you may be perfectly sure it is one of the Cobras, and that it is a very highly venomous serpent.

\section{The Poison Apparatus.}

The Cobra has strong poison fangs in the upper jaw-two on each side. These fangs are deeply grooved down their front

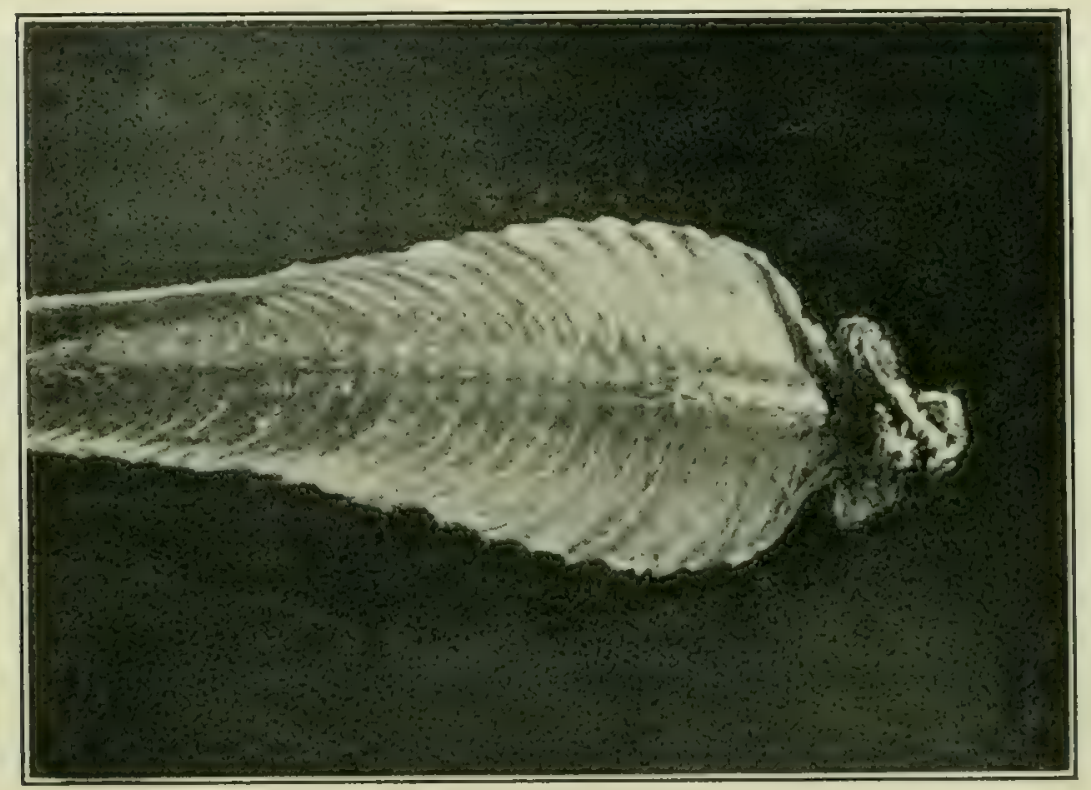

FIG. 75.-This picture shows the elongated ribs of the neck of a Cobra with the muscle attachments. By means of these long ribs and muscles the hood is spread. The head is on the right.

surface. In most individuals the sides of the channels meet and form hollow fangs. The grooves or channels are for the conveyance of the venom from the poison glands into the wounds made by the fangs. The bite and the compression and contraction of the poison glands is simultaneous.

The fangs of Cobras are set in front of the upper jaw, in a bone called the anterior maxillary. This bone is not very movable. On the contrary, with the Viper family of snakes it is mobile, and hinge-like in its movements. 


\section{Cobra and Mungoose Fight.}

Once whilst resting under some thick foliage one hot summer's day, and hearing a rustling noise, I peered carefully through the dense curtain of leaves and saw in the glade about ten yards distant from where I was, a Grey Mungoose (Herpestes caffer) in combat with a large Brown variety of cobra. The snake was erect, with hood expanded, keenly watching every movement of its enemy, and so quick was it that the Mungoose failed to get it at a disadvantage. Suddenly the wily Mungoose changed its tactics, and instead of making feints, it began circling round the Cobra with quick, springy movements. The snake turned round and round, facing its enemy bravely, but eventually it either got giddy or the muscles ceased to act, for it toppled over, and before it could recover, the Mungoose leapt upon it and crushed its head and neck between its sharp-toothed jaws. It then chewed off the head and ate it, and began to dine off the body.

\section{Billy, the MeErcat.}

I once had a tame meercat known to my friends as "Billy." This fearless little fellow would devour any snakes I threw to him. Several times I threw live snakes down in front of him, which he instantly pounced on and devoured. So quick were his movements he even overcame and killed a fair-sized Ringhals Cobra which I placed before him. Quick as lightning he sprang at it, seized it by the head, crushed its cranium between his jaws, and bit it severely along the vertebræ of the neck. Then he ate the head and a portion of the neck.

\section{CAnnibal Cobras.}

If the Mamba is lord of the arboreal realms, assuredly the Cobra reigns supreme over terra firma. He is ever ready for a fight. He fears no foe but man. Even man has good cause to be wary when tackling him. He will instantly face his enemy, ready to deliver a thrust with his channelled fangs, which, if driven home, leave behind them a fluid so potent that a drop will kill the strongest man. Swiftly and powerfully he 
I78 THE SNAKES OF SOUTH AFRICA.

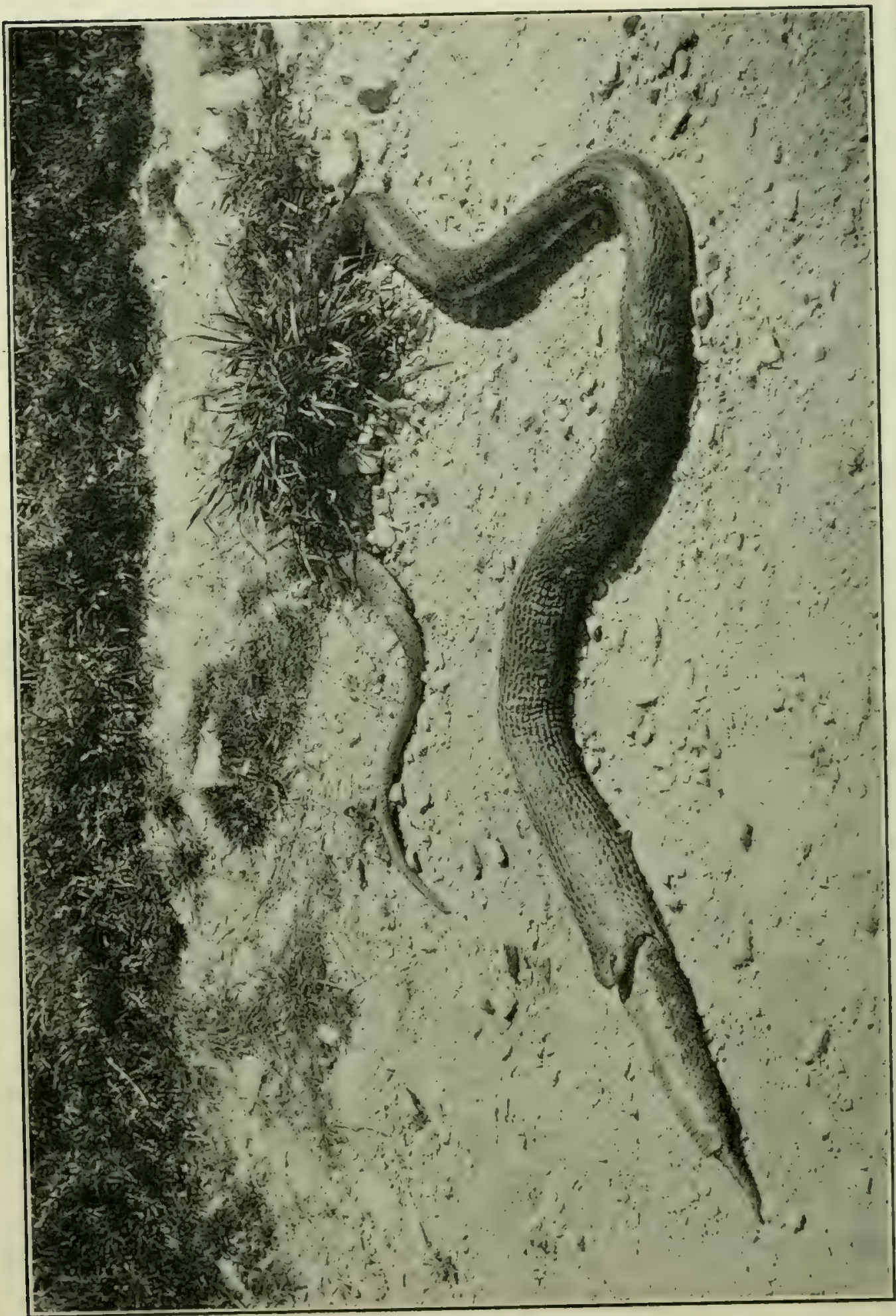

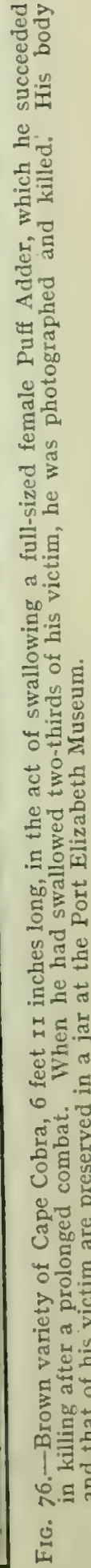


attacks and overcomes the cells in the nerve centres of the brain, causing rapid paralysis and death. True, the Nungoose, Muishond, and Meercat attack him at times, and succeed in overcoming and devouring him. He is never afraid of them. With a third of the anterior part of his body erect, he boldly and defiantly faces them and fights on till death overtakes him.

When on the prowl for provender, a hungry Cobra will attack and devour any snake he may. meet. So bold, fierce and strong is he, that he is able to overcome and swallow a full-grown Puff Adder, as seen in the illustration. Lying still as if dead, he keeps a sharp watch with his shiny black eyes upon the beaten track of a field rat or Vley Otomys. The rat, all unconscious of danger, trots along his usual road on his quest for food, when, without a second's warning, he receives a blow on the back. Instantly a stinging pain shoots through his network of nerves; he cries out, attempts to escape, but a deadly numbness grips him, and he is dead.

The bare-legged Kafir, wending his way along one of those well-known, single-file, native foot tracks across the bush-veld, his mind maybe full of the prospective delights of a beer drink and feast of meat at a neighbouring kraal where a wedding is in progress, feels a prick upon his calf, followed instantly by a sharp burning pain. With a hoarse yell he leaps into the air, glances back, sees a Cobra in menacing attitude reared in the grass adjacent to the path. A benumbing sense of terror seizes the man. He staggers off to the nearest kraal, and collapses in a more or less paralysed condition. If the Cobra has succeeded in delivering a full bite, then there is no hope for him. He is doomed. If not, and if his constitution is able to put up a successful fight against the paralysing power of the venom, he eventually recovers, and ever afterwards extols the virtues of some "cure" which the hastily summoned native medicine-man has given him to swallow, or applied to the bitten part.

When spring is advancing into summer, the Cobra joins his mate. The gravid female seeks out some suitable spot such as a crevice among the tangled roots of trees, the nest hole of a Starling or Kingfisher in a bank, a rat or mole hole in the ground, in the hollow interior parts of an old sod fence, under decaying vegetation, manure heaps, or in the thatch of houses. There she deposits her batch of eggs, and departs. In due time they 
are hatched out by the natural heat at some period during the autumn. The baby Cobras sally forth and scatter to take up the struggle for life all alone. A fierce struggle it is, too. He is beset and encompassed around by enemies. Creatures which would flee from an adult Cobra boldly attack and eat him up. Even his parents, if he subsequently crosses their path, know him not, and devour him. Snakes of other species attack and overpower him. Food, perchance, is scarce, and winter is fast approaching. If a certain amount of fat is not laid by in his interior, he knows untaught that the chills of winter will freeze his sluggish blood and destroy his life. He, perhaps, is successful in his hunting excursions, and, sleek and fat, he retires into the innermost corner of a crevice, hole, or under some decaying leaves, to sleep out the winter. Even here he is not safe. Big carnivorous beetles and rats find him out and devour him.

The Cobra is so active that he can often succeed in dodging stones aimed at him for some time without being struck. One day I bombarded a large Cobra with stones, and for several minutes did not succeed in striking him. With body reared, he faced me, and seemed to move his body just sufficiently to avoid the missile. A walking-stick was hurled at him, but instantly he dropped upon the ground, to be again up in an instant.

I watched a waggon-driver slashing at a Cobra with a long whip. He delivered blow after blow in a lateral direction, so that the end of the lash would catch the Cobra on the reared part of his body. However, for ten minutes or more that Cobra dodged the lash by rapidly dropping upon the ground and rearing again when the lash swept past him.

\section{A Cobra in a Schoolroom.}

One day recently, when a lady principal was in the micldle of a school lesson, she heard a slight rustling noise near her clbow. Glancing down, she was horrified to see the head and forepart of a yellow variety of Cape Cobra in the act of climbing up her chair. Vacating the chair with more haste than dignity, she joined the crowd of coloured school-children who were making for the door. The new's soon spread, and within half an hour an army of Malay's, Chinamen, and folk of every shade of colour, 
from white to ebony black, had gathered round the building, and were excitedly discussing the situation. Not one had the boldness to enter. The Cobra held the fort until a European arrived on the scene with a shotgun. Cautiously peering in at the open doorway, he observed the snake endeavouring to climb a partition. He entered the schoolroom and blew it to pieces with a charge of shot. The remains were brought to me for identification. The Cobra measured five feet eleven and a half inches.

The superstitious parents of the children refused to allow then to return to the school, declaring that the Cobra's mate was sure to be somewhere in hiding under the floor or elsewhere in the building, and that it would issue forth to avenge its mate. The school principal was in a dilemma. The School Board Secretary advised her to come to me. Sending a message to Mr. Williams, the snake catcher, I asked him to go along and search every part of the school. He did so, but found no widow Cobra or any other kind of snake. Instead, he discovered a horde of rats, which was strong circumstantial evidence there were no snakes inhabiting the cellars of the school. This inspection ie-assured the parents, who allowed their children to return.

\section{DeAth From Cobra Bite.}

A sad case resently occurred near Graaff Reinet of the death of the wife of a well-known farmer from the bite of a Cape Cobra She was walking in the vegetable garden, and happened to tread upon the tail of a Cobra, which instantly bit her on the ankle. Both of the fangs penetrated an artery, and the blood gushed out in two jets. In five minutes' time she was blind, and within ten ninutes was in a state of complete collapse. She sank and died within three-quarters of an hour. The lady did not die of loss of blood, for the bleeding was stopped after a few minutes. After death the whole body turned bluish-black. The Cobra was a large one, and doubtless a fairly large dose of venom had been injected. However, the artery being punctured by both fangs would have the effect of causing some of the venom to be carried out with the gush of blood; but a proportion of it would be swept along the blood current and reach the general circulation in a few moments, hence the rapid symptoms of poisoning. 


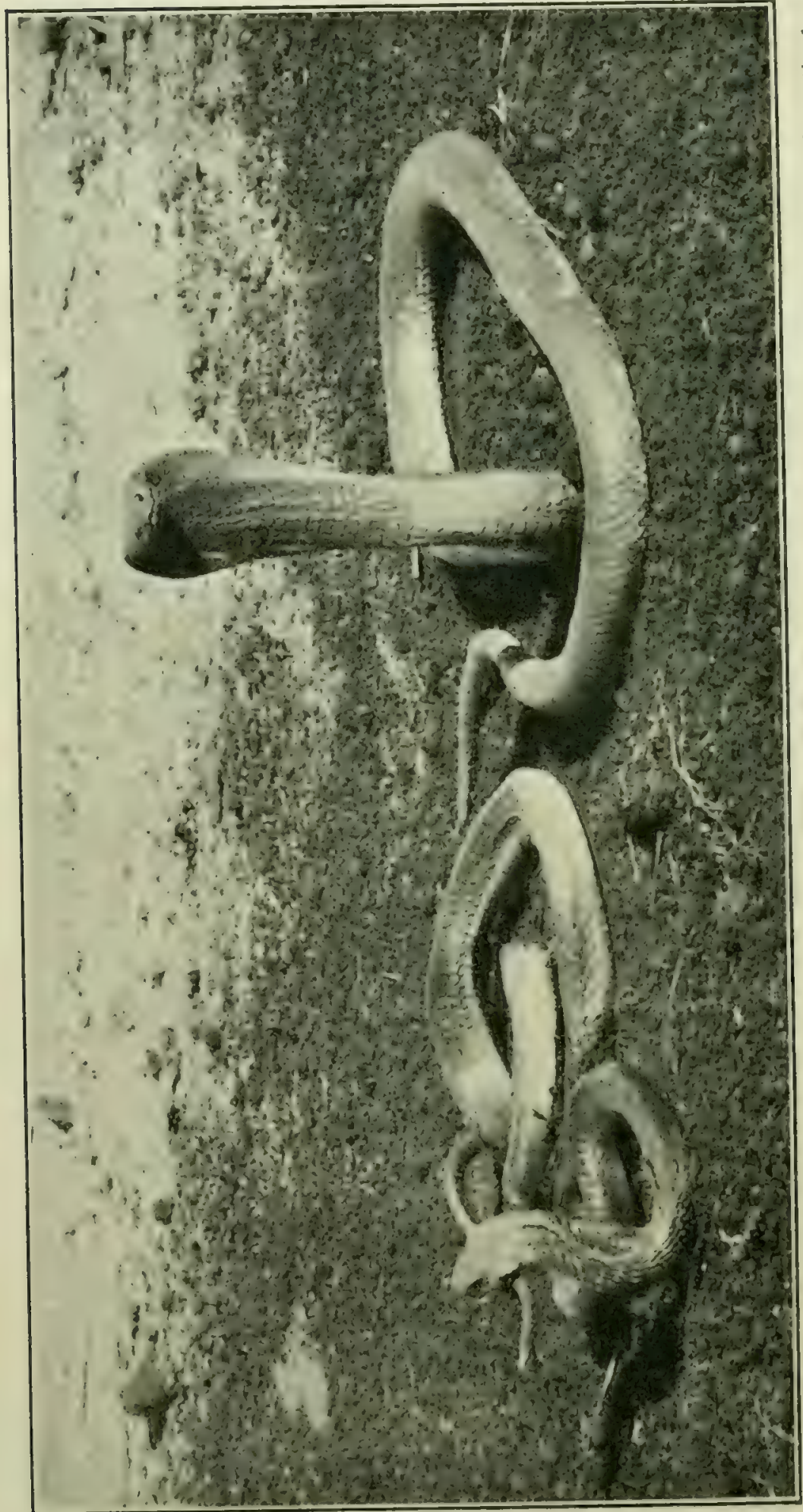




\section{THE RINGHALS COBRA, OR SPITTING SNAKES. I83}

\section{Three Cannibal Cobras.}

Four months ago I secured three fine Cape Cobras of the yellow variety. I put them in one of the snake cages at the Port Elizabeth Museum. I conceived the idea of keeping certain lizards, etc., alive; so, to make room for them, I collected the smaller live snakes, viz. the Night Adders, Schaapstekers, Garter Snakes, and several others, and put them along with the Cobras, as their cage was big and roomy. One day I happened to be passing, and saw a Yellow Cobra chasing a Spotted Schaapsteker. Presently it overtook and bit it. The Cobra held on firmly for some seconds, and was seen to push its fangs deep down into its victim's body. The Schaapsteker, within five minutes, began to grow limp. The Cobra, taking the head in its mouth, slowly swallowed the unfortunate Schaapsteker. Opening the door of the cage, I searched in the various corners and nooks for the other small snakes, and found that the Cobras had, within the past two weeks, swallowed about a dozen of them.

I was rather glad that the Cobras had started eating voluntarily, for these perverse reptiles often refuse food, and have to be fed artificially, which is dangerous to the feeders, and besides, it is not very satisfactory. The snakes do not thrive nearly so well as when they eat willingly. So, summoning Williams, I told him to scour the neighbourhood for small snakes. These we put into the Cobra cage. In due time they vanished from sight to undergo the process of digestion and assimilation inside one or other of those three cannibal Cobras. Up to the present they have eaten about thirty other snakes.

\section{The Ringhals Cobra, or Spitting Sinake. \\ (Sepedon hamachates.)}

The Ringhals Cohra, although belonging to the Cobra family, is a good deal different in its scale formation to its cousins of the genus Naia. The Ringhals is classified under the genus Sepedon, and is the only species in the world under that particular genus. The Ringhals Cobra is common throughout South Africa. It extends from Cape Colony as far north as Namaqualand and Damaraland. There are two varieties, the difference being 


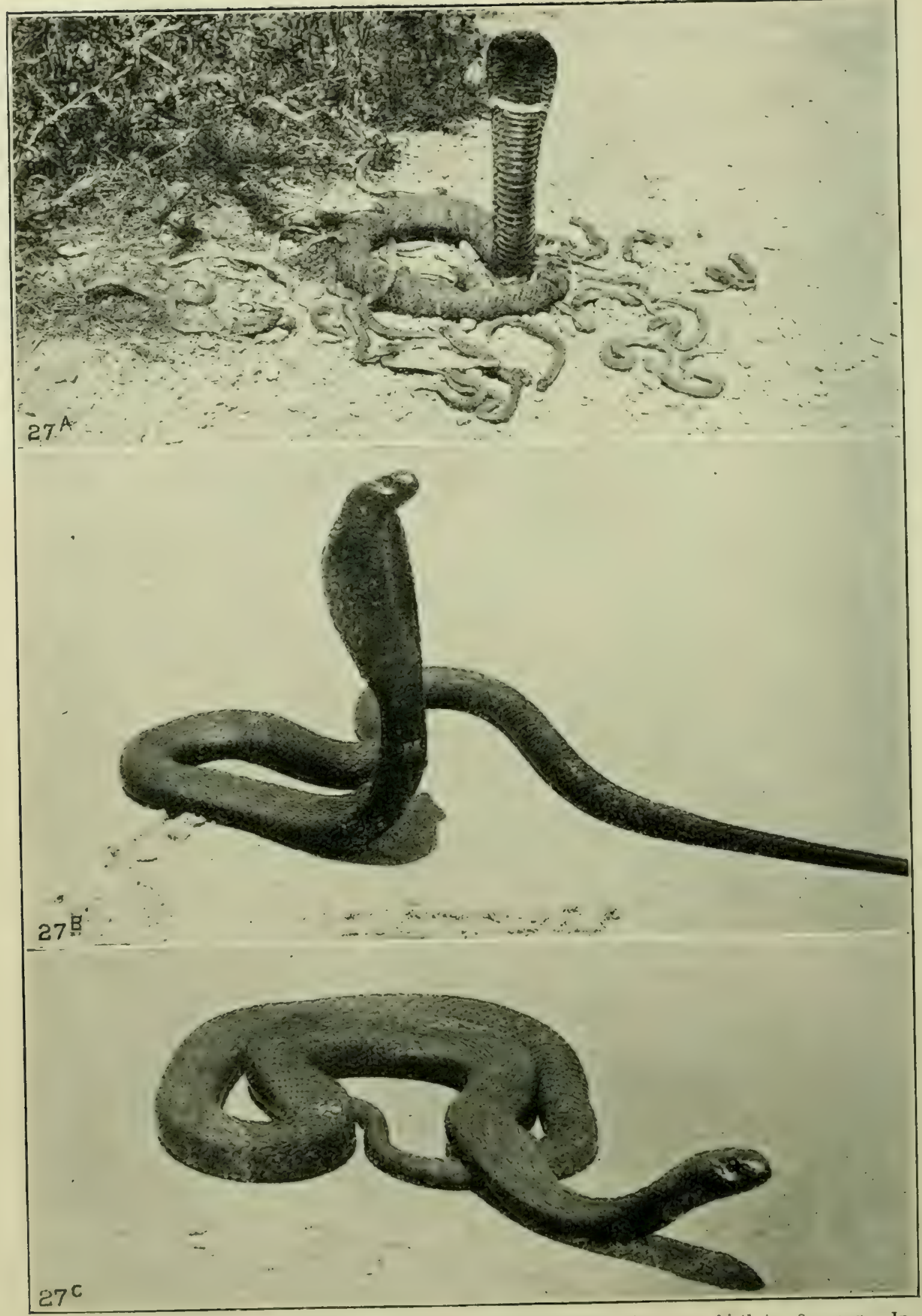

Fic. 78 - (27 A) A Ringhals or Spitting Snake, with hood expanded. She gave birth to 28 young. In colour they resembled the mother. Note white band across throat of parent. 'This is why these snakes are called Ringhals.

(27B) The large black Ringhals referred to in text. This snake is fierce and aggressive. It is alive in a snake cage at the Port Elizabeth Museum. 
in colouration only. The typical kind is black above with irregular cross markings of brown. The abdomen is livid black, with sometimes a few of the scales white. The throat is banded with one, sometimes two, white or yellowish bands across the neck-hence the name Ringhals, which is a Dutch word meaning Ring-neck. A peculiarity of the Ringhals is that the abdomen is very shiny, and the back dull, rough, and dingy. The other variety is termed the $Z$ wart Ringhals, which means Black Ringhals. The colouration is entirely black often without any trace of the white collar or transverse brown bands on the back. In some of the specimens a few odd shields on the abdomen are blotched with white. This black variety attains a greater length and thickness than the former.

I kept a large specimen under careful observation, and immediately it shed its old skin I removed it from its cage and examined it in a strong light, and counted over half a dozen of the wavy brown markings across its back. Within a week, however, these farled from view. This goes to show the typical Ringhals is the one with the wavy brown markings, and that the black one is a modification or variety, having lost its brown markings, due doubtless to climatic conditions.

\section{How one was CAPTURED}

Mr. Godlonton, at Fort Beaufort, Cape Colony, captured a magnificent specimen of the Black Ringhals. It measured four feet eleven inches. He came across it on his farm. It lay basking in the sun at the entrance to a hole, down which it glided on observing hirf. He summoned assistance, and after tracing the hole for over seven feet, he came across the snake about a foot from the surface of the ground. He pinned it down with a forked stick, and seizing it by the neck, between his finger and thumb, thrust it into a biscuit tin and despatched it alive to me.

It looked quite a giant in comparison with the other Ringhals in the cage. For the first couple of weeks it fiercely resented the visitors who peered at it through the plate glass of the cage. From time to time it would send a shower of venom at them, which bespattered the glass. For some time it was so fierce, the assistant was obliged to be exceedingly careful when opening the 
door to renew the water in the drinking vessel, for the snake would either dart at him, or send a shower of venom in the direction of his face.

\section{How we Photographed this Ringhals.}

"Fine specimen that Ringhals is, sir!" quoth my assistant. "Yes, rather. We must have a photograph of him before he loses his fire and energy." So I summoned my snake photographer and departed one fine morning for the adjacent veld with our Ringhals in a box.

The camera was rigged up. We donned our goggles, grasped each a stick with a fork at the end, and then released the snake. Out he darted, and on seeing us, with a ferocious series of hisses, he faced about and stood at bay. A magnificent sight he was, with his glittering black eyes, shiny under surface, and fully expanded hood. Then the fun began. That snake conceived a special hatred for the camera. Evidently he considered it to be a more formidable enemy than ourselves. He had often seen our species before and watched them scuttle off when he reared and hissed. The camera was an unknown foe. "I say, Ullyett! I want him taken as large as possible. No! that won't do. Get closer." "But, sir, won't he bite?" "Never you mind about that. We will keep him off." But we didn't. When Ulyett's head was hidden under the camera cloth, the snake suddenly dropped his hitherto raised head and body on to the ground, and made a charge at the photographer's legs. "Look out, Ullyett!" I yelled. Ullyett sprinted back without loss of time. Then the snake changed his tactics. Instead of making short rushes at us, he bespattered us with his renom, which he sent out in showers, finely sprayed. We did not mind, for our eyes were safely protected. Ullyett was rather nervous after such a narrow escape of being bitten. Every time he got his camera near enough, the snake made unpleasant demonstrations. I began to grow weary of it all. The troublesome thing was determined not to allow us to obtain a good photo of it. "Look here, Ullyett, I have an idea. Just focus your camera on this spot, and have it ready to take a snap shot." When the camera was 
focussed, we pinned down the snake, lifted him up by the neck and tail, and, holding him down on the focussed spot, suddenly released him and sprang away, the photographer at the same instant taking his photo just when the snake reared, as seen in the picture. Trying again, he reared as usual, but in an instant was down and on his way to Ullyett's legs, which were within four feet of him. Snapping the shutter, the photographer sprinted off. Luckily the picture turned out well, as you see it in the illustration.

That Ringhals, somehow, seemed bent upon doing some damage to the photographer. My assistant picked up the snake, and, holding it sect rely between finger and thumb, walked off with the intention of thrusting it into its box. Ullyett was walking behind and had removed his glasses, thinking there was no further occasion for them. Suddenly there was a fierce hiss, and Ullyett uttered an exclamation of alarm. He had received a dose of venom on his throat, chin, and mouth. Being so close the venom had not sprayed much, and luckily, none had entered his eyes. We wiped the poison off his face, and assured him he would come to no harm unless any portion of his skin happened to be scratched. He had shaved that morning, and his skin was tender, and he feared lest some might get absorbed; but fortunately it did not do so.

Many of the photographs in this volume have only been secured after considerable risk, expenditure of time, and waste of piles of photographic plates. It all seems so easy in theory, but it is not so in practice.

\section{Fierce ANd Aggressive.}

The Ringhals is undoubtedly as fierce, if not fiercer, than the Cobra. When disturbed he will stand with expanded hood ready to give battle-aye! and he will not hesitate to advance on and even pursue a man for a considerable distance. The prevalent belief that the Cobra and Ringhals can overtake a swift horse is nonsense. They cannot even overtake a man running at full speed.

One day I came across a Ringhals out on the veld. He 


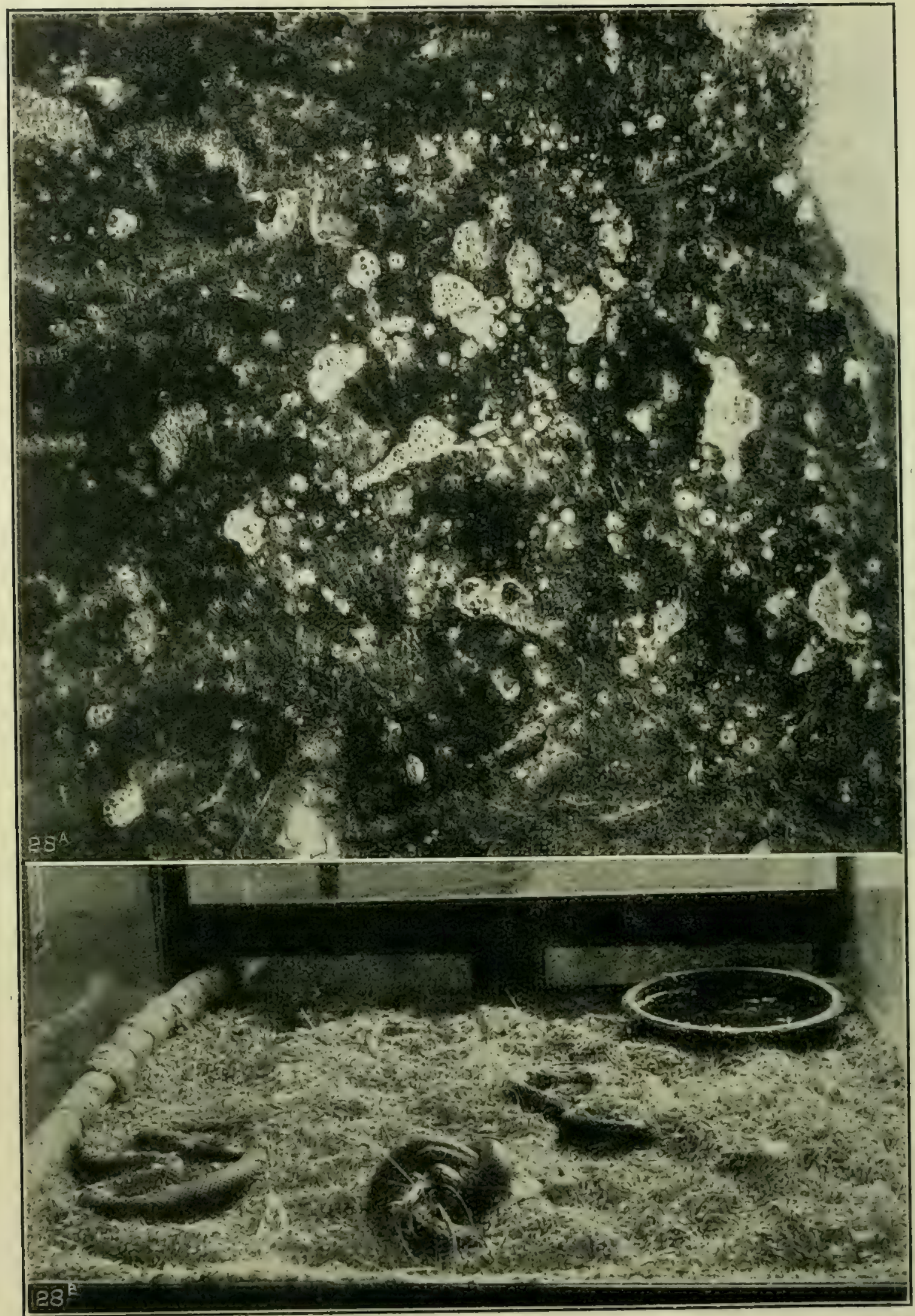

Fig. 79.- $-28 \mathrm{~A})$ This is a sheet of plate glass 4 by 4 feet, bespattered with venom spat by the Black Ringhals seen in p. 184 . For a week or two after capture, it sent a shower of venom at every visitor. Ringhals seen in p. 184 . For a week kill 100 men. (28B) The appearance of glass when free from There is enough venom on glass to kill The accumulation of verom on glass in top picture is so great venom. Note how transparent it is. The accumulation of verom on glass in top picture is so great. that, although several snakes are on the stump of a trec behind, nothing can be scen of them.
When actually looking at the glass, the contents can be dimly discerned. This snake cage is in the Port Elizabeth Muscum. 
instantly reared and remained on the defensive. I kept out of reach of any venom he might spit at me, and adopting the Mungoose plan, began circling around him. As I moved he turned and faced me, but after some time his brain grew dizzy with the rapid revolutions, and, observing him wobble, I shielded my face with my hat, rushed forward, and smashed him with a blow from a stout stick.

\section{How THEY SPIT,}

Various are the theories in regard to the nature of the fluid, and the manner in which it is ejected or " spat out " by the Ringhals, all of which are more or less incorrect. I have had exceptional opportunities for closely studying snakes and their habits, having kept live snakes in captivity for many years in Natal, and at the Port Elizabeth Museum.

I have scores of times purposely irritated our captive Ringhals snakes, and closely observed the manner in which they ejected the fluid. The fluid is not saliva, as generally supposed, but pure venom ejected in two streams from the poison fangs. When the snake struck the glass in the act of spitting (see Fig. 79), the venom was ejected from the fangs in two streams which ran down the glass, but if a couple or more feet away, the venom would be sprayed in a fine shower. This spraying of the venom is mainly accomplished by the expulsion of air from the lung sac, simultaneously with the ejection of the venom from the fangs. The air is expelled very forcibly, and is accompanied by a short but loud hiss.

\section{Rapid Secretion of Venom.}

The venom is evidently secreted at a very rapid rate when the snake is enraged, for I observed that a large Black Ringhals discharged five showers of venom within as many minutes. For the first day or two of a Ringhals' captivity, it spits at every one who approaches. A single snake covered a sheet of plate glass four feet by four feet all over with venom in a day.

The venom on exposure rapidly hardens, cracks irregularly, and assumes a straw-yellow colour. When first ejected it is colourless, and is of the consistency of glycerine. 


\section{EXPERIMENTS WITH THE VENOM.}

On many occasions I have scraped the ejected venom from the glass of the Ringhals' cage and injected it into animals. It, in every case, proved fatal to them, killing them off as rapidly as if the snake had bitten them. Venom which had been on the glass in a dry state for two years was found to be quite as poisonous as fresh venom. If the venom was kept moist for a few weeks it decomposed, and lost its toxic or poisonous properties.

\section{An Astonishing Fact.}

The Ringhals is well aware of its spitting power, and its value as a weapon of defence, which is proved by the intelligent way in which it goes about the business.

I have experimented many scores of times, and know for certain the Ringhals always directs its venom at the face of its foe. It is needless to go into detail as to all my methods to ascertain that this is a fact.

It seems wonderful that the snake should possess the instinctive knowledge that unless the fluid enters the eyes it is innocuous, for it has no effect whatsoever upon the unbroken skin. This spitting power has undoubtedly been evolved as an extra weapon of defence, the serpent's object being to blind its foe and then make its escape.

\section{The Effect upon the Eyfs.}

The first effect of the entry of the venom into the eyes is intense smarting, quickly followed by inflammation and partial or total blindness. If the eyes are promptly and efficiently treated, the inflammation subsides and sight is recovered. The eyes should be well washed with a weak solution of permanganate of potash, and olive, castor, or some other bland oil dropped in. If no water be obtainable, a grain or two of the potash should be mixed with saliva and rubbed into the eyes. Be very careful not to apply a strong solution of the potash, as it will seriously burn 
the delicate membranes of the eyes. Several cases have come under my observation of total and permanent blindness ensuing after the entry of the venom into the eyes. As a general rule, the sight is either wholly recovered or partially so. I have known several instances of Europeans and natives who partially recovered their sight, and after two or three months the cornea of the eye became opaque and the sight was permanently lost. I met a miserable-looking, blind old Hottentot one day, and on inquiry, his friends informed me that about twenty years ago a Ringhals spat in his eyes and blinded him. I noticed the corneas of his eyes were opaque.

It is quite a common occurrence for dogs to lose the sight of one or both eyes. When out in the veld one day, my pointer dog became suddenly rigid and " pointed." Advancing to investigate, a Ringhals reared up, lunged forward, and the next instant the dog was running about and crying out most piteously. I did not know in those days what to do in such emergencies, so I got the dog home as best I could, but the poor beast never recovered his sight.

On another occasion I lost a pointer dog, but this time a Ringhals bit him in the flank. He was dead in half an hour. The Ringhals died, too, for I shot his head off.

\section{Consequences of Being Bitten.}

If an adult Ringhals bite a man, and if the bite be full and complete, and no efficient antidotal measures be immediately taken, death is certain to take place, even if the person bitten be hale and healthy. A Ringhals is capable of injecting five to ten drops of venom at a time. One drop will kill a man.

The fangs of the Ringhals, like those of the Cape Cobra, are grooved and short, and if one of these reptiles bite a man through his trousers, a certain amount of the venom will probable be absorbed by the cloth. In other cases, only one fang inflicts a wound, or the fangs may barely scratch the skin. In these instances recovery is very probable, even if no preventive measures be taken. Many worthless substances obtain a bogus reputation as antidotes in consequence. 


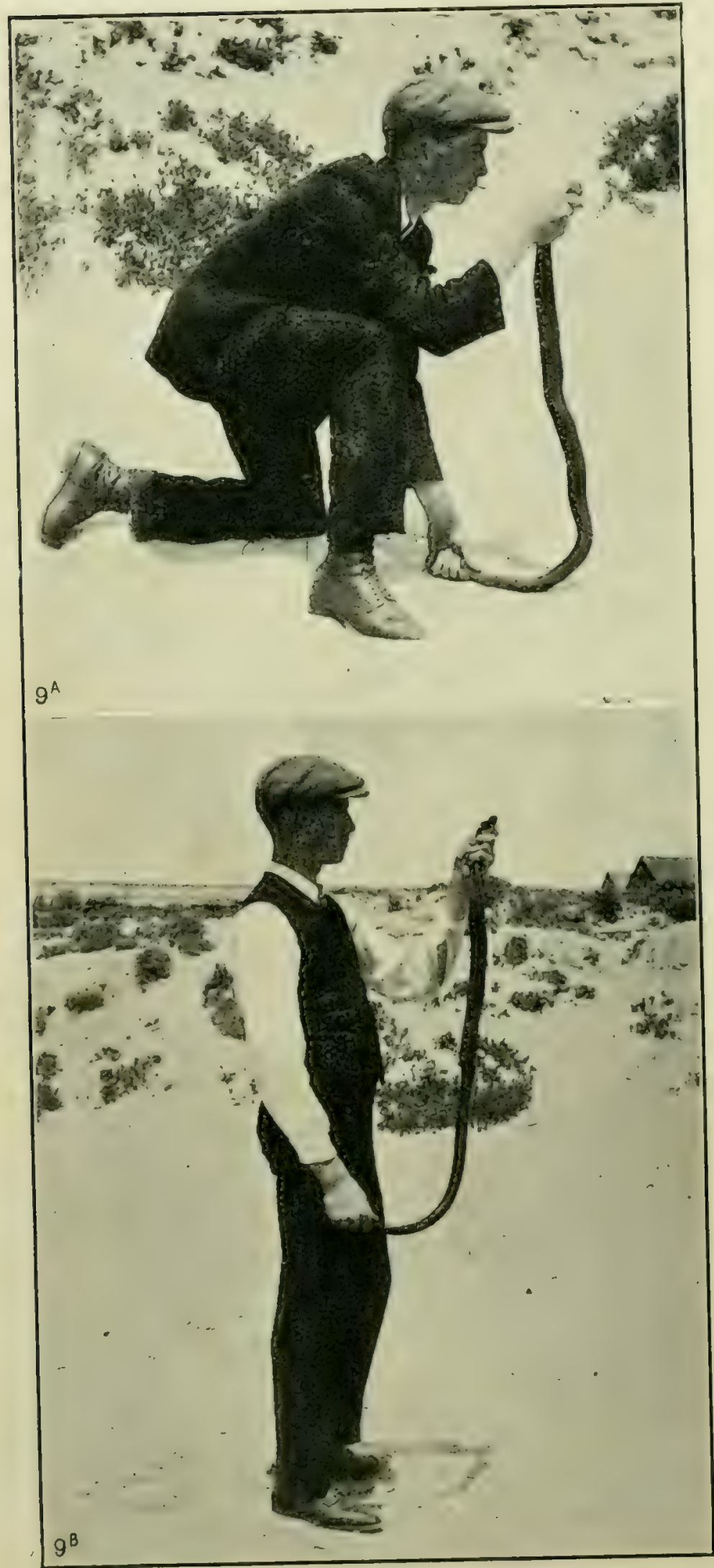

Fig. 80.-(9A) If you want to capture a venomous snake alive, and if it be too active to be noosed, then pin it down by pressing a forked stick on the back of its neck. Advance carefully, sliding your hand down the stick until you reach the reptile. Seize it firmly by the throat between your finger and thumb, as seen here. With the other hand grasp its tail, to prevent its coiling round the arm. It is dangerous to allow a venomous snake to do this, for if it should manage to jerk its head free, it will bite the hand or arm, perhaps many. times, before it can be cast away. The second picture $(9 \mathrm{~B})$ shows more clearly how to grasp a snake. When held in this manner, it is quite powerless. In this instance the snake is a Black variety of Ringhals, 5 feet in length, which had just been captured. A bite from this reptile would be fatal within a very short space of time. It is now alive in the Port Eliza beth Museum. In no case do we remove the fangs of the snakes. When we require fangs for any special purpose, we extract them. The business is a dangerous one, even when great care is exercised. Snipping fangs out in a rough manner with a pair of scissors usually results in injury to the mouth and jaw, which induces abscesses, and the snake languishes and dies. 


\section{A Ringhals Gives Birth to Young.}

The Ringhals gives birth to young, which are of the same colour as the adult, viz. black with wavy brown cross-bands. One in the Port Elizabeth Museum gave birth to as many as twenty-eight. Immediately after being born, the young, if irritated, rear, expand their hoods, and attempt to bite. Their poison glands are active, and capable of secreting venom. The bite of a baby Ringhals two hours after birth will kill a fowl.

The number of young given birth to by a large female Ringhals varies from about thirty to over sixty. Sixty-three is the largest number I have known.

\section{A Ringhals Feigns Death.}

Ringhals are the only snakes I know which actually feign death. I have killed, captured, and kept in captivity nearly all the other South African snakes, but have never seen any attempt to feign death in this way, except with this species of snake. That the Ringhals does so I am certain. Mr. Williams, of Boomslang fame, captured an adult Ringhals. When handling it, the snake suddenly became limp. It was placed on the ground, and immediately turned over and lay on its back. We moved off and hid. Presently it turned over on its abdomen, cautiously raised its head, looked round, and then began moving off. We captured it, and again it feigned death. We presently placed it on the ground upon its back, and once more secreted ourselves. After the lapse of five or ten minutes, the snake again showed signs of life, turned over, looked around and then endeavoured to escape. This clever ruse, however, is not usual with them. I have observed it only occasionally. As a rule, the Ringhals will fight bitterly to the last, and in captivity he is ever ready to deal a deadly blow. A series of photographs of a Ringhals simulating death are included in the Addenda at the end of the book.

A medical correspondent writes me as follows-

"In a fatal case of Ringhals' bite, where the patient could not swallow, I used whisky subcutaneously (under the skin), which only rallied the insensible patient's pulse for a short time; but hypodermic injections of one-tenth grain doses of strychnine had a better and more lasting effect, as he seemed on the point of recovering consciousness. After twenty-eight hours' treatment, 
and thirty-one hours after the bite, paralytic congestion of the lungs supervened, and carried him off in an hour, to the surprise of the assembled English, Dutch, Kafir, and Hottentot bystanders, who all averred that the Ringhals was not poisonous. I had no serum, otherwise I might have saved the man."

\section{The Deadly Mamba.}

\section{(Dendraspis angusticeps.)}

Imamba Eminyama or Black Mamba: Imamba Eluhlaza or Green Mamba (Zulu).

In Natal the most dreaded of all snakes is the Black Mamba, and a report of one being in the neighbourhood sends a thrill of fear through people living in the vicinity. And well it may, for during the pairing season these snakes are very aggressive, and will at times boldly attack any one courageous enough to venture into their haunts. They often prowl around the habitations of man, drawn thither by the presence of chickens, rats, and mice. If attacked they will show fight, and so quick are their movements that the aggressor must have all his wits about him and be well armed, else the chances are he will lose his life.

\section{Black and Green Mambas.}

There are two varieties of the Mamba. One is vivid leafgreen, the other is olive or brownish-black. However, these shades vary somewhat. I noticed those procured from the thick tangled woodlands in the moist valleys were bright leaf-green above, with a paler shade of green, or yellowish-green below. On the contrary, I noticed the Green Mambas, which frequented localities more exposed to sunlight, were of a darker bluish tint. A picture from the photo of the skull of a Green Mamba which I killed after keeping it alive for a couple of months, is shown elsewhere in this volume. The characteristic Mamba fangs are clearly seen.

There is no anatomical difference between the two varieties. The Green Mamba is often confounded by amateur naturalists with the green variety of the Boomslang (Dispholidus typus) or the Eastern Green Tree Snake (Chlorophis matalensis). I have 


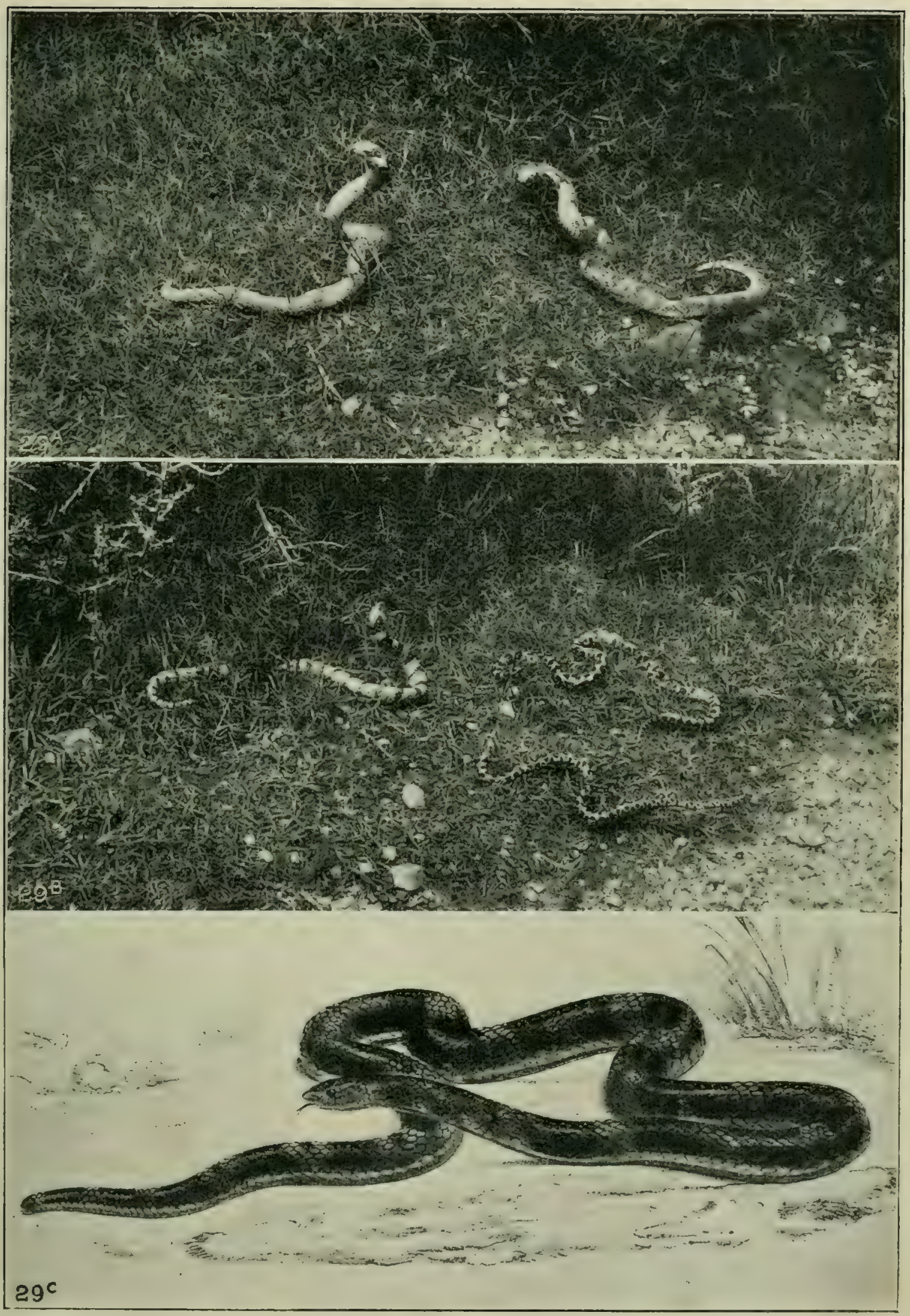

FIG. 8r.-(29A) Shield Snake (Aspidelaps scutatus). (29B) Larger snake on left is the Coral Snake or Koraal Slang (Aspidelaps lubricus). The smaller specimens are Southern Garter Snakes or Streep Kousband Slang (Homorelaps lacteus).

(29c) Sundevall's Garter Snake (Elapechis sundevallii). See list of Elapinæ snakes. 
frequently kept Green Mambas in captivity for the purpose of studying their habits. They are at first exceedingly active, and evince a disposition to bite if approached. However, they soon lose all spirit, and will allow themselves to be freely handled without showing any alarm. Those I kept in captivity were bright grass-green at first, but gradually darkened in colour. I was unable to keep them alive long enough to ascertain if they would eventually have changed to olive-brown or blackish. The existence of a green variety of Mamba is either doubted or positively denied by most Colonists. There is no doubt at all of its existence. I have examined many. Their poison fangs, other teeth and scale formation were similar to these distinguishing characters in the Black Mamba.

I have never met with the green variety of Mamba anywhere but the coastal districts of Natal in the dense forests. In the uplands of Natal and Zululand I have only seen the Black variety.

A controversy has been, and is, waged as to whether the Green Mamba remains green all its life, or gradually darkens in colour with age. The so-called Black Mamba is usually oliveblack in colour, varying in its degrees of intensity. Some specimens are uniformly dark olive or olive-black, others have the tips of the scales edged with black. Green Mambas of all lengths up to eight and nine feet have been frequently observed.

On the contrary, Black Mambas have been killed which measured thirteen feet from nose to tip of tail. It is almost a daily occurrence for Black Mambas, averaging eight to nine feet in length, to be killed in Natal, Zululand, and Transvaal.

Green Mambas are always found in the forests, clumps of tangled creeper-covered bush, and wooded valleys. The Black Mamba is often found in more open situations, and wanders far afield, and even penetrates the dwellings of man. It is quite a common occurrence for Black Mambas to be found in the thatch of old farm buildings, or amongst the refuse near by, drawn there by the presence of rats and mice. I have several times seen and killed Black Mambas in trees on the outskirts of the forests, or on branches overhanging beaten tracks, where they lie watching for rodents and other prey, but I found them more abundantly on the ground basking in the sun on the bare sloping sides of streams and dongas. On being alarmed, they rapidly glided off to a hole, into which they vanished. 
Their habits vary according to the nature of the country. In those parts of Natal, Zululand, and Transvaal which are covered with forests, and where there is an abundance of food, the Black Mamba rarely leaves the precincts of his leafy home, except for an occasional terrestrial hunting excursion. In sparsely-wooded districts, or where the bush grows in isolated clumps, the Black Mamba scours the neighbourhood for food. It is at these times he is usually observed, for in his retreat amongst the branches of thick-foliaged trees, it requires a keen and practised eye to detect him. In these situations his hidingplace has frequently been revealed to me by the excited chattering of forest birds, intent upon scolding and intimidating him, with a view of getting him to remove his dangerous person from the neighbourhood of their nests. It has not yet been satisfactorily ascertained what shade of colour the young of the green variety of Mamba produces. If the black and the green varieties pair indiscriminately, then it is reasonable to assume the young would vary in colouration, some being dark and others green. However, it has not, to my knowledge, been conclusively shown that the Black Mamba pairs with the Green Mamba.

Mr. W. E. Jones, who collects Mamba venom for research purposes, has frequently seen young Black Mambas from eighteen inches to two feet in length. He says they are innocent, inoffensive little creatures, with a fine "bloom" on their tender jet black skins. At this time of life they do not seem to realize danger, at least, from the human animal, for they permit one to inspect them closely while they lie along a branch intently alert. Doubtless they are prompted by the instinct which impels them to lie immovable with the object of escaping detection.

A young Black Mamba, eighteen inches long, possesses venom sufficiently strong to kill a large rat in an hour.

For the first year they grow rapidly, attaining a length of close upon six feet.

Mr. Jones informs me he has killed Mambas containing eggs in all stages of growth, from the size of a pin's head to an inch and a half in length. The latter size do not number more than a dozen or fourteen. The eggs at this stage show on one side a black patch which is the embryo in its first stage of fœtal development.

Mr. Jones has counted over sixty eggs, large and small, in a 
single snake. Mambas are very sociable, several males and females being frequently found inhabiting the same hollow in the trunk of a tree, a crevice among boulders, or a hole in a bank. Ir. Jones tells me he has found as many as half a dozen pairs inhabiting the same hole. He says they have no objection to residing beside the true Cobras, as he has often found Black Nambas and Cobras (Naia nigricollis) sharing the same retreat.

\section{How and Why they Change Colour-A Theory.}

The female Mamba lays its eggs in the dense bush, where the young, when hatched, will have fewer natural enemies than if in more open localities. The young take to the trees, and would, most likely, haunt the woodlands until nearly adult, when the struggle for existence becoming keener, they or many of them, would wander further afield for food, which had hitherto been chicfly birds, their young and eggs, chameleons and other tree lizards. On leaving the dim, moist, and shady forest, and venturing out into the open country, the strong actinic rays of light from the sun would very soon cause the vivid green pigment of the skin to assume an olive tint, which would subsequently darken and become the characteristic colour of the Black Mamba. In Mamba infested forests in Zululand where Black Mambas abound, there are many open bare spaces upon which Black Mambas bask in the hot sun. This habit of lying exposed to the strong rays of sunlight might have been a contributing cause to the determination of their colour.

Green, especially the more vivid shades, is rapidly acted upon by strong white light. The fresh skin of a Green Mamba, if placed in a strong light, will rapidly change to blue or olive, then to olive-black. If dried in a dark place, rolled up and packed away, it will retain its green colour.

There are males and females amongst the green and black varicties of Mambas. Eggs have been found in both varietics.

The question of colouration in snakes is a very puzzling one. We find Mole Snakes (Pscudaspis cana) of several colours. Some are uniform shiny black, others are reddish-brown, brownishblack, or brown mottled and waved with black, and sometimes spotted and lined with white.

The Boomslang or Tree Snake (Dispholidus typus) also differs 
HOW AND WHY THEY CHANGE COLOUR. I99 considerably in colouration, some specimens are uniform dull red

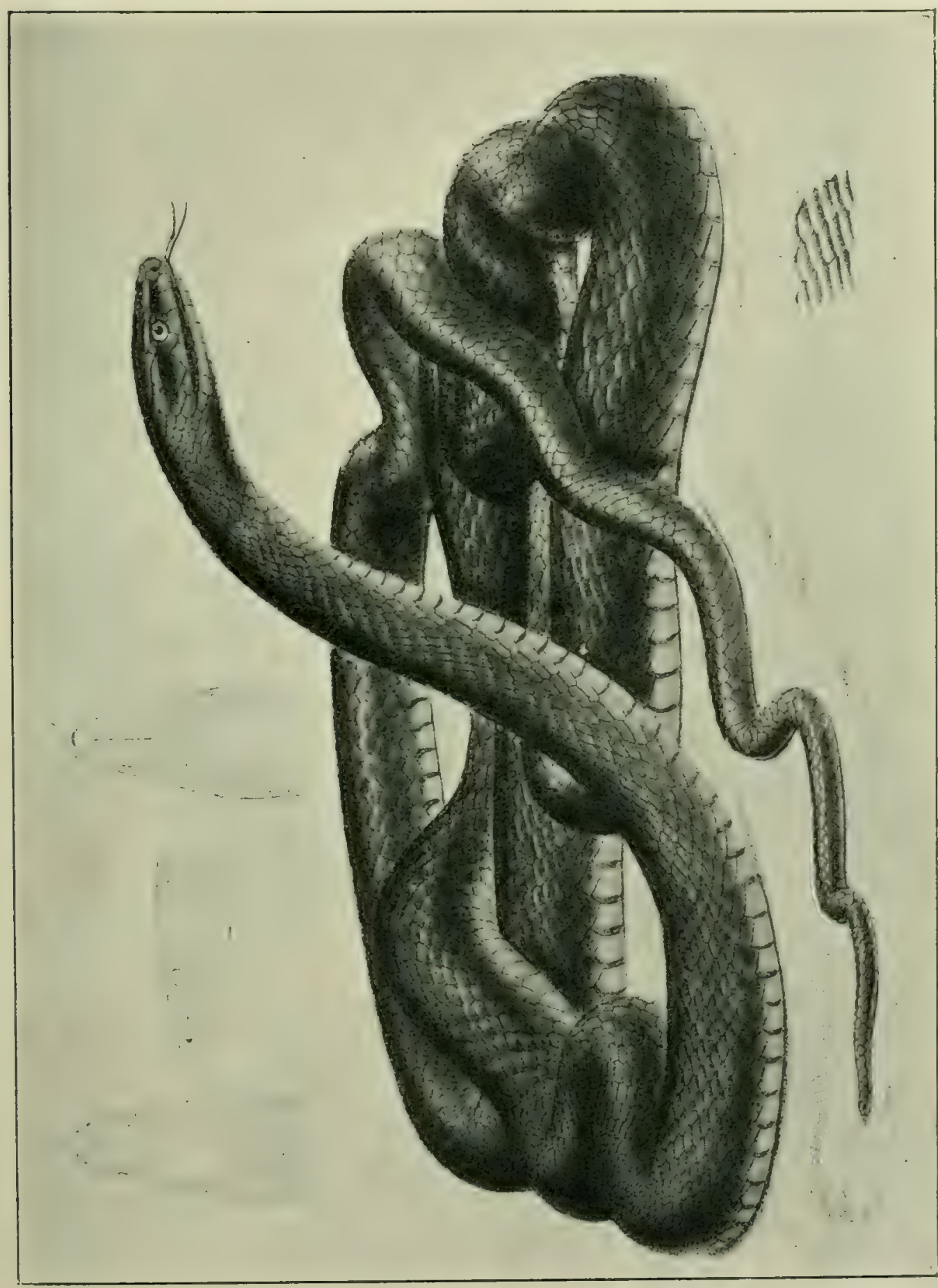

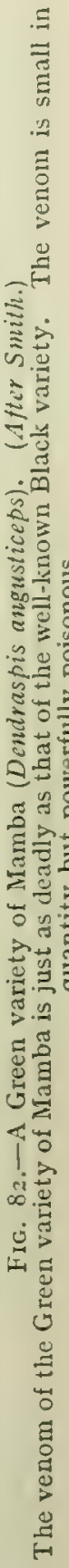

or purplish-brown. Others are yellowish-green streaked laterally with black. Others again, are uniform green. The degrees of 
light and shade, climate, colouration of the surroundings, and nature of the diet, seem the most likely factors in determining this variety in colour.

\section{A Difficult Probiem.}

The diversity of opinion is very great as to whether the Green Mamba changes colour when it attains the full adult stage. Many colonists assert most positively that the Green Mamba has never been known to attain a length over nine feet, and that no Black Mamba has ever been seen of a lesser length than eight feet. Some say the green variety changes colour, others assert the contrary, while others claim to have scen and killed young specimens of both varieties. However, I usually found on inquiry that most of the opinions were put forth without any actual knowledge. Other persons confused different species of snakes with the Mamba.

A well-known gentleman living at Stamford Hill, Durban, writes to me as follows: "Mambas are generally found amongst roots and rubbish, especially the exposed roots of the bamboos, which have been grubbed round and left after having been cut down. Those I have seen have been from eighteen inches upwards, and when disturbed will attack at once. They make straight for you."

Matthew Bedlington, Esq., of the Berea, Durban, says: "Some eighteen months ago I saw a young Black Mamba about five inches in length. Colour glossy black, eyes disproportionately large, and very glittering. Again, only a few months ago, I killed a young Black Mamba, length seven inches. About the same time two Black Mambas were killed, length eight feet each. I have not seen or heard of a Green Mamba exceeding eight feet, while Black Mambas of twelve feet and upwards are common."

The late Mr. C - told me that he was once out shooting attended by a Kafir, when the latter, who happened to be some distance in front, ran back shouting "Mamba, Baas!" and Mr. $\mathrm{C}$ - saw the snake chasing the native, but, owing to the man's position, he was unable to shoot. The Mamba reared up and struck the Kafir at the back of his neck, and he shortly afterwards died. I merely mention this incident as proof of the statement that a Black Mamba will chase a person." (The 
gentleman referred to was a prominent citizen of Pinetown, Natal.)

Mr. W. A. Lutman, of Durban, writes: "I have had considerable experience with Mambas in my various shooting expeditions, being bitten on one occasion by a Green Mamba, and on several occasions I have killed Black Mambas under six feet long. It is quite true that the Green Mamba when aged, turns colour, but not anything like the colour of the Black Mamba. The colour is something like stcel blue, such as is seen on clock springs, turning, as the snake gets older, to dark navy blue, but only along the back, the sides retaining sufficient green to distinguish the snake. The natives assert that both the Black and the Green Mamba, on attaining a certain age, develop a crest of feathers on their heads. For this I cannot vouch. I have shot both green and black; the last Green Mamba that I shot measured nine feet two inches, and was just turning steel-blue at the back of its neck; no sign of feathers. The last Black Mamba I shot measured seven feet four inches, and was, I believe, laying, or had already laid eggs, because it chased me, and it was only by a lucky shot that I was prevented from being bitten."

Mr. H. W. Bell-Marley, of Durban, who is a keen observer, and who has had much experience of Mambas, says: "The first signs of this snake losing his green coat is between eight and nine feet, when, instead of his being brown, he is of a greenish-brown colour, which soon changes as he ages to black. I think when he is eleven feet in length he is what we might term an adult, or at his largest dimensions."

H. W. James, Esq., of Zwelle Estate, Verulam, Natal, says : "I have lived for many years in this part of Natal, which is fully supplied with Mambas. My parents have also resided here since the early sixtics. I can certainly state, both from hearsay and also from my own experience, that Mambas of the green variety grow to a large size, and I have myself shot one over nine feet in length, and my parents killed one in the early days which, when measured, proved to be fifteen feet long. As regards Black Mambas, a few years ago I found a newly-hatched lot of just one dozen, and as lately as January of this year (I9IO), when cutting cane, killed one nine feet long, and a few minutes later, within a yard or two, killed a young one of about two feet long." 


\section{A District Native Commissioner's Evidence.}

John L. Knight, Esq., District Native Commissioner, District No. I, Natal, writes me the following interesting and seemingly convincing letter: "The individual habits and characteristics of the Black and Green varieties of Mambas are so distinct, numerous, and marked, as to leave no manner of doubt in my mind whether the Green Mamba ever changes and becomes a Black Mamba. The Green Mamba spends the most of its life in the boughs of trees, and I cannot call to mind ever having seen one on the ground, until killed. On the other hand, I have never seen a Black Mamba in a tree.

"I have probably killed, or seen killed, as many of each variety as any person in South Africa, having lived in "Mamba country' practically all my life. I have killed, or seen killed, Black Mambas measuring about eighteen inches in length up to fully twelve feet, and the only difference in colour is that the fullgrown creature in colour is slightly deeper black.

" On the other hand, I have had the same experiences with Green Mambas, the latter, however, never reaching so great a length as the Black - say not more than eight feet to nine feet. In this case also the only difference in the colour being that the larger ones are a slightly deeper green than the young ones.

"When both black and green have recently sloughed, their colour is brighter, and approximates nearer to the young of cach variety. I have seen and had many cases of Mamba bite by both varieties come under my notice-the bitten consisting for the most part of natives, with a few Europeans, and also animals, such as horses and cattle. When the bite has been by the Black Namba the result is almost invariably fatal. When by the Green Mamba, it is seldom, if ever, fatal. There is a somewhat mythical snake in Natal and Zululand, known to the natives as Indhlonhlo, said to have a feather in its head. Europeans believe this to be only a very old Black Mamba, whose head has become tinted with a grayish powdery pigment, which, at a distance gives the optical delusion of a feather."

A Durban lady, whose father was an enthusiastic amateur naturalist, and whose special hobby was the collection of specimens of snakes preserved in spirit, and who naturally was well acquainted 
with the different species of snakes found in the vicinity of Durban, writes me as follows:-

"During our travels, we once found a mass of eggs of some sort. Father, thinking they would probably turn out chameleons, or something equally harmless, kept them till they hatched. We watched the gradually darkening mass, having a peep cvery day, until one day, on lifting the lid of the box they were in, out popped thirteen very lively 'Black Mambas'-quite black. As far as I can remember, they were about four to six inches in length. My father knows a Black Mamba when he sees one, so do my brothers. There is a black snake very like the Black Mamba, but it is distinguished from the Mamba by its tail and shiny coat."

\section{Crested Mambas.}

The natives of Zululand and Natal firmly believe there is a Mamba possessing a feathered crest, which it spreads out like a fan when disturbed. Many colonists also hold this belief. For years I was on the look-out for a snake with some sort of a crest, but in vain. Believing that most popular beliefs and legendary tales have, or had, some foundation in fact, I was quite prepared to believe that there might be a snake with elongated scales or something of the sort on its head. Mr. H. W. Bell-Marley's explanation is as follows:- "I am told by the natives near the kloof that there is an old Mamba that has been there since their fathers' time, and lives by himself, being most vicious. When he is angry he raises his head and spreads a feather behind. For some time I tried to find out what they alluded to, as it was a common belief amongst all, and given me quite bona fide. One day, when looking for some Sun Birds, I heard a rustling close by, and was just in time to raise my breech-loader and fire at a retreating Mamba. I shot him badly in the neck and head, and found, although he did not exceed thirteen feet, that he was quite black in appearance, and the scales behind the head, for four inches down in line, had so grown together that they formed a ridge or crest. Some of the scales were larger than others. The Mamba was the largest I had lilled so far, and the oldest, judging by its appearance. This ridge of skin and scales was evidently 
the origin of the belief of the feather-crested snake. It would, I suppose, when the snake raised its head, spread into a file, giving him the appearance of wearing a feather. The snake when casting his skin had been unable to rid himself of the neck-skin, and this had accumulated for years. It must be sometimes a source of great annoyance to the owner, making him vicious. I showed the natives this skin, but they would not be convinced about its being an explanation of the feather business. They told me their fathers wouldn't kill the Mamba, as it would have provoked the wrath of the mighty Umtagati (God)."

This explanation of Mr. Marley's seems to offer a fairly reasonable explanation, but it is not, I think, the one which accounts for this widespread belief amongst the natives of the existence of a Crested Mamba.

Mr. W. F. Jones is a gentleman who has lived for years in those parts of Zululand most frequented by Black Mambas. He has hunted them daily for the purpose of collecting their venom for scientific purposes. He has been responsible for the deaths of many hundreds. He writes me as follows :- "It may not be generally known, but Black Mambas have the power of apparently inflating the greater portion of the body and neck. The neck is not distended in the manner of the Cobra family, but the sides appear to be compressed together so that when seen straight on, this section of the body presents the appearance of a narrow ridge. When viewed sideways it gives the creature with its very small head a grotesque appearance. The full distension is rarely resorted to. It moves deliberately and even awkwardly, and quite unlike itself when the distension is complete, and it would be a very dangerous proceeding to molest one at such times. A nine to twelve foot Mamba at this time looks twice its usual girth, and is a startling object. Before there is time to recover from the surprise, the snake has achieved its purpose, and vanished. This is merely a temporary ruse to cover retreat over ground exposed to the view of an intruder. The moment the snake is out of sight the body assumes its usual outline, and either glides off rapidly, or remains perfectly still and intensely vigilant. Undoubtedly, the snake wishes you to believe it has gone to ground, and it is safest that you should so believe, and cross it no more for that day. Though it is a comparatively rare occurrence for the Black Namba to assume this guise, the 
fact must frequently have been observed by the Zulu, who has mistaken the semblance of size for the bodily reality. This is sufficient to account for the exaggeration they betray when recounting their experiences of these reptiles."

Mr. Jones' explanation seems to explain satisfactorily the origin of the belief in Crested Mambas.

I have killed and been present at the killing of many, but have not been fortunate enough to witness the phenomenon described by Mr. Jones. However, I nuticed that one which I kept in captivity, when irritated, assumed this flattened appear-

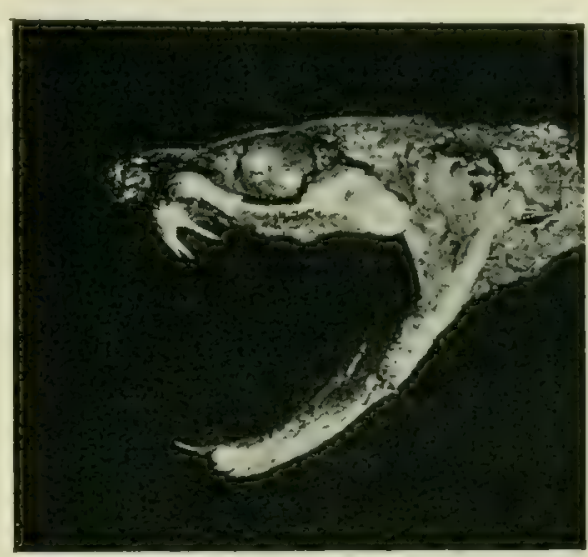

FIG. 83.-Skull and poison apparatus of a green variety of Mamba (Dendraspis angusticeps). The Mamba has a duplicate pair of fangs. Poison gland is seen behind the eye. It is connected with the base of the fang by a tube or duct. ance to a certain degree.

The Boomslang has a somewhat similar habit. When unusually excited, it dilates its throat considerably, giving the head a weird and uncanny appearance. In the Addenda at the end of the book, photos recently taken show this wonderful phenomenon.

\section{Killed by a Black Mamba.}

Some of the favourite resting places of Mambas are the branches of thick-foliaged trees. Entwining themselves amongst the twigs they lie perfectly still. They frequently select branches of trees overhanging the Kafir paths which wind through the forests in various directions. These Kafir paths are made by the natives, who always walk single file. They are merely tracks worn by the feet of the natives. Many a native has met his death by being bitten on the head, neck, or shoulders whilst passing under a branch in the foliage on which one of these venomous snakes lay concealed.

One day, when out buck-hunting, I was leisurely riding along a Kafir path in the outskirts of a forest, when suddenly a black streak shot out from a clump of stunted bush a few yards ahead, and next instant I saw it was a great Black Mamba, and that it had buried its fangs up to the hilt in a burly Zulu's bare shoulder. 
The native, with a hoarse yell, bounded into the air, fell, recovered himself, and rushed away at full speed down the path. Making a detour to avoid the snake, I came upon the man, ten minutes later, in the throes of death.

Naturally, in all cases death would not have been so startlingly sudden, but the man received a full bite in the shoulder-muscles by a large and vigorous snake, and running at such great speed the blood coursed with tremendous rapidity through his blood vessels, and quickly carried the venom to every part.

Another day when out on horse-back, away in the wilds of Natal, I noticed a movement in a large tree overhead, and detected a Green Mamba. Moving further away, I sent a charge of No. 6 shot at him. Down he tumbled on to the grass, but alas! my favourite terrier dog darted forward at the wounded snake, and was instantly bitten in the side. I quickly killed the reptile, and attended to the dog, but in spite of every effort to save his life, he died in fifteen minutes.

The Mamba does not deliberately take up a position in a branch overhanging a Kafir path with the intention of viciously biting some unwary passer-by. He is either there with the purpose of sunning himself, to escape from the terrible closeness of the forest air on a hot summer's day, or with the object of watching out for a meal. These Kafir paths are much frequented by small rodents and forest birds, and it is these which the Namba is anxious to secure for a meal. Naturally, if lying concealed amongst the foliage of a low branch, and if suddenly aroused from slumber, or approached too closely or actually brushed against, when he is lying wide awake, and intent upon watching for prey, the Mamba will strike.

The stroke is invariably fatal, for it is received usually upon the head, neck, or shoulders.

A favourite position assumed by the Black Mamba when sleeping, is a coiled-up attitude upon some twigs, with the head tucked away under or between one or two folds of the body. In this position it will lie for hours, relying upon its protective colouration to escape detection. At these times it may casily be approached and secured alive with a large butterfly net, if the branch should happen to be in a situation easy of silent approach, and sufficiently near to the ground. The slightest vibration of the branch, or the cracking of a twig will cause it 
instantly to awake, whereupon it silently glides out of sight among the foliage.

On these occasions if you happen to be between the reptile and its retreat, the chances are you will be bitten. The snake gives you no time to think. The thinking and acting must be simultaneous. A sudden uncoiling, a blur, and next instant the smart of the venom is felt in face, arms, or legs. An impotent struggle of the will against the subtle, paralyzing power of the venom, then the cold chills of death are felt stealing through the frame, followed by oblivion and death.

\section{A Faithful Dog.}

Near the Tugela River, a Zulu girl was once busy with her duties of rolling up the sleeping mats and brushing out the hut which was the usual circular grass structure, when, to her horror, a large Black Mamba dropped out of the thatch on to the floor. The girl screamed and crouched in a corner, the snake being between her and the small door. Just at that critical instant her pet dog rushed in through the doorway, and, seeing the Mamba advancing upon the girl, he instantly tackled it. The Mamba rained blow after blow upon the dog, who grimly held the snake between his jaws. In a minute or two the venom began to exert its wellknown deadly effects. The faithful dog staggered and collapsed, but, with a last expiring effort, he so effectually mangled the snake that it was powerless to escape or attack the girl, who slipped past it and escaped.

\section{The King of South African Snakes.}

Many and varied are the stories told of the terrible Mambas. Sitting within the cheerful glow of camp fires, after a day's tough riding and climbing, I have passed many a happy hour listening to thrilling, if legendary tales, of the evil powers and fierce aggressiveness of the Mamba. I think there is no happier life than to live for months at a time away from all the cares, bickerings, conventionalities, and empty vanity with which town life is so permeated, and with a companion or two, a favourite horse, a few affectionate and devoted dogs, 
and a couple of trusty Zulu servants, to go right into the wilds, away from all civilization, and live surrounded by Nature, and study the ways of her creations.

So great is the dread of the Mamba in the native mind, that if one be known to inhabit any particular locality, few, if any, natives will venture there. In fact, a wide detour is always made. As a general rule, the more we learn about snakes and their ways, the less fear we have of them. This is usually not so with the Mamba. The more one learns of his ways, the greater grows the dread of him. He, without doubt, is the king of snakes in South Africa. For quickness, aggressiveness, and the deadly nature of his venom, he has no equal.

After two or three encounters with large Black Mambas, I learned to be wary. I found that even a gun was not always a protection, so quick and sinuous were his movements. A Black Mamba should never be attacked in the bush or long grass. I have frequently startled Mambas out of a nap on the Kafir paths in the bushy parts of Natal. Sometimes they would glide off and away into the undergrowth, but as likely as not the Namba would slide up a shrub at the side of the path, and remain on the defensive. If a stone be thrown at him, or if he be wounded, he will, as likely as not, make straight at his aggressor, and with body raised, bite him.

I once lost a Zulu servant in this way. He had lost most of his superstitious fear of Mambas, having been with me on many expeditions, and witnessed numbers of these reptiles being killed. Disregarding the advice of the other natives, he ventured up a kloof in search of a duiker buck which was seen to enter. $\mathrm{He}$ came back, foaming at the mouth, and gasping out the word "Mamba!" and, pointing to the upper part of his thioh, he was seized with terrible convulsions and died. I mourned for long over this boy, for he rwas so true, so brave, so simple, so devoted. Yes, there is no savage upon the face of the earth to equal a real uncivilized Zulu of the kraal type, unstained and free from the degrading and soul-blighting influences of the lower stratum of humanity often inhabiting towns.

The quickness of movement, grace, and ease with which the Mamba glides about in his native habitat is very lucidly summed up by Mr. W. F. Jones, of Zululand. "The Mamba is essentially partial to trees, and thorns make no difference to the ease of its 
movements. Our large dongas are matted in places with a dense network of bramble-like growths, which extend searchingly in long, sinuous branches, which are studded with formidable thorns, curved like the claws of a cat. Whatever road he elects to take, whether on the top or along and through this cruel maze of brake, it is the same to this graceful creature. To see a startled Mamba making for his home along the crown of one of these thickets is a marvel of perfected movement. The small head, with its full prominent eyes, the long body, partially raised and sweeping from side to side with a forward throw, so swift and sudden as to bewilder one into believing that the creature is bounding along with ten-feet gaps between the curves. And as the tail disappears into the dark cavity edging the donga, there follows immediate stillness and peace. But, on the first sunny day, some person steals along with a gun charged with No. 6 shot, and midway in the passage home this time there is a sharp decisive pause. We are using smokeless powder, and, without taking the eye off the line of the barrels, the lightning turn of the head can be followed as it darts viciously back at the gaping wound halfway down the body. Realizing its impotence, it strikes hither and thither at leaf or branch. In a few moments we see the jaws opening widely, the writhe of the contorted body showing the clean white belly, and we know that the end of so much beauty and menace has come."

\section{A Farmer's Extraordinary Experience.}

Mr. T. Braithwaite, senr., had (says the Natal Witness) a most remarkable experience at his farm "Gracelands," in Muden, on Wednesday last. To have a snake up the leg of one's trousers is a most unenviable experience, and to stand perfectly calm and still while it remained in such close proximity was an act of amazing presence of mind. The story is best related in Mr. Braithwaite's orvn words :-

"I sent two natives to clear an irrigation furrow with sickles. They returned after the lapse of about one hour, and informed me that they were afraid to continue working there, as they had seen a large green Mamba in the vicinity. I took my D.B. and went back with them.

"We searched some time without success, the grass and other 
herbage being very long and luxurious, when suddenly I felt a great commotion in my left trouser leg, and knew at once that a snake was there. Another snake at the same time darted away from my feet.

"The one in my trousers went up as far as the pocket, and then turned downwards. I could see by the shape it gave my trousers, and feel by its strength, that it was no small one.

"I kept perfectly still, and called to a native who was a safe distance away to come and catch hold of the snake's tail and jerk it out. But he would not come. The snake then poked its black snout and shining eyes out below my trousers. On looking at it I discovered that I was treading on it about a foot from the end of its tail.

"I gently raised my foot, and the reptile immediately glided away, and so quickly that I could not get a shot, although my gun was at the 'ready.'

"We afterwards found and shot one of the two snakes, a greyish-green Mamba, about five and a half feet long, but whether it was the one who had 'worn the maister's breeks,' I cannot say."

The following appeared in the Eastern Province Horald, June 27 th, I9II :-

\section{Young Surveyor's SAD Death.}

"The many friends of Mr. Claud ('Punch') Moller, who until recently played full back for the Gardens Rugby Football Club, Capetown, were grieved to hear of his death from the bite of a Mamba. The sad event occurred some sixty miles from Malapyre, Bechuanaland, and details of the occurrence have just come to hand.

"Mr. Moller left Capetown for Rhodesia some two months back, on a surveying trip, as assistant to Mr. Hector M. Shaw, Government Land Surveyor. On Sunday, the IIth inst., he and Mr. Shaw were sitting at a camp table alongside of the wagon, writing letters. Young Moller had just finished a letter to his mother when he heard a shot fired close to the camp. Knowing that the natives were in search of another buck, the skin of which would complete the required number to make a kaross which he wanted, Mr. Moller folded the letter with the remark to Mr. Shaw: 
'Please address this to my mother,' and grabbing his gun, he started for the spot where the natives had fired the shot. About sixty yards from the camp, and a few yards away from where the natives stood, Moller had his eyes fixed on the latter when he suddenly put his foot on a large black Mamba snake, measuring over six feet long. In a moment the snake reared and put its fangs in his foot above the left ankle. Moller, with presence of mind, cut away the part bitten with a penknife, and tightly tied a bootlace above the wound and another strap below the knee. Mr. Shaw came upon the scene immediately, and two more ligaments were put on. Everything possible was done, and remedies were applied as well. Moller apparently recovered, and the poison was stayed. Preparations were then made to go into Malapyre, but just as they were starting, some six or seven hours afterwards, Moller's left side suddenly became paralyzed, and in a few minutes he had expired." A full account of this sad case is given in the Addenda at the end of the book.

\section{The Rush of the Mamba.}

The Black Mamba, as a general rule, has some secure retreat to which it decamps when alarmed. If a Mamba be surprised when out in the open, and if you happen to be between it and its retreat, it will not rush off in an opposite direction, as most animals would do, but will instantly dart off at terrific speed, apparently charging right at you. If a Mamba should act in this manner, and if you are not prepared to defend yourself, your safest plan is to sprint off without an instant's delay. Whilst travelling at great speed, a Mamba can strike right and left with consummate ease, without apparently abating its speed in the slightest. To stand in the path of a Mamba rushing off to its lair, is fraught with the gravest danger, even if well armed. At such times the nerves are none too steady, and it is as likely as not that even an expert with the gun will miss his aim. There is no time for reloading, and often not even time to take a second aim should the gun be a double-barrelled one, before the snake has swept past, and in the passing deposited its death-dealing venom.

When making off through the bushveld, the Black Mamba, with a rapid and continuous succession of forward propulsions, 
glides over the stubble, the head and anterior part of its body being sometimes several feet off the ground. When a bush fire is raging Mambas may be seen escaping in this way at a swift pace. Viewed at a distance they seem to be gliding over the tops of the long grass and low shrubs. Cases are on record of men being bitten as high up as the thigh, when mounted on horseback.

\section{Distribution.}

The Mamba (Dendraspis angisticeps) is very abundant throughout the wooded districts of Natal, Zululand, Eastern Transvaal, British Bechuanaland, Rhodesia, and north to Central Africa.

Another species of Mamba has recently been discovered in the Transvaal by Dr. Gough. It is named Dendraspis Mamba. This makes two species found in South Africa. 


\section{CHAPTER VII.}

The Proteroglypha or Front-Fanged Snakes

(SOLENOGLYPHA.)

FAMILY V.-VIPERIDE.

Adders, Vipers and Pit-Vipers.

THE Viper family of snakes, with one or two exceptions, are different in appearance to those of the Colubrine family, to which

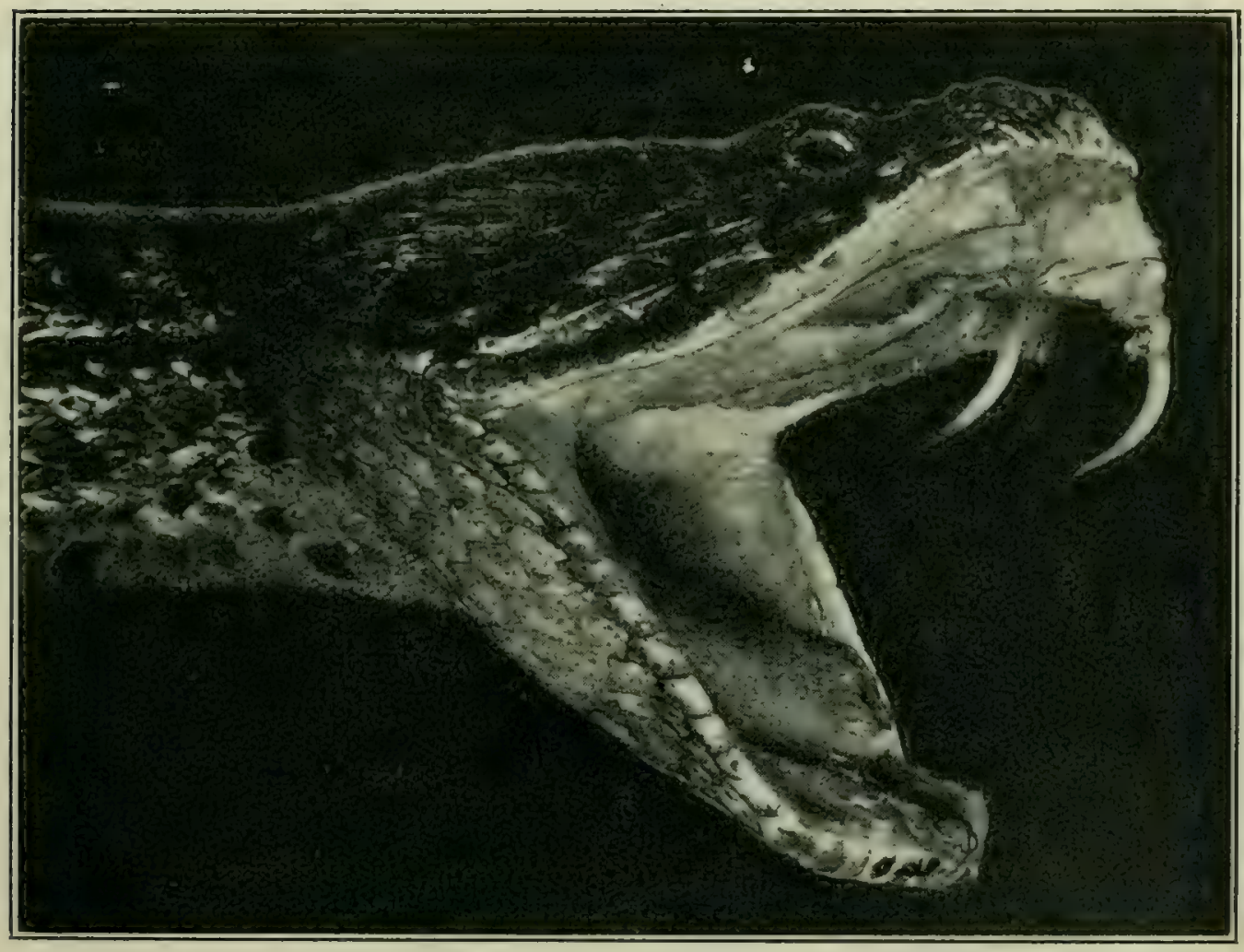

FrG. 84.-The life-size head and poison fangs of the typical viper of South Africa, viz. the Puff Adder (Bitis arietans).

the Cobra belongs. They have flat heads, usually more or less triangular, bodies thick and plump, and tails short. All are venomous. 
Apart from the outward form, the Viperine snakes differ from the Colubrines in the formation of the upper jaw bones. The maxillary bones in which the fangs are set are molile, allowing erection and depression of the poison fangs, which are large, re-curved and hollow, like the necdle of a hypodermic syringe. Behind the front fangs several duplicate sets of fangs are stowed away, graded in size down to mere specks. These are the Viper's reserve set of weapons. If the front active pair of fangs be shed or lost accidentally, the first pair of the reserve set take their place, and become connected with the ducts communicating with the poison glands. The supply of these reserve fangs is indefinite. If those which are visible are removed, others develop.

\section{Numbers and Distribution.}

There are about forty-two species of Vipers, and sixty-four species of what are known as Pit-Vipers. The Vipers inhabit Africa, Europe and Asia. The Pit-Vipers are unknown in Africa, but occur all over Southern Asia, Central and South America. The Rattle-snakes of America are Pit-Vipers. They are termed such because of a pair of deep pits in the fore part of the head, between the eyes and nostrils. The Pit-Vipers are classified under the Sub-Family Crotalinæ. In South Africa we have ten species or kinds of Vipers.

\section{SYNOPSIS OF THE GENERA.}

Genus CAUsus.-Head distinct from neck, covered with symmetrical shields; nostril between two nasals and the internasal; loreal present; eye moderate, with round pupil, separated from the labials by suboculars. Scales smooth or keeled, with apical pits, oblique on the sides, in 15 to 22 rows; ventrals rounded. Tail; short, sub-caudals in two rows or single.

Genus Bitis.-Head very distinct from neck, covered with small imbricate scales; eye moderate or rather small, with vertical pupil, separated from the labials by small scales; nostrils directed upwards, or upwards and outwards, pierced in a single or divided nasal, with a deep pit or pocket above, closed by a valvular, crescentric supranasal. Postfrontal bone very large, in contact with the ectoptergoid, which has an outer, hookshaped process. Scales keeled, with apical pits, in 22 to $4 \mathrm{I}$ rows ; lateral scales in some species slightly oblique; ventrals rounded. Tail very short; sub-caudals in two rows.

GENUS ATRACTASPIS.-Poison fangs enormously developed; a few teeth on the palatines, none of the pterygoids. Head small, not distinct from neck, covered with large symmetrical shields. Nostril between two nasals; no loreal. Eye minute, with round pupil. Postfrontal bone absent. Body cylindrical. Scales smooth, without pits, in $I_{7}$ to 37 rows; ventrals rounded. Tail short. 


\section{Genus CAUSUS.}

Two Species in South Africa. KEY TO THE SPECIES.

Snout obtuse, more or less prominent; ventrals I20-I55. Poison glands considerably elongated $, \ldots, \quad \ldots, \quad \ldots, \quad \ldots, \ldots$

Snout pointed, prominent, more or less turned up at the end; ventrals II $3^{-125} \quad \ldots \quad \ldots \quad \ldots$ Causus defillippii.

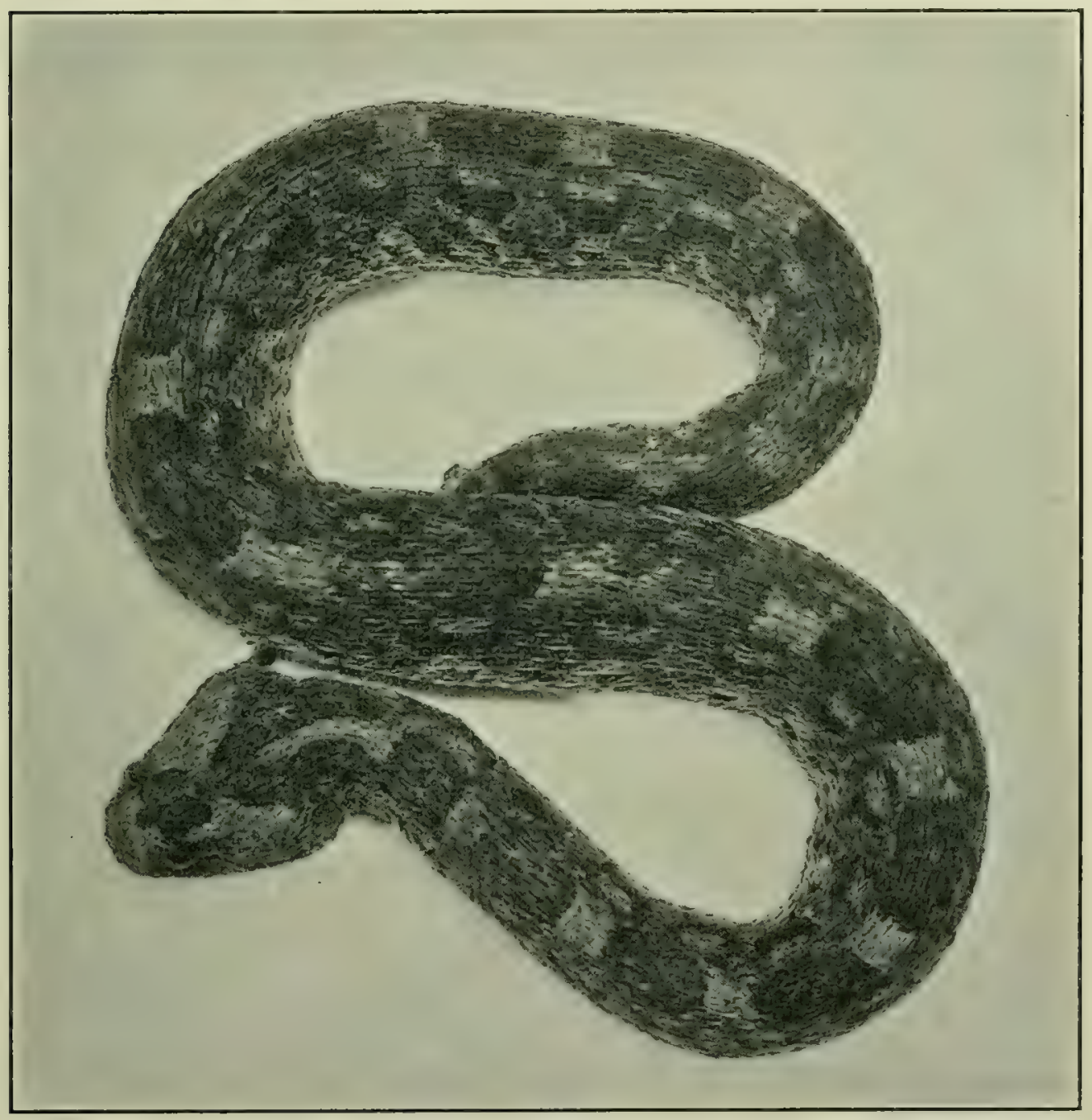

Fig. 85.-The venomous Hornsman or Horned Adder (Bitis caudalis) of the sandy inland parts of South Africa (two-thirds natural size).

I. Causus Rhombeatus. Night or Demon Adder. Nacht Ader (Adder). Synonyms-Sepedon rhombeatus; Distichurus maculatus; Aspidelaps rhombeatus.

Colour-Olive or pale brown above, rarely uniform, usually with a dorsal series of large rhomboidal or V-shaped dark brown spots which may be edged with whitish; usually a large dark $\Lambda_{\text {-shaped }}$ marking on the back of the head, the point on the frontal, and 
an oblique dark streak behind the eye; labials usually darkedged; lower parts yellowish white or grey, uniform, or the shields edged with black.

Average length -2 feet.

Distribution-All over South Africa; North to Tropical Africa.

2. Causus Defillippir. Snouted Night Adder. Snoet Nacht Adder. (Gesnoet Nacht Adder.)

Synonyms-Heterodon defillippii; Causus rostratus.

Colour - Grey or brown above, vertebral region darker, with a series of large rhomboidal or V-shaped dark brown spots; a large $\Lambda$-shaped dark brown marking on the occiput, the point on the frontal; an oblique dark streak behind the eye; upper labials dark edged; yellowish white beneath, uniform, or with small greyish-brown spots.

Average length - I foot 6 inches.

Distribution-Griqualand; Natal ; Zululand; Transvaal; Southern Rhodesia; East and Central Africa.

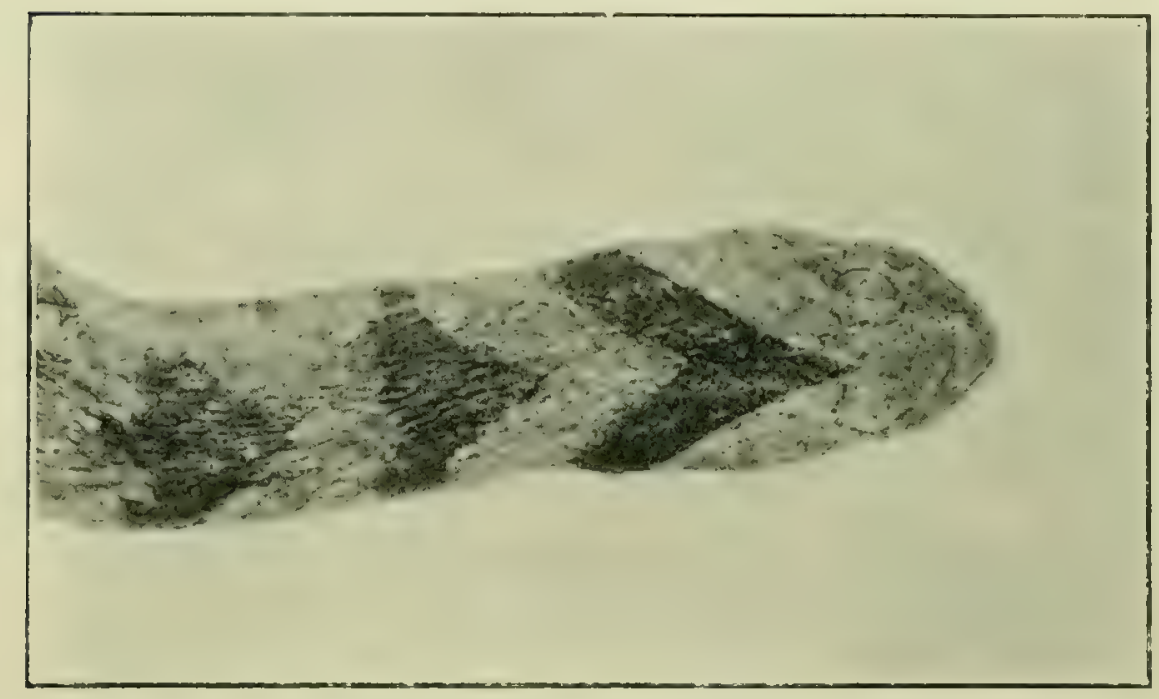

Fig. 86.-Head and neck of the poisonous Night or Demon Adder (Causus thombealus).

Note the triangular blackish mark on its head.

Genus BITIS.

Six Species in South Africa.

KEY TO THE SPECIES.

Nostrils directed upwards; scales in $3 \mathrm{I}$ to $4 \mathrm{I}$ rows ..

Nostrils directed upwards and outwards; scales in $2 \mathrm{I}$

Bitis arietans.

to 3 I rows. Supraocular region not raised, without horn-like scales; sub-caudals well developed and smooth in both sexes. Outer row of scales smooth . . . . . . . . .

Same as the former except that outer row of scales are keeled . . . . . . . . .

Supraocular region raised, without horn-like scales; sub-caudals well developed and smooth in both sexes ..

Bitis peringueyi.

Bitis atropos.

Bitis inornata. 
Supraocular region usually with horn-like scales; sub-caudals, in females, small and scale-like, more or less distinctly keeled. Two or more supraorbital horns .. $\quad$. $\quad \ldots \quad$.. $\quad$. .

Bitis cormuta.

Supraorbital region with only one horn-like erect scale. Sometimes it is not present .. .. . . Bitis caudalis.

I. Bitis arietans. Puff Adder; Pof Adder. Synonyms-Vipera arietans: Cobralachesis; Clotho arietans : Echidna arietans.

Colour-Yellow, pale brown, or orange above, marked with regular chevron-shaped dark brown or black bars pointing backwards, or black with orange or yellow markings; a large dark blotch covering the crown, separated from a smaller interorbital blotch by a transverse yellow line; an oblique dark band below, and another behind the eye; yellowish white beneath, uniform, or with small dark spots.

Average length -2 feet 6 inches to 3 feet. Attains a length of 5 feet.

Distribution-All parts of South Africa. Northwards through Tropical Africa to Arabia.

2. Bitis Peringueyi. Peringuey's Adder.

Synonym-Vipera peringueyi.

Colour-Pale buff or greenish olive above, with three longitudinal series of grey or blackish spots, the outer ocellar, enclosing a white centre; head sometimes with a trident-shaped dark marking on the crown, followed by a cross and two large markings on the occiput: whitish beneath, with small dark spots.

Average length-I foot.

Distribution-Kalahari ; German South-West Africa; Angola.

3. Bitis atropos. Berg Adder.

Synonyms-Coluber atropos: Cobra atropos; Vipera atropos; Clotho atropos; Echidna atropos.

Colour-Brown or greyish brown above, with four longitudinal series of large dark brown, black and white edged spots, formed by the breaking up into two of the two series of sub-circular spots ; a continuous or interrupted whitish streak running between, and dividing the spots on each side of the back, and another lower down on the sides; two large dark markings on the head, from the nape to between the eyes; an oblique, light, darkedged streak from behind the eye to the mouth; belly grey or brown, spotted with darker.

Average length - I foot 6 inches.

Distribution-Both provinces of Cape Colony; Basutoland; Griqualand; Orange River Colony; Natal; Zululand; Transvaal. (Mountainous regions, as its name implies.)

4. Bitis inornata. The Cape Puff Adder. Kaap Pof Adder.

Synonyms-Echidna inornata; Vipera atropoides; Vipera inornata. Colour-Variable.

A. Dark yellowish-brown above, with faint traces of darker markings, brownish-yellow beneath, with a few dark dots; head marbled with dark brown.

B. Brown above, with two dorsal series of dark brown, black-edged spots.

C. Reddish brown above, marked as in Bitis cornuta.

Average length -18 inches.

Distribution-Both provinces of Cape Colony. (Very uncommon.) 
5. Bitrs cornuta. Hornsman or Horned Adder; Hoornsman. Synonyms-Vipera comita; Vipera armata; Cerastes cormuta; Clotho cormuta: Cerastes lophophrys.

Colour-Greyish or reddish brown above, with dark brown spots, often edged with whitish, disposed in three or four longitudinal series, with or without light spots between them; head with more or less distinct symmetrical markings; an oblique dark streak from the eye to the mouth; yellowish white or brownish beneath, uniform or spotted with dark brown.

Average length $\mathrm{I}$ foot to $\mathrm{I}$ foot 6 inches.

Distribution-Both provinces of Cape Colony, including British Bechuanaland; German South-West Africa. (Partial to sandy regions.)

5. Bitis caudalis. Horned Puff Adder. Hoorn Pof Adder. Also called Hornsman.

Synonyms-Vipera ocellata: Cerastes ocellatus; Vipera caudalis : Cerastes caudalis; Vipera schneideri.

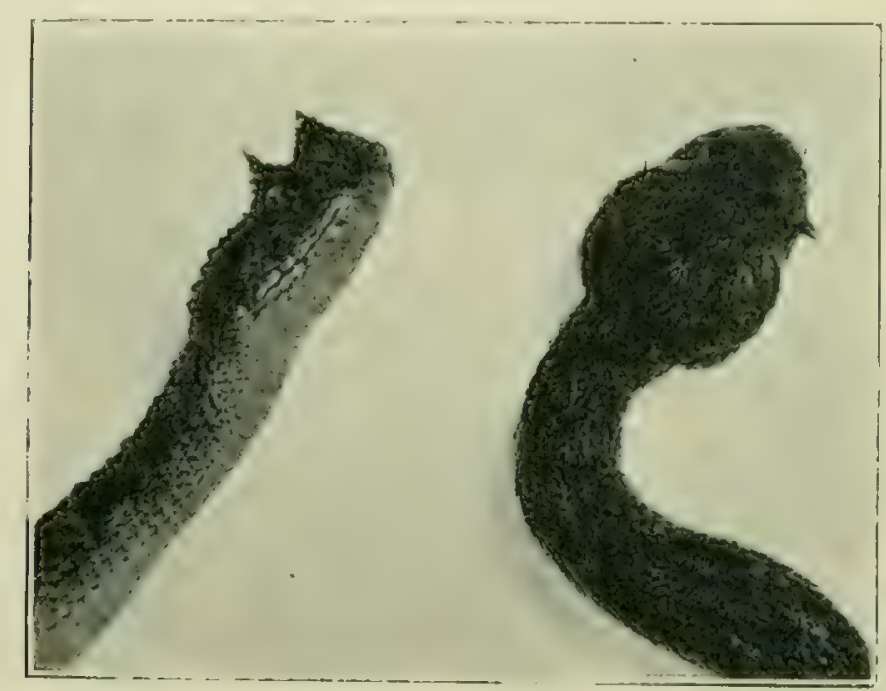

FrG. 87.-Head and neck of the Horned Adder (Bitis caudalis).

A pair of erect horn-like scales on the head. Body rough-looking and dingy. Head that and broad.

Colour-Pale buff, reddish or sandy grey above, with two series of brown spots with light centres, and frequently a vertebral series of narrower spots; the spots may be edged with yellow; ycllowish white beneath, uniform or with small blackish spots on the sides.

Average length-I 4 inches.

Distribution - Eastern Province of Cape Colony; Orange River Colony and Transvaal; Southern Rhodesia; German South-West Africa; Angola.

6. Bitis gabonica. The West African Adder.

Synonyms-Cerastes nasicomis; Echidna gabonica; Vipera rhinoceros: Clotho rhinoceros: Bitis rhinoceros.

Colour-Brown above, with a vertebral scries of elongate, quadrangular yellowish or light brown spots connected by hour-glass shaped dark brown markings. A series of crescentic or angular dark brown markings on each side; head pale above with a dark brown median line; a dark brown oblique band behind the eye, widening towards the mouth. Yellowish bencath, with small brown or blackish spots.

Average length -3 to 4 feet.

Distribution-Amatongaland; Damaraland; South Central Africa. 


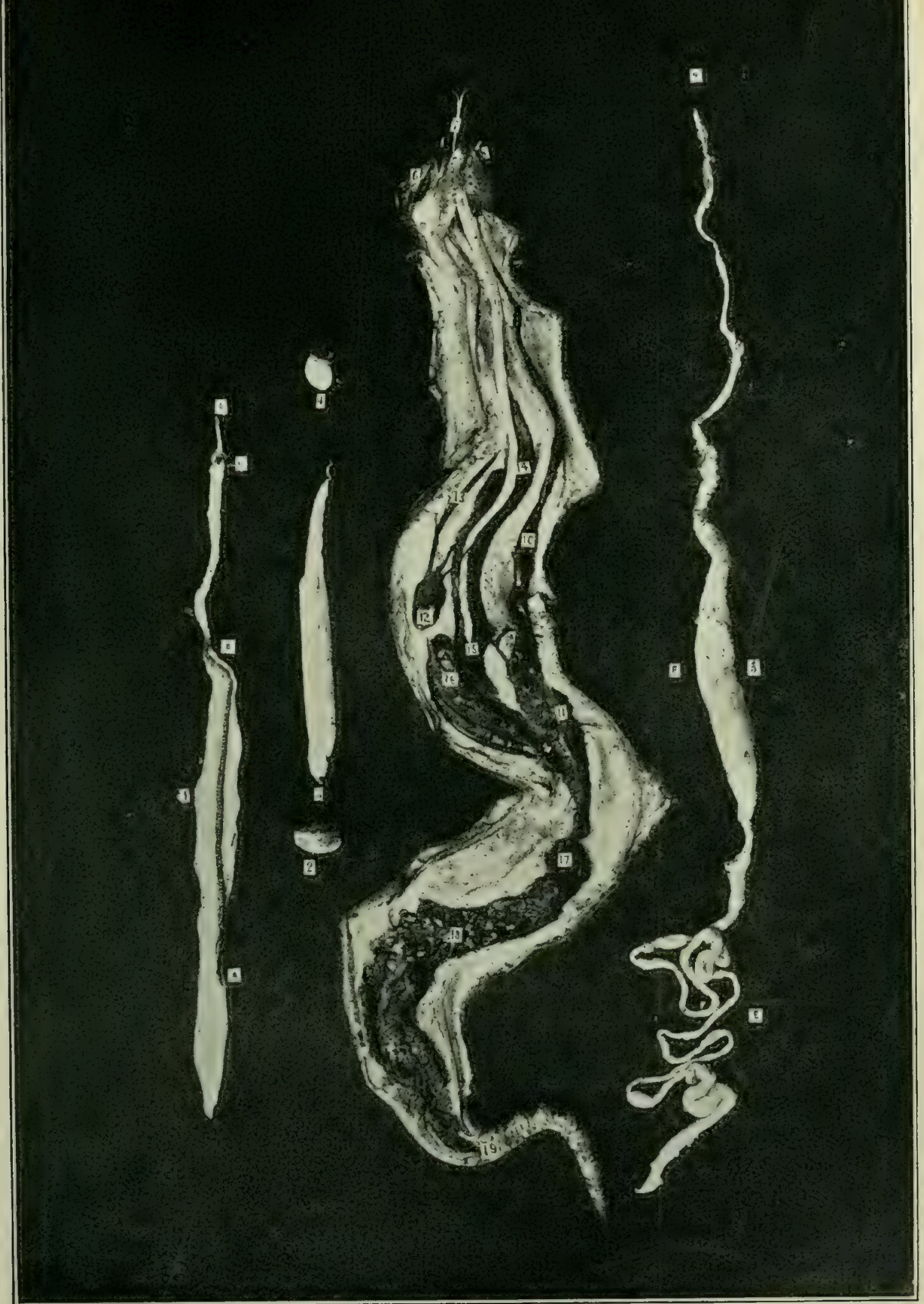

FIG. 88.-The internal organs of a Puff Adder (Bitis arietans). (I) Figure on the left, the lung. The dark line running down over the surface is the windpipe. The air entry is at spot marked A. Higher up at $B$ is top of lung. $C$ is entrance to the windpipe. $D$ is the extended portion which snake can protrude from the jaws in order to breathe when swallowing large prey, which causes great distension of jaws. (2) Gall bladder. (3) Liver. (4) Heart. (5) Figure on right, the whole digestive tract. The top is entrance to gullet leading from mouth down to stomach, which is the largest portion in centre. Lower portions marked $\mathrm{E}$ are intestines. The slightly larger part at end of bowels is the cloaca, and vent. Central figure is a Puff Adder laid open. (I) Fang. (3) Lower jaw. (6) Poison gland. (7) Tongue. (9) Windpipe. (10) The stomach (coloured white) showing gullet leading down from mouth. The black-looking parts on which it rests are masses of yellowish fat. (Ir) Beginning of the intestines (covered with fat). (12) Heart. (I3) Veins and arteries. (I4) Lung (coloured black). White streak along it is the windpipe. (15) Entrance of windpipe into bottom of lung. (16) Liver. (I7) and (I8) Intestines. These are enveloped in fat. (I9) Vent. (If the numbers appear indistinct, use a small magnifying glass.) 


\section{GENUS ATRAC'TASPIS.}

Two Species in South Africa.

KEY TO THE SPECIIS.

Ventrals $22 \mathrm{I}-260 \quad \ldots \quad \ldots \quad \ldots \quad \ldots \quad \ldots \quad \ldots$ Atractaspis bibronii.

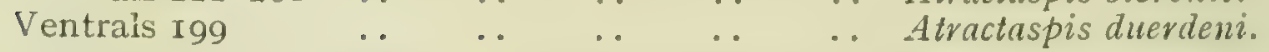

I. Atractaspis bibronit. Oviparous Adder. Ei-leggend Adder. (Eicrleggend slang.)

Synonyms-Atractaspis inornatus; Atractaspis irregularis.

Colour-Dark purplish-brown above, yellowish or pale brown beneath. Average length -2 feet.

Distribution-Cape Colony; Orange River Colony; Griqualand; Natal; Zululand; Transvaal; German South-West. Africa ; Angola; Delagoa Bay; Portuguese East Africa.

2. Atractaspis duerdeni. Duerden's Adder.

Colour-Cream coloured above, lighter below.

Average length-I foot 6 inches.

Distribution-North-East Kalahari.

\section{The Puff Adder.}

\section{(Bitis arietans.)}

\section{ZULU : ibululu.}

The Puff Adder is South Africa's typical viper, being one of the commonest and most widespread snakes in the sub-continent. It is exceedingly venomous and dangerous to man, owing to its labit of haunting the vicinity of dwellings, enticed thither in scarch of rats, mice, and chickens. It is quite a common occurrence to find Puff Adders actually crawling about the rooms.

One day a lady at Walmer, a suburb of Port Elizabeth, went to her kitchen-dresser for a dish, and there amongst the plates was a large live Puff Adder. Aided by her daughter, she captured it alive, and brought it in triumph to me.

Once I was staying with a friend for a few days one winter in Natal. He and his wife proposed a walk. She retired to put on her bonnet, when presently she rushed forth and fell into her husband's arms in a fainting condition. It seems a venturesome Puff Adder had gained access to the house, found the wardrobe door ajar and no lid on the bonnet box, and forthwith settled himself to hibernate for the winter in the bonnet, evidently congratulating himself on finding so cosy a place. 
THE TYPICAL VENOMOUS SNAKES OF SOUTH AFRICA.

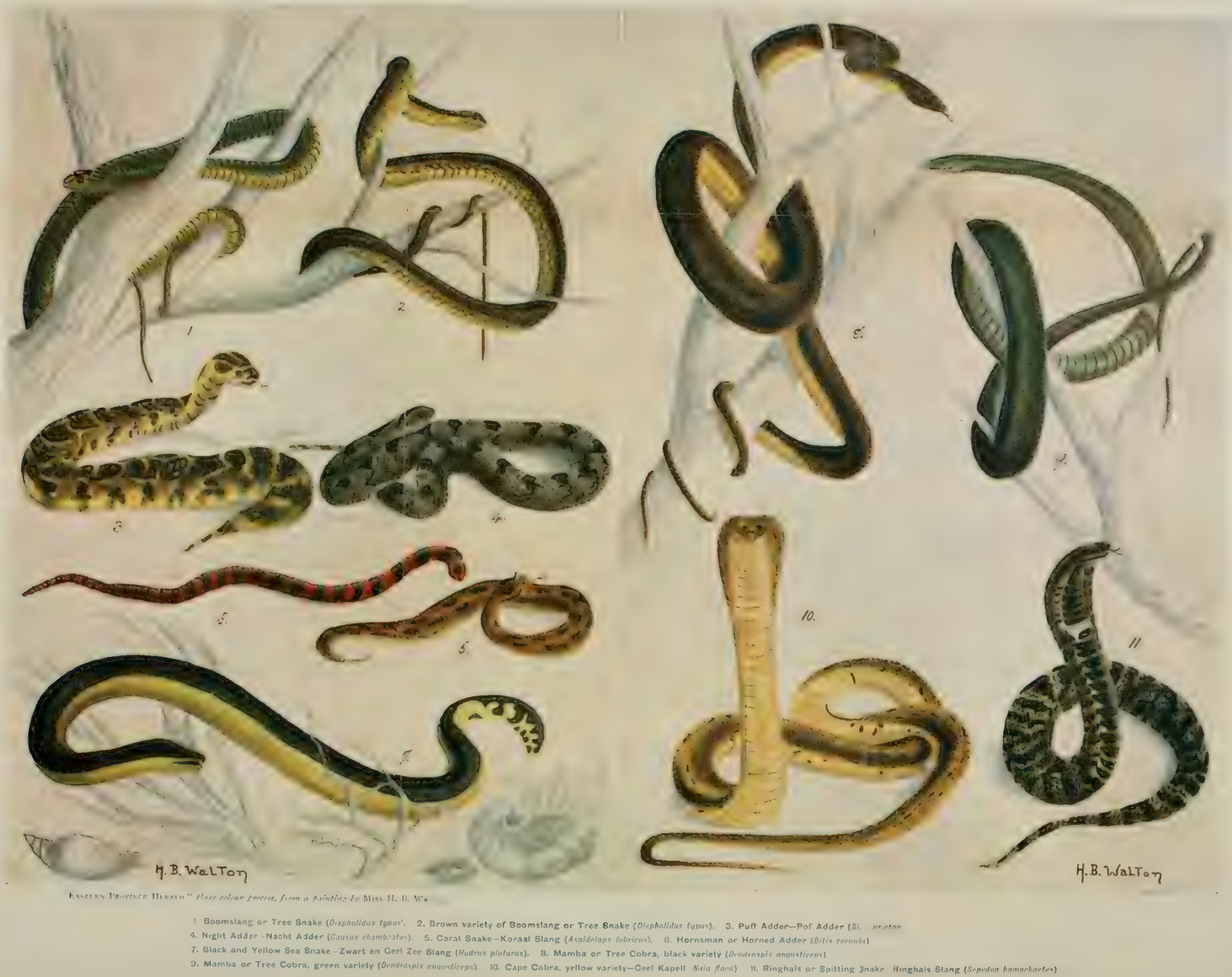




\section{The Hiss of the Puff Adder.}

It can hiss loudly, and many a man has cause to be grateful that Nature has provided the Puff Adder with that mode of warning his enemies.

The Puff Adder hisses by drawing air into its sac-like lung and forcing it out rapidly through the glottis and nostrils. These and most other snakes have only one active lung, which is in the form of a long bag. The second lung is rudimentary.

\section{The Fangs.}

The dentition of the Puff Adder is elaborate. The poison fangs are long and powerful. They are hollow, not grooved like those of the Cobra family. Naturally, if such large fangs were fixed solidly in the jaw like those of the Cobra, the snake could not close its mouth. Nature has provided against this, and furnished it with fangs with hinges. The fangs are set in the anterior maxillary bone, which can be moved backwards and forwards like a hinge. So, when the mouth closes, the fangs lie along the sides of the upper jaw, enveloped in a protecting sheath, known as the mucous capsule or vagina dentis. The small teeth in the back part of the upper jaw, and in the lower jaw, are for the purpose of helping to hold the captured prey, and aid in forcing it down the gullet. They are solid and harmless teeth, as far as venom is concerned. To render a Puff Adder harmless the front fangs and the duplicate sets must all be removed, as well as the anterior maxillary bone, otherwise more will develop in time.

\section{HOW THEIR YOUng ARE BORN.}

Eggs are developed within the body of the female Puff Adder. These grow full size and incubate within the body. They lie in two long rows on each side of the backbone. Each snake is enveloped by a thin transparent skin. There are two vaginas, which join at the vent. The young lie one above the other along these vaginal tubes. They are born fully developed, and come forth coiled up within a transparent membraneous sac, which their active struggling soon ruptures, and they crawl away and henceforth lead an existence quite independent of the mother. 
The young Puff Adders average seven inches in length at birth. They are venomous as soon as born, and will strike fiercely if irritated. Mice bitten by them died within a few minutes. I have made them bite full-grown rats, which died in half an hour. A friend was bitten on the hand by a young Puff Adder a day or two old. His arm swelled, and there was a good deal of constitutional disturbance, but he recovered in a few days.

During April of IgIo, five Puff Adders gave birth to young in the Port Elizabeth Museum. Three of the Adders brought forth the whole of the young alive. The other two gave birth to many fully-developed ones, as well as about a dozen only two-thirds

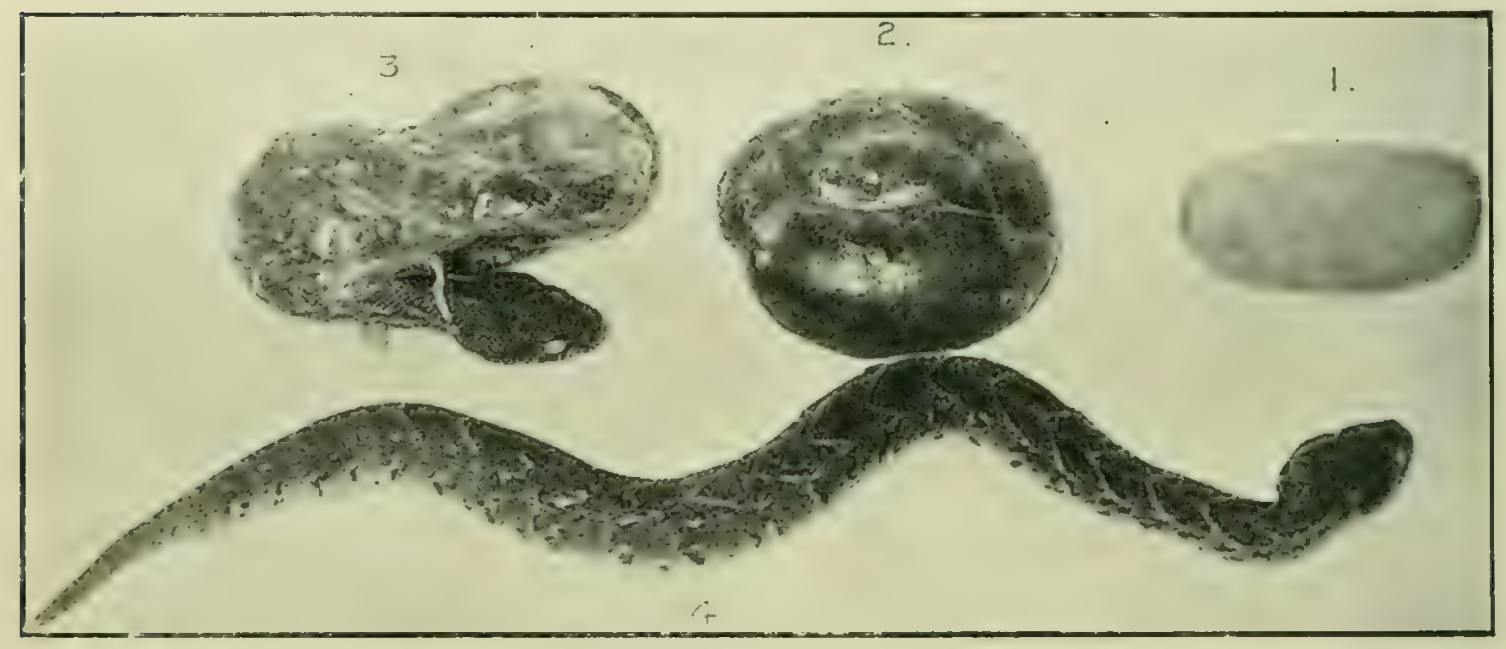

FIG. 89.-(I) The egg of a Puff Adder. These eggs develop inside the snake, and lie in two long rows. They incubate within the body of the parent. (2) A young Puff Adder just born, but only partly developed. In the front is seen some of the egg still unabsorbed. The embryo is enveloped in a membraneous bag. (3) A young Puff Adder, fully developed, just born. It is struggling out of the transparent membraneous sheath in which it was born. Its head is protruding. (4) A young Puff Adder, half an hour after birth, $7 \frac{1}{2}$ inches long. One hour after birth it bit a rat. The rat was dead in fifteen minutes.

matured. I have frequently noticed on dissecting Puff Adders that the young are not always developed to the same degree. Sometimes the eggs fail to incubate. In this case they harden, and are sometimes passed out. In other cases they remain in the snake, and their presence eventually kills her.

Puff Adders have given birth to young a great many times in our snake cages at the Port Elizabeth Museum during the months of March, April, and May. This would lead us to conclude that the development of the eggs and incubation period within the mother is about six or seven months, as the Puff Adders begin coming forth from their winter retreats mostly during October 
in this district, and it would be about this time impregnation of the female would take place.

I have noticed that captive Puff Adders are active in the pursuit of the females in October, November, and December, and that during the autumn they show no inclination.

Young Puff Adders will live in apparent health for as long as three months after birth without food. They also grow larger in girth and increase in length sometimes by as much as two inches. I have noticed this on several occasions. I have at present a batch under observation. They refuse all food. It is now two months since they were born, and yet they do not show any signs of emaciation. Some have increased half an inch, others up to one and a half inches in length. All are slightly larger in girth than when born.

On the $24^{\text {th }}$ June, I9II, I captured a large female Puff Adder, which appeared to be gravid. I killed the reptile, and, on opening it, found eleven fully-developed eggs lying in a row along one side of the backbone and sixteen on the other. I carefully examined these eggs, but could not find the slightest signs of an embryo. Whether they were impregnated or not I cannot say. June is mid-winter in South Africa, and if these eggs were impregnated then it must have occurred during the previous autumn, as this snake was hibernating when I secured it.

In July another large female Puff Adder was captured, which, when killed, and opened was found to contain twenty-four fullydeveloped eggs. They lay in two equal rows on each side of the backbone. There was a good deal of fat in flaky masses covering the eggs, although the winter was well advanced. There was no signs at all of the eggs having been impregnated. It seems to me to be very likely that at least in the case of Puff Adders, the eggs develop during the period of hibernation, as snakes are invariably very fat and in excellent condition late in the autumn. Then, when the female issues forth in the spring, she is impregnated by the male, and the eggs forthwith begin to incubate. I have found that Puff Adders always give birth to their young in the autumn.

\section{Puff Adders in Captivity.}

These snakes in captivity thrive if kept in natural conditions, but unless they have plenty of sunshine, and the temperature of 


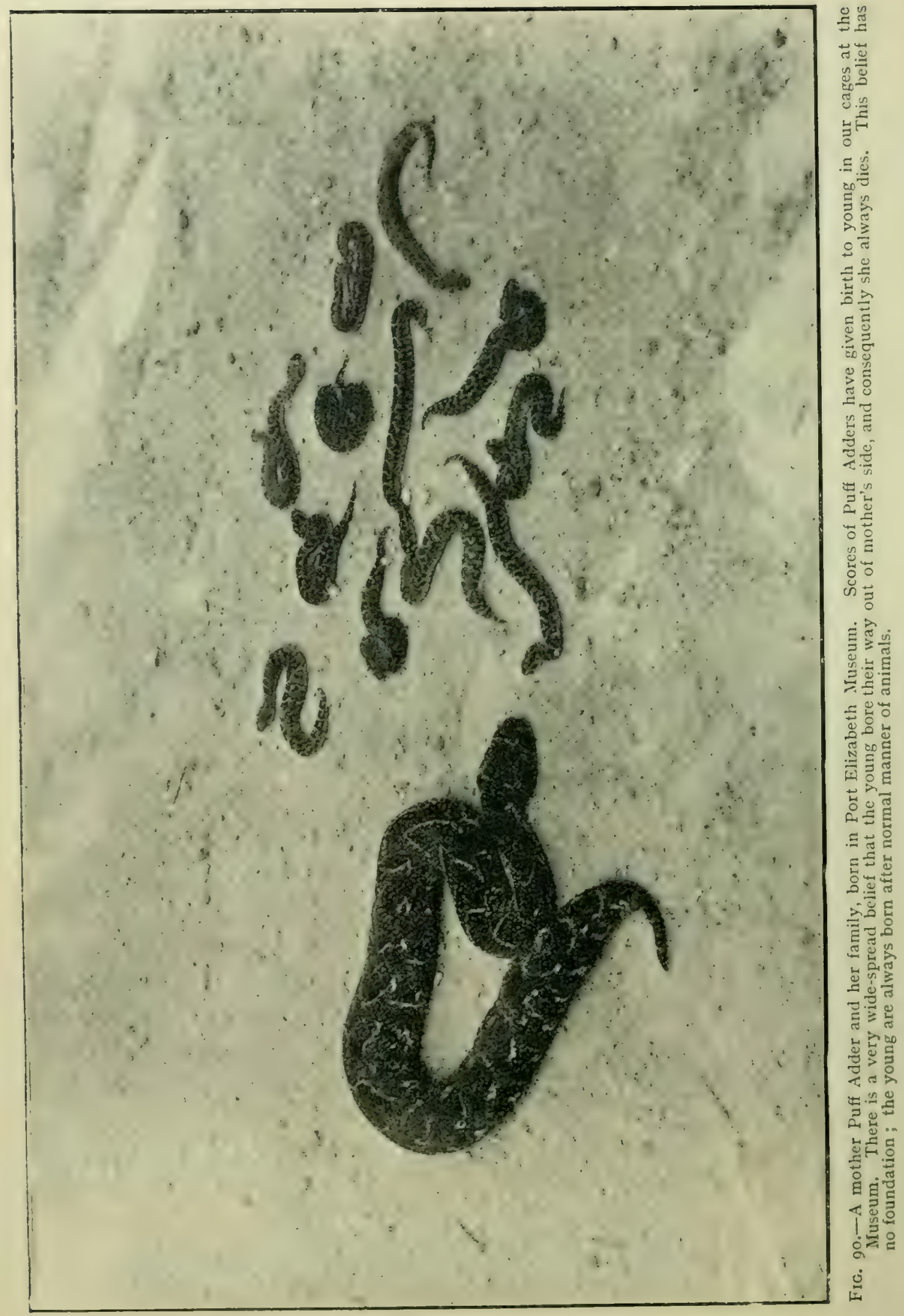


the air in the cage be warm, they become sluggish, refusing all food, and die of starvation. After swallowing a rat, a Puff Adder will rarely take food again for at least a month. I have succeeded in keeping Puff Adders alive for considerable periods by artificially feeding them. An oiled rubber tube is slipped down the reptile's throat and the contents of fowls' eggs are squirted down into the stomach by means of a syringe. 'The rubber tube can be dispensed with, and the nozzle of the syringe inserted into the snake's throat. An easy plan is to insert the tube of a glass funnel into the reptile's throat and pour the liquid food into the funnel. If it does not run down freely, it may be worked down by manipulating the snake's throat with the fingers.

\section{How They kill Their Prey.}

A Puff Adder can swallow the largest of barn rats with ease. Whenever a live rat is introduced into a cage containing Puff Adders, whichever of them is in a mood for feeding will wait till the rat approaches sufficiently close, then, with a swinging side stroke of lightning-like rapidity, the fangs are driven home. Although rats are exceedingly nimble, the stroke is so rapid that the rodent has no time to spring away. Disengaging its fangs, the snake keeps the rat in view, but makes no attempt to capture it, evidently well aware its victim is incapable of moving far away. The stricken rat runs about at random in a dazed sort of way for a minute or two, then the back legs become paralyzed, and the victim rapidly dies. The instant the victim ceases to move, the snake leisurely advances, investigates with its sensitive forked tongue, and finding the head, forthwith begins the swallowing process, which, in the case of a very large rat, lasts about half an hour.

Rats, when introduced into a cage containing venomous snakes, show little or no fear. On several occasions I have allowed rats to remain with Puff Adders and other venomous snakes overnight, and in the morning discovered one, sometimes several, snakes dead, and parts of their bodies eaten, the rats sitting in corners or on the branches in the cage, quite contented, and fast asleep. Rats will even kill the fierce Cobra at times.

When a venomous snake bites its prey, the nervous system is rapidly benumbed, and all sensation lost; therefore, practically speaking, the victim does not suffer pain. 


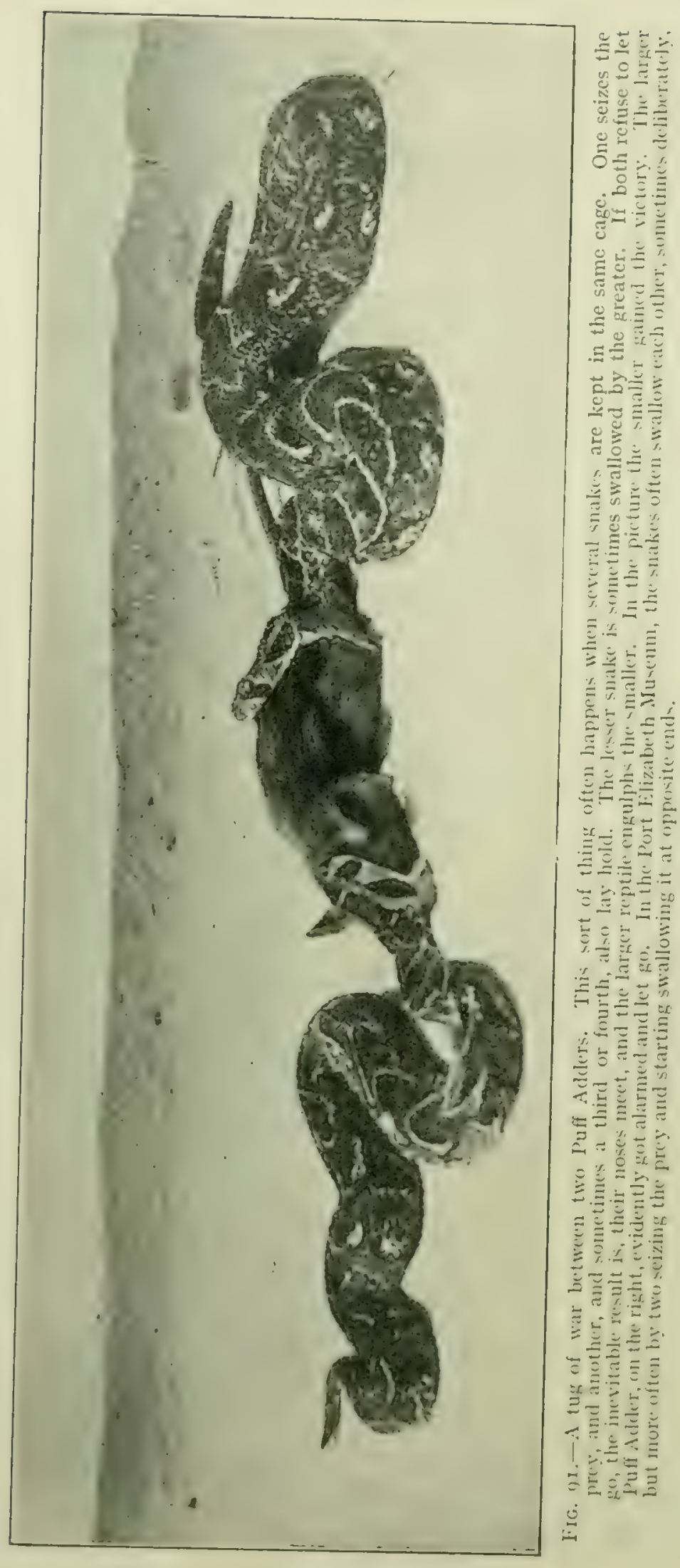


The favourite food of the Puff Adder is rats and mice. He will, when his choice food is scarce, eat toads, lizards, and other creatures. When making a meal of a toad, the Puff Adder simply seizes it by the head, without bothering to strike it first, and proceeds to swallow it alive.

\section{A Modern Jonah.}

One day, away in the wilds of Zululand, I was sitting in a dreamy mood on an ant heap, when out of a shrub hopped a toad followed by a Puff Adder, which seized it. My natural prompting was to rescue the toad, but my investigating instinct got the better of me, so I just sat still and watched the snake swallow the toad. It took about half an hour, because the latter was a big one. At last it finished, and yawned several times, like the man who dines not wisely, but too well. Then my turn came, and I shot him. With my hunting knife I carefully disembowelled him, disinterred the toad, and laid it on the ground. It was an elongated thing of the nature of a sausage, covered all over with slime.

Presently the slimy object moved. It inhaled a breath of air. It got broader. Its limbs began to come back into their natural positions, and it sat up, opened its eyes and looked around in a dazed sort of way. Then it gave a few preliminary jumps, and finding its limbs to be serviceable, hopped off into the bush, apparently not a bit the worse for its Jonah-like adventure. This incident happened many years ago, and since then I have had similar experiences on several occasions. A toad is a reptile, and very tenacious of life, and can exist for a considerable time without breathing. It is not possible for any warm-blooded creature, such as a mammal or bird, to exist alive after being swallowed by a snake, because immediately the breathing is arrested the creature dies.

\section{A Gruesome Sight.}

Once I observed an enormous swarm of those dreaded pests, the Red Ants. They seemed to be actively employed, so I went closer, and discovered they were swarming over a Puff Adder. The snake was wriggling and struggling furiously. I retired out of the way of the ants, of which I had already very painful 

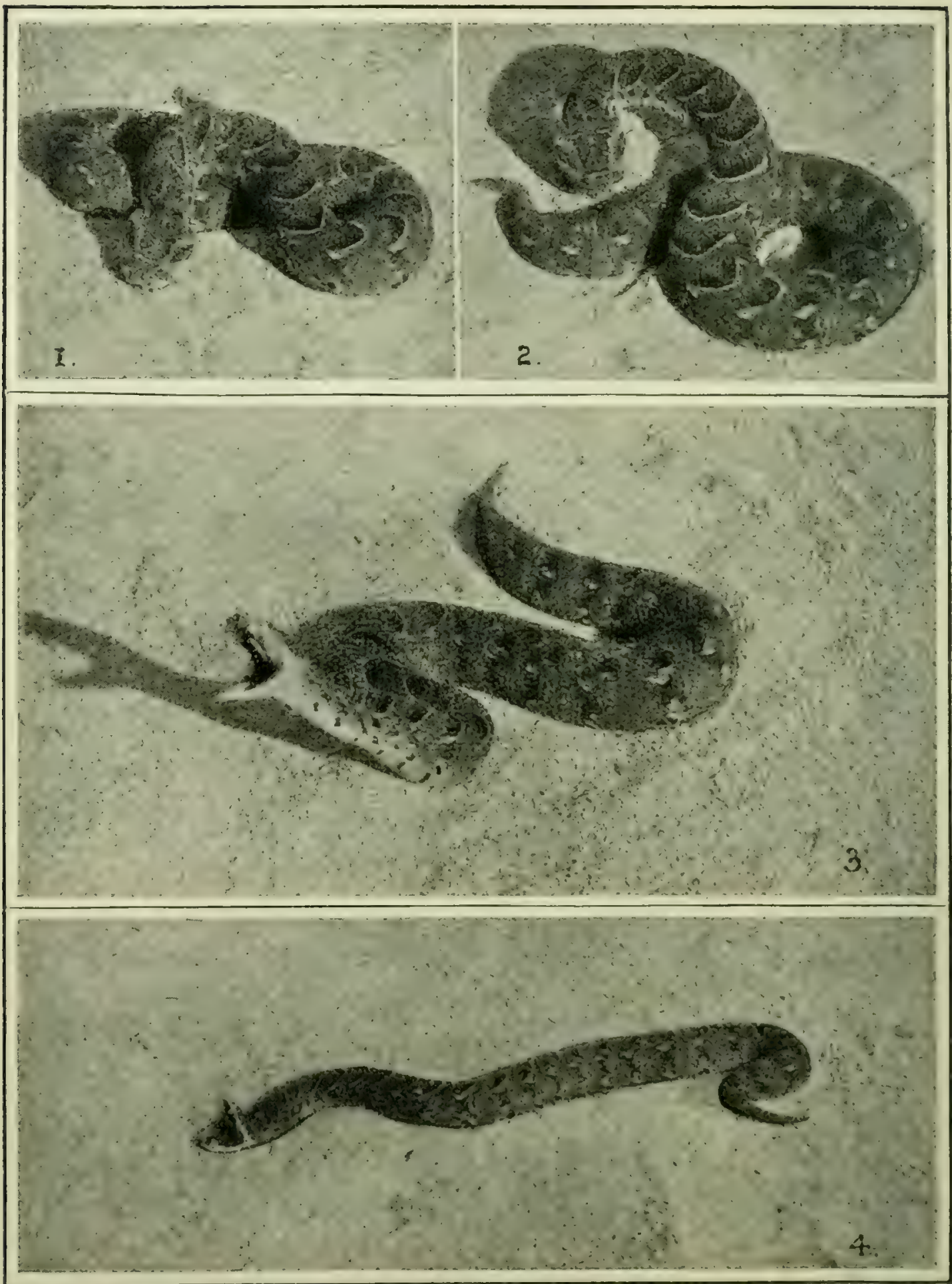

FrG. 92.-I. Puff Adder braced up and on the defensive ready for a forward thrust.

2. The first movement in the act of striking. The head and anterior part of the body is thrown backward with lightning rapidity.

3. Then with gaping jaws the snake makes a rapid forward stroke.

4. If he does not succeed in driving his fangs home in the object aimed at, he falls the whole length of his body, as seen in this picture. 
experiences, and sat down on a fallen tree to watch. In about an hour the ants had cleaned every particle of flesh from the snake's skeleton, leaving it beautifully white and clean.

\section{A TERrifying Experience.}

When out seeking for a Cheetah or Hunting Leopard, which had been carrying off the farmers' stock in the neighbourhood, my two Dutch friends and I cast ourselves down upon the grass under a tree, for the sun was very hot. I was busy looking over my notes, and my friends were meditatively smoking their pipes, when one hoarsely whispered, "Hendrik, don't move! Don't move an inch, I say!" I glanced at his face. It was deathly white. Following his gaze, a shiver of fear crept over me, for there, with its head and a foot of its body up the other Dutchman's trouser-leg, was a Puff Adder. The other man was a hardy old Boer, whom I had seen in many a tight fix, but who never for an instant lost his nerve. $\mathrm{He}$ silently, and with a swift movement, seized the reptile's tail, gave a terrific jerk, and sent it hurtling a score of yards away. Then he picked up his gun, sought out the snake, and shot it.

\section{Puff Adders VARy in COlOUR.}

Puff Adders vary considerably in coloration, although the shape of the markings is always the same. The nature of the surroundings seems to determine the shade of colour. The prevailing colour is dull brown, with yellow markings. Just after the skin-casting process they are at their best. The markings are then bright yellow. A large female Puff Adder, which was captured amongst some town refuse near Port Elizabeth by Mr. J. Williams, had the usual brown ground colour, but the markings were all pure white instead of yellow. There was not a trace of yellow on the snake. Two others have been captured.

\section{The SeXes.}

In the great majority of snakes there is no outward sign by which the sexes of snakes may be determined. A male snake may be distinguished by firmly pressing the thumb or finger on the under part of the tail-region, two inches below the vent. Continue to press firmly, and at the same time slowly slide the 
finger or fingers up towards the vent, whereupon, if the snake be a male, two roundish, slender, soft-looking appendages will protrude themselves. In average-sized snakes these are about two inches long. If the snake be dead, then, instead of pressing the fingers as stated, cut open the skin on the underpart, from the vent towards the tail. Partly remove the skin and lay the flesh bare. If a male, these two vascular, elongated bodies will be observed lying side by side, reaching up to the lower edge of the vent. These are the male generative organs. In the female they are lacking.

\section{Fatalities.}

The number of deaths from the bites of Puff Adders is considerable, especially amongst the native population. European

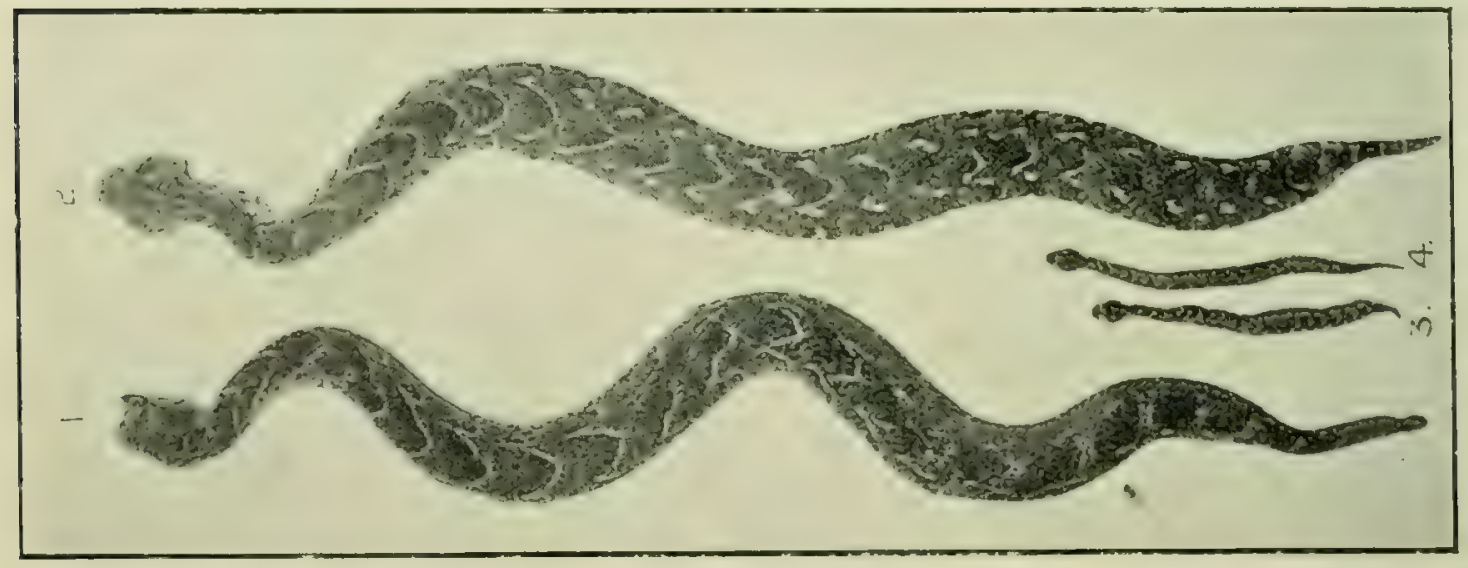

FIg. 93.-I. Male Puff Adder. 2. Female Puff Adder (Adults). 3. Young Female Puff Adder just born. 4. Young Male ditto. In the male the tail is more elongated; that of the female comes to a rather abrupt end. The distance from the vent to the end of the tail is greater in the malc than in the female.

children are often bitten and die. Children are far more likely to be victims than adults, for the reason that, when playing, they rush about excitedly and tread upon Puff Adders before these reptiles are able to emit their characteristic warning hiss. When disturbed, the Puff Adder endeavours to escape observation by coiling up and lying still. If trodden upon, or if the foot be placed near one when in such a position, it immediately delivers a powerful forward stroke. The head is drawn back with a jerk to gain more power for the forward thrust, the mouth gapes enormously, and in the twinkling of an eye the long, curved poison fangs are buried decp in the victim's flesh. There is, 
indeed, a poor chance of recovery if a Puff Adder succeeds in driving both his fangs home and getting a grip, which he assuredly will do, if he possibly can. He knows full well that if he can succeed in hanging on for a few seconds, he will be able to drive the whole of his stored-up venom into the wounds. A full discharge of venom will often amount to ten drops, two or three of which are sufficient to cause death in a robust man.

The little daughter of a farmer friend of mine lost her life by the bite of a Puff Adder. She trod upon the tail of the reptile, whereupon it made a fierce lunge, striking her leg just behind the knee. One of the fangs lacerated an artery, and the parents, not knowing what to do, she rapidly bled to death.

In Natal, a native labourer was once gathering up a pile of brushwood. A Puff Adder happened to be lying concealed beneath it. The instant his hand touched the reptile, it struck and buried its fangs in his arm. With a loarse cry, he summoned his fellow-labourers, but within two minutes of being bitten, the man was dead. The post-mortem showed that one of the snake's fangs had penetrated the vein which lies just beneath the skin on the inner side of the elbow. A charge of venom had been injected therein, which caused almost instant clotting of the blood, and death. Happily, such cases of direct injection of venom into a vein by a snake are uncommon.

I was driving a two-horse Cape cart one day along a country road, followed by my two fox terriers. Presently I spied a Puff Adder sluggishly crawling across the road about forty paces head. One of my terriers, seeing it, made a dash, but, failing to swerve aside sufficiently, the reptile coiled, and shot forward like a released steel spring. The force of the blow knocked the dog on his side. However, he was quickly up, and attempted to run off, but the snake held on firmly. By this time the horses had taken alarm, and attempted to bolt. Three minutes later, when I had succeeded in pulling them up, the stricken terrier came bounding up to me, apparently all right. Without the slightest warning, however, he suddenly turned a somersault, gave a few gasps, and lay dead.

The snake had evidently discharged a large dose of venom into him, which caused clotting of the blood, and consequent rapid death. 


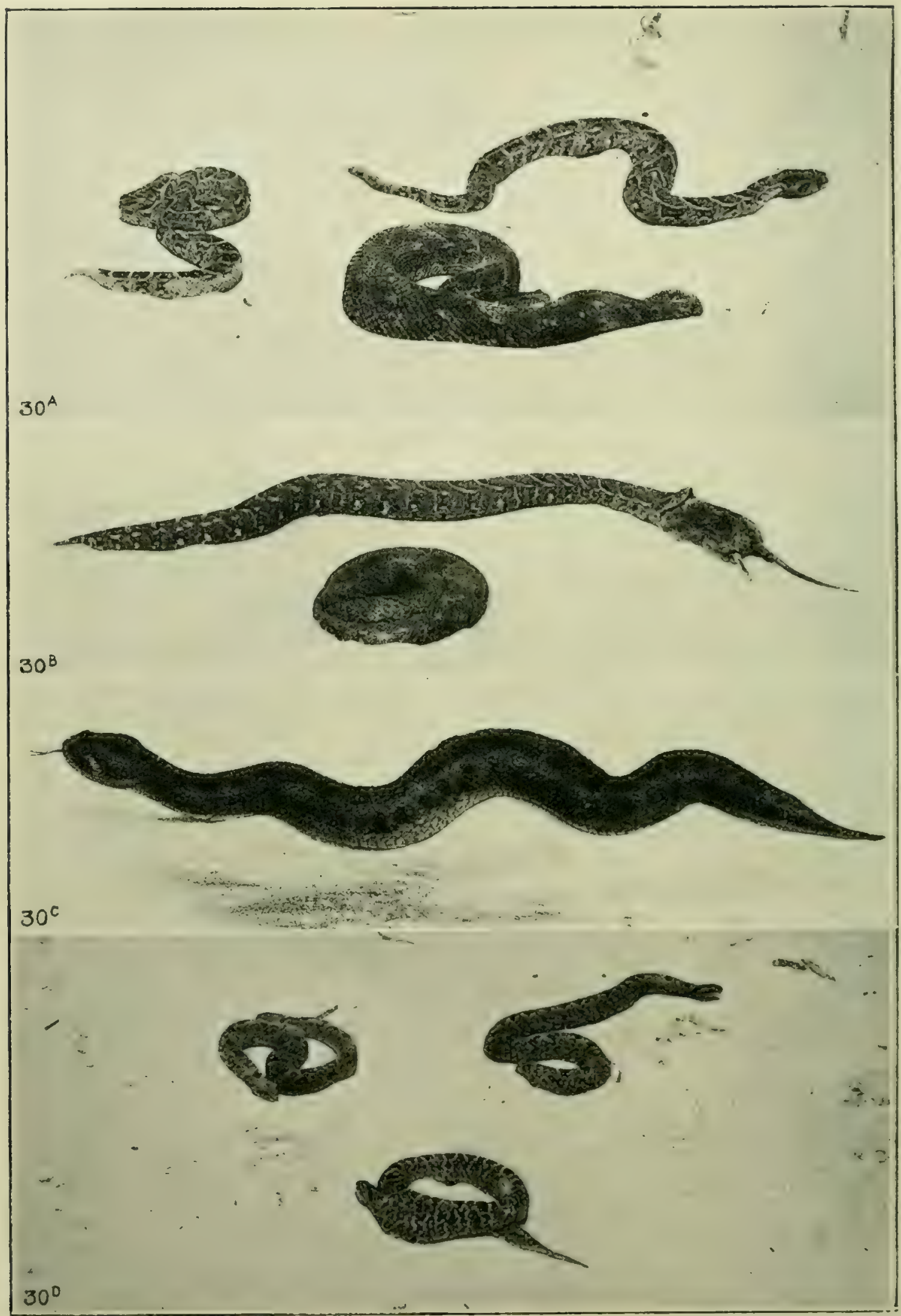

FIG. 94.-30A. Puff Adders (Bitis arictans) basking in sun upon the sand, Port Elizabeth. 30B. Puff Adder in act of swallowing a rat. Another coiled up asleep. $30 \mathrm{C}$. A Berg Adder (Bitis atropos). 300. Night or Demon Adders (Causus rhombeatus) basking in sun upon the sand, Port Elizabeth-from life. 
The Night or Demon Adder.

\section{(Causus rhombeatus.)}

\section{ZULU: INHLANGWANA.}

The range of the Night Adder is very widespread in South Africa. Moist, vegetation-covered localities are its favourite haunts. It is frequently found about and in the habitations of man, owing to its fondness for mice, which haunt dwellings, especially old outhouses, piles of wood, and refuse. It scours the kitchen garden in search of the common garden toad. Many a time I have surprised a Night Adder in my garden in Natal almost choked with the effort to swallow a great fat toad, too large even for the distensible maw of a snake. I found one of these snakes dead one day, with a large toad firmly wedged in its mouth. The reptile, in its efforts to swallow the toad, had evidently stretched its skin so taut that it was powerless to disgorge the victim, and so died of suffocation. The toad was still alive, but in a very feeble condition. I put it aside, but it died shortly afterwards. Toads, although susceptible to the venom of snakes, owing to their sluggish blood-circulation and tenacity of life, sometimes live for days after being bitten by a venomous snake. Frogs, on the contrary, die almost instantly.

When the Night Adder finds himself in a house in his quest for mice, he seeks to conceal himself in whatever place is handiest. Consequently, where Night Adders are common, as in Natal, it is quite an everyday occurrence to find them in cupboards, under beds, chests of drawers, and various other hiding-places in houses. When turning out lumber from old outhouses, I have often killed a dozen Night Adders, and many scores of young ones.

I have always found these snakes to be exceptionally inoffensive. Unless hurt or irritated by rough handling, or very much frightened, they never attempt to bite. Those which I have kept in captivity became so tame that if lifted up gently they showed no disposition whatever to bite.

One day I was helping my men to renew some fencing-posts, which those pests, the "White Ants" (Termites) had eaten up. Kneeling down, I thrust my hand into a hole from which an old 
post had been withdrawn, and pulled out a handful of rubbish, amongst which a Night Adder was coiled. It did not attempt to bite. The one idea was to escape. One of these snakes nearly got its fangs into my hand one day. Riding across the veld, I spied the cast skin of a snake in a tuft of grass. Dismounting, I examined it, and seeing that it was unbroken, I determined to secure it.

Inch by inch I disengaged it, when, simultaneously as I pressed something soft, I heard a hiss. A dark body shot forward, and, with a thud, its forepart struck the ground violently. A Night Adder was in the act of casting its skin, and when I inadvertently pinched its tail, it waxed wrathful. It aimed straight enough, but my hand was not there, for I had jerked it away.

\section{The Venom of the Night Adder.}

The Night Adder is greatly dreaded, the prevalent belief being that a bite from one of these snakes will certainly prove fatal unless antidotal measures are promptly taken.

After a series of experiments on animals I have found that its venom, although potent, is not nearly so powerful as that of the Cobra, Namba, Puff Adder, or Boomslang. Animals bitten by Night Adders usually recovered completely after moping for two or three days. Local swelling and more or less hemorrhage took place. In recent experiments I found that when a large, well-nourished Night Adder was allowed to bite the leg of a fowl or rabbit, and retain its grip for two seconds, the rictim died in from half a day to a day. In the majority of the cases when the snake was allowed to bite fully, but not to retain its hold, the animals recovered in a couple or three days. A strong, vigorous man would not be likely to die if bitten by one of these snakes in the ordinary way.

In the Eastern Prozince Herald, February, IgII, the following account of the death of a well-known man in these parts is reported:-

"Private telegrams were received in town early yesterday morning conveying the sad news of the demise of Mr. R. C. Parkin, of Bluegum Arenue, one of the oldest and most respected farmers in the district. 


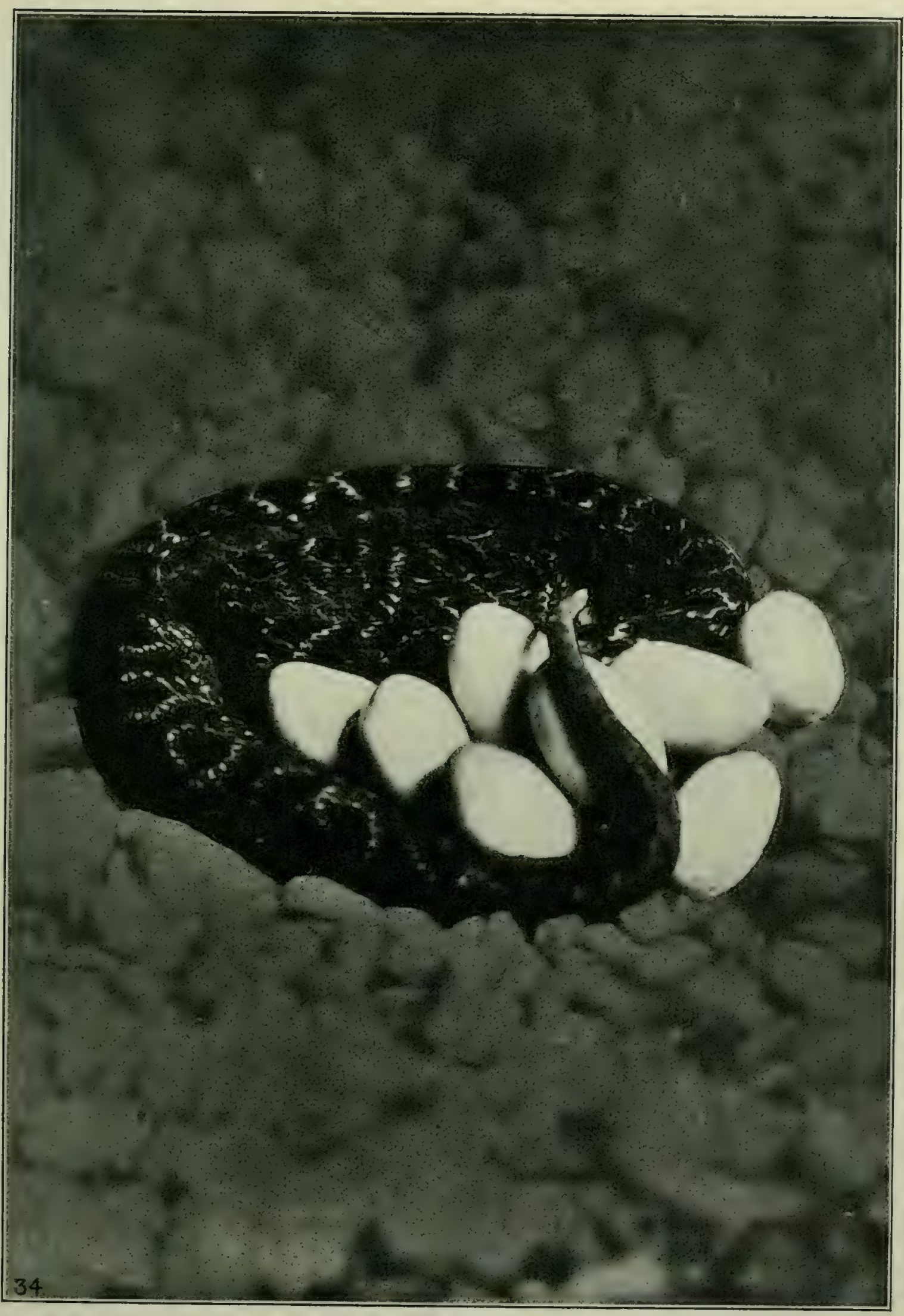

NIGHT ADDER LAYING EGGS.

FiG. 95.-A Night or Demon Adder (Causus rhombeatus) at Pt. Elizabeth Museum, laying Eggs. It laid I4 eggs, and remained several days, until disturbed by the assistant. Eggs are laid mostly in Nov., Dec, and Jan., and hatch about March. 
"It appears that at about eleven o'clock on Tuesday morning, Mr. Parkin was bitten in the thumb by a Night Adder, and following the usual course adopted in such cases, he immediately proceeded to suck the poison out. This seemed to have the desired effect, and to all appearance it seemed as though the puncture had been a slight one.

"Later in the afternoon, however, his face and head commenced to swell up, and Mr. Parkin's condition became exceedingly alarming. Every possible deterrent available was tried, but to no effect, and death ensued at seven o'clock in the evening.

"It is thought that some of the poison injected by the fangs of the Adder sucked from the wound had re-entered Mr. Parkin's system by means of a scratch or bruise in the mouth or tongue, but this is mere surmise."

On making inquiries, I ascertained that Mr. Parkin's head and throat were greatly swollen, and the muscles of the mouth, eyelids, and face were paralyzed. The throat continued to swell, and he eventually died of suffocation. If an air-tube had been inserted in the windpipe below the swelling, his life might have been saved, as the swelling would gradually have subsided.

There can be little doubt that the deceased gentleman was suffering at the time from inflammation of some portion of the lining membranes of his mouth, or perhaps the teeth were decayed or the gums ulcerated or otherwise injured, which allowed some of the venom to be absorbed. These parts are so intensely susceptible to the action of venom, that a very small quantity will cause extensive swelling of the mouth and throat. In medical literature, cases are recorded of men dying of suffocation caused by extensive swelling of the throat consequent upon the sting of a hornet, wasp, or bee, which had been accidentally swallowed with some beverage, and, in passing, stung the back of the throat.

If sucking is resorted to in cases of snake bite, when the person is not sure his mouth is in good condition, he should put a tiny pinch of crystals of permanganate of potash in the palm of his hand, spit on them, mix and lick it, just previous to applying his mouth to the wound. The permanganate will kill any venom sucked up. Of course, if permanganate is rubbed into the wounds, and if they are subsequently sucked, there will be no 


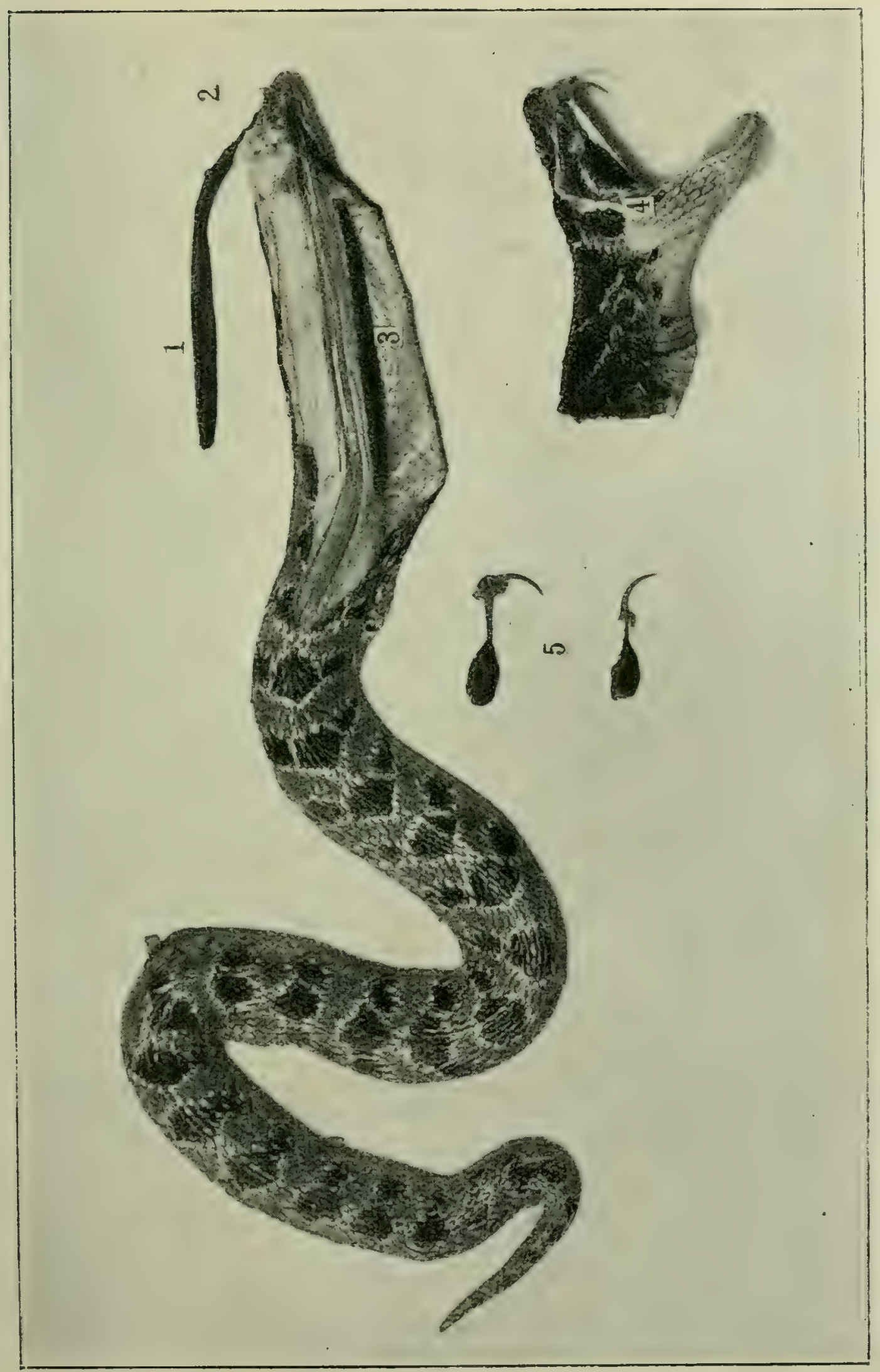

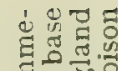

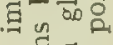

흥휴류

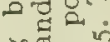

然管此

तै 롱

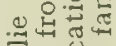

渮응

要表

琼

i 递点

茫

क्षे

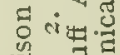

क

爷。敋

द

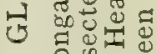

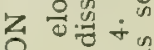

苛

कि 4 ज्ञ

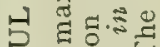

证

要

a

का हैे क्ष

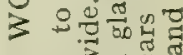

n 0 당

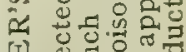

至

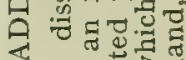

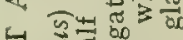

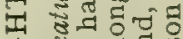

눙

z 궁

되

yํำ

건

ड़요

的宁

㟧

द

a w

의

हुํำ

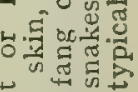

藏苞寻

治节节

4200

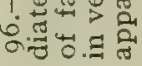
它 
danger of the venom being absorbed by the mouth, for the sucked up venom will be mixed with blood, mucous, and permanganate. The presence of the latter will render the poison harmless.

An acquaintance of mine was bitten on the little finger by a Night Adder. He instantly undid a bootlace and ligatured the finger at the base. Sitting down, he scarified the wound, and started sucking it. The snake bit him at ro a.m. in his garden. At 3.30 p.m. we found him still sucking the wound. He said that he had been sucking it at short intervals ever since being bitten. He was in a state of partial collapse, which I attributed to nerve shock, believing as he did that a bite from a Night Adder was almost certain to terminate fatally. The following day he had recovered, but the finger suppurated, and refused to heal for four months. A year later it again broke out, and a large dark scab formed over the site where the snake had bitten him. The skin of the whole finger sloughed off, and the wound healed. The following year it again broke out and did likewise. The third year the same thing occurred, but to a lesser degree. Since then there has been no recurrence of the symptoms.

In cases of bites by Puff Adders I have known the same thing often occur. The popular belief is that this periodic ulceration at the site of the bite will continue until the death of the snake which inflicted the bite. This, of course, is quite without foundation. The origin of this superstition can be traced to the natives, who are firm believers in it. I have known Kafirs to seek for days for the snake which had bitten one of their friends, in order to kill it, so that the wound would quickly heal.

\section{Remarkable Poison Glands.}

With perhaps two or three exceptions, renomous snales have their poison glands situated at the sides of their heads, just beneath and behind the eyes. The glands are almond-shaped. The Night Adder is an exception to this general rule. Its poison glands are very long, and lie on each side of the backbone of the neck-region communicating with the poison fangs in the mouth by means of the usual duct, which is also unusually long. The illustration (Fig. 96) shows this apparatus.

The Night Adders are the most interesting of all South 
African snakes to keep in captivity. They are bright and active and become very tame, and, moreover, unlike most other snakes, they will feed very freely. I have kept several for many years, some of which have grown considerably since their capture. They are fed upon frogs and toads.

There is always great danger of treading upon and getting bitten by Night Adders, because they are very sluggish, and do not make much effort to get out of the way, often preferring to lie quiet, seeking to escape observation by that means. The danger is increased by their habit of lying across pathways, their colour harmonizing with that of the ground. They are termed Night Adders because they usually issue forth from their lairs about dusk.

Although belonging to the Viper family, the Night Adders are oviparous; that is, they lay eggs. Those I have kept in captivity laid batches of eggs varying in number from a dozen to twenty-five, during the summer months. None of the eggs showed any signs of incubation. The parent in most instances coiled round her eggs and remained there several days, but eventually abandoned them owing to being repeatedly disturbed by the other snakes, and the attendant who cleaned out the cage and renewed the water in the water-vessel. In nearly every case the parent showed the desire to incubate the eggs, and from this I infer they often remain coiled round the eggs, until they are incubated, in the wild state. The eggs of snakes can easily be hatched by placing them in damp earth and putting them in a chicken incubator. A farmer gave me some Night Adder eggs which he ploughed up in a field. I placed them in a box of damp earth and dead leaves and left them out in the sun. In a month's time they hatched out.

\section{ERRATA.}

In the "Cambridge Natural History on Amphibia and Reptiles," by Gadow, page 638, there is the following: "All the Viperidæ are very poisonous, and all except the African Atractaspis are viviparous."

Fayrer, in his "Thanatophidia of India" says: "All the Viper family of snakes, as their name implies, are viviparous."

The Atractaspis snakes, viz. the Oviparous Adder and 


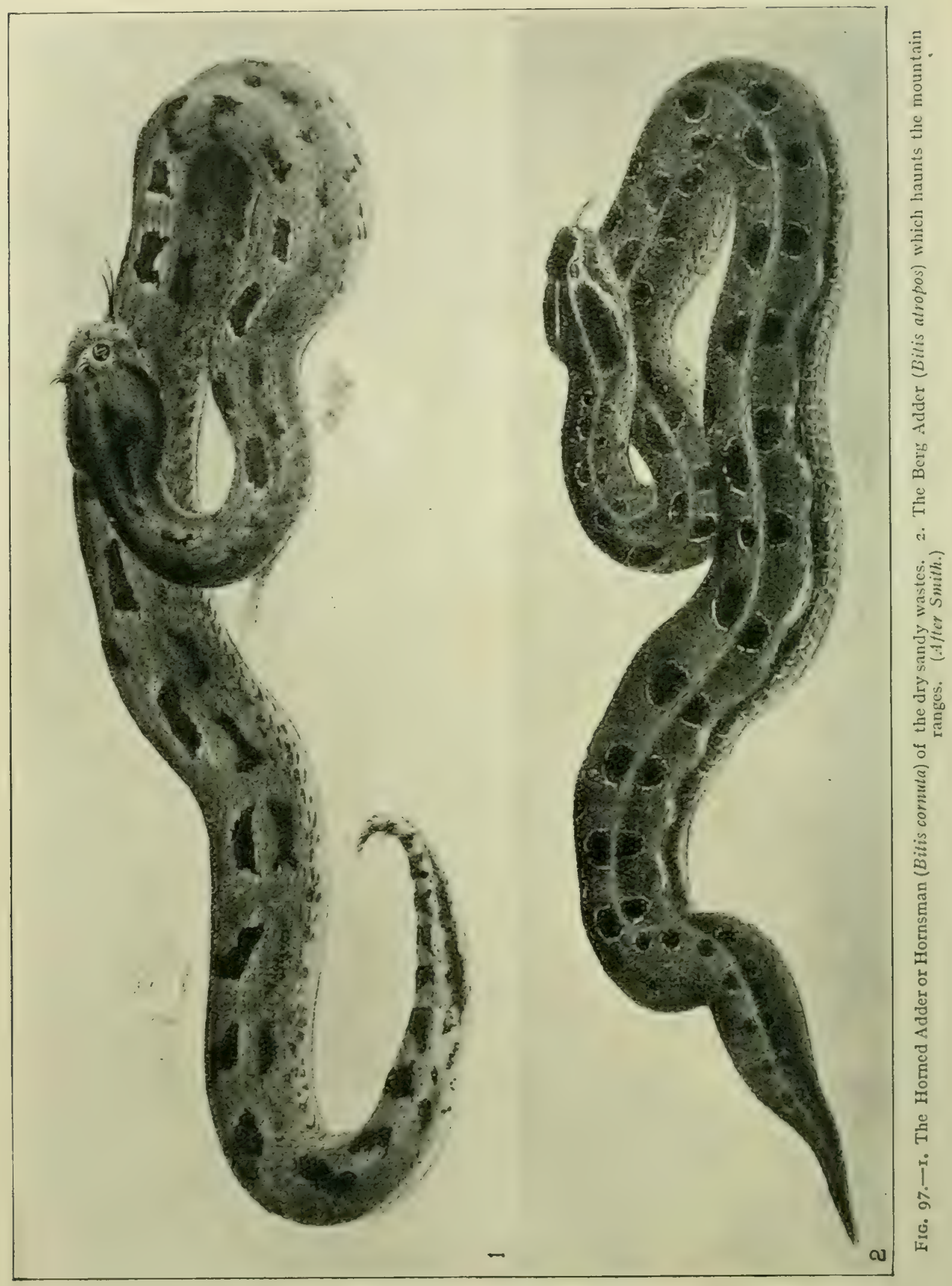


Duerden's Adder, lay eggs, but the Night Adder (Causus rhombeatus) does also. Doubtless the other species of the Genus Causus are also oviparous.

\section{The Horned Adder, or Hornsman.}

The Hornsman is a small adder with the characteristic flattish body and broad head of the Viperine family of snakes. These vipers are usually about a foot to one foot six inches in length. There are two species, the only notable difference between them being that the one known as Bitis cormuta has two or more erect horn-like scales over each eye, while the other, which is known as Bitis caudalis, never has more than one erect horn-like scale over the eye. The former occurs in the sandy districts of the Western Province of the Cape Colony and northwards to German West Africa. The latter is found in the midlands of both provinces of Cape Colony, and extends to Rhodesia. They have a habit of burying their bodies in the loose sand, the head only being above. In this position they will lie for hours, often for a whole day on the watch for lizards and other small creatures on which they feed. Being practically invisible when thus concealed, they are especially dangerous to the bare-footed native, who is bitten the instant he places his foot upon one, unless he luckily happens to step right upon its head. Even then the chances are the snake will extricate its head in time to deliver a bite before the foot has been withdrawn. These snakes are capable of inflicting a bite which will cause death to a man. However, the chance of a fatal issue is considerably less than if bitten by a Puff Adder or Cobra. This adder gets its name of Hornsman from the fact of its having two or more erect scales on its eyebrows, which look like tiny horns. They give birth to young, usually a dozen to sixteen in number, in the early autumn.

Unless kept in captivity in a large cage out in the open in which plenty of sand is strewn, these snakes will not live, as they refuse to eat, and die in a short time. They are, moreover, very susceptible to a change of environment. I have obtained scores of them (Bitis caudalis) from the Karroo and endeavoured to keep them alive at Port Elizabeth without success. The atmosphere is evidently too moist for them. The dry sandy wastes are their natural habitats. 


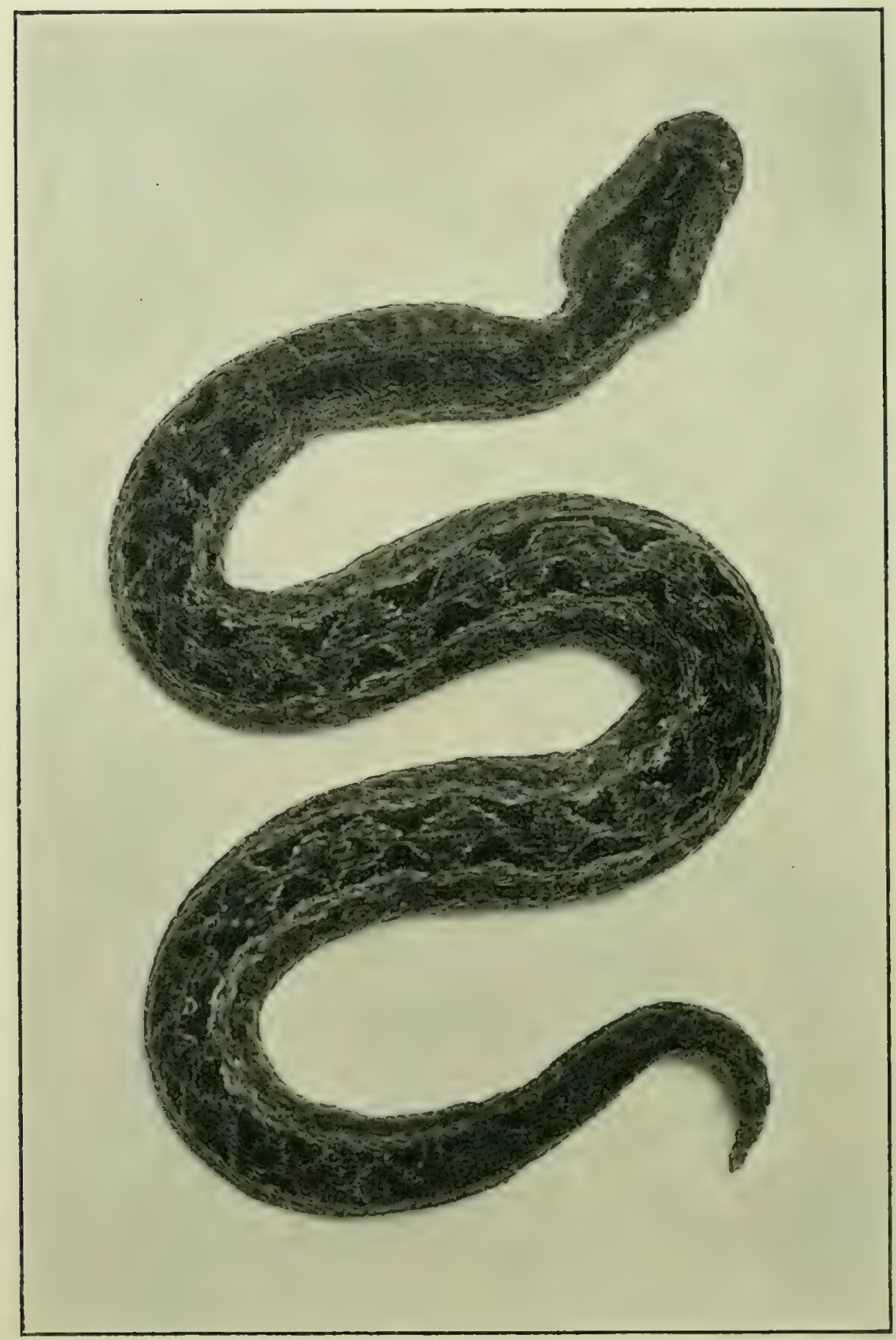

FIG. 98.-The venomous Berg Adder (Bitis atropos) which inhabits the mountainous parts of South Africa. 


\section{THE BERG ADder.}

\section{(Bitis atropos.)}

The Berg Adder, as its name implies, is a snake which inhabits mountainous regions.

This Mountain Adder inhabits the mountain ranges of the whole of South Africa. In these parts it is frequently met with out on the bare hillsides prowling round in search of lizards on which it principally feeds. When the occasion presents itself, the Berg Adder will devour the fallow young of birds which build their nests upon the ground. The chicks of the Mountain Partridge or Francolin frequently fall victims to this crafty Adder, who lies as still as the stones and earth which he so closely resembles. Mice, rats, the larger larvæ of insects, etc., are also eaten by it. The Berg Adder is as venomous as the Puff Adder. I have never succeeded in keeping these snakes alive for long in captivity. Unless kept under strictly natural conditions, and in a climate similar to that of their native home, they, like many other species of snakes, decline in health, refuse to eat, and die. At the Port Elizabeth Museum I have tried many times to keep Berg Adders alive by artificially feeding them. The temperature of the air was warm enough for their requirements, their cage was large and cosy, but there was something wrong. It was evidently the change from a high altitude and dry crisp air, to the moistureladen air of the seaside.

\section{The Atractaspis Vipers.}

These snakes, although classed with the Viper family, are altogether different in shape from most other members of this family. Their bodies are cylindrical, head small and not distinct from the neck, eyes very small, and scales smooth and closefitting. In fact, any one is apt to mistake these vipers for harmless Blind Burrowing snakes (Typhlops), for, in addition to their outward appearance being somewhat similar, their habits are more or less the same as those of the Blind Burrowing snakes, or Acontias or Legless Burrowing Lizards. There are eleven species of these Atractaspis snakes in Africa, two of which inhabit South Africa, viz., the Oviparous Adder and Duerden's Adder.

A remarkable thing about them is the development of their 


$$
\{
$$


fangs. The fangs are abnormally developed, so much so that I do not think it possible for the jaws to be opened sufficiently wide for the snake to inflict a bite. Most of the solid teeth have disappeared, or are in a rudimentary condition. There can be little doubt but that these Atractaspis vipers once had the general appearance and habits of other members of the family, but owing to their taking to burrowing habits, their outward form has gradually been undergoing a change, and doubtless in course of time the fangs will disappear or become considerably smaller. Owing to its habit of burrowing, this genus of snake is seldom found.

The Atractaspis Vipers furnish us with an illustration of what Darwin means by the Evolution of species. Here we have a Viper which, through changing climate and other conditions, took to burrowing habits. The whole anatomy of the creature has been slowly modified to suit its new environment.

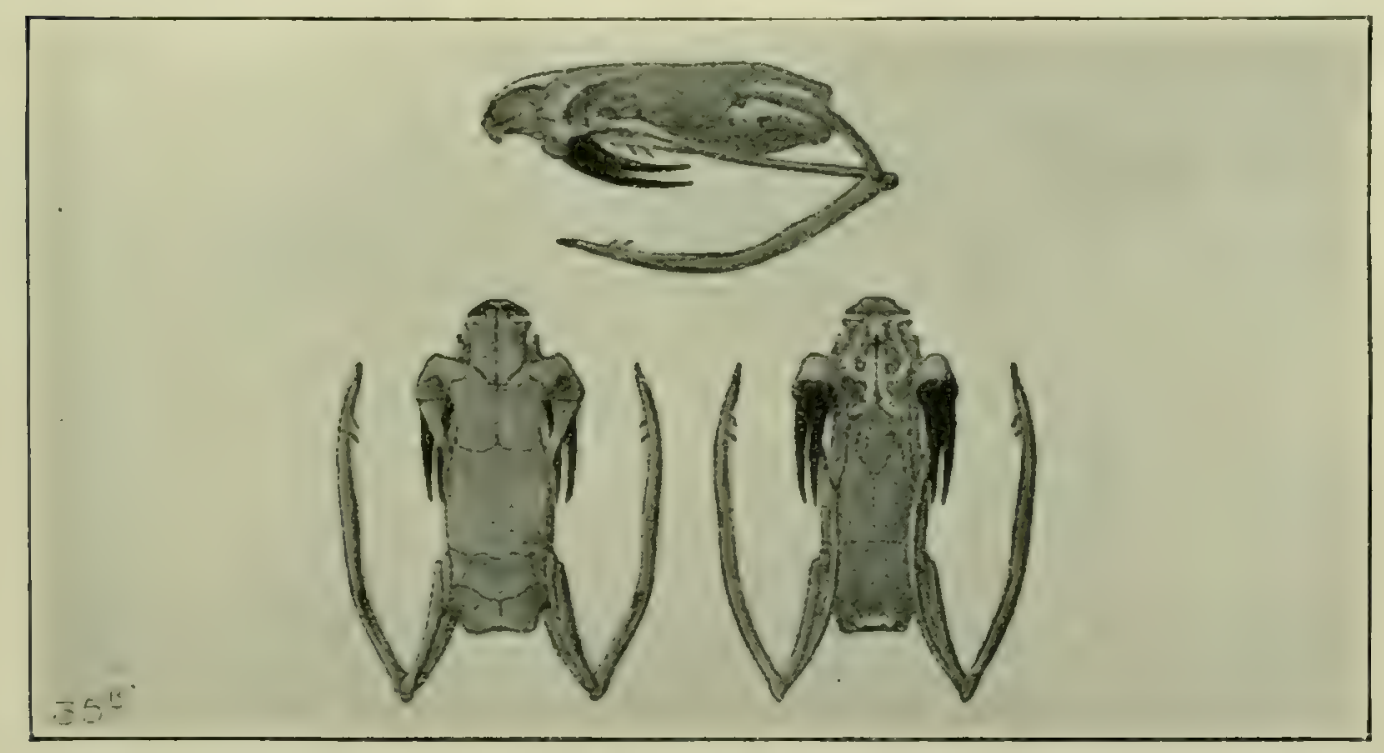

FIG. I00.-35B. Fangs of an Atractaspis Adder. Its nose is sharp and hard, and suited for digging in soft ground, and its body is smooth and formed for gliding through loose earth and sand with the minimum amount of resistance and friction. 


\section{CHAPTER VIII.}

\section{SNAKE ChARMERS.}

SNAKE charmers have existed for long ages in India. They are referred to in ancient Sanskrit books.

The typical dress of a snake charmer is yellow clothes and a great turban. The musical instrument which they allege is an indispensable adjunct in charming snakes is a double pipe mounted on the dry shell or rind of a calabash or gourd. It is known as a "Tubri." The sound produced is somewhat similar to that of the Highland bagpipes.

Snakes are very susceptible to strong vibrations of sharp penetrating sound. The effect of the high-keyed notes produced by the snake charmer's instrument, causes intense uneasiness and alarm in wild snakes. Even snakes which have been kept for a long period in captivity, and which have been habituated to the sound, will invariably become active and assume a defensive attitude when this instrument is played.

When released from its dark prison in the snake charmer's basket, a Cobra will always rear, expand its hood, and be instantly on the defensive, if sharp and shrill music be played near it. The onlookers imagine the music has charmed the snake. The snake charmer fully understanding the ways and habits of the Cobra, can therefore anticipate its movements. By swaying the instrument and his body from side to side, he can apparently make the serpent imitate his movements. This swaying of the reared portion of the snake's body is natural to the Cobra. When reared and on the defensive, the Cobra carefully watches his enemy and follows his every movement. By sitting on the ground in front of a reared Cobra and gently swaying the body from side to side, anybody can made the reptile do likewise. When a Cobra is alarmed, his first instinct is to face his aggressor and continue 
facing him, for the snake is well aware that he is at a serious disadvantage if taken in the rear. If you start walking round a Cobra you will find he will face you all the time. He carefully turns his body to time with your degree of speed. By walking round and round a Cobra for some time, he can be completely exhausted.

I have, many times, succeeded in doing with Cape Cobras what the Indian snake charmers do with their Cobras, but the snakes were by no means charmed or hypnotized, for the simple reason, as already stated, that it is a natural habit of the Cobra to follow any sudden or rhythmic movements of the hands, head, or body. The snake charmers usually render the snakes they handle harmless by removing their fangs, by either snipping them off or dissecting out the anterior maxillary bone to which they are attached. This latter operation prevents any subsequent development of fangs.

I have examined the collections of snakes of a considerable number of snake charmers, and found that most, and sometimes all the snakes belonged to the harmless species.

The snake charmers always positively refused to allow me to examine the mouths of the reptiles, hypocritically pretending that I would be bitten and die.

However, the fangs are not always removed. It is a fact that the more daring and fatalistic snake charmers freely handle the deadly Indian Cobra. These men are, from long observation, thoroughly acquainted with the natural movements of this snake, and are exceedingly dexterous in the use of their hands, for they all practise the conjuring art, which mainly takes the form of deceiving the eye by the rapid movements of the hands.

Although apparently careless in handling these deadly serpents, the snake charmers are, nevertheless, keenly on the alert, knowing full well that a bite will probably result in death. Many cases are on record of snake charmers having lost their lives by being bitten by the snakes they professed to charm.

These men profess to charm snakes from houses and other retreats. What they really do is to conceal one or more snakes about their persons, the fangs of which, of course, they have carefully removed previously. Sleight-of-hand work being their profession, they invariably find it an easy matter to withdraw one of the concealed snakes and surreptitiously place it in the spot 
desired. Then the charming begins and the snake is discovered. These snake charmers often have allies who place a snake in the spot required prior to the advent of the charmer.

When a snake charmer is kept under careful and close scrutiny, these snake-charming operations fail. A gentleman tells how he detected one of these men. Raising a great noise he declared to his Indian servants that a Cobra was in his study. He sent a messenger to the village snake charmer to come immediately and charm out the snake. He arrived in due time and began operations by playing upon his pipes at intervals, and poking about amongst the furniture. Suddenly he began playing rigorously in a corner of the room, near some bundles of books and magazines on the floor. From amongst them the head and neck of a Cobra reared itself. The gentleman advanced and flourished a stick, pretending he was anxious to kill the reptile. The charmer interfered and barred the way, declaring that he wanted to capture the snake and keep it alive. He was firm in his refusal to permit the gentleman to advance. Then, stooping down, he began blowing his pipes again, and the instant the Cobra reared he seized and transferred it to a bag amidst the horrified exclamations of the Indian servants. Needless to say the alarm was a bogus one. The snake was one which had been secretly dropped by the charmer when he was fussing about the room on his hands and knees.

When one becomes familiar with the habits and ways of snakes, and if due care is exercised in handling them, there is little real risk of being bitten. For twenty years past I have freely handled snakes, and have only been bitten a few times, but the bites have never been full ones. Naturally one is apt to become careless when frequently handling snakes, and so reasonable precautions are neglected.

To those more or less unacquainted with snakes, these reptiles are regarded with extreme horror, and the most ludicrous beliefs are entertained in regard to them; so much so, that any one handling venomous snakes freely, and apparently in a careless way, is thought either to exercise some hypnotic power over the creatures, or else he is taking appalling risks. Snake charmers, knowing this, take advantage of it. The traditional love of serpents for music is a myth. The only effect music has is to frighten, irritate, or excite the curiosity of snakes. A snake will 
frequently protrude its head from its place of concealment in a hole, crevice, or amongst the herbage when shrill music is played, or even the clinking of a chain, or beating a steel triangle. Sounds of high pitch excite it. Low muffled sounds or the beating of a drum it pays little or no heed to.

\section{The Port Elizabeth Snake Catcher.}

The snake charmers of India would pale into insignificance when compared with Mr. James Williams, the Port Elizabeth Snake Catcher, who for some years past has captured venomous snakes for my experiments, and for exhibition in the Port Elizabeth IIuseum. He makes no pretence of exercising any hypnotic power over these reptiles. From the very beginning he evinced a keen interest in snakes. Nothing pleased him so much as to be helping with my experiments. He gloried in holding venomous snakes between his finger and thumb while I extracted their venom for experimental purposes. $H e$ is an Irishman, and like the majority of that nationality, always willing to take big risks.

He knows all about the ways and habits of the local snakes, and therefore can find and capture snakes almost at any time. I must admit, however, that the doings of Mr. Williams, and his absolute fearlessness, in fact I may say recklessness, startle even me. As will have been read elsewhere (on p. I4I), he was once bitten by a Boomslang and lay apparently dying for a couple of weeks, with huge dark purple patches caused by hæmorrhage, all over his body. He lay there suffering agonies of pain, due to acute inflammation of the mucous surfaces of his bowels and other parts, and for a considerable time after rising from his sick-bed he felt the after-effects.

Yet James Williams will come sauntering along to me, and with a tired and indifferent voice observes: "Sir, I managed to catch two fine Boomslangs to-day." Diving his hand into a satchel or linen bag, he forthwith drags out the writhing, struggling reptiles, and allows them to twist and coil about his arms and neck. He just smiles and remarks that Boomslangs seldom bite if they are handled gently when they have once been captured and kept for a time in a dark bag. 
He brings along Puff Adders, Cobras, Ringhals, Night Adders, and in fact every kind of snake obtainable in Port Elizabeth district. As often as not he has his pockets stuffed full of live snakes, which are prevented from escaping by the lapels being pinned down. If pins are not available, he utilizes the sharp thorns of the Mimosa tree.

Long ago I carefully instructed him what to do in case of being bitten. He instantly sucks the wound if there be no abrasions of skin in his mouth. Meanwhile, he is feeling for his penknife, with which he scarifies the flesh over the punctures, rubs them full of permanganate crystals and immediately applies a ligature at a convenient place between the wound and the heart. He then encourages the wound to bleed by manipulating the surrounding flesh with his fingers, and if the snake be a very venomous one, such for instance as a Ringhals, Cape Cobra, or Puff Adder, he severs two or three of the veins in the ligatured leg or arm as the case may be and thus lets out some of the poisoned blood before taking off the ligature. Then the ligature is momentarily loosened at intervals, until, after an hour or so, it is discarded.

When assisting with experiments and artificially feeding our captive snakes, he has been bitten three or four times; but, owing to prompt treatment, he got off with only slight constitutional disturbance in each case. I have not yet had occasion to resort to the injection of anti-venine serum. True, he needed it badly when he was bitten three years ago by a Boomslang, but unfortunately none was at hand.

\section{Bent on Collecting.}

Williams sets out, armed with a forked stick about five feet in length, and a rather large linen bag similar to an ordinary pillow case, and tramps the country for a score of miles, visiting all the favourite haunts of snakes. A serpent once sighted has little chance of ultimate escape. Even the swift Boomslang is no match for him. Knowing its habit of darting into the thick foliage and vanishing in an instant, he cautiously stalks it as it lies basking in the sunshine out in the open upon the ground. With a swift rush he is upon it. Before the bewildered snake can 


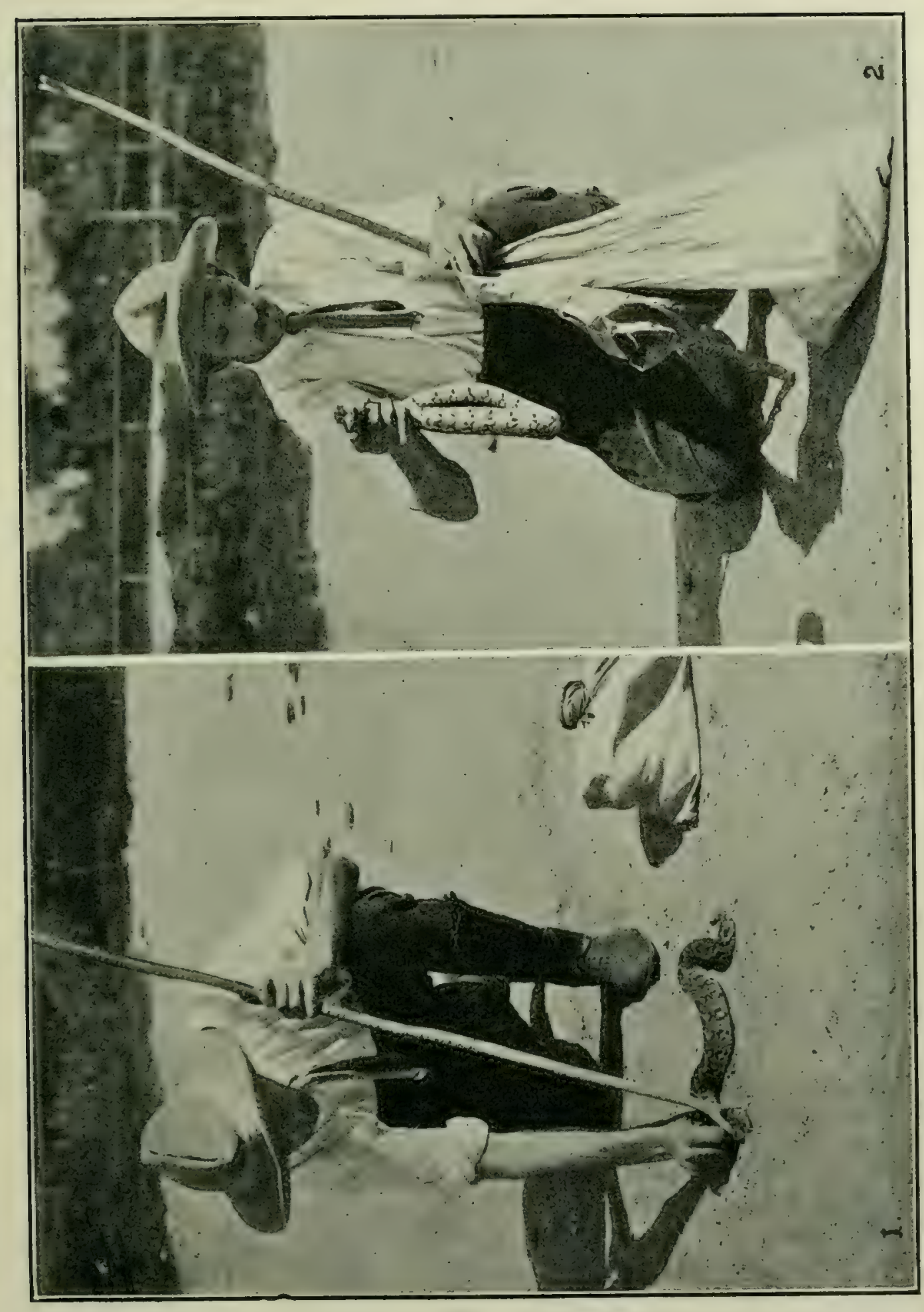


put its three hundred odd ribs and scales in motion to effect its escape, he has secured it. If it should succeed in getting into the bush, he follows without a second's delay, plunging headlong in its wake. The very impetuosity of his onslaught is a safeguard, for the snake is usually too bewildered or terrified to think of turning upon him to bite. Swinging his captive round and round by the tail, he opens the mouth of his bag and drops the dizzy reptile therein. Picking up his stick he resumes his quest.

Spying a Puff Adder or Cobra vanishing into the thick tangled scrub, he springs forward, grabs its tail, and carefully pulling it out gives it a few swings round his body at arm's length, and then bags it. Puff Adders he has a great contempt for. He lays hold of the tail, and without any preliminary swinging drops the reptile into his bag. All the snakes captured during the day's excursion are consigned to the same receptacle.

The next morning he brings them along to me. "Well, Williams, any luck yesterday?" "Yes, I got a few." Opening the mouth of the bag, and drawing out a Puff Adder by the tail, or with his finger round its throat, and his thumb pressing its neck just behind the head, he holds it up for inspection, observing, "It's a beauty, isn't it?" He heeds not my warnings. I continually assure him he will die a miserable death from snake bite one day, away out upon the lonely bush-veld; but he merely smiles and says that he has got to die some day anyway, so as well from the bite of a snake as sickness or old age.

Whenever Indian snake charmers visit Port Elizabeth, Williams amuses himself by stepping out from the assembled crowd of onlookers, picks up and examines the dentition of the snakes which the Indian has been charming, and which he has assured the people are highly venomous. Finding the snakes to be of the harmless species, or the fangs removed, he thrusts his finger into the mouths of two or three.

Indian snake charmers in Port Elizabeth have a bad time when Williams is about, for, somehow, coins do not flow in so readily from the onlookers when they find out the snakes are, after all, quite harmless.

On evening during a lecture on snakes to farmers, who firmly believed that every snake was venomous, Williams handled a large number of non-venomous Mole Snakes and House Snakes. At 


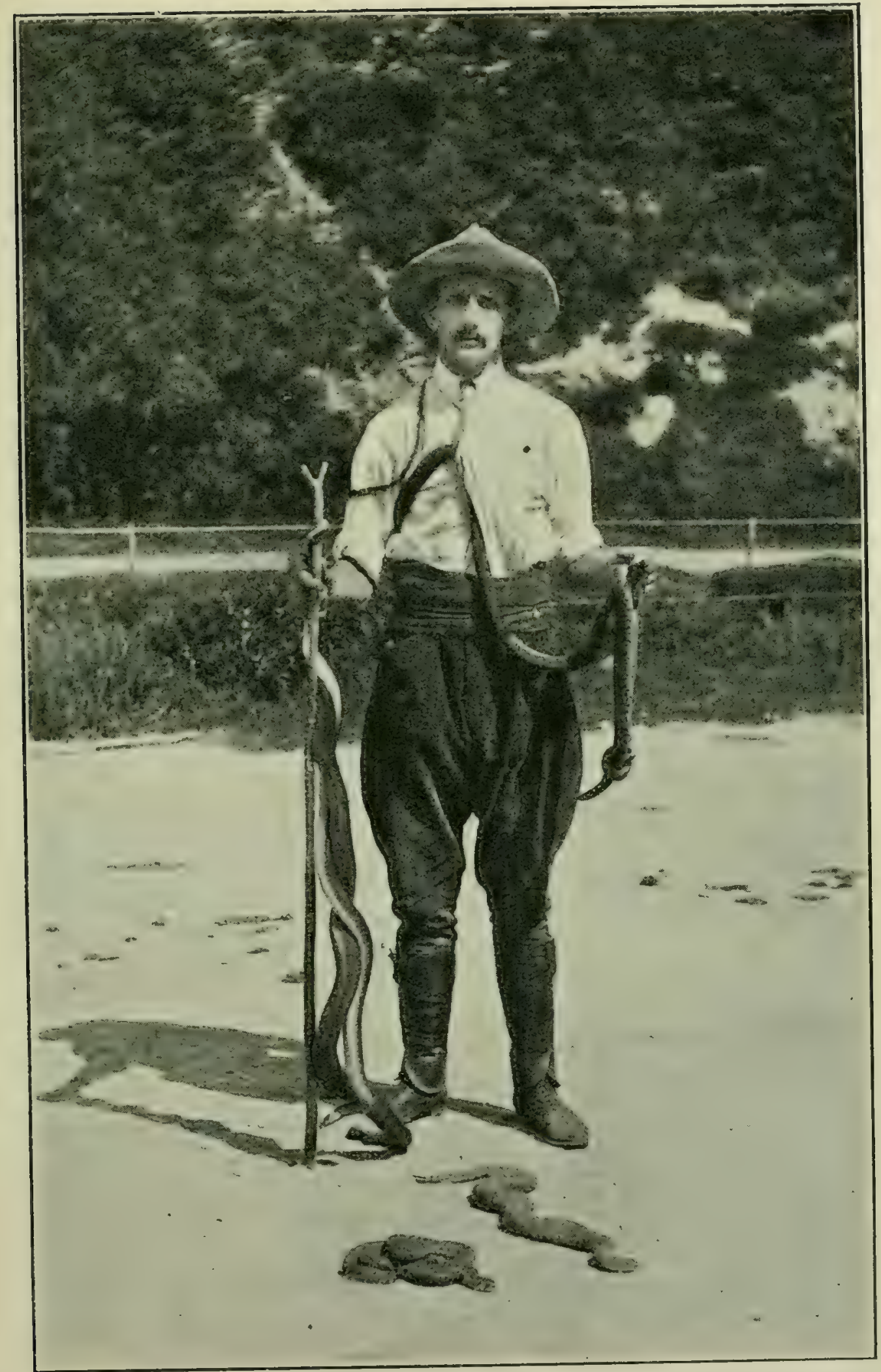

FIG. I02.-Williams has returned from a snake hunt, and is showing me his captives. The snakes at his feet are Puff Adders; in his right hand, Mole Snakes; in his left, Boomslangs. 
the conclusion of the lecture I counted sixteen bites on his bared arms, hands, and neck.

\section{An American Snake Catcher.}

I was much amused to read an illustrated article in a wellknown magazine of the "daring and perilous " exploits of a snake collector in America. This brave man who " ran the most appalling risks " of death from snake bite, issued forth on his snake-catching excursions clothed in a leather shirt, a pair of tough leather breeches, top boots, gauntlet gloves and a mask. What a brave man he was, and what a perilous occupation was his! Williams, the South African snake catcher, sallies forth in a cotton shirt, slouch hat, rolled up sleeves, and as likely as not a pair of thin khaki trousers. Occasionally he wears leather gaiters. These latter he dons for protection against the thorny shrubs which abound in the South African veld, more than as a safeguard against snake bite.

\section{Can Snakes fascinate Their Prey?}

That snakes are able to exercise some power of mesmeric or hypnotic power and so paralyze the movements of their intended victims, is almost universally believed throughout the Western world, except amongst those few naturalists who have made a close study of the subject. Popular literature is teeming with anecdotes and essays on the power of snakes to fascinate birds, small mammals, and even human beings.

In all literature, ancient and modern, frequent references are made to snakes. In Egypt there are many ancient carvings of the Egyptian Cobra on the old ruins of a past civilization.

The fact that a snake carries a subtle, potent fluid, and an apparatus by which, at any moment, when least expected, a death wound may be inflicted, has caused mankind to invest snakes with the most magical and diabolical of powers, leading to snakeworship and the belief that serpents are the incarnation of all that is cvil and demoniacal. The Cobra is an object of reneration and superstitious dread even to-day among the natives of India. 
Owing to the death-dealing powers of serpents, and the heredi-

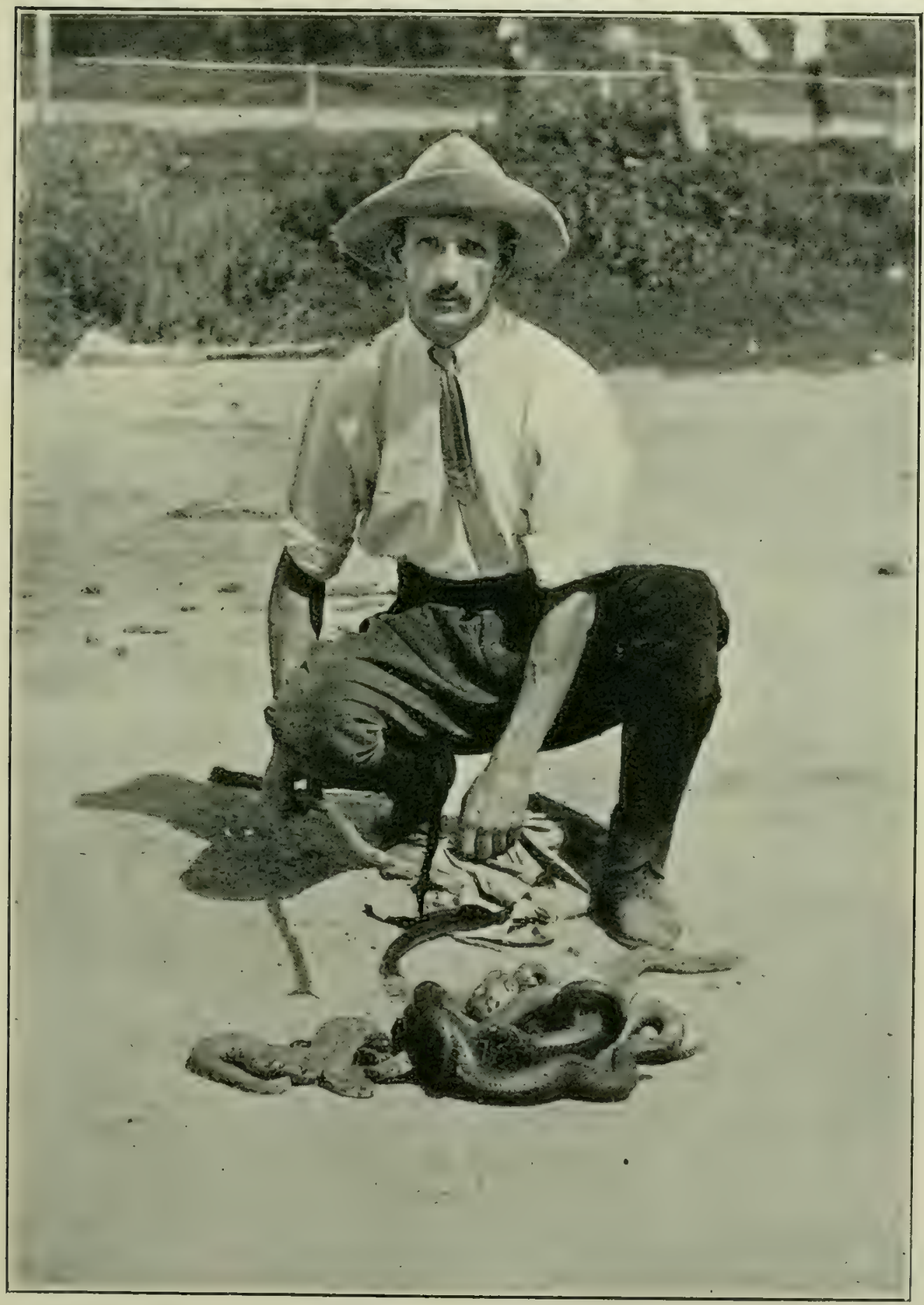

FIG. I03.-The contents of Williams' bag-Puff Adders, Boomslangs, Mole Snakes, Cobras,

tary influence upon our minds of the beliefs and fears of our 
ancestors, we have come to regard snakes with the profoundest awe and dread. Writers have not been slow to profit by this universal interest in snakes and their venom, and thrilling anecdotes and other writings have been the outcome. Remarkably interesting and imagination-stirring articles have frequently been written on the powers of fascination supposed to be exerted by snakes.

Practically all the popular beliefs in regard to snakes have very little foundation in fact. This belief, however, is so widespread, and its truth insisted upon so strongly, that many naturalists have unquestioningly accepted it as true, and recorded it in literature as being a fact.

Now, I have had much experience of snakes, and have made it my business to observe carefully their habits and ways, both in their natural condition in the wild state and in captivity, and in no instance have I ever known a snake to fascinate an animal in the manner it is alleged they do.

I have seen Boomslangs and Mambas many a time in trees, surrounded by a crowd of fluttering, chattering, excited birds. The birds were not fascinated by the snake; they were endearouring to intimidate it in order to frighten it from their haunts.

\section{What Really Happens.}

Carefully concealing myself one day, I watched a Mamba (Dendraspis angusticeps) surrounded by several chattering birds. mostly Bulbuls and Flycatchers. The snake, with elevated head, and body bent in a favourable position for a forward spring, remained amongst the branches as immovable as the Sphinx, its lidless, unwinking, shiny eyes giving forth a stony stare. I'resently a Bulbul, which had worked itself up into a frenzy of excitement, fluttered within striking distance. Like a stone from a catapult, the head and forepart of the snake shot forward, and next instant I saw the struggling bird in the serpent's jaws. The rest of the birds instantly fled. Now, the snake did not throw out any mysterious, mesmeric or hypnotic power. It simply awaited its opportunity, cool and collected, and captured an excited and venturesome bird. The bird was 
evidently unaware of the power of the snake to propel its coiledup body. I once saw a Green Mamba coiled up on a branch, and quick as thought, propel itself full length, and seize a bird in its jaws, meanwhile gripping the branch with its tail. The instant it seized the bird it swung head downward until the victim ceased to struggle. The snake then raised itself, assumed a comfortable position, and swallowed its prey.

Birds, with few exceptions, have highly impressionable. and excitable nervous organizations, as is proven by their hot blood, quick circulation, fine texture brain, and intricate nervous system. Now, we all know how birds will mob an owl which ventures into their haunts during the daytime, but we never think of investing the owl with any powers of fascination.

Birds recognize snakes as their enemies, and if a bird discovers a snake in its haunts, particularly in the vicinity of its nest, it instantly sets up a shrill chattering and flies and hops excitedly round the intruder. Its cries and actions attract its mate and other birds, until eventually there may be as many as a score around the snake. Their noisy demonstrations are sometimes so great, and their demeanour so threatening, that the serpent loses nerve and retreats, much to the relief and satisfaction of the birds who pursue him for some distance.

In most cases, however, the serpent remains immovable until one of the birds, in the excitement of the moment, or braver than the rest, approaches within striking distance.

It is quite possible, and even very probable, that a bird may work itself up into such a frenzy of excitement, as temporarily to lose the power of flight, and so fall a victim. Others, in their frenzy, may actually rush at the snake, particularly so if in defence of their homes and young.

\section{The Heroism of Birds.}

I have witnessed several instances of the heroism of birds in defence of their eggs and young. In Natal, one hot midsummer day, I lay on my back resting under the shade of a great forest tree. Hearing a noise above, I looked up, and high up in the branches I espied a pair of Sparrow Hawks near their nest endeavouring to beat off a Green Mamba, which was evidently 
intent upon securing their eggs or babies. Presently the snake reached the nest, whereupon one of the hawks flew fiercely at the serpent and gripped it with claws and bill. Instantly the snake struck out, again and again, and threw a coil or two round the bird. Down came the two, hurtling through the branches to the ground. The bird was either killed by the fall or the snake's venom, but its powerful claws were still embedded deep in the reptile's flesh. The snake struggled fiercely to release itself, but before it could succeed I killed it.

On another occasion, hearing a noisy clamour in a tree, I crept silently forward and saw a Boomslang or Tree Snake approach a nest and seize a fluffy baby bird. The youngster screamed and struggled frantically, whereupon the parent bird, in a frenzy of fury, flew at the snake. The reptile dropped the young bird, but, alas! it instantly gripped the brave mother. I ran forward, but the crafty serpent glided off amongst the leafage and vanished from sight with its victim.

\section{Wrong CONCLUSIONS.}

The ground-frequenting venomous snakes, such as the Cobras and Vipers, invariably strike their prey and immediately release it, knowing the potent action of their venom, and realizing the stricken creature will be quickly overcome by the poison. When a rat is introduced into a cage containing a Puff Adder or Cobra, the snake, after striking the victim, releases it, and contents itself with keeping it under observation. The rat, after being struck, grows dizzy, runs here and there at random, and is quickly overcome by the virulence of the venom. Often the bitten creature is instantly paralysed.

Now, if a bird, whilst feeding upon the ground, is struck by a venomous snake which has been lying in ambush, the victim invariably flies up to the nearest branch or twig; screams, flutters, sways unsteadily, and within a few minutes, being no longer able to retain its hold, flutters down dying to the expectant snake below, which in all probability, is intently watching its movements. Sometimes, after being bitten, the bird instantly loses the power of flight, and remains on the ground in front of the snake, fluttering and screaming. 
Seeing a bird in either of these positions would seem to the casual observer proof positive that it was being fascinated by the snake.

If a rat is cornered by a snake it often loses all presence of mind, and facing the reptile it simply squeals. This, however, is more usually the case after the snake has bitten it.

If a water snake should swim toward a frog sitting on the bank, the latter, whose dominant instinct is to dive into the water, becomes paralyzed with fear, and, sitting still, it emits a series of squeaks.

\section{Captive Snakes and Birds.}

British and European birds, having no snake enemies, are in consequence not at all afraid of these creatures. If placed in the same cage with snakes, they will confidently hop amongst the reptiles, and even perch on their bodies.

If birds of this country be placed in an aviary with snakes, they show little or no alarm if they are able to fly up to perches out of the reach of the snakes. After a few days they get quite indifferent to the presence of the reptiles, and will not hesitate to feed upon the ground within a few inches of their enemies. Perches have been so arranged that the birds were just out of reach of the snakes, and in no single instance did any of the various species of snakes ever exercise any fascinating power over them. Any bird which became over-confident and approached within striking distance was invariably bitten if the snake was in a mood for eating. If not, the birds were not molested. Practically all the popular beliefs about snakes in South Africa are more or less untrue. Most, if not all, of these erroneous beliefs have originated from the natives. If they were all collected they would fill a large volume, and provide entertaining reading to lovers of fiction.

\section{He was paralyzed with Fear.}

A friend had just arrived from the Homeland. I took him out to show him the luxuriant semi-tropical vegetation which is so profuse in Natal. Meandering along a kafir track through a forest, I paused for a moment to examine a curious insect. On 
stepping forward again, I noticed my friend was standing stiff and still. Then my eyes caught a glint of yellow, and a blackish patch. Yes, it was a Black-necked Cobra or Imfezi (Naia nigricollis) with forepart of body reared nearly two feet vertically, and hood fully expanded. There it stood, rigid, except for a slight, gentle movement from side to side. Its shiny black eyes

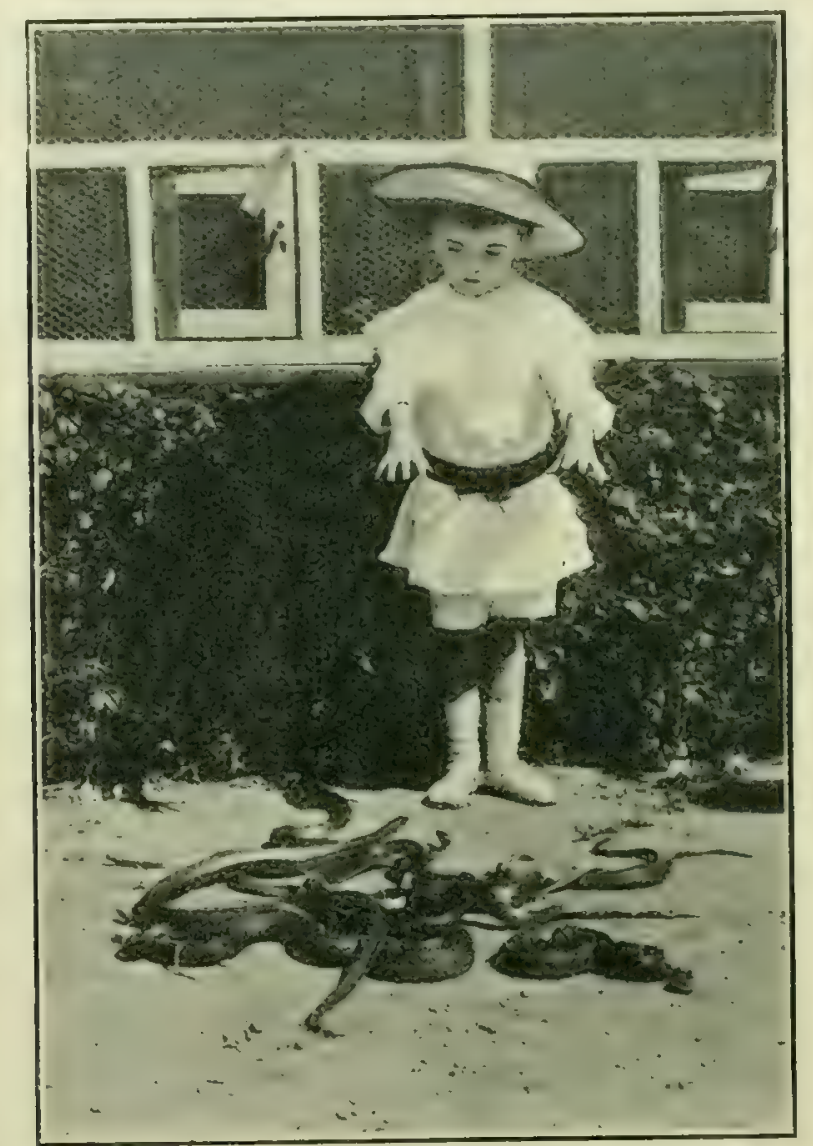

FIG, 104.-A juvenile snake charmer. This is Desmond FitzSimons and his collection of pet Mole and House Snakes.

were intently fixed upon my friend. Becoming alarmed for my friend's safety, I hastened forward and killed the snake with my staff.

Glancing at the young man's face, I was amazed to observe that it was fixed and set, the eyes staring rigidly in the direction of the Cobra.

I grasped his arm and shook him, whereupon a tremor ran through his frame, and, with a gasp and a succession of deep sobs, he collapsed and lay quite limp. 
When he had sufficiently recovered, he told me he had never seen a snake in the wild state before. He had only seen half-dead looking specimens behind thick sheets of glass in a Zoo. When he suddenly saw the form of a six-foot Cobra, with hood expanded, facing him threateningly, he instantly lost all power of movement. He said he seemed to freeze. He essayed to cry out, but his tongue and larynx were paralyzed. In fact, the sudden shock and fright had temporarily paralyzed the nerve centres in his brain which controlled the movements of his muscles. He was unconscious to all else but the Cobra. Its keen shiny eyes and threatening aspect monopolized his senses. In a dim far-off way he wondered when it was going to bite.

The man was certainly completely fascinated, but the condition was induced by the sudden shock of extreme fright to his nervous system, not by any hypnotic power exercised upon him by the snake. The sight for the first time of a large Cobra, with hood expanded, and reared ready to deliver a deadly thrust, shocked his motor nerve centres into a state of temporary paralysis.

\section{HYPNOTISM.}

It is quite possible for a person to induce a condition of selfhypnosis by focussing or concentrating his mind upon some object, such as a bright coin, or staring fixedly at the reflection of his eyes in a mirror and suggesting to himself that he is growing sleepy, more sleepy, asleep. He may not be able to induce a condition of actual unconsciousness in this way, but this concentration of the mind and repeated suggestion of sleep will make him very susceptible. Self-suggestion is a great aid in helping to overcome bad habits and nervous diseases. I have known people, who, by intently watching some object and excluding everything else from their minds, lose all power of movement. They remained, sometimes for half an hour, staring fixedly, and when the condition of hypnosis passed off, or when aroused by being shaken, they declared they either could not remember anything, or had only a glimmering of consciousness after concentrating for five minutes upon whatever object was selected.

There is no reason to doubt that this condition can be induced 
by intently watching a snake, particularly so if it be a Cobra reared, with expanded hood, keenly fixing the watcher with its shiny, black, unwinking eyes. Many individuals are very sensi-

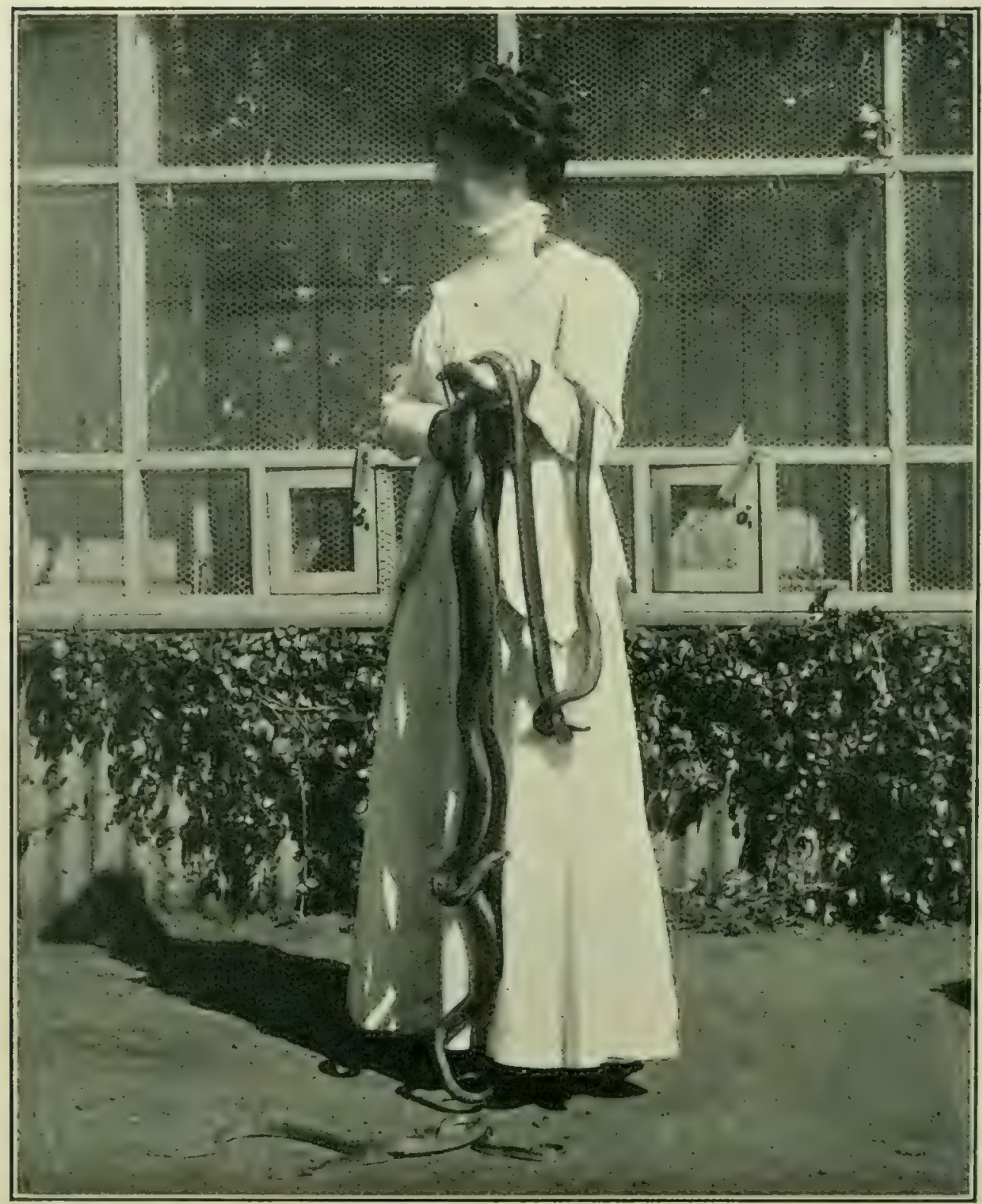

FIG. I05.-Some live snakes of different species.

tive to self-induced hypnosis, as well as suggestions or mesmeric passes by another person. Because there are individuals who can intentionally or unintentionally lapse into a hypnotic condition, this is no argument in favour of a snake possessing hypnotic 
power. It may certainly be the negative cause of self-hypnotization.

Apart from actual hypnotism and acute paralyzing fright, some persons' minds are so constituted that when faced with a sudden and unexpected emergency they lose all self-control, and act in a variety of ways. Some remain rigid, with bulging eyes. Others become hysterical; others again gibber and talk utter nonsense. The lower animals are apt to act similarly.

It must be borne in mind that humanfolk, as a general rule, regard snakes with extreme dread and horror, and when unexpectedly confronted by one, the working power of all the brain centres is apt to become temporarily paralyzed, as is frequently the case with lower animals when suddenly faced by a much-dreaded foe.

One night I spread my tired body under my blankets near our camp fire, and in stretching my legs to get the blankets all round me, my leg touched something cold, which hissed. I shot out of my blankets like the release of a coiled steel spring. The cause of the bother was a Cobra who had made himself comfortable among my blankets. I learned from that experience to shake out my bed-clothes carefully before lying down on the veld.

One day I thrust my hand and

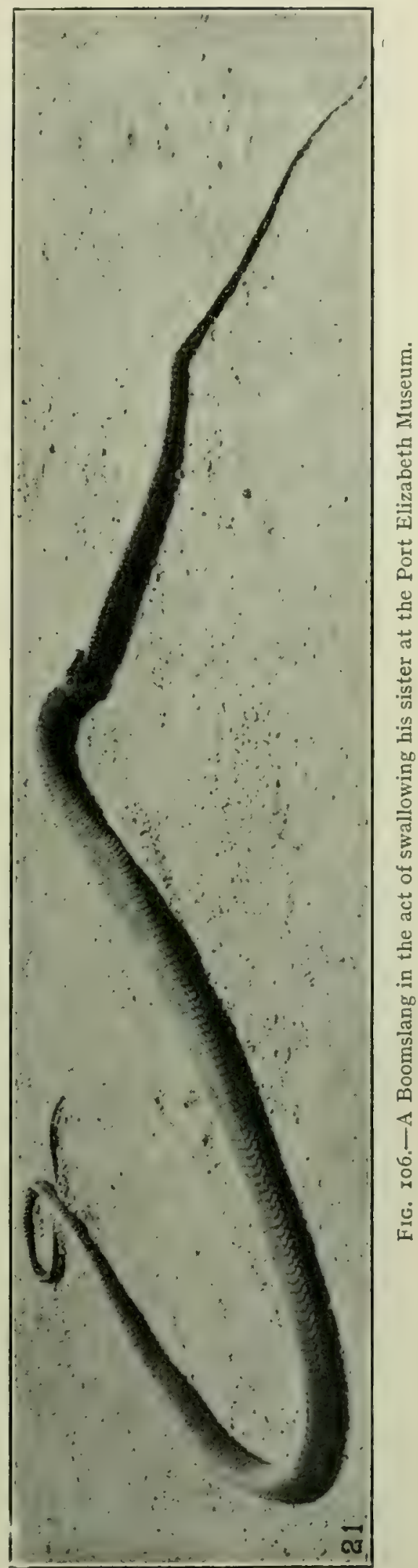


arm into the nest-hole of a Spreeuw (Starling) in a bank. Instead of my fingers touching the eggs as I expected, they closed around a snake's body. He was evidently too cramped up to bite quickly, but I never put my arm into a Spreeuw's nesthole again!

\section{Advice to Campers Out.}

Snakes strongly object to the smell of disinfectants. When snakes are kept in captivity, great care has to be taken when disinfecting their cages to allow the smell to evaporate before putting the snakes back into the cages, for the fumes given out will in all likelihood kill them. Those who have occasion to camp out in tents should dip a piece of rope or plaited cloth in sheep dip, creosote, or carbolic acid, and lay it round the outside of the tent. This will prevent venomous snakes, spiders, scorpions and centipedes from crawling inside.

\section{HoRSEHAIR ROPES.}

When a boy I revelled in the stories of the adventures of the cowboys and frontiersmen of the backwoods of America; and used to read that these men often carried a horsehair rope with them, and regarded it as a valuable possession. When camping out at night, they would lay it in a ring upon the ground and lie down and sleep within that magic circle, quite confident that no venomous serpent would molest them. They had not the slightest idea why the hair rope should prevent serpents from creeping in under their blankets and snuggling up for warmth about their persons, but they, nevertheless, had firm faith in the serpentrepelling properties of their hair ropes.

Naturalists ridicule the idea of the hair rope being efficacious. Now, just let us review the evidence. A plaited horsehair rope is bristling with hundreds of little hair-points sticking out in all directions. A snake progresses by means of his ribs, which are worked by sets of muscles. Each pair of ribs is attached to one of the abdominal shields. These shields or scales are moved forwards, and elevated for the purpose of gripping the ground or whatever surface the snake may be crawling over. Now, each 
time the shield or scale is moved forward, the tender skin between it and the next one is exposed, so when a snake tries to pass over the rope, the little bristles prick his stomach, and if he were foolish enough to crawl right over that rope he would be pricked all along his body, from his neck to his tail. Naturally, if a snake made the attempt to crawl over a hair rope and got pricked, he would instantly turn back.

At other times, doubtless, the snake would investigate the rope with his sensitive forked tongue, and ascertain by that means it was not a desirable object to pass over.

So, you see, there is good reason after all for believing that hair ropes are useful to keep snakes out of our tents and other sleeping-places, when out in the veld or bush.

\section{Cow-MILKING SNÁkes.}

Farmers have often told me about snakes sucking the teats of cows. I have read many accounts in books, in newspapers, and have before me several letters by well-known farmers who positively declare that there is no doubt at all about the truth of it. Some of them declare they actually witnessed Cobras and Ringhals sucking cows' and goats' teats. The belief is very general. It puzzles me. I do not say it is untrue, but I cannot bring myself to believe it. The thing is apparently so unreasonable. It would require a great deal of evidence to establish it as a fact. Now, when you come to think it out, it seems very absurd to think a snake would be able to suck milk from a cow's udder. In a physiological sense it is practically impossible. Venomous snakes would, in most cases, at least scratch the adder and cause poisoning. A snake is very low in the scale of intelligence. And such an act as sucking a cow's udder implies a good deal of intelligence. Animals all have more or less an instinctive dread of snakes. In most of the accounts there is a serious flaw. It is invariably stated that the cow or goat comes home milkless. Now, even a big Cobra could not swallow more than about half a pint of milk. If it did, the milk would be forced out again by the natural pressure of the distended skin, muscles, and ribs. I have tried it on captive snakes. I injected various quantities of milk. So long as I held them in my hand head upwards, and body hanging, the milk was 
retained, but as soon as they were placed on the ground, most of the milk ran out of the mouth.

I have often been told that snakes were killed, and the milk came out when their bodies were smashed up. What really took place, I expect, was, when the snake's body was shot to pieces or pounded with sticks or stones, the eggs which were in it, got smashed, and the creamy-white contents were mistaken for clotted milk.

\section{Snakes and Their Mates.}

In South Africa the belief is widespread that if a snake is killed its mate will, sooner or later, appear upon the scene of the tragedy, and wreak vengeance upon the slayer. So strong is this belief that if a venomous snake should be killed in or near a dwelling, the occupants are in a state of nervous dread for many days afterwards. In Natal many a time my native servants have positively refused to kill a snake, fearing lest its mate would seek them out during the darkness of the night, or lie concealed in some lurking place and deal them a revengeful fatal thrust.

Like most popular beliefs, this particular one has some slight foundation in fact. It is a case of facts being misinterpreted and grossly exaggerated.

During the summer season, which is the time when snakes lead an active existence, they are frequently found in pairs, or the male may be observed in search of the female. When a snake is killed near a habitation, the occupants, believing the mate will turn up on vengeance intent, either make a careful search of the neighbourhood, or else are keenly on the alert. If the mate should be somewhere near, it will probably be found. Any one who has hunted snakes in a systematic manner, knows that when these reptiles are not specially sought for, they are seldom seen. Naturally if a systematic hunt be organized for the supposed mate of a slain snake, one of the same species is likely to be discovered somewhere in the vicinity.

Snakes find their mates mainly by the sense of smell. A male snake is able thus to follow the spoor of a female for considerable distances. I have frequently watched Puff Adders and Night Adders which I kept in captivity in large enclosures, following in 
the wake of a female which had vanished from sight. Wherever the female crept, the male would be observed following. She would creep into some crevice or tuft of herbage and be quite concealed from view, yet the male would be seen slowly creeping along the track which she took.

S. IV. Smith; Esq., J.P., of Griquatown, told me an interesting experience in this connection. He said a female Puff Adder was killed in his flower garden under a geranium bush. The following day a male Puff Adder was seen and killed within a few feet of the spot where the female had been killed. Mr. Smith says that he and a native traced the spoor of the two snakes in the soft sandy soil for a couple of hundred yards and found that the male had followed the trail of the female, his spoor blending most of the time with that made by the female. This occurrence was quite fresh in Mr. Smith's mind, it having taken place shortly before he saw me. He says he knows the spoor of a Puff Adder in the sand, and is positive the two spoors were not made at the same time, for one was partly obliterated and the other quite fresh.

\section{Catching Live Snakes.}

Unless the snake collector is quite certain of the identity of snakes he should not take liberties when capturing them. If you know for certain they are of the harmless division such as the Mole Snakes, House Snakes, Green Water Snakes and others, then you may boldly advance and seize them. The only damage they are capable of doing is to puncture the skin slightly with their numerous small solid teeth. To avoid being bitten, hold a handkerchief in front of the snake, and when it bites the material, instantly seize it by the neck.

Venomous snakes may be safely secured by pinning them down to the earth with a long stick with forks at the end of about an inch or so in length.

If a snake is pinned down with a forked stick to the ground he is quite powerless, and can then be gripped by the neck and transferred to a bag or box. Grip the neck just at the base of the head. Then let go the stick with the other hand and grasp the reptile's tail. It is then utterly powerless. It is risky to hold a venomous snake by the neck and allow it to coil round the hand and arm. By 
the leverage thus obtained it can sometimes jerk its head free, and before it is possible to shake it off, it may have the opportunity of inflicting two or three bites. On the other hand, if you are holding the snake's tail in one hand, and if by chance the head should slip from the fingers of the other hand, the reptile can be instantly dropped or cast away before it is possible for it to bite.

A snake when gripped by the neck just behind the head cannot possibly turn and bite.

When dropped into a bag, the captive snake does not struggle. It coils up and lies quite still. It makes no attempt to bite through the bag.

Puff Adders may be safely approached from behind and noosed, as shown in the illustration. It is not true that they are able to bite by casting themselves backwards. The idea has arisen through the habit of the Puff Adder of throwing back his head and portion of the body to obtain a greater impetus in order to cast himself forward when about to bite. Be careful when standing in front of a Puff Adder, especially if he be coiled up, for he is able to cast himself forward the full length of his body and even a little further. Keep at least twice the length of his body from him. A Puff Adder nearly bit my photographer by springing forward at him. The reptile shot out the full length of its body, making a desperate lunge at the man's legs with its great fangs. Quick as thought it coiled, and again launched itself forward, but the photographer happened to be young and active and sprang aside. If I were to tell you all that we did to obtain the facts and photos for this book, and how we collected venom for all the experiments, it would make your blood feel as cold as that of a snake.

Many kinds of snakes may be captured simply by putting the end of your walking stick across the neck and pressing it down. The snake may then be taken by the neck with the finger and thumb. Tree snakes should be chased until you get them into an isolated tree, or away from trees altogether. If cornered in a tree they assume the defensive attitude and can then be noosed from the end of a long stick. If a snake is noosed in the way shown in the illustration, it can be carried for quite a long time without injuring it if you hold its tail firmly so that its body lies along the stick. Never allow a snake's body to dangle, as this will very 


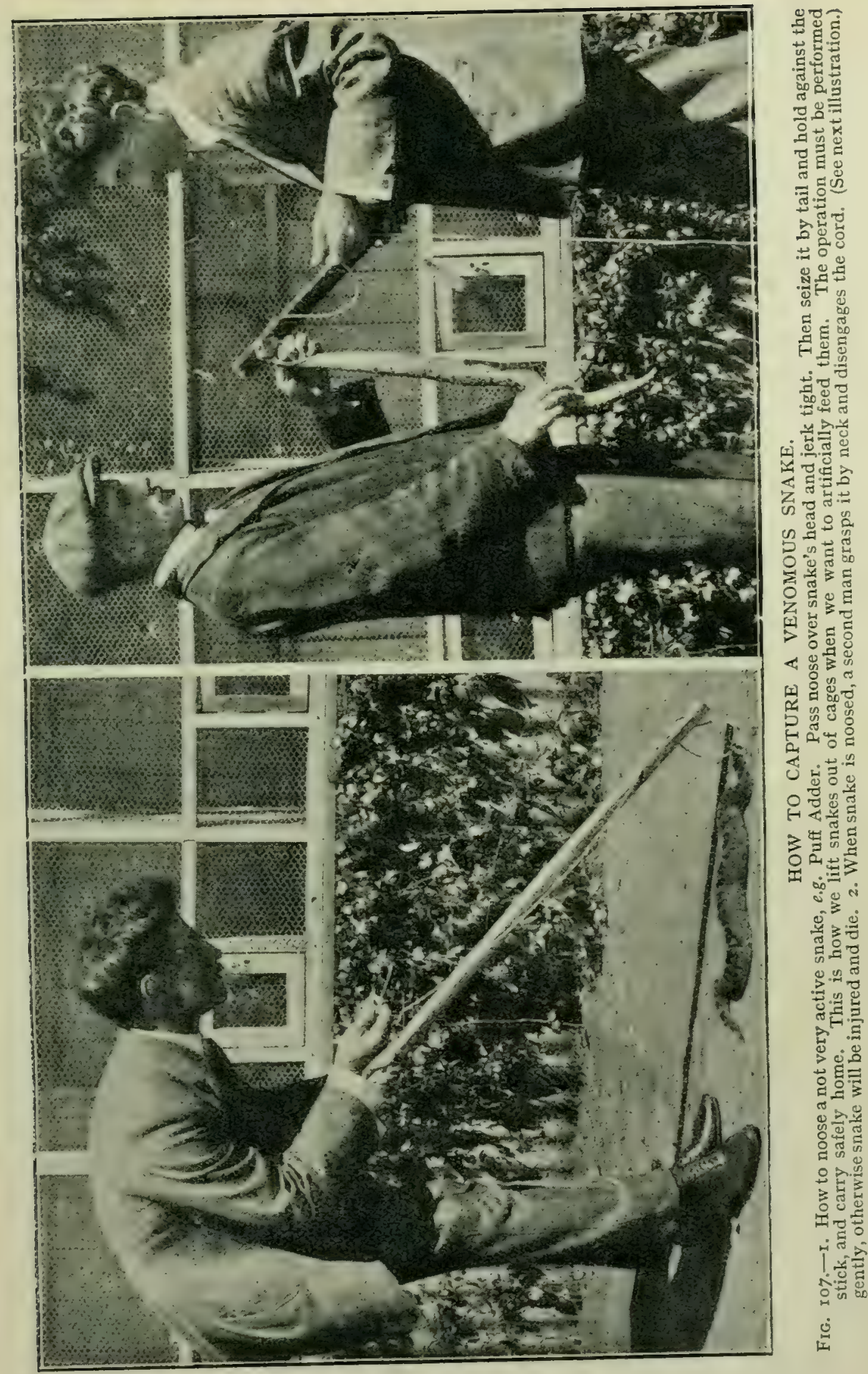


soon strangle it, or so injure its neck that it will die later of the injury. To disengage a snake from the noose, grip it by the neck and tail and, with the disengaged fingers, relax the cord and slip the noose over its head. Snakes may be securely captured in a butterfly net made of strong material. Tree snakes are often captured in this way.

When out snake hunting, wear a pair of strong leather gaiters or top boots. Thick gauntlet gloves may be worn, but they have the disadvantage of making the fingers feel clumsy. Besides, it is rather awkward carrying a big pair of gloves about.

A snake cannot bite through a pair of leather gaiters of average thickness. In capturing a Ringhals Cobra, take care it does not discharge a shower of venom into your eyes.

\section{How to Collect and Preserve Snakes.}

The collection and preservation of snakes is a most interesting hobby. Provide yourself with some permanganate of potash, a sharp penknife, and a ligature in case of a chance bite from a snake; also some good receptacle for your specimens. Take also a long forked stick, the points of which should be sharpened. When a snake is observed, it is usually quite easy to pin him down with the forked end of the stick, by pressing down on the back of his neck. Then apply some oil from the stem of an old tobacco pipe to the end of a wand and rub it in the snake's gaping mouth. This will either kill him outright or put him in a trance-like condition. To make sure he does not revive later, make a tiny incision at the back of neck and sever the connection of the spinal cord with the base of the skull. By employing these methods you will obtain a perfect specimen.

Another method is to strike the snake sharply across the back near the head with a stick. This invariably dislocates or breaks the backbone. Then the creature may be killed with the nicotine oil. It is, however, never wise to injure a snake by striking it if it can be avoided, as subsequently, on immersion in the preservative fluid, the injured part gets puffy, and the scales come off. 


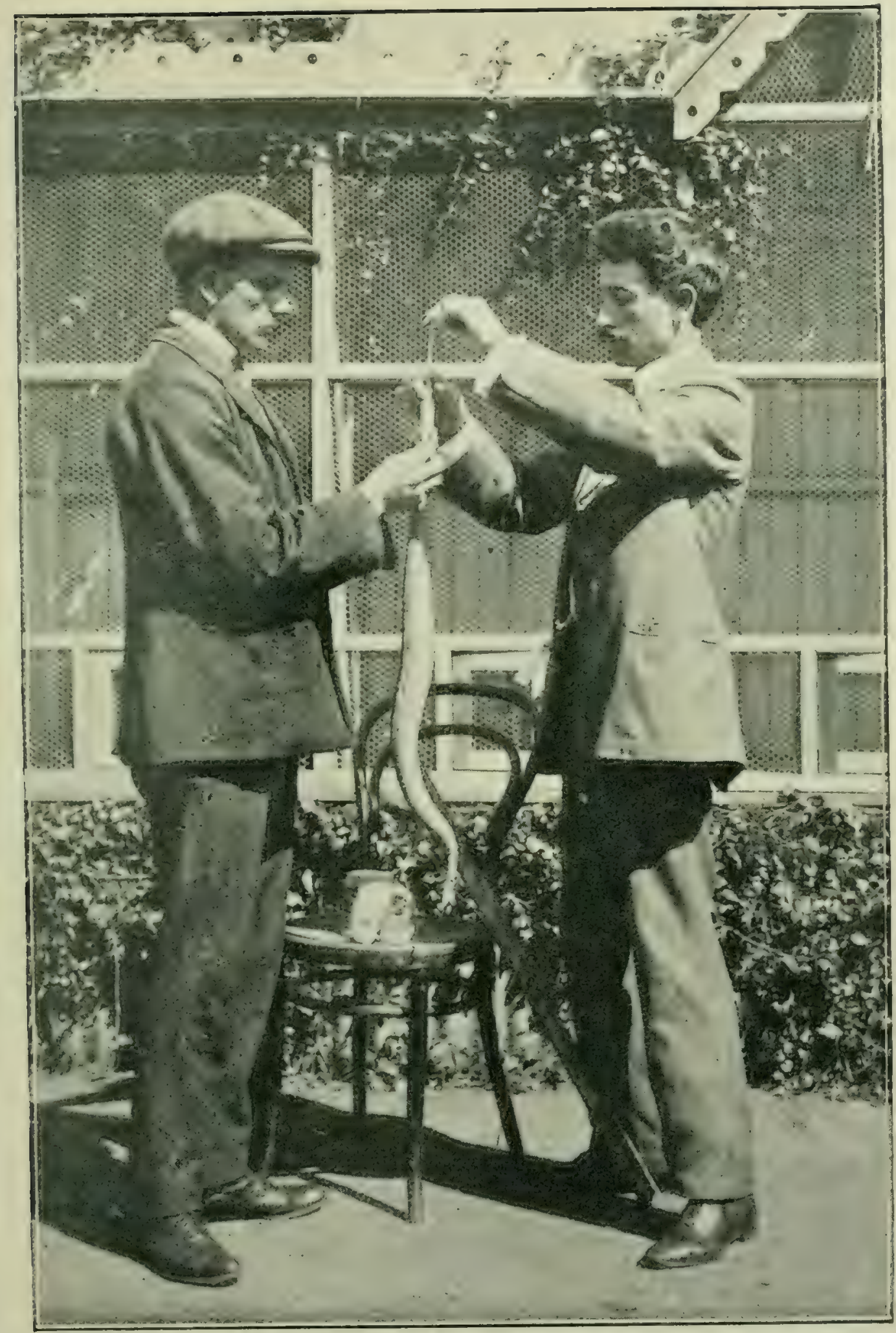

Fig, I08-He opens its mouth. The operators then stand well back, as the snake often struggles fiercely, and venom is often forcibly squirted from the fangs. To avoid this struggles fercely, and the snake's mouth is turned sideways. Then the glass syringe is getting into the eyes, the snakes mouth of eggs or milk. The nozzle is pusher into the snake's throat and the contents squirted down. Sometimes two or three doses are given. A glass funnel may be used instead of a syringe. 


\section{How to Preserve SNakes.}

The preservative fluid commonly used is ordinary methylated spirit ; Cape Dop brandy, or any other kind of strong alcohol, will do. Lay out your specimen, abdomen uppermost; make an incision of one to two inches along the middle part of its abdomen longitudinally. Search for and remove the gall. On reference to the illustration of dissection of a Puff Adder you will find the locality of the gall. It is a roundish bag of greenish-yellow fluid attached to the liver. If there be anything in the alimentary (food) tube, remove it. It is not necessary to remove the gallbladders of small snakes. It is advisable to do so with large specimens, as gall frequently escapes into the spirit and discolours it. The next operation is to inject some spirit into the snake's body, through the incision. An ordinary glass syringe will do. Plug up the incision with cotton-wool, and, if necessary, bring the edges together with a few stitches. After washing the snake clean, place it for a couple or three days in a jar or bottle of spirit to soak. The object of this preparatory pickling is to allow of the spirit taking the place of the natural water of the snake's body. The reason snakes so frequently go bad in pickle is because this precaution is not observed. The water from the snake's body naturally weakens the preservative fluid, and sooner or later the specimen decays. The permanent specimen jar or bottle should be of clear glass, and with a glass stopper if possible. For private collections ordinary round bottles will serve the purpose. In museums these are no longer used, as they distort the specimens. Jars with flat sides are better. Do not cram the specimen into the bottle carelessly. Arrange its body neatly in coils. Open the jaws and erect the fangs, if the snake be a venomous one. Fill your bottle up with spirit and cork it. Your next business is to write its name, the locality where it was captured, and the date. Affix the label on the bottle and write the same date on a small neat tag and drop it into the bottle in case the other label should pull off and get lost. This is an important detail. Valuable collections have been rendered practically valueless by neglecting to do this. Keep a catalogue of your specimens, and write down everything of interest connected with them. Write all the interesting information about them which you can cull from books or discover by personal observation. If you cannot 


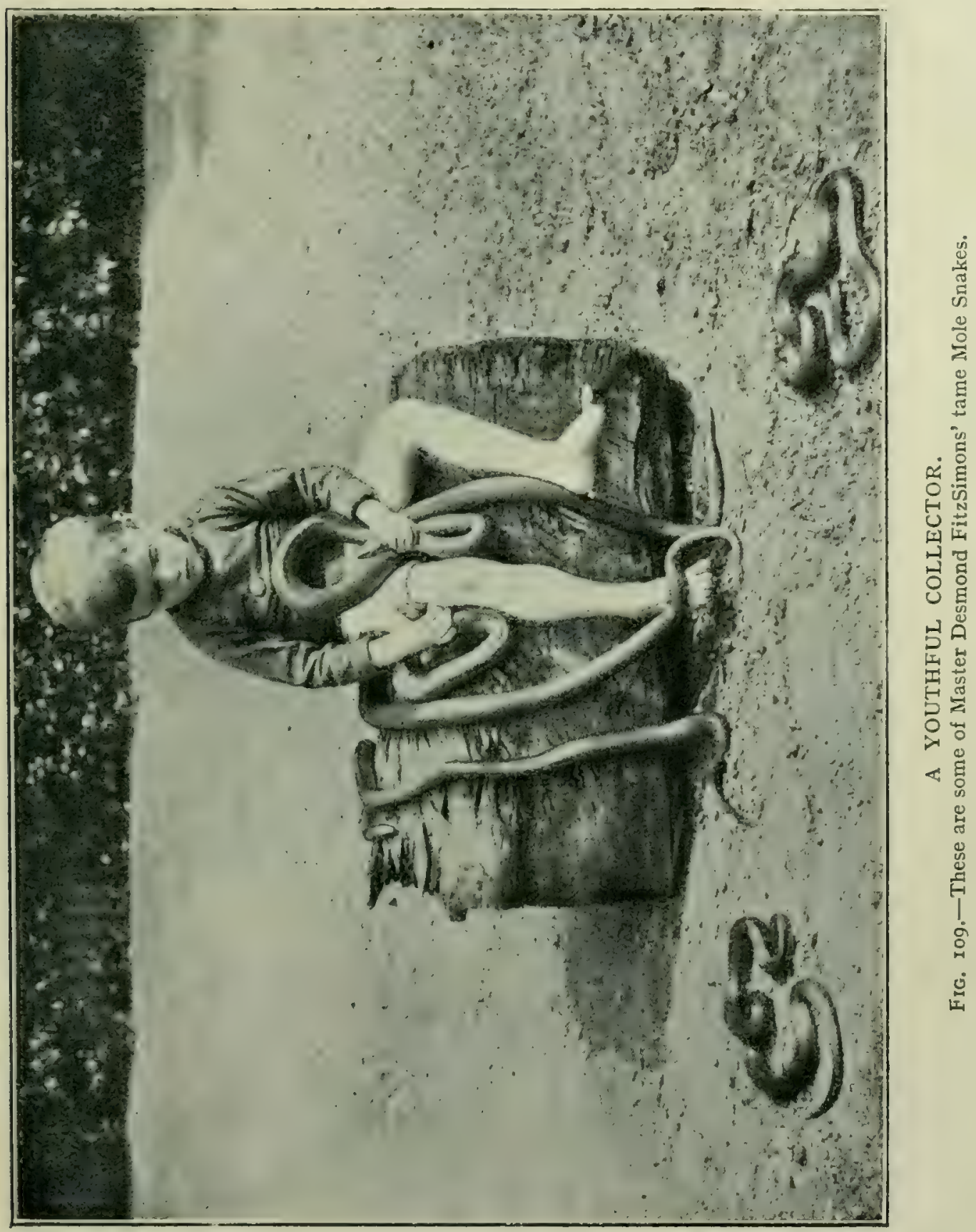


identify your specimen, take or send it to the nearest museum, and ask for information. The best plan is to collect two specimens. Keep one for yourself, and send the other to a museum as a donation, and ask the museum officials to let you know its name. If they cannot identify it themselves, they will send it to some authority on snakes, who will be able to tell them.

First of all, learn to recognize the three great divisions-the solid-toothed, harmless snakes, the intermediate, back-fanged snakes, and the typically, venomous, front-fanged snakes.

In the preservation of snakes, a wood-spirit known as formalin is frequently used. It is sold by all chemists. It has the advantage of being quite colourless, and it does not dissolve out the colouring matter of the specimen to the same extent as does alcohol. However, it often partly dissolves the bones of the specimen, making it useless for dissection at any future time. I have kept various reptiles in formalin for fifteen years, and they are to-day as fresh as ever. The exposed fangs of the snakes, however, crumbled away when touched. The lime-dissolving power of formalin can be neutralized by reducing its acidity, viz. by adding a little colourless solution of lime (lime-water), and keeping the specimens in a feeble light. The less light which reaches the specimens the better, as light bleaches them. The collection may be kept in a dark cupboard or on a shelf in a feeble light, or with a curtain on rings hanging in front. Formalin, if used, should be diluted. For the preservation of snakes, add ten to fifteen parts of water to one of formalin. It can be diluted to a greater extent if the specimen has had a preparatory soaking for a few days, as mentioned above.

To skin a snake with the intention of stuffing it, the best plan is to turn it inside out by removing the skin from around the lips, working it down to the neck, and slowly drawing it off. Then dust it over with a preservative mixture consisting of one-third white arsenic and two-thirds burnt powdered alum, and carefully turn the skin right side out again. Fill the body with fine sawdust to the proper dimensions, insert a piece of putty into the neck, and replace the skull, after winding a little cotton wool on it to replace the muscles and glands which have been removed. Putty or modelling clay is, however, better than cotton wool. Fasten the lips with tiny pins or a few stitches, as naturally as possible. Put in a pair of artificial eyes, mould the body into its 


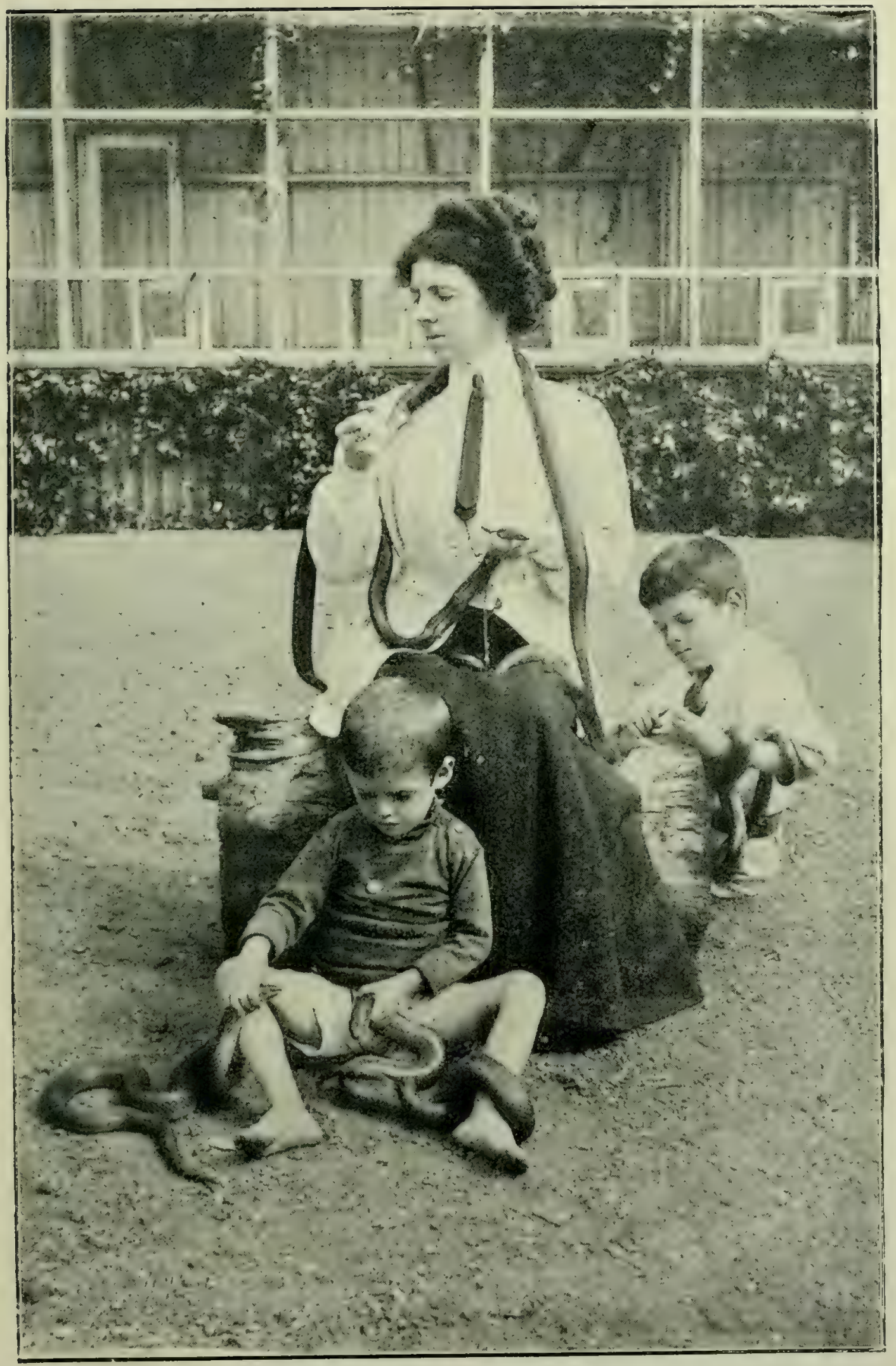

FIG. I I0.-Some of the author's tame Mole Snakes. They like to be carried out into the warm sunshine. 
natural shape, coil it in the position desired, and leave it aside to dry. When quite stiff and dry, take out the pins or stitches from the lips, clean oft any loose bits of clay, etc., and give the whole skin a coating of gold-size varnish. Place it upon a board prepared for the purpose, and finally put it in a glass cabinet or case. A nice attractive stand can be made by imitating the natural surroundings of the snake.

If you dip the snake's head in a solution of permanganate of potash before beginning to skin it, and during the process, there will be little, if any, danger of getting poisoned. A safer plan when skinning a venomous snake is to make a longitudinal incision in the throat a few inches from the head. Skin round the body, then sever it and skin off the neck and head first. Then remove the body portion of the snake.

Flat skins may be made by ripping the abdomen from chin to end of tail and removing the body. Rub the preservative mixture on the inner side of the skin and tack it out on a plank, until dry. Then turn it over and give it a coating of gold-size varnish. When quite dry, roll up and put away.

To make a skin permanently proof against the attacks of moths and mites, steep it for ten minutes or so in methylated spirit, or ordinary alcohol in which a pinch of powdered corrosive sublimate (Bi-chloride of mercury) has been dissolved. It is best to have a stock bottle of it. Take a pint of methylated spirit and put as much powdered corrosive sublimate into it as will lie heaped on a three-penny piece. Shake, and allow to stand for a day. It is then ready for use. Instead of soaking the skin in the solution, it may be painted on with a brush. Be sure that both sides of the skin are well painted. This substance will cure a skin as well as render it insect proof. It is a capital preparation to poison beetles, butterflies, etc., with, before pinning them out in your cabinet. Corrosive sublimate is a poison, so be careful to label the bottle suitably.

\section{KAfir SUPERSTItions.}

The Kafirs are intensely superstitious. The instinct of reverence when rightly trained, and guided by an educated intellect, strongly impels the individual to be genuinely and 
truly reverent and religious. It gives a strong desire for, and belief in, continued existence after physical death.

In the Kafirs this emotion runs riot. It impels them to perpetrate the most diabolical cruelties.

They believe that the spirit of a dead Kafir has the power of influencing the survivors of his own family for good or evil. So far the belief is reasonable enough, but the Kafir family believes that if cattle, goats, fowls, etc., are sacrificed to this spirit relative,

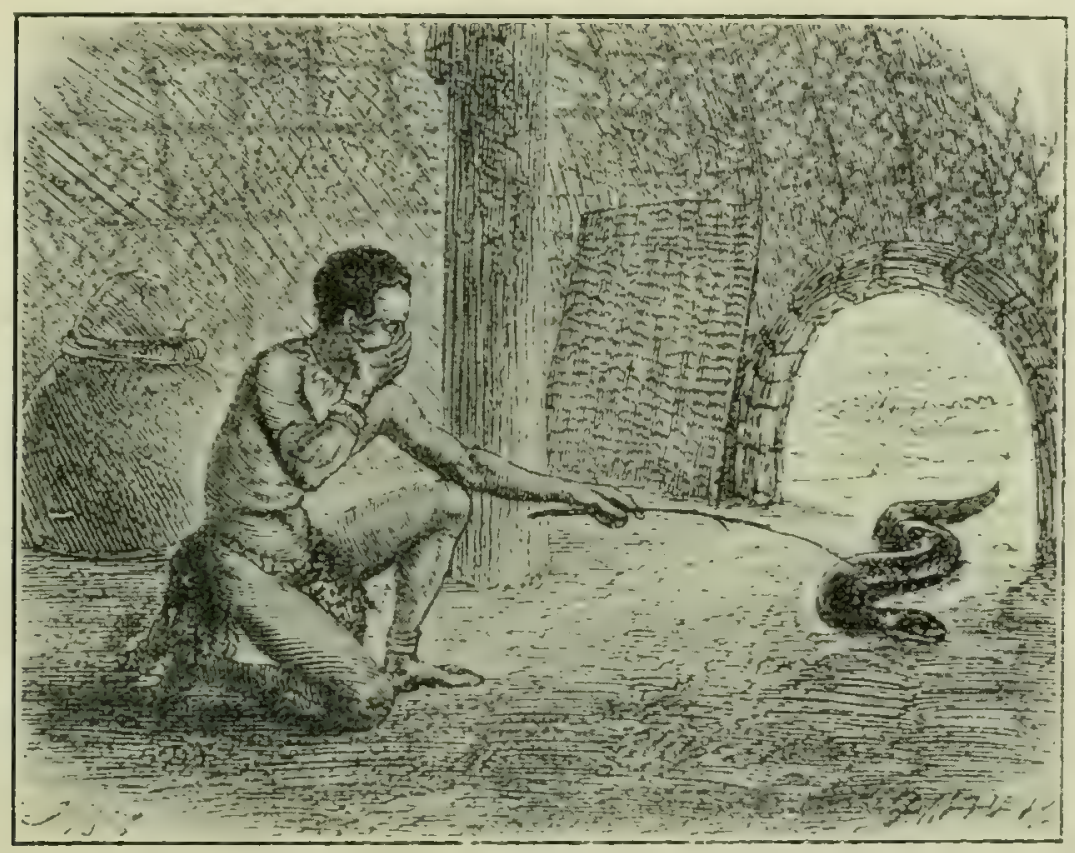

FIG. III.-Applying the test to see if the snake is obsessed by the spirit of a beloved relative or a foe. (After J. G. Wood.)

then their spirits go to him and help swell his herd of spirit cattle, etc., in the shades below. He does not mind his friends feasting upon the flesh of the sacrificed animal. All he covets is the spirit of the creature. If he considers that his friends on earth are neglecting him, he pays them a visit, and afflicts them or their domestic animals with disease. If the disease should be severe, then the relatives imagine that nothing short of the sacrifice of a cow or ox will appease the indignant deceased relative. If the sickness should be a minor one, then a goat is thought to be adequate. Sheep never seem to be used for these sacrifices. 
These dissatisfied or revengeful spirits sometimes come in their own form, but usually they appear in the form of some such creature as a snake. If a snake should enter a Kafir's hut, he concludes that it is possessed by the spirit of a friend or foe. To determine satisfactorily for what intent the spirit has visited him, he takes a stick, and covering his face with one hand, lays the stick gently over the back of the serpent. If it should not show any sign of anger or resentment, he is assured it is the spirit of a beloved dead ancestor. If this is the case, he instantly goes forth and sacrifices an $\mathrm{ox}$, if he has one to spare. If not, a goat or two serves the purpose. He argues that the spirit of a dead ancestor would not take the trouble to visit the earth and appear to him, unless as a warning to be more careful in future, and treat him with greater respect by offering sacrifices more frequently to him.

If the serpent should show irritability or anger, the Kafir makes up his mind it is the spirit of an enemy who is intent upon doing him some grave hurt. He therefore abandons the hut, at least for a period. As a consequence of this belief, Kafirs, as a rule, have a strong dislike to killing snakes in the vicinity of their dwellings, for fear they may be offering an insult to a dead ancestor, who will revenge himself upon them. If the snake should be possessed of the spirit of a foe, and be killed, the hatred of that enemy is increased an hundred fold.

Contact with Europeans, however, is rapidly undermining these old traditions and beliefs of the Kafirs.

On an occasion when I was camping out at a Kafir kraal, a Puff Adder crawled through the doorway into the centre of the hut. The usual testing took place to ascertain if it were an ancestor, or a bitter enemy. It proved to be the former. The friends of the owner of the hut gathered around him, and brought all their influence to bear upon him to sacrifice a cow forthwith. I ridiculed the whole affair, and told him that his friends were trying to scare him into killing a fat cow so that they might participate in a glorious feast. I offered to kill the snake and bring the penalty upon myself. No, he would not permit that, because his dead ancestor would be doubly furious with him for allowing a white man to interfere and insult him. The simpleton was utterly terrified by the forecastings of his friends, if he did not appease the ancestor with the spirit of a good cow. 
Consequently, that night there was much feasting and beerdrinking in the kraal.

\section{An Exciting InCIDENT.}

A friend of mine, who was formerly a magistrate in a certain part of South Africa, was rather interested in snakes, so much so that he collected the venom from every poisonous snake he killed. He used small-pox vaccine tubes for storing it in.

Being in a country district, he always kept a good supply of small-pox vaccine on hand for the use of the District Surgeon when periodically vaccinating the natives of the district. It seems that it was a constant source of annoyance to his wife to see his private office in such an untidy condition. One day, when her husband was away on a hut-tax collecting tour, she thought she would give him a pleasant surprise on his return; so she had his office thoroughly cleaned up -its first cleaning for years. Of course, she did not know the difference between snake venom and small-pox vaccine, so she mixed the lot together. Next morning the District Surgeon turned up, helped himself to some tubes of small-pox vaccine from the box, and went off. In a week's time, the magistrate returned. He was duly informed of the visit of the medical man, but attached no importance to the incident. Several days later he killed a large Cobra, and, collecting its venom on a bit of glass, proceeded to his office to put it into one of the phials, and found they had vanished. Rushing off with more haste than dignity, he inquired of his wife if she had seen them. "Oh yes!" said she. "I put them all together! They are in the drawer with the rest." Then the magistrate's hair stood on end, and a cold sweat broke out from every pore. He was speechless. Regaining his senses he dashed off to the office, and tremblingly examined the contents of the drawer. Unfortunately, he could not remember how many phials he had which contained snake venom. He knew by this time the District Surgeon would have done all his vaccinating, and therefore it was useless to take any steps. Besides, he did not know where the medical man was. He told me that for a couple of weeks he lived in a state of nervous dread and mental agony unspeakable. However, not hearing of any mysterious deaths among the Kafirs of the district, he grew calmer. He says 
he kept the incident a dead secret, and not even the District Surgeon knew about it. He does not know to this day whether one or more phials of his venom may not be lurking in some District Surgeon's drawer. Moral-always be careful to label poisonous substances!

\section{Feeding Snakes on Live Animals.}

It is popularly supposed that if rats, mice, rabbits, guineapigs, wild birds or domestic fowls are placed in a cage containing live snakes, that they will suffer agonies of fear. This is not so. Wild birds, when introduced into a snake cage, immediately fly out of reach of any snakes which may be present ; but if their food is placed upon the ground, they will after a few hours readily fly down and begin eating, utterly oblivious of the presence of their enemies. In a few days they take no notice at all of the snakes, and even hop about on their bodies. However, it is not pleasant to contemplate that such lovely and bright little creatures should be devoured by these reptiles. I could never bring myself to feed snakes with live birds, although there is no actual cruelty involved.

Rats, mice, rabbits, guinea-pigs, and fowls, when put into a snake cage, are timid at first, owing to the strangeness of their surroundings, but in a very short time they are quite at home, and do not show the least fear of the snakes. If a snake, such for instance as a python, is disposed to dine, with a sudden and unexpected movement he seizes his victim, and next instant his deadly coils have done their work, and it is limp and dead - killed so rapidly that death is practically painless. All constrictor snakes kill their prey very rapidly. A rat will be, perchance, nibbling some food, and the spectator sees an instant later a confused mass of coils, and realizes a snake has the rat in those coils, and already its life is fast ebbing away. If the snake be a venomous one, the poison rapidly benumbs the victim, and, although it may not die immediately, it does not suffer any pain beyond a momentary smart when the fangs penetrate the skin. The venom has the property of narcotizing the sensory nerves.

Although snakes may be kept alive in captivity for prolonged 
FEEDING SNAKES ON LIVE ANIMALS. 28I

periods by artificially feeding them, such a plan is not nearly so satisfactory as allowing them to kill and eat their food in a natural

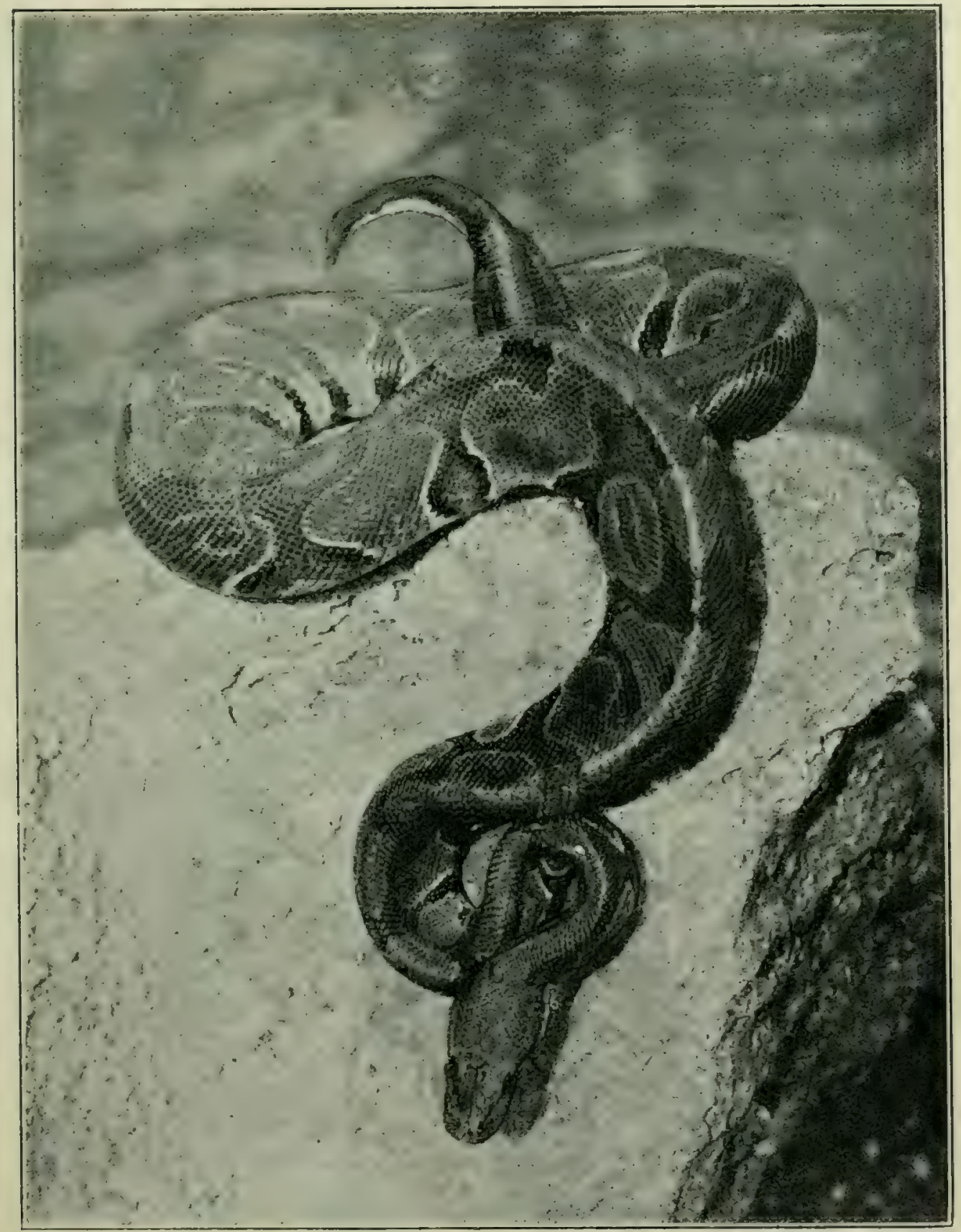

FIG. I12.-The Royal Python (Python regius) of Senegambia and Sierra Leone.

way. The mortality among artificially fed snakes is great. When made to swallow against their will, the food frequently fails to digest, putrifies in the alimentary canal, and so poisons the reptile. 
Others develop abscesses in the mouth, from which they usually die. However, snakes kept for public exhibition in Zoological Gardens and elsewhere, should on no account ever be fed when the public are present, especially children, for such sights only generate an unwholesome morbid curiosity, and besides, there is the semblance of cruelty, if not the actual reality. Many things must be done which are very unpleasant, and go against one's natural inclinations, but when called upon to perform such duties they need never be paraded unnecessarily.

If a snake can once be induced to eat of its own accord, there is no further difficulty, for it afterwards feeds freely if the air in its cage is genial and warm. Such a snake, if placed in a cage with others which have previously refused to eat, will often induce them to make a beginning. 


\section{CHAPTER IX.}

\section{The Brain and Nervous System.}

IN order to understand clearly what has been written in this book

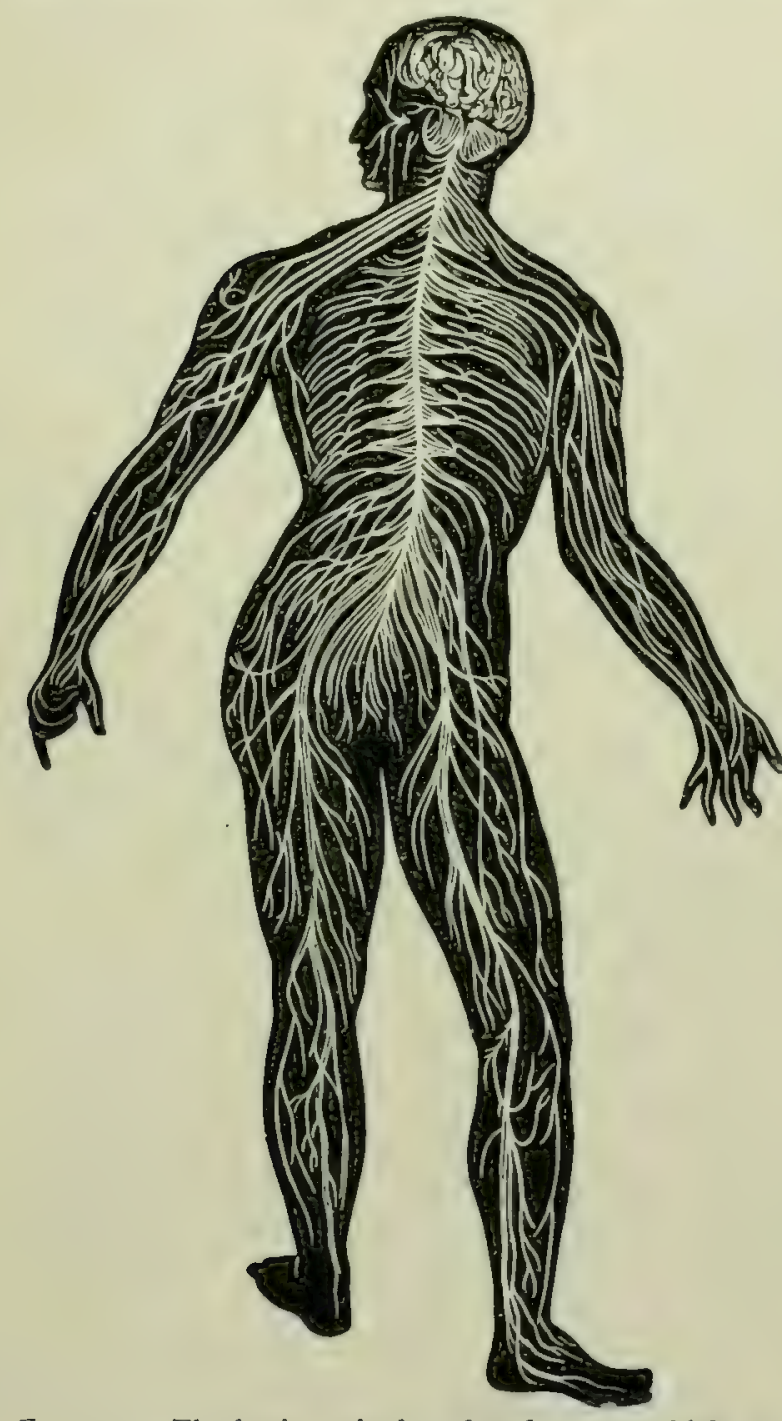

FIG. II3.-The brain, spinal cord and nerves which run to every part of the body. They are the telegraph wires of the brain, and form a vast network all over the body. (From Blackie's Physiology.) on the effects of snake venom and the treatment of snake bite, some elementary knowledge of the circulation of the blood, the digestive organs, brain, and nervous system is essential.

A chapter on human physiology, therefore, has been introduced, as the aim of this book is to make knowledge of snakes, their venom, and the treatment of snake bite, as practical and as understandable as possible to the average man and woman living in countries swarming with venomous snakes.

Owing to lack of knowledge of the circulation of the blood, the digestive apparatus, the brain, nervous system, etc., methods in the treatment of snake bite are employed which are utterly ridiculous, alarming, and manifestly absurd to those possessing 
an elementary knowledge of physiology. The patient is often liberally dosed with drastic drugs in large quantities-drugs which a doctor would hesitate to prescribe even in small doses. Many other methods even more harmful and pernicious are resorted to, and worthless so-called snake bite remedies command a ready sale among the ignorant.

\section{The Functions of the Brain.}

The brain is the source of all thinking and feeling powers possessed by us. All intelligence lies in what is known as the grey matter, which is composed of a layer of greyish cells, which covers the entire brain.

The body is a machine with marvellously intricate machinery, but it is utterly devoid of intelligence. It is merely the medium through which the brain operates upon physical matter. The body carries out the commands of the brain or mind. When we see the dead body of a man, we do not say it is the man himself. We say it is his dead body. The spirit which worked the cells of the brain, which in turn operated upon the various parts of the body, has fled, never to return. The bacteria of decay then assume command, and convert the body back to its original elements.

The driver of the wonderful human machine is the brain, which is enclosed in the skull. The brain is divided into two parts, the main portion being known as the Cerebrum. The other part is the Cerebellum, which lies at the base of the skull, behind the ears. Both the Cerebrum and the Cerebellum are divided into two parts, which are known as hemispheres. These parts are united at the base by nerve fibres. The brain is really a great mass of nerve matter. The average weight of the brain of an adult male is about forty-nine and a half ounces, and forty-four ounces in females.

The brain is covered, first by the skull, then with a tough membrane known as the Dura Mater. This membrane is charged with blood vessels which supply nourishment to the brain and skull.

Under this tough covering is a delicate membrane, not unlike a fine spider's web in appearance, known as the Arachnoid membrane. Yet another membrane envelops the brain; it is known as the Pia Mater. It lies right upon the substance of the 
brain, and is composed mainly of blood vessels which run down into the brain matter.

The right side of the brain supplies the left side of the body with nerves, and vice versa. This is why an injury to the motor centres of the right side of the brain will paralyse the body on the opposite side.

\section{The Seat of Intelligence}

When all the membranes covering the brain are removed, its surface is seen to be covered with deep depressions. This is due

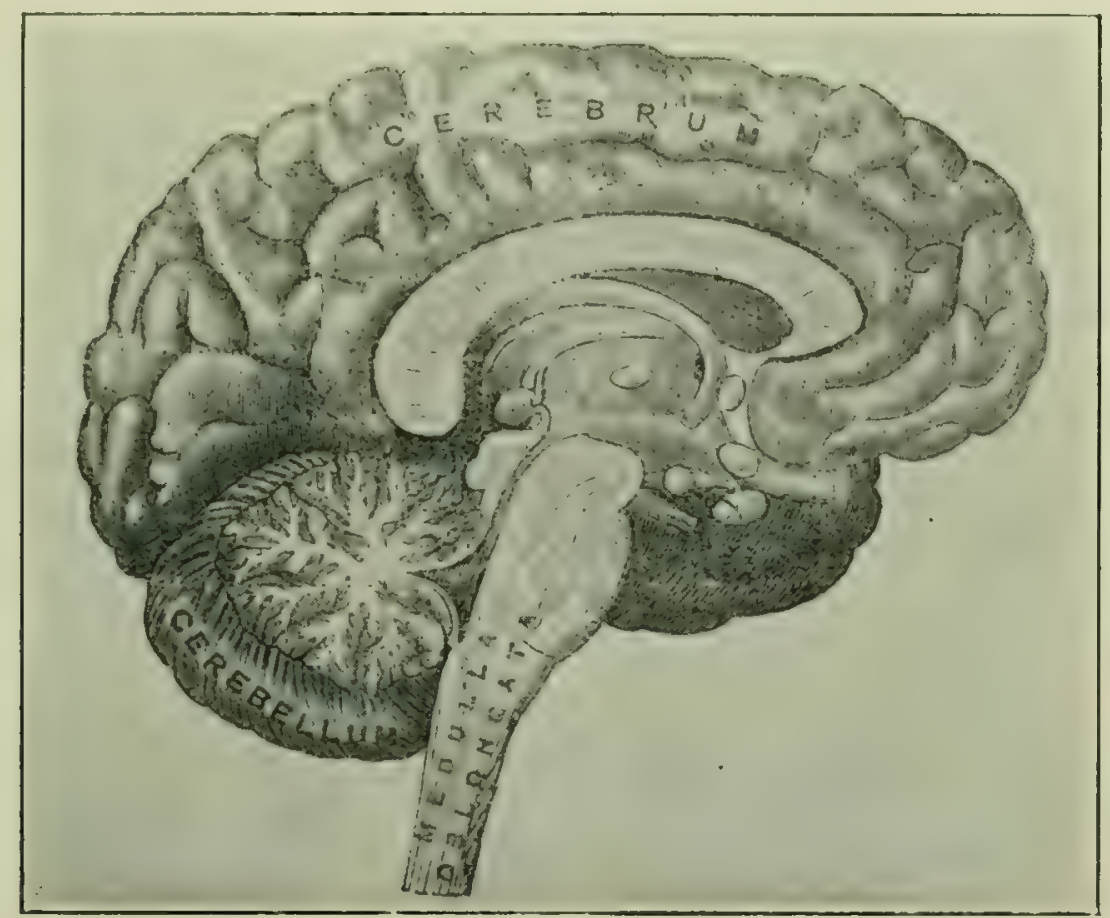

FIG. II4.-Section of the human brain showing one hemisphere of the Cerebrum and Cerebellum. The part on the right is the forehead portion. Note the foldings or convolutions. (From Blackie's Physiology.)

to the foldings of the outer layers of brain matter. These foldings are known as convolutions. The object of these depressions and foldings is to provide as large a surface as possible, without unduly enlarging the brain and skull. This extensive surface is covered with a layer of nerve cells of a greyish colour. The thickness of the grey matter is determined by the degree of mental evolution of the individual. This layer of microscopically small cells of a greyish colour, which is usually only about the eighth of an inch thick, gives rise to every thought, every desire, and every emotion 
which stirs us, every hope and ambition which thrills us, the glow of love which goes out from us, the pain, the anger and the worries of life. Yes, all these and more, have their birth in the groups of cells which are formed in this thin grey layer which covers our brain like a cloth.

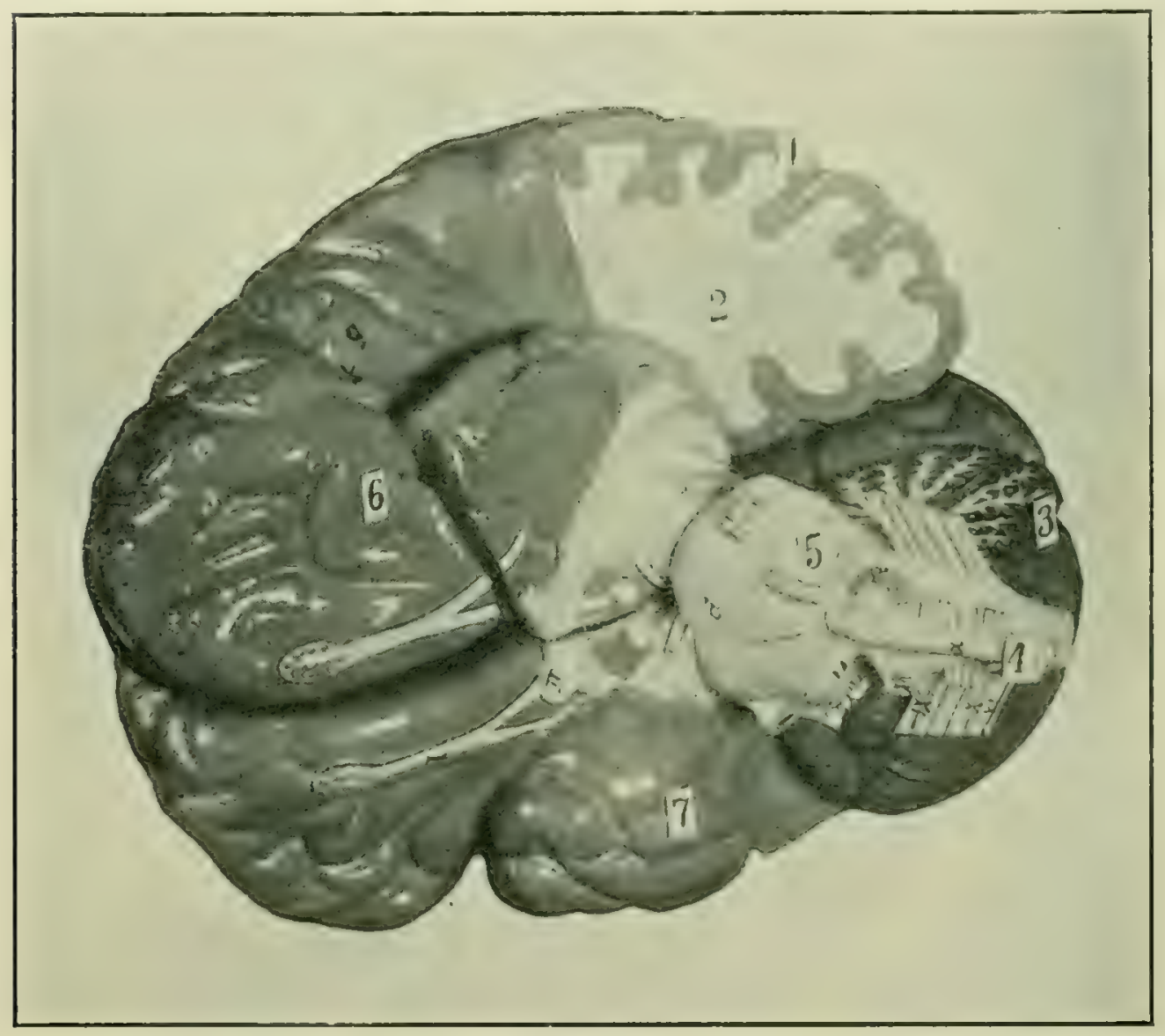

THE HUMAN BRAIN.

FIG. II 5.-1. The layer of Grey Matter composed of tiny cells where all intelligence, emotions and desires have their origin. This is the "Book of Life" - the phonographic record.

2. Interior portion of the brain composed of vast numbers of nerve fibres which conduct messages to and from the Grey Cells.

3. The Cerebellum or Little Brain cut in half to show nature of its substance. It is the seat of various physical functions and the amative desires.

4. Top of the Spinal Cord known as the Medulla Oblongata showing nerves branching out from it.

5. Top of Medulla Oblongata known as the Bulbs. This and the former are strongly affected by Cobra venom.

6. The Cerebrum (left hemisphere) showing the convolutions or foldings of its surface.

7. Right side or hemisphere of the brain.

The grey cells which envelop the brain-substance follow the convolutions down into all their foldings. This wonderful grey coating is known as the Cortex, which means bark. 
The inner part of the brain is whitish-cream in colour, and is a vast mass of nerve fibres for the transmission of the commands of the grey cells to the various parts of the body.

According to phrenology, there is a special centre in the brain for the manifestation of each of the great variety of thoughts, desires, and emotions, in addition to the nerve centres which control all movements, etc., of the body, and which carry out

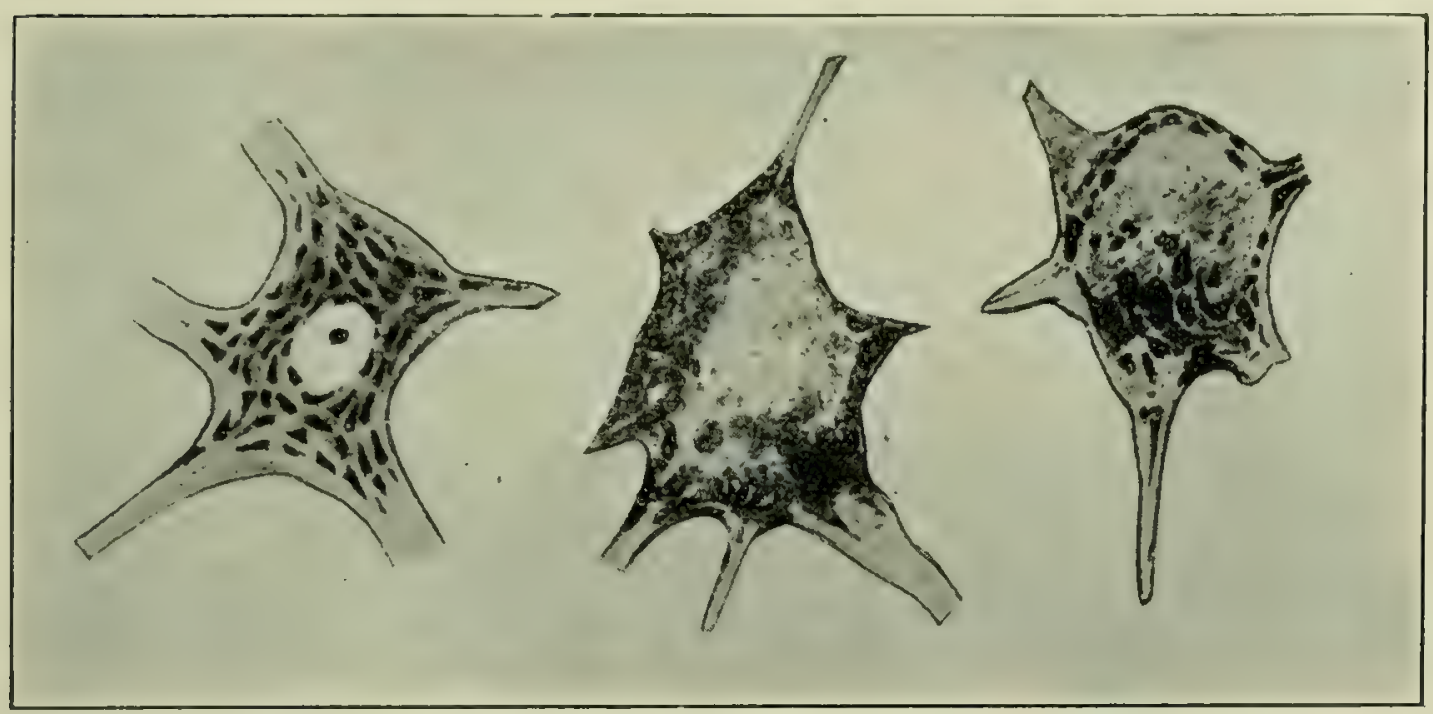

FiG. 116.-Brain cells which are paralysed and destroyed by poisons such as snake venom, narcotic drugs and alcohol. The one to the left is a healthy normal cell, showing the nucleus clear and distinct. The next one is swollen and sickly. The third is dead, the nucleus having been entirely destroyed.

the commands of the brain centres. These latter are called by phrenologists the Psychical Brain Centres.

\section{An Elaborate Telephone System.}

The grey matter of the brain is a great collection of groups of nerve cells, each group having a special function to perform in controlling and directing the vital functions, and the generation of thoughts, emotions and desires. From each group of grey cells, nerve fibres run out and are connected up with other brain groups and nerves running to the various parts of the body.

The marrow or spinal cord enclosed in the backbone is the main cable from the brain. From this great cord, which can be compared to a telephone cable composed of great numbers of wires, nerves-just like telephone wires running out at intervals 
from a telephone cable branch off, divide and sub-divide, until

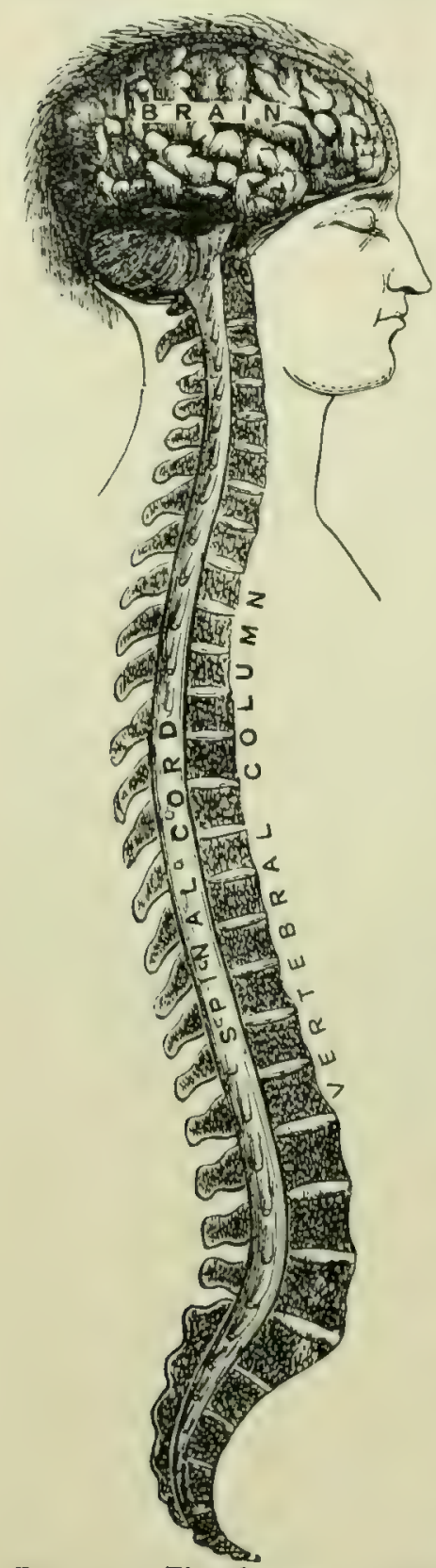

FIG, II7.-The human power house (the brain) and the main cable or spinal cord, showing the large telegraph wires or main nerves which run out from it, dividing and sub-dividing all over the body. (From Blackie's Physiology). the whole body, from the tips of the toes to the crown of the head, is a complete network of nerves. These are the telephone or telegraph wires of the brain. Within the brain, as it were, the intelligent operator lives; the nervous system is his means of communication with the remotest parts of his body. From his dwelling-place within the skull, he can control every part of the human engine to the very smallest detail.

The world-famous medical author, Dr. J. H. Kellogg, says-

"The brain is the great centre from which emanates the nerve force which vitallizes and energizes every part of the body. It is the seat of government in the vital domain, the nerves being its servants through which it receives information of the external world, and by means of which it is able to execute its mandates in all parts of its province, even extending beyond itself and the limits of the body, and operating upon external things through the medium of its instruments."

\section{Snake Venom and the Nerve Cells.}

Every nerve thread, when examined under a microscope, is seen to be composed of a number of nerves, all of which are enclosed in a sheath. In fact, every nerve thread is a bundle of nerves bound together and carefully sheathed. The nerves themselves are composed of tiny cells of nervous matter.

It is these cells which are poisoned when snake venom gets into the blood. The venoms of the different kinds of snakes 
do not all have the same pathological effect. One kind of venom will have a specially poisonous effect upon certain groups of nerve cells and nerve centres, while another kind of venom will exert little or no poisonous, paralyzing influence upon those nerve centres, but will act with powerful effect upon some other groups. For instance, Cobra venom poisons the nerve centres which control the automatic movements of the lungs. Puff Adder venom does not have this effect. This venom and that of the Boomslang act powerfully on the nerve endings and bloodvessel walls, causing more or less extensive hæmorrhage into the tissues.

A strong man is far more difficult to overthrow than a weak one. So, too, is the nervous system and brain. If you have strong, healthy nerve and brain cells, snake venom or disease microbes will be far less likely to kill than if the brain and nerve cells are weak, sickly, or inflamed.

The chief cause of this unhealthy condition of the cells of the brain and nerves, is the habitual indulgence in alcoholic liquor. It has been established as a fact in science, after exhaustive experimentation and observation, that alcohol poisons, weakens, distorts, inflames, and kills these cells.

\section{How our Blood is Made-A Marvellous Process.}

It is blood which builds up the tissues of all living creatures upon our world, ourselves included. It is the blood which supplies every particle of nourishment required for our bones, muscles, brain, nerves, nails, and hair.

Where does the blood come from, and how is it made? Yes, we all know it is made from the food we eat, and the water we drink-but how? Has it never struck you that the process must be a marvellous one which converts beef, potatoes, bread, and all our foods, into blood? It is the digestive apparatus which performs this wonderful feat. The lowest forms of animal life upon our world are tiny creatures which live in the ocean. They are simply living stomachs. We human folk, too, are stomachs-with appendages.

Well, now let us carefully trace the journey taken by our dinner, and see what becomes of it. 


\section{The Salivary Glands and Teeth.}

We are provided with incisor or front teeth for biting and tearing our food; and molars for the purpose of carefully grinding up the food before it is swallowed. True, we have canine

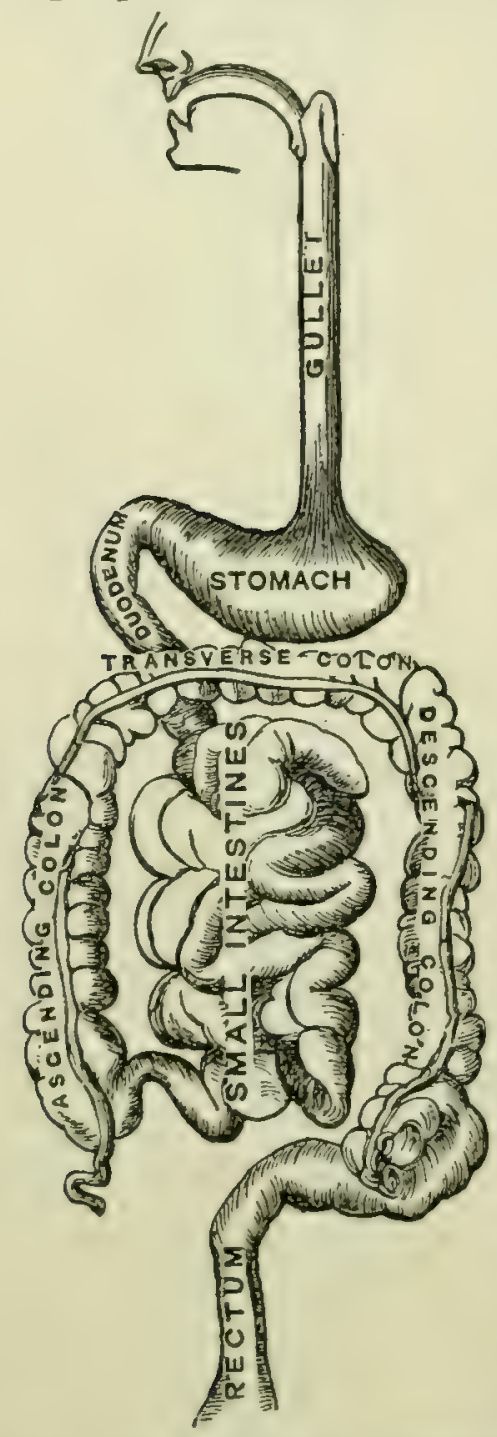

Fig. II 8 .- The whole digestive apparatus of a human being It is about 30 feet in length. (From Blackie's Phy'siology.)

teeth, with which our primitive ancestors fought their enemies, before they evolved the idea of using branches of trees as clubs, and stones as weapons. The instant food enters the mouth, the salivary glands pour out their secretion, which is known as saliva. This saliva is very important, for it performs a work which the stomach is unable to do. The saliva has the power of changing the starchy parts of the food into quite another substance. In fact, it partly digests and prepares it for another process which will take place later in the stomach and bowels.

It is very important that we should chew up our food thoroughly before swallowing it. Parents should take the greatest possible care of their children's teeth. The teeth should be cleaned, and the mouth washed every morning, and at bedtime. The mouth-wash should contain some antiseptic. Opa is one of the best. Three or four drops in a wine-glass of water is sufficient. Without good teeth, the food cannot be properly prepared for the stomach. Good tecth and a healthy stomach are a child's great asset.

\section{The Stomach.}

When the food is swallowed, it goes down a long tube called the gullet or Esophagus. The instant it enters the stomach, the gastric nerves receive a stimulus, and digestion begins. The stomach is a large, hollow, muscular bag. Emberded in its 
inner walls are millions of tiny glands which are known as gastric glands. These little glands become excited, and pour out a sticky juice, which is known as gastric juice. It oozes out, just like perspiration upon the skin. The muscular walls of the stomach are meanwhile twisting, writhing, and turning, with the object of swishing and swirling the food round its inner walls, so that the gastric juice may be washed off. This gastric juice mingles with the food, and begins to break it up. The churning process goes on for four to five hours, until the whole of the food has been broken up into a creamylooking, liquid mass. It then passes out into the first part of the intestine, called the duodenum. Its presence excites certain nerve ends, which cause the bile from the gall bladder to run out into the food. The secretion known as the pancreaticjuice, manufactured by the pancreas or melt, is also poured into the food for the purpose of completing its digestion.

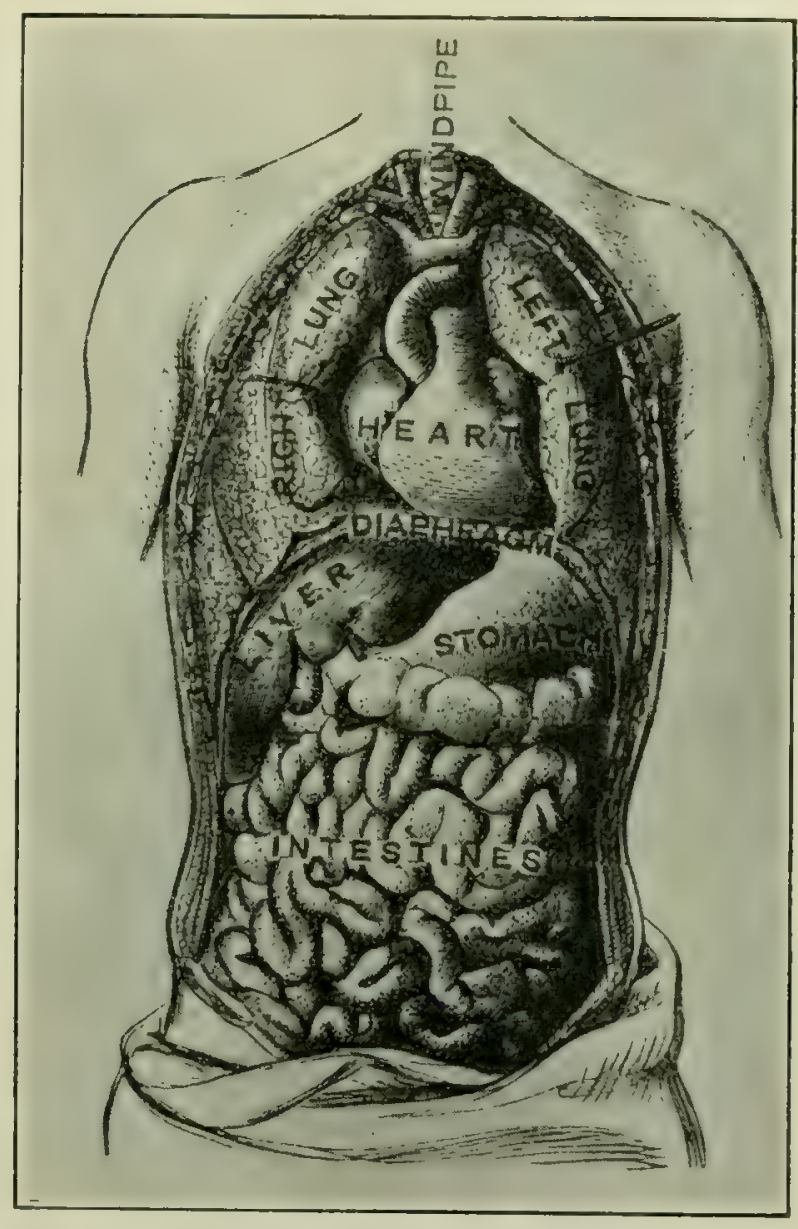

FIG. II9.-The organs of the human body, in situ, the abuse of which induces disease, suffering and premature death. (From Blackie's Physiology.)

\section{The Intestines.}

By a sort of squeezing process performed by the muscular walls of the intestines or bowels, and which is known as the peristaltic movement, the food is worked slowly down. As it proceeds, more juices are poured out to complete the digestion of any parts of 
the food which may have escaped perfect digestion by the other fluids. Then the food is ready to be taken up and converted into blood. In the inner walls of the bowels there are millions of tiny mouths, which greedily suck up the digested food. These little suckers are called lacteals. There is another set known as venous absorbents. Some of the absorbed food is carried to the liver to be filtered and purified before finding its way into the blood stream. The portion which does not need to be acted upon by the liver, is carried through a long slender tube known as the thoracic duct, and poured into a large vein.

\section{Converted into Blood.}

The liquid food mingles with the venous blood and eventually pours into the right side of the heart, and is pumped up in to the lungs. Here a marvellous change takes place. The air we breathe contains a large amount of oxygen, if it be fresh and pure. This oxygen gas instantly combines with the venous blood, and a lightning-like chemical change takes place. The food is changed into living blood, which is made up of tiny discs known as corpuscles, which float in a fluid substance we call serum. The blood is then returned to the heart, but this time to the left half. From here it is pumped all over the body through vessels known as arteries. These divide and subdivide until they become mere threads, so tiny that they are invisible to the naked eye. These are known as capillaries. So numerous are they that you cannot prick your flesh anywhere with the finest needle-point without rupturing several of them.

\section{HeAlTh LaWs.}

There are laws governing every department of Nature. To disobey any of these natural laws means punishment in some shape or form. These laws work automatically. Whether violated wilfully or ignorantly the punishment is the same. There is no escape. We may perhaps escape the consequences of the breaking of man-made laws, but not the laws of God. They are self-acting.

Science is finding out more about these great natural laws, and how they work. In proportion to our knowledge of the workings 
of Nature's laws, so shall we be able to avoid suffering and sorrow. If a man knows there are treacherous bogs at each side of the road he is travelling, he will be doubly careful to keep from straying off the road. If we have been instructed in the

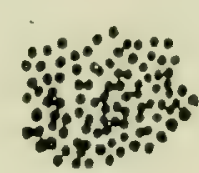

Fig. 1.
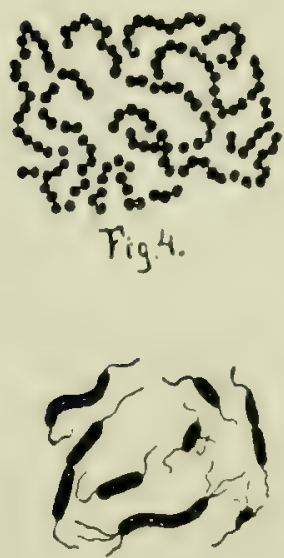

Fig. T.

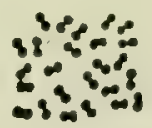

Fig 2

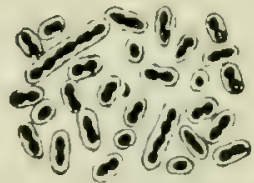

rig. 5 .

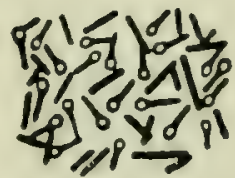

Fig 8
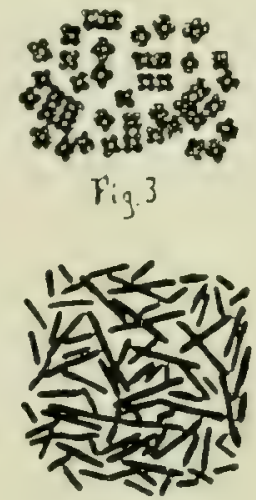

Figo
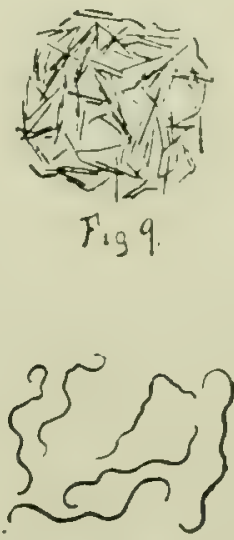

Fig. 12

FIG. 120.-I. One of the most common species of bacteria which cause suppuration (Micrococcus pyogenes).

2. Spheroidal bacteria arranged in pairs (Diplococcus).

3. Spheroidal bacteria grouped in cuboidal masses (Sarcina).

4. Spheroidal bacteria grouped in chains (Streptococcus). These produce erysipelas.

5. Diplococci slightly lance-shaped and surrounded by a capsule. These cause acute pneumonia.

6. The bacteria which cause typhoid fever.

7. Bacilli with cilia.

8. These bacilli with spores produce lockjaw.

9. The bacilli of consumption.

10. The bacteria of diphtheria.

I I. The microbes of Asiatic cholera.

12. The microbes of recurrent fever. (From Standard Dictionary.)

knowledge that certain habits and acts are violations of natural laws, and that punishment in some form is bound to follow, the fear of consequences, if no higher motive, will keep us in the straight path. The very things most essential for every grown 
up boy and girl to know are usually concealed from them. Surely it seems a most essential thing for boys and girls to be taught how to keep the mechanism of their bodies in good going order. Have you ever seriously asked yourself the question, "Why do I eat certain foods, and swallow certain drinks? Are they good or bad for me? Do they suit my constitution, my habits of life, and do they contain the right elements of foodmaterial necessary for the nourishing of brain, bone, and muscle?"

\section{The Science of Eating.}

The science of eating includes not only the study of the food values of the various articles of diet, and how to prepare them. It is necessary also to understand the physiology of digestion; to know exactly what takes place after the food is swallowed. If we make a study of this, we shall find out just how long it takes the various kinds of food to digest. We shall know that wellcooked rice is digested in an hour and a half. Pork from five to six hours, and possibly not at all if the stomach is not strong. We shall know that an average meal takes about five hours to digest, and that to swallow fresh food when the last meal is still digesting, will sooner or later weaken the strongest digestive system, because it is a violation of a natural law.

\section{What a Famous Physician Says.}

In this connection, it will not be out of place to quote what Dr. J. H. Kellogg, a famous medical author, says: "Eating between meals is a gross breach of the requirements of good digestion. The habit many have of eating fruit, confectionery, nuts, sweetmeats, etc., between meals, is a certain cause of dyspepsia. No stomach can endure such usage. Those who indulge in this mannner, complain of little appetite, and wonder why they have no relish for their food, strangely overlooking the real cause, and utterly disregarding one of the plainest laws of Nature. This evil practice is often begun in early childhood. Indeed, it is too often cultivated by mothers, and the would-be friends of the little ones, who seek to gratify them by presents of confectionery and other tit-bits of various sorts. Under 
such a regimen it is not singular that so many thousands of children annually fall victims to stomach and intestinal diseases of various forms. In great numbers of cases early indiscretions of this sort are the real causes of fully developed dyspepsia of later years."

\section{A Living, Self-Acting Pump and the Elixir of Life.}

Poets and lovers wax eloquent about the heart, as though it were capable of thought. We love with our heart, so we are told. Well, the heart, in reality, is nothing more or less than a self-acting pump, composed of four chambers, and has not any sense at all. Love is the rousing into activity of certain brain centres. The heart is a powerful muscle, or rather a combination of muscles. The two top chambers are the auricles, the bottom ones are the ventricles. The purpose of the heart is to pump the blood through the body. The human heart, in size and shape, is almost identical with that of a pig's heart. The heart is situated just under the breast bone, in the chest cavity, which is known as the thorax. It is turned slightly to the left side.

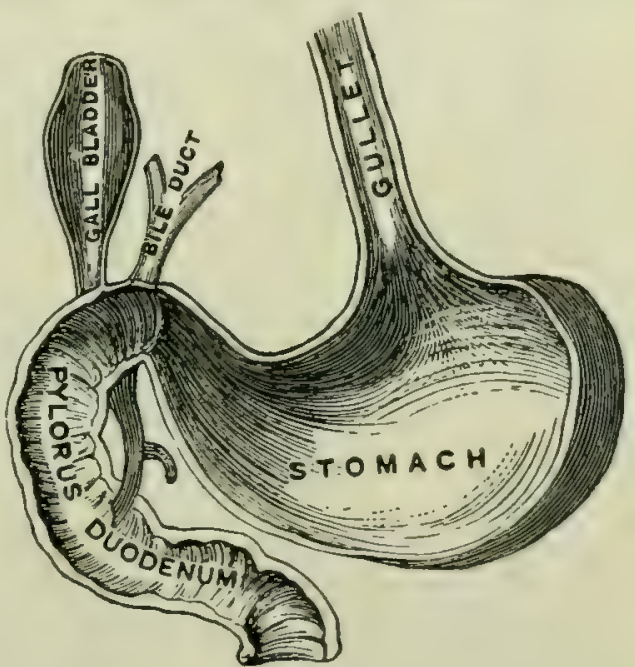

Fig. 12I.-A section of the human stomach which is the most abused and overworked part of the mechanism of the body. (From Blackie's Physiology.)

The weight of the heart averages 8 to Io ounces in women, and Io to I2 ounces in men. We really have two hearts joined together. The right side of the heart is for the purpose of pumping the blood up into the lungs. The left side is for driving it all over the body, hence the reason that the ventricle on the left side is three or four times as thick as that on the opposite side, because it has to pump the blood to the most distant parts of the body; whereas its companion only has to drive the blood a very short distance. The Dugong, a warm-blooded animal which lives in the ocean, and which has given rise to the mermaid myth, has two hearts, quite separate. 


\section{The Elixir of Life.}

Connected with the heart is an endless system of tubes, which carry the blood all over the body.

The blood is the elixir of life. The stomach, with the aid of the liver, pancreas, bowels, and lungs, changes the food which we eat into blood, in a most marvellous way. The blood is composed of tiny bodies, known as corpuscles and a watery fluid known as Liquor Sanguinis. There are red, and there are

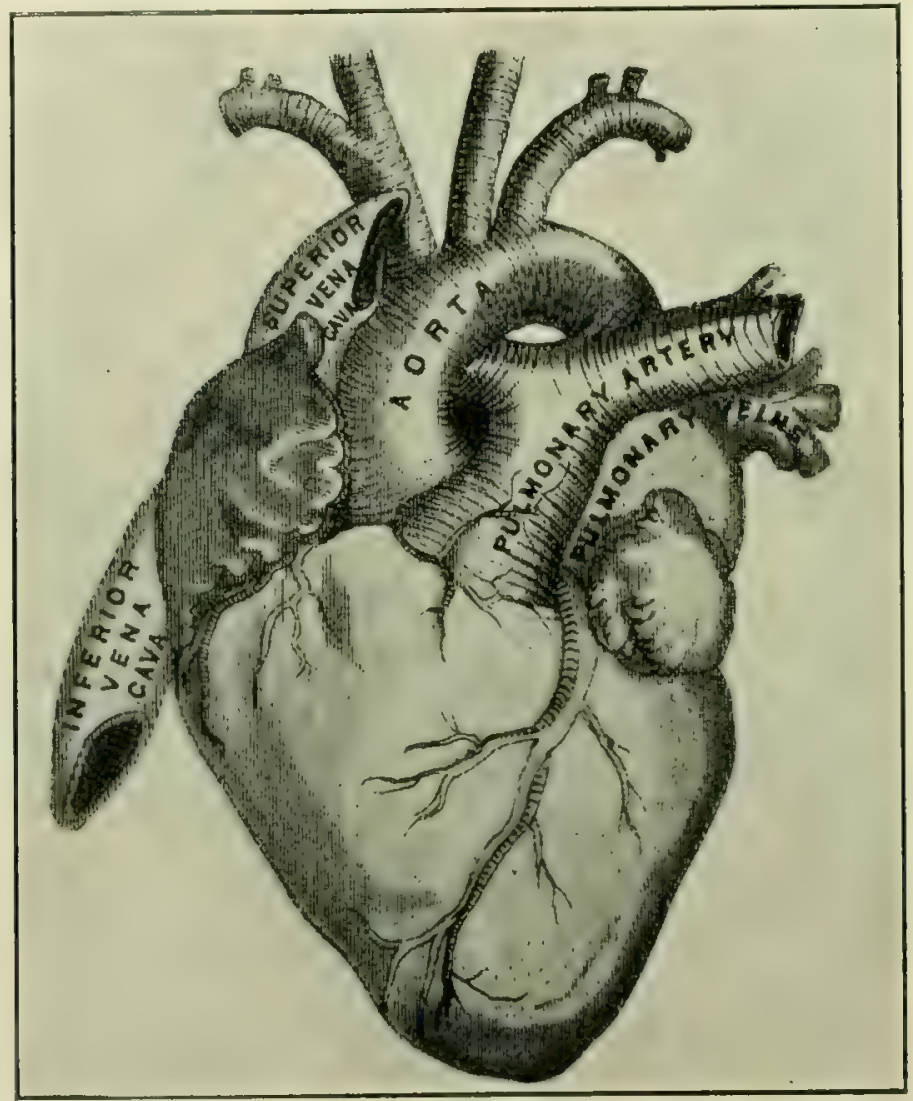

F1G. 322.-Exterior view of the human heart and the great blood vessels. The heart has four chambers - two auricles and two ventricles. (From Blackie's Physiology.)

white corpuscles. The red corpuscles are those which make the blood appear red. They and the Liquor Sanguinis carry food to every cell of the body. In fact, they are living foodthe elixir of life. They renew the wasted cells. They are the builders. As quickly as the cells of the body are broken down, so they build up more. The white blood corpuscles are also known as Phagocytes or Leucocytes. They attack and eat up disease microbes, and repair wounds. 


\section{The Circulation of the Blood.}

Now, let us follow the blood as it comes rushing along from the various parts of the body, and pours itself into the right auricle of the heart. From this chamber it is forced down into the bottom chamber, on the same side, and is prevented from rushing back by a wonderful system of valves, which allow it to rush down, but not back again. From the ventricle, the heart-muscles pump the blood up into the lungs. Here it spreads out into smaller and smaller tubes, until they are so small they cannot be seen with the naked eye. This blood, which the heart has pumped into the lungs, is called Venous blood, because it is full of poison gathered up from all over the body. The body is constantly burning. The cells which compose it are dying in millions every second of life. Their dead bodies fall into the blood and are carried away to the heart and pumped into the lungs. Now, when we take in a breath of fresh air, we breathe in a quantity of gas, known as oxygen.

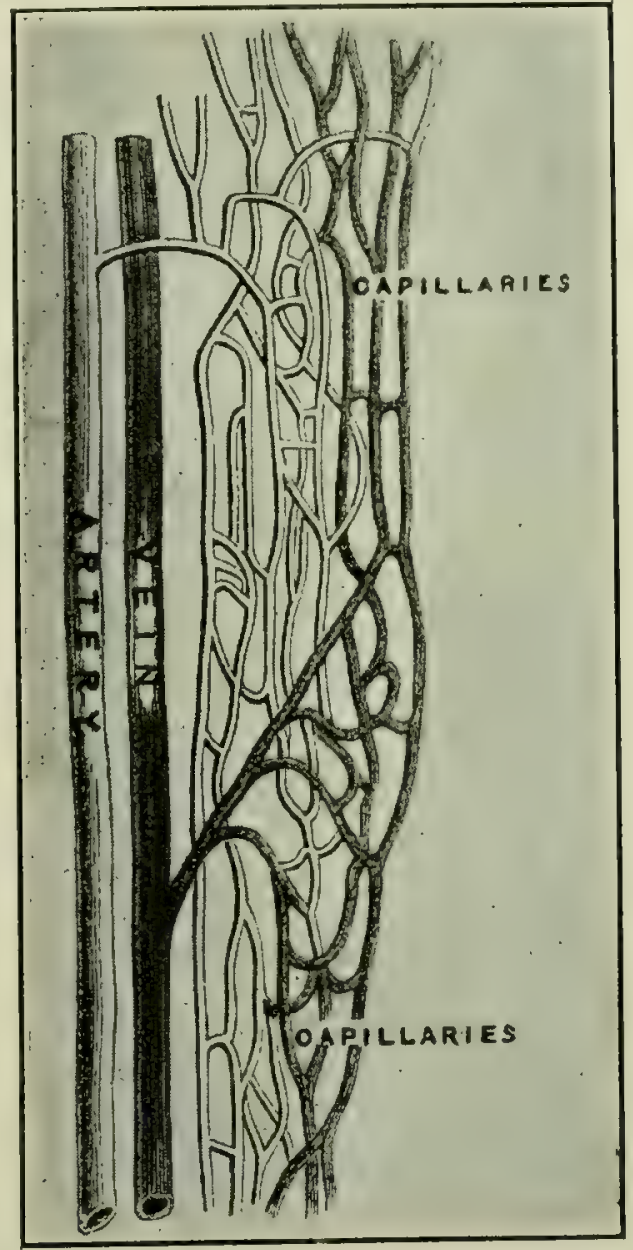

Fig. 123.-From the artery the blood runs into smaller and smaller channels, so small that they can only be seen with a strong microscope. They again run together and pour their contents into a vein. (From Blackie's Physiology.)

The lungs contain millions of little hollow bags, known as sacs. Around these, the tiny blood vessels are embedded. They are gorged with blood. Their walls are very thin, so that when the air rushes into these tiny bags, the oxygen is sucked up into the blood through the thin walls of the blood vessels. It instantly mixes with the poisons in the blood, and a wonderful, 
and marvellous change takes place. It is no longer oxygen. It has combined with the poisons, and has changed them into a gas. This gas is called carbonic-acid gas, or carbon-di-oxide. This we breathe out, and thus get rid of many of the poisons in our blood. This air we breathe out is poison in a gaseous form. If we could condense it, we should see a mass of putrid filth.

Now, think carefully over this wonderful mechanism which God has provided for the casting out of poisons, and purifying

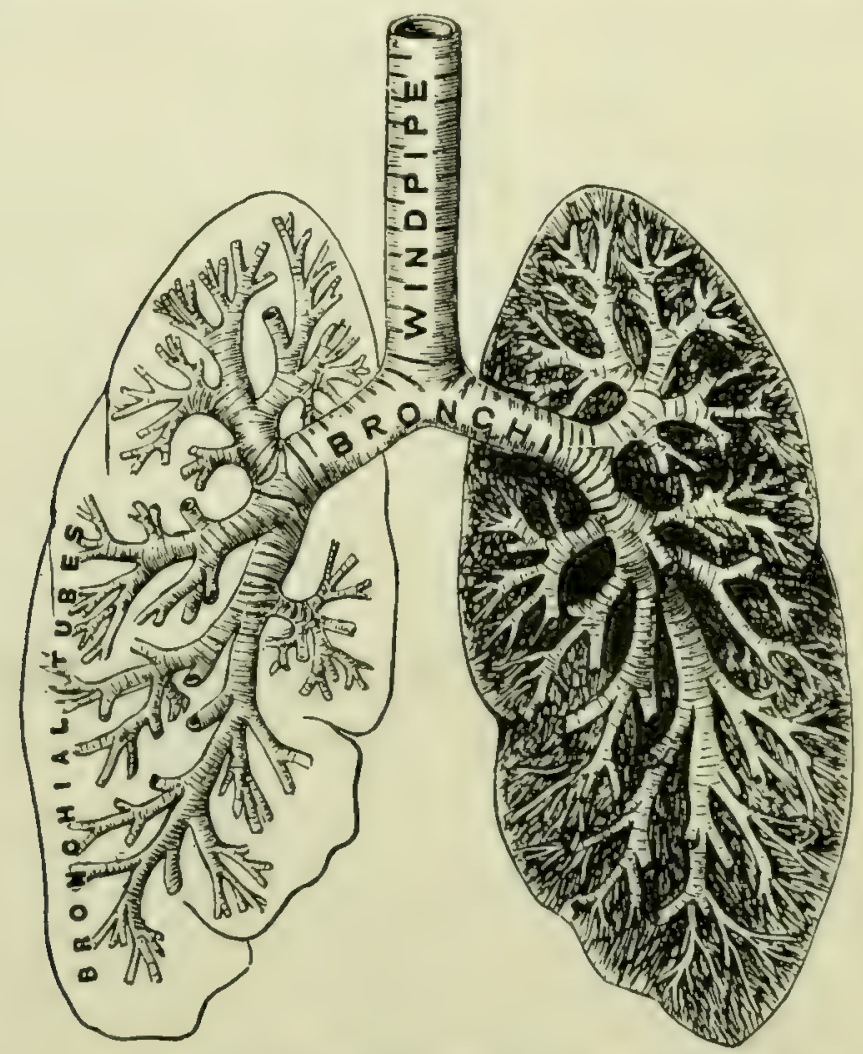

Fig. 124. -The pipes which carry air to and from the lungs. They divide and sub-divide and penetrate to every part of the lungs. They terminate in little bags or sacs. There are millions of them. (From Blackie's Physiology.)

our blood, and remember if you want your blood to be pure, you must breathe fresh air. You cannot get fresh air, if you live indoors, and shut out the pure air. You are breathing poison when you do this. You are re-breathing your own breath, or that of other people, and poisoning your blood, instead of purifying it. Remember always to breathe pure, fresh air. Flood your dwellings, offices, and workshops with it. Fresh air and conl breezes don't give a "cold." That belief has been exploded. "Colds" are caused by the attacks of microbes 
which can only breed in your throat, when your blood is impure.

\section{A Remarkaible Change.}

When the oxygen has combined with the poisons in the blood and removed them in the form of carbonic acid gas, the blood, instead of being a purplish colour, is now bright red. It has been changed from venous blood, to arterial blood. It is now pure again, loaded with oxygen. The tiny blood vessels gradually merge one into another, like a multitude of little rivulets running together. Larger and larger become the vessels or tubes, until they all merge into great channels through which the blood is poured into the auricle or top chamber of the left side of the heart. From here, it is pumped down into the ventricle or bottom chamber, and with a mighty throb, the heart drives it all over the body. It rushes out, dividing and sub-dividing into smaller and smaller channels, until they are so small that a strong microscope is needed to see them. Through the walls of these tiny blood vessels nourishment is supplied to the cells of the body, and the dead used-up material absorbed; so that, as. it slowly makes its way along, it gives off all the nourishment it is capable of for the time being, and with its load of poison, it hurries away back to the heart, to be pumped once again into the lungs, to be re-vitalized, cleansed, and purified by the oxygen in the air we breathe.

\section{How we POISON OUR BLOOD.}

There are more ways of poisoning our blood than breathing impure air. A good many of the liquids and foods which we swallow also poison the blood. People make themselves ill by eating wrong foods, or too much food, and instead of fasting they swallow great quantities of poisonous drugs. Drugs should not be taken, unless by a physician's orders.

If the foods which we eat are not thoroughly digested they ferment and become putrid, especially animal food, in the bowels. The liquid portion of this putrid mass is sucked up by little vessels known as lacteals, and poured into the blood, fouling and poisoning it. The phagosytes or white blood corpuscles are 
thus benumbed, and rendered incapable of killing off disease microbes, which multiply and cause a disease peculiar to their species or kind. If you disregard the laws of eating and drinking then you should not blame Providence if the machinery of your body gets out of gear, and disease microbes attack it.

\section{How to Keep your Blood Pure.}

The first essential is to breathe plenty of oxygen, and inhale deeply. A great many people get into the habit of breathing

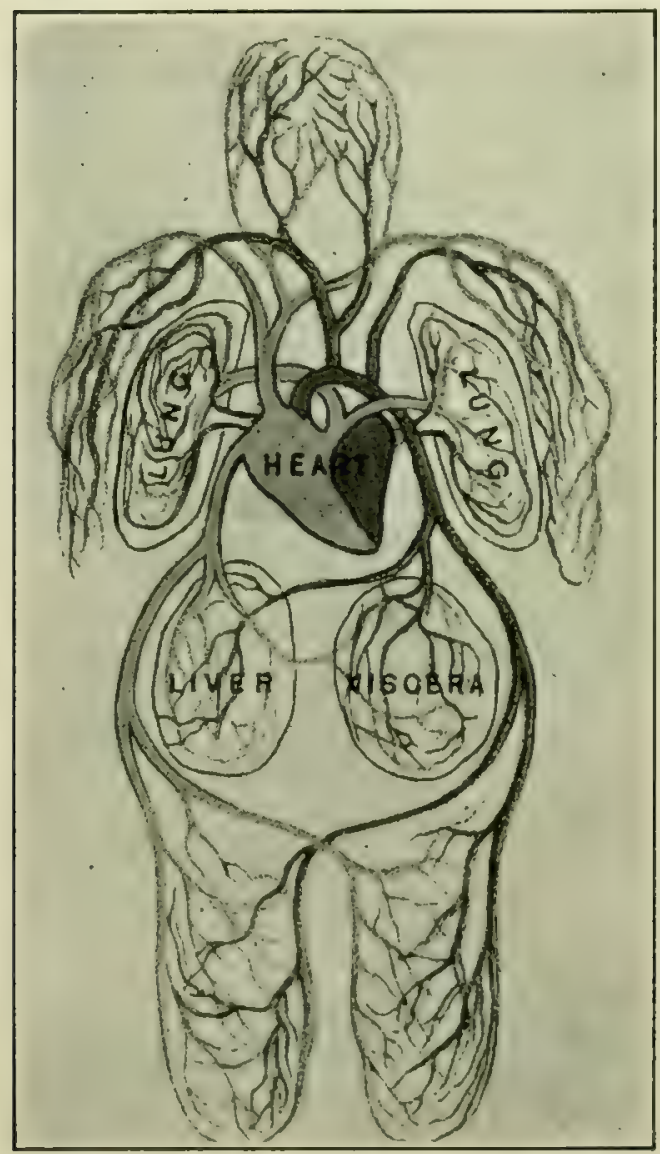

FIG. I25. Rough diagram showing how the blood circulates through the body. Poisonladen blood runs to the heart from all over the body. It is then pumped into the lungs and purified by the air we breathe. It returns to the heart to be again pumped to the remotest corners of the body. (From Blackie's Physiology.) in a very shallow way, inflating only a portion of their lungs. Boys and girls who have flat chests should be compelled to take systematic club, dumb-bell, or other suitable physical exercises for enlarging the chest and lung capacity. The exercises should not be discontinued until the chest becomes convex.

Practise deep breathing until it becomes a habit. Sit in a chair with a straight back, bolt upright. Slowly breathe as much air into your lungs as you are able to force down. Retain it till you count five, then slowly exhale it. Continue this for fifteen minutes, twice a day if possible. At first you will feel a trifle giddy with the unaccustomed amount of oxygen which gets into your blood, but this soon wears off. Breathe through your nose. It is a microbe and dust filter, and warms the air also. 


\section{EATING AND DRINKING.}

Be careful to eat good, plain, wholesome foods. It takes an ordinary meal fully four to five hours to digest. While food is digesting no more should be put into the stomach, therefore three meals a day are sufficient, unless of course in cases, under a medical man's care, where special measures are necessary. The ancient Greeks and Persians only ate twice daily. The
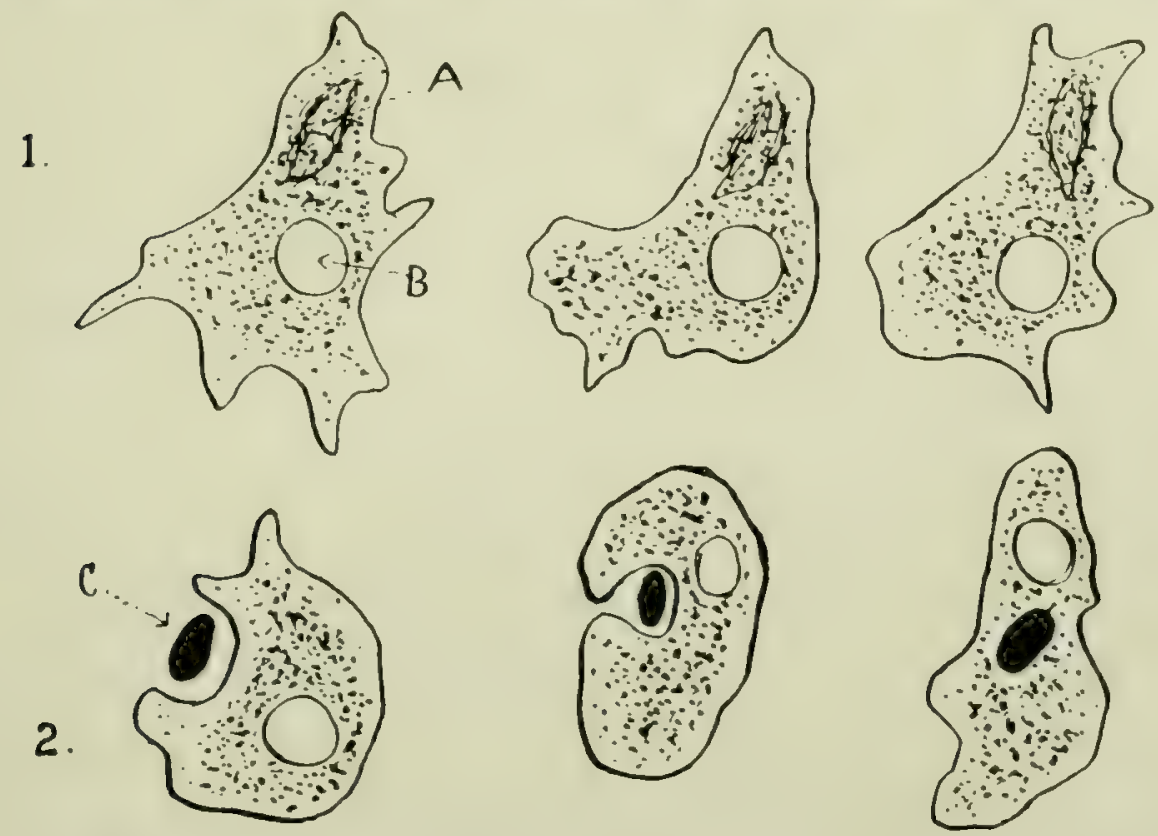

FIG. 126. - These are the Phagosytes which help to make up the blood of our bodies. They look like bits of jelly, and are so small that it requires a powerful microscope to see them.

The top row is what they look like when they are swimming in the liquid part of the blood.

A. This is the nucleus from which radiates the life-principle of the phagosyte.

B. This is a tiny cavity which holds liquid.

The second row shows a Phagosyte attacking, seizing and digesting a disease microbe.

There are countless millions of Phagosytes in our blood. They attack and eat up disease microbes which get into the blood. They repair wounds and build up parts of the body.

C. This is a disease microbe.

Alcohol and the nicotine in tobacco shrivels up and kills these microbe-killing phagosytes when it gets into the blood. Those it does not kill, it cripples.

Romans did likewise, until they grew into luxurious ways of living.

When there is anything wrong with the digestive organs or their appendages, such as ordinary indigestion, catarrh, biliousness, or constipation, then careful dieting or a temporary fast is necessary, else the blood will be rendered foul by the poisons released from the decomposing food. 


\section{EXERCISE.}

Regular exercise of the body in the fresh air daily, is necessary to increase the heart's action; and to draw the blood in to the muscles, and thus relieve the congestion of the brain and internal organs which occur when the muscles are not regularly used. The increased circulation drives the blood with greater speed through the sluggish capillaries, and carries an increased amount of poison out of the body. The nervous system is also aroused, the internal organs become more active, and an all-round improvement thus takes place.

To keep the blood pure, and to have good sound health, it is necessary to eat plain, wholesome food at regular intervals only. Lead a temperate life, abstaining from all that which is harmful. Breathe fresh air. Be out as much as possible in the sunshine. Take plenty of exercise out of doors. Breathe deeply and develop the chest.

How Food, Drink, and Poisons are Conveyed to the Cells of the Human Body.

The blood in our arteries is charged with the digested food which we eat, and the liquids we drink, as well as the oxygen gas we breathe. But how does this food, drink, and oxygen get into contact with the countless millions of tiny cells which compose our bodies? The blood, as we know, is enclosed in channels or tubes. These tubes divide and sub-divide until they form an exceedingly fine network of tiny blood vessels so thickly permeating the flesh, that the finest needle-point cannot puncture the skin without penetrating and tearing a great many of them. But how does the nourishment in the blood get outside the membraneous walls of the vessels which enclose it?

Imagine, if you can, a great swamp full of rushes, reeds, and grasses. This vegetation sends out roots in all directions, which permeate the ooze in a fine network. Imagine this network of roots to be the blood vessels in your body, and the water which surrounds those roots on all sides to be a colourless fluid known as lymph. This water-looking lymph saturates the tissues of the body and surrounds the capillary blood vessels. You all know what lymph is. It is the watery, colourless fluid which 
accumulates under the skin, and forms blisters when you get badly sun-burned.

\section{WHAT THE LYMPH DOES.}

Well now, a most marvellous thing occurs within our bodies. This lymph which saturates the body like water in a bog, sucks from the blood its oxygen and digested nourishment through the walls of the blood vessels, and so feeds the cells of our bodies. Our bodies are burning all the time. We are constantly using up the cells of our bodies. They burn away in countless millions every instant of time, and are replaced by new cells created from the nourishment supplied indirectly by the blood, and directly by the lymph. The dead cells, when burned up within the body, take the form of carbonic acid. This gas is sucked up by the lymph, and through the walls of the tiny capillary blood vessels. The latter carry it away instantly to the larger veins which in turn pour into yet larger ones still, until the poison-laden blood reaches the heart. This human pump then forces it up into the lungs where it is changed by the oxygen gas we inhale. The poisons are thus breathed out and escape from the body.

\section{The Lymphatics.}

Now, you wonder, perchance, how the watery lymph, laden with impurities, is drained away. Like a thick network, countless numbers of tiny tubes spread out under the skin, and amongst the tissues. These are known as lymphatic vessels, because they carry lymph. The blood vessels are unending. They proceed from the heart, divide and sub-divide until they form a fine network of tiny tubes. These small blood ressels have no blind or open endings. When their work is done in supplying the lymph with their load of nourishment, and when they have sucked up as much poisonous dead matter as they can in the form of gas, they begin to run together, forming larger and yet larger channels which conduct the blood back to the heart to be once again pumped into the lungs. On the contrary, the lymphatics have open mouths. The lymph, which saturates the tissues, is drained off by these little lymphatic tubes, the open mouths of which suck it up and hurry it along into larger 
and larger lymphatic ressels, until at last it is poured through two big tubes in the neck into two large reins, and thence to the heart to be pumped, along with the renous or impure blood, into the lungs to get rid of its load of poison.

\section{How Snake Venom is Sucked up.}

This vast network of absorbent lymphatic ressels and capillaries, which spread out under the skin, and in all directions

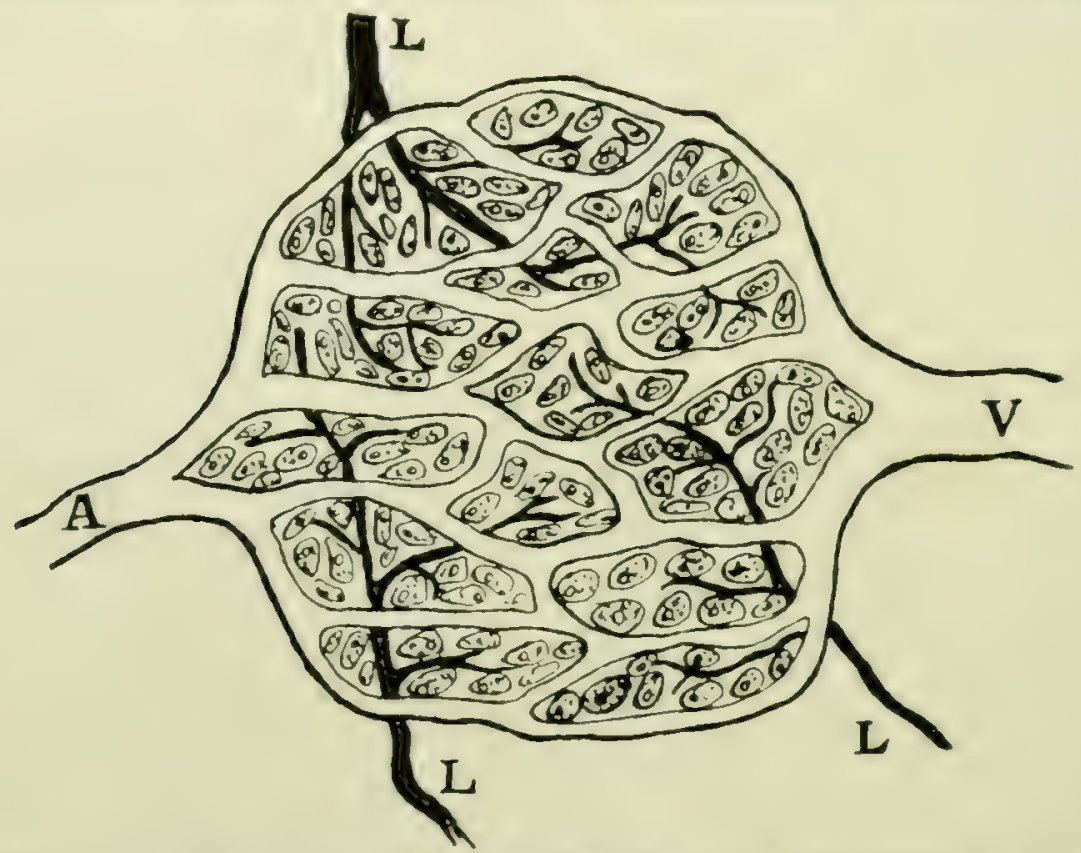

Fig. 127-This drawing serves to show how an artery breaks up into small channels which are called capillaries. They are so small that they cannot be seen except with a powerful microscope. After nourishing the cells, they run together again, and form what is known as a vein. The little bodies in the spaces are the cells of the tissues. They are surrounded by lymph. The black lines are the Lymphatics which have open mouths to suck up the lymph and all it might contain, and carry it away to the blood.

A. Artery. V. Vein. L. Lymphatics.

through the tissues of the body, sucks up any fluid which may be injected, or otherwise find its way under the skin, or into the muscles. Drugs are frequently administered thus. They find their way more rapidly and efficiently into the general circulation when hypodermically injected, than if swallowed.

Ordinary cases of blood poisoning occur in this manner. The poison is sucked up from the wound. Microbes of various diseases gain an entry into the blood also in this manner, hence the reason why all wounds, and even slight abrasions of the 
skin, should be cleaned and dressed with a germ-killing substance, such as boracic acid.

When a snake drives its fangs through the skin, the venom is discharged into the watery lymph and amongst a close network of lymphatic tubes, the absorbent mouths of which are intensely irritated by the venom. Being thus stimulated, they and the small blood vessels rapidly suck it up. In a marvellously short space of time it is distributed throughout the body by means of the blood vessels. Not being convertible into a gas by the lungs the latter have little or no power of expelling it with the exhaled breath, as is the case with ordinary tissue waste matters.

\section{Destroy the VENOM AT ONCE.}

Now, it is apparent if the spot where the fangs entered is well scarified and allowed to bleed freely or sucked, the venom, or at least some of it, will be washed out or drawn out by suction. Permanganate of potash kills snake venom, if brought into actual contact with it, so, it is obvious that if this salt is rubbed into the scarified part within five minutes of being bitten by a snake, more or less of the venom will be destroyed in the wound. This method naturally does not always save the bitten person's life, because, when a large and very venomous snake, such as a Cobra, inflicts a full and complete bite, enough venom is sucked up within a minute or two into the body, to cause death, although the permanganate might have destroyed two-thirds or even more of the quantity injected by the snake.

It is unwise to rely entirely upon permanganate of potash in the treatment of snake bite, even if it be applied within a minute of being bitten, especially if the snake be a Cobra, Mamba, or large Puff Adder. The victim should be injected with Anti-venine Serum, which men of science now prepare for the treatment of snake bite, and which is fully discussed elsewhere in this book.

A series of experiments which I conducted during the past ten years all go to show that none of the popular South African "cures" retard death in the least when applied in cases of snake bite on animals. 
Knowing how the venom is carried into the general circulation, it will be apparent that a ligature applied above the

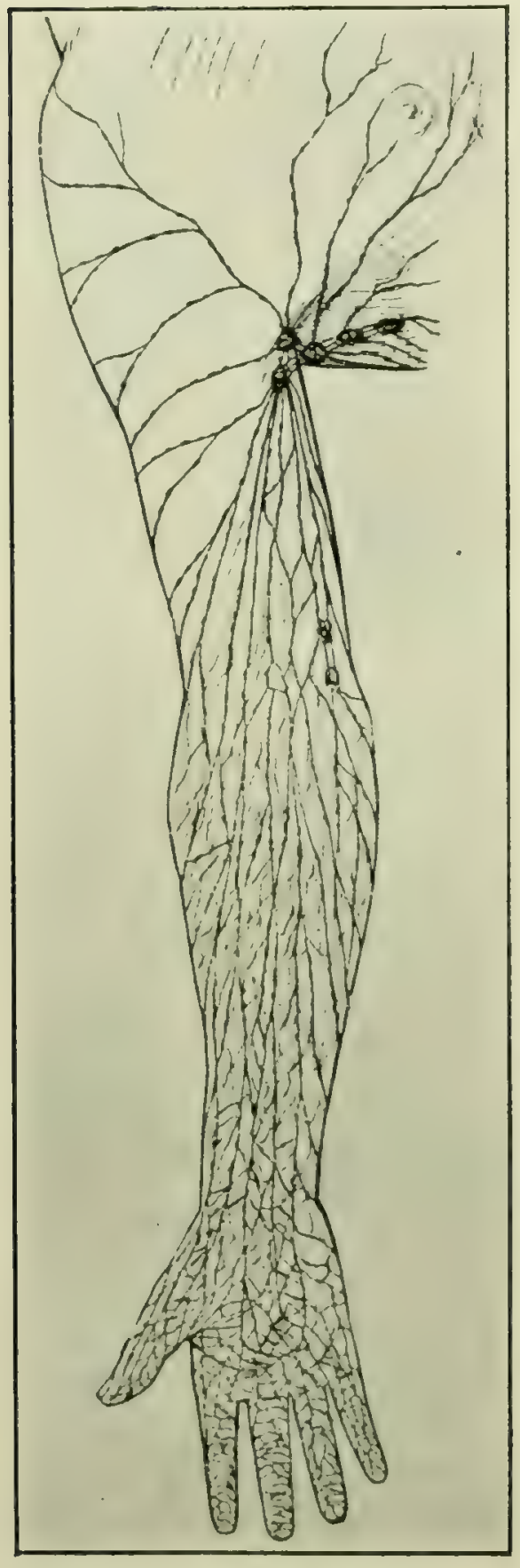

焉 wound would considerably retard the flow of the blood and lymph into the body. However, great care must always be exercised so as not to allow a very tight ligature to remain on for more than half an hour to an hour, else the limb may mortify. The ligature should be slightly loosened for a moment at intervals, so as to allow the venom to get into the circulation so slowly that the vital functions may be able to cope with, overcome, and cast it out before it can succeed in paralyzing the nerve centres, and thus cause death. Much of the poison-charged blood may be got rid of in the ligatured part, by opening one or two of the veins which look like blue lines under the skin.

There is no risk of bleeding to death from an ordinary surface vein. It is the arteries which are difficult to stop bleeding when severed. They, however, lie deep down in the tissues, not just under the skin, except at places such as the ankle and skull where the muscles are thin or absent. All the blue-looking blood channels seen under the skin are veins. 


\section{How Venom gets in and out of the Blood.}

The nourishment and other substances held in solution in the blood pass out through the walls of the microscopically small capillary blood vessels into the lymph by means of which they reach the cells to nourish, paralyze or kill them, according to the nature of the substance.-- Now, suppose you take a glass bottle without a bottom. Over the bottom part stretch a piece of bladder and tie it securely. Make a solution of sulphate of copper and place it in the bottle. You will find it will not ooze through the bladder membrane.

Now place the bottle in a glass of water. Presently you will observe the water becoming blue. This shows that the copper sulphate is oozing through the bladder into the water. This is called Osmosis, and shows exactly how nourishment, poisons, etc., pass through the walls of the blood vessels into the watery lymph by which they are surrounded, and reach the cells to rebuild or poison them. At the same time the water from outside will ooze through the membrane over the bottom of the bottle, and mingle with the contents, until the solution inside and outside the bottle is of the same density. Now, when a snake discharges its venom into the watery lymph amongst the blood vessels under the skin, a portion of it oozes through the walls of the tiny capillary blood vessels and enters the blood-stream. It is carried along with the blood, and if

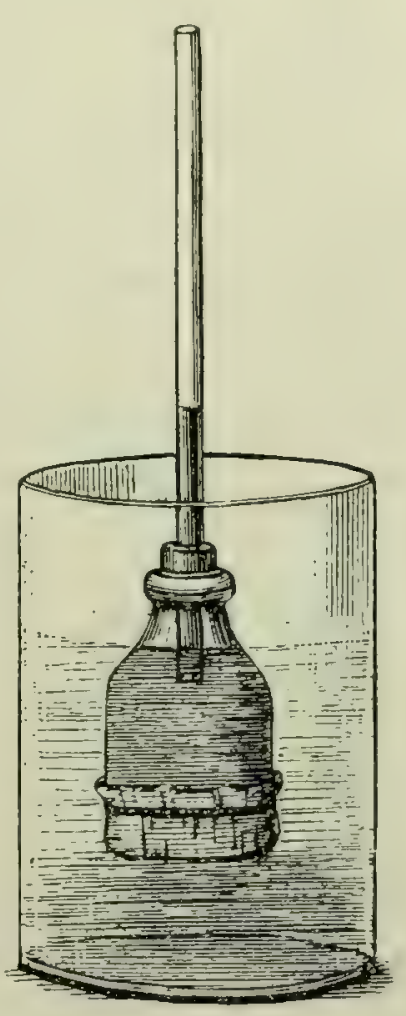

F1G. 129. it be Viperine (Adder) venom, it will at once begin to attack the capillary walls and the blood, dissolving the red colouring matter out of the red corpuscles, and otherwise breaking it up, causing it to ooze out through the blood-vessel walls and spread in dark bluish-black patches under the skin, and amongst the muscles. If it be Cobra venom it will ooze out through the walls of the blood vessels, and be absorbed by the cells of various nerve centres in the brain and top of the spinal cord, and poison them. 
If snake venom in solution with water, instead of sulphate of copper, is placed in the bottle shown in the illustration, it will not ooze out. But if the bottle is placed in a glass of water it will begin to ooze through, and vice versa until the water inside and outside the bottle will be equally poisonous.

It can thus clearly be seen that if snake venom has been sucked up and has already acted extensively upon the blood and nerve cells previous to the injection of an antidote, the latter, even if administered copiously, may fail to avert a fatal issue. It is obvious that if the nerve cells be extensively poisoned, or the blood broken up beyond recovery, there cannot be any other result than death. It is practically impossible for us to judge whether the patient has passed the border-line or not, unless he is actually dying and the fact is patent; therefore in these cases we always recommend injecting three times the ordinary dose of anti-venine serum. This serum will be dealt with fully in the next chapter. Place no reliance upon any quack so-called cure. If the anti-venine will not save the patient from death, nothing else will. I wish to impress this fully upon the minds of readers, for the majority of people have some kind of worthless cure which they have such faith in, that nothing else would be used if a case of snake bite should occur.

In places in this volume there may seem to be unnecessary reiteration. Whenever I have dwelt more than once upon the same topic it is with the definite purpose of impressing the minds of readers with matters which are of grave importance. 


\section{CHAPTER X.}

Alleged Snake Bite Cures-Results of Experiments.

In all countries where venomous snakes abound, so-called antidotes to snake bite spring up like crops of weeds upon a rank soil. In India at least a score of alleged antidotes were largely advertised and otherwise advocated. Each "cure" had its adherents, many of whom testified to its power to cure snake bite. Doctors Fayrer, Brunton, Rogers, and other eminent experimenters exhaustively tested the alleged antidotes in use in India, and found them one and all, to be of little or no value. Colonists in South Africa invariably attach much importance to the assertions of the natives in regard to alleged snake bite remedies. This faith has, doubtless, been considerably strengthened by the crafty " Kafir doctors" " tactics.

\section{How Beliefs are Spread.}

These "doctors" tell of the wonderful virtues of some favourite remedy for snake bite, and when urged to divulge its nature, make a profound mystery of it, declaring that fabulous sums would not tempt them to disclose the secret. Naturally the inquirer is impressed, more or less. Many of these " doctors" have accomplices, who pretend to be suffering seriously from snake bite. With much mystery and fuss, the doctor appears upon the scene and applies his remedy. The man makes an apparent rapid recovery, and the "cure" is heralded all over the neighbourhood. I have, however, met many of these native doctors, who, I have every reason to believe, had firm faith in the antidotal properties of their snake bite "mooti" (medicine). 


\section{Apparent Cures.}

In the past I have treated, and seen treated, many cases of snake bite. It was in the days when little or nothing was known of the present approved methods of treatment. I had strong faith in alcohol, strychnine, ammonia, and one or two proprietary substances, the active principle of which, I afterwards ascertained, was either ammonia or strychnine, or both. Many of the cases so treated were practically "cured" twelve or twenty-four hours after treatment. I have often seen the same thing occur when native "cures" were applied.

\section{The Reason Why.}

However, when I began the serious study of snakes and their venom, I found that a large percentage of the snakes of South Africa were non-venomous, many others were only venomous to a slight degree, and others powerfully venomous. Now, a harmless snake, or a slightly venomous one will, in nearly all cases, instantly bite if trodden upon or roughly handled. Some of them are actually vicious, and will lunge fiercely at any one coming near to them. The commonest place to be bitten is upon the hand. In gardening work, removing lumber, and in a multitude of other out-of-door occupations, the hands are employed in moving, turning over, carrying, etc: If the fingers should touch a snake, or the hand come within striking distance of it, the reptile will often lunge with gaping jaws and inflict a wound. The victim sees the snake bite him. That is enough for him. He rushes off in terror, forthwith swallows all the brandy, whisky, or gin he is able to imbibe, or perhaps other "cures" are applied. If the strong spirit does not poison him, or cause acute inflammation of the stomach and death, he recovers and swears ever after that he drank a bottle or two of spirits and it cured him. If the cure should happen to be some simple remedy, such as native "mooti," or something else recommended by a neighbour, and he finds he is none the worse for the bite, he is never weary of advocating the treatment, whatever its nature might have been, although in all probability the snake which bit him was one of the harmless species. 
Even when bitten by highly venomous snakes, it does not follow that death, or even serious illness, will result. If a poisonous snake should succeed in inflicting a full and complete bite, and if that snake should happen to be a healthy one of adult size, then if death does not take place, very serious constitutional effects are bound to follow. Often, however, the venom, or most of it, is absorbed by the clothing, or the skin is barely scratched. In other cases a partial bite with only one fang is inflicted. It is impossible to know for certain whether any alleged cure is what it claims to be or not, unless tested under proper conditions. The conditions must be such as to leave no possibility of doubt as to the identity of the snake used for the purpose. In experimental work one test is not sufficient. A series of experiments are necessary.

It by no means follows that a fatal dose, or even a dose sufficient to cause noticeable symptoms of poisoning, will be injected even if a snake should puncture the flesh with both fangs. Often the snake miscalculates his distance, and the venom squirts out before the fangs penetrate the skin. In these cases only a fractional dose is injected. At other times a fierce thrust is made which either misses or strikes the boot or clothing at an oblique angle. Like a flash a second blow is delivered. This time the fangs, perchance, are driven home. In such cases as these the venom would be driven out of the poison glands and shed by the first thrust, leaving very little for injection by the second bite. In fact I have often found that the masseter muscles which squeeze the glands and expel the poison, do not always respond a second time, unless there is a pause between the first and second bite.

During the course of my experiments it was abundantly evident that a bite from a venomous snake did not always mean the injection of a fatal dose of venom. I will give one instance from scores in my note book.

A large Puff Adder which had been in captivity five days, was held by the finger and thumb and allowed to bite the lower part of the thigh of a Cape Jackal which was as large as a fullgrown Pointer dog. The snake drove both fangs into the flesh. It bit a second time, but only one fang penetrated halfway.

Five minutes later a second Puff Adder was held to the thigh of the Jackal. At first it refused to bite, but when its nose was 
violently rubbed against the Jackal's leg, it bit rapidly and let
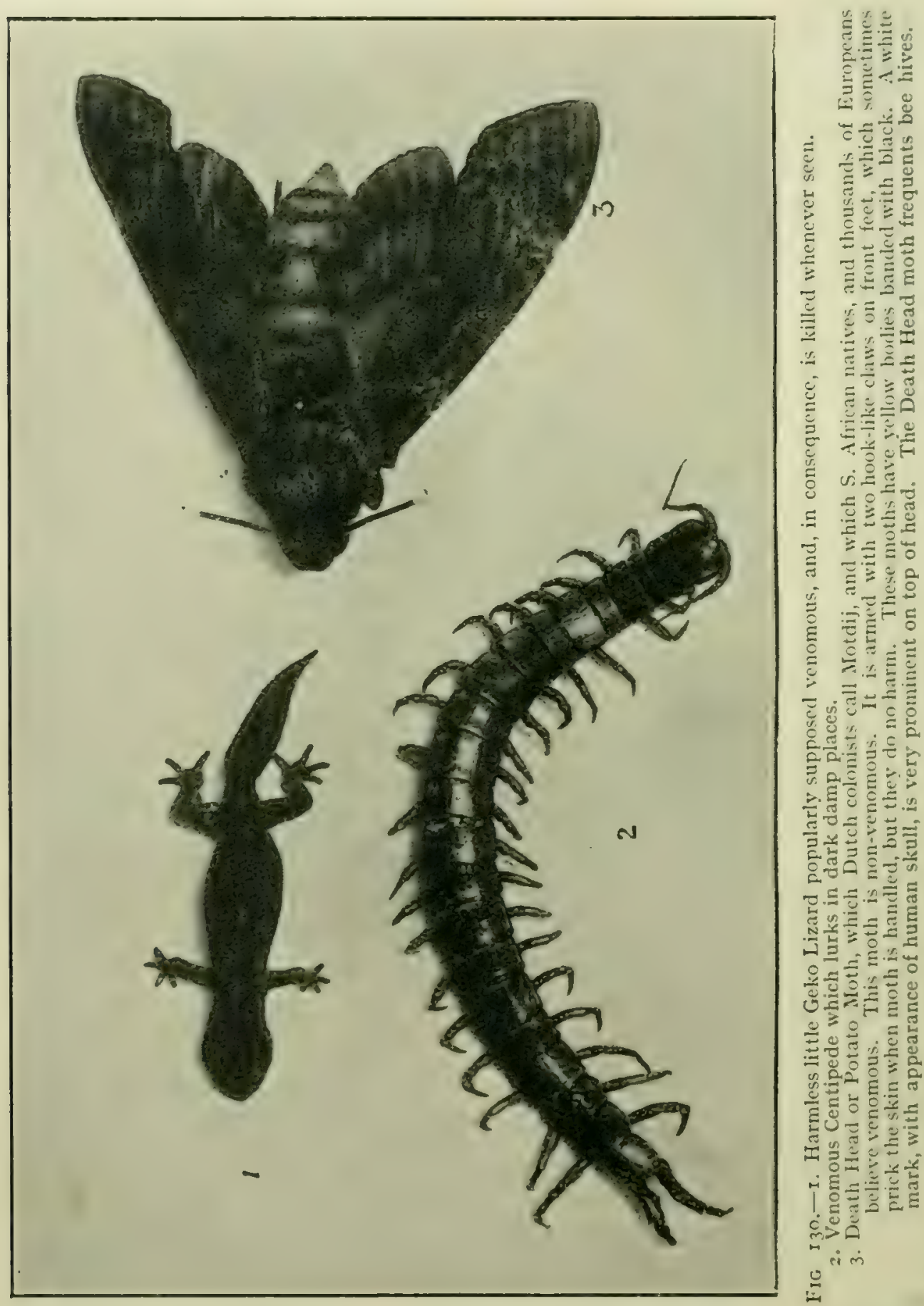

go, leaving two punctures. Again it bit in exactly the same way, leaving two punctures which bled slightly.

All that day, and for three days following, the Jackal showed 
no outward symptoms of poisoning. There was no swelling, and the animal fed as usual, and was as lively as ever.

On the fourth day I extracted three drops of venom from one of the Puff Adders which had bitten the Jackal. This was mixed with a teaspoonful of pure water and injected into the muscles of the other thigh of the Jackal, by means of a serum syringe. One hour later the Jackal was dead. A post-mortem showed the limb swollen twice its normal size. The flesh of the whole limb from the toes up to the junction with the body, was saturated with blood which had oozed through the walls of the blood vessels into the surrounding tissues. The muscles of the whole body were more or less stained with extravasated blood, and the heart was also affected.

The limb was then examined which had been bitten by the two Puff Adders. All about the sites of the bites the muscles were much discoloured with blood, which had oozed into the tissues. This was traced up the leg and half-way along the side. It was apparent that venom had been injected when the snakes inflicted their bites, but not in sufficient quantity to cause swelling or other noticeable symptoms. Now, if I had relied upon this case as a demonstration of the efficacy of some favourite "cure," I should have been altogether wrong in my conclusions.

\section{The Quantity of Venom Injected.}

When a venomous snake inflicts a full bite he drives his fangs into the flesh and retains his hold for a moment or two, at the same time gripping hard. Now, in most cases of snake bite with human beings and the larger animals, the victim generally sees the snake lunge and springs away or shakes off the reptile the moment it bites. If he does not happen to see it strike he will, on the instant, leap, kick, or otherwise disengage the snake's fangs before it is able to grip the flesh and press in a full charge of venom. I have frequently made snakes bite animals with the object of demonstrating that if a snake is allowed to get a full grip and hold on for a second or two, the amount of venom injected is double and often ten or more times greater than if the reptile struck and instantly disengaged its fangs. This is ascertained by observing the length of time the animals survived. 
In many cases when the snake was allowed simply to puncture the flesh for an instant, the animal recovered. Often the symptoms of poisoning were only comparatively slight. In all cases when a Cobra, Puff Adder, or Boomslang was allowed to inflict a full bite, death followed. The fangs of the Cobra family of snakes are short and the channel down which the venom flows is very small. I have carefully tested and found that the Cobra, Ringhals, and Mamba, expel their venom at the rate of about a drop from each fang in one second. With the available constricting power exerted on the poison glands, the venom is pressed out with great power, but the channels down which the venom is forced are so small that it issues in a very fine stream. The Puff Adder and others of the adder family have larger fangs, and their venom, moreover, being thinner than that of the Cobras, they are, in consequence, able to inject it at a more rapid rate. The reason Nature has not evolved larger grooves through which to drive a bigger dose of venom into the victim in the case of the Cobras and Mambas is that it is not at all necessary, for weight for weight, Cobra and Mamba venom exceed Puff Adder and other adder venom in its death-dealing properties. One drop of Cobra venom will kill a large dog in half an hour, sometimes less. The same quantity of Puff Adder venom causes constitutional disturbances which are usually recovered from.

\section{Alleged Cures.}

Every native "cure" submitted to me so far has proved, upon experimentation, to be absolutely worthless. I have also tested some alleged South African cures, which are proprietary, with equally disappointing results. An owner of a certain proprietary "cure" was very anxious that I should experiment with it. He evidently had a good deal of faith in it himself. I intimated that such experiments cost money. I was quite willing to bear such cost in the interests of science, but I presumed he would have no objection to allowing me to publish the results. No, he could not permit such a thing until he first learned the result. Then he would decide. I asked him in the event of failure would he be prepared to withdraw his "cure" 
from the market? "No, of course not." Many a valuable life is lost in South Africa, not to mention stock which have cost the owner large sums, because of his faith in the efficacy of these bogus cures for snake bite.

The base of nearly all of these proprietary "cures" is strychnine and ammonia. Those drugs, especially the former, are occasionally of some service as heart and nerve stimulants, but unless administered very carefully they are apt to do more harm than good. In cases of Colubrine snake bite (Cobra family), strychnine in medicinal doses might be of some little service in rousing the nerve-centres.

A heart stimulant is rarely, if ever, required in serious cases of snake bite. Cobra venom itself acts as a powerful heart stimulant. So strongly is the heart stimulated that, for several minutes after the lungs have ceased to act and somatic (physical) death has taken place, the heart is stil! beating. Cobra venom tends to paralyze the nerve centres, and strychnine injected under the skin, or nux vomica swallowed with a little water, might prove somewhat beneficial. Electric shocks would probably be more efficacious.

Adder venom, as a rule, acts largely upon the blood, dissolving out the red colouring matter (hæmoglobin) from the red corpuscles, and relaxing the walls of the blood vessels. It is, therefore, apparent that a heart stimulant in these cases would result in the blood being pumped through the vessels with greater force and pressure, resulting in increased hæmorrhage into the tissues and under the skin.

The base of one of the popular South African proprietary cures is extract of Male Fern Root. This is an excellent remedy for tape worm, but not for snake bite.

\section{The famous Zibiba Cure-Results of Experimentation.}

In South Africa, particularly in Rhodesia, Transvaal, Swaziland, Zululand, and Natal, there is an alleged native remedy for snake bite known by the native name of "Zibiba," or "Sebiba." This cure is, according to the native doctors, an infallible remedy for snake bite. Natives have absolute faith in their doctors. These doctors claim their substance to be 
an antidote; therefore, in consequence, the same belief is held by the native population. Large numbers of colonists also have unquestioning faith in its efficacy.

A certain well-known South African journal, in a leading article on "Zibiba," voices the public belief in this substance as follows:- "We have been assured by Native Commissioners and other men of position in the Transvaal that they have personally witnessed marvellous cures worked by this substance. A very small quantity - as much as will cover the point of an ordinary penknife-taken internally, and a little of it rubbed into the wound and into small incisions on the wounded limb above the wound, has been known to restore the bitten man to complete convalescence within twenty-four hours after his condition had been so precarious that he had already become unconscious, and also blind from the consequences of a Puff Adder's bite.

"Other unquestionable evidence could, if necessary, be adduced to bear out the assertion that 'Zibiba' is not a mere palliative, but a sure and indubitable cure for snake bites. From what plant or substance 'Zibiba' is prepared by the native doctors is as yet a secret which they have managed strictly to preserve."

\section{EXPERIMENTS WITH ZiBIBA.}

The Hon. F. W. Reitz, Ex-President of the Orange Free State, and a former State Secretary of the Transvaal, and President of the Senate of the Union of South Africa, who takes a keen interest in the quest for a reliable snake-bite antidote other than serum, sent me a phial of genuine fresh "Zibiba," to enable me to carry out a series of experiments. This "Zibiba," on examination through a microscope, appears to be the root of a plant. The root is finely pulverized, and is of a reddishsandy shade in colour. Realizing the unsatisfactory nature of experiments of this kind on small creatures, such as rats, guineapigs, rabbits, etc., I procured a large male Vervet Monkey ( $\mathrm{Ccr}$ copithecus pygerythrus) in the fullest vigour and health. Mixing a heaping egg-spoonful of "Zibiba" with a piece of banana, I gave it to the monkey. After an interval of fifteen minutes, a four-foot Brown Cape Cobra, or Bruin Kapell (Naia flar'a), which 
had been in captivity a year, and was in poor condition, bit the animal on the tail, one foot from the root, on a spot previously shaved. Within one minute the site of the bite was scarified thoroughly, and "Zibiba" powder rubbed in. Other incisions were made between the site of the bite and the heart, and more "Zibiba" rubbed in. After an interval of two minutes, more of the remedy was applied to the incisions. Each incision was smothered with it. As is usual in cases of bites from Cobras, the animal did not suffer any pain. The only pain was a momentary twinge when the rapid incisions in the skin were made with a sharp lancet. The animal did not show the least sign of any inconvenience for fifteen minutes. Then it began to get drowsy. This was due to the paralyzing action of the Cobra venom on the nerve centres. This increased progressively until the animal became unconscious. It died in forty minutes. After breathing ceased, the heart beat vigorously for five minutes, then gradually slowed and stopped after another two minutes. This is not unusual in cases of death from Cobra venom. It has always occurred in my experience, hence the reason I advocate the adoption of artificial respiration methods, if breathing should cease suddenly. On dissection, it was clearly evident the animal had died of Cobra venom poisoning, and not from any possible toxic action of the "Zibiba." Subsequent experiments of a conclusive nature have confirmed the negative results of the first case. It is unnecessary to give them in detail.

\section{Further EXPERIMENTS.}

After the publication of the results of my Zibiba experiments in the several South African Agricultural Journals, I received the following communication from a well-known gentleman in Natal. He wrote: "I have discussed your direct statement with regard to Zibiba. I have witnessed both animals and human beings bitten by Puff Adders and Night Adders. In all these cases Zibiba was used, both internally and externally, with unqualified success. I mention this, because I have seen the snakes which caused the bites, and the antidote, and knew it to be Zibiba."

I procured some of this Zibiba, which was such an infallible cure, from this gentleman, who assured me he obtained it direct from 
a native medicine man. On examination, the stuff appeared to be exactly the same as that which had been supplied to me by the Hon. F. W. Reitz, for my first series of experiments.

It is needless to detail the experiments. It is sufficient to say, although the Zibiba was applied as directed, both internally and to the incised wound, it did not delay a fatal issue. In no case did it even prolong life.

Another communication was received from a prominent farmer in the Transvaal. He stated that all the farmers in his district carried a "Snake bite cure" in a small bag sewn to their belt or braces. The women carried it stitched to a garter. These people believe the substance to be a certain cure for snake bite, and in consequence display absolute fearlessness when in the presence of snakes. He was given a small bag of this cure and told to carry it about with him always, because it was a certain cure, provided the wound was scarified, and the powder rubbed well in, and a small quantity swallowed. He says it is also believed that if the skin is cut in several places once yearly, and the powder rubbed in, it will give absolute immunity for at least a year. My correspondent is prepared to contest this cure against any other. A sample of this wonderful powder was sent to me. It turned out to be Zibiba. Again I conducted a series of experiments, with the same results as before. I carried out the instructions carefully, viz. putting a little of the Zibiba at the back of the tongue, scarifying the site of the bite, and rubbing some of the powder well in. In other cases I scarified the flesh in three or four places and rubbed the powder into the cuts. Rubbing some on a piece of meat, I gave it to a Jackal. After a lapse of fifteen minutes, to give the Zibiba every chance of being absorbed into the blood, the Jackal was bitten on the thigh by a Cape Cobra. The site of the punctures was scarified and smothered with the stuff. The Jackal died in less than an hour.

\section{Further ProOFs.}

Another gentleman from the Transvaal wrote suggesting that the first sample of Zibiba I experimented with, might not have been the genuine article. He wrote as follows: "I had a fair quantity of Zibiba some time back which came from the heart 
of Swaziland. It turned out to be the real stuff, so I was very soon relieved of most of it by my neighbours. However, the following two cases came under my notice which made me believe it to be the genuine stuff. A neighbour of mine had the misfortune to be bitten by a Puff Adder, on the instep. He was barefooted. He ran to his house, a distance of about a hundred yards. Reaching the dining-room, he practically collapsed. Fortunately, his Kafir cook was at hand, and on hearing the news, immediately broke a bottle, and with a piece of the glass scarified right and left across the punctures. He rubbed in a quantity of Zibiba (not very much), and the bitten man swallowed a quantity, as much as would cover the point of an ordinary penknife. Nothing else was done. For two days the leg was considerably swollen, but on the third, it went down, and the man in question recovered.

"The second case was with a dog. My pointer one morning, under my very nose, was bitten, also by a Puff Adder, on the lower lip. He gave a startled yelp, and at once scratched his head most violently with his fore paws. Within five minutes his whole body contracted into large bumps, and his head assumed most startling proportions, so much so that the eyes could not be seen. As I usually carry Zibiba with me, and a sharp Gillette Safety Razor blade, I called a boy, who held the dog down. I examined his head, found two large punctures on the lower lip. These I scarified and rubbed in Zibiba, and gave him a good dose also. After two hours he seemed very bad, so I gave him a half cup of French brandy with a little water, after which he lay quite still. The next day the swellings on his body were gone. His head was still a bit swollen, but he was otherwise none the worse for the bite.

"These two cases are quite genuine. I have about a sufficient quantity of this Zibiba left for a cure, which I will willingly forward if you are prepared to test it upon animals bitten by Puff Adders. Let the bite be on the hind-quarters, thereupon immediately scarify the wounds, rub in a fair quantity of the Zibiba, and give the rest internally. This Zibiba has cured two cases to my knowledge, and should you be successful, I think that would be sufficient proof that it is a positive cure." 


\section{The TESTS.}

A small quantity of this Zibiba was procured and forwarded to me.

A large domestic tom-cat was chosen for the first experiment, for the reason that cats resist the action of snake venom much more successfully than any other animal of the same size with which experiments have been made. A large pinch of the powder was dropped into the cat's open mouth, which fell into the throat and was swallowed. A Puff Adder was then allowed to inflict one full bite on the upper part of the cat's back leg. The spot was instantly scarified, three cuts being made. The wounds were rubbed thoroughly with Zibiba. After an interval, more was applied. Later, the wound was rubbed with a third dose. The cat died in one hour twenty-seven minutes after.

Some of this Zibiba was mixed with the venom of a Puff Adder and rubbed into a cut in the leg of a fowl. The fowl died in half an hour. Zibiba was mixed with two drops of Puff Adder venom and some water and allowed to stand a whole day. The mixture was rubbed into a cut in a fowl's leg. The fowl died. Other experiments followed, with similar results.

A full-grown Vervet or Blue Ape, similar to the one used in the original experiment with Zibiba, was obtained. I inserted a fair quantity of the Zibiba powder supplied by Mr. Reitz, and some of that which was supposed to have cured the man and the dog when bitten by Puff Adders, into a piece of banana. The monkey ate the banana. Allowing an interval of fifteen minutes, I caused a Puff Adder to bite the monkey in the lower part of the back leg. The site of the punctures was instantly scarified thoroughly, and the wounds smothered with a mixture of the two samples of Zibiba. The monkey, within five minutes of the bite, showed signs of poisoning. The symptoms steadily developed, until death took place twenty minutes after the infliction of the bite.

The Puff Adder was a fresh one which I had captured a week previously. The bite it inflicted was a complete one. It was held by the neck and allowed to retain its hold two seconds.

Samples of Zibiba from the Transvaal, Swaziland, and Natal were mixed together. A teaspoonful of water and six drops of 
Puff Adder venom were added. The mixture was thoroughly mixed and allowed to stand six hours. It was then carefully strained. The liquid, which was reddish-brown in colour, was divided into two portions and injected under the skin of the thighs of two fowls. Both fowls died in less than two hours.

Since writing the foregoing a friend has succeeded in obtaining a sample of Zibiba from a Kafir medicine man in Swaziland. He stated it to be the pulverized bark of a root mixed with the powdered remains of the entire head of an adult Puff Adder. It seems the head is first thoroughly dried and then pounded with the bark. This preparation is supposed to be a certain cure for the bite of a Puff Adder. The directions of the medicine man were, to place a pinch or two on the tongue and swallow it; to scarify the wound and rub some into the cuts. Truly this was a curious sort of "cure." A moment's reflection would make it clear that the application of the pulverized head of a venomous snake to a wound would simply increase the poisonous symptoms, for snake venom does not lose any of its poisonous properties if dried, unless allowed to decompose before drying it.

However, I experimented with the substance in the usual way, but, like the other samples of Zibiba, it had no curative effect. Some was rubbed into incisions made in the legs of fowls which had not been previously bitten or otherwise injected with snake venom.

Both fowls showed slight symptoms of viperine poisoning.

\section{Misplaced Confidence.}

So, it seems after all, the confidence of the public has been misplaced, and that of the native population as well. "Zibiba," which, since the advent of the white man to South Africa, has been regarded as an absolute cure for snake bite, has proved to belong to those many popular " cures" which have failed utterly when tested under proper conditions. Personally, I am in no way prejudiced in favour of or against any alleged remedy. Rightly or wrongly, I think it a duty to test these alleged snake bite cures. It is a pity that it should be necessary that living creatures should have to be sacrificed that we may be in a position to prove conclusively whether alleged snake bite remedies are genuine or not. However, there is no other way we know of. Provided 
experiments are conducted as humanely as possible, the end, I think, more than justifies the means. In this case thousands of colonists and tens of thousands of natives, if not millions, have absolute faith in the antidotal properties of "Zibiba." The inevitable result is that, instead of approved remedies being applied, such, for instance, as those advocated in this book, this worthless "Zibiba" or some other equally useless stuff is administered by the victim's friends, a native "doctor," or applied by himself. No other treatment is thought to be necessary. Thus valuable human lives are lost-lives which could easily be saved.

As far as I can ascertain, "Zibiba" contains no medicinal substance which is of a nature to be rapidly absorbed by the mucous membrane of the stomach, or the absorbent vessels under the skin. When mixed with snake venom it does not destroy its poisonous properties. If it has not this effect outside the body it would not be likely to have the contrary effect within the body.

\section{KNowledge IS Power.}

If people would only make themselves acquainted with the nature of snake venom, approved antidotes, the treatment of snake bite, the nature of the venom of each species, how to distinguish venomous from slightly venomous or non-venomous snakes, fewer deaths would take place amongst human beings and stock from snake bite, and the almost universal fear and dread of snakes would be much lessened. So strong is this dread of snakes and their venom that many cases are on record of people collapsing and dying after being bitten by non-venomous snakes. I have not seen cases of people actually dying, but I have seen them in a state of great nervous collapse simply through fear and dread, induced by the firm belief that death was likely to occur.

Zibiba, I am informed, is known by different names in various parts of the country. What those synonyms are I have been unable to ascertain. Colonists, or most of them who keep some of this alleged snake-bite remedy, simply call it "Kafir mooti." 


\section{Croft's Tincture.}

A full-grown Cape Jackal (Canis mesomelas) was bitten by a Cape Cobra on a portion of the thigh previously shaved. A rubber tube was thrust into the gullet of the animal and a dose of Croft's Tincture, properly diluted, was injected into its stomach by means of a syringe. The site of the bite was at once scarified and the undiluted tincture was well rubbed in several times. The Jackal was dead in twenty-two minutes.

Another Jackal was taken. A dose of Croft's Tincture was pumped into the creature's stomach. After five minutes' interval, a Puff Adder was made to bite the animal on the bared thigh. The wounds were promptly scarified, and the undiluted tincture rubbed in three times. The Jackal died in seventy minutes.

In February, IgII, Mr. Robert Parkin of Thornhill, near Port Elizabeth, was bitten on the hand by a Night Adder (Causus rhombeatus). He immediately sucked the wound, scarified it and applied pipe oil. Shortly afterwards Mr. Newton appeared, and administered Croft's Tincture. Mr. Parkin was bitten in the morning. He slowly sank and died at 7.30 p.m., notwithstanding the administration of Croft's Tincture.

The following is the account of the incident, as related in the Eastern Province Herald.

" On Tuesday morning, after breakfast, Mr. Robert Parkin was working in his garden, when a Night Adder bit him on the finger. He immediately sucked the wound, scarifying same, and applied nicotine. Shortly afterwards Mr. Newton appeared and administered Croft's Tincture; Mr. Parkin appeared to get better, but later in the afternoon his face and throat began to swell, and despite all efforts, he got worse, and expired at 7.30."

Taking half a spoonful of undiluted Croft's Tincture I added three drops of snake venom, and put it aside for several hours. The tincture to which the venom had been added was then diluted with water, and a small amount of it injected into the thigh of a fowl which died of the usual symptoms of snake venom poisoning. Other tests of a similar nature resulted in the death of the creature every time. It is therefore apparent that the tincture in no way destroys the poisonous properties of the venom even when mixed with it in full strength. If Croft's Tincture is incapable of destroying venom when mixed with it in this 


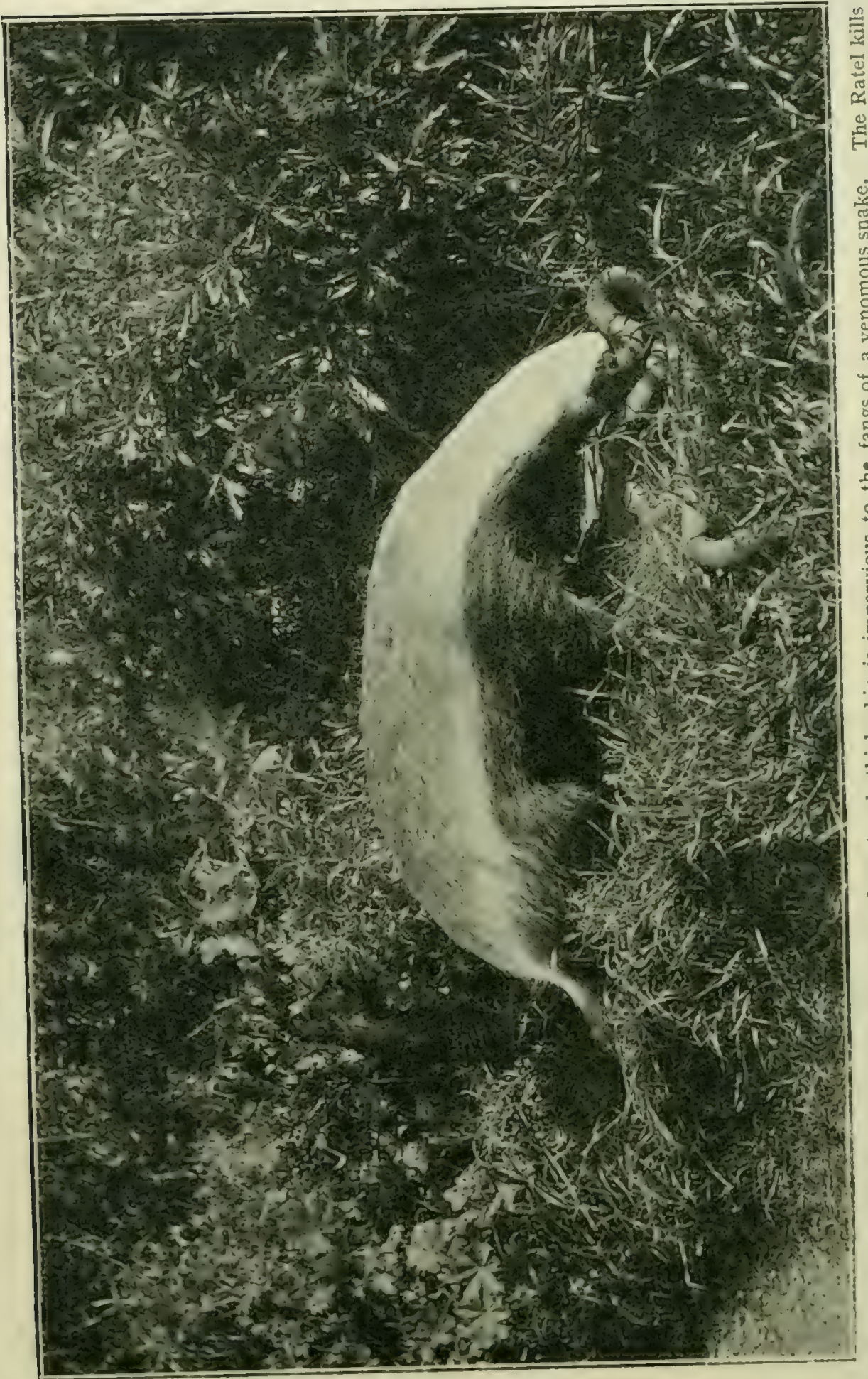


way, it would not be likely to do so if rubbed into a wound or swallowed.

\section{The Alcohol Cure for Snake Bite.}

Of the many popular "cures" for snake bite, alcohol is one of the most widespread. In - South Africa it is universally believed to exert a strong curative effect in cases of snake bite. In Australia and America the popular faith in this substance is equally strong. Unfortunately, however, when subjected to careful scientific experimentation alcohol is found to have no antidotal power in snake venom poisoning. The belief in alcohol is so strong that if it be at hand, no other means of averting a fatal issue is thought of. The patient is plied with brandy or whisky until he is unable to swallow any more. Often one, two, and three bottles of brandy are given, and as likely as not without being previously diluted with water. The idea is that if the patient can be intoxicated, he will be saved. In cases of snake bite the nervous centres are more or less benumbed, and the stomach is often incapable of absorbing much, if any liquid which may enter it. If the nerve centres are already benumbed by snake venom, the alcohol will naturally fail to have any effect upon them. If the stomach is inert through the paralysis of the gastric nerve centres, then all or most of the alcohol will lie in the stomach unabsorbed. This is why alcoholic intoxication does not always follow after the administration of even a whole bottle of brandy. However, if the snake venom symptoms be only slight, or if the patient is beginning to rally from the effects of the venom, then the alcohol will begin to produce intoxication, and the patient will soon be drunk and incapable. If the alcohol does not succeed in destroying his life, he will in due course wake up from his drunken stupor, apparently cured.

The administration of large doses of alcohol to any one whose body has not been accustomed to strong doses of this poisonous drug, will either cause death or serious damage. The delicate lining membrane of the stomach may be so extensively burned that subsequent inflammation of the stomach may cause death; or if recovery should take place, the digestive powers are ruined for life, owing to the destruction of large patches of 
the mucous surface and peptic glands of the stomach. The
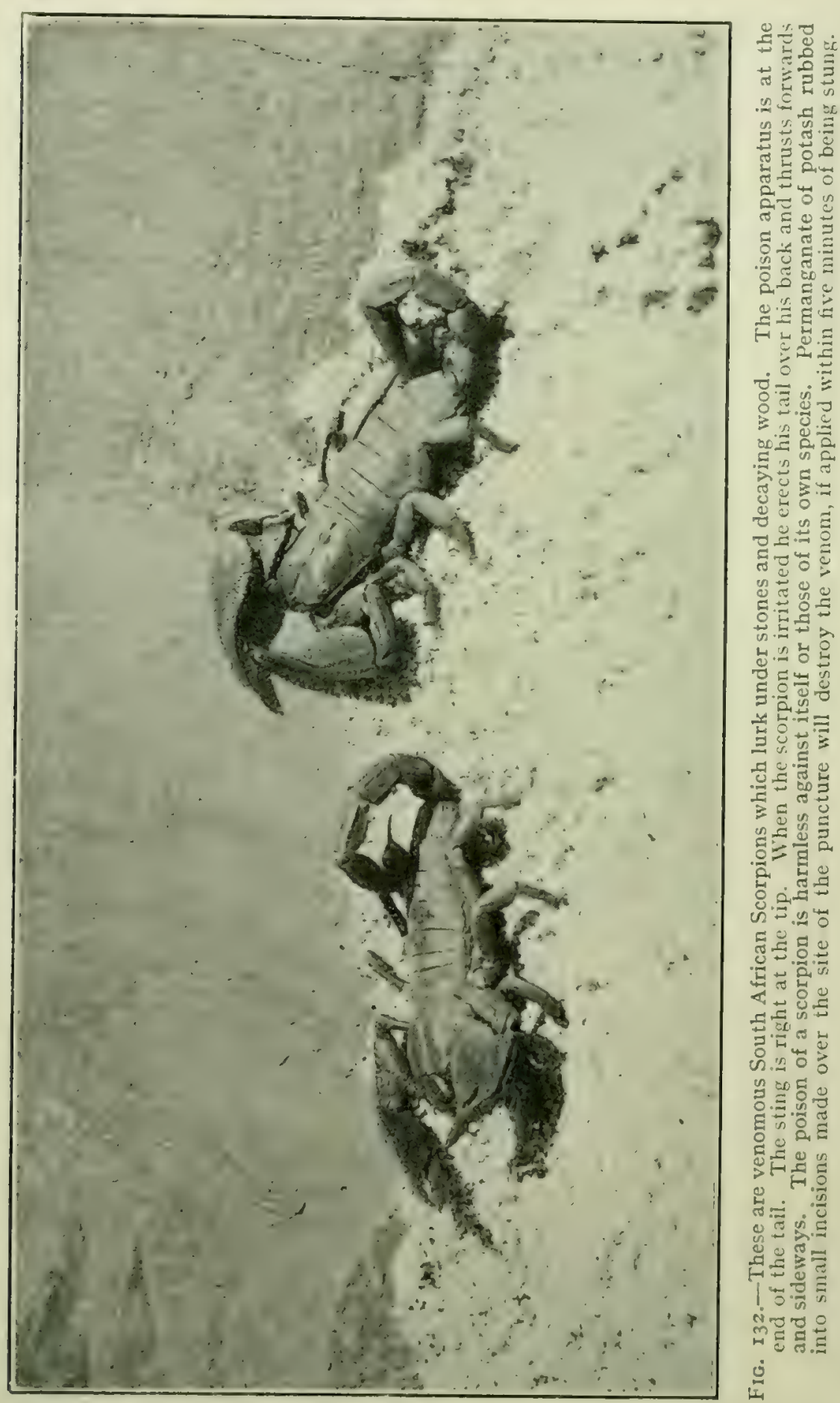

flooding of the blood with strong spirit causes cxtensive destruction of the corpuscles of the blood and nerve cells. The latter 
are often destroyed in such numbers and the rest so shrivelled and otherwise damaged, that the functions of the brain are, ever afterwards, impaired even to the degree of permanent weakening of the intellect.

All these terrible risks are taken because of the belief that alcohol cures snake bite.

Alcohol has no curative effect. When brandy or whisky is mixed with snake venom and injected into animals, the poisonous properties of the venom are in no degree lessened. The animals die just as rapidly as if the venom had been injected pure.

Animals have been made incapably drunk with alcohol and injected with snake venom. Others have been injected with exactly the same dose of venom, but were not treated with alcohol. Those previously made drunk died just as soon, often sooner, than those not so treated. I have measured out doses of venom and injected it in equal proportions into two animals at a time. One was then dosed freely with alcohol, the other was kept warm and left to itself. The creature treated with alcohol died first. These experiments were repeated several times.

When snake venom is mixed with absolute alcohol, a white precipitate is thrown down, but the poisonous properties which have been thrown out of solution are just as soluble as ever, and if injected into the blood, exert the same poisonous effects as venom direct from a snake. If alcohol had the power of rendering the poisonous parts of snake venom insoluble, or changing its nature, then if the blood was saturated with alcohol it would have some curative effect, but this is not so. Even overproof spirit does not lessen its poisonous properties when mixed with it. The only good effect of alcohol in the treatment of snake bite is its power in somewhat deadening the patient's sense of fear and dread. In this connection it is often useful, for in many cases the shock to the nervous system through fear is more to be dreaded than the venom. Naturally when the nervous system is more or less benumbed through shock due to terror, the vitality is at low ebb, and the natural resistance of the body to the venom is considerably lessened.

However, large doses are never justified. In fact, the only times when alcohol is suggested is in slight cases of snake bite, to blunt the patient's sense of fear. It is valueless as an actual 
antidote. In all serious cases, particularly those suffering from the venom of the Adders, or Boomslang, it is distinctly dangerous to administer strong doses of alcohol, as it would increase the hæmorrhage into the tissues and under the skin.

\section{Horniball's Patent Wonderful Extract.}

In the Eastern Province of the Cape Colony, "Horniball's Patent Wonderful Extract" is in great farour as a remedy for snake bite.

In appearance it is a blackish substance of the consistency of vaseline. It smells like extract of male fern.

It is stated to be specially efficacious in cases of bites by Puff Adders.

Taking a quantity of this extract, I diluted it slightly with water and added two drops of Puff Adder venom, stirred it well in, and left the mixture for several hours. It was then injected under the skin of a large fowl. The fowl underwent the usual symptoms of poisoning by snake venom and died in threequarters of an hour. The leg was swollen and saturated with extravasated blood.

Smaller quantities of snake venom were mixed with the extract and injected after the mixture had stood several hours. The fowls died as rapidly as when the same quantities of renom were injected with pure water.

If this extract can exert no neutralizing effect upon snake venom when actually mixed with it, even in a concentrated form, it most certainly will not exert any curative power if applied to the punctures, and it is not conceivable that it would have any better effect if swallowed.

\section{The Stockholm Tar and Fowl Flesh Cures.}

I have always been willing to submit any popular so-called South African antidote to a fair trial, but some of the "cures" which I have been assured even on oath are absolute antidotes for snake bite are absurd and ridiculous, showing that those who believe in them have not eren a rudimentary idea of human physiology. A farmer's wife called on me one day and said she wanted me to make it known through the medium of my 
STOCKHOLM TAR AND FOWL FLESH CURES. 329

"Science Notes" in the press, of a certain cure. She assured

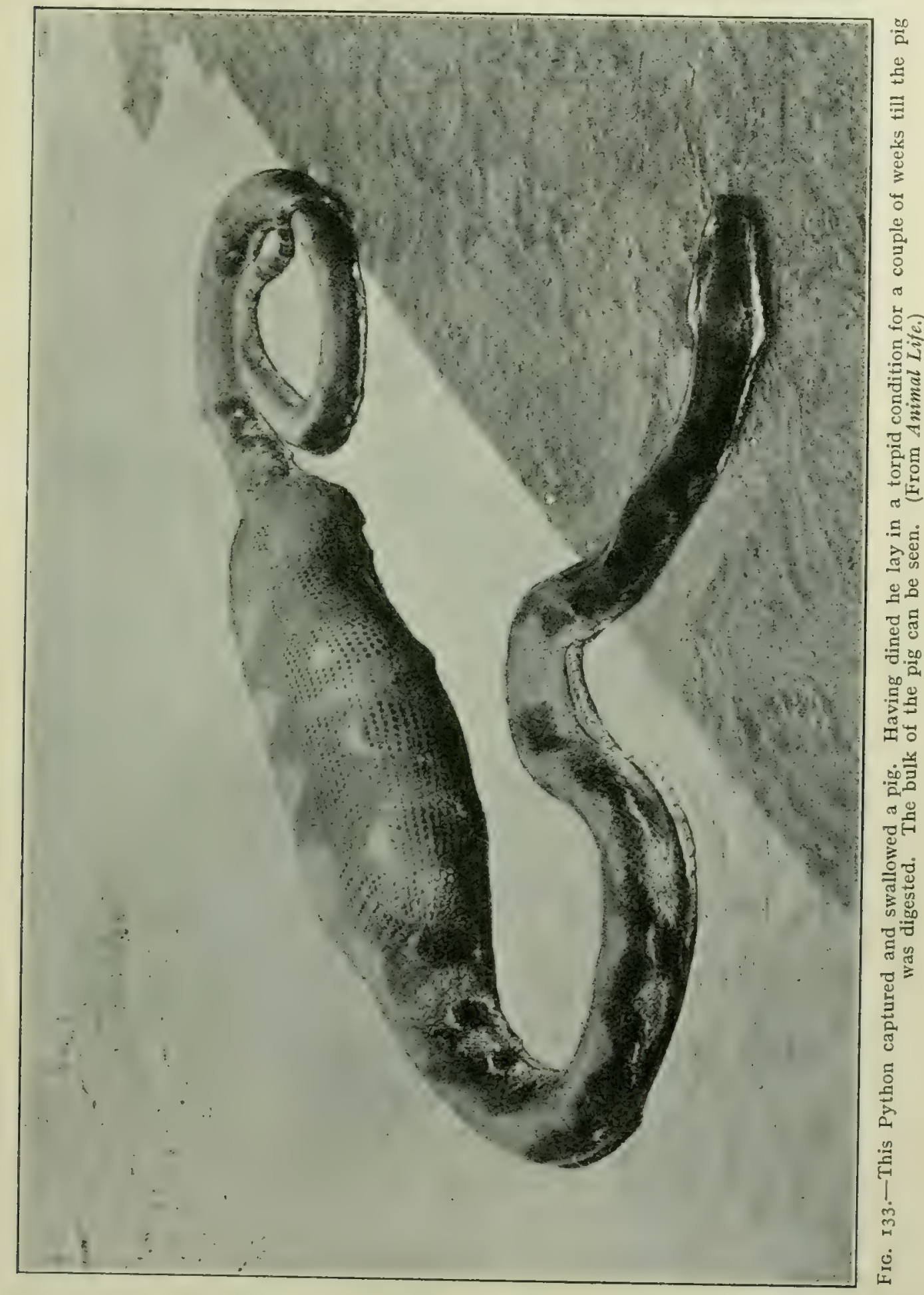

me that everybody in her district, both white and black, had 
firm faith in it. Snakes had bitten her, she declared, and she had proven the remedy to be genuine. "All you have got to do is, if a snake bites you on the foot, to get some good Stockholm tar and smear a ring of it round your leg on the skin between the bitten spot and the heart." "You see," said the lady, " the tar on the skin prevents the poison going past. It drives it back, and it runs out with a lot of black blood from the wounds inflicted by the snake." This wasn't all. She had another sure cure. "If a snake should bite you, catch a fowl or a pigeon, split it open, and hold its warm flesh to the site of the bite. The flesh will draw out all the poison." This latter "cure "I have found to be firmly believed in by a large section of the farming class.

\section{So-Called Cures which Kill.}

To the medical man it is alarming how the public swallow drugs without knowing anything of their properties. Great doses of most potent medicinal substances are taken with the object of curing some complaint, or for the treatment of snake bite. There can be no doubt that considerable numbers of people are killed, and others ruined physically for life by swallowing drastic drugs, the properties of which, and their effects upon the organs and tissues of the body, they are profoundly ignorant.

In treating cattle, farmers will often make a concoction of the most poisonous of substances and pour it into the sick beast. If the animal should eventually recover, the farmer triumphantly heralds his cure all over the neighbourhood.

Some so-called snake bite antidotes which I have been told are often administered, would certainly seriously upset the individual to whom any of them were given, if they did not actually kill him. One of the antidotes is the drinking of a mixture of paraffin, Stockholm tar, and salt. Another is pipe oil, and a bottle of brandy neat.

\section{EAU-DE-LUCE.}

Eau-de-luce at one time was generally believed to be the finest thing known for the cure of snake bite. It was administered by the medical profession. Any one doubting its efficacy 
would have been regarded as an enemy of mankind, especially so if he made his opinions public. The faith in this supposed cure waned as the years went by. Dr. Fayrer, the great experimenter with Indian snakes, made full and complete experiments with this eau-de-luce, and found it to be quite worthless. It did not delay death in the slightest degree. Experiments which I have made with South African snakes showed that it was of no antidotal value. The animals died just as quickly as when no so-called cure was given. If you have eau-de-luce in your house, use it as smelling salts, or put it in your private collection of curiosities, but do not rely upon it to cure cases of snake bite.

A European boy named J. Jackson was bitten on the calf of the leg by a Black Mamba at Umgeni, near Pietermaritzburg. A. E. Gayer, Esq., who was present, gives me the details which are as follows: "The boy ran a little way after being bitten. Two bottles of eau-de-luce were administered to him according to directions. He suffered agony at first until mortification started to set in. He died peacefully the evening of the day he was bitten."

\section{Ipecacuanha, Liouor Potassee, Caustics.}

Ipecacuanha has long been considered an excellent remedy for snake bite. It has been carefully tested and found to have no antidotal value. It may possibly be of some slight service in secondary treatment, owing to its stimulating effects upon the liver, bowels, and kidneys. It, however, exerts a depressing influence upon the heart, which causes a slowing down of the circulation. When administered to animals into which snake venom has been injected, it seems to hasten death somewhat.

Ipecacuanha is the dried root of Psychotria ipecacuanha. The active principle is in the bark; the inner or woody part contains but little. It is obtained from South America.

Liquor potassæ is a solution of potash. This substance has long been believed to have a curative influence in cases of snake bite. It has in the past been very extensively used in India and elsewhere. Applied to the incised wounds it was supposed to destroy the vitality of the part, and kill the snake venom. Dr. Fayrer tested liquor potassæ as a curative agent against the bites of Indian venomous snakes. After a long series of 
experiments he pronounced it to be of no value. In all cases it did not retard a fatal issue in the least. Its effect is nil when applied to the bitten parts of animals injected with the renom of South African snakes. Even if applied within a minute of the injection of renom it fails to exert any curative influence.

Carbolic acid is largely used in cases of snake bite. If applied to the incised wounds immediately after the infliction of the bite it helps slightly to prevent the absorption of the venom. Its influence, however, is so small that it is, practically speaking, valueless.

The actual burning of the scarified bitten part with a red-hot iron, coal, or exploding gunpowder, destroys the renom in the wounds, but unless done within five or ten minutes of the infliction of the bite it is of no value at all. At best it is a dreadfully drastic remedy. Dr. Fayrer in experiments with the venom of the Indian Cobra found that the poison was so rapid in its action that, although he thoroughly cauterized the wounds with two white-hot needles plunged into the punctures within a second of the infliction of the bite, and although he then quickly burned the flesh with a hot iron and ligatured the limb, the animal died. I have found the venom of the South African Cobras, notably that of the Cape Cobra, to be equally swift and deadly under similar circumstances.

Bluestone is another substance largely used, which is of no value at all in the treatment of snake bite.

\section{Strychnine and Ammonia.}

The bases of most proprietary cures for snake bites are strychnine and ammonia. Neither of these substances is of any value in neutralizing the poisonous properties of snake venom. Ammonia is of no use whatsoever when taken internally, injected into a vein, or applied to the bite. It does not delay death in the slightest. If mixed with venom it does not destroy or neutralize its poisonous properties in any way. Experiments have been carried out which conclusively prove that this is so. As a stimulant it is not to be recommended.

In cases of Colubrine snake bite (Cobras), strychnine in medicinal doses administered internally or by injection under the skin might possibly be of some little service as a nerve 
stimulant, although on experimentation with animals I found it useless. The animals died as rapidly as when no treatment had been administered. Strychnine is a dangerous substance in the hands of most people. It should never be used, unless by or under the direction of a medical man or some one clse who thoroughly understands its use, and the exact dose.

Although Fontana nearly a hundred years ago showed that ammonia was of no value in cases of snake bite, it continued to be used extensively all over the snake-inhabited world, and is still being relied upon. The reason is, that scientific discoveries, as a general rule, are published only in scientific journals which the generality of people never read, or if they did read them they would, in all probability, not understand them, owing to the technical terminology usually employed when writing about simple facts.

Quinine, Tanjore Pills, Snake's Gall, Vinegar, Water.

Quinine, whether administered internally or applied to the bitten part, is of no curative value, although it is largely employed in the treatment of snake bite.

A remedy commonly used in the East, mostly in India, and known as the Tanjore Pill, has a great reputation as a snake bite antidote. It is an arsenical preparation. Doctors Fayrer and Brunton have shown that the belief in this famous cure is without any foundation.

A popular remedy for snake bite among the colonists and natives of South Africa is the contents of the gall of a venomous snake of the species which inflicted the bite. It is firmly believed that if a person is bitten, the snake killed and the contents of its gall bladder swallowed, it is an infallible cure.

I have tried this gall remedy on animals, but it does not retard death in the least. A snake was allowed to bite an animal. It was then instantly killed, and half the contents of the gall bladder injected under the skin of the victim, and the other half, mixed with a little water, was forced into the animal's stomach by means of a rubber tube and syringe.

In other cases the bile was administered internally only. The animals died as quickly as when no remedy had been given.

In other cases the blood of the snake which caused the bite 
was injected under the skin of the victim. This also was without curative effect.

Vinegar is another popular remedy which has failed when scientifically tested.

In Australia the natives have great faith in the water cure for snake bite. They, or a great many of them, believe that if the bitten part is immersed in cold water, or better still, if the whole of the body be submerged for an hour or more, the venom will be drawn out through the skin. This water cure is believed in by numbers of Australian colonists. Cold water has no effect in drawing any substance from the blood through the skin. The application of hot water, on the contrary, would open the pores and cause perspiration to issue forth. In this way it is possible some of the venom might be drained out.

Momentary cold plunges, or dashing cold water over the skin would have the effect of stimulating the nerves and increasing the activity of the brain and other organs, but beyond this, cold water can have no actual curative influence in cases of snake bite.

\section{Dried Snake Venom Cure.}

A medical friend from Bechuanaland writes me as follows: "Dried snake poison is used by Bushmen as an antidote for snake bite, as they have implicit faith in its efficacy. I never saw a case of its being used, but reliable European Kalahari Desert hunters assured me that with a supply of this they feared no snake bite; that they had repeatedly used it with the most satisfactory results. It is rubbed into a scarified surface over the site of the punctures inflicted by the snake."

I have heard of this "cure" in many parts of South Africa. A sample was sent me. It consisted of the pulverized poison glands of a Puff Adder. When mixed with water a little was injected into several animals. They all showed symptoms of snake venom poisoning, although they eventually recovered, owing to the small quantity of venom in the solution.

The venoms of all species of snakes, when dry, have exactly the same poisonous properties as when fresh. In scores of my experiments I have used the dried venom. Its effects are as powerful as the venom just extracted from the snake. Even 
after a great many years its poisonous properties seem in no way diminished. To rub dry snake venom into a cut with the idea that it will cure a case of snake bite, is simply idiotic. Such an action would materially lessen the chances of recovery, for the simple reason that an extra supply of venom was being introduced into the blood. The venom of one species of snake has absolutely no neutralizing effect upon that of another. If several venoms are mixed and injected into an animal it dies rapidly.

Colonists would be well advised to leave all native "cures" severely alone. Some are harmless enough, but others are distinctly hurtful and .lessen the chances of recovery. There is one thing quite certain. If you desire to make the recovery of a person bitten by a snake impossible, then rub in plenty of this famous dried venom "cure" in which thousands of colonists and natives profoundly believe.

\section{RoOTs, BARK, AND HERBS.}

In all countries where venomous snakes abound the majority of the popular remedies are preparations of roots, bark, or herbs.

In the East Indies a plant is largely used in the treatment of snake bite. It is known as the Mungoose Plant (Ophiorrhiza mungos) of the order "Rubiaceæ."

In North America the following are in great demand-the roots of Aristolochia reticulata, or Texas Snake Root, Liatris spicata and Eryngium acquaticum, known as the Button Snake Root, also Eupatorium altissimum, or White Snake Root.

The active principles in these roots are substances which stimulate the skin and kidneys (Diaphoretic and Dinuretic).

The various preparations in South Africa, of vegetable origin, are of no use at all as antidotes to snake venom. Tinctures and decoctions prepared from them cause various constitutional disturbances. The main effects are stimulation of the kidneys, skin, or bowels. If any one is desirous of producing the same effects as these vegetable preparations which are usually sold at a high price, he has only to go to a chemist's shop and ask for a medicine which increases the action of the skin or kidneys, or bowels, and for sixpence he will obtain as much as he would 
otherwise pay Ios. for, with the additional advantage of getting the stuff in concentrated form and the exact dose.

\section{The Snake Blood and Gall Cure.}

There is a widespread belief in South Africa that if the snake which inflicted the bite can be killed, and its blood or gall obtained, that either of these will prove antidotes to the venom. The natives are strong believers in the snake gall cure. The contents of the gall are swallowed. Usually the gall bladder, with its contents is swallowed entire. It is regarded as a certain cure. If a little of the blood of the snake which inflicted the bite, or even of the same species, be swallowed, it is also reckoned to be a sure cure. I have given animals the blood and gall, both internally and rubbed it into the scarified sites of the fang punctures, but in no case did it have any curative effect.

I have mixed the contents of a snake's gall bladder with three drops of its own venom, and injected it into a fowl. I repeated this. In each case the fowl died. I did the same with the blood. Drawing the venom from a Puff Adder I then killed the reptile and collected an ounce of its blood in a wineglass. To this I added six drops of the venom, taken from the same snake, and mixed it thoroughly with the blood. The mixture was allowed to stand for several minutes. It was equally divided, and injected under the skin of the thighs of two fowls. The fowls died as rapidly as if the pure venom had been injected.

\section{SNAKE STONES.}

Snake stones for the cure of snake bite have, for centuries, been in great demand. They are regarded by millions of Indians with awe and reverence. To them it is blasphemy to doubt the efficacy of a Snake stone. Of all snake bite "cures" the Snake stone is regarded as the most effective. Its power of drawing the poison out of the wound does not admit of a doubt. The man who expresses disbelief in its wonderful powers is regarded with contempt. Such is the belief which has fastened itself upon millions of minds.

Professor Faraday examined a famous Indian Snake stone and said: "It is a piece of charred bone which has been filled 
with blood, perhaps several times, and then carefully charred again."

Doctor Davy examined several of these Snake stones, and his opinion coincided with that of Professor Faraday. The monks of Manilla manufacture and supply Snake stones to Indian merchants, and the trade is very lucrative.

The stones vary in composition. Some are of charred bone, or merely pieces of chalk, and others are made up of a composition of vegetable matter. They are all more or less absorbent.

I have not had an opportunity of testing these Snake stones, but experiments are quite unnecessary, for the field has already been covered by Doctors Fayrer, Brunton, Rogers, and other scientific men. It has been conclusively demonstrated that the application of Snake stones to the site of the bite of a really venomous snake was of no antidotal value, even when the site of the punctures was well scarified to allcw of the stone adhering firmly.

It is alleged that the stone, when applied to the site of the bite, will draw out the venom. This would prove so to a certain degree, if applied within a few minutes of being bitten, provided the stones were powerfully absorbent, but they are not so. The small quantity of blood which penetrates their substance has little or no influence for good. The advocates of Snake stones assert that it is not even necessary to scarify the flesh prior to applying the stone. That the stone has the power of drawing all the venom out through the two tiny punctures made in the skin by the snakes' fangs.

When a snake drives its fangs into the flesh it injects a quantity of venom which spreads out and is rapidly sucked up by the numerous absorbent vessels known as Lymphatics and Capillaries, and hurried away to the heart. If fully bitten by a large Cobra, enough venom is absorbed into the circulation within one minute to cause death, unless 30 to 50 cubic centimetres of Anti-venine Serum are injected before paralysis of the nerve centres takes place.

Nothing short of powerful suction with the mouth, a vacuum tube, or pump, is sufficient to draw out the venom in sufficient quantity to be of any practical value.

Snake stones being rather expensive, they are naturally in the hands of the few, consequently if a man is bitten his friends 
rush off with all speed for the nearest possessor of a Snake stone. It is in these cases practically impossible for it to be applied within five minutes or so, therefore even admitting it possessed the virtues attributed to it, the venom would already have entered the general circulation, and no amount of suction at the site of the bite would draw it out again.

The belief in Snake stones, the application of the palpitating flesh of fowls and pigeons to the site of the bite, and other popular remedies are dangerous delusions.

When the Dutch first settled at the Cape and established a Station there as a sort of half-way house in their East Indian trade, which was conducted by the East Indian Netherland's Company, sometime about the year 1652, they brought a few of these Snake stones from the Indies, principally Malabar.

Some of these stones are, to the present day, in the possession of old Boer families, whose faith in their efficacy for the cure of snake bite is unshakable.

\section{Swallowing Snake Venom.}

It is a general belief amongst the natives, and a large section of the colonists of South Africa, that, if snake venom is swallowed it will confer immunity to snake bite. In consequence the pigmy Bushmen, Hottentots, and Kafirs, after killing a venomous snake, cut out its venom glands and swallowed them.

I have met many colonists who were so sure of their immunity that they offered to allow me to inject them with snake venom. The offers certainly were tempting, but my conscience and the law would not permit it.

At intervals during the past ten years or so I have fed various species of animals, domestic and otherwise, on the venoms of different kinds of South African snakes. When any of these creatures were bitten by a snake or injected with its venom by means of a hypodermic syringe, they died just as rapidly as animals which had not been fed upon snake venom.

The following is one instance from a score in my note-book. An adult Cape jackal, the size of a spaniel, was fed for six weeks with Puff Adder venom. Every second day half a dozen Puff Adders were forced to bite a lump of raw meat, which was immediately afterwards given to the jackal. On three occasions the 


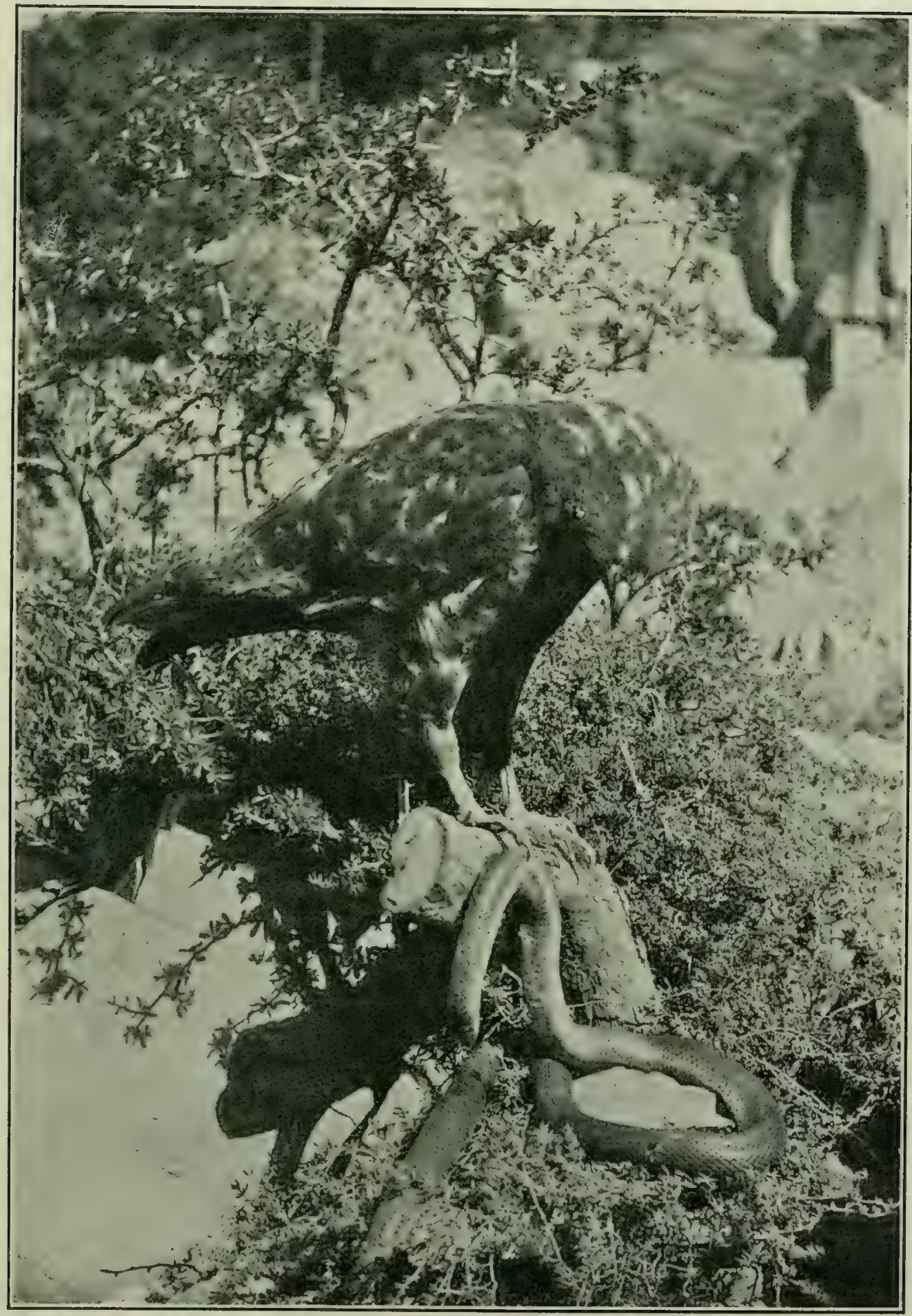

Fra. I34.-This is a Jackal Buzzard (Buteo jakal). - He is a great pest to the farmer because he is so fond of chickens; but he also kills and devours snakes. 
venom from six Puff Adders, viz. forty drops, was collected in a wineglass and mixed with raw meat. This the jackal at once ate. Whenever a Puff Adder was killed its poison glands were inserted into a bit of meat and given to the jackal. Puff Adders were allowed to bite dead birds freely, until the flesh was reeking with venom. These were fed to the jackal.

Then we decided to apply the test. Surely, we thought, if swallowing venom will confer immunity, this jackal should be absolutely proof, for it had during the six weeks swallowed enough Puff Adder venom to kill a couple of hundred men.

A Puff Adder was held by the neck and allowed to bite the jackal on the thigh. It bit twice, but only pecked. Refusing to bite again, we procured another and forced it to bite the same part of the leg, twice. IVe did not previously shave the hair, and although in each case the reptiles punctured the flesh, we noticed they shed a good deal of venom on the fur, and did not bite eagerly. One, two, three, four days went by and the jackal showed no outward symptoms of poisoning. It was as lively as ever, and ate as usual. No swelling was apparent. "I told you, Sir," quoth my now jubilant assistant, "that the jackal would prove to be immune." "No, I am not at all satisfied," said I. "There's something wrong. Those snakes didn't inject enough venom. Come along, we will make sure this time." So we forthwith seized a big Puff Adder and levied toll on his store of poison. Measuring out three drops, I mixed it with about a teaspoonful of water and injected it by means of a serum syringe, into the muscles of the unbitten thigh of the jackal. A Puff Adder was allowed to give one quick bite, but was not permitted to hang on or worry the flesh. In five minutes' time the jackal began to show symptoms of poisoning. In slightly less than one hour it was dead.

Removing the skin from the thigh and cutting into the flesh, it was found to be charged with extravasated blood from the toes right up to the junction with the body. The whole flesh of the limb was saturated with blood, which had oozed through the walls of the blood vessels. The limb itself had swollen to three times its normal size. Opening up the body I found that blood had oozed out into the muscles covering the abdomen and ribs, giving them a patchy blood-stained appearance. The heart-muscles were also affected, small irregular red patches 
covering them. The lungs were not visibly damaged. Removing the skin from the thigh which the Puff Adders had bitten without apparently producing any poisonous effects, I found the muscles in the vicinity of the punctures to be very much discoloured with blood, which had oozed into them. This discolouration was traced up, and half-way along the muscles of the ribs on one side. Growing fainter and fainter, it disappeared. It was quite apparent that those Puff Adders had not succeeded in injecting sufficient venom to cause serious symptoms. If the jackal had not been dissected, the extravasated blood would have been absorbed by degrees without any outward symptoms being apparent. An examination of the jackal's stomach and intestines showed them to be perfectly normal. Evidently the copious internal dosing with venom had not produced any illeffects.

I keep a half-grown Chacma Baboon which, for the past four months, I have fed at intervals with Cape Cobra venom. The venom has, so far, produced no poisonous effects, although by now it must have swallowed something like a quarter of an ounce of venom.

This is contrary to the prevalent belief among scientific men in regard to Cobra venom.

Many people think that experiments on animals are not satisfactory. They seem to think that the human animal is altogether different in his composition. This is by no means so. The structure of a human being is exactly the same as that of a warm-blooded lower animal (mammal). The mechanism of his body works in the same way in all respects. Like the various species of lower animals, man differs in shape, but that does not alter the fact that he is physiologically the same as they are. Man differs in a physical sense from all lower animals in having a larger and more complex brain. He has evolved faculties of the mind which none of the lower animals possess. True, he has brain organs similar to theirs, but he has added many more which make him what he is. 


\section{CHAPTER XI.}

Snake Venom, its Nature and Effects.

Venomous Snakes and their Poison.

THE three great sub-families of highly venomous snakes of South Africa are the Sea Snakes (Hydrophiince); the Cobras, Nambas, Coral Snakes, etc. (Elapina); and the Adders (Viperinci). The only Sea Snake which frequents the South African coasts is the Black and Yellow species (Hydrus platurus) which sometimes gets stranded among the rocks on the sea-shore, and is usually mistaken for an eel. In South Africa south of the Zambesi there are fourteen species or kinds of Cobra (Colubrine), and eleven of the Adder (Viperine) family.

\section{The Aglypha.}

There are three great classes or divisions of snakes, viz. those which have solid teeth without any trace of grooving. These snakes are all quite non-venomous. They are known as the Aglypha, which means snakes with solid teeth.

\section{The Opisthoglypha.}

The second division are what are termed Hind-fanged Snakes, having one or more of the back teeth in the upper jaw more or less grooved, and possessing poison glands in a more or less imperfect or rudimentary state. These snakes are regarded as either non-venomous, or only venomous to a very slight degree.

They are known as the Opisthoglypha, which means having the posterior or back maxillary teeth grooved.

\section{The Proteroglypha.}

The third division are the typical highly venomous snakes, having the grooved or hollow fangs set in the front of the upper 
jaw in the bone known as the anterior maxillary. All this class are venomous. They are known as the Proteroglypha, which means snakes with the anterior (front) maxillary teeth grooved or hollow.

\section{Result of Investigation.}

Our well-known Boomslang or Tree Snake (Dispholidus typus) is a member of the Opisthoglypha or Hind-fanged Snakes, which is generally believed to be at most very slightly venomous-only sufficiently so to enable it to paralyse its prey before deglutition.

The reasons for this belief are based on the fact of the snakes of this class possessing imperfectly developed poison glands which are not connected with the grooved teeth by well-defined poison ducts, as is the case with the typical venomous snakes; hence they are considered to be in a more or less rudimentary or transition stage.

The results of my experiments with the Boomslang, given in detail in a former chapter, have, I think, conclusively shown that one member at least of this class of so-called slightly venomous snakes is as highly venomous as the Cape Cobra or Puff Adder. It is reasonable, therefore, to assume a good many of the others would, on investigation, be found to be equally venomous. Therefore, until each individual of this large division of snakes has been carefully experimented with, it would be unwise to lead the public to infer they were either practically harmless or only slightly venomous. In 'South Africa we have twenty-six species of these Hind-fanged Snakes so far recorded.

\section{Poison Apparatus.}

The venom of snakes is secreted by a pair of glands lying on each side of the skull beneath the skin, situated just under and behind the eyes. The Night Adder (Causus rhombeatus) is an exception to this rule. The venom glands are almond-shaped, and are composed of great numbers of cells. Within the glands are cavities known as Alveoli. These are lined with short columnar cells. In these cavities the venom is stored until squeezed out by the contraction of the gland by certain muscles. The glands are termed Racemose Glands because the cells are 
clustered together like a bunch of grapes-racemose meaning " arranged in grape-like clusters." These venom glands were

A STUDY PLATE FOR SCIENTIFIC STUDENTS.

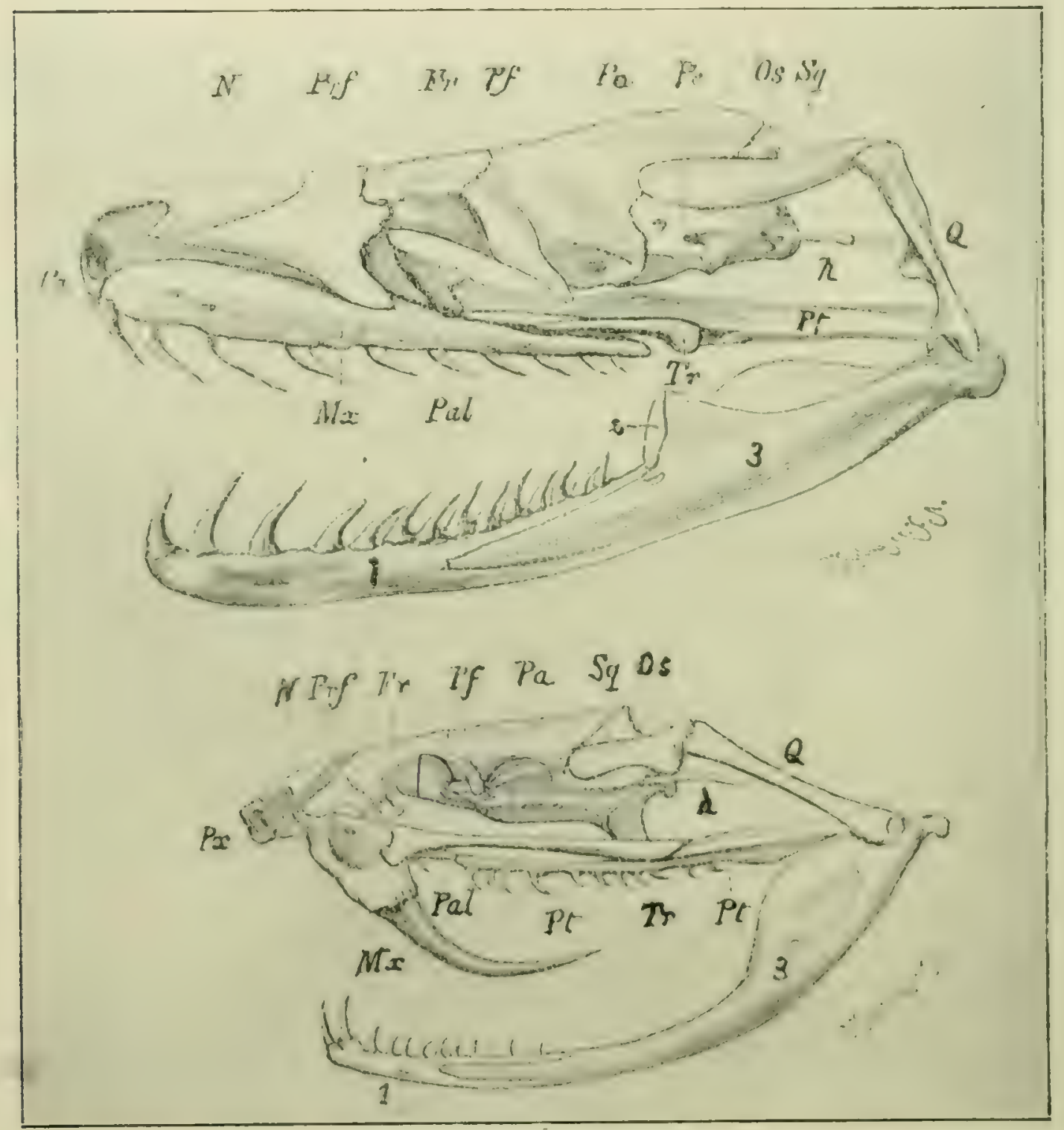

THE DENTITION OF SNAKES.

FiG. I35.-The skull of a typical non-venomous snake (Boa) and that of a typical venomous snake: (Crotalus) seen from the side and somewhat from above.

N-Nasal. Prf-Prefrontal. Fr.-Frontal. Pf-Post frontal. Pa-Parietal. Pc-

Petrostral. Os-Supra-occipital. Sq-Squamosal. $Q$-Quadrate. $H$-Ear bone. $P$ -

Pterygoid. Px-Pre-maxilla. M $x$-Maxilla. Pal-Palatine. Tr-Transverse bone. I$2-3-$ Bones of lower jaw.

once upon a time ordinary salivary glands, and under that mysterious law of God which we term Evolution, these harmless 
salivary glands underwent a gradual change, and the fluid they secrete is now of a totally different character. In scientific terminology they are " the homologues of the parotid salivary glands in other vertebrate creatures."

We find the venom glands and fangs of snakes in various stages of evolution. In the division known as the Aglypha, we do not find any trace of grooved fangs or poison glands. The teeth are all solid. In some of the species a few of the teeth are fang-like, being longer than the rest, but these also are quite solid. In the second division of snakes, which are known as the Opisthoglypha, the fangs are in various stages of development, and are situated half-way back in the upper jaw. There are usually two or three fangs, which are grooved. However, there are no well-defined poison glands with ducts, consequently this division of Hind-fanged Snakes has been regarded as practically non-venomous. The Boomslang (Dispholidus typus) is a member of this division of snakes.

In the third division, known as the Proteroglypha, we find the fangs and poison glands in a high degree of development. All of this class of snakes are known to be venomous to a greater or lesser degree.

The fangs of the viper family are long and re-curved, and the bone they are set in is very mobile and works like a hinge. This provision of Nature is very necessary in order to elevate the fangs to allow of their points striking the victim at a proper angle. When the mouth closes, the fangs are automatically drawn back, and lie along the sides of the upper jaw, enveloped in a membranous sheath, known as the Vagina dentis.

The fangs of Cobras are small in comparison with those of the Adders, and are incapable of much movement, such not being necessary for their effective use. They are received into a small cavity in the lower jaw when the mouth is closed.

When the snake's mouth is closed, the end of the poison duct becomes disconnected with the hole in the top or base of the fang, but the instant the mouth is opened to strike, the end of this duct, by means of an intricate and delicate apparatus, completes the connection with exactness.

The instant the fangs penetrate the flesh of the victim, the snake closes his jaws over the bitten part and presses strongly, 
thus forcing the maximum amount of venom into the punctures. Many snakes, such as the Puff Adder and Boomslang, hang on and worry the flesh if allowed.

Inserted into the tough fibrous capsule of the poison glands are some of the fibres of the Masseter muscles. The instant the snake bites, these muscle fibres contract powerfully, and the gland is wrung after the manner of twisting and wringing a wet rag to remove its moisture. A comparatively large lymph-like space surrounds the gland, and so permits of this wringing. The

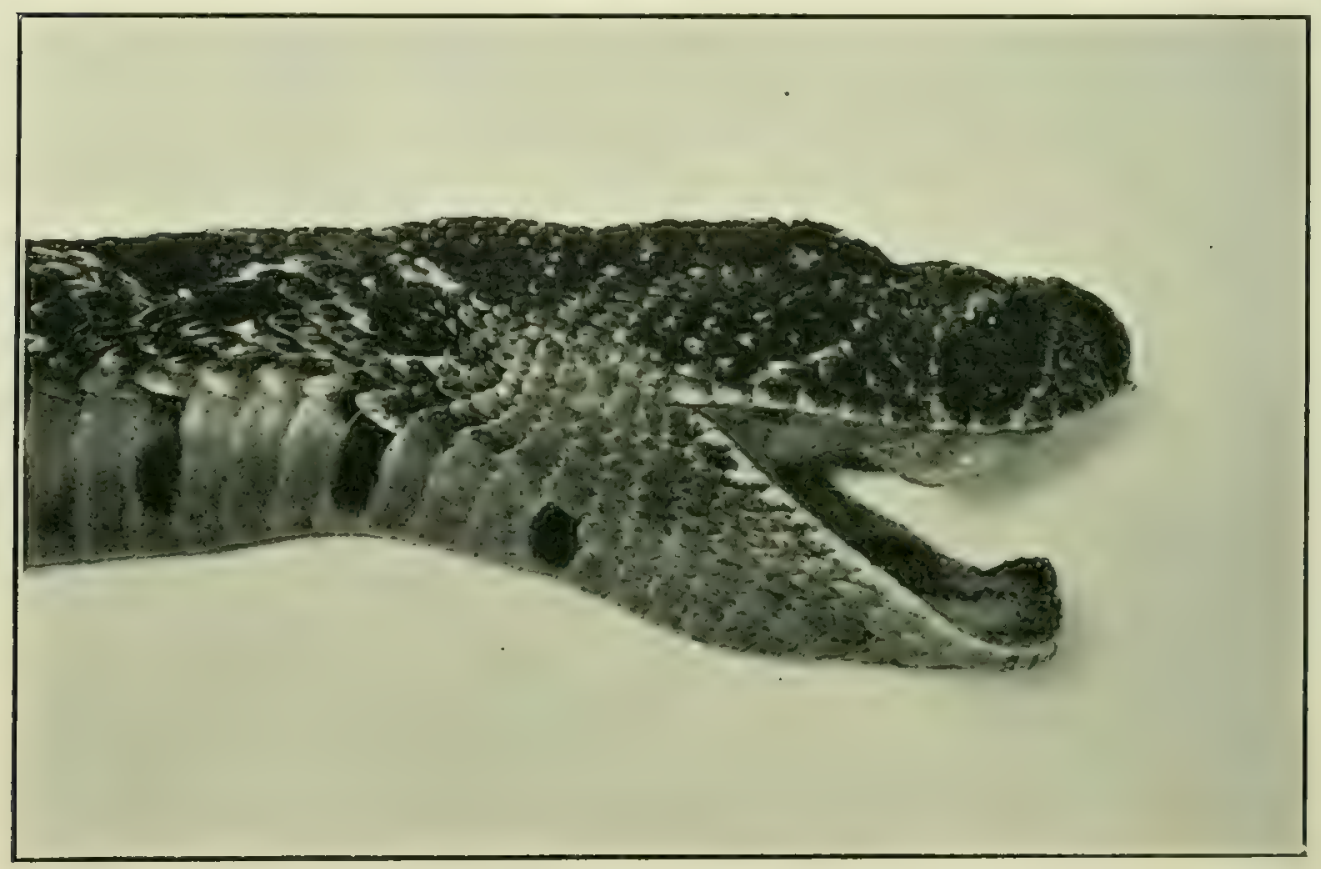

FIG. $\$ 36$. - The sheathed fangs of a Puff Adder. When lying back in this position they arc enveloped by a protecting membrane or sheath known as the Vagina dentis.

venom which is stored up in the numerous little cavities within the glands is thus driven with considerable power into the channels or conducting tubes which communicate with the bases of the hollow or grooved fangs. It rushes down the grooved or hollow fangs and issues out in two fine streams.

The bringing together of the end of the poison duct with the hole at the base of the fang is completed with marvellous exactness. By a wonderful arrangement of muscle-fibres, the harder the snake presses his jaws when biting, the tighter does the papilla at the end of the duct plug the hole in the fang. In fact, 
the hole at the base of the fang is actually corked, with the difference that the papilla cork allows the venom to stream through it into the grooved or hollow fang and then the other or both simultaneously until removed. Unless the snake is able to deliver a full bite and close its jaws firmly over the bitten part, a full charge of venom is not delivered. It can thus be clearly seen that recovery may take place without any antidotal treatment after being imperfectly bitten by a snake whose full bite is fatal. In this way faith is established in various worthless so-called snake bite "cures."

However, it must be borne in mind that highly venomous snakes such as Cobras, Mambas, amd Puff Adders, are able to inject far more venom at a single full bite than is sufficient to kill a man. An instance in point is given by Dr. Hanna. He says, "The gentleman, who was the writer's co-worker in India, was one day cleansing the mucus from the mouth of a Cobra, which was being held by a snake charmer preparatory to expressing the poison, when he inadvertently pushed the top of his thumb against the fang. He fancied that as the Cobra had not bitten him he had not received any poison, although the fang had penetrated deeply; he did no more therefore than suck the wound. In about two hours he had weakness of the limbs, drowsiness, vomiting, and was unable to feel in his thumb. and first two fingers. The parts, swelled, and it was only after considerable time he recovered by energetic treatment with antivenine serum. He ultimately lost the top of his thumb as a result of necrosis and death of the tissues."

Here we have an instance of a man who was wounded by only one fang which could not have discharged much venom for there was no pressure exerted by the snake, yet if the venom had not been neutralized in time in the man's blood by the injection of liberal quantities of anti-venine serum, he would undoubtedly have died.

Half a drop of Cobra venom is sufficient to kill a man unless his vital resistance happens to be strong. One full drop is a fatal dose to any one. In collecting venom for research purposes I have drawn ten drops at a time from a six-foot Cape Cobra. If this Cobra had bitten a man, and had been allowed to retain its grip for a couple of seconds, it was capable of injecting something like fifteen to twenty fatal doses into him. 
Three drops of Puff Adder venom is enough to cause such extensive hæmorrhage into the tissues of a man as to kill him.

In a man whose blood is altered by habitual indulgence in alcohol even in moderation, less than a drop would suffice to kill him. In monkeys which have been given a fair quantity of alcohol daily for a month, about a quarter of a drop of Puff Adder venom is sufficient to kill them. They die of hæmorrhage and mortification. Often the site of the injection turns black. This mortification of the tissues at the site of the entry of the venom, spreads into the body and causes death.

\section{Discharging VENOM.}

It is believed by most naturalists that the act of gaping the jaws and erecting the fangs causes an automatic action of the muscles controlling the poison glands forcing the venom out. This is not so. The poison is not expelled every time the snake gapes its jaws.

Puff Adders frequently yawn, gaping their jaws widely. Sometimes both fangs are erected to their fullest extent. At other times, the snake raises and depresses them in turn. This is done carefully and deliberately, seemingly for the purpose of exercise. The occasional raising of the fangs evidently gives some measure of relief or satisfaction to the snake. It is rare for Cobras to yawn, except after a meal. The Adders do it at various times.

When artificially feeding Puff Adders, venom frequently squirts from the fangs when the mouth is forced open and the fangs erected. In these cases, the reptiles are naturally in a state of irritation. This causes the constriction of the glands the instant the fangs assume the erect posture. At these feeding times I have collected as much as eleven drops of venom from a single Puff Adder.

Care has to be exercised at feeding times to hold the snake's head in such a position that the fangs point away from the faces of the operators. My assistant one day received a full charge of venom over his mouth, moustache, and chin. I,uckily, none entered his eyes, else there would have been trouble. 
The venom, on these occasions, is sometimes discharged a distance of five feet. One day, a rat was introduced into a cage
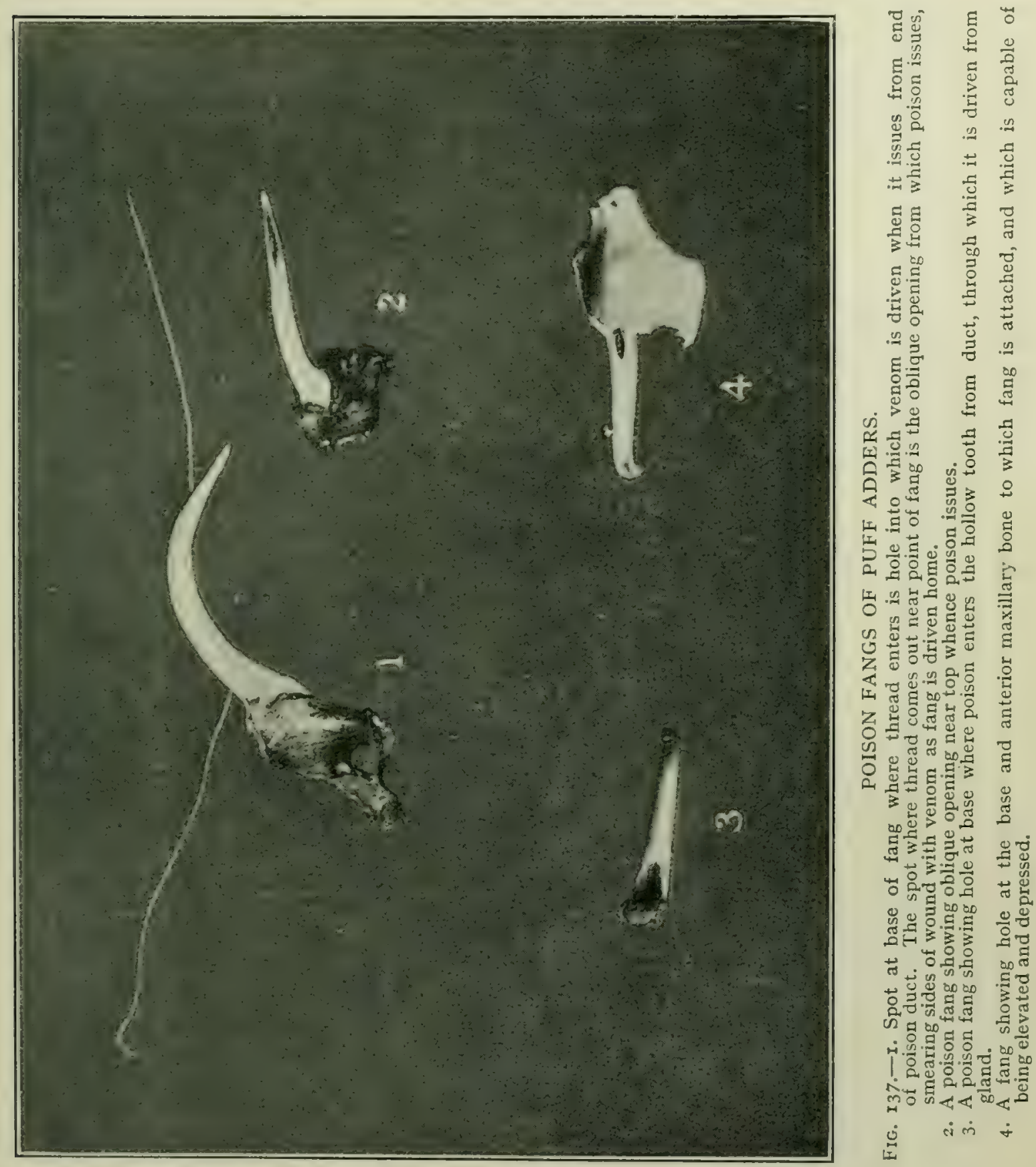

containing several Puff Adders. Two were lying sleeping on the top of an old tree stump. The rat, in springing upon the stump, 
suddenly disturbed their slumbers, whereupon both simultaneously struck fiercely at the intruder. Both missed their aim, and four streams of venom struck one of the plate glass sides of the cage and ran down the glass. The venom, when ejected, is watery, more so than that of the Cobra.

In the process of collecting venom by forcing a snake to bite over the rubber-covered rim of a watch-glass or wine-glass, the fangs are often erected and remain so, but no venom flows until the glands are compressed with the fingers.

It was amply demonstrated in this manner that the erection of the fangs did not cause an automatic constriction of the masseter muscle fibres. To eject a full charge of venom, the snake is obliged to grip and compress its head strongly. The jaws of Puff Adders may be extended to their fullest extent yet the fangs are not elevated unless the reptile so desires. I have frequently distended the jaws of Puff Adders and watched them elevate and depress their fangs. The anterior maxillary bones to which the fangs are attached are worked independently of any other parts of the mechanism of the jaws.

Taking twelve Puff Adders, I made each in turn bite over the thick rim of an ice-cream glass. The instant the rim of the glass touched the snake's nose it bit fiercely, both fangs darting up at the proper striking angle, and then descending with great violence against the inner side of the glass. Each snake was made to bite three or four times. The fangs in each instance would strike the glass and slip upwards towards the rim. Not even the fraction of a drop of venom was shed by five of the snakes. One yielded about three drops, and the rest a very small quantity. From the twelve snakes, I collected seven drops of venom. I tried this experiment several times and found that, although the snake bit the side of the glass freely, cither no venom, or only a very small quantity was shed. On the contrary, when I covered the top of the ice-cream glass with a rather thick piece of sheet rubber, these same Puff Adders in biting through it, shed an average of three to five drops and even ten drops each, into the glass.

In the former experiments, I was careful to examine the reptiles' mouths to see if venom by any chance had been shed within the mouth, but, with one or two exceptions, there was not a trace of venom to be seen. 
This, I think, clearly demonstrates that, although a snake

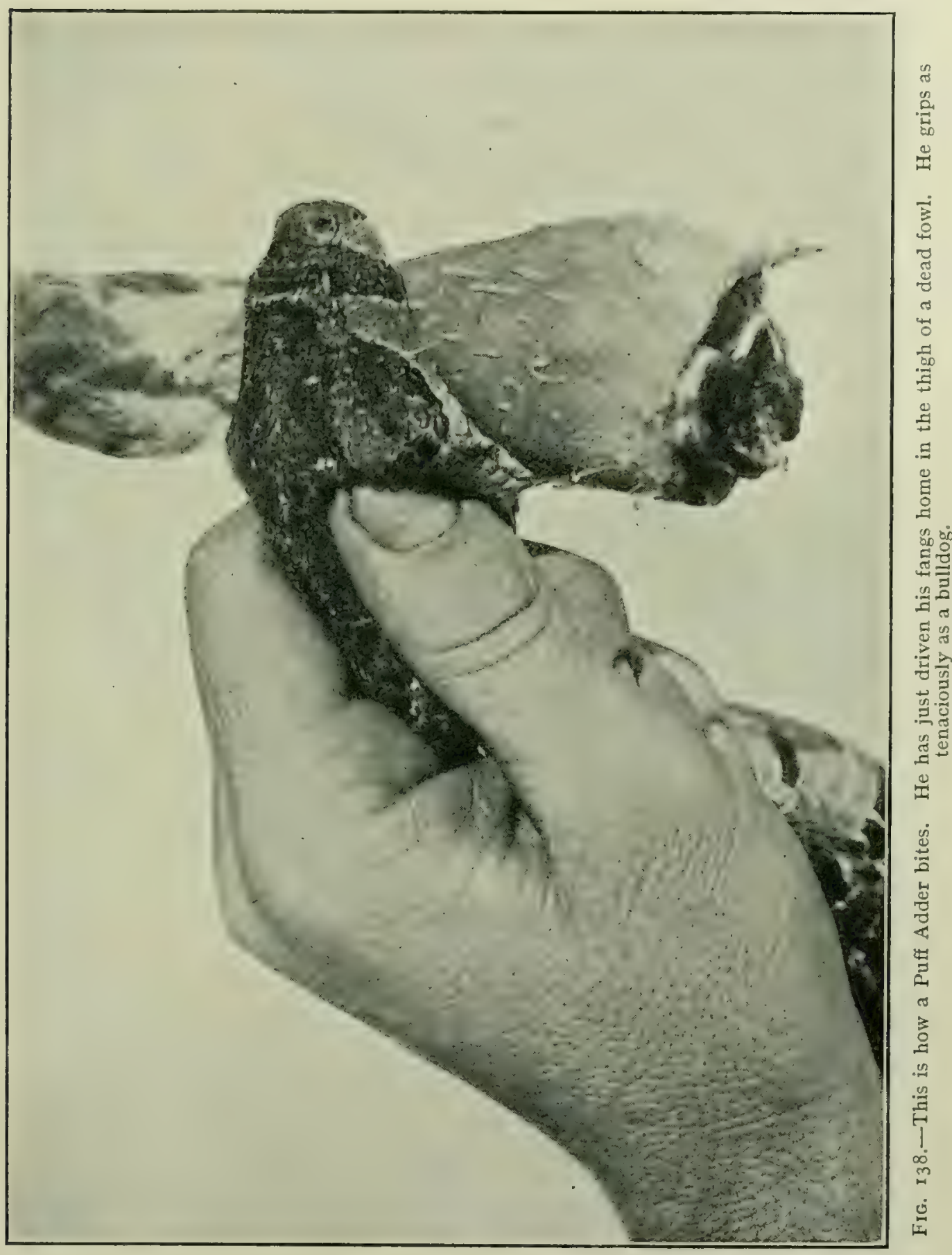

may bite with both fangs, yet it does not follow that venom will be ejected. I have found that if the snake is allowed to bite 
through some soft substance like sheet rubber loosely stretched over the mouth of a wine-glass, a limited amount of venom is shed, but that if the same snake is allowed to bite into the leg of a dead fowl or a lump of meat, and provided the reptile is allowed to grip like a dog and compress its jaws strongly, from two to six times the amount of venom is discharged, compared with the amount usually obtained by allowing the snake to bite through rubber or thin glazed cloth stretched over a glass.

If a man be hungry and you give him a piece of dry cork or wood to bite or chew, little if any salivary fluid will flow into his mouth; but if you give that same man a morsel of appetizing food to bite or chew, an abundance of saliva will flow, and the salivary glands will receive a powerful stimulus, and will instantly exert themselves to manufacture more saliva. So it is, in a sense, with venomous snakes. By the same pyschological influence their venom glands, and the nerves which work them, are roused into intense activity when the snake, with malice intent, deliberately bites the flesh of an enemy or some substance which deceives him into that belief or which tends to impart the same feeling.

Now and then when a snake lunges and misses his aim, the entire contents of the venom glands are shed, but in these cases the reptile has been wrought up to the highest pitch of excitement, and in the act of lunging the glands are compressed violently, there being no time to counteract the impulse imparted, as is the case with a man who aims a blow with his fist at some object which dodges just at the critical instant. The man is unable to counteract the command sent to the muscles of his arm to deliver a blow.

When a snake is dead, the venom oozes from the fangs on the slightest pressure on the glands, and can be easily collected by elevating the fangs and compressing the venom glands.

\section{Nature of Snake Venom.}

Cobra venom is a slightly acid fluid of about the same consistency as glycerine, and is very similar in appearance. Viperine venom is more watery than glycerine. Howerer, on exposure to the air and light, it changes to a light straw-yellow colour. When exposed to the atmosphere it quickly dries and cracks 

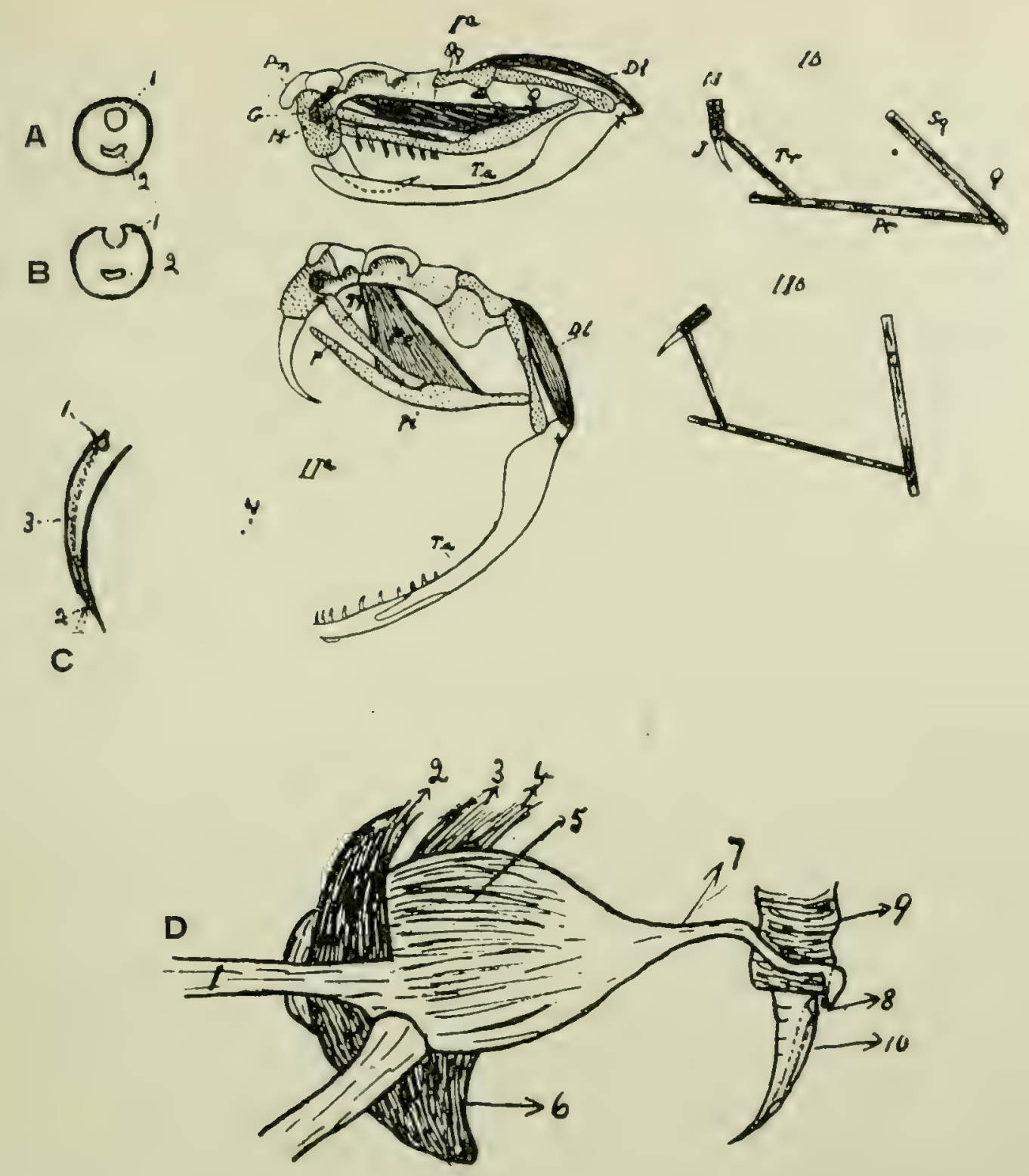

FIG. I39.-A. Section of a Viperine Fang. I. Canal through which the venom runs. 2. The central pulp of the tooth. B. Section of a Colubrine Fang. r. Groove down which the venom runs. 2. Central pulp of the tooth. C. Fang of a Viperine Snake. I. Hole through which the venom enters the canal. The end of the duct from the poison gland is connected with this hole. 2. The outlet of the hole near the end of the fang through which the venom escapes. The outlet is oblique, and is not at the extreme tip of the fang. 3. The direction of the canal through the tooth. 1a. Skull of a Viperine Snake, showing the position of the bones, muscles, and fang when the mouth is closed. Ib. A diagram showing principle how the fang is worked. In this figure the fang is depressed to represent the mouth closing. xxa and IIb. Position of the apparatus when the mouth is opened widely; the spheno-pterygoid muscle $(\mathrm{Pe})$ is contracted : the Pterygoid ( $\mathrm{Pt}$ ) is pulled forwards, the transverse bone or Ectopterygoid ( $\mathrm{Tr}$ ) pushes the Maxilary (M) rotates it, and thereby causes the Poison Fang (J) to assume an erect position. (Di) Digastric Muscle, contraction of which lowers, or opens the lower jaw. (J) Poison Fang, (M) Maxillary, (P) Palatine, (Pe) Spheno-pterygoid Muscle, (Pm) Pre-maxillary, (Pt) Pterygoid, (Q) Quadrate, (Sq) Squamosal, (Ta) Insertion of the anterior temporal muscle, by contraction of which the mouth is shut. D. The whole poison apparatus of a Viperine Snake. I. Articular-maxillary ligament. 2, 3, and 4. Temporal Muscles. 5 and 6, Constrictor Muscles of Poison Gland. 7. Duct. 8. Outlet of Duct. This is the point where the venom enters the canal in the fang. 9. Maxillary Bone. ro. The canal through the fang. No. 5 and 6 are the Constrictor Muscles which wring the poison gland, and cause its contents to run along the duct into the hollow fang. The mechanism of Colubrine snakes is the same, excepting that their fangs are usually grooved, instead of being hollow. 
like gum, but does not crystallize. The acid, being of a volatile nature, disappears, leaving the dry venom neutral. Venom either dry or fluid will retain its toxic or poisonous properties a great number of years. Dried venom will readily dissolve in warm water. When kept in solution in water, snake venom decomposes and loses its poisonous properties in a month or two. On the other hand, if venom be mixed with glycerine it will keep indefinitely. Dr. Weir Mitchell kept venom for thirty-two years, and Dr. J. C. Martin for thirteen years without it losing any of its poisonous properties. I have also found that after the lapse of years its effect is just as potent upon animals as when injected fresh. Snake venom is an albuminous substance of the nature of the raw albuminous or "white" part of an egg. All attempts to fully isolate or separate the toxic or poisonous qualities have so far failed. It is thought that the active principle is caused by a special arrangement or grouping of the atoms of the albuminous fluid, forming a solution of poisonous proteids. Snake venoms are very complex and varied in their action. The composition, nature, and effects of venoms differ considerably. Pure Puff Adder venom, if allowed to stand in a glass tube, deposits a white flocculent mass. The rest of the venom becomes light amber in colour and sets to the consistency of jelly a few hours after being drawn from the snake. If mixed with water and stirred, the white precipitate is dissolved. Cobra venom remains in a transparent condition.

Dr. C. J. Martin, Director of the Lister Bacteriological Institute of London, says:- " The analysis of the physiological action of venoms has proved them to be made up of a great many more constituents than would be imagined from their chemical examination. Different venoms have been found to contain one or more of the following: (I) A powerful fibrinferment; (2) an anti-fibrin ferment; (3) A proteolytic ferment; (4) various cytolysins capable of acting upon red blood corpuscles, ( phagosytes, endothelial cells of blood vessels, nerve cells, and the cells of various other tissues. In addition to the above, various other more remote pathological conditions are induced."

The various venoms being so different in their combination or " make up," it naturally follows that the venoms of various kinds of snakes would induce symptoms more or less dissimilar. This is the reason the serum from an animal immunized to the 
venom of only one species of snake fails to act as a sufficiently satisfactory antidote in all forms of snake bite.

The difference in the constituents of venom is so great that the venom of each species of snake differs in its action, even with those belonging to the same genus. For instance, the serum of an animal rendered immune to the bite of a Cape Cobra (Naia flava) proved on experimentation to be an antidote to the bite of this particular species of snake, but only had a partial antidotal effect upon the venom of another species of Cobra, nearly double the dose being necessary to neutralize the venom injected. Tested on animals bitten by Puff Adders, or injected with fatal doses of their venom, this serum had very little curative power.

The poisonous substances in snake venom may be separated into three main parts.

(I) Neurotoxins, or nerve poisons. These combine with the nerve cells and paralyse them. Neurotoxins are present in all venoms, but are most potent in the poison of the Cobra.

The nerve poisons, of some species of snakes, will cause paralysis of the nerve centres controlling the breathing, resulting in collapse of the lungs. Each variety of nerve poison acts with greater or lesser power upon the various groups of nerve centres, according to its nature. The nerve poison in one species of snake will cause complete paralysis of a certain set of nerve centres, while the nerve poison of another kind of venom will have little or no poisonous effect upon that particular nerve centre, but will concentrate its benumbing power on a group of nerve cells which the former venom has either not affected at all, or only to a slight degree.

In severe cases of Cobra poisoning, a certain amount of structural change takes place in the nerve cells, numbers of them being broken up and destroyed. However, death is not usually caused by wholesale destruction of nerve cells, but by the paralyzing action of the neurotoxin upon the cells. This neurotoxin is strong in Cobra venom.

(2) Hamorrhagins, or blood poison. This portion of the venom acts upon the endothelial cells, phagosytes, and red corpuscles of the blood. The endothelial cells are the cells of a membrane which lines the inside walls of blood vessels. The cells are thin and flat. The venom alters their shape, changes and expands their structure sufficiently to allow the altered 
blood to escape through the walls of the blood vessels into the surrounding tissues. The phagosytes are the white corpuscles of the blood. They are altered, damaged, and often more or less dissolved by the action of the hæmorrhagin principle in snake venom. The chief action, however, is upon the red corpuscles of the blood. The hæmorrhagin attacks these corpuscles, dissolving out their colouring matter and rendering them spherical and sticky. This dissolved colouring matter then escapes through the expanded walls of the blood vessels and finds its way into the tissues, spreading out under the skin and causing purple blotches more or less extensive. This escape of blood into the tissues is greatest near the various small arteries which branch off and terminate in a fine network of capillaries. The reason is that, at these points, the pressure of blood upon the capillaries is greatest.

The broken-up blood also oozes out through the mucous or lining membranes of the mouth, nose, lungs, stomach, bowels, and bladder. This blood-destroying poison predominates in Adder venom. Recent experiments, however, tend to show that the venom of the Puff Adder acts chiefly if not entirely on the endothelial cells, and not on the blood corpuscles.

(3) Fibrin-ferments. These cause the fibrin of the blood to solidify, which produces clotting. These fibrin ferments are usually strongest in Viper venoms, although they are present in lesser or greater degree in the poisons of all snakes.

When human subjects are bitten by Vipers (Adders) this fibrin-ferment does not cause coagulation of the blood, unless injected in an unusually large quantity, or direct into a vein (intravenously). In the latter cases, coagulation of the blood and death may occur at any instant. When injected direct into a vein even in small quantity death occurs within a few moments.

However, when the small animals on which snakes feed, such as rats, mice, or birds, are bitten by Adders, the fibrin-ferment in the venom almost instantly coagulates their blood, causing rapid death. This is due to the relatively large dose of venom injected. In the case of man or the larger mammals, sufficient of the fibrin-ferment principle in the venom does not usually enter the blood all at once to cause clotting, as is usual with small creatures. In the case of Cobras, the neurotoxin or nerve poison is the principal factor in causing the rapid death of their prey. 
The majority of snake venoms contain all three of the above-

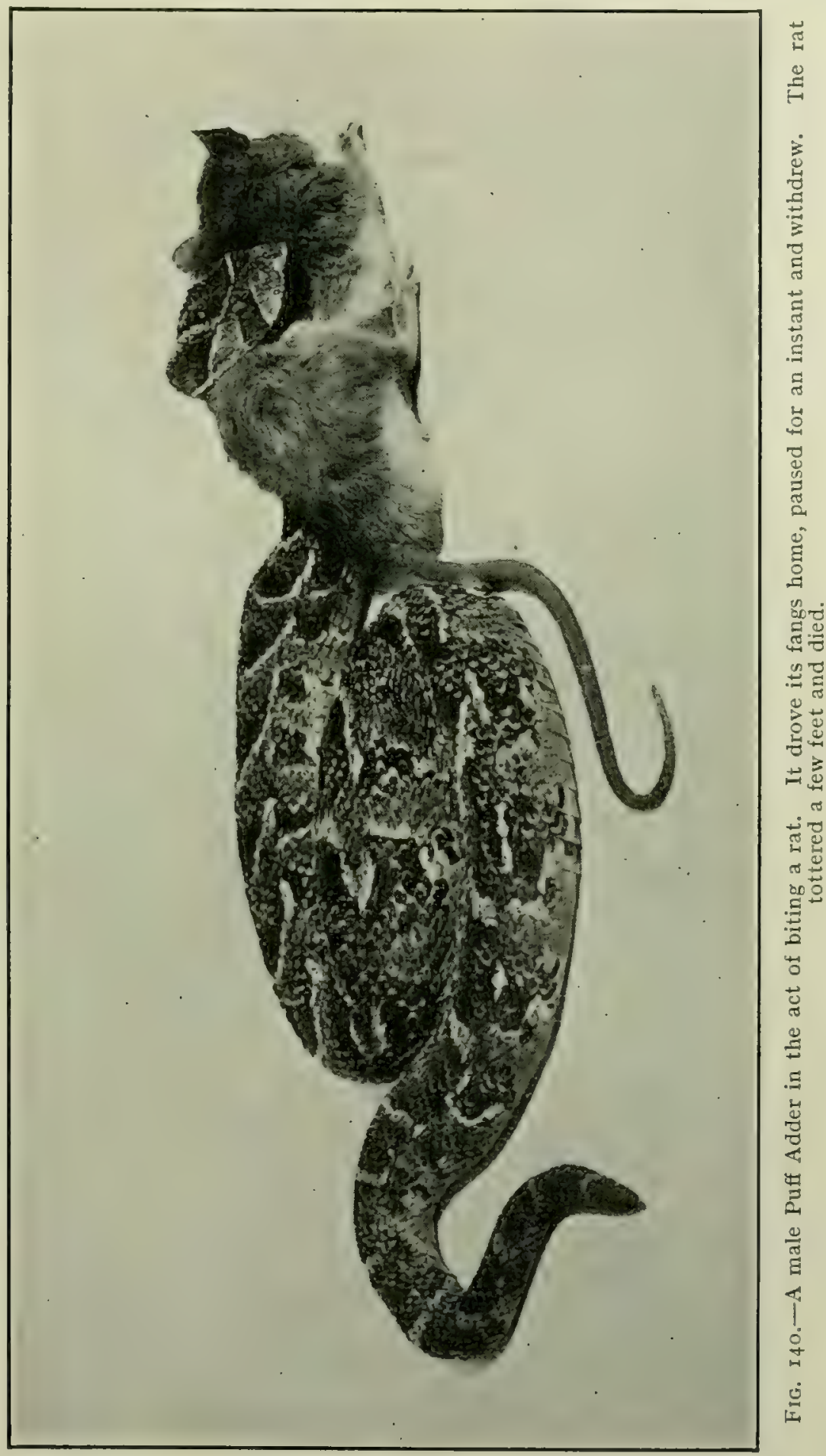

mentioned poisons. In each species of snake they are not only different more or less in their physiological action, but they are 
in varying proportions, hence the reason of the differences in the effects on the human body and the symptoms arising from those effects.

The nerve poison (neurotoxin) can be separated from the blood poison (hæmorrhagin) of Cobra venom, by adding lecithin dissolved in chloroform, with a solution of venom, and shaking vigorously. The blood-poison combines with the lecithin to form an active lecithide which dissolves in the chloroform and can be afterwards precipitated by ether.

The neurotoxin or nerve-poisoning principle of the venom remains in the liquid solution. The part which has been precipitated, if injected into animals, destroys the red corpuscles of their blood, inducing hæmorrhage into the tissues. Its action is very rapid, especially when a concentrated solution is used, being then much more active than before separation from the neurotoxin:

Weight for weight, the venoms of the different species of snakes vary considerably. The venoms of the Mamba, Cape Cobra, and Boomslang have as powerful poisoning effect as three times the weight or bulk of Puff Adder, Berg Adder, or Night Adder venom.

The poisonous effects of all venoms vary according to the size and vital resistance of the victim. For instance, a cat is of about the same weight, or even less, than a large fowl or rabbit, yet its power of resistance to the poisonous action of venom is considerably greater. A Boomslang was forced to bite the bared thigh of a domestic cat of adult size, and was permitted to retain its grip for half a minute. The cat gradually developed symptoms of poisoning and died in thirty hours. Large cock fowls and rabbits bitten by the same snake died within fifteen minutes. An interesting feature of these cases was the different symptoms. The cat was strongly acted upon by the bloodpoisoning principle of the venom, for the wound oozed blood all the time, and the mucous surfaces discharged blood; and after death, extravasated blood was found in various tissues. On the contrary, no such symptoms were apparent in the fowls and rabbits. The neurotoxin or nerve-poisoning principle in the venom caused almost instant paralysis of the motor nerve centres. After death, little or no alteration to the blood could be detected. 
It must, however, not be inferred that the cat is as strongly immune to all venoms, for cats bitten by Cape Cobras died in fifteen to twenty minutes.

Snakes kept in captivity, unless under strictly natural conditions out-of-doors, and in their native country, do not thrive, and their venom becomes less in quantity although not usually poorer in quality. I have noticed that snakes which have been subjected to different climatic conditions to those of their native habitat deteriorate the most. In fact, they invariably refuse all food and die in a short time. Some species of snakes are so susceptible to a sudden change of environment that they perish in a month or so, although the temperature of the air be maintained at that of their native haunts.

\section{Effects of Snake Venom.}

According to Fraser, about 30 mgrms. (about half a drop) of Indian Cobra venom is sufficient to kill a man. This means that a full-sized Cobra would be able to eject enough venom at a single full and complete bite to kill about twenty men.

Dr. Hanna and others state that the Indian Cobra yields as much as twenty drops of venom. Dr. Hanna mentions having obtained as much as twenty-eight drops.

In experiments with the venom of the Cape Cobra I found that one drop diluted in a little water and injected into the tissues of the leg of a large monkey killed it in half an hour's time. A fraction of a drop was sufficient to kill a rat and a fowl within half an hour. One drop was sufficient to kill adult Chacma Baboons within three hours. Judging from the effects of Cobra venom on the higher animals such as monkeys, I consider that one full drop is a fatal dose for a strong healthy man. This fact makes the treatment of snake bite a most complicated one. It will clearly be seen that if a Cobra or Namba should succeed in delivering a full bite, many times a fatal dose is likely to be injected; therefore, in spite of prompt applications of permanganate of potash, ligatures and the injection of serum, the victim might die. The only hope in these cases is the copious intravenous injection of anti-venine serum.

Cobras and Mambas are far more to be dreaded than Vipers 
because their venom acts so rapidly on the nerve centres, often causing death or reducing the person bitten to a condition impossible of recovery before there is time to apply any remedial measures.

However, the venoms of all snakes of the Colubrine family do not act in this rapid way upon the nerve-centres in the brain and medulla. The venoms of many act primarily on the blood and secondarily on the nerve centres, as for instance in the case of the Boomslang, which is a member of the Colubrine family, although in classification it is placed in a sub-family with other back-fanged snakes.

When a dose of viper venom is injected into a vein, even if the quantity be small, death rapidly results from clotting of the blood, chiefly in the pulmonary arteries. In animals, if a small fraction of a drop is injected direct into a vein, death quickly follows from clotting of the blood caused by a poisonous principle in the venom known as Fibrin-ferment.

In these cases no remedial measures are of any avail.

The venoms of the different species of snakes differ considerably in the blending of the nerve poisons (neurotoxins), blood poisons (hæmorrhagins), and blood-clotting poison (Fibrinferment). This being so, the symptoms vary more or less widely. The venoms of two different species of snakes which apparently produce the same outward physiological effects are found, when examined, to be more or less dissimilar in their composition. However, when the victims are subjected to post-mortem it will be discovered that the venom of one snake has produced internal effects considerably different from the other.

The venoms of the Colubrine (Cobra) family of snakes and the Viperine (Adder) family differ most widely in their nature and effects. Generally speaking, we can say that the venom of the typical Cobra family of snakes acts rapidly and chiefly on the nerve-centres, causing rapid paralysis and death; while the venom of the Adders, although causing severe nerve depression, exerts a powerful poisonous influence on the blood and walls of blood vessels.

Snake venom, when mixed with ammonium sulphate or absolute alcohol causes the poisonous substances (proteids) to be separated. These fall to the bottom but retain all their original poisonous properties. 
The solution (filtrate) is not poisonous. The poisonous principles of the venom which have been precipitated, if injected under the skin of an animal, will cause death just as rapidly as if the pure unaltered venom had been injected. It will thus be seen that alcohol, even if it were possible to drink it in the absolute or pure form, would not destroy the venom in the slightest.

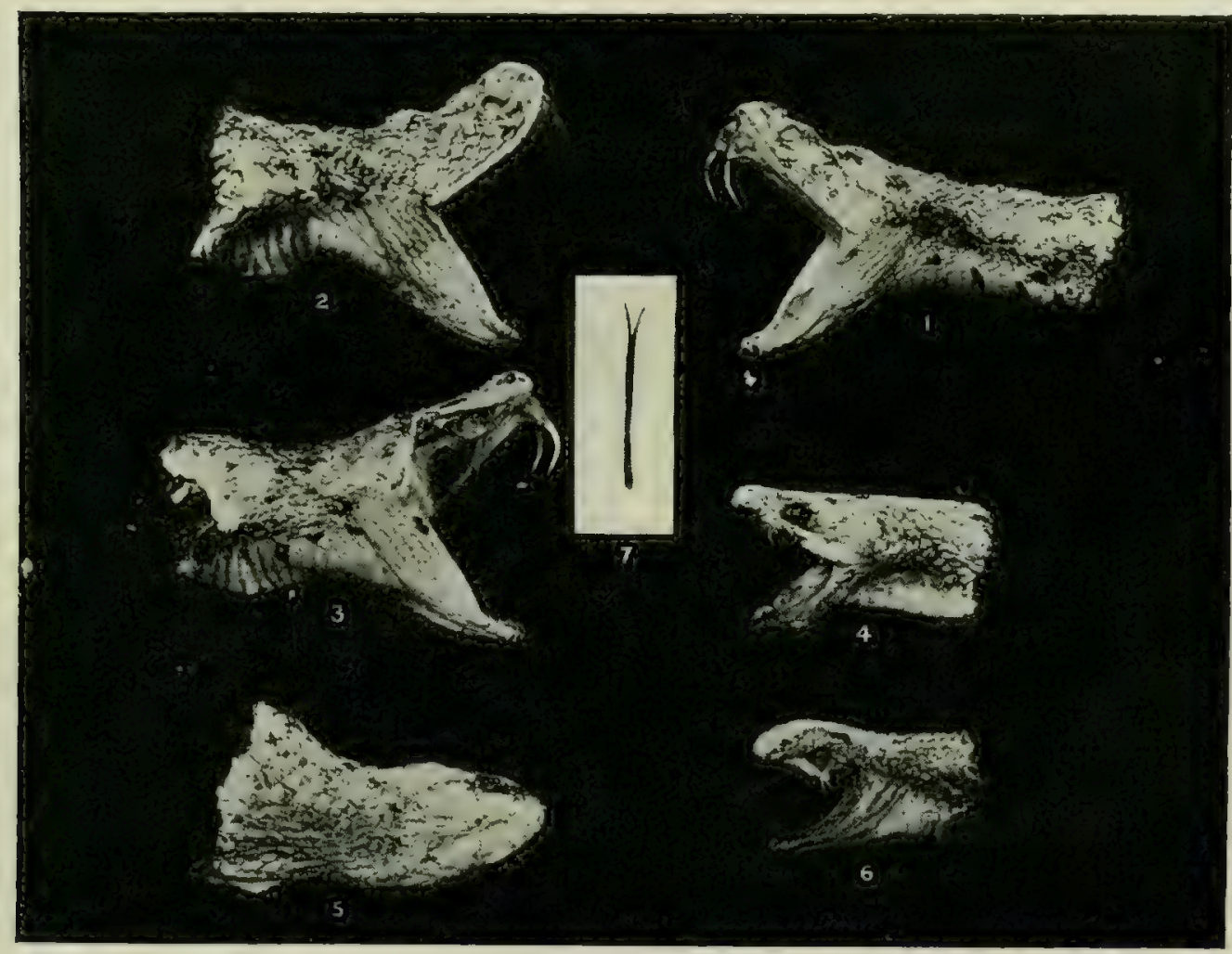

FIG. I4I.-I. Unsheathed Poison Fangs of a Puff Adder in act of striking. 2. Erected fangs of a Puff Adder covered with the membraneous sheath (Vagina dentis) which protects them from injury. When the mouth is closed the fangs lie within these sheaths along the jaw. 3. The dissected head of a Puff Adder showing the erect fangs, the poison bag or gland, and the channel along which the venom runs to the hollow tooth. The black patch under the eye is the poison gland. 4. Fangs of a Cape Cobra. Note how small they are in comparison with those of the Puff Adder. 5. Cape Cobra's head, back view, 6. Dissected head of a Boomslang, showing the poison fangs and gland. Note bow far back in the jaw they are. The black spot at the back of the fangs is the gland. There is no duct or channel leading from it. The venom oozes into a sheath at the base of the grooved fangs. 7. The bifid or forked tongue of a snake. Snakes do not sting with their tongues.

The venoms of all snakes are rendered harmless after boiling several hours. Adder poison is destroyed more or less after a few minutes' boiling, but Cobra venom resists the action of heat much longer. When boiled in solution with water, or raised to a temperature of $70^{\circ}$ to $80^{\circ} \mathrm{C}$., snake venom throws down a white flocculent precipitate. After the removal of this sediment 
the solution is found in the case of Cobra venom to be quite or almost as deadly as before boiling. Several hours' boiling, however, entirely destroys the poisonous properties of Cobra venom.

It will thus be seen how very sensitive the venoms of Adders are to heat when in solution, and how strongly Cobra renom, under similar conditions, resists heat.

Venom, in a dry condition, may be heated to $100^{\circ} \mathrm{C}$. or a little over without any alteration in its poisonous properties.

If a blood vessel be punctured and the venom enters the circulation direct, the effect is practically instantaneous, and death occurs within a few moments. I found when the venoms of the Boomslang and the Cape Cobra were injected direct into the veins of animals, they were stricken with death as swiftly as if shot through the brain. In one instance death occurred while the dose was being injected.

However, in cases of snake bite, the venom is usually deposited in the muscular tissues and is absorbed by the small capillary blood vessels and lymphatics adjacent to the bitten part, and finds its way into the general circulation at a much slower rate.

The symptoms of snake bite vary according to the quantity of venom absorbed, and its nature.

Dr. C. J. Martin states that "Feeding an animal with snake poisons, even when the diet contains daily one hundred times the fatal dose, does not produce any symptoms of poisoning, provided there be no abrasion of the mucous membranes."

For several years I have at intervals experimented in this manner, administering fifty times a fatal dose of venom daily for several days, without any apparent bad effect. I have fed rats, fowls, cats, dogs, jackals, mungooses and monkeys on the venoms of South African snakes without any symptoms of poisoning ensuing.

It is a common practice of the Kafirs and Hottentots to swallow snake venom under the mistaken belief that it renders them immune to snake bite.

The South African Bushmen poisoned their arrow heads with snake venom for the purpose of killing animals for food. They were in the habit of eating the animals killed in this way without previously draining out any of the blood, and only partially cooking the flesh, often eating it practically raw. All they did 
was to cut out and throw away the discoloured flesh around the site of the poisoned arrow wound.

The blood of an animal which has died of snake bite will kill if introduced into the blood of another. Dr. Fayrer transmitted the venom through three animals with fatal results. That is, he injected venom into one animal. Then he inoculated the second animal with the blood of the first. When this second animal was dying he took some of its blood and injected it into a third animal. All three died.

The venom of a snake can be absorbed into the blood through the delicate membranes of the eye and cause death, as in ordinary snake bite. There is danger of this happening with the Ringhals or Spitting Snake. If death does not occur, serious damage to the eyes or permanent blindness might ensue.

Venom acts on cold-blooded animals, viz. reptiles, but not so rapidly as is the case with warm-tlooded creatures. Birds and small animals usually die within a few minutes of being bitten by a very venomous snake.

Dr. Fayrer says the venom of adult deadly snakes does not affect each other. This is only sometimes so, not by any means always. Experiments in proof of this are detailed elsewhere in this book.

On several occasions I have removed the poison glands from dead Cobras and Puff Adders after the bodies had become slightly stale, sufficiently so to give off a disagreeable odour. The venom was squeezed out of the glands and injected into fowls under the skin of the thigh and wing. No poisonous symptoms followed. I concluded from these experiments that after the death of a snake the venom rapidly deteriorates and entirely loses its toxic properties when decomposition of the flesh of the reptile begins.

Dr. Günther says: "The degree of danger depends but little on the species of snake which has inflicted the wound, but rather on the bulk of the individual, on the quantity of its poison, on the temperature and on the place of the wound."

On the contrary, there is a considerable difference in the poisonous properties of the venoms of the different species of snakes. The venom of a Cape Cobra or Mamba, for instance, is swift and sure. That of the Puff Adder is slow in comparison. In toxic power, one drop of the venom of the Cape Cobra, Mamba, 
and Boomslang is equal to two or three drops of Puff Adder venom. Fayrer, Brunton and several others claim that Cobra venom is as poisonous in its action when swallowed as when injected under the skin.

I have experimented upon a variety of animals, including Chacma Baboons, by introducing the venoms of the various South African snakes into their food. In no case were they affected in the slightest degree. The venoms of all the typically poisonous snakes were used. The Cape Cobra and the Puff Adder, being typical representatives of the Colubrine and Viperine families of snakes, their venoms were selected chiefly for these experiments. Thirty drops of freshly-drawn Cobra venom introduced into about an ounce of food was given on several occasions without any poisonous symptoms supervening.

If venom taken into the stomachs of such highly evolved animals as Baboons produces no poisonous effects, it is fairly safe to assume that it would act similarly in the healthy human organism. In fact, this has been sufficiently demonstrated by the fact that the Bushmen of the past ate the venom-poisoned flesh of animals.

An Australian scientist, in a recent article on the Snakes of Australia, declares positively that the venom of the Colubrine (Cobra) family of snakes is rendered harmless by the gastric juices when swallowed, but that Viperine (Adder) venoms, on the contrary, are not so destroyed. Gadow states that, with the exception of Cobra (Colubrine) venom, all venoms are not absorbed by the mouth or alimentary canal, unless there be abrasions.

On the contrary, Drs. C. J. Martin, G. Lamb, and Weir Nitchell, all of whom are recognized authorities on snake venom, declare that all venoms are destroyed by the gastric and pancreatic juices. Some are acted upon by the gastric juices; others, which these juices have no power to neutralize, are rendered harmless by the pancreatic fluids.

\section{Venom is Digested.}

Snake venom when swallowed is completely digested by the digestive juices. It has been frequently demonstrated that the secretion of the Pancreas, known as the pancreatic juice, which 
pours into the Duodenum during the process of digestion, completely destroys snake venom. This pancreatic juice, when taken from an animal and mixed with snake poison, will completely destroy its toxic or poisonous properties if heated to the normal temperature of the body. In fact, the venom is digested and chemically changed. Careful analysis of the excreta of animals fed with snake poison has failed to show any trace of venom, therefore it must have been destroyed by the digestive juices, or else absorbed into the blood unchanged, in which case it would have set up characteristic symptoms of snake venom poisoning.

It is, however, unsafe for human beings to swallow venom, as the digestive organs of the majority in civilized communities are in anything but a healthy state, and it is quite possible a state of catarrh of the inner walls of the stomach or intestines may exist. Then, again, if the digestive organs be weak, the gastric and pancreatic juices may not be sufficiently abundant or concentrated to digest the venom, which would pass down into the intestines, and may possibly get absorbed into the blood.

If the stomach be ulcerated or otherwise inflamed, snake venom is capable of finding its way into the blood through these inflamed surfaces. In this case it will have the same effect as if injected direct into the blood.

In most cases of serious illness the digestive apparatus is rendered torpid to a greater or lesser degree. This means that the Liver, Pancreas, and gastric glands secrete little or no digestive fluid; consequently, if venom is swallowed at such a time, it is either only partially neutralized, or not acted upon at all. If it should pass the stomach and enter the small intestines without being previously digested by these glandular secretions, especially the pancreatic juice, it will probably be sucked up by the tiny mouths known as Villi, millions of which line the intestine walls. In due time it will find its way into the blood and cause poisonous symptoms, the same as if it had been absorbed in the ordinary way in cases of snake bite. This can be demonstrated by introducing snake venom direct into the small intestines of animals, when in an empty condition. Cobra venom in this way is absorbed and acts more rapidly than Adder venom.

C. J. Martin mentions that paralysis of the lungs can be 
rapidly induced in animals by introducing a few drops of Cobra venom into the fourth ventricle of the brain.

\section{Two Distinct Classes of Venom.}

Although there is a difference in the action of the venom of each species of snake, we find there is a general similarity in the symptoms produced by the venoms of all snakes.

The greatest difference is with the two families of venomous snakes, viz., the Colubrines and Viperines. The Colubrine snakes include our well-known Cobra, Ringhals and Mamba. The Viperines include all the Adders. These two families comprise all the very venomous South African snakes, with the exception of the Boomslang, which has only recently been shown to be a highly-venomous snake and which is classed in a sub-family of Colubrines. There is a marked difference in the symptoms produced by Colubrine venom and Viperine venom.

\section{Action of Colubrine Venom.}

Colubrine (Cobra family) venom acts directly and speedily upon the nervous system. Viperine venom is slower, and operates both upon the nervous system and blood. If a fatal dose of Cobra venom be injected direct into a vein, it is speedily carried to the heart, instantly stopping the action of that organ, and causing death in a few moments. A dose injected into a vein in the thigh of a dog caused instant death. This effect, however, is only produced when the venom is injected direct into the veins. When Cobra venom is injected into the tissues, as invariably happens in ordinary cases of snake bite, the poison is absorbed less rapidly, and instead of stopping the heart's action. it has a contrary effect, stimulating it into increased activity.

The venom acts directly upon the nervous system, causing gradual cerebro-spinal paraly:is. If a fatal dose has been introduced and absorbed into the blood, the nerves controlling the automatic action of the lungs are paralyzed, and breathing ceases, although the heart is unaffected and continues beating for some minutes, which clearly shows its vasomotor nerve centres are unaffected by the venom. The lungs having ceased 
to act, the blood quickly becomes charged with carbonic acid, due to the accumulation of the waste products of the body. This vitiated blood quickly stops the beating of the heart, and extinguishes life. The object of breathing is to inhale air, the oxygen in which combines with the blood, burning up and converting the impurities contained therein, giving off in the process carbonic acid gas, which is breathed out. The importance of this blood-purifying process is so great that if the lungs cease to act, death or a trance-like condition ensues within a few minutes. Now, in the treatment of a patient bitten by a Cobra, Ringhals or Mamba, be very vigilant. If the breathing should suddenly cease, instantly resort to artificial breathing and keep it up until the patient breathes of his own accord. If necessary, continue this artificial breathing process for a couple of hours. In dealing with the treatment of snake bite later on, artificial respiration methods will be more fully explained.

\section{Symptoms of Cobra Venom.}

The special principle known as neurotoxin or nerve poison seems to be particularly strong and active in Cobra venom. This neurotoxin causes structural changes and paralysis of various groups of nerve cells in the spinal cord and medulla. However, when death ensues within four or five hours after the injection of the venom, no changes in the nerve cells take place, death being due to rapid paralysis of the main nerve centres. Cobra venom also acts upon the blood cells, but its principal and most dangerous action is on the nervous system.

The general symptoms of Cobra poison are according to Dr. C. J. Martin more or less as follows:- "Burning pain at seat of wound, followed by sleepiness and weakness in the legs after half an hour. Then profuse salivation, paralysis of the tongue and larynx and an inability to speak. Vomiting, incapability of movement. The patient seems to be conscious, but is unable to express himself. The breathing becomes difficult. The heart's action is quickened. The pupil remains contracted and reacts to light. At length breathing ceases, with or without convulsions, and the heart slowly stops. Should the patient survive, he returns rapidly to complete health." 
Cobra venom contains an anti-fibrin ferment, and prevents the coagulation of the blood. This is not, however, by any means the case with all Colubrine snakes.

Cobra venom, when diluted one in ten million with water, is a heart stimulant if injected under the skin or into a vein.

\section{VIPERINE VENOM.}

The venom of Viperine snakes, of which our Puff Adder, Horned Adder, and Berg Adder are examples, differs considerably in its physiological action from that of the Cobra (Colubrine) family. The neurotoxins or nerve poisons in it are not nearly so potent in their action as is the case with the nerve poisons in Cobra venom. But, whereas Cobra venom causes increased action of the heart and consequent increased blood pressure, Viperine venom slows down the pulsation of the heart and circulation of the blood. This narcotic power of the venom extends to the general nervous system, bringing about a state of nerve depression more or less severe according to the amount of venom injected.

Cobra venom acts powerfully upon the nerve centres controlling the breathing functions, and tends to stop the action of the lungs. Viperine venom, on the other hand, exerts no special effect upon these nerve centres.

\section{General Tendency of Viperine Venom.}

The tendency of Viperine venom is to produce a gradual and general paralysis of the nerve centres which causes a feeble action of all the vital functions. If the dose injected be a fatal one, this slowing-down action progresses steadily but surely until death takes place. The venom of Viperine snakes contains a powerful poison known as a fibrin-ferment causing the blood to clot. If the venom be injected direct into a vein in sufficient quantity in reptile, mammal or man, coagulation or clotting of the blood takes place, followed rapidly by death.

However, when the venom is injected into the muscular tissues as is usually the case in bites from snakes, the poison is not absorbed with sufficient rapidity to cause coagulation until after death. 


\section{NATURE'S REsistance.}

Nature sets up a resistance against all foreign substances when introduced into the body, endeavouring to overcome and cast them out again. In those cases where she fails, the dose has been too large, or the vitality and mechanism of the body is more or less impaired by disregard of the laws of hygiene. The habitual indulgence in alcohol is a potent factor in the breaking down of the natural inherent power of the body to withstand and overcome any form of disease or poisoning. Habitual moderate drinkers of alcoholic liquors succumb rapidly even to a small dose of snake venom-a dose not sufficient to produce serious symptoms in a non-drinker. Animals dosed with alcohol for a few months, given in regular doses, died rapidly when injected with a small dose of snake venom, showing clearly that alcohol destroys the inherent vital resistance to snake venom, as medical science informs us it does with all forms of disease or ordinary blood-poisoning.

\section{Hæmorrhage into the Tissues.}

A characteristic action of Viperine venom is to cause hæmorrhage into the tissues in various parts of the body. A toxic property in the venom acts upon the walls of the capillary blood vessels, causing expansion of their cells, or, to put it in scientific terms, "a dissolution of their continuity." This effect of the venom upon the walls of the blood vessels allows the blood to ooze through and into the tissues, causing purplish blue patches under the skin. The escape of blood through the walls of the capillaries is always greatest near the small arteries owing to the increased blood pressure at these places. The effect of Viperine venom upon the circulatory system seems to be threefold - the red corpuscles are in most cases acted upon, causing them to release their hamoglobin or colouring matter, and to distort and alter their natural shape; the phagosytes or white blood corpuscles are more or less broken up; the cells composing the walls of the smaller blood vessels are caused to expand, allowing the blood to escape into the surrounding tissues. 


\section{Hæmorrhage and Mortification.}

In Viperine poisoning, such as is occasioned by the bite of the Puff Adder, there is always grave danger of death supervening from gangrene or extensive suppuration, owing to the hæmorrhage into the tissues in various parts of the body. Death may occur from these causes a week or more after the infliction of the bite. The hæmorrhage or extravasation of blood into the tissues occurs more or less extensively in patches, causing bluish-black discolouration. There is also- oozing of blood from the mucous surfaces of the mouth, lungs, bowels, kidneys, bladder and stomach; and sometimes suffusion of blood into the brain tissues. If this latter should take place death follows at once.

I have many times examined natives with large cavities in the calves of their legs, due to the sloughing away of the flesh around the site of the bite of a Puff Adder. Other cases have come under my observation where the flesh sloughed to a certain extent, around the part bitten, then healed, only to break out again later and discharge a quantity of matter, and remain in a suppurating condition for a month or two, and finally heal. This suppuration and subsequent healing of the wound occurred at intervals, in one case extending over a period of three years. In this latter case most of the calf of the man's leg had sloughed away. Yet he eventually recovered.

\section{Viperine Poison Symptoms.}

The symptoms of Viperine poisoning are as follows:Intense but not prolonged smarting, discolouration, and swelling at the site of the fang punctures. Within twenty minutes the venom begins to bring about constitutional symptoms such as giddiness, and irregular fluctuating pulso. The skin grows cold and clammy, the pupils of the eyes are dilated, followed by intense nausea and vomiting, often accompanied with evacuations from the bowels. If death fails to take place within twelve hours, the swelling becomes more extensive. If the bite be on the lower part of the leg, the swelling gradually extends upwards and into the body. At the same time hæmorrhage from the walls of the capillary blood vessels takes place, causing purple patches, more 0 : less large, to appear in various parts of the body. Oozing of 


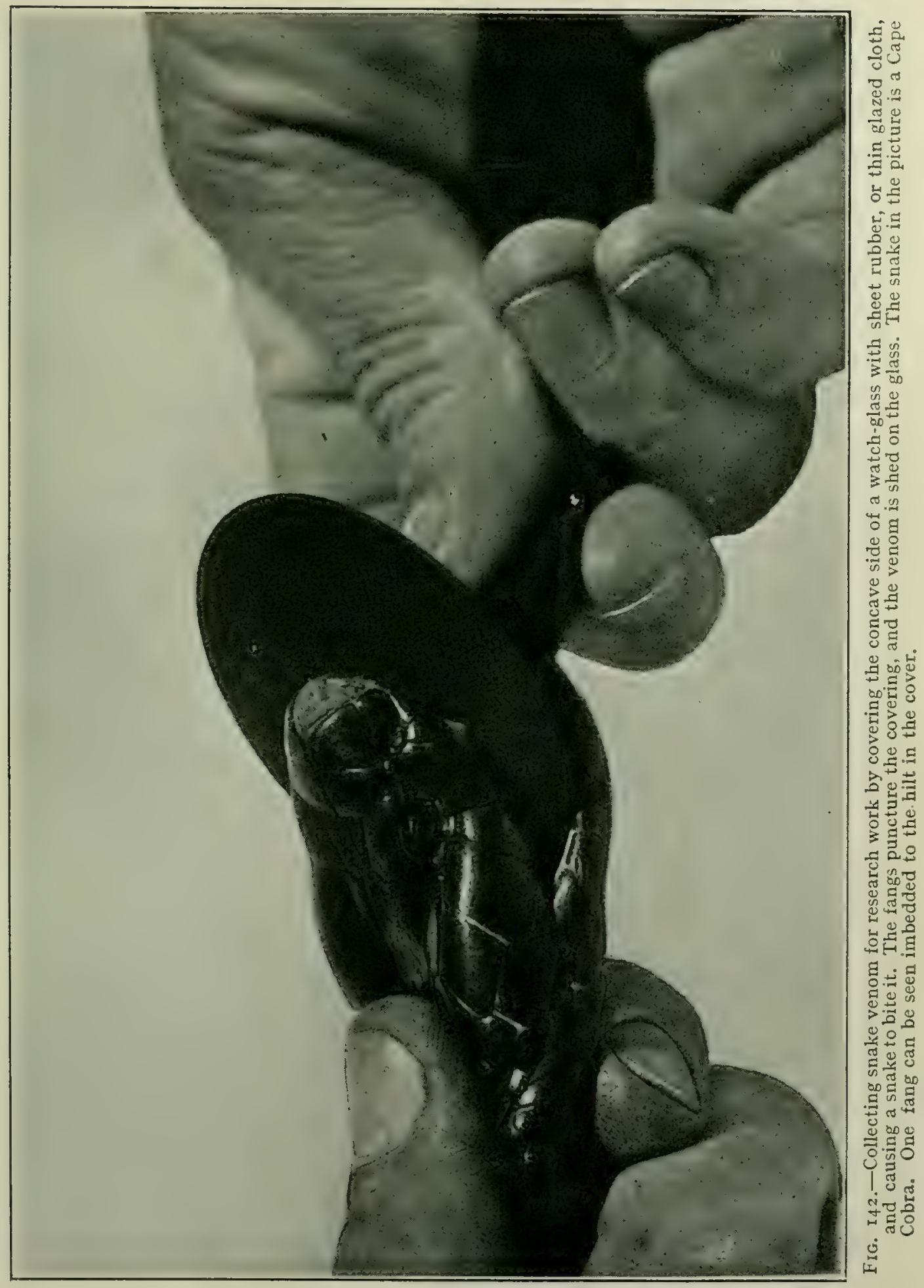


blood from the gums, lining membrane of bowels and bladder also occurs.

If the patient survives this stage, any extensive escape of blood into the tissues may set up mortification or gangrene, and death may take place two or three weeks after the bite. But once the danger point has been passed, however, the patient rapidly becomes mentally active and cheerful, and recovery quickly follows.

\section{How to Collect Snake Venom.}

One of the best ways to collect quite pure snake venom for purposes of experimentation and chemical analysis is to procure a large and strong watch-glass, as convex as possible. Obtain a piece of sheet rubber or thin glazed cloth, preferably the latter. Stretch this loosely over the rim of the concave side of the watch-glass, bunch it up and tie it at the centre of the convex side. Hold the live snake by the neck, the forefinger of the right hand (unless you are left-handed) round its throat, and the thumb pressed firmly on the back of its neck, just behind the head. Seize the tail firmly in the left hand. If the watch-glass can be fitted into some fixture, all the better and safer. Failing this, an assistant holds it with his fingers and presses its edge against the front of the lower jaw of the snake. The reptile instantly bites, its fangs penetrate the stretched rubber or cloth, and the renom is discharged on the concave side of the glass. If it should show a desire to grip firmly and hold on, quickly iransfer the tail of the snake to the free fingers of the right hand. Then, with two fingers of the left hand, gently but firmly, press each side of the head behind the eyes, working your finger-tips forward. In this way you will succeed in pressing out most of the venom remaining in the glands. Put the snake away, and repeat the process in a day or two. Remove the rubber from the watch-glass and allow the venom to dry on the glass by placing it in a current of air, or in some warm, dry place. Use the same glass repeatedly until sufficient renom has been collected to make it worth while to transfer it to a bottle with a good tight cork. Before putting the renom into the bottle, be sure that it is perfectly dry, else it will decompose and lose its poisonous properties. It may be very effectually dried in a desiccator over calcium chloride. It dries rapidly at $16^{\circ}$ to 


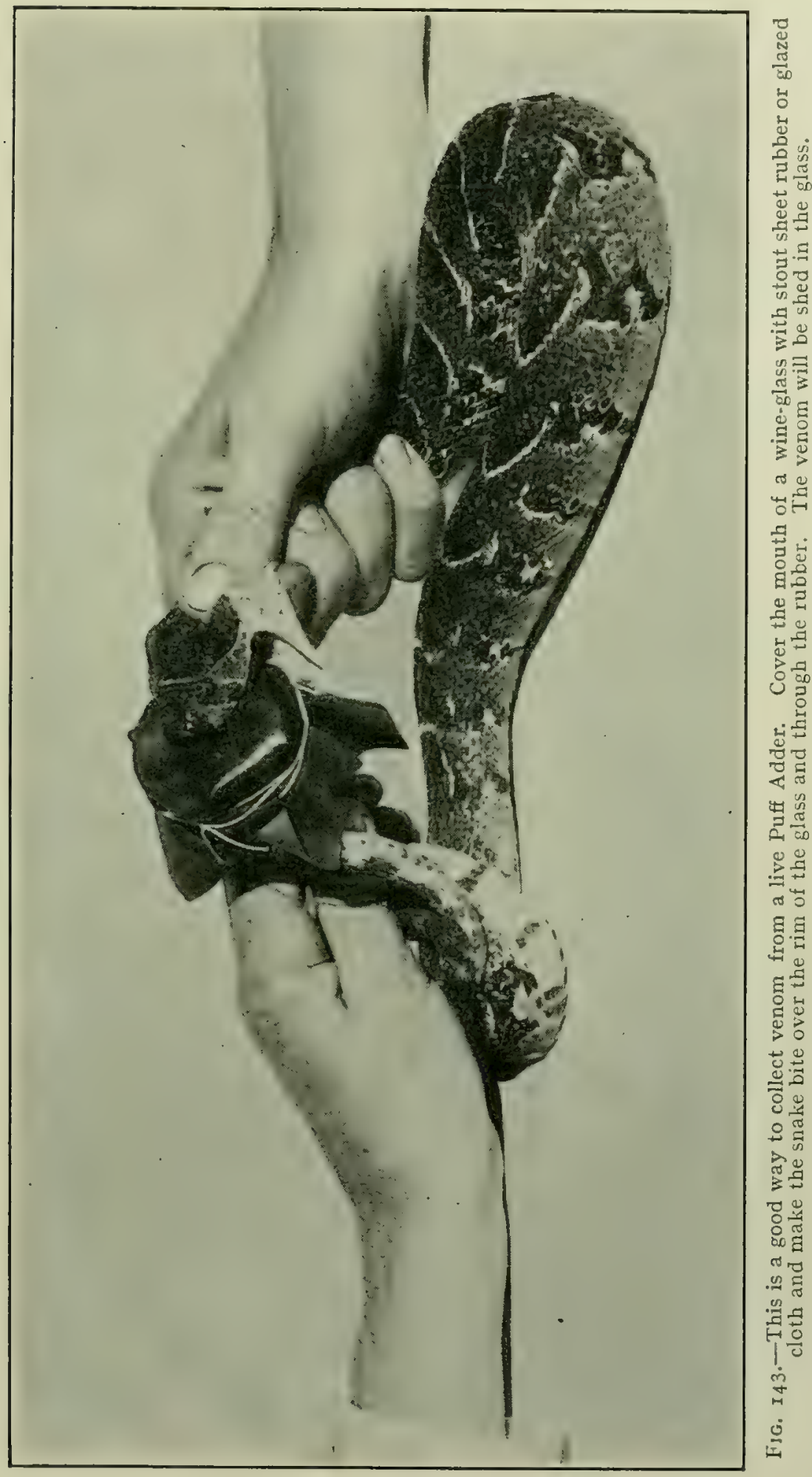


$20^{\circ} \mathrm{C}$. The calcium chloride sucks up the moisture in the air and makes it very dry. Just previous to transferring the dry venom to a bottle for storage, it would be advisable to dry (desiccate) it with calcium chloride. However, in South Africa I have never had occasion to use calcium chloride. The air dries the venom rapidly. Then, if the stopper of the bottle is a good one, the venom will keep dry indefinitely. With Puff Adders and most other Vipers, a wine-glass is better than a watchglass, owing to the long fangs rendering it more or less difficult to operate with so shallow a receptacle as a watch-glass. Moreover, it is much safer.

Another method, which was employed in India by Dr. W. Hanna, M.A., M.B., is explained as follows:-Haring shaken or pulled the snake, be it Cobra or Viper, out of the box to the ground, he allows it to make off, and following, he grasps its tail with his left hand and elevates it, so that the snake is unable to turn upon him-it simply hisses loudly.

He allows it to steady its head on the ground, and while so doing, he gently but firmly places a strong slender stick across its neck, pinning its.head down. He now lowers his left hand and places the tail under his naked left foot, and with the left hand grasps the neck firmly, close to the head, the stick keeping the head steady until he has accomplished his object. By taking the tail in his right hand he has now complete control of the snake. His first object is to take the poison from the snake. After washing the mouth (if mucus or dirt be present) with a fine stream of water from a wash bottle, the snake man, steadying the tail under his toes, compresses the poison glands gently and gradually, with the thumb and forefinger of his right hand. The poison is forced along the ducts, and issues from the mouth in drops; these are received into a clean watch-glass held underneath.

If a snake is freshly killed, the glands may be dissected out and the duct tied. Unless this operation is carefully and gently performed, nearly all the venom will be squeezed out and lost. It is better to remove the skin from the nose, raise the poison ducts with the tip of a penknife, tie them with fine thread, and then proceed to remove the glands. If the poison ducts be tied in this manner, little or no venom will be lost.

If the glands are quickly dried and stored in a well-corked 


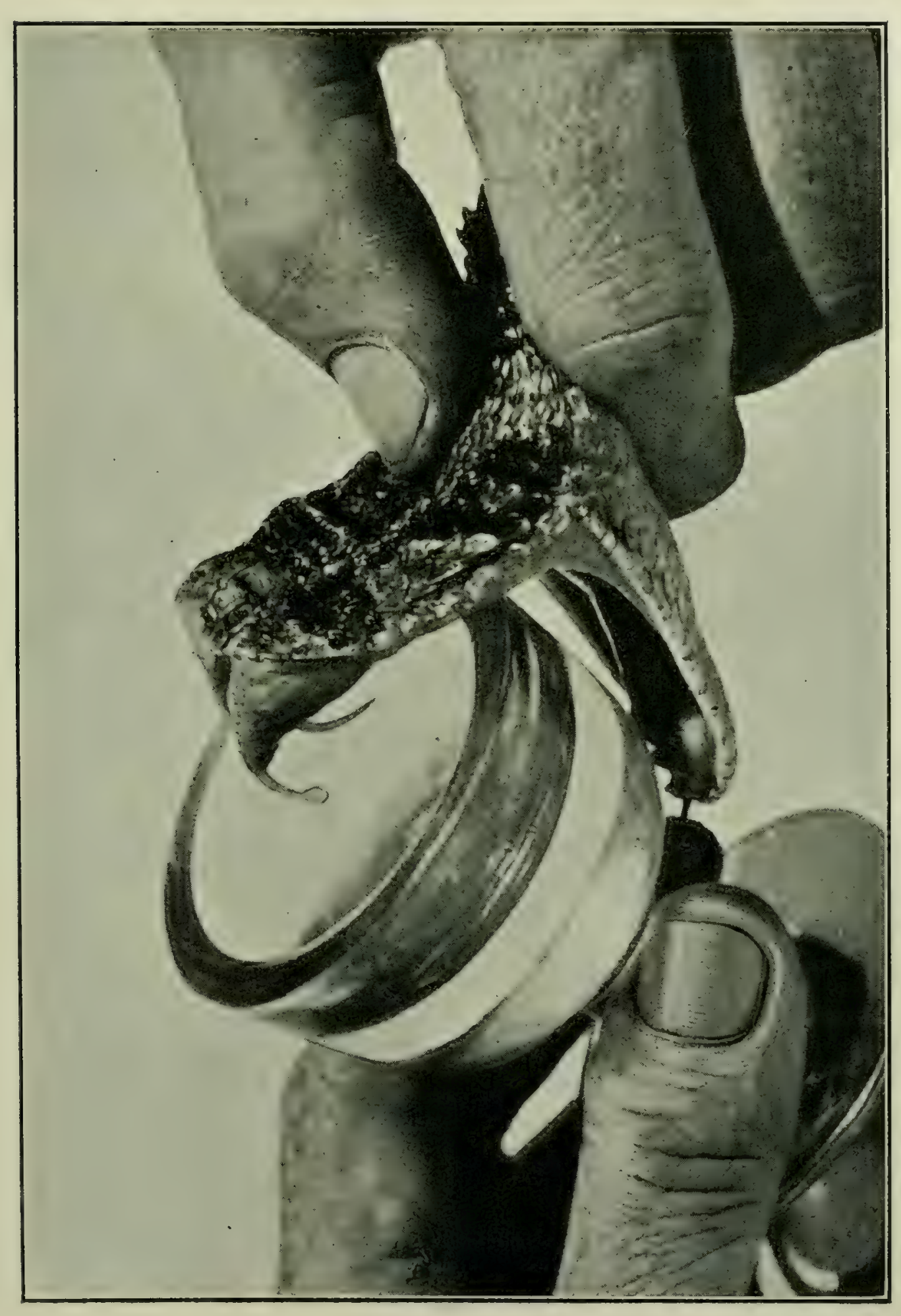

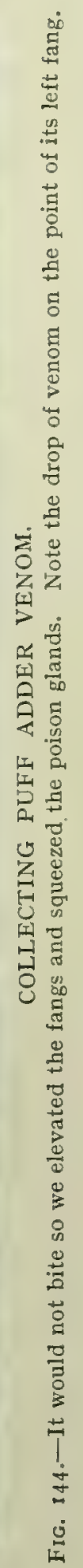


bottle, the dry venom with which they are charged will remain active indefinitely.

The quantity of venom collected at one time from a freshly caught six-foot Cape Cobra varies from six to ten drops-sometimes a little more. When the weather is moist and warm, the glands seem to be most active. A snake, which has been kept in captivity, even for only a few days and which has been handled freely, will not give nearly so much venom as one freshly caught and operated on at once.

The reason is, the latter is in a fierce state of anger and fear. This condition is exceedingly favourable for the rapid secretion and ejection of venom. Snakes, when often handled, become increasingly passive, even refusing to bite under the strongest provocation. I have frequently, with finger and thumb, opened the jaws of snakes and placed them over the rim of the rubbercovered glass, but they persistently refused to bite. The only thing to do in these cases is to elevate the fangs with a bit of pointed wood and compress the head and manipulate the poison glands. Mechanical pressure of the glands is not nearly so successful in expelling the venom as the natural action of the Masseter muscle fibres which wring the glands, when the snake desires to bite. In very large freshly caught Cobras, as much as fifteen drops of venom may be collected within ten minutes by allowing the reptile to retain its hold, meanwhile irritating it now and then by rubbing its nose with a bit of blunt stick. Dr. Hanna mentions having obtained as much as twenty-eight drops of venom from a fresh Indian Cobra. In captivity he found the same species of snakes only yielded from five to ten drops.

I was holding an average-sized Puff Adder by the neck on my table when, with an unexpected tug, it jerked its head free and aimed a blow at my left hand which I succeeded in jerking away in time. The snake's head struck the table with a loud thump and a quantity of venom was ejected upon the glossy American Leather cover. I collected eight drops and calculated that two or three more drops remained which could not be removed from the cloth. The average quantity of venom obtained from a large freshly caught Puff Adder is about ten drops by allowing it to discharge venom voluntarily and by squeezing the glands with the fingers. Puff Adders, after being kept in captivity for 
two or three months, yield an average of four or five drops of venom. Sometimes only a drop or two can be obtained. I have noticed that when a snake makes a full bite on a living animal, usually no poison oozes out of the punctures. The reason is that the venom is driven into the tissues with great force, and at the same time the punctures are plugged by the fangs, consequently the venom spreads out into the tissues around the wounds. This being so, it is desirable, if an attempt is being made to suck out the poison by mouth suction, that the flesh be previously well scarified over the site of the punctures. Of course, while the knife is being got ready, the punctures should be sucked meanwhile, as this retards the absorbing power of the capillary blood vessels and lymphatics, which lie in a thick network under the skin and among the muscles.

Snake venom is slightly acid. Sometimes it is found to be more or less alkaline. This is due to admixture with the secretions of the mouth. Cobra venom is intensely bitter. Viper venom is more or less tasteless. The specific gravity of Cobra venom, according to Martin, averages II'IO ; that of the Daboia (Indian Adder), I0\%7. The amount of solids contained in these two venoms corresponded with the specific gravity-the percentage of solids in Cobra venom averaged $3 \mathrm{r}^{\circ} 5$ and in the poison of the Daboia 24\%. C. J. Martin states that the variations are considerable in the case of the Cobra, being from 23 to 38 per cent. Pure venom, when examined microscopically, reveals nothing. If it be contaminated with the fluids of the snake's mouth, salivary corpuscles, bacteria, and epithelial cells are seen.

Snake venom, if kept in solution with pure glycerine or in a dry condition, will keep indefinitely. Cobra venom, when dry, presents a cracked appearance like gum and looks like little yellowish scales. Viper venom cracks up into needle-like pieces which radiate from the centre of the dry mass of venom. When scraped up it has the appearance of yellow sugar.

Effect of the Venom of one Snake upon other Snakes.

The venom of the Puff Adder apparently has no poisonous effect upon those of its own kind or species. I have frequently forced adult Puff Adders to bite themselves without any illeffects. I have injected Puff Adder venom into others of the 
same species several times without any poisonous symptoms supervening. In three separate instances I collected six drops of venom from fresh Puff Adders and injected it without effect.

Collecting a full charge of venom from an adult Puff Adder, I mixed it with a little water and injected it under the skin of the snake I had drawn it from. It produced no poisonous symptoms. I repeated the experiment with two other Puff Adders, with like results.

Puff Adders occasionally die when bitten by snakes of other species such as the Cobra, Ringhals, Mamba and Boomslang. Extreme internal hæmorrhage occurred in two bitten by a Boomslang. However, it is only now and then that Puff Adders die when bitten by other venomous snakes. I have several times injected Puff Adders with Cape Cobra venom, and in other cases allowed the reptile to inflict a full bite in the tail region. I have injected five drops at a time under the skin of a Puff Adder without poisonous effect. This means that in these cases the Puff Adders withstood enough Cobra venom to kill six or more men.

It will thus be seen that the venom of the Puff Adder is not poisonous to those of its own species, or even if one be allowed to bite itself, or if its venom be collected and injected hypodermically into it. This would seem to indicate that the blood of a Puff Adder should be an antidote to its own venom, and others of its species. Strange to say this is not so. Collecting the venom from a Puff Adder I measured out three drops, and killing the snake, I took half an ounce of its blood and mixed the three drops of venom with it and allowed it to stand five minutes. Stirring it well, I injected it under the skin of the thigh of a fowl. The fowl died in four hours. Other tests ended similarly. Mixing the gall of the same snake with two drops of the venom, I injected it into another fowl. The fowl died in six and a half hours.

\section{Cape Cobras and Ringhals.}

I have demonstrated by repeated experiments that the venom of the Cape Cobra produces inflammation of the tissues and eventual death in those of its own species when the venom is injected under the skin or when another of its own species is allowed to deliver a full bite. Cobras which were forced to bite 
themselves also died, but with adult specimens death did not take place for a week, or even two or three months.

For some considerable time we have kept a large collection of live snakes at the Port Elizabeth Museum. In one cage we had seven Cape Cobras of the yellow and brown varieties. These snakes ranged from four feet to six feet five inches in length. One day they were stirred up by the introduction of a fresh specimen and began to fight fiercely with each other. They were all bitten, some several times. The bites were mostly about the head and neck.

Three lingered for a week and died. One lived a month. The other three survived for nearly four months. During the whole time their heads were swollen and inflamed, particularly in the region of the venom glands. After four weeks the scales were shed from the head and the inflammation increased. The eye scales grew opaque and the reptiles became blind. They remained in this condition till death took place-no new scales forming.

Subsequent experiments conclusively proved that the venom of the Cape Cobra was invariably fatal to those of the same species, causing necrosis and death. Young specimens died within a few hours to a day or two of being bitten or injected. The adults survived for one week to three or even four months. The heads in all cases swelled, the shields were shed and the mouth became inflamed. Usually from two weeks to a month after being bitten or injected, the eye scales became opaque.

I conducted several experiments with the Ringhals Cobra. On four occasions I allowed an adult Ringhals to bite the tail end of another of the same species, after scraping away the scales from the part. I also made two bite themselves and injected one with its own venom. In none of these cases did any poisonous symptoms follow. I also allowed Puff Adders, Boomslangs, and Night Adders to bite Ringhals snakes in the tail region, but in no case did any of them seem the worse.

Being desirous of knowing if the venom of the Ringhals would have any poisonous effect upon non-venomous snakes I made one bite a Mole snake several times, drawing blood. The Ringhals was a large specimen of the black variety. No bad effects followed, although I kept the Mole snake for several months afterwards. 
I once also caused a Puff Adder to bite a Cape Cobra in the tail region. It gave two full bites, driving its fangs deep into the flesh. Care was taken that the bite should be in the muscles between the vent and the tip of the tail, as sometimes the mechanical injury of the large fangs of a Puff Adder will cause death, if the bite should be over the parts containing the vital organs. The bitten snake died the following day. On two subsequent occasions I diluted eight drops of Puff Adder venom with a little pure water. Dividing this mixture into portions I injected it under the skin of two Cape Cobras, each four feet in length. The Cobras showed no symptoms of poisoning and continued to remain in their normal condition during the six weeks they were under observation.

The experiments on non-venomous Mole snakes were somewhat contradictory. Two adult Cape Cobras bit two Mole snakes, each four feet in length. The bites were full ones, being in the muscles of the tail region on spots from which the scales had been removed. The Mole snakes did not develop any symptoms of poisoning.

Taking two more adult Mole snakes I allowed large yellow Cape Cobras to bite them effectually in the tail region. I then made two small incisions and introduced some Cobra venom on the point of a penknife. The Mole snakes died within fifteen hours. One died in twelve hours and the other in fourteen hours. Careful dissection showed no traces of hæmorrhage. Some other experiments followed which showed that sometimes Mole snakes died after being bitten, but more usually they exhibited no symptoms of poisoning.

\section{Non-Venomous Snakes.}

The venom of the Cape Cobra is usually fatal to small snakes of the non-venomous species. Frogs die almost instantly. Toads linger a long time and often make a complete recovery.

Mole snakes as a rule are not affected by the venom of poisonous snakes. If an exceptionally large dose be injected they sometimes die. When six drops of Cobra or Puff Adder venom was injected under the skin on the middle part of the back of the snake it was generally fatal. 
I injected six drops of Puff Adder venom into a large Mole snake, four feet six inches long. The injection was made in the middle part of the back under the skin. The Mole snake survived three days and died. Another lived nine days. If a large dose (six drops) is injected right into the abdominal cavity, it is invariably fatal.

A Mole snake was also bitten by a variegated variety of Boomslang in the muscles of the back a few inches above the tail, on a spot from which the scales had been scraped off. The Boomslang was allowed to hold on for three or four minutes and worry the flesh. The venom shed on the skin was then scraped up and rubbed into a cut in the back of the Mole snake. No poisonous effects followed. 


\section{CHAPTER XII.}

The Scientific Treatment of Snake Bite.

\section{Permanganate of Potash-Results of Experiments- The Serum Treatment.}

Experiments by Doctors Brunton, Fayrer, Rogers, Martin, Lamb, Richards, Lacerda, and other eminent authorities show that perchloride of platinum, chloride of gold, and permanganate of potash are all chemical antidotes to the venom of snakes. It was found that if any one of these three salts was mixed with an equal weight of venom it instantly neutralized it. Permanganate of potash being the cheapest and easiest to apply was selected, carefully tested, and found to have the power of immediately destroying the toxic properties of snake venom. It was found to be equally effective with the venom of a great number of venomous snakes - in fact all kinds of venom. By experimentation I have found it kills the poisonous properties of the venom of all South African snakes, and that of venomous insects. The potash was mixed in equal proportions with various snake venoms and injected direct into the veins and tissues of animals, and no symptoms of poisoning followed. This has been tested on various species of animals by many other experimenters.

In the work on the "Poison of Venomous Snakes," by Doctors Brunton, Rogers, and Fayrer, there is the following interesting account of some experiments by Dr. V. Richards :-

"In the winter of $\mathrm{I} 88 \mathrm{I}$ a number of experiments were made by Dr. Vincent Richards, who found, like the previous experimenters, that Cobra venom was completely destroyed by permanganate of potash when mixed with it in vitro, so that death did not follow the injection of the mixture either hypodermically or into a vein. He found also that when Cobra poison was injected into a dog and the injection made either immediately or after an interval of four minutes into the same part by a hypodermic injection, of a solution of permanganate of potash, no 
symptoms of Cobra poisoning resulted, but after the development of symptoms of Cobra poisoning, permanganate of potash failed to have any effect whether injected locally, into a vein, or both."

These results were also obtained by Lacerda (Couty and Lacerda, Comptes Rendus, Vol. xcii., p. 465), and by Richards.

\section{Persistently Tested.}

Many experimenters at first were very discouraged and inclined to think permanganate of potash was of no practical value, for it was found that when rabbits, pigeons, and fowls were injected with venom and the wounds immediately scarified and permanganate rubbed in, the creatures in most cases died. It must, however, be borne in mind that these species of animals are extremely susceptible to the poison of snakes, and that in these experiments, doses of venom averaging from five to fifty fatal doses had been administered at one injection. Such a comparatively large quantity of venom being introduced caused enough to get into the general circulation to kill these highlysusceptible animals, in spite of the permanganate neutralizing the venom not yet absorbed from the site of the injection. It was noted, however, that the application of the permanganate delayed death in most instances.

Much more satisfactory results were obtained with animals of a higher order whose bodily organizations were more akin to that of human beings, such, for instance, as monkeys, cats, and dogs. Dr. Lauder Brunton and several others found that cats recovered when permanganate was rubbed into the incisions made over the site of the injection, although ten ordinary fatal doses of venom had been given, or in other words enough venom was injected at a dose into each cat to kill ten cats, and when permanganate was applied the animals recovered.

These experiments were carried out extensively, and in all but two or three cases the animals recovered.

In Dr. Brunton's experiments the venom was first injected, a ligature applied, the flesh over the site of the injection deeply scarified, and permanganate rubbed into the tissues. After five minutes the ligature was removed. The animals experimented on received an average of five to ten ordinary fatal doses at a single injection, yet they recovered. 
In experiments which I conducted, the results were more or less similar to the above. I found that in all cases when symptoms of poisoning had started, the local application of permanganate was of no use, a fatal dose of venom having evidently got into the circulation before the application of the permanganate.

\section{A Man Bitten.}

Mr. James Williams, a temporary assistant at the Port Elizabeth Museum, captured a full-sized Berg Adder (Bitis atropos) and brought it to me. In carelessly handling it the snake succeeded in imbedding its fangs in the ball of his forefinger, and gripped with great tenacity and power. He tore it away, and in doing so the fangs slit the flesh, leaving a spurt of venom along the slit. It was evident a good dose of venom had been injected, for the pain was very intense, and the wounds began to grow congested almost immediately. Within five minutes I had ligatured the wound and injected a solution of permanganate of potash into and around the punctures. I then scarified the wounds and forced as much blood out as possible, and in half an hour's time I removed the ligature. The arm swelled somewhat, the glands under the armpit were tender and swollen, and there was slight constitutional disturbance. Within two days all symptoms of poisoning had subsided, and the man was quite well.

On another occasion he and I were artificially feeding some Puff Adders when one got partly loose and made a drive at his hand, imbedding one of its long fangs in the ball of his thumb. Within two minutes I scarified the wound and rubbed in permanganate crystals. A ligature was applied, and as much blood as possible forced out of the wound by manipulating the thumb. Williams then sucked the wound for five minutes, and I removed the ligature. The symptoms of poisoning which followed were slight.

\section{VARIOUS EXPERIMENTS.}

It is quite unnecessary to mention my various experiments in extenso. I found that when permanganate of potash was immediately rubbed into free incisions made over the site of the injection of snake venom, or the direct bites of venomous 
snakes, recovery frequently took place when higher animals were experimented on. Success was in proportion to the quantity of poison injected, the time which had clapsed between the application of the remedy and the time of the injection of the venom. If the potash was applied five minutes or more after the injection of venom, it was unsuccessful, and death always occurred. In every case animals showed absolutely no signs of poisoning when I injected a mixture of venom and permanganate. In many instances I mixed fifty times a fatal dose of Cobra venom with a little permanganate and injected it without any poisonous effect.

The permanganate of potash was found to be useless in the case of highly susceptible animals such as fowls and rabbits, these creatures often dying within five minutes after the entry of the venom into their tissues. On experimentation I found that fowls and rabbits died rapidly if even a very small dose of venom was injected into them-a dose not nearly sufficient to cause death in higher animals. They were particularly susceptible to Cobra, Ringhals, and Boomslang venom, usually dying within ten minutes-sometimes instantly. It was apparent that when these animals were bitten, enough venom was at once taken up into the blood vessels to cause death, hence the reason the potash did not avert a fatal issue.

This can be better realized when it is learned that a Cobra is able to inject a hundred or more fatal doses into a small animal at a single full bite. In experiments on Vervet monkeys and half-grown Baboons with Cape Cobras I found that if a full bite was inflicted, it was useless ligaturing and applying permanganate to the scarified wounds. The reason was that sufficient venom got absorbed to cause death before it was possible to apply any treatment for the purpose of retarding the absorption of the venom, or destroying it in the wound. A full bite is understood to mean when the snake grips like a dog and holds on for a few seconds.

Judging from these experiments, it is reasonable to conclude that if a person be bitten by a venomous snake, and if he rubs permanganate of potash into incisions made over the site of the punctures and a ligature applied within five minutes of the infliction of the bite, and if proper secondary treatment is carried out, he would, in most instances, recover. It must be remembered, 
however, that some people die of blood-poisoning even if an exceedingly small quantity of venom should enter their bodies, particularly if they are of intemperate habits.

\section{COUTY AND LACERDA.}

Drs. Couty and Lacerda carried out a series of experiments with permanganate of potash and snake venom, and found that this salt not only destroyed the poisonous properties of the venom when mixed with it, but also proved an antidote when a one per cent. solution was injected into the tissues at the site of the injection of the snake venom.

They also found that when both permanganate and venom were separately injected into a vein, no symptoms of poisoning followed; but if the venom got a start and had already produced symptoms of poisoning the injection of permanganate into a vein had no curative effect. The same result occurred when venom was injected into the tissues and the salt injected after symptoms of poisoning had begun to manifest. Dr. Vincent Richards' experiments and those of Drs. Fayrer, Brunton, and many others bear out the findings of Couty and Lacerda.

However, it has recently been shown that the injection of solutions of permanganate of potash direct into the veins may cause serious harm if not death, therefore injections of this salt direct into the blood-stream are apparently unsafe.

\section{Three Important Facts.}

Three very important facts to be remembered are: permanganate, if swallowed, has no effect at all upon snake venom which has got into the blood. If injected into a vein after symptoms of poisoning have set in, permanganate of potash has no antidotal effect. If injected or rubbed into the tissues at the site of the wound ten or more minutes after the infliction of the bite, it is of little or no use as an antidote.

\section{Power of Permanganate of Potash.}

A large Cobra, Ringhals, Mamba, or Puff Adder is capable 
of injecting many times a fatal dose if the bite be full and complete, but as I have already pointed out the snake does not always get an opportunity of driving both its fangs right home in to the flesh of a human being.

However, experiments by Dr. Brunton and other well-known investigators have shown that although even ten fatal doses be injected into a cat or monkey, if the wound be instantly scarified, treated with permanganate of potash and ligatured, recovery usually took place. The only conclusion we can arrive at from the results of these experiments and those of a similar nature which I have conducted is, that if a human being be bitten by a venomous snake, and even ten ordinary fatal doses of venom injected, the person would recover if promptly treated with permanganate of potash and ligatures. I cannot, however, claim that the prompt application of permanganate and ligatures always saved the lives of the bitten animals. About sixty per cent. recovered. Those not treated always died. The animals which usually died were those fully bitten by Cobras or injected with fifteen or more fatal doses of their venom.

\section{ABSORPTION OF VENOM.}

It has been asserted that the venom, after injection into the tissues, enters the circulation so rapidly that local applications would be futile. This has been proven to be the case with such animals as forvls, rabbits, and guinea pigs, whose organizations are extremely sensitive to the venom of snakes, but not necessarily so with higher animals, except, of course, when a vein is punctured, or an unusually large dose of venom is injected.

When venom is injected into the tissues, for the first few seconds rapid absorption takes place, owing to the intense irritation of the venom on the walls of the capillary blood vessels and the mouths of the lymphatics.

However, the tissues around the punctures quickly become congested, and absorption of the venom then occurs more slowly. The application of permanganate of potash not only destroys all the venom it actually comes in contact with in the wounds, but owing to its cauterizing action, the power of absorption from the parts thus treated, is practically stopped. 


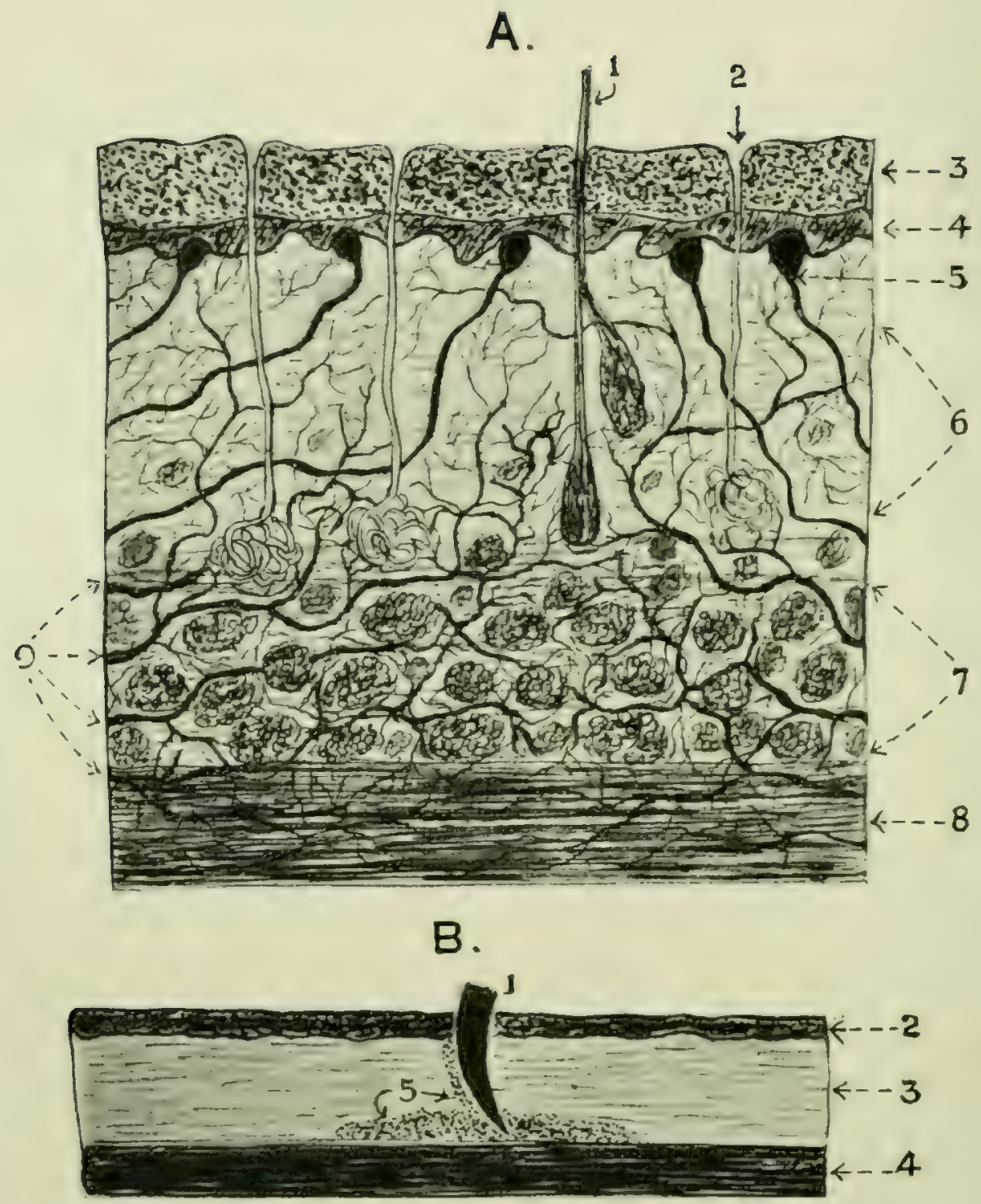

Fig. 145.-A. Section of the human skin, highly magnified.

1. A hair showing its root and oil gland.

2. One of the pores of the skin showing the sweat gland at the end. There are millions of these in the skin.

3. The Epidermis or outer skin in which there are no nerves or blood vessels. It is made of tiny scale-like cells.

4. The Malpighian layer of skin on which lies a layer of cells containing colouring matter or pigment. In coloured folk this is where the pigment lies.

5. 'The nerves of sensation, showing the bulbous end just under the skin.

6. The Dermis or under skin, which is full of tiny blood vessels and absorbent lymphatic vessels. These suck up snake venom when it is injected.

7. Layer of fatty cells which lie under the Dermis, and which also is full of small blood vessels and lymphatics.

8. Muscle or red llesh which lies beneath the skin, and which also is full of blood vessels and lymphatics.

э. Blood vessels and lymphatics which divide and sub-divide, and which suck up snakc venom.

13. I. The fang of a snake.

2. The Epidermis or outer skin.

3. The under skin or Dermis and layer of fatty cells. This is tecming with tiny blood vessels and lymphatic channels.

4. The muscles or red flesh beneath the skin.

5. These tiny dots show where the snake venom is usually lodged when a snake drives its fangs home. The force with which the venom is discharged causes it to spread in the tissues, hence the reason why it is essential to scarify the site of the punctures freely before rubbing in permanganate of potash. 


\section{EXPERIMENTS.}

When venom was injected direct into the veins of animals, death always took place within a few minutes. The animal would often drop dead immediately after the injection. However, if the same quantity was injected into the muscles, death did not usually occur for hours, sometimes days.

These experiments conclusively prove the venom is not all instantly absorbed, as some writers so positively assert.

The experiments of Doctor Brunton and other eminent men have also demonstrated this to be a fact, for it was found that the animals often recovered if the seat of the injection of venom was scarified and permanganate of potash applied within five or ten minutes after the injection of the venom.

\section{A Fact to be Remembered.}

It must be distinctly understood that permanganate of potash is not an antidote. It is of the nature of a "First Aid Treatment." It will destroy any venom it actually comes in contact with if rubbed into incisions made over the site of the bite. It is absolutely useless unless applied immediately after the bite. If the snake's fangs happen to penetrate a vein and the venom be discharged therein, the poison is instantly carried into the general circulation, and local applications of permanganate of potash would be valueless. This permanganate salt should always be carried, so as to be available for first-aid treatment. But " anti-venene" serum should be in the home of every farmer, so that a cure may be available. The permanganate of potash should not be relied on too much. It is practically useless as a treatment for snake bite in domestic animals, for it is seldom an animal is seen to be bitten. The first indication which causes suspicion of snake bite is local swelling, trembling, and exhaustion. If serum be at hand and the animal injected freely with it, its life would be saved, even many hours after the infliction of the bite. Unless, of course, the damage done to the nerve centres and blood is too great to make recovery possible.

In scarifying the site of the bite the incisions should be made freely, because the venom is injected so forcibly, that it often spreads out under the skin for about half an inch around the site of the fang punctures. Then again, a snake may, when 
biting, drag the loose skin of the bitten part so much that most of the venom will be shed perhaps half an inch from the site of the punctures. So, to guard against these eventualities, be careful always to scarify freely so that the permanganate will come into contact with all the venom.

\section{The Serum Treatment for Snake Bite. Results of SCIENTIFIC EXPERIMENTATION.}

Failing to find any antidote to snake bite amongst known medicines, either vegetable or mineral, men of science began investigations in another direction. Quite independent of each other, Doctors Fayrer and Calmette conducted a series of experiments with snake venom.

Animals, preferably horses, were injected with minute doses of Cobra venom, and on the symptoms of poisoning subsiding, a larger dose would be injected. This immunizing process was carried on from one to two years, the dosage being progressively increased until 50 to 200 fatal doses could be injected at one dose without any apparent harmful effect. Some of the blood of the horses was then withdrawn, the serum separated and injected into animals bitten by snakes of the same species to the venom of which the horses had been rendered immune. The effect was magical, for almost instantly the venom was neutralized, the symptoms subsided, and the animals recovered.

It is well known in medical science that any poison, however potent, if taken into the human body in carefully graduated doses, confers a peculiar mysterious tolerance to that particular poison. The same holds good with all medicinal substances. After repeated dosage the ordinary prescribed quantities fail to have the desired effect. An acquaintance of mine was a victim of the opium habit, and took sufficient opium in the course of the day to kill twenty men not accustomed to its use. Inveterate smokers will take into their bodies daily sufficient nicotine and other tobacco poisons to kill off half a dozen nonsmokers. Naturally, however, if poisonous drugs be persistently introduced into the body, they, in time, will shatter the toughest constitution. Two drops of the oil from a tobacco pipe placed upon a dog's tongue will kill it within one minute. A few specks of strychnine will have the same effect. Tobacco oil 
(nicotine) from a pipe stem will, if a small quantity be placed in a snake's mouth, instantly paralyze it. It grows utterly limp and ceases to breathe, but sometimes revives in about an hour's time. This fact should be remembered by collectors.

\section{Rendering Animals Immune.}

The following extract, written by Dr. J. G. McPherson on Dr. Fraser's experiments with the immunization of animals, will give an idea of the process of rendering animals immune to the bites of snakes:- "Having ascertained the minimum dose required to cause the death of an animal, he started below that amount and gradually increased the dose after intervals of ten days. By this process of gradual increases in the dose of snake poison, he found the animal receiving as much at one time as fifty times the amount of the miniraum lethal (fatal) dose, without it causing any perceptible bad effects. In the meantime, Professor Fraser has not carried his experiments of quantity further than fifty times a fatal dose at one time; but still when he had got to that point the animal was receiving in a single dose without being affected, enough venom to kill fifty animals of the same size and weight. One of the animals which he had treated by this gradual increasing quantity had in two months received enough poison to kill 370 animals of equal size and weight, supposing that each just got the minimum fatal dose $\mathrm{He}$ then described a second series of experiments in which he used the blood serum of these animals which had been immunized, as an antidote for the venom. He mixed an equal part of this blood serum and venom together, and injected the mixture into a fresh animal. This produced no poisonous effect, the serum counteracting the toxic properties of the venom. Next he injected some of the immunized blood serum, which he has named 'anti-venene,' into a fresh animal, and then some venom afterwards, but the serum hindered any action of the venom.

"Then he took another fresh animal and injected venom, waiting till symptoms of poisoning were manifest; at once he injected his anti-venene, and put a stop to any further action of the poison. All this points to the conclusion that the blood serum of an animal that has been able to stand fifty fatal doses 
with impunity at a time by the increasing dose process, is really an antidote to the poison of snakes."

However, subsequent experiments have shown that this antivenene is a perfect antidote only to the venom of the species of snake to which the animal was rendered immune.

\section{VENOMS DIFFER IN THEIR ACTION.}

The venom of every species of poisonous snake, as has already been pointed out, is different in its composition, although its various parts cannot be chemically separated as efficiently as we would wish.

We have, however, abundant evidence of this fact by extensive observations of the effects of the different venoms on animals. In Australia a professional snake-catcher rendered himself immune to the bite of a common highly venomous snake, and in the presence of men of science allowed himself to be bitten repeatedly. No poisonous symptoms supervened, although the bite from this particular species of snake would, in most cases, cause rapid death in any one not immunized.

This man acting under the impression that in consequence he was immune to the venom of other species of snakes, once carelessly handled a Denisonia superba, but was bitten, and died the following day.

\section{How to BECOME Immune.}

A man can, with patience, render himself immune to the bites of venomous snakes. For instance, if he desires to be immune from the venom of a Puff Adder and Cape Cobra, it would be necessary for him to inject under his skin an exceedingly small dose (the fraction of a drop) of the mixed venoms of these two snakes, and after the lapse of a fortnight or longer, inject a slightly larger quantity, and continue the process every two weeks with increasingly large doses, until he is able to tolerate enough venom at a dose as would kill half a dozen men. The operation would, however, be very tedious and prolonged, and would have to be repeated over again with the venom of other species of venomous South African Snakes if he desired to be quite immune to the venoms of them all. If, however, a man was immune to the venom of the two typical representatives of the great snake families, viz. the Cobra and Puff Adder (Colubrine and 
Viperine), he would not be likely to die if bitten by any other species of South African venomous snake. Such experiments are fraught with danger, for if the individual be in the habit of drinking alcohol, or if, through over-eating or indulgence in a too free meat diet, his blood should be in an inflammatory and impure condition, then blood poison would as likely as not set in at the point of the injection, and if death did not occur, sloughing of the flesh, more or less extensive, would supervene.

\section{VARIETY OF VENOMS.}

The venoms of many of the Indian, Australian, American and African snakes differ widely in their poisoning properties, and therefore it is clear that the serum treatment of snake bite is beset with many difficulties. However, if the authorities in each of these countries set themselves in real earnest to immunize animals to the venom of the most poisonous of the snakes of the country, a first-class serum of high anti-toxic power could be prepared and sold to the public. The greatest difficulty seems to be the collection of sufficient venom for the purpose.

\section{HyPER-SENSIBILITY.}

A remarkable and mystifying fact in the immunizing of animals against snake bite by the injection of graduated doses of venom is, that when an animal becomes highly immune and is able to tolerate a very great number of ordinarily fatal doses without showing any symptoms of poisoning, this high degree of immunity often becomes suddenly reversed, and a condition of extreme sensitiveness (hyper-sensibility) to snake venom sets in, and the animal will succumb even to a very small quantity of venom.

There seems to be a point beyond which tolerance to any poison cannot go, and some sudden physiological change takes place, doubtless in the cells of the brain, the nerves, and the constituents of the blood, making the body susceptible to the toxic action of only a small quantity of the poison to which the system was hitherto immune, even when given in very large doses.

It is ever thus in scientific research, when one mystery is solved others arise, and so it will be to the end. 


\section{Collapse through Fear.}

A case came under my observation of a native woman who was bitten on the calf of the leg by a large Mole Snake (Psendaspis cana) which she took to be a Cobra. Now, in spite of the fact of the Mole Snake being quite harmless, the woman rapidly collapsed, and much alarm was expressed at her condition. I was called and found her in a condition of nervous collapse, the circulation sluggish, pulse feeble and heart's action dangerously slow. Her skin felt cold and clammy, and she shivered. Glancing at the snake which had bitten her, and which her friends had subsequently killed, I realized at once it was a case of shock due to fear. Mixing a little permanganate with water, I made her drink it, and told her it would positively cure her within a few minutes. I repeated the suggestion several times that she was "getting better, much better." In ten minutes' time she was on her feet, declaring she was quite cured, and marvelling at the magical powers of the " antidote" I had given her. Next day I found myself to be an "Inkos m'kulu" (Big Chief) amongst her tribe.

Another case occurred of a European woman who was bitten on the hand by a slightly venomous snake, and it was doubtful if the little grooved back teeth had even scratched the skin, However, she showed alarming symptoms of nervous collapse, and was dosed by her friends with brandy till she was senseless. She fortunately recovered from the alcoholic poisoning after two weeks of severe gastric inflammation, due to the action of the strong spirit on the delicate mucous lining of her stomach.

\section{Why PeOple Recover.}

During the hottest season of the year the venom of snakes reaches its highest degree of virulence, waning in toxic power and quantity as the chilly weather approaches.

Full-grown snakes are naturally more likely to inflict a fatal bite than young specimens. The venom of snakes in good vigorous health is far more poisonous and abundant than of those in poor condition. The venoms of different species of snakes vary considerably in toxic power, a full and complete bite of some species would rarely cause death in a healthy man, whilst such a bite given by a Cobra, Ringhals, Mamba. or Puff 
Adder would mean certain death, if prompt and energetic treatment was not resorted to. In striking at the clothed leg of a man, a good deal of the venom is usually arrested by the clothing, which also prevents the fangs being driven fully home. This is especially so with the Cobras and Mambas which have comparatively short grooved fangs. In other cases only one fang penetrates the flesh, or perchance the skin is only scratched. It will thus be seen that even if no treatment be applied a large percentage of cases would recover.

\section{FitzSimons' Snake Bite Outfit.}

I have found from long experience that the vast majority of people, other than medical men and veterinary surgeons, do not know how to handle a serum syringe, and regard the process of injecting serum as quite beyond them. They seem to be nervous and lack confidence in themselves, even after the process has been carefully explained, unless it be done by actual demonstrations or carefully prepared illustrations, accompanied by simplyworded instructions.

During my lecturing tours, many a farmer has shown me a bottle of anti-venomous serum which he has treasured up for years, and in many cases had no syringe at all, or perhaps produced a large rusty veterinary syringe, or a small ordinary hypodermic one.

Twenty years of such experiences have convinced me that to make the serum treatment for snake bite of real practical, lasting value to the general public, and especially to the farming community, it is essential that a thoroughly effective and complete outfit be available. As there is no really efficient serum outfit for the treatment of snake bite known to me, I have patented a complete first aid and serum treatment outfit, with an illustrated booklet of instructions which any child can understand.*

\section{Anti-Venomous Serum.}

Anti-venene, anti-venom, and anti-venomous serum are all one and the same substance.

* See advertisement of "FitzSimons" Snake Bite Outfit," by the distributing agent, at the end of this book. 
Of course anti-venomous serum has its limitations. It will not perform miracles. It has the power of neutralizing the poisonous properties of snake venom if mixed with the poison in sufficient quantity. If injected into the blood it will destroy the poisonous properties of the venom therein, in proportion to the amount injected.

Now, it is quite apparent that if the nerve centres have been poisoned and benumbed beyond the possibility of recovery, or if the blood corpuscles be broken up, and extensive hemorrhage into the tissues has taken place, the injection of anti-venene would be useless. However, it is practically impossible to know for certain if the venom has acted upon the nervous system, brain and blood, sufficiently to make death a certainty, therefore while life remains the anti-venene should be injected.

In all cases where serious symptoms of poisoning have developed, the anti-venene should be injected direct into a vein so that it may enter the circulation with the least possible delay, for at such a critical time every moment is precious. When life's forces are slowing down, the absorbent or sucking-up power of the small blood vessels (capillaries) and lymphatics is sluggish, and in some cases suspended.

If the fangs of a venomous snake should puncture a vein and venom be discharged therein, the poisonous effects are so rapid that death takes place in spite of the injection of antivenene. In fact in these cases the patient is usually dead before the serum can be injected, even if it be at hand. Fortunately such cases are not common.

Anti-venene, if injected, will render a man more or less immune to snake bite for several days. Its antidotal power, however, grows less daily. In no case does it confer any degree of immunity for more than three weeks. Hunters and others who are about to run grave risk of snake bite, would do well to inject themselves previously with a dose or two of anti-venene. Sometimes a sort of nettle rash appears about the sites of the injections. This, however, need occasion no alarm. It will pass off in a few days.

Anti-venene is a watery fluid, and when injected, is absorbed and mingles with the natural serum of the blood. Many have expressed fear lest its injection might do harm if introduced 
into a person and it happened that the snake which bit him was a harmless one. It does no harm at all.

Iany also imagine that so large a quantity of serum as a dose of 25 c.c., viz. $\frac{7}{8}$ ounce, cannot possibly get absorbed into the blood from under the skin. On the contrary, large quantities of fluids are capable of absorption into the blood in this way. In serious cases of poisoning by acids when the stomach is so severely burned as to make it impossible for the patient to swallow, water is injected under the skin. Instances are on record in medical literature of as much as four pints of water being absorbed in this way in a day.

\section{Penny Wise and Pound Foolish.}

I would strongly advise that in all cases of snake bite when even slight poisonous symptoms have manifested, that at least two doses of anti-venene serum of Io c.c. each or one dose of 25 c.c. be injected in several places under the skin of the arms and legs, or better still direct into a vein. It is always preferable to err on the right side. An extra dose or two will frequently turn the scale from otherwise certain death to life and health.

The lack of intelligence of some people is really surprising. Rather than expend a few shillings on a reliable remedy for snake bite, they trust to the most absurd methods of treatment, or pin their faith to some worthless popular proprietary " cure," or a mysterious Kafir mixture. Others are content to stock a single dose of serum, trusting to luck that it will effect a cure. Some foolishly rely entirely upon the local application of permanganate of potash and ligatures.

20 or 25 c.c., at least, of anti-venene and a serum syringe should be in the home of every country resident, and others whose occupations take them where there is risk of being bitten by a venomous snake. In fact, all who can afford it should have as much again handy, and when a case of snake bite occurs, inject a dose, direct into a vein for preference, and then carefully watch the effects. If the patient seems to be growing worse, inject the second dose, then if it be possible for him to recover, he will soon begin to rally. 
The serum should be kept in a cool dark place-the cooler and darker the better. It should be examined every now and again, and if the fluid be observed to be getting increasingly milky or opaque in appearance, it is a certain sign that it is going bad. It must then be thrown away as it is useless, and a fresh supply obtained. If kept cool and in a dark place, it ought to keep good for several years. I have had a bottle for five years, and it is still in good condition.

When kept for some time and not moved, a slight flaky sediment forms at the bottom of the bottle. This is not a sign of deterioration. The sediment will readily re-dissolve if the bottle be shaken. If the cork be withdrawn or tampered with in any way the content of the bottle must be thrown away as it will not keep if air gets to it, for it contains no chemical preservatives.

The anti-venene is sterilized and, provided no bacteria gain entry, there is no reason why it should not keep indefinitely. But, although it may not actually go bad, there is every reason to believe it deteriorates in strength the longer it is kept, as is the case with the anti-toxin serums in use in the treatment of various diseases. The fresher the anti-venene is the better, therefore it is advisable to obtain a fresh supply every eighteen months or two years. If the previous supply should still appear to be sotiud, then do not throw it away. Keep it also for use, as you cannot have too much of it. You may need three or four doses at any time. A valuable human life, or stock costing large sums of money, may be saved by a liberal injection of the antivenene, even if bitten fully by the deadliest South African serpent.

Valuable stock, and a considerable number of human lives are annually lost in South Africa, from snake bite. It is therefore a necessity to have some means at hand by which this mortality may be checked. Hardly a farmer in the country has not had scrious losses in stock from the bites of venomous snakes.

The universal faith in one or more of the many popular, so-called cures, prevents reliable measures being taken to combat the effects of snake venom. Elsewhere in this volume the results of experiments with most of those remedies have been given. He who pins his faith to any of them is unwise. His 
faith is misplaced in spite of apparent recoveries from snake bite after the administration of one or other of these " cures."

\section{The Serum Treatment and its Limitations.}

The serum treatment for snake bite is yet in its infancy. Many difficulties beset the path of the scientific investigator. The main obstacle is the difficulty of obtaining sufficient venom, and the extreme care which is required to be exercised in the process of rendering animals immune. Even with the greatest care, the horses and mules which are usually used as subjects do not survive the ordeal. At other times frightful ulcers form at the seat of the injection of venom, and frequently the flesh sloughs away more or less extensively. The aim is to make the animal immune to as large a dosage of the mixed venoms of various species of snakes as possible.

For instance, the serum from a horse which has been rendered immune to a hundred ordinarily fatal doses of venom is twice as strong in its venom-killing powers as the serum from a horse which is immune to fifty ordinarily fatal doses of venom. Every year progress is made, and there can be little doubt that before long a better method of immunizing animals will be discovered, and a much stronger anti-venom serum will be prepared.

The anti-venene now prepared is the only substance which is of any value in destroying snake venom after it has entered the blood circulation. The more copiously it is injected the better chance there will be of recovery. If the venom has begun its onslaught upon the nerve centres or blood, or both, liberal quantities of serum will need to be injected to overtake and neutralize its death-dealing powers. I would advise medical practitioners to inject not less than 25 c.c. direct into a vein if symptoms of poisoning have already set in, and to inject a second dose after an interval. Those, other than medical men, should carefully practise injecting water into dead animals' veins and under the skin, so that they may know exactly what to do and how to do it should occasion arise. A dead plucked fowl is a good subject to practise upon. If a little permanganate is added to the water previous to injection under the skin, it 
will prove a good object-lesson in showing just how the scrum would spread, if injected.

Knowledge makes a man confident. It is the lack of knowing just what to do when faced with an emergency that makes him "lose his head."

Anti-venene serum is the only substance for secondary treatment recommended by science as possessing curative value in cases of snake bite, and which can be injected under the skin without any risk. There is an element of risk in injecting it direct into a vein. This will be explained later.

If bitten by an unknown snake, it is advisable to inject a dose of serum if any be at hand. It will do no harm if the snake should happen to be a harmless one, and will serve the purpose of allaying the nervous dread of the bitten person. It is at times difficult to distinguish the symptoms produced by nerve-shock exhibited by most people bitten by snakes, and the real symptoms of snake venom poisoning, especially that of the Cobra which acts mainly upon the nervous system.

\section{The Treatment of Snake Bite.}

\section{What to do if bitten.}

The most practical thing to do if bitten by a snake is to prevent the absorption of the venom into the general circulation. If a large dose of venom should get into the body it will be pumped by the heart to the remotest parts. So we must immediately attack the venom at the spot where it has been injected.

There is very little chance of preventing at least some of the venom getting into the blood circulation, but that will not matter provided a fatal dose has not been absorbed. Every moment is precious, as the venom after its injection under the skin is being greedily sucked up through the walls of the tiny blood vessels and absorbent lymphatic channels.

Knowing that permanganate of potash destroys any venom it may actually come in contact with, it is presumed you will have some at hand. A sharp penknife and a small tube or pill-box full of permanganate should be carried by everybody who runs any risk of snake bite. In a country like that of South 
Africa every country resident should have some permanganate and a penknife upon his person. Then, if he or any of his native labourers, or stock should get bitten by a snake, curative measures can be promptly taken. Brunton's First Aid instrument is usually carried. This, however, is not a satisfactory instrument for the reason that with the lancet the punctures cannot be deeply and freely scarified without using undue force, which is likely to snap the lancet or make unsatisfactory cuts. Secondly, the permanganate is apt to be spilled and lost at the critical moment by unscrewing the wrong end in error, or bungling when removing the capsule. For bites by long-fanged snakes, the lancet is of small practical value. To meet the need, I have patented an instrument which has a sharp folding blade with a receptacle in the handle for the permanganate. This instrument, being of the nature of a small ordinary penknife, can be carried in the waistcoat pocket and can be utilized as a

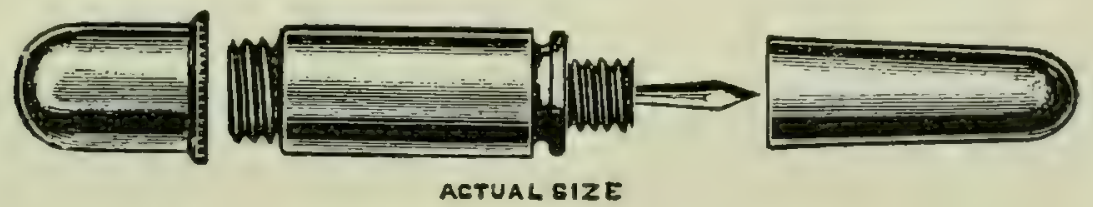

FIG. I46.-Brunton's " First Aid " instrument.

penknife, with the additional advantage of having the permanganate included in case of emergency. This instrument is supplied with "FitzSimons' Outfit" already referred to, or separately if desired.

We will presume that you have been bitten upon the leg a few inches above the ankle. Without one instant's delay, make three or four cuts about a quarter of an inch deep, and half to three-quarters of an inch long, over each fang puncture. There can be no difficulty in finding it, for there will be considerable smarting, and the punctures will be slightly discoloured. If the bite be actually on the muscles, then cross cuts should be made in addition to the others, as no harm can very well be done. When, however, the bite is upon the back of the hand, wrist, or front surface of the foot, cross cuts should never be made, or you will probably sever one or more sinews and cripple the hand or foot permanently.

Open the incisions with your fingers and fill the wounds 
with permanganate crystals and rub them vigorously in. A grood plan is to spit on the hollow palm of your hand, pour some permanganate crystals into the fluid, work it into a paste and then rub it into the wounds. If a friend be at hand he must be, meanwhile, applying a ligature, or else you can be doing this while he attends to the scarifying and permanganate application. The ligature must be applied between the wound and the heart at a spot best calculated to compress the blood vessels (veins) and lymphatics. If bitten; on the foot or ankle-region, a ligature just above the knee is best. If on the forearm or hand,

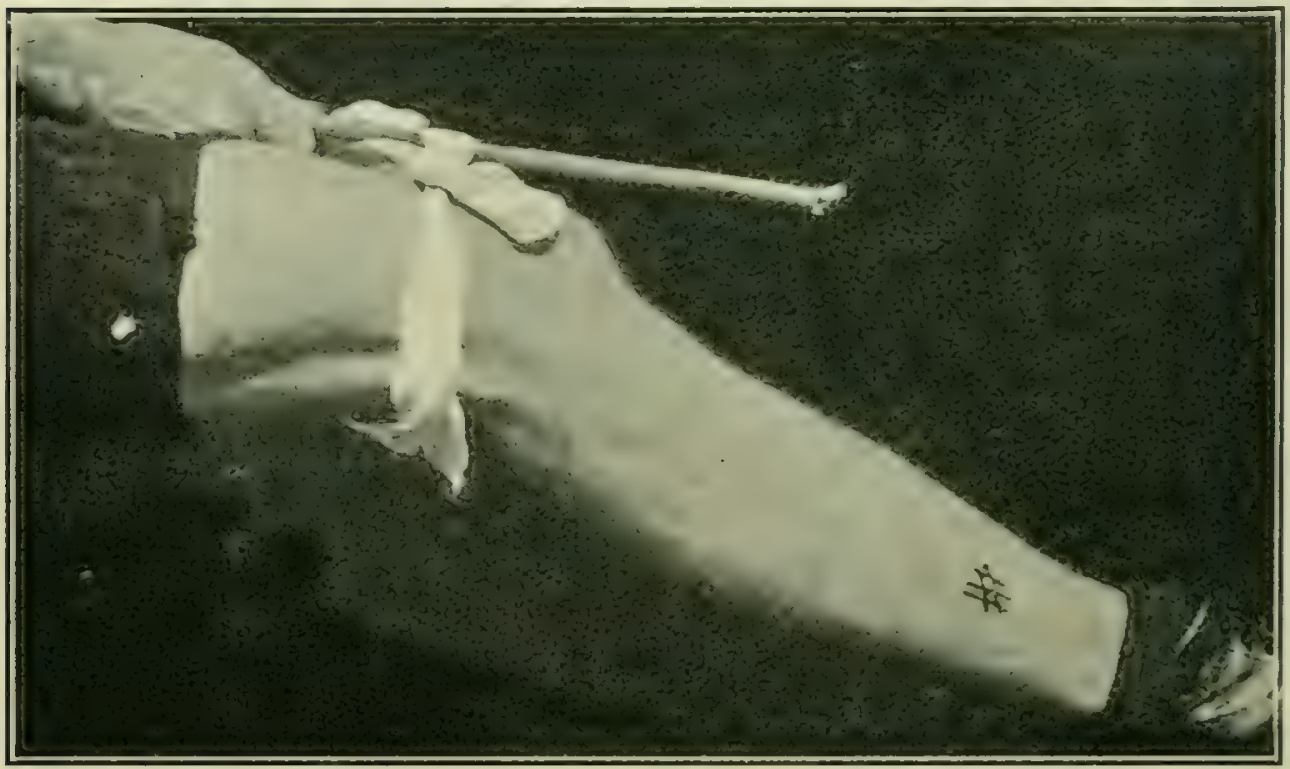

FIG. 147 . The ligature is best applicd above the knee, because there is only one bone, consequently the pressure is more uniform all round the leg. The black crossed lines above the sock are the incisions over the site of the fang punctures.

apply the ligature above the elbow joint. To tighten the ligature, a strong twig, a lead pencil, or a broken walking-stick, should be inserted in a loop in the ligature and twisted up as tightly as the patient is able to bear it. Tie the stick against the leg or arm as the case may be, to prevent it reversing itself after you let it go. If a syringe be handy, a teaspoonful of solution of permanganate with water may be injected obliquely under the skin over the site of the fang punctures.

It is a doubtful point whether the scarifying and application of the potash, or the ligature should be applied first. If the permanganate can be applied almost instantly, then it is preferable 
to scarify and apply it first. If there is any delay, or if no crystals be at hand, then instantly affix the ligature. A good plan is to jerk out your handkerchief and tie it as tightly as you can with your hands, and then scarify the punctures and apply your potash. Afterwards the ligature can be tightened to a greater degree by the insertion of a stick.

If a friend is at hand, then both operations may be carried out simultaneously.

As a general rule, if a ligature can be applied within a minute

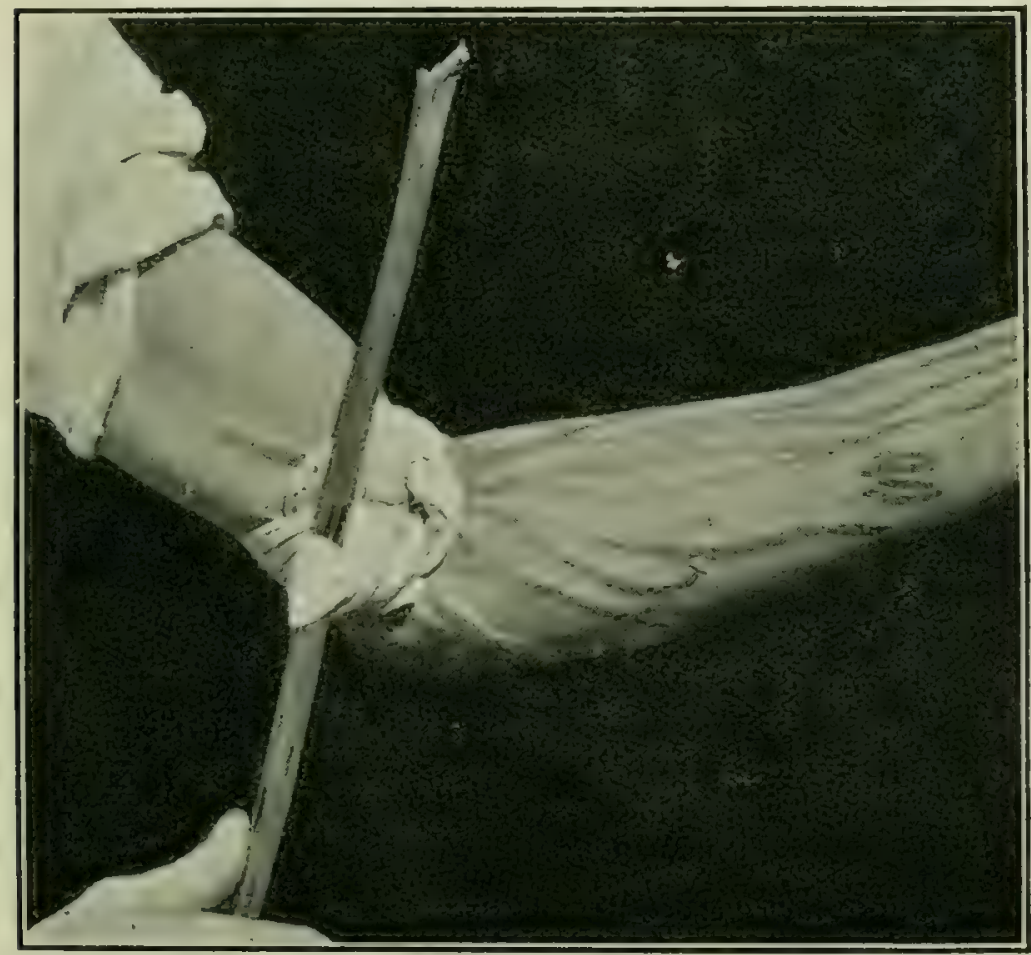

Fig. I 48. - If bitten by a snake between the wrist and elbow apply a ligature as shown here. If on the hand apply an additional ligature on the wrist, or at the base of a finger if one should be bitten. The long dark lines show the course of the larger veins under the skin. The short dark lines indicate the site of the bite.

of the infliction of the bite, it is best to affix it first, then apply the potash as soon after as possible. Everything depends upon expertness and promptness.

After the permanganate has been applied, and the limb ligatured, press and rub the parts about the incisions with the fingers, with a view of forcing out as much blood as possible. The severing of two or three small veins in the ligatured member, helps to get rid of the poisoned blood. If there should be no 


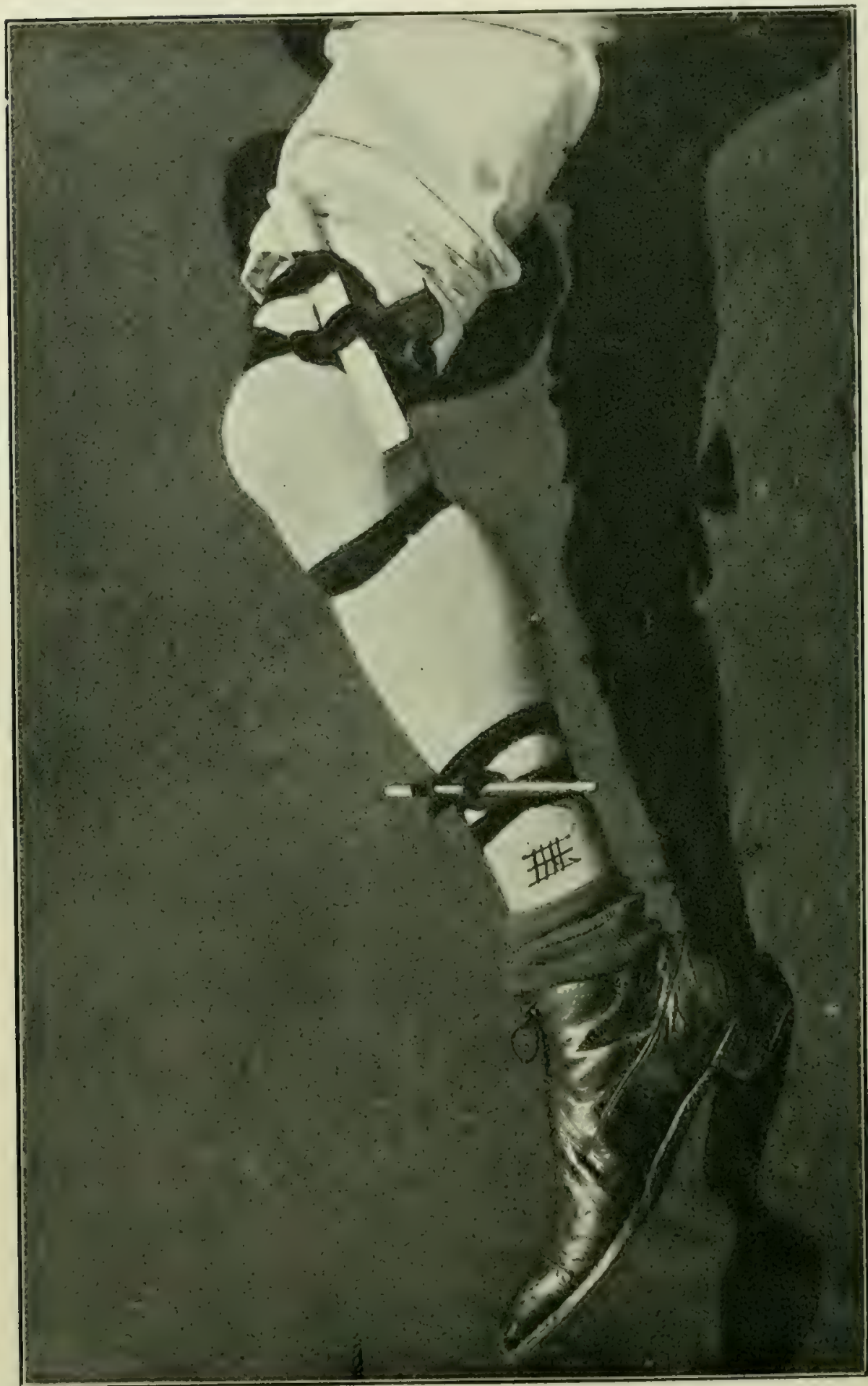

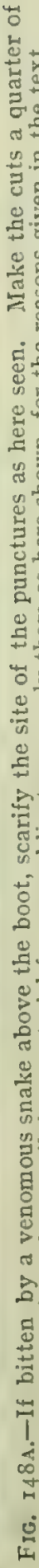


permanganate at hand, apply a ligature instantly, and scarify the site of the bite. If there are no cuts, abrasions or ulcers in the mouth or on the lips, the wound can be safely sucked. If the part bitten be laid open and well cauterized by flashing gunpowder in the wound, some of the venom may thus be destroyed. This, however, is useless unless done within five to ten minutes of the infliction of the bite. Ammonia and tobacco juice are useless, - the latter is dangerous.

There is no possibility of bleeding to death if any of the surface veins are severed. The veins are the blood vessels which carry the venous blood to the heart. The blood moves along sluggishly in them. On the contrary, the blood in the arteries courses along at a great rate, and if one of these vessels be cut, the blood squirts out powerfully in jets. Nature, however,

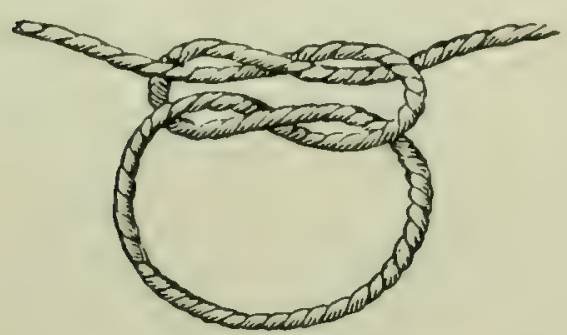

SQUARE KNOT

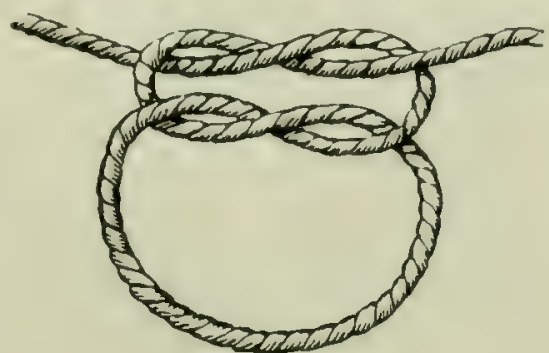

Granny Knot

FIG. I49.- When you tie a knot do not make a Granny Knot, or else it will be sure to slip and come loose. Tie the Square Knot like this. The harder it is pulled the tighter it will get. It cannot slip.

has carefully guarded these important blood-vessels from injury by burying them deep in the tissues. The only places where arteries come near the surface are where they pass over the ankles and skull. The blue lines just under the skin are all veins. In the ligatured limb they will stand out like cords. Select two or three of those which apparently lead from the vicinity of the bite, and make small longitudinal incisions in them. Never cut them across. Cut along the course of the vein. By bleeding the ligatured limb, some of the poison will be got rid of. A vein, unless a very large one, will usually stop bleeding itself after a time. If not, then place a little hard pad over the bleeding part and bind it down tightly.

Elevating the limb will often stop the bleeding, or sewing up the wound with two or three fine stitches.

If a snake should inflict a bite upon the face, head, neck or 
trunk, scarify the punctures freely to make as much blood as possible flow out, and then apply permanganate of potash. If a friend be at hand, get him to suck the wound if no permanganate be available. Before sucking, the punctures should be scarified to facilitate the withdrawal of the venom.

Bear in mind, especially, that there is grave danger of mortification of the limb setting in, if a ligature is left on 100 long. After half an hour, or as soon as you have applied potash and bled the limb, slacken the ligature very slightly for just one instant, and tighten up again. Repeat this operation every five minutes or so for half an hour to an hour. The object of this is to allow only a small quantity of the poisoned blood at a time into the body and thus give Nature's resistant forces a chance to cope with, overcome, and expel the poison before a fresh supply enters. Should there be a good deal of venom in the blood of the ligatured limb, it is obvious that if allowed all at once to rush into the body, it would be likely to overcome Nature's resistance and cause death.

About a yard of strong rubber of about the calibre of a lead pencil makes a splendid ligature, as, then a stick can be dispensed with. The rubber grips the flesh uniformly all round the limb, and if twisted round a couple or more times as tightly as possible, its constricting power would be very great.

\section{More Remarks on Ligaturing.}

In Figs. I47 and I48 it will be observed only one ligature is applied. This, as a general rule, is sufficient, but if enough material is at hand to convert into several ligatures, it is desirable to be more thorough, and apply ligatures as shown in the accompanying illustrations. When a snake bites, it injects venom into the muscular tisue. In the case of the Puff Adder the fangs may penetrate about half an inch. In these cases it will be necessary to scarify the punctures to that depth. As a general rule, it is advisable to make the cuts about a quarter of an inch deep. The venom often spreads out in the tissues, hence the necessity of freely cutting the site of the bite so that the permanganate of potash, when rubbed in, may reach all the venom, or most of it. Now, when snake venom is injected into the tissues it is rapidly sucked up by millions of tiny blood-vessels 


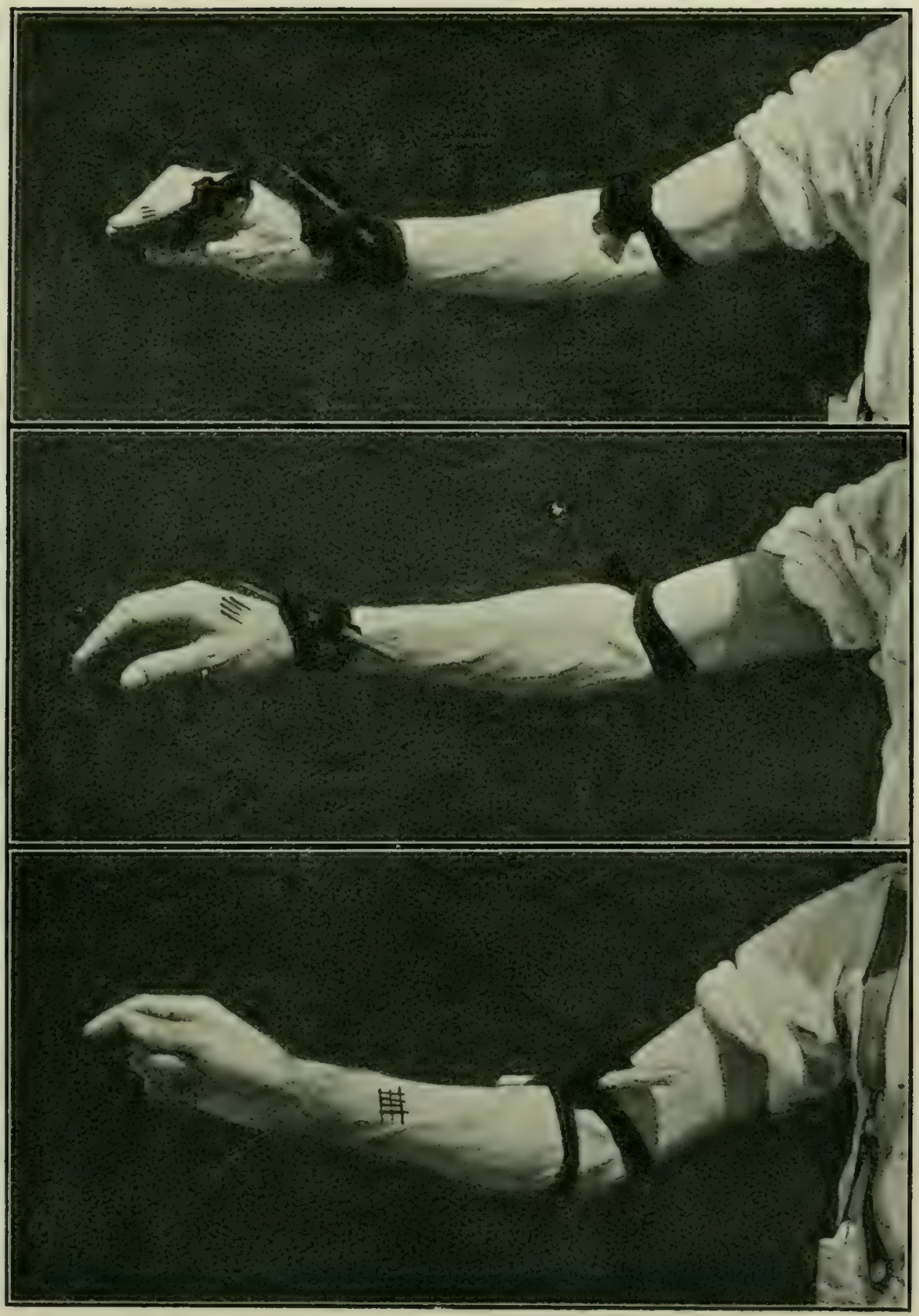

FiG. I49A.-If bitten by a venomous snake on the fingerscarify the site of the punctures as here shown, not across the finger lest you sever the sinews. The same applies to the second illustration. In the third, the bite is on the muscles of the forearm. In this case the cuts may be criss-crossed. The reasons why more than one ligature is desirable are mentioned in the text. 
called Capillaries, and ressels known as Lymphatics, which carry lymph. It is, therefore, obvious that if a ligature is applied as close above the punctures as possible, it will tend to delay the absorption of the venom and confine it to that region of the limb. Then, if another is applied higher up it will act as a second safeguard. A third ligature would also tend to help. The use of two or three ligatures is highly desirable in cases of poisoning by all the species of snakes whose venom acts mainly upon the blood and its vessels - such snakes for instance as the Boomslang and the Adder family, which includes the Puff Adder, Horned Adder, Berg Adder, and Night Adder.

I have recently arrived at this conclusion after experiments on animals. I found that by applying a ligature just above the site of the bite I was able to prevent the venom acting upon the muscles above the ligature. Now, for instance, if a man were bitten on the instep and he applied one ligature above the knee the muscles of the leg from the foot to the ligature would probably be charged with extravasated blood, which later might result in mortification of the limb.

In applying a ligature, the object is to prevent the return of the venous blood and lymph from the site of the entry of the venom. The object is not to constrict an artery.

In conclusion, it must be borne in mind that ligaturing and applying permanganate of potash is of little or no antidotal value if not applied within fifteen minutes of the infliction of the bite. In the majority of cases if not applied within five minutes, death will ensue, should a fatal dose of venom happen to have been injected.

Ligaturing is at best but a first-aid, temporary measure, the object being to gain time for other remedial measures, such as the injection of anti-venomous serum, which is, as I have already mentioned in this book, the only antidote recognized by science, and the only one which I have found to be of value among all those with which I have experimented.

\section{The Serum Treatment-Methods of Injection.}

The next thing to do is to procure and inject an anti-venene serum with the least possible delay.

With a suitable serum syringe inject the serum under the 
skin of the arms, abdomen and legs for preference. The point of the needle should be pushed about an inch in an oblique direction under the skin, and the serum injected into the tissues. The skin of the abdomen, buttocks, thighs and forearms are also suitable sites. It is less painful to inject into the buttocks and abdomen than the arms. Always choose-a part where the skin is loose and flabby. Never push the needle deep down into the muscles. Take hold of the skin with your fingers, pull it up in the form of a ridge, and run the needle in from one end. After the injection carefully withdraw the needle with a rapid movement, put your finger on the puncture and press for a moment along the direction traversed by the needle. This prevents any serum escaping from

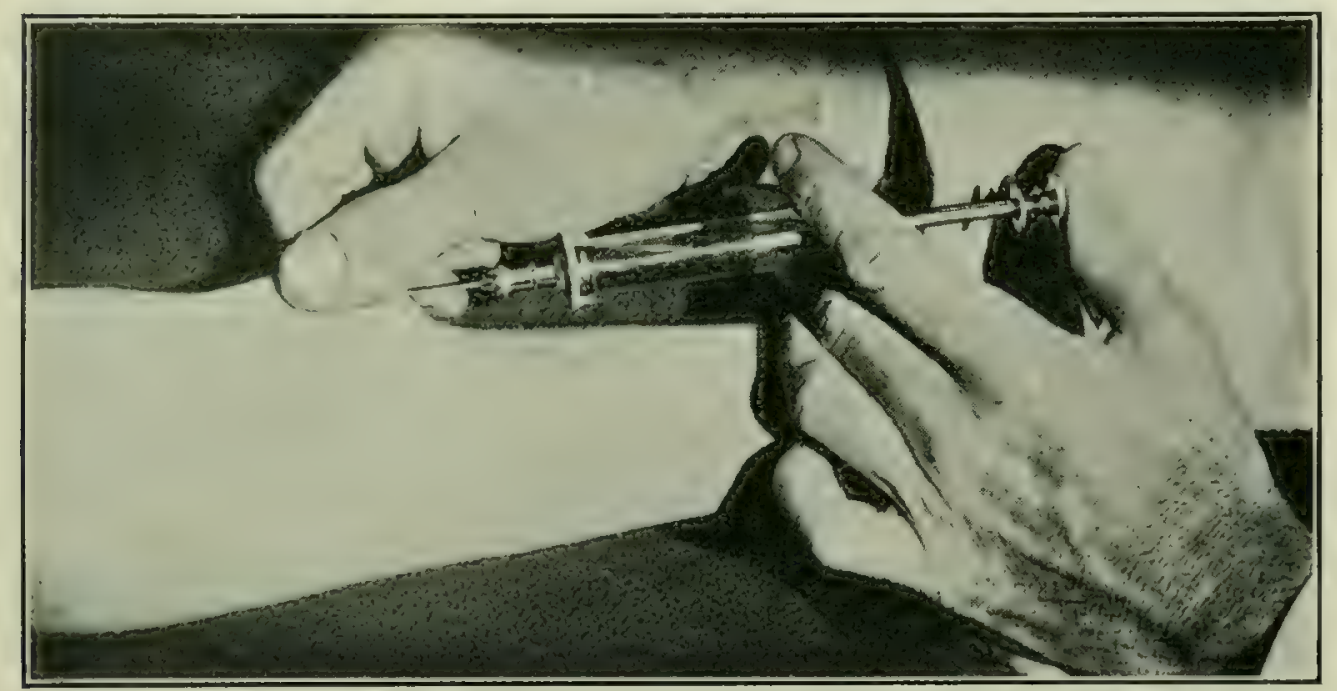

FIG. I50.-Injecting the serum into the forearm with a serum syringe. The skin is held up, the needle inserted, and the serum forced in. Always inject upwards toward the root of the limb.

the needle-puncture. A Io c.c. or 20 c.c. serum syringe can be used. A neat little syringe can be obtained to hold eighty drops, and it is sufficiently large to contain enough serum to inject at one spot. The syringe in "FitzSimons' Snake-bite Outfit" is specially designed to suit the purpose. Be careful not to use a small hypodermic syringe, as the aperture of the needle is so small that it is likely to get clogged. After using a syringe, boil the needle in water in which some borax has been added. The borax will prevent subsequent rusting of the metal. Always see that your syringe is scrupulously clean.

A bottle containing 25 c.c. (cubic centimetres) should be injected in two or three places. Two to three teaspoonfuls of 
serum may conveniently be injected at one spot. More may be introduced under the skin in one place, but it is absorbed more rapidly when injected in several places. The arms and legs are usually selected because the skin does not adhere firmly to the muscles on those parts, and it is therefore easier to inject the serum under the skin. Moreover, it circulates much better. After the serum has been injected, gently rub the injected part to make the serum dissipate under the skin.

If the bite has been promptly treated with permanganate and the part ligatured within five minutes of being bitten and no symptoms of poisoning have set in, then 20 or 25 c.c. anti-

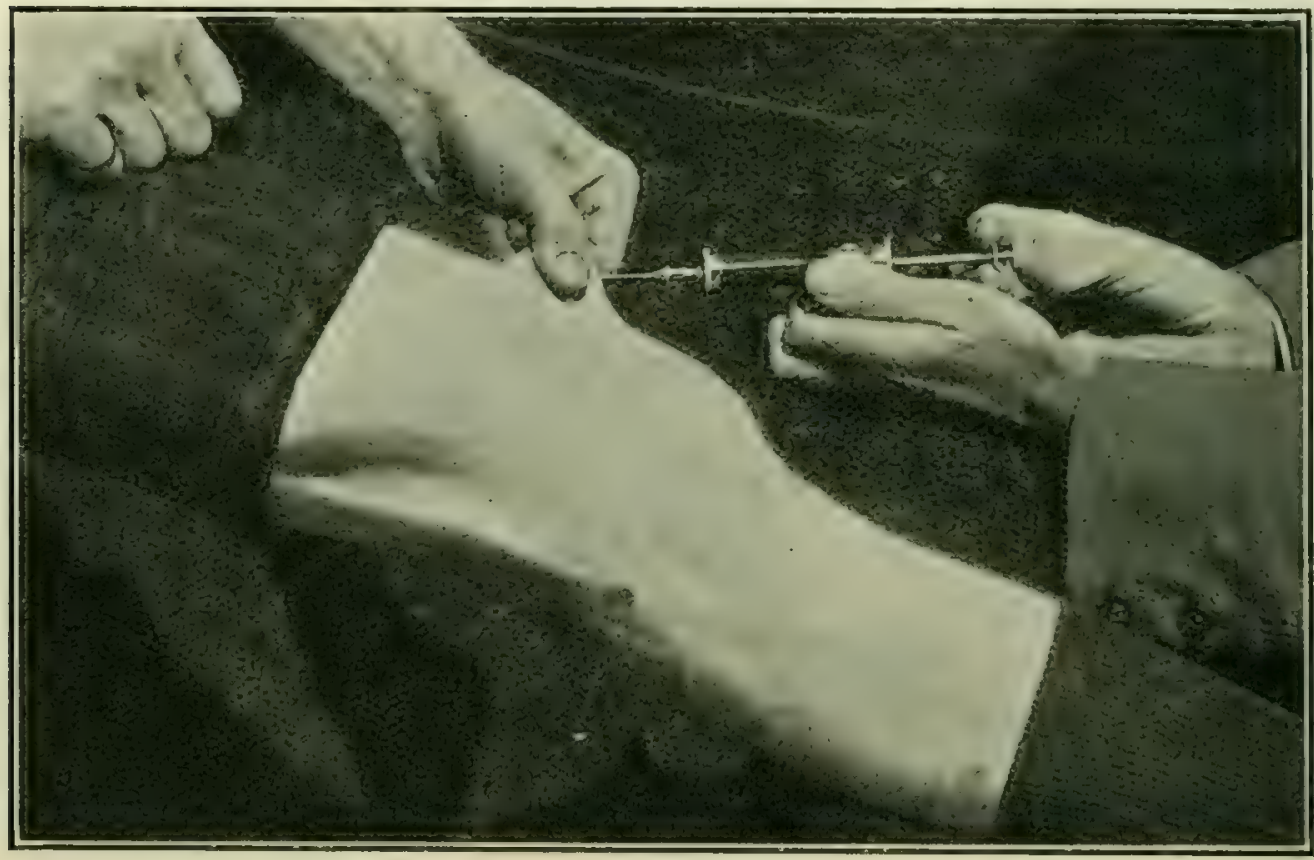

FIG. I5I.-Injecting serum under the skin of the thigh. Always thrust the needle point up towards the body. Do not inject into a ligatured $\operatorname{limb}$ below the ligature.

venene may be injected. But if, after an interval, dangerous symptoms appear, then inject a second dose, and even a third or fourth. It can do no harm, and will probably make all the difference and save the life of the patient. At such critical times it is extremely false economy to withhold an extra dose or two of serum. Always bear in mind that the more you inject, the better the chance of a complete recovery.

If serious symptoms of poisoning have set in before the application of the serum, it should be injected direct into a vein so that it may be carried as rapidly as possible throughout the circulation. 
When symptoms of poisoning have begun to appear, it means that the poison has started its deadly work of benumbing the nerve cells, or destroying the blood, or both; therefore it is imperative that there should be as little delay as possible in bringing the serum into actual contact with it. Anti-venene serum, if injected direct into the blood-stream, is considerably stronger in its power of neutralizing the venom than if injected under the skin. This must be carefully borne in mind.

To medical men and others, experienced in the use of a serum syringe, I would recommend that in all cases the serum be

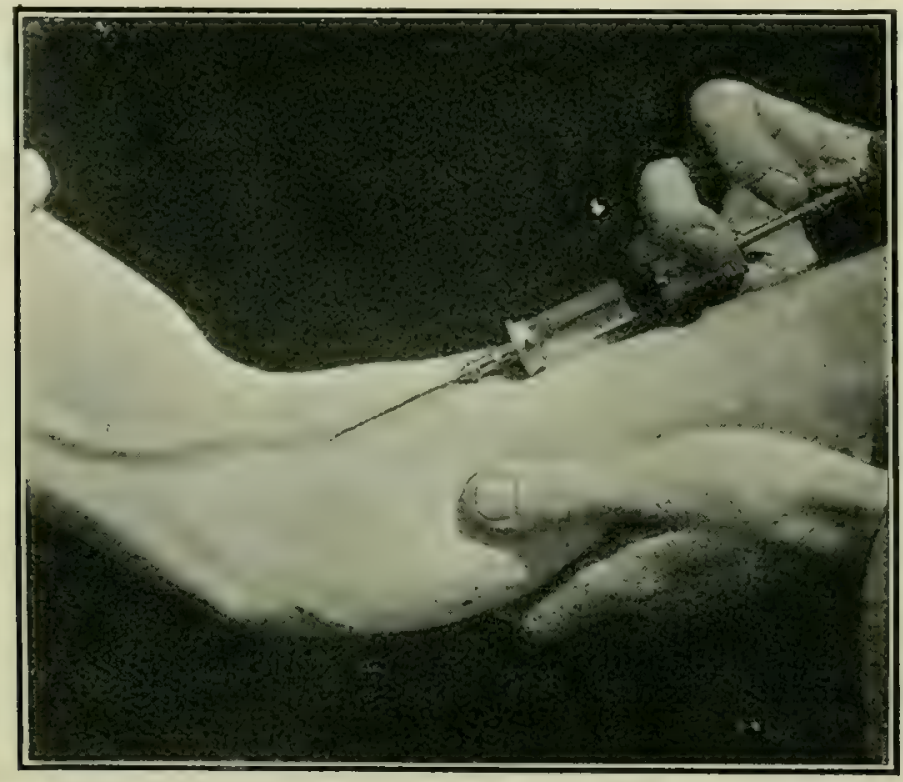

Fig. I52.- Injecting serum into a vein in the forearm. Select one of the surface veins at the back of the hand, arm or leg. Push the needle point into the vein along its course, and slowly inject. Always inject the serum upwards in the direction of the heart.

injected direct into a vein. Farmers and people who have had no experience in handling a serum syringe would do well to practise on animals by injecting salty water. It will do the animal no harm and will establish confidence in the operator; for if no air-bubbles or sediment be forced into the vein, no injury can possibly result. Use a syringe with a transparent barrel.

Before selecting a vein for injection, apply a temporary ligature to make the veins bulge. When the needle is inserted, draw out a little blood into the syringe to make certain the vein has been punctured, remove the ligature and inject the serum. 
Inject the serum slowly but forcibly. Here I would warn the operator to see that no air-bubbles or particles of solid sediment are injected into the blood, as they might cause serious mischief, and even death. It is safest to strain the serum if it is to be injected direct into a vein. Draining it through butter muslin will do. Remember the syringe should be completely filled with serum so as to allow no space for air. Do not inject the whole of it. Leave a little in the syringe. This will prevent any chance of air-bubbles being injected. It is well to put a piece of butter muslin in the box with the serum so as to be ready for use.

In drawing up the serum into the syringe, pull the piston rod slowly. Do not jerk it up rapidly, because air is likely to get in. Sometimes the knob of the piston rod does not fit the barrel sufficiently tightly to cause a full charge to be sucked up. But it usually gets tight enough when a little serum is taken up, as the fluid causes it to expand. If it remains unsatisfactory, remove the rod and wind a little cotton thread round it to make it fit more tightly.

Of course, the syringe and needle must be scrupulously clean.

Sometimes a kind of nettle rash appears when the venom has been injected, but this need cause no alarm. It will disappear in a day or two.

If the serum be injected direct into a vein in sufficient quantity before any symptoms of poisoning have set in, it will neutralize the poison and no poisonous symptoms will appear. On the other hand, if alarming symptoms of swelling, nausea, clammy skin and lethargy have set in before the injection, then at least double the usual dosage of serum must be injected. In these advanced cases 40 or 50 c.c. of serum should be immediately injected. Still a further dose of 25 c.c. should be injected, if the symptoms are very grave. Provided sufficient serum has been injected, and if the patient's nervous system is not paralyzed, or his blood damaged beyond recovery, then he should begin slowly to mend. From hour to hour he will improve, until complete recovery takes place. If there be extensive swelling it will slowly disappear. It will in no case subside all at once.

The effect of the anti-venene, when injected in sufficient quantity, is to stop the development of any further symptoms of 
poisoning. Therefore it is apparent that if the patient is not already too far gone to make recovery possible, he should quite recover.

\section{Treatment of Animals.}

The treatment of snake bite in animals is the same as that in the human subject. It has, of course, to be modified according to circumstances, and the kind of animal treated. Do not attempt to force the syringe-needle through the thick parts of the hide. Select the soft parts on the inner portions of the thighs and forelegs, for injection. In the treatment of cattle, a larger and stronger syringe is preferable, such as those used by veterinary surgeons.

Animals, when injected with ten fatal doses of venom, will not develop serious symptoms of poisoring, if the serum treatment be given directly afterwards. If injected in sufficient quantity into a vein after unmistakable signs of poisoning have set in, the serum checks the symptoms and saves the creature's life.

As a general rule, snakes are not seen to inflict a bite on animals, unless it be a dog. Invariably in the case of cattle, sheep, goats or ostriches, the attention is first drawn to the swelling and hæmorrhage, or a more or less paralyzed condition of the creature. If the bite be that of a Puff Adder there will be swelling arising from the site of the entry of the venom. If a Cobra, there will be little or no swelling. In both cases the victim will stagger or lie upon the ground in more or less an exhausted condition; therefore in nearly, if not in all cases, it is best to inject the serum direct into a vein. The same quantity of serum should be used as that recommended for a man. An extra dose is advisable for larger animals such as cattle and horses.

\section{Experiments with Anti-Venene Serum.}

Mr. T. Norsworthy, the station master at Thornygrove, Somerset East, who is an enthusiastic advocate of scientific methods for the treatment of snake bite, determined personally to test the anti-venene serum which is now prepared by bacteriologists for the treatment of snake bite. 
Procuring a kid (goat) five months old, he allowed a large Puff Adder, which had been freshly caught, to bite it upon the thigh. The snake gripped hard and hung on, worrying the flesh for one minute. It was then removed, and a bottle of antivenene containing 25 c.c., which is almost an ounce in bulk, was injected under the skin of the bitten animal. It died in an hour. In this case the snake bit fully, and was permitted to retain its hold for the space of a minute. Being a fresh snake, something like eight or ten drops of venom must have been injected. Two drops of the venom were sufficient to kill the kid within a few hours. One dose of anti-venene serum was not sufficient to neutralize enough of the venom in this instance to avert a fatal issue.

I explained this to Mr. Norsworthy, and he decided to try a more satisfactory test.

Taking a tough old goat, an adult male Puff Adder which had been in captivity a few weeks, was induced to bite it. It struck the goat on the hind leg just above the hoof and instantly withdrew. It struck again near the same spot. Both bites were of the nature of pecks. The snake did not grip or retain its hold for more than an instant.

About an hour later the limb began to swell from the site of the punctures. The swelling gradually extended upwards and along the abdomen. The leg swelled to three times its normal size.

The goat was bitten at II a.m. and was kept in a warm shed. At 7.30 p.m. hæmorrhage began near the site of the bites and up the limb. At 7 a.m. the following morning, the swelling had extended all along the abdomen and between the forelegs, and the hæmorrhage had spread nearly all over the body, the swollen skin being now purplish-black owing to the extensive hæmorrhage through the walls of the capillary blood-vessels. The goat remained in this condition until it died twenty-six hours twenty-five minutes after being bitten. It fell down on the ground one and a half hours before death and did not rise again. Yet it ate food at intervals until shortly before it died.

\section{Bitten and injected with Anti-Venene.}

Mr. Norsworthy also recently caught a female Puff Adder, which was allowed to bite the hind legs of an old goat 
at II a.m. Four full bites were given. The snake was allowed to retain its hold and firmly grip and worry the bitten parts.

Two bottles of anti-venene serum were then injected in several places under the skin of the inner parts of the legs and between the shoulders. Each bottle of serum contained nearly an ounce, viz. 25 c.c. Shortly after being bitten, the leg swelled slightly. After six hours the leg swelled somewhat more and the sites of the bites looked inflamed. The goat seemed in its usual health and continued so. After eight or nine hours, the swelling began to subside. There was no sign of hæmorrhage under the skin. The goat made a complete recovery. $\mathrm{Mr}$. Norsworthy informs me that several prominent farmers witnessed these experiments, and all agreed that the bites inflicted were full and complete ones. In fact, Mr. Norsworthy complained that they were too exacting.

A freshly caught adult Puff Adder is capable of injecting at least ten drops of venom at a single bite. When a snake is in a state of extreme anger, as was the case with the one which bit the goat, the glands manufacture venom at an exceedingly rapid rate, therefore it is fairly safe to assume that the snake injected ten to fifteen drops of venom into the goat, two of which were sufficient to kill it.

Mr. E. Burls, a well-known farmer who witnessed the experiment and who is the owner of the goat, writes to Mr. Norsworthy as follows :- "The goat has quite recovered. I defy any one to detect anything wrong with her. You can safely tell FitzSimons that the serum cured her. She had a rough time of it, but that was, I believe, owing to her having four bites, and the broken teeth at the fourth bite were not taken out."

\section{OTHER EXPERIMENTS.}

I have made a good many experiments with this anti-venene, which is stated to be the strongest and best for the treatment of bites given by all species of venomous snakes. It is said to be particularly powerful in its power of neutralizing Puff Adder and other Viperine venoms.

I found that if a Puff Adder was allowed to deliver one full bite on the leg of a full-grown Chacma baboon or a large dog, 
and if 50 c.c. of anti-venene was immediately afterwards injected under the skin, the animals recovered, although a certain amount of hæmorrhage and swelling occurred. The animals were sometimes in a state of nerve depression for a couple or three days. If five drops of Puff Adder venom were injected with a syringe under the skin, and a dose of 25 c.c. of anti-venene was injected in a similar manner before poisonous symptoms had set in, the animals recovered in most instances, although in all cases they showed symptoms of poisoning such as hæmorrhage, swelling, and nerve depression. The hair in most cases came off for several inches around the site of the injection of the venom, and the skin was shed, along with dried blood and dead tissue.

When 25 c.c. of anti-venene were injected direct into a vein immediately after the injection of the venom into the tissues, the only parts affected were the vicinity of the punctures. One of the animals was killed after it had apparently made a complete recovery, and it was found that there was rather extensive hæmorrhage about the site of the entry of the venom and along the leg for some distance. By the appearance of the tissues, it was evident the dead blood was being absorbed, and the injured tissues were beginning to assume their normal appearance.

When 25 c.c. of serum (nearly one oz.) were injected direct into a vein after symptoms of poisoning had set in, the animals in most instances recovered, although they seemed to have rather a bad time. But after pronounced signs of poisoning appeared, I found that, although the injection of 25 c.c. in several places under the skin delayed death, it did not in the majority of instances, avert a fatal issue.

From these experiments, therefore, I was convinced that unless two doses, each of 25 c.c., were injected direct into a vein, death would often occur in the human subject, if very serious symptoms of poisoning had already set in.

The smaller animals always died if a Puff Adder delivered a full bite, or if five or six drops of the venom were injected into the muscles with a syringe followed by an injection of 25 c.c. of anti-venene direct into a vein. In these cases, 25 c.c. of the anti-venene was evidently not sufficient to overtake and neutralize enough of the venom to save the lives of the creatures. 
Experiments with anti-venene on animals bitten by Cobras, or injected with their venom, were less satisfactory, the reason being that the venoms of these snakes act so rapidly on the nerve-centres of the smaller animals, destroying life before the serum could combine with and destroy the poison. If four drops of Cobra or Mamba venom were mixed with 25 c.c. of the antivenene and injected into the leg of a dog, or an average-sized monkey, it did not avert a fatal issue. If a Cobra or Mamba (green variety) delivered one full bite and was allowed to retain its hold for a few seconds, the injection under the skin of two doses, viz. 5o c.c. of anti-venene, rarely prevented death.

From the results of these and many other experiments, I would strongly advise that 30 to 50 c.c. (cubic centimetres) of anti-venene be injected in these cases into the human subject. In fact, in the treatment of very serious cases of Cobra, Ringhals, and Mamba bite, as much as Ioo c.c. (roughly $3 \frac{1}{2}$ ounces) may be injected. In the great majority of cases I have no doubt that 50 c.c. or even 25 c.c. would save the life of the bitten person, as it is not often that a snake is able to deliver a full bite and inject a maximum amount of venom. However, it may do so, and it is as well for everybody to know, that 50 c.c. of anti-venene may possibly not suffice to effect a cure.

\section{Experiments on Fowls.}

As already mentioned, the anti-venene which is especially strong in its power of neutralizing Puff Adder venom, was again experimented with on fowls. I made a freshly caught adult Puff Adder bite through a piece of sheet rubber stretched over the mouth of a wineglass, and thus obtained exactly six drops of venom, absolutely pure. I mixed this with 25 c.c. of antivenene which had just been received from the laboratory and was in the freshest possible condition, being perfectly transparent. The mixture was thoroughly stirred up and allowed to stand for one hour. It was again stirred up and divided into two equal parts. One part was injected into the muscles of a fullgrown healthy fowl, namely, in both thighs and under one wing. The other half was injected in a similar manner into another fowl. 
This was done at II a.m. Five hours later, one fowl began to sicken, and its injected wing hung rather loosely. The other fowl seemed quite sound. The following morning both fowls seemed sickly weak. I examined them and found that the injected thighs and wings were swollen to nearly twice their normal size, and considerable hæmorrhage in those parts had taken place.

For three days the fowls remained in about the same condition, when one recovered its normal cheerfulness and seemed well. I examined it and found that the swellings had subsided, and the vicinity of the injections were not so purplish as before. Three days later the parts were greenish-yellow in appearance, indicating that the dead blood under the skin and in the muscles was being rapidly re-absorbed.

The other fowl did not fare so well. Evidently it had received a slightly larger dose of venom than the other fowl, or else it was more susceptible to the poison. Both its limbs became paralyzed, owing mainly to extensive hæmorrhage under the skin of the thighs.

On the sixth day after the injection, it began to recover the use of its legs. I then killed it and made a careful examination. I found that the skin on both thighs was dead and came away when I pulled it, revealing a mass of coffeecoloured matter, practically dry, underneath. This was the residue of the blood which had oozed out of the blood-vessels. The flesh under this, for nearly a quarter of an inch deep, was dark brown, and in a jelly-like condition. Beneath this layer the flesh was perfectly sound. The healing processes were well proceeding, and the fowl would have, no doubt, made a complete recovery. On examination, the flesh of the breast was stained with blood in small patches, owing to slight hæmorrhage through the capillary blood-vessels of those parts.

\section{Deductions.}

Similar experiments were repeated, with more or less the same results. It is obvious that three drops of Puff Adder venom is a fatal dose for any fowl. In fact, one drop is sufficient if injected into the muscles. From the results of these experiments, 
then, it is certain that the anti-venene destroyed a considerable quantity of the venom, otherwise the fowls would, in every case, have certainly died. However, it was clearly evident that all the poison was not destroyed. Therefore we can safely conclude that $12 \frac{1}{2}$ cubic centimetres (half a 25 c.c. dose) of anti-venene is not sufficient to neutralize three drops of Puff Adder venom when the two are mixed together. The 25 c.c. of anti-venene seemed capable of destroying about five or five and a half drops of Puff Adder venom when mixed with it, and then injected. In all cases when 50 c.c. of anti-venene were mixed with six drops of Puff Adder venom, the latter was entirely neutralized.

Now, at first sight, this seems very satisfactory, for it would be assumed that if two doses, viz. 50 c.c. of anti-venene, were injected, it would be capable of neutralizing something like ten drops of venom. Unfortunately, this is not usually so in actual practice.

It has been found that if a snake inflicts a bite and if the anti-venene be injected under the skin immediately afterwards, something like ten to twenty times the quantity is necessary to exert the same neutralizing power over the venom, as when mixed with it, and the two are injected together, as mentioned in the above experiments.

Now, I am laying particular stress upon this point, as I want readers to know exactly what anti-venene is capable of doing, and the difference in the results which follow the injection under the skin and into veins direct, for I have noticed in the instructions sometimes issued with these anti-venene serums, that injections are recommended to be given under the skin, unless serious symptoms of poisoning have set in. The dose prescribed is moreover quite inadequate in those cases where even a moderate quantity of venom is injected. But where a maximum dose of venom has been'given by any venomous snake, the quantity recommended is of little curative value.

\section{Injecting Anti-Venene direct into Veins.}

In the directions for the treatment of a case of snake bite it will be noticed I recommend to those qualified to do so, (I) the 
injection of anti-venene direct into veins in preference to discharging it under the skin (subcutaneously), (2) that anti-venene may be injected under the skin when no symptoms of poisoning are apparent, and (3) then to inject a dose into a vein if such symptoms should develop, where cases have been already treated with permanganate and ligatures, for usually here not much venom would have gained entry into the circulation. For, while most of it was being temporarily pent up in the ligatured limb, the anti-venene would have a better chance of getting into the blood-stream to meet the venom.

There are many people either clumsy or nervous who could not be trusted to inject anti-venene with safety direct into a vein. Such people would be wiser not to attempt it. For the great majority of cases the injection of the serum under the skin would effect a cure.

In conclusion, remember that anti-venene injected direct into a vein has usually some twenty more times the venom-destroying power than if injected in the ordinary way under the skin. In fact, it is almost as strong as when mixed with the venom and injected, as mentioned in my experiments. It was seen that in this way 25 c.c. of anti-venene was able to neutralize something like five and a half drops of Puff Adder venom.

Another important thing to bear in mind is, that if poisonous symptoms have set in before the injection of anti-venene, twice as much, and even more, will be necessary to prevent the mixing of the venom with the nerve cells and blood, and save the life of the patient. So, if a person is competent to inject anti-venene direct into a vein, do so in these serious cases. If not, then practise on the lines already suggested, until confidence is gained.

Rest assured that if a person carries permanganate about with him and scarifies the site of the bite and ligatures the limb in the way directed, and if 25 c.c. of anti-venene is injected within a reasonable time, complete recovery will be well-nigh an absolute certainty.

Accept one final warning; do not trust to any of the popular so-called cures. If in spite of what has been written here you still have firm faith in some favourite root, herb, or tincture, then by all means apply it if you so desire, but please do not trust to it to effect a cure. 


\section{Anti-Venene Therapeutics.}

The following extract from an article by Charles J. Martin, II.B., D.Sc., F.R.S., Director of the Lister Bacteriological Institute of London, and Major George Lamb, M.D., I.M.S., in "A System of Medicine," will no doubt prove of considerable interest to medical men. It is as follows:"Calmette considers that Io c.c. of the Lille serum is sufficient in most cases of snake bite; but that if the treatment is delayed, or if the snake is a Cobra or a Krait, 30 c.c. should be used. He recommends that the injection should be given subcutaneously unless symptoms are already present, in which case an intravenous injection of Io or 20 c.c. is required. For reasons which will appear below we are convinced that these small quantities are quite sufficient in the case of the Cobra, against which the Lille serum is practically anti-toxic. In orde: to arrive at an accurate therapeutic dose of an anti-venomous serum, three factors must be determined: ( $I$ ) the neutralizing power of the serum, that is to say the exact amount of serum which can neutralize a given amount of venom; (2) the amount of poison which a snake can inject; (3) the quantity of venom, the injection of which a man can survive.

"Two c.c. of the Lille serum are stated to have the power of neutralizing I mgrm. of dried Cobra venom, and the serum issued by the Pasteur Institute of India is double this strength. If this is expressed in terms of the number of fatal doses for a guinea-pig of 8 grms. which can be neutralized by I c.c of serum, a comparison may be drawn between the relative potency of anti-venom and the anti-toxins for diphtheria and tetanus. Expressed in this way, I c.c. of the Indian serum neutralizes only ro minimal fatal doses for a guinea-pig of standard weight. On the other hand, one in every four horses will produce a diphtheria anti-toxin, I c.c. of which, when tested under the same conditions, will neutralize 100,000 minimal fatal doses of toxin, or if immunized against tetanus will furnish tetanus anti-toxin, I c.c. of which will neutralize 200,000 minimal fatal doses. It will be seen at once that, compared with these anti-toxins, anti-venene is very weak.

"We have thought it advisable to lay stress upon the real anti-toxic value of anti-venoms, because we think the point has been very imperfectly realized. 
"The second point, namely, the amount of venom which a snake can inject, has been settled in the case of (Indian) Cobra and Daboia venoms by actual experiment. In the Cobra the amount varies from 200 to 350 mgrms. of dried venom, and in the case of the Dobaia it is somewhat less, viz. I50 to 250 mgrms. These observations were carried out on snakes freshly caught.

"Calmette has made a series of experiments with Cobras which had evidently been kept in captivity for some time; the greatest amount of dried venom which he was able to procure was 48 mgrms, and the average amount was about 20 mgrms.

"The therapeutic dose of serum recommended by him is calculated on this basis, and is evidently, therefore, much too small. It is obvious that in estimating the dose of anti-venomous serum to be used in the treatment of any case, say of Cobra bite, it should be borne in mind that the snake may have injected as much as 350 mgrms., for the neutralization of which quantity, sufficient serum must be injected in order to save the patient's life. There must be, of course, many cases in which lessprobably a good deal less-venom would be injected, and a smaller amount of serum would then suffice; but there are no means by which this point can be estimated, and as treatment must be immediate there is no time to wait and watch the development of the case.

"The third factor, the amount of venom a man can survive, must next be considered. This, of course, can only be estimated roughly by experiments on animals. Basing our calculations on results obtained with monkeys, we have arrived at the conclusion that for an average man the lethal dose of (Indian) Cobra venom would be about 15 to 20 mgrms., and of (Indian) Daboia venom about 60 mgrms. A man would therefore be able to survive slightly less than these amounts.

"Having as far as possible arrived at the data on which the dose of serum to be used in any case of Cobra or Daboia bite rests, we shall have to calculate what this dose ought to be.

"In the case of a Cobra bite, supposing the serum to be of such strength that I c.c. is able to neutralize I mgrm. of pure Cobra venom if the snake has injected the maximum of poison, 
namely, about 350 mgrms., we can calculate that in order to neutralize this quantity of venom and thus save the life of the patient 350 c.c. of serum would have to be brought in contact with it. In the case of a Daboia bite a much smaller quantity of serum would serve the same purpose, as we have seen that this snake does not inject so much venom as the Cobra, that the serum neutralizes about double the amount of Daboia venom, and further that the minimum lethal dose of Daboia venom by subcutaneous injection is much greater that than of Cobra venom. We can therefore calculate that Ioo c.c. of serum would be sufficient to neutralize the amount of venom which a full-sized Daboia would be able to inject.

"We have still to consider the method of injection, as these quantities of serum are the amounts which would be required to neutralize completely the venoms when they are mixed, in vitro, before injection. If, however, the serum be injected subcutaneousily at the same time as the venom, it was found that from Io to 20 times the neutralizing dose of serum was required to save the life of the animal. Applying these observations to our present purpose, we arrive at the conclusion that in treating a case of Cobra bite in which the snake has injected the maximum amount of poison, we should have to inject 350 c.c. of serum intravenously or from 3500 to 7000 c.c. subcutaneously in order to save the life of the patient, and in the case of Daboia bites Ioo c.c. intravenously, or from Iooo to 2000 c.c. subcutaneously.

"Further, if symptoms have already appeared before treatment was begun, larger amounts of serum would be required to dissociate the poison from its junction with the cells. If the Lille serum be employed, these quantities must be doubled, as it is only half the strength of that issued by the Pasteur Institute of India.

"We have no desire to discourage the use of serums, for once the poison has been absorbed they are the only remedies available; but we wish to point out what is the real neutralizing value of the scrum, and what may reasonably be expected from its use, and, further, to emphasize that quantities of Io to 30 c.c. as recommended by Calmette are hopelessly inadequate, and only likely to lead to disappointment." 


\section{Deductions.}

I have quoted the above extract in support of the claims I have made that the dosage of anti-venene sometimes recommended by those who issue the serum is altogether inadequate, and calculated occasionally to lead to disappointing results. I am well aware that in the great majority of cases of snake bite in the human subject, nothing like a maximum dose of venom is injected. However, in a minority of cases a full charge of venom is injected, and a man should not be led to believe that 20 or 30 c.c. of antivenene will cure with certainty.

As I have mentioned before, anti-renene has its limitations, and everybody should know just what it is capable of. I have met scores of men who treasure up a phial of Io c.c. antivenene, confident that it will cure any case of snake bite. In the French Congo and elsewhere great numbers of people, including District Surgeons, believe that Io c.c. of anti-venene will cure most snake bites, and that 20 c.c. will cure the very worst cases. Numbers of lives have been lost in consequence.

Although, since Martin and Lamb wrote up the results of their experiments with anti-venene, it has been increased somewhat in strength or venom-neutralizing power, and is now polyvalent, yet in the light of a careful series of experiments which I have conducted, I am confident that it by no means possesses the high standard of venom-killing power some people claim for it.

\section{Instructions in Brief for the Use of Anti-venomous Serum.}

(I) Anti-venene is the serum of horses highly immunized with Cobra and Viper venoms (Colubrine and Viperine).

Its curative properties have been tested on animals against these venoms and found to be effective.

(2) In case of either Cobra or Viper bite when the patient is at hand and before symptoms have set in, 25 to 30 c.c. of anti-venene should be injected under the skin into any part of the body where the skin is loose, such as in the region of the flanks. For preference inject into the loose tissues or 
folds of the abdomen at the sides between the last rib and pelvis.

(3) In a case when a patient is not seen until symptoms of poisoning have set in, the same amount of serum should be given by injection direct into a vein. But when the snake is large and the bite is a full one with both fangs, an extra dose should be injected.

(4) If serum has been injected under the skin, and if the patient seems to be developing alarming symptoms, inject at least 25 c.c. direct into a vein.

(5) For intravenous injection, a vein of the forearm should be selected for preference. The vein should be made prominent by pressure above. The syringe and needle should be held almost parallel to the vein, keeping the oblique opening at the point of the needle upwards. The operator steadies the vein with his left hand and introduces the needle. When the needle is kept parallel to the vein with the slant at the point upwards, steady pressure carries it into the vein without difficulty, and avoids puncturing both walls of the blood-vessel. As soon as the needle is in the vein, remove the pressure above, and slowly inject the serum. A local subcutaneous swelling appearing during the operation of injection shows that the needle is not in the vein, and a fresh attempt should be made to introduce it.

(6) If there are any albuminous deposits or flocculi in the bottle, the serum should be filtered through the corner of a clean linen pocket-handkerchief or a piece of clean rag into a wineglass or other convenient receptacle, previous to using it. This is not essential if injecting under the skin.

If boiling water be at hand, dip the cloth into it and wash out the vessel before straining. A weak solution of permanganate of potash or boracic acid would do instead of boiling water, for sterilizing the cloth and vessel.

(7) The serum syringe should be perfectly clean. The best plan is to boil it in water to which some borax has been added. Then dry and put it away in its case, ready for use. Examine it occasionally to see that the needle is not getting rusty.

If any weak antiseptic such as boracic acid or permanganate in solution be at hand, wash the site of the proposed injection with it. If no antiseptic is to be had, then rub the spot clean.

(8) An albuminous precipitate in the bottle does not indicate 
contamination, and would be quite harmless if given subcutaneously.

For obvious reasons, it would not be safe to inject a precipitate of any kind direct into a vein, hence the necessity for filtering the serum through a clean cloth before injection into a vein.

(9) Be sure that your syringe is in good working order, so that it will take up a charge of serum without any difficulty.

(I0) The serum contains no toxic or poisonous substances of any kind.

(II) It does no harm if injected, and it is subsequently discovered that the snake which inflicted the bite was a harmless one.

(I2) The bottles of serum should be kept in the dark, and in the coolest place in the house. Heat and light are the two chicf causes in bringing about a deterioration in the strength of the antitoxic properties of the serum.

(13) When kept in a dark and cool place, the serum loses very little of its antitoxic properties in a year-probably not more than 5 per cent., even if as much. An increase of dose would make up for this loss.

(I4) Sometimes a kind of nettle-rash appears on the skin after the subcutaneous injection of serum. This will disappear in a day or two, and need cause no alarm.

(I5) Serum injected in excess does no harm. Occasionally what is known as serum sickness (anaphylaxis) supervenes, but this is slight.

(I6) If nerrous about injecting serum direct into a vein, then inject copiously under the skin in bad cases. Use even as much as 50 cubic centimetres (nearly $2 \mathrm{oz}_{\text {。 }}$ ) if necessary.

\section{Secondary Treatment for Snake Bite, effective in} all Serious Cases.

Now, we will suppose the punctures have been thoroughly scarified, permanganate of potash rubbed in, a ligature applied, and the patient is now at home, and has been injected with anti-venene serum and the ligature removed. He must be stripped and put into bed at once, and kept warm. Apply hot-water bags to his feet, stomach, and chest. If none are available, fill stone jars, bottles, or anything handy 
which will hold hot water. Wrap these separately in flannel, or some other kind of cloth, to prevent them burning the patient, and place them at his feet, sides of the body, and back of the neck. If no water-bottles are available, boil a quantity of water and get flannel cloths; failing these, big towels will do. Seize the ends and twist them up. Then dip the middle part in the boiling water, wring thoroughly and wrap the patient's feet in one of these hot cloths; put another over his abdomen and one at the back of his neck. These should be renewed after ten minutes or so. Be careful not to burn the patient's skin. To avoid this, spread a thin cloth over the parts previous to the application of the hot fomentation. If the patient seems to be sinking, apply hot and cold fomentations alternately. Keep each on for five minutes, and persevere for half an hour or more, as this treatment tends strongly to rouse the patient's nerve centres. These tomentations should be applied over the lower portion of the abdomen, the stomach, the back of the head, and the feet. At all of these centres the nervous system can be effectually acted upon. Cover up your patient immediately you apply the fomentations.

In the early stages of snake venom poisoning, in addition to, or in the absence of any drug or serum treatment, the patient should be made to vomit any food there may be in his stomach. This can be accomplished by giving him a teaspoonful of mustard, or salt, stirred in a pint of warm water. If there is no mustard or salt, or any means of heating water, then make him drink a lot of water and thrust his finger down his throat, so as to irritate the entrance to the gullet. This will induce vomiting. The mustard and warm water is the best, for it strongly irritates the lining membrane of the stomach, causing it to pour out a watery mucous, in which there may be some of the venom, which is harmless when inside the stomach. Then a quick-acting purgative should be given, such as castor oil. This flushes out the bowels, and also causes a watery discharge through the walls of the intestines, which will also tend to drain off some of the venom in the blood. Then, every effort should be made to induce perspiration. The patient can be soaked in a bath of hot water, adding still hotter water, as he is able to bear it. The water should be as hot as he can endure. In ten or fifteen minutes take him out, and instantly cover him with blankets. 


\section{STIMULANTS.}

In cases of Cobra and Mamba bite, teaspoonful doses of hot brandy and water will do no harm. The aim should be to prevent the poison from benumbing the nerve centres beyond the possibility of recovery. In all cases of Adder and Boomslang venom poisoning alcohol is distinctly harmful. Nux vomica, which is a preparation of strychnine, administered internally in medicinal doses will tend temporarily to rouse the nervous system. So, too, will the injection of strychnine. This, however, is dangerous unless the operator knows the exact dosage. Tabloids containing the proper dose for injection may be obtained from any chemist.

The best nerve stimulant at these times is a fresh, hot infusion of tea. Make it very strong, but do not allow it to infuse more than three to five minutes. Tea contains a powerful alkaloid drug, known as Theine, which powerfully stimulates the nerve centres. If the tea is brewed for five minutes or longer, the infusion certainly gets strong, but it is then impregnated with tannic acid, which is highly injurious. Give the tea to the patient in small sips, so as not to upset or overburden his stomach, which at this time is apt to reject anything swallowed. Give the hot tea off and on at intervals, so as to keep up the stimulation. Strong coffee may be used, but tea is better.

Never dose the patient with large doses of alcohol or ammonia, and do not on any account rub pipe oil (nicotine) into the wounds made over the site of the bite, or allow it to be swallowed.

If you keep the patient warm and apply the hot bottles or fomentations, and give small repeated closes of very strong freshly brewed tea, that is all that you can do to aid Nature.

If no serum has been injected, then carry out all the foregoing secondary treatment, if possible, more energetically. If the patient continues to shiver, and if the surface of his body feels clammy and cold, it would do him good to soak his body in a bath of hot water now and then for five minutes at a time. After such a bath he must instantly be put back in bed and covered up.

When the patient show's signs of reviring, and seems on the road to recovery, cease to administer stimulants, or give them at longer intervals. 
The scarified site of the bite must be regularly washed with an antiseptic and carefully bandaged, after smothering it with boracic acid. This must on no account be neglected. Do it twice a day.

During convalescence from snake bite the diet should be very light, such as hot milk taken in small sips, milk puddings, artificial infants' food, rusks soaked in milk, soft ripe fruit, wellcooked rice and milk, etc. Do not give meat or meat soups, or any food containing added fat, or fried foods. The organs of the body at this time must be handicapped as little as possible, for if the venom be that of an Adder or Boomslang there will be more or less extensive hæmorrhage. This dead blood will require to be reabsorbed and cast out of the body by the various organs, else mortification and death will occur.

Many cases have been related to me of remarkable cures having been effected by certain roots, herbs, tinctures, alcohol, etc., but on close investigation it was evident the patient would have recovered just as quickly if nothing had been administered. When snake venom does not kill, recovery is usually very rapid, and this is invariably attributed to something in the way of an antidote given the patient. No known medicine taken internally is a remedy for snake bite.

\section{Paralysis of the Respiratory Nerve Centres.}

What to do if the breathing should suddenly stop.

The venom of the Elapinæ or sub-family of snakes to which the Cobra belongs acts powerfully upon the nerve-centres, and tends to paralyse their action. Its principal effect is upon the nerve-centres controlling the automatic movements of the lungs. By paralyzing these nerve-centres the lungs collapse, breathing ceases, and the patient dies.

Now, if you are nursing a person suffering from the bite of any one of these snakes, and if you observe the breathing to grow shallow and hurried, carefully watch him. Then, if the breathing should cease altogether, you should instantly resort to artificial respiration methods, and keep them up without a pause for an hour at least, or until a medical man tells you to desist. 
The easiest and most efficient method to apply is as follows: Place the patient straight out upon his chest and abdomen on a fairly hard and flat surface, turn his head slightly to one side, so that his mouth and nose may be free. Kneel beside his legs, facing his head. Place the palms of your hands flat upon the lower parts of his ribs, one hand on each side, and

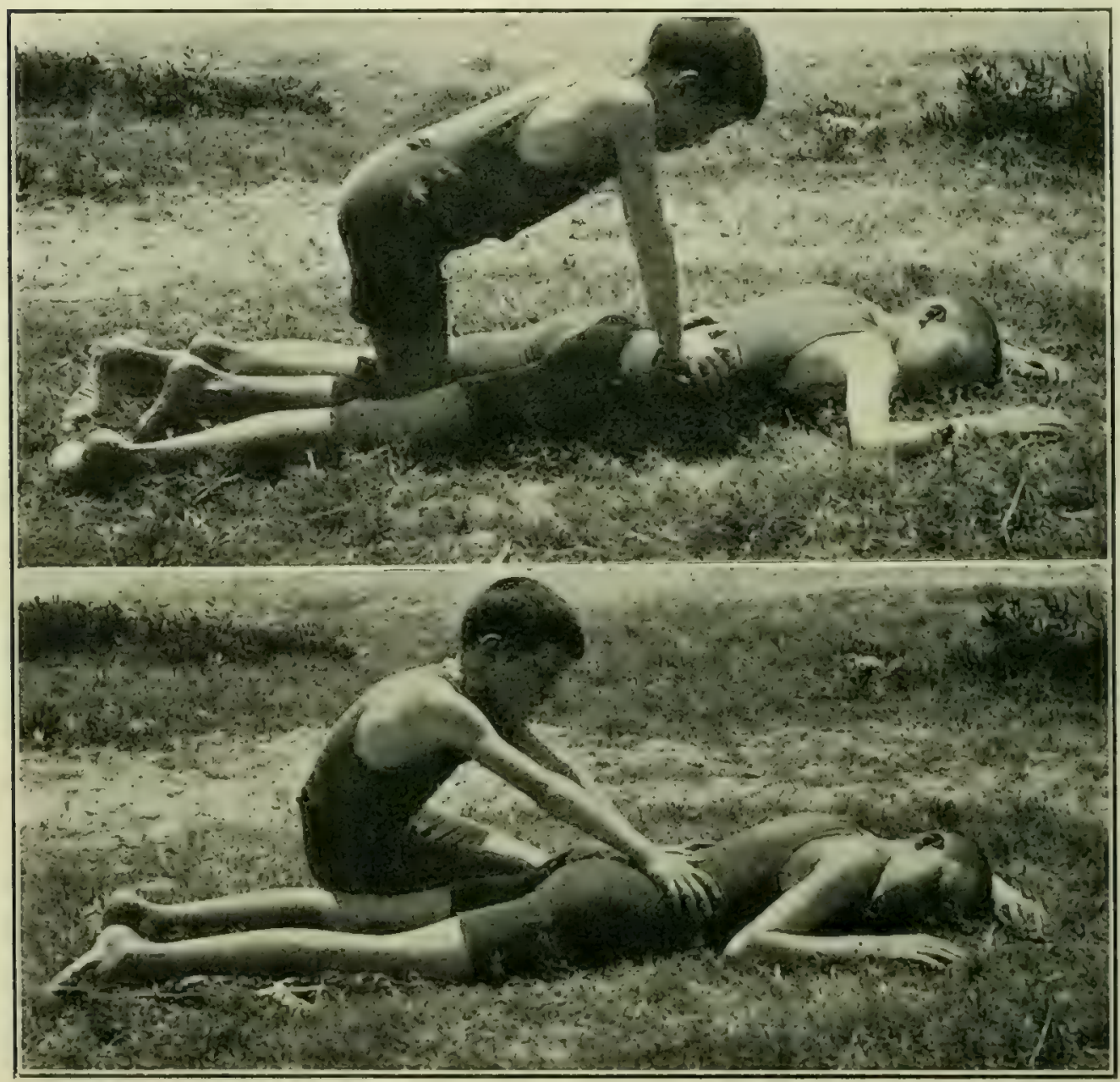

I'IG. I53.-This is the best way to perform the artificial breathing operation which is fully explained in the text.

press gently but firmly, not with a sudden jerk. Pause a second or two, and then draw your hands back, raising the patient's chest an inch or so with your fingers as you draw back (see Fig. 2 of picture). Keep on repeating this process, for hours if necessary. When you press the rib-region downwards, you are driving the air out of the lungs. The moment you let go, the lungs again expand, and air rushes in. Time your movements, so that they 
may be as near as possible to the ordinary breathing of a person. This artificial breathing method should be instantly employed in all cases of accident, such as drowning, suffocation by gases, smoke, or a blow over the region of the stomach, which often
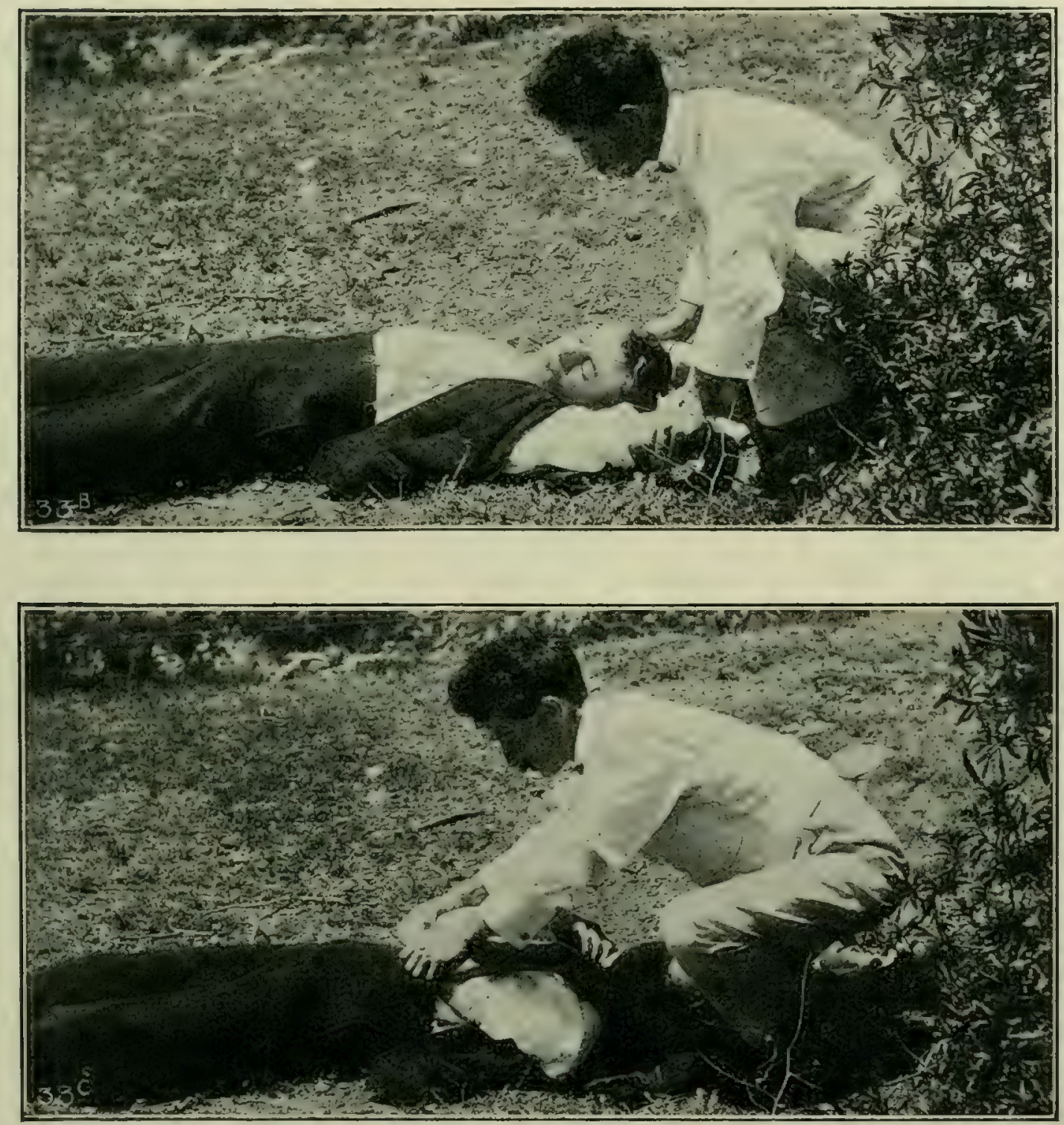

FIG. I54--Another method of performing the artificial breathing operation. If the patient is iying on his back as in this case, his tongue must be pulled forward and fastened, to prevent it sagging back and blocking up the air passage to the lungs.

deprives the victim of the power of breathing, and who might otherwise die of suffocation. This sometimes happens on the football field. Of course, you must always use careful judgment. The sooner artificial breathing is resorted to after normal breathing 
ceases, the better chance there is of a recovery. The advantage of the above method over others is that there is no necessity to pull out and secure the tongue to prevent it blocking the entrance to the windpipe. When the patient lies on his abdomen and chest, and the head slightly turned aside, the tongue naturally falls forward, and any froth, mucous, or water will run out of the mouth or nose without in any way obstructing the air passages.

The second method is as follows. It is, however, not so practical and simple as the first.

Place the patient flat upon his back, put a pillow under his shoulder-blades, let his head hang slightly back, pull his tongue forward and fasten it, kneel over him, as shown in the illustration, seize his elbows in your hands, and with a quick movement bring his arms over his head, as far as they will go, so as to expand the chest to the uttermost, pause an instant, then bring them forward and press gently but strongly against his ribs to expel the air in his lungs. Keep on doing this without pausing. The quicker you start the process after natural breathing ceases the better.

The instant the patient starts to breathe of his own accord, cease your manipulations and massage his legs and body vigorously. As soon as he is able to swallow, give a little very strong freshly brewed tea, or a few sips of hot brandy and water. If you should notice the breathing beginning to cease, or if it should suddenly stop, then at once resume the artificial breathing operations. These efforts should be kept up for an hour at least, or until a medical man pronounces life to be extinct.

\section{Hope of Recovery for the Apparently Dead.}

The venoms of all species of snakes exert a poisonous, paralyzing influence upon the nerve centres in the brain, and nervous system generally, differing more or less in their pathological effects according to the species.

However, although the venoms of the different species of snakes vary more or less in their effects, yet they, one and all, act as powerful nerve poisons. It has been urged by some 
writers and lecturers that a dose of venom sufficient to kill a healthy man will assuredly prove fatal if no actual antidotal measures are taken, such as the injection of anti-venene serum, for the reason that the venom destroys the nerve centres beyond the possibility of recovery. In other words, the venom actually annihilates the life of the nerve centres, by so altering the structure of their cells that it is quite impossible for recovery to take place.

Others ridicule the idea of a man's life being saved after breathing has ceased. Consequently they maintain that in cases of snake bite it is useless to resort to artificial respiration.

In animals injected with fatal doses of Cobra venom no destruction of the nerve cells was observed if they died within six hours. But in all cases where life was prolonged for twelve hours or more, it was noticed that preparations of nerve-substance, stained by Nissel's method, showed that the venom had acted upon considerable numbers of nerve cells. In some instances the outer coating of the cell had vanished; in others the whole cell was completely destroyed. This was particularly noticeable in the spinal cord.

However, except in extreme cases due to an excessive dose of Cobra venom, sufficient nerve cells are not destroyed to be the actual cause of death.

Snake venom, like other hypnotic drugs, poisons the nerve centres in the brain, medulla oblongata and spinal cords, more or less in accordance with the nature of the poison and the quantity introduced into the blood. Alcoholic liquor also causes extensive destruction of nerve cells, but does not usually destroy sufficiently to be a direct cause of death.

Animals which have been paralyzed by snake venom often recover. I have kept such animals for many months, and in no case have they showed any symptoms afterwards of damaged nervous systems.

Human beings who recover from snake bite become healthy and strong again. I have seen men lying insensible and apparently too far gone to recover. Yet they rallied and made complete recoveries. The case of Mr. James Williams, my assistant, is an excellent illustration. He was bitten by a Tree Snake or Boomslang (Dispholidus typus), and was as near 
death as it was possible for a man, and yet he lived. He lay for days almost insensible and completely paralyzed from head to foot.

Now, if snake venom permanently destroys the nerve centres, rendering them for ever incapable of resuming their functions, how comes it that Williams made a complete recovery? I have kept him under observation for three and a half years, and have failed to detect any harm having resulted to his nervous system. His mental functions remain unimpaired. Physically, he is as vigorous as he was prior to being bitten. For some months there were some slight after-effects, such as giddiness, but this can be attributed to the terrible benumbing influence which the venom exerted upon his whole nervous organization, and the mucous membranes of his body. It is a matter of surprise to all that he made so rapid a recovery, for the condition he was in for a week or two was most serious. To be realized fully it had to be witnessed.

When snake venom does not kill men, recovery invariably takes place rapidly. I have observed the same rapid recovery in animals. Those which I injected with a small amount of venom appeared as though about to die. After a time they rallied, and soon were as well as ever, excepting perhaps for local swellings, or patches of blood which had oozed from the small blood-vessels and accumulated under the skin. Rapid recoveries, however, are not usual with men who habitually use alcoholic liquor. In these cases I have observed more or less serious after-effects supervene, such as the sloughing away of the flesh at and near the site of the bite, and even mortification which necessitated amputation.

\section{Curare and Snake Venom.}

Curare is a powerful poison of vegetable origin, used by the natives of the northern parts of South America for poisoning the tips of their arrows. Curare acts upon the nerve centres in very much the same manner as snake venom. Like the latter, it is harmless if swallowed, providing, of course, there are no abrasions of the mouth, or catarrhal conditions of the stomach. 
When introduced into the blood it paralyzes the motor nerve centres in the brain, causing complete paralysis of the whole body.

It is well known in medical science that, in cases of poisoning by curare, if artificial respiration methods be resorted to after the patient has ceased to breathe and lies apparently dead, he can be restored. This clearly demonstrates that the poison benumbs the nerve centres, but does not destroy them.

Now, if patients can be restored by artificial respiration methods after being poisoned with curare when natural breathing has ceased and they lie apparently dead, such recoveries may also take place with those poisoned by snake venom.

\section{Elimination of the Poison.}

So long as the patient is breathing, the vital functions are active, and the venom is being slowly overcome and cast out of the body in a variety of ways; but the instant the breathing ceases, the functions of the body are suspended, the blood becomes charged with poisonous waste matters, and the patient rapidly dies, unless artificial respiration is resorted to in order to supply the blood with oxygen from the air.

If the victim of a Cobra bite sinks into unconsciousness, and the breathing ceases, it indicates that the venom has completely paralyzed the nerve centres controlling the lungs.

Now, if we instantly resort to artificial respiration methods, or if a cannula be inserted into the windpipe, and the lungs be inflated and deflated regularly, then, if the patient be not actually dead, the blood will begin to circulate, the vital functions will show signs of recovery, and natural breathing will, sooner or later, commence.

The object of artificial breathing in cases of snake bite is to keep the body alive long enough for it to expel sufficient of the venom to make recovery possible. As in cases of serious illness from other causes, so with snake bite. A crisis comes on, and if the patient can be kept alive while this terrible struggle between life's forces and deati is going on, by helping the resisting powers of the body, then it is possible for recovery to take place when otherwise death would have ensued. 
Naturally, if more venom is taken into the body than is sufficient under normal conditions to kill, artificial respiration would be useless, but no man can know just how much the snake has injected, and therefore it is desirable to resort to artificial respiration when the victim of snake bite has ceased to breathe.

\section{Experiments on ANiMALs.}

Experiments have been made on animals by injecting them with snake venoms and resorting to artificial respiration immediately breathing ceases. In this way life has been prolonged many hours. In one notable case a dog was bitten by a Sea Snake. Two hours later it ceased to breathe, apparently dying in convulsions. Artificial respiration was resorted to. This was kept up for some hours. A galvanic current was then applied, but no muscular contractions were aroused, and the eyes continued to be glazed, dry, and insensible to the touch.

The animal seemed as dead as it was possible for it to be. No sign of life remained. Any medical man would have pronounced it so. The last spark of life seemed to have gone out. But artificial respiration was kept up by relays of assistants. After sixteen hours the dog showed signs of life. The galvanic battery was again applied. This time the muscles contracted, and caused various movements of the body. The bowels and bladder acted. Another five hours showed still more advanced signs of recovery in the dog. The eyes were no longer dry and glazed. Tears were secreted, and suffused the eyes. Saliva flowed. The eye-lids closed and opened when the now sensitive cornea was touched, or when drops of water were poured into the eyes. The dog made attempts to swallow when water was poured into its mouth. It eventually partially recovered its senses, and moved its body and wagged its tail. Twice the animal relapsed, and artificial breathing was again resorted to. However, after twenty-four and a half hours, when recovery seemed certain, the dog began to sink. The heart slowed down, and eventually ceased to beat. All subsequent attempts at resuscitation failed.

Now, although this dog was, to all intents and purposes, dead, yet under artificial respiration methods it revived, and recovered 
the use of its muscles, brain, and nervous system to a certain degree. Yet although the dog did not eventually recover, the experiment demonstrated clearly that an animal apparently dead of snake venom could at least be temporarily revived. The dose of venom was evidently too great in this case to make recovery possible. In the case of curare the same thing happens. If the dose is large, artificial respiration methods fail to revive the victim.

The power of resistance to snake venom is much greater in vigorous, healthy human beings than it is in most animals such as dogs, monkeys, goats, sheep, rabbits. A full bite from an adult Cobra will kill a large dog or monkey within an hour In my experiments some died in ten minutes. A healthy human being would survive from two to six hours.

Dr. Vincent Richards succeeded in keeping a man bitten by an Indian Cobra alive for thirty hours by means of artificial respiration after normal breathing had ceased. Now, if it is possible to keep a man alive for thirty hours in this way, it is quite possible to save his life, because if anti-venene has been injected in sufficient quantity into a vein, it will neutralize the poison if the victim can be kept alive long enough. If a sufficient dose of anti-venene has been injected into a man and he should cease to breathe an hour or two later, it indicates that the remedy has not had sufficient time to penetrate into the lymph, and come into sufficiently close contact with the poisoned nerve, brain, and blood cells to exert its venom-neutralizing properties. Therefore if the patient can be kept alive for a few hours by means of artificial respiration and so give the anti-venene time to act fully upon the poison, there is no reason why he should not make a complete recovery. Of course, in these cases the anti-venene would have to be injected direct into a vein and in liberal quantities.

During the whole time artificial breathing methods were being carried on, the anti-venene would be busy preventing the venom from mixing with the nerve and blood cells. 



\section{CHAPTER XIII}

Latest Systematic List of South African Snakes for the Use of Museum Curators and Scientific Students.

Compiled by Dr. G. A. Boulenger, F.R.S., V.P.Z.S., of the British Museum.

(Inserted by kind permission of the British Museum Authorities and Dr. Boulenger.)

\section{PART II.-OPHIDIA.}

Synopsis of the Families represented in South Africa.

I. Worm-like, with the eyes under the more or less transparent head-shields; mouth very small, either the upper or the lower toothless; body covered with uniform scales.

Lower jaw toothless; ocular shield not bordering the mouth; at least 20 scales round the body .. ..

Upper jaw toothless; ocular shield bordering the mouth ; I.t scales round the body $\ldots$. . . Typhlopide.

Glanconiidee.

II. Eyes exposed; both jaws toothed; enlarged ventral shields usually present.

A. Maxillary bone horizontal, not vertically movable; poison-fangs, if present, small or rather small.

Præmaxillary bone toothed; rudiments of hind limbs, usually appearing externally as a claw-like horny spine on each side of the vent; labial shields with pits $\ldots \quad \ldots \ldots$. $\quad \ldots$.

No præmaxillary tooth; no rudiments of hind limbs;

labial shields without pits
B. Maxillary bone very short, vertically movable, bearing only the poison-fangs, which are usually very large.

\section{FAMILY TYPHLOPIDA. \\ A Single Genus in South Africa.}

\section{TYPHLOPS.}

Boida.

Colubrida.

Viperide.

Schneid. Hist. Amph. ii. p. 339 ; Bouleng. Cat. Sn. i. p. 7.

\section{Ten Species in South Africa.}

I. Snout rounded; 22 or 24 scales round the body.

Preocular much narrower than the ocular, in contact with the second and third labials ; diameter of body 42 to 45 times in total length

T. verticalis. 
Præocular a little narrower than the ocular, in contact with the second labial only; diameter of body 23 to 30 times in total length .. . . . ..

II. Snout with obtusely angular, not trenchant, horizontal edge.

24 scales round the body ; præocular in contact with the second and third labials; diameter of body 30 times in total length . . . . . . . . .

30 or 32 scales round the body; præocular in contact with the second labial only; diameter of body 24 times in total length; eye not distinguishable ...

30 to 34 scales round the body; præocular in contact with the second labial (rarely second and third); diameter of body 28 to 36 times in total length; eye distinct .. ... ...

III. Snout with sharp, trenchant, horizontal edge. A. Snout not hooked (in profile).

28 to 30 scales round body; diameter of body 35 to 50 times in total length .. . . . . . .

30 to 38 scales round body; diameter of body 25 to 35 times in total length .. .. . . . .

34 to 40 scales round body; diameter of body 42 to $f^{6}$ times in total length .. .. .. . . .

4o to 44 scales round body; diameter of body 25 to 30 times in total length .. . . . . . . B. Snout hooked; 24 or 26 scales round body; diameter of body 45 to 57 times in total length

T. formasinii.

T. mossambicus.

T. anchiete.

\title{
T. bibronii.
}

\author{
T. delalandii. \\ T. mucruso. \\ T. dinga. \\ T. schlegelii.
}

T. schinzi.

I. TYPHLOPS VERTICALIS.

Onychocephalus verticalis, Smith, Ill., Rept. pl. liv.

Typhlops verticalis, Bouleng., t.c., p. 32 .

Interior of South Africa.

Malmesbury (H. Gird).

2. Typhlops fornasinit, Bianconi, Spec, Zool. Mosamb. p. I3, pl. iii. fig. I; Bouleng., t.c., p. 38.

Portuguese East Africa.

Delagoa Bay (De Coster).

3. TYPhLOPS mossambicus.

Onychocephalus mossambicus, Peters, Mon. Berl. Ac., I854, p. 62 I.

Typhlops mossambicus, Bouleng., t.c., P. $4 \mathrm{I}$.

Portuguese East Africa, Zululand.

4. Typhlops anchiet.e, Bocage, Jorn. Sc. Lisb. xi. I 886, p. I 72 ; Bouleng., t.c., p. 4 o.

Angola, Transvaal.

5. TYPHLOPS BIBRONII.

Onychocephalus bibronii, Smith, Ill., Rept. pl. li. fig. 2, and liv. figs. $5-8$.

Typhlops bibronii, Bouleng., t.c., p. 44 .

Cape Colony, Basutoland, Natal.

Cape Colony: Malnuesbury (Gird) ; Bathurst District (Becker) ; Port St. Johns (Shortridge); Matatiele, East Griqualand (Tyrrel); Little Namaqualand (Péringuey).

Basutoland: Morija (Dyke).

Transvaal: Lydenburg (Kilgour).

6. Typhlops delalandr, Schleg. Abbild. p. $3^{8}$, pl. xxxii. figs. I7-20 ; Bouleng., t.c., p. 45 . 
Cape Colony, Natal, Orange River Colony, Transvaal, Southern Rhodesia.

Cape Colony: Cape Peninsula (Fairbridge, de Souza, Purcell) ; Malmesbury (Gird); Burghersdorp (Kannemeyer); Tulbagh (Kleinschmidt); Prince Albert (Purcell); Innsna (Maritz) ; Port Elizabeth (Weale, Drege); Middelburg (Piers); Calvinia (Leipoldt); Caledon (Burger); Worcester (Purcell, Paynter) ; Stellenbosch (Lightfoot): Robertson (Melle); Hanover (Schreiner) ; Graaff-Reinet (Paynter); Touw's River, Worcester District (Purcell) ; Iittle Namaqualand (Péringuey).

Orange River Colony: Smithfield (Kannemeyer).

7. Typhlops MUCRUSO.

Onychocephalus mucruso, Peters, Mon. Berl. Ac., I854, p. $62 \mathrm{I}$.

Typhlops mucruso, Bouleng., t.c., p. 46.

Tropical Africa to Portuguese East Africa, Southern Rhodesia, and Transvaal.

Transvaal: Barberton (Rendall).

Southern Rhodesia: Salisbury (Darling, Marshall).

Portuguese East Africa: Delagoa Bay (De Coster).

8. Typhlops Dinga.

Onychocephahus dinga, Peters, Mon. Berl. Ar.., 1854, p. 620.

Typhlops dinga, Bouleng., t.c., p. 45.

Portuguese East Africa, Southern Rhodesia.

9. Typhlops schlegeli, Bianconi, Spec. Zool. Mosamb. p. 13, pl. iii. tig. 2 ; Bouleng., t.c., p. 44.

East and Central Africa to Portuguese East Africa and Southern Rhorlesia.

Delagoa Bay (De Coster).

Io. Typhlops schinzi, Boettger, Ber. Senck. Ges., I887, p. I54, pl. V. fig. I ; Bouleng., t.c., p. 47.

Northern parts of Cape Colony.

Little Namaqualand (Turle) ; Carnarvon (Hanau).

FAMILY GLAUCONIIDAE.

A single Genus in South Africa.

I. GLAUCONIA.

Gray, Cat. Liz. p. I39; Bouleng. Cat. Sn. i. p. 59.

Six Species in South Africa.

I. Supraocular present.

A. Rostral separated from the supraocular by the upper part of the nasal; diameter of body $4^{\circ}$ to 60 times in total length ... .. ..

B. Rostral in contact with the supraocular.

a. Rostral not more than twice the width of the nasal, extending to or slightly beyond a line connecting the posterior borders of the eyes.

Diameter of body 47 to 70 times in total length

G. nigricans.

Diameter of body 90 to I Io times in total length

$b$. Rostral very large, at least tivice as broad as

G. conjuncta. the nasal and extending beyond a line connecting the posterior border of the eyes; diameter of body 50 to 80 times in total length.

G. gracilior. 
$\begin{array}{lllllllllll}\text { Snout rounded } & \ldots & \ldots & \ldots & \ldots & \ldots & \ldots & \text { G. scutifrons. }\end{array}$

Snout with the preoral part concave, appearing slightly

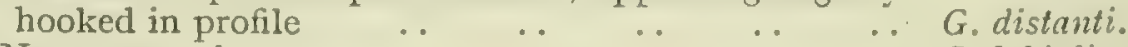

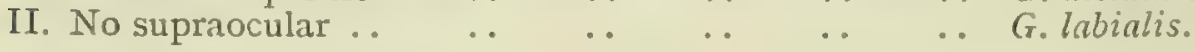

I. Glauconia nigricans.

Typhlops nigricans, Schleg. Abbild. p. 3S, pl. xxxii. figs. 21-24.

Glauconia nigricans, Bouleng., t.c., p. 67.

South Africa.

Cape Colony: Kentani (Kolbe) ; Swellendam (Fry); Engcobo (Weisbecker); Port Elizabeth (Weale, Drege).

2. Glauconia conjuncta.

Stenostoma conjunctum, Jan, Arch. Zool. Anat. Phys. i., I86I, p. I89.

Glauconia conjuncta, Bouleng., t.c., p. 67 .

South and East Africa.

Cape Colony: Swellendam (Fry); Engcobo (Weisbecker); Aliwal North (Weisbecker) ; Burghersdorp (Kannemeyer).

Basutoland: Korokoro (Sclater).

Natal: Umvoti (Fry).

Transvaal: Lydenburg (Fry); Modderfontein (Purcell).

3. Glauconia gracilior, sp. n.

Cape Colony.

Van Rynsdorp (A. W. Rogers); Matjesfontein (Purcell) ; Clanwilliam (Leipoldt).

4. Glauconia scutifrons.

Stenostoma scutifrons, Peters, Mon. Berl. Ac., I854, p. 621.

Glauconia scutifrons, Bouleng., t.c., p. 68.

Glauconia latifrons, Sternfeld, Sitzb. Ges. Nat. Fr. Berl., I9oS, p. 94.

South Africa, Angola.

Cape Colony: Burghersdorp (Kannemeyer).

Natal: Umvoti (Fry).

Transvaal: Pietersburg (Daneel).

Southern Rhodesia: Bulawayo (Kolbe); Matoppo Hills (Pillans) Salisbury (Marshall).

5. Glauconia distanti, Bouleng, in Distant, Nat. Transv. p. I75, fig., and t.c., P. 62.

Transvaal, Southern Rhodesia, British Central Africa.

Transvaal: Pretoria (Gough); Pietersburg (Daneel).

Southern Rhodesia: Palapye, Bechuanaland (Fry).

6. Glauconia labialis, Sternfeld, $t . c$, p. 92.

German South-West Africa.

FAMILY BOIDE.

A single Genus in South Africa.

I. PYTHON.

Daud. Hist. Rept. v. p. 266 ; Bouleng. Cat. Sn. i. p. 85.

I. PYTHON SEBK.

Coluber seba, Gmel. S. N. i. p. II I 8.

Python sebre, Bouleng., t.c., p. 86.

Natal, Zululand, Transvaal, Southern Rhodesia, Portuguese East Africa, Tropical Africa.

Natal: Durban (Bowker).

Southern Rhodesia: Salisbury (Thomas). 
FAMILY COLUBRIDE.

Synopsis of the South African Genera.

I. Aglypha, without grooved fangs in the upper jaw.Harmless.

A. Scales smooth, in I9 rows or more.

I. Pupil round; posterior maxillary teeth longest.

Scales in I9 rows; internasal not entering the nostril; snout rounded ..

Scales in 27 to $3 I$ rows ; internasal entering the nostril ; snout with vertical sides, more or less prominent...

2. Pupil vertically elliptic or subelliptic; anal entire.

Scales in I9 rows; frontal at least once and a half as long as broad; maxillary teeth equal .....

Scales in I9 to 23 rows; frontal broad and short; posterior maxillary teeth shortest $\cdots$. .

Scales in 23 to 33 rows, with apical pits; anterior
maxillary teeth strongly enlarged .. B. Scales smooth, in I 5 or 17 rows.

I. Tail short (sub-caudals not more than 50 pairs).

Pupil vertically elliptic ; rostral small; antericr maxillary teeth longest .. . . . . . .

Pupil vertically elliptic; rostral very large, with angular horizontal edge; posterior maxillary teeth strongly enlarged $\quad . \quad \ldots \quad \ldots \quad \ldots \ldots \ldots$.

Pupil round; rostral smaill nasal single; anterior maxillary teeth longest ... . . . .

2. Tail long (sub-caudals more than 80 pairs); pupil round; posterior maxillary teeth longest.

Sub-caudals not reeled

Sub-caudals keeled and notched $\cdots \quad \ldots \quad \ldots \quad \ldots$

C. Scales keeled; pupil vertically elliptic.

Scales in 15 to 17 rows, of vertebral row enlarged and bicarinate; anterior maxillary teeth longest ..

Scales in 23 to 27 rows, laterals very oblique and with serrated keels; teeth very small and few .. ..

II. Opisthoglyphe, with grooved fangs at the posterior end of the upper jaw.-More or less poisonous.

A. Eye moderate or large ; head more or less distinct from neck.

I. Subcaudals single; pupil vertically elliptic ; parietals broken up into small shields ..

2. Subcaudals in pairs.

a. Pupil vertically elliptic; scales in $\mathbf{I} 7$ or I9 rows.

Anal divided; loreal separated from the eye by the præocular: maxillary teeth decreasing in size posteriorly .. . . . . . . . . . .

Anal entire; 1 oreal separated from the eye by the præocular; maxillary teeth increasing in size pos-

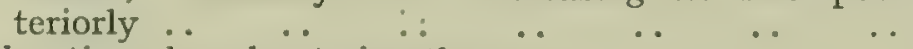

Anal entire; loreal entering the eye $\quad \ldots \quad \ldots$

Tropidonotus.

Pseudaspis.

Ablabophis.

Lamprophis.

Boodon.

Lycophidium.

Prosymna.

Homalosoma.

Chlorophis.

Philothammus.

Simocephalus.

Dasypeltis.

Pythonodipsas.

Tarbophes

Leptodira.

Chametortus.

$b$. Pupil round.

$\alpha$. Scales smooth (or feebly keeled on the posterior part of the back) in I3 to 17 rows. 
Rostral moderate; nostril in a single, semidivided nasal Rostral moderate; nostril between two nasals and the internasal; maxillary teeth subequal .. ..

Rostral large, projecting, snout pointed .. ... ..

Rostral moderate; nostril between the nasals; one or two middle maxillary teeth much enlarged . .

$\beta$. Scales keeled, in 19 or $2 \mathrm{I}$ rows; eye very large .. ... .. . .

c. Pupil horizontal; eye large; scales in I9 rows; body very slender... ..

B. Eye small or very small; head not distinct from

Amplorhinus.

Trimerorhinus.

Rhamphiophis.

Psammophis.

Dispholidus.

Thelotornis. neck.

r. Sub-caudals in pairs; no præocular.

Scales in 15 rows; no internasals .. .. .. Amblyodipsas.

Scales in 17 or 19 rows; internasals present $\ldots \quad \ldots$ Calamelaps.

2. Sub-caudals single.

Scales in 23 to 27 rows; no præocular .. ... .. Macrelaps.

Scales in 15 rows; nasal in contact with a pracocular .. Aparallactus.

III. Proteroglypha, with grooved fangs at the anterior end of the upper jaw.-Poisonous.

A. Tail compressed, oar-shaped; head narrow and elongate; no distinctly enlarged ventrals (Seasnakes)

B. Tail cylindrical, ending in a point.

-Hydrus.

I. Head short.

a. Scales in 17 rows or more; internasal bordering the nostril.

Rostral moderate; scales smooth .. . . . Naia.

Rostral moderate; scales strongly keeled $\quad \ldots \quad \ldots$ Sepedon.

Rostral very large, detached on the sides; scales smooth

or keeled on posterior part of body .. .. .. Aspidelaps.

b. Scales in $\mathbf{I} 3$ or $\mathbf{I} 5$ rows.

Nostril between two nasals; scales in 13 rows; eye

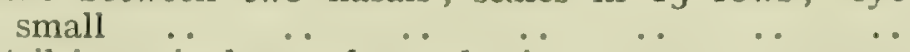

Nostril in a single nasal; scales in 15 rows; eye very

small 2. Head narrow, elongate; scales very oblique,

in I9 to 23 rows; body slender .. .. Dendraspis.

\section{A.-AGLYPHE.}

\section{TROPIDONOTUS.}

Kuhl, Bull. Sc. Nat. ii., I824, p. 8 I ; Bouleng. Cat. Sn. i. p. I92.

\section{Two Species in South Africa.}

Ventrals $162-180$; anal entire . $\quad \ldots \quad \ldots \quad \ldots$ T. lavissmus.

Ventrals I $3 \mathrm{I}-\mathrm{r} 49$; anal divided $\ldots \quad \ldots \quad \ldots \quad \ldots T$. olivaceus.

I. TROPIDONOTUS LAVISSIMUS.

Natrix lavissima, Günth. Ann. \& Mag. N. H. (3) ix., 1862, p. I24, pl. ix. fig. 4 .

Tropidonotus lavissimus, Bouleng., t.c., p. 226.

Grayia lubrica, W. Sclater, Ann. S. Afr. Mus. i., 1898, p. Iog, pl. V, fig. I.

Cape Colony, Natal.

Tsomo, Transkei District.-Type of Grayia lubrica. 
2. Tropidonotus olivaceus.

Coronella olivacea, Peters, Mon. Berl. Ac., I854, p. 622.

Tropidonotus olivaceus, Bouleng., t.c., p. 227.

Tropical Africa to Southern Rhodesia.

Mashonaland: Salisbury (Marshall).

\section{ABLABOPHIS.}

Bouleng. Cat. Sn. i. p. 318.

I. ABlabophis REFULUS.

Coronella nufula, Lichtenst, Veru. Doubl. Mus. Berlz. p. Io5.

Ablabophis rufulus, Bouleng., t.c.

South Africa.

Cape Colony: Cape Town (de Souza, Oakley) ; Robben Island (Fisk) ; Stellenbosch (Péringuey) ; Knysna (Groom); Port St. Johns (Shortridge); Touw's River, Worcester (Le Fèvre); Prince Albert (Purcell); Burghersdorp (Kannemeyer); Clanwilliam (Leipoldt); George (Leipoldt); Port Elizabeth (Drege, Moorhouse); Albany District (French).

Natal: Durban (Bowker, Sanderson).

Transvaal: Modderfontein (Haagnef).

German South-West Africa: Damaraland (Palgrave).

\section{LAMPROPHIS.}

Smitn, Ill., Rept.; Bouleng. Cat. Sn. i. p. 320.

\section{Four Species.}

I. Scales in 23 rows.

Internasals a little shorter than the præfrontals; loreal a little longer than deep $\ldots$.. $\quad . \quad \ldots$

Internasals much shorter than the præfrontals; loreal at least nearly twice as long as deep .. . . . .

Internasals longer than the præfrontals; loreal as long as deep or a little longer than deep .. .. .. L. fiskii.

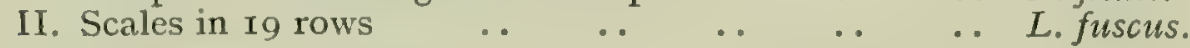

I. LAMPROPHIS AURORA.

Coluber aurora, Linn. S. N. i. p. 379.

Lamprophis aurora, Bouleng., t.c., p. $32 \mathrm{I}$.

Cape Colony, Orange River Colony, Transvaal.

Cape Colony: Cape Town (Stevens, Gardiner, E. A. Morris), Burghersdorp (Kannemeyer).

Orange River Colony: Smithfield (Kannemeyer).

Transvaal: Modderfontein (Haagner).

2. Lamprophis inornatus, Dum. \& Bibr. Erp. Gén. vii. p. 464.

Cape Colony.

Cape Town (French). Also 2655.

3. LaMProphis FISkir, Bouleng. P.Z.S., I887, p. 398, pl. xxxiv., and t.c. p. 322.

Cape Colony.

Worcester (Le Fèvre).

4. Lamprophis fuscus, Bouleng. Cat. Sn. i. p. 322, pl. xx., fig. 4.

Cape of Good Hope. 
4. BOODON.

Dum. \& Bibr. Mém. Ac. Sc. xxiii., 1853, p. 460 ; Bouleng. Cat.

Sn. i. p. 327 .

Four Species in South Africa.

I. Scales in 23 or 25 rows; three labials entering the eye.

Two postoculars; præocular not extending to upper surface of head; ventrals I75-196 .. .. ..

Three postoculars; præocular extending to upper surface of head; ventrals $196-2$ ro . . . . . . . . B. guttatus.

II. Scales in 27 to 33 rows; ventrals 192-237.

Two (rarely three) labials entering the eye ; two pairs of chin-shields in contact with each other ... ..

Three labials entering the eyc; only one pair of chinshields meeting on the median line .. $\quad . . \quad \ldots \quad B$, mentalis.

I. Boodon infernalis, Günth. Cat. Col. Sn. p. Ig9; Bouleng., t.c., p. 330, pl. xxi. fig. $I$.

East and South Africa.

Cape Colony: Cape Town (Southey, Oakley); Cape Division (Layard, Southey, Oakley, Sclater); Robben Island (Denysson, Péringuey); Inysna (Groom); Port St. Johns (Shortridge); Kimberley (French); King William's Town (Godfrey).

2. Boodon Guttatus.

Lycodon guttatus, Smith, Ill., Rept. pl. xxiii.

Boodon guttatus, Bouleng., t.c., p. 33I.

Cape Colony.

Cape Town (Layard); O'okiep (Howard); Burghersdorp (Kannemeyer).

3. Boodon lineatus, Dum. \& Bibr. Erp. Gén. vii. p. 363 ; Bouleng., t.c., p. 332 .

Tropical and South Africa.

Cape Colony: Cape Division (no history); Burghersdorp (Kannemeyer) ; Port St. John's (Shortridge) ; Knysna (Groom) ; Touw's River, Worcester Division (Le Fevre, Purcell); Beaconsfield (Paynter); Robertson (Melle); Hanover (Schreiner); Beaufort West (Haagner) ; Ograbis, Little Namaqualand (Strauss).

Natal: Durban (Bowker, Sanderson).

Transvaal: Modderfontein (Haagner); Potchefstroom (Gilchrist).

Rhodesia: Mazoe (Darling); Salisbury (Darling, Marshall, Thomas) ; Livingstone (Sykes).

Portuguese East Afica: Delagoa Bay (De Coster).

4. Boodon mentalis, Günth. Ann. \& Mag. N. H. (6) i., I888, p. 33 i, pl. xx. fig. A; Bouleng., t.c.. p. 335 .

Damaraland.

\section{LYCOPHIDIUM.}

Dum. \&e Bibr. MIém. Ac. Sc. xxiii., 1853, p. 462 ; Bouleng. Cat. Sn. i. p. 336 .

Two Species in South Africa.

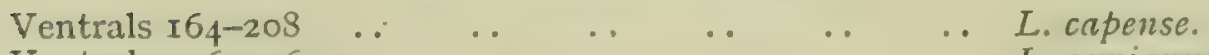

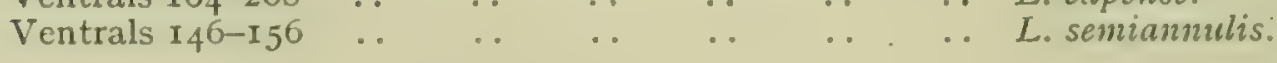


1. LyCOPHIDIUM CAPENSE.

Lycodon capensis, Smith, S. Afr. Quart. Journ. No. 5, I83I, p. I8.

Lycophidium capense, Bouleng., t.c., p. 339.

Tropical and South Africa.

Cape Colony: Grahamstown (Schönland); Port Elizabeth (Moorhouse): Burghersdorp (Kannemeyer).

Natal: Durban (Bowker).

Transveaal: Johannesburg (Elleman).

Southern Rhodesia: Mazoe (Darling); Salisbury (Marshall, Thomas).

2. Lycophidium Semiannulis, Peters, Mon. Berl. Ac., I854, p. 622 ; Bouleng., t.c., p. 339.

Portuguese East Africa, Zululand.

\section{SIMOCEPHALUS.}

Günth. Cat. Col. Sn. p. 194; Bouleng. Cat. Sn. i. p. 344.

Two Species in South Africa.

Frontal a little shorter than the parietals; two postoculars; ventrals $203^{-2} 4^{\mathrm{I}} \quad . \quad \ldots \quad . . \quad \ldots$ S. capensis.

Frontal much shorter than the parietals : a single post-

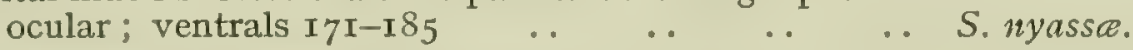

I. Simocephalus CAPENSIS.

Heterolepis capensis, Smith, Ill., Rept. pl. 1v.

Simocephalus capensis, Bouleng., t.c., p. 345.

Central Africa, Portuguese East Africa, Southern Rhodesia, Natal.

Natal: Durban (Bowker); Southern Rhodesia: Salisbury (Marshall).

2. Simocephalus nyass $x$, Günth. Ann. \& Mag. N. H. (6) i., I888, p. 328 ;

Bouleng., t.c., p. 347 , pl. xxiii. fig. 2.

East and Central Africa, Portuguese East Africa, Natal, Transvaal.

Natal: Durban (Bowker).

Portuguese East Africa: Delagoa Bay (Péringuey).

\section{PSEUDASPIS.}

Cope, Proc. Ac. Philad., I864, p. I68; Bouleng. Cat. Sn. i. p. 373.

I. Pseudaspis cana.

Coluber cana, Linn. S. N. i. p. $38 z$.

Pseudaspis cana, Bouleng., l.c.

South Africa to Angola and British East Africa.

Cape Colony: Cape Division (Smith, Bishop, Layard, Southey, Oakley,

Kolbe); Tzitzikamma River (Harrison); Beaufort West (Jackson); Graaff-Reinet (Kannemeyer); Burghersdorp (Kannemeyer); Middelburg (Picrs); Tsomo, Transkei (Watermeyer); Port Elizabeth (Drege, Moorhouse); Port Nolloth (Howard) ; Hanover (Schreiner); Worcester (Paynter); Littlc Namaqualand (Péringuey, Christensen, Scully).

Natal (Sanderson).

Orange River Colony: Smithfield (Kannemeyer).

Transvaal: Johannesburg (Ross); Modderfontein (Haagner).

Southern Rhodesia: Mazoe (Darling); Salisbury (Thomas). 


\section{CHLOROPHIS.}

Hallow. Proc. Ac. Philad., 1857, p. 52 ; Bouleng. Cat. Sn. ii. p. 91.

$$
\text { Four Species in South Africa. }
$$

I. Ventrals without keels.

Two labials entering the eye; sub-caudals 85-107 .. C. hoplogaster.

II. Ventrals with distinct lateral keels.

Two labials entering the eye ; a single anterior temporal ; sub-caudals 77-II4 … … $\quad \ldots$.

Two labials entering the eye; usually two superposed anterior temporals; sub-caudals II $4-I_{4}{ }^{\circ} \ldots$. . C. natalensis.

Three labials entering the eye; sub-caudals $94-133 \quad \ldots \quad$ C. irregularis.

I. Chlorophis hoplogaster.

Ahretulla hoplogaster, Günth. Ann. \& Mag. N. H. (3) xi., I863, p. 284. Chlorophis hoplogaster, Bouleng., t.c., p. 93, pl. v. fig. 2.

South Africa, Central and East Africa.

Cape Colony: Wynberg? (Gardner); Port Elizabeth (Cregoe, Moorhouse) ; Port St. Johns (Shortridge); Innysna (Baimbridge).

Natal: Durban (Bowker, Sanderson).

Transvaal: Barberton (Rendall).

2. Chlorophis NEGLECTUS.

Philothammus neglectus, Peters, Mon. Berl. Ac., I866, p. 890.

Chlorophis neglectus, Bouleng., t.c., p. 94.

East Africa, Southern Rhodesia, British Central Africa.

Southern Rhodesia: Salisbury (Marshall).

3. Chlorophis natalensis.

Dendrophis natalensis, Smith, Ill., Rept. pl. lxiv.

Chlorophis natalensis, Bouleng., t.c., P. 94.

South and Central Africa.

Cape Colony: Mossel Bay (Layard); Port St. Johns (Shortridge) : Port Elizabeth (Moorhouse); Kimberley (French); Tsomo (Watermeyer).

Natal: Durban (Sanderson).

Transvaal: Lydenburg (Kilgou).

North Western Rhodesia: Kafue River (Drury).

4. Chlorophis irregularis.

Coluber irregularis, Leach, in Bowdich, Ashantee, p. 494.

Chlorophis irregularis, Bouleng., t.c., p. 96.

Tropical Africa, Southern Rhodesia.

Southern Rhodesia: Mazoe (Darling): Salisbury (Marshall, Thomas).

\section{PHILOTHAMNUS.}

Smith, Ill., Rept. ; Bouleng. Cat. Sn. ii. p. $9^{8 .}$

\section{A single Species in South Africa.}

Philothamnus semivariegatus, Smith, op. co, pls. lix. and $1 \mathrm{x}$.; Bouleng., t.c., p. 99.

Tropical and South Africa.

Cape Colony: Douglas (Orpen).

Transvaal: Barberton (Rendall).

Rhodesia: Salisbury (Thomas, Darling); Livingstone (Stephenson).

Portuguese East Africa: Delagoa Bay (De Coster). 


\author{
Io. PROSYMNA.
}

Gray, Cat. Sn. p. 80 ; Bouleng. Cat. Sn. ii. p. 246.

Five Species in South Africa.

I. Scales smooth, in I5 rows.

A. Internasal paired; two superposed anterior

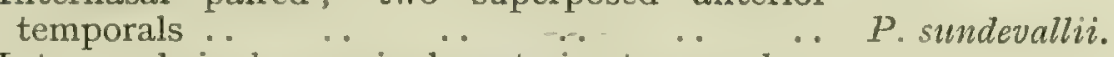

B. Internasal single; a single anterior temporal.

Width of the frontal not half the width of the head; ventrals 167 ; subcaudals $50 \ldots$... ...

Width of the frontal more than half the width of the head; ventrals I3I-I53; subcaudals I9-34 ..

Width of the frontal more than half the width of the head; ventrals $169-185$; subcaudals $38-49 \ldots$ bergeri.

II. Scales keeled, in 17 rows; a single internasal _. P. jani.

I. Prosymna sundevalliI.

Temnorhynchus sundevallii, Smith, Ill., Rept., App. p. I7.

Prosymna sundevallii, Bouleng., t.c., p. 247.

Cape Colony, Natal Orange River Colony, Transvaal.

Cape Colony: Burghersdorp (Kannemeyer) Clanwilliam (Slabber); Hanover (Schreiner) ; Graaff-Reinet (Paynter) ; Tulbagh (Lightfoot) ; Little Namaqualand.

2. Prosymana frontalis.

Temnorhynchus frontalis, Peters, Mon. Berl. Ac., 1867, p. 236, pl. fig. $I$.

Prosymna frontalis, Bouleng., t.c., p. 248.

German South-West Africa, Angola.

3. Prosyma ambigua, Bocage, Jorn. Sc. Lisb. iv., I873, p. 218 ; Bouleng., t.c., p. 248.

Southern Rhodesia, Zululand, East Africa, Angola.

4. Prosyma bergeri, Lindholm, Jahrb. Nassau. Ver. lv., 1902, p. 57.

German South-West Africa.

5. Prosymna Jani, Bianconi, Mem. Acc. Bologna (2) i. i862, p. 470, pl. i. ; Bouleng., t.c., p. 249.

Portuguese East Africa, Zululand.

\title{
I I. HOMALOSOMA.
}

Wagler, Syst. Amph. p. I90; Bouleng. Cat. Sn. ii. p. 273. Two Species in South Africa.

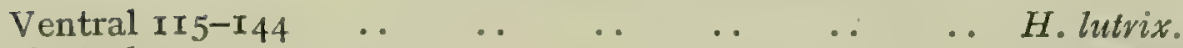

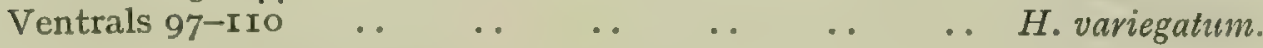

I. Homalosoma lutRix.

Coluber lutrix, Linn. S. N. i. p. 375.

Homalosoma hutrix, Bouleng., t.c., p. 274.

Homalosoma shiranum, Bouleng., t.c., p. 276.

South Africa, Central and East Africa.

Cape Colony: Cape Town (Oakley); East London (Wood) ; Caledon (Burgess) ; Port St. Johns (Shortridge); Innsna (Groom) ; Burghersdorp (Kannemeyer) ; Middelburg (Piers) ; Paarl (Purcell) : Port Elizabeth (Moorhousc); Little Namaqualand (Péringuey).

Transvaal: Barberton (Rendall). 
2. Homalosoma variegatum, Peters, Mion. Berl. Ac., I854, p. 622; Bouleng., t.c., p. 276.

Portuguese East Africa, Zululand.

Delagoa Bay (De Coster).

\section{I2. DASYPELTIS.}

Wagler, Syst. Amph. p. I 78 ; Bouleng. Cat. Sn. ii. p. 353.

A single Species in South Africa.

I. DASYPELTIS SCABRA.

Coluber scaber, Linn. S. N. i. p. 384.

Dasypeltis scabra, Bouleng., t.c., p. 354.

Tropical and South Africa, Egypt.

Cape Colony: Cape Town (Pillans); Swellendam (Cairncross) ; Worcester (Le Fèvre); Murraysburg (Tyson) ; East London (Wood) :

Port St. Johns (Shortridge); Burghersdorp (Kannemeyer) ; Clanwilliam (Schlechter); Hanover (Schreiner); Graaff-Reinet (Paynter); Port Elizabeth (Drege); Little Namaqualand (Warden).

Basutoland: Morija (Dyke).

Natal: Durban (Bowker).

Transvaal: Johannesburg (Ross); Modderfontein (Haagner).

Southern Rhodesia: Salisbury (Thomas, Darling)

Portuguese East Africa: Delagoa Bay (De Coster).

\section{B.-OPISTHOGLYPHE.}

\section{I3. PYTHONODIPSAS.}

Günth. Ann. \& Mag. N. H. (4) i., I868, p. 425; Bouleng. Cat. Sn. iii. p. 45 .

I. Pythonodipsas carinata, Günth., t.c., p. 426 ; Bouleng., l.c.

Zambesi, Damaraland.

Damaraland (Nightingale).

\section{I4. TARBOPHIS.}

Fleischm. Dalm. nov. Serp. Gen. p. I7; Bouleng. Cat. Sn. iii. p. 47. A single Species in South Africa.

I. TARBOpHis semiannulatus.

Telescopus semiannulatus, Smith, Ill., Rept. pl. Lxxii.

Tarbophis semiamulatus, Bouleng., t.c., p. 5I.

Basutoland, Transvaal, Rhodesia, Portuguese East Africa, Central and liast Africa.

Basutoland: Sesheke (Jella).

Transvaal: Barberton (Randall).

Portuguese East Africa: Delagoa Bay (De Coster).

\section{I5. LEP'TODIRA.}

Günth. Cat. Col.Sn. p. 165 ; Bouleng. Cat. Sn. iii. p. 88.

A single Species in South Africa.

I. I.EPTODIRA hotAMiBEIA.

Coronella hotamboia, Laurenti, Syn. Rept. p. 85 . 
Leptodiva hotambcia, Bouleng., t.c., p. 89.

Tropical and South Africa.

Cape Colony: Cape Town (de Souza); Port Elizabeth (Moorhouse, Drege); Burghersdorp (Kannemeyer); Clanwilliam (Leipoldt) ; Worcester (Purcell); East London (Wood); Port St. Johns (Shortridge); Hanover (Schreiner); Kimberley (French); Little Namaqualand (Schlechter).

Basutoland: Morija (Dyke).

Natal : Pine Town (Bowker) ; Malvern (Bowker).

Transvaal: Barberton (Rendall).

Southern Rhodesia: Salisbury (Marshall).

Portuguese East Africa: Delagoa Bay (De Coster).

\section{I6. CHAM E⿰TORTUS.}

Günth. P.Z.S., r864, p. 310; Bouleng. Cat. Sn. iii. p. 98.

1. Chametortus aulicus.

Günth., l.c., pl. xxvi. fig. 2 ; Bouleng., l.c.

East and Central Africa, Portuguese East Africa, Transvaal.

Leydsdorp, Transvaal (Norton).

\section{I7. AMPLORHINUS.}

Smith, Ill., Rept. ; Bouleng. Cat. Sn. iii. p. I24.

I. Amplorhinus multimaculatus, Smith, op.c., pl. lvii.; Bouleng., t.c., P. I25.

Cape Peninsula.

Cape Peninsula (de Souza, Sclater).

I8. TRIMERORHINUS.

Smith. Ill., Rept.; Bouleng. Cat. Sn. iii. p. 138 .

Two Species in South Africa.

Eye as long as its distance from the nostril . . . T. rhombeatus.

Eye shorter than its distance from the nostril .. .. T. tritceniatus.

I. TRIMERORHINUS RHOMBEATUS.

Coluber rhombeatus, Linn. S. N. i. p. 380.

Trimerorhinus rhombeatus, Bouleng., l.c.

Psammophis longementalis, Roux, Zool. Jahrb., Syst. xxv., 1907, p. 736, pl. xxvii.

South Africa, Angola.

Cape Colony: Cape Peninsula (Finlay, Sclater): Tulbagh (Kleinschmidt) ; Touw's River (Le Fevre) ; Knysna (Groom) ; Burghersdorp (Kannemeyer); Robertson (Melle); Worcester (Paynter) ; Clanwilliam (Schlechter) : Middelburg (Piers) ; George (Leipoldt) : Caledon (Burges); Uitenhage (O'Neil); Port Elizabeth (Moorhouse); Kimberley (French); Tsomo, Transkei (Watermeyer).

Orange River Colony: Harrismith (Ross).

Transvaal : Lydenburg (Kilgour); Krugersdorp (Watson).

2. TRIMERORHINUS TRITENIATUS.

Rhagerrhis tritceniata, Günth., Ann. \& Mag. N. H. (4) i., I868, p. 423, pl. xix. fig. $\mathrm{H}$.

Trimerorhinus tritceniatus, Bouleng., t.c., p. I39.

Northern parts of Cape Colony, Transvaal, Tropical Africa.

Cape Colony: Barkly West (Tucker); Kuruman (Moffat).

Southern Rhodesia: Salisbury (Marshall). 
19. RHAMPHIOPHIS.

Peters, Mon. Berl. Ac., I854, p. 624; Bouleng. Cat. Sn. iii. p. I44. A single Species in South Africa.

I. Rhamphiophis multimaculatus.

Coronella multimaculata, Smith, Ill., Rept. pl. lxi.

Rhamphiophis multimaculatus, Bouleng., t.c., p. I $4^{8 .}$

Northern parts of Cape Colony, Orange River Colony, German SouthWest Africa.

Cape Colony : Little Namaqualand (Howard) : Kenhardt (Schlechter) : Hanover (Schreiner); Burghersdorp (Kannemeyer).

Orange River Colony: Smithfield (Kannemeyer).

\section{PSAMMOPHIS.}

Boic, Isis, I 827 , p. 52 ; Bouleng. Cat. Sn. iii. p. I 52.

\section{Ten Species in South Africa.}

I. Scales in 17 rows; ventrals $154-198$.

A. Anal entire; two præoculars .. .. .. P. notostictus.

B. Anal divided (rarely entire).

I. Præocular extensively in contact with the frontal; forehead concave ; two labials entering the eye... ... ...

2. Præocular narrowly in contact with or separated from the frontal.

a. Two præoculars; rostral considerably broader than deep.

8 upper labials, 3 entering the eye .. $\quad \ldots \quad \ldots \quad$. . transvaaliensis.

9 upper labials, 2 entering the eye $\quad . \quad \ldots \quad \ldots P$. trigrammus.

9 upper labials, 3 entering the eye .. . . . P. bocagii.

b. A single præocular; rostral as deep as broad or slightly broader than deep ; two labials entering the eye.

Frontal, in the middle, narrower than the supraocular ; sub-caudals $90-116 \ldots$. . . . . .

Frontal, in the middle, nearly as broad as the supraocular; sub-caudals $64-95 \ldots \ldots$. . . . . . Previrostris.

II. Scales in 15 rows.

Præocular extensively in contact with the frontal;

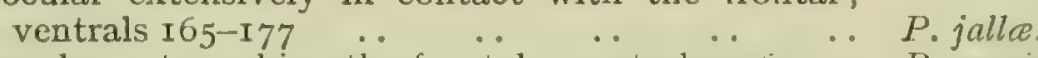

Præocular not reaching the frontal; ventrals I $36-155 \quad P$. crucifor.

III. Scales in I3 rows; ventrals $\mathrm{I}_{4}^{\mathrm{I}-\mathrm{I} 55} \quad \ldots \quad \ldots P_{\text {. angolensis. }}$

I. Psammophis notostictus, Peters, Mon. Berl. Ac., I867, p. 237 ; Bouleng., t.c., p. 156 .

South Africa, Angola, Lower Congo.

Cape Colony: Cape Town (Rosser, Lightfoot); Stellenbosch (Francke); Grahamstown; Middelburg (Piers); Victoria West (Piers); 'Touw's River (Le Fèvre); Beaufort West (Jackson); GraaffReinet (Paynter); Burghersdorp (Kannemeyer); Malmesbury Division (Kisel) ; Ceres (Purcell) ; Caledon (Burges); Robertson (Melle); Hanover (Schreiner); Port St. Johns (Shortridge) : Little Namaqualand (Schlechter).

Orange River Colony: Smithfield (Kannemeyer).

German South-West Africa: Damaraland (Nightingale). 


\section{LIST OF SOUTH AFRICAN SNAKES.}

2. Psammophis furcatus, Peters, t.c., p. 236 ; Bouleng., t.c., p. I64.

Cape Colony, Transvaal, Southern Rhodesia, German South-West Africa.

Cape Colony: Cape Town (Fisk), Burghersdorp (Kannemeyer), Little Namaqualand (Péringuey, Schlechter), Ograbies (Strauss).

Psammophis leightoni, Bouleng. P.Z.S., I902, i. p. I26, pl. xii., I now regard as not separable from $P$. furcatus, the chief difference being that the dark and light markings on the back of the head are transverse in the former, longitudinal in the latter.

3. Psammophis transvaaliensis, Gough, Ann. Transv. Mus. i., igo8, Transvaal. p. $3 \mathrm{I}$, fig.

4. Psammophis trigrammus, Günth. Ann. \& Mag. N. H. (3) xv., I865, p. 95, pl. ii. fig. E. ; Bouleng. Cat. Sn. iii. p. I59.

Namaqualand.

5. Psammophis bocagir, Bouleng. Cat. Sn. iii. p. I6r, pl. viii. fig. I.

Southern Rhodesia, Angola.

Victoria Falls (Sclater).

6. Psammophis sibilans.

Coluber sibilans, Linn. S. N. i. p. 383 .

Psammophis sibilans, Bouleng., l.c.

Psammophis thomasi, Gough, Ann. Transv. Mus. i., I908, p. 30, fig.

Egypt, Tropical Africa, northern parts of South Africa.

Cape Colony: Little Namaqualand (Strauss).

Transvaal: Leydsdorp (Norton); Irene (Taylor).

Rhodesia: Salisbury (Thomas); Mazoe (Alston); Kafue River (Drury).

7. Psammophis Brevriostris, Peters, Sitzb. Ges. Naturf. Fr., i88i, p. 89 ; Bouleng., t.c., p. I66.

South Africa, Angola.

Cape Colony: Cape Division (F. L. Alcock) ; Tulbagh (Kleinans).

Natal: Durban (Bowker); Pine Town (McKerr).

8. Psammophis Jalle, Peracca, Boll. Mus. Torin. xi., I 896, No. 255, fig.

Southern Rhodesia.

Importuni District (Pillans).

9. Psammophis CRUCifer.

Coluber crucifer, Daud. Hist. Rept. vii. p. I89.

Psammophis crucifer, Bouleng., t.c., p. I69.

South Africa.

Cape Colony : Cape Peninsula (Fisk, Taylor, Howes, Southey) ; Stellenbosch (Purcell) ; Knysna (Groom) ; Port Elizabeth (Moorhouse, Weale); Burghersdorp (Kannemeyer); Beaconsfield (French); Grahamstown (Jupp) ; Beaufort West (Rice) ; Little Namaqualand (Scully, Schlechter).

Transvaal: Krugersdorp (Watson); Johannesburg (Cregoe); Lydenburg (Kilgour).

Basutoland: Morija (Sclater).

Io. PSAMmophis angolensis.

Amphiophis angolensis, Bocage, Jorn. Sc. Lisb. iv., I872, p. 82.

Psammophis angolensis, Bouleng., t.c., p. I 7o.

East and Central Africa, Angola, Orange River Colony. 


\author{
2I. THELOTORNIS.
}

Smith, Ill., Rept. ; Bouleng. Cat. Sn. ii.. p. I84.

I. THELOTORNIS KIRTLANDII.

Leptophis kivtlandii, Hallow. Proc. Ac. Philad., I844, p. 62.

Thelotornis kirtlandii, Bouleng., t.c., p. I85.

Tropical Africa, Southern Rhodesia, Portuguese East Africa, Zululand, Natal.

Natal: Durban (Bowker).

Portuguese East Africa: Delagoa Bay (De Coster).

Southern Rhodesia: Irome (Blackbeard); Zambesi (Chapman).

\title{
22. DISPHOLIDUS.
}

Duvernoy, Ann. Sc. Nat. xxvi., I832, p. I50; Bouleng. Cat. Sn. iii. p. 186.

I. Dispholidus typus.

Bucephalus typus, Smith, Zool. Journ. iv., I829, p. 44I.

Dispholidus typus, Bouleng., t.c., p. 187 .

Tropical and South Africa.

Cape Colony: Cape Peninsula (Layard, Howes, Sclater); Knysna (Groom) ; Burghersdorp (Kannemeyer) ; Port St. Johns (Shortridge); Port Elizabeth (Moorhouse).

Natal: Durban (Bowker).

Portuguese East Africa: Delagoa Bay (De Coster).

Southern Rhodesia: Salisbury (Darling); Mazoe (Darling); Shangani District (Pillans).

\section{AMBLYODIPSAS.}

Peters, Mon. Berl. Ac., I856, p. 592 ; Bouleng. Cat. Sn. iii. p. 244.

I. AMBLYODIPSAS MiCROPHTHALMA.

Calamaria microphthalma, Bianconi, Spec. Zool. Mosamb. p. 94, pl. xii. fig. I.

Amblyodipsas microphthalma, Bouleng., l.c.

Portuguese East Africa, Zululand.

\section{CALAMELAPS.}

Günth. Ann. \& Mag. N. H. (3) xviii, I 866, p. 26 ; Bouleng. Cat. Sn. iii. p. 245 .

Two Species in South Africa.

Scales in I9 rows; ventrals $16 \mathrm{I}-\mathrm{I} 74 \ldots \ldots$.. $\ldots$ C. warreni.

Scales in I7 rows; ventrals I33-I34 $\ldots \ldots \ldots$.

I. Calamelaps Warreni, Bouleng. Ann. Natal Mus. i., 1908, p. 234, fig. \%ululand, Basutoland.

Sesheke, Basutoland (Jalle).

2. Calamelaps concolor.

Choristodon concolor, Smith, Ill., Rept., App. p. IS.

Calamelaps concolor, Bouleng. Cat. Sn. iii. p. 2.46.

Calamelaps mironi, Mocquard, Bull. Mus. Paris, 1905, p. 77.

Caffraria, Natal. 


\section{MACRELAPS.}

Bouleng. Cat. Sn. iii. p. 255 .

I. MACRELAPS Microlepidotus.

Uriechis microlepidotus, Günth. Ann. \& Mag. N. H. (3) v., I 860, p. I68, pl. ix.

Macrelaps microlepidotus, Bouleng., l.c.

Natal, Eastern parts of Cape Colony.

Cape Colony : Port St. Johns (Kannemeyer).

Natal: Durban (Bowker).

\section{APARALLACTUS.}

Smith, Ill., Rept., App. p. I5 ; Bouleng. Cat. Sn. iii. p. 255.

Two Species in South Africa.

Nasal divided; ventrals $\mathrm{I} 53-\mathrm{I} 80 \quad \ldots \quad \ldots \quad \ldots$ A. guentheri.

Nasal entire; ventrals $138-166 \quad \ldots \quad \ldots . \quad \ldots$ A. capensis.

I. Aparallactus guentheri, Bouleng. Ann \& Mag. N. H. (6) xvi., I895, p. I72, and t.c., p. 259, pl. xi. fig. 2.

Fast and Central Africa, Angola, Southern Rhodesia.

2. Aparallactus capensis, Smith, op. c., p. I6 ; Bouleng., t.c., p. 259.

South and East Africa,

Cape Colony: East London (Londt); Burghersdorp (Kannemeyer).

Transvaal: Leydenburg (Kilgour); Modderfontein (Haagner).

\section{C.-OPISTHOGLYPHAE.}

\section{HYDRUS.}

Schneid. Hist. Amph. i. p. 233 ; Bouleng. Cat. Sn. iii. p. 266.

I. Hydrus platurus.

Anguis platurus, Linn. S. N. i. p. 39I.

Hydrus platurus, Bouleng., t.c., p. 267.

Indian Ocean and Tropical Pacific; coast of Cape Colony.

Table Bay and False Bay (Stockdale, Fisk); George; Cape Agulhas (J. van Breda).

28. NAIA.

Laurenti, Syn. Rept. p. 90 ; Bouleng. Cat. Sn. iii. p. 372.

Four Species in South Africa.

I. Suboculars separate the eye from the upper labials.

$2 I$ or 23 scales across neck, I9 to 2 I across middle of body .. .. . . . . . . .

I7 scales across neck as well as across body ... ... . haie.

II. Third or third and fourth upper labials entering the eye.

Sixth upper labial largest and in contact with postoculars ; 23 scales across neck .. .. ..

Third upper labial deepest, sixth not in contact with postoculars; 23 to 29 scales across neck

N. anchiete.

N. flava.

$N$. nigricollis. 
I. NAIA HAIE.

Coluber haie, Linn. S. N. i. p. 387 .

Naia haie, Bouleng., t.c., p. 374 .

Southern Palestine, North and East Africa, Southern Rhodesia, Zululand, Transvaal.

Portuguese East Africa: Delagoa Bay (De Coster).

Southern Rhodesia: Hunyani River (Thomas, Darling); Salisbury (Darling).

2. NAIA ANchiete, Bocage, Jorn. Sc. Lisb. vii. I879, p. 89 ; Bouleng., t.c., p. 387 .

Angola and German South-West Africa, North-West Rhodesia.

Livingstone, North.West Rhodesia (Syles).

3. Naia flava.

Vipera flava, Merrem, Tent. Syst. Amph. p. I54.

Naia flava, Bouleng., t.c., p. 376.

Cape Colony, German South-West Africa.

Cape Town (Fairbridge); Worcester (Le Fèvre); Burghersdorp (Kannemeyer); Douglas (Orpen); Caledon; Riversdale ; Knysna; Port Elizabeth (Moorhouse) ; \&c.

4. NAIA NIGricolis, Reinh. Vid. Selsk. Skrift. x. I843, p. 269, pl. iii. figs. 5-7; Bouleng., t.c., p. 378 .

From_Senegambia and Upper Egypt to Angola, German South-West Africa, Little Namaqualand, Southern Rhodesia, the Transvaal, and Natal.

Cape Colony: Little Namaqualand (Schlechter).

Natal: Victoria County (Bowker).

Transvaal: Barberton (Rendall); Modderfontein (Haagner).

Southern Rhodesia: Mazoe (Darling).

German South-West Africa: Damaraland (Hutchinson).

\section{SEPEDON.}

Merrem, Tent. Syst. Amph. p. I46; Bouleng, Cat. Sn. iii. p. 388.

I. SEPEdon hremachates.

Coluber hamachata, Lacep. Hist. Serp. ii. p. I2I.

Sepedon hemachates, Bouleng., t.c., p. 389.

Cape Colony, Natal, Orange River Colony, Transvaal, German South. West Africa.

Cape Colony : Cape Peninsula (Bishop, Howes, Turley, Carr) ; Tulbagh (Kleinschmidt); Tsomo, Transkei (Watermeyer); Beaufort West (Rice) ; George (Leipoldt).

Basutoland: Morija (Dyke).

Transvaal: Johannesburg (Fry); Krugersdorp (Watson); Modderfontein (Haagner).

\section{ASPIDELAPS.}

Smith, Ill.; Rept., App. ; Bouleng. Cat. Sn. iii. p. 390.

Two Species.

Internasals in contact behind the rostral; third and fourth upper labials entering the eye; scales all smooth; ventrals I $46-176 \ldots$. . . .

Internasals separated by the rostrai ; fourth upper labial entering the eye; scales on posterior part of body keeled; ventrals_I I 5-I35 
I. Aspidelaps lubricus.

Natrix lubrica, Laurenti, Syn. Rept. p. 80.

Aspidelaps lubricus, Bouleng., l.c.

Cape Colony, German South-West Africa, Rhodesia.

Cape Colony: Cape Town (Layard) ; Durbanville (Schabort) ; Malmesbury (Gird \& Lightfoot); Robertson (Hodges); Burghersdorp (Kannemeyer): Clanwilliam (Leipoldt, Smolke, Lightfoot); Middelburg (Piers); Upington; Hanover (Schreiner); Port Nolloth (Howard); Namaqualand (Péringuey).

Zambesi (Chapman).

2. Aspidelaps scutatus.

Cyrtophis scutatus, Smith, Ill., Rept., App. p. 22.

Aspidelaps scutatus, Bouleng., t.c., p. $39 \mathrm{I}$.

Natal, Portuguese East Africa, Southern Rhodesia.

Portuguese East Africa; Delagoa Bay (De Coster).

\section{I. ELAPECHIS.}

Bouleng. Cat. Sn. iii. p. $35^{8}$.

Three Species in South Africa.

Portion of rostral visible from above not half as long as its distance from the frontal, which shield is a little shorter than the parietals ; diameter of eye less than its distance from the nostril in the adult .. . .

Portion of rostral visible from above at least half as long as its distance from the frontal, which shield is much shorter than the parietals; diameter of eye less than its distance from the nostril in the adult .. . .

E. guentheri.

E. sundevallii.

Portion of rostral visible from above at least half as long as its distance from the frontal, which shield is much shorter than the parietals; diameter of eye equal to its distance from the nostril .. $\quad . . \quad \ldots . \quad \ldots \quad$. decosteri.

I. ElAPECHIS GUENTHERI.

Elapsoidea guentheri, Bocage, Jorn. Sc. Lisb. i., I866, p. 7o, pl. i. fig. 3 . Elapechis guentheri, Bouleng., t.c., p. 359.

Tropical Africa, Transvaal.

2. ElapECHIS SUNDEVALIII.

Elaps sundevalli, Smith, Ill., Rept. pl. lxvi.

Elapechis sundevallii, Bouleng., t.c., p. 360.

Natal.

Estcourt.

3. ELAPECHIS DECOSTERI.

Elapsoidea decosteri, Bouleng., Ann. \& Mag. N. H. (6) ii., I888, p. I4I.

Elapechis decosteri, Bouleng., t.c., p. 360.

Portuguese East Africa, Zululand.

Delagoa Bay (De Coster).-Type.

\section{HOMORELAPS.}

Jan, Rev. et Mag. Zool., I858, p. 518; Bouleng. Cat. Sn. iii. p. 408, Two Species.

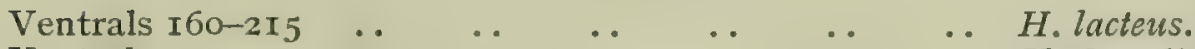

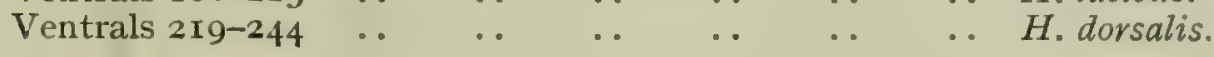


I. Homorelaps lacteus.

Coluber lacteus, Linn. S. N. i. p. 38 I.

Homorelaps lacteus, Bouleng., t.c., p. 409.

Cape Colony, Natal, Orange River Colony.

Cape Colony: Cape Peninsula (Southey); Worcester (Lycett) ; Robertson (Hodges) ; George (Frere) ; Piquetburg (Watermeyer) : Caledon (Burgess; Port Elizabeth (Matcham); Kimberley (French).

Natal (Ellman).

Transvaal: Ermelo (Watermeyer).

2. HOMORELAPS DORSALIS.

Elaps dorsalis, Smith, Ill., Rept., App. P. 2 I.

Homorelaps dorsalis, Bouleng., t.c., p. 4ro.

- Eastern parts of Cape Colony, Natal, Orange River Colony.

Orange River Colony: Brandfort (Haagner) ; Smithfield (Kiannemeyer).

\section{DENDRASPIS.}

Schleg. Versl. Zool. Gen. Amsterd. 1848 ; Bouleng., Cat. Sn. iii. p. 434.

Two Species in South Africa.

Scales in 19 to 23 rows in the middle of the body; 8 upper labials; upper anterior temporal not longer than the lower .. $\quad \because \ldots \ldots$.. $\quad \ldots \quad \ldots$

Scales in 25 rows ; 9 upper labials ; upper anterior temporal twice as long as the lower . . . . D. mamba.

I. DENDRASPIS ANGUSTICEPS.

Naja angusticeps, Smith, I1l., Rept. pl. lxx.

Dendraspis angusticeps, Bouleng., t.c., p. 437.

Natal, Zululand, Transvaal, Southern Rhodesia, East and Central Africa.

Natal: Durban (Butler); Zululand (Jones).

2. Dendraspis mamba, Gough, Ann. Transv. Mus, i., I9o8, p. 37, fig. Transvaal.

\section{FAMILY VIPERIDA:}

Synopsis of the South African Genera.

Eye moderate, with round pupil; head covered with large symmetrical shields; loreal present .. ..

Eye moderate or small, with vertical pupil ; head covered with scales $\quad . \quad \ldots \quad \ldots \quad \ldots \ldots$

Eye minute, with round pupil; head small, covered with large symmetrical shields; loreal absent .. .. Atractaspis.

\section{CAUSUS.}

Wagler, Syst. Amph. p. I72; Bouleng. Cat. Sn. iii. p. 465 .

Two Species in South Africa.

Snout obtuse, more or less prominent; ventrals I20-I55

Snout pointed, prominent, more or less turned up at the end; ventrals $113-125$

C. rhombeatus.

C. defilippii. 
I. Causus RHOMbeatus.

Sepedon rhombeatus, Lichtenst. Verz. Doubl. Mus. Berl. p. Io6.

Causus rhombeatus, Bouleng., t.c., p. 467.

Tropical and South Africa.

Cape Colony: Cape Peninsula (Tinley) ; Inysna (Oakley) ; Burghersdorp (Kannemeyer); Tsomo, Transkei (Watermeyer); George (Leipoldt) ; Port St. Johns (Shortridge); Kimberley (French).

Basutoland: Morija (Dyke).

Natal: Durban (Bowker).

Transvaal : Barberton (Rendall) ; Krugersdorp (Watson).

Southern Rhodesia: Salisbury (Marshall); Mazoe (Darling).

2. Causus defilippir.

Heterodon defilippii, Jan, Arch. Zool. Anat. Phys. ii. I862, p. 225.

Causus defilippii, Bouleng., t.c., p. 469.

Natal, Transvaal, Southern Rhodesia, Central and East Africa.

Natal: Pinetown (Bowker).

Transvaal: Barberton (Rendall).

Rhodesia: Salisbury (Thomas); Livingstone (Sykes).

\section{BITIS.}

Gray, Zool. Miscell. p. 69 ; Bouleng. Cat. Sn. iii. p. 492.

Six Species in South Africa.

I. Nostrils directed upwards ; scales in $3 \mathrm{I}$ to $4 \mathrm{I}$ rows ..

II. Nostrils directed upwards and outwards; scales in

$B$. arietans.

$2 I$ to 3 I rows

A. Supraocular region not raised, without horn-like scales; sub-caudals well developed and smooth in both sexes.

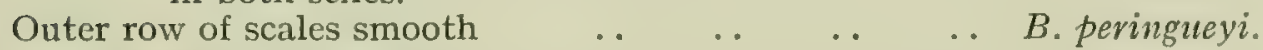

Outer row of scales keeled .. $\quad \ldots \quad \ldots \quad \ldots \quad \ldots \quad \ldots$ atropos.

B. Supraocular region raised, without horn-like scales; sub-caudals well developed and smooth in both sexes .. $\quad . . \quad \ldots \quad \ldots$

C. Supraocular region usually with horn-like scales ;

B. inornata. sub-caudals, in females, small and scale-like, more or less distinctly keeled.

Several supraorbital horns $\quad . . \quad \ldots \quad \ldots \quad \ldots \quad \ldots$ B. cornuta.

Supraorbital horn, if present, single $\quad \ldots \quad \ldots \quad \ldots \quad$. . candalis.

I. Bitis ARIETANS.

Vipera arietans, Merrem, Tent. Syst. Amph. p. I52.

Bitis arietans, Bouleng., t.c., p. 493.

Tropical and South Africa, Arabia.

Cape Colony: Cape Peninsula (Oakley); Paarl (Hugo) ; Port St. Johns (Shortridge); Port Elizabeth (Moorhouse); Iittle Namaqualand (Péringuey).

Basutoland: Morija (Dyke).

Natal: Victoria County (Bowker).

Southern Rhodesia: Mazoe (Darling); Hunyani River (Thomas); Salisbury (Thomas).

German South-West Africa: Damaraland (Fairbridge).

2. Bitis PERINGUEYI.

Vipera peringueyi, Bouleng. Ann. \& Mag. N. H. (2) ii., I888, p. I4I.

Bitis peringueyi, Bouleng., t.c., p. 495.

German South West Africa, Kalahari, Angola.

Walfisch Bay territory (Nightingale), type. 
3. Bitis Atropos.

Coluber atropos, Linn. S. N. i. p. 375.

Bitis atropos, Bouleng., t.c., p. 495.

Cape Colony, Transvaal.

Cape Colony: Cape Peninsula (Fairbridge, Layard, Lightfoot) ; Ińnysna (Oakley); East London (Wood); Port Elizabeth (Drege, Moorhouse).

Transvaal: Lydenburg (Kilgour).

4. Bitis inornata.

Echidna innorata, Smith, Ill., Rept. pl. iv.

Bitis innorata, Bouleng., t.c., 496.

Cape Colony.

5. Bitis CORNuTA.

Vipera cornuta, Daud. Hist. Rept. vi. p. I 88.

Bitis cornuta, Bouleng., t.c., p. 497.

Cape Colony, German South West Africa.

Cape Colony: Cape Peninsula (Oakley, Ogilvie) ; Calvinia, Clanwilliam (Schlechter); Worcester (Le Fèvre, Paynter) ; Serowe, Bechuanaland (Schönland); Little Namaqualand (Turle); Tulbagh (Kleinschmidt).

6. Bitis CaUdalis.

Vipera caudalis, Smith, Ill., Rept. pl. vii.

Bitis caudalis, Bouleng., t.c., p. 498 .

Angola to the north part of Cape Colony and Southern Rhodesia.

Cape Colony: Little Namaqualand (Hirsch, Scully, Thomas, Turle) ; Victoria West (Piers); Serowe, Bechuanaland (Blackbeard).

Southern Rhodesia: Insiza (French).

\section{ATRACTASPIS.}

Smith, Ill., Rept.; Bouleng. Cat. Sn. iii. p. 5 Io.

Two Species in South Africa.

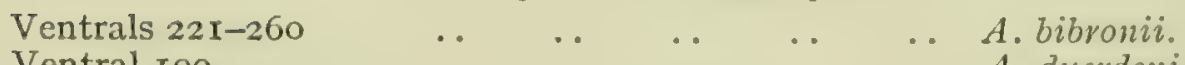

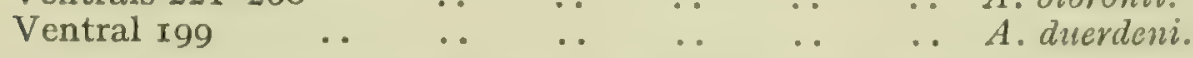

I. Atractaspis bibronir, Smith, op.c., pl. lxxi.; Bouleng., t.c., p. 5 I5.

Cape Colony, Natal, Zululand, Transvaal, Portuguese. East Africa, German South West Africa, Angola.

Natal: Durban (Bowker).

Transvaal: Barberton (Kolbe).

Portuguese East Africa: Delagoa Bay (De Coster).

2. Atractaspis duerdeni, Gough, Albany Mus. Rec, ii., I907, p. I78, fig. North East Kalahari.

\section{DESCRIPTION OF NEW SPECIES.}

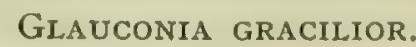

Snout rounded; supraocular present, not much larger than the frontal, a little broader than long; rostral about one-third the width of the head, hardly twice the width of the nasal, not extending posteriorly beyond the level of the eyes, in contact behind with the frontal and the supraoculars; nasal completely divided into two; ocular bordering the lip, between two labials, the anterior of which is very small. Body very slender, its diameter 90 to 1 ro times in the total length. If scales round the body. Length of tail ro to I5 times in total length. Uniform blackish brown. Total length, $230 \mathrm{~mm}$.

Numerous specimens from various localities in Cape Colony (Van Rynsdorp, Robertson, Clanwilliam, Matjesfontein). 


\title{
CHAPTER XIV.
}

\author{
ITEMS OF SNAKE KNOWLEDGE.
}

MAINLY A SUMMARY IN BRIEF FORM OF THE CONTENTS OF THE BOOK.

SNAKES evolved from Lizard-like creatures with legs.

Fossil remains of Flying Reptiles have been dircovered. They had membraneous wings and tails, like those of bats. Their long bill-like jaws were toothed.

Birds evolved from reptiles. The reptile developed membraneous wings. Later, feathers were evolved.

Snakes are reptiles. Birds evolved from reptiles, therefore birds are relatives of snakes.

Snakes are found all over Tropical and Temperate portions of the world, excepting New Zealand.

No traces of snakes have ever been found in New Zealand.

In South Africa there are Burrowing Lizards which have no trace of legs. They shine like burnished copper. Their tails are blunt. They are usually mistaken for snakes.

Some snakes lay eggs. Others give birth to young.

Snakes' eggs have no hard shell like those of birds. The covering of the egg is soft, but tough and leathery.

Snakes lay their eggs in warm places, such as holes in the ground, and amongst decaying vegetation. When vegetable matter is decaying it generates heat sufficient to hatch snakes' eggs.

Snakes only have one active lung. It is a long hollow tube.

A snake's heart will continue beating, sometimes for fifteen minutes or more, after its removal from the body.

If a snake's head be cut off, its heart will continue to beat, often for a whole day.

Snakes hiss by expelling air forcibly through the glottis and nostrils. They do not make any actual sound.

Snakes crawl by moving their ribs. The muscles move the ribs. The ribs operate the shields on the abdomen. These shields are elevated and their edges grip the ground, tree, or whatever the reptiles crawl over.

A man may become immune to the bite of any particular kind of snake by injecting himself with venom of the same species. He must start with a very small dose, and gradually increase it. Such an experiment is not to be recommended. It might prove fatal. 
The Grass and Sand Snake, when alarmed, glide off over the stunted herbage and grass with quick undulating motions. So quick are the movements that, to the eye, they seem to be bowling along like a hoop. Colonists know these as Whip Snakes.

When a Puff Adder is about to strike he withdraws his head and bunches up his body. He can propel himself the full length of his body.

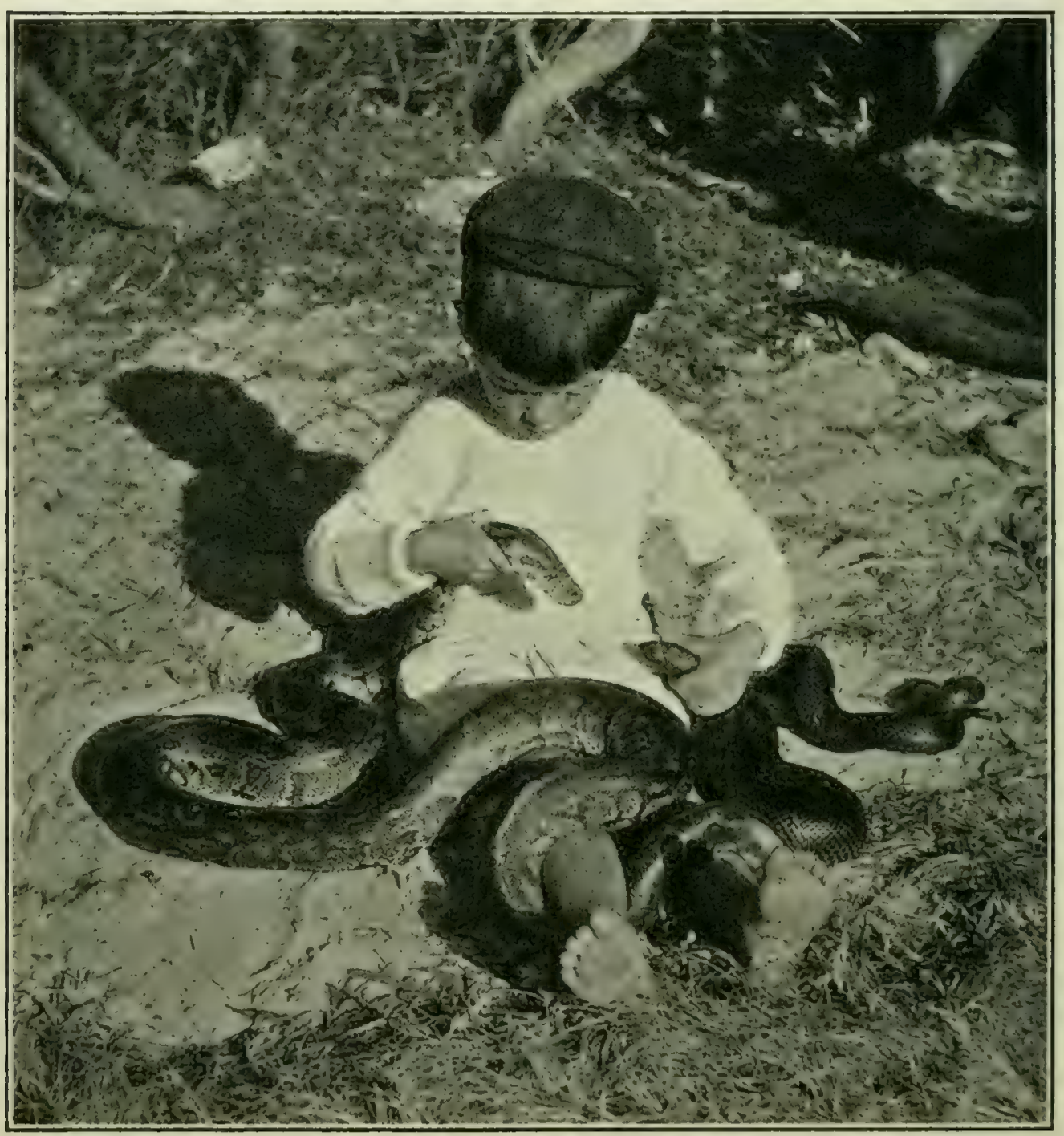

FrG. 155.-Three great chums-a Black Mole Snake, a baby Python, and a baby boy.

Puff Adders do not strike backwards. In the act of striking they throw the head well back, then forwards or sideways.

There is no such reptile as a Two-headed Snake. People often call the blind Burrowing Snake (Typhlops), a two-headed snake because of its blunt tail, which has the appearance of a liead. 
The Ringhals Snake, although belonging to the Cobra family, has keeled scales like those of the Puff Adder.

A snake strikes with its fangs so quickly that the eye cannot follow the movement of the head.

Snakes eat rats, and these rodents in turn devour young snakes and snakes' eggs.

A large barn rat introduced into a cage containing seven Puff Adders, killed three of them by biting them at the back of the neck. It ate a portion of one.

Puff Adders have several pairs of duplicate fangs. The active pair of fangs sometimes attains a length of three-quarters of an inch.

A Puff Adder possesses about I50 pairs of ribs.

Snakes are the most graceful of all reptiles. The Siamese call them "Sunbeams."

Most Pythons possess two horny spurs in the tail region. These are the last vestiges of legs. They are useful for gripping purposes when the reptile climbs or swings from branches.

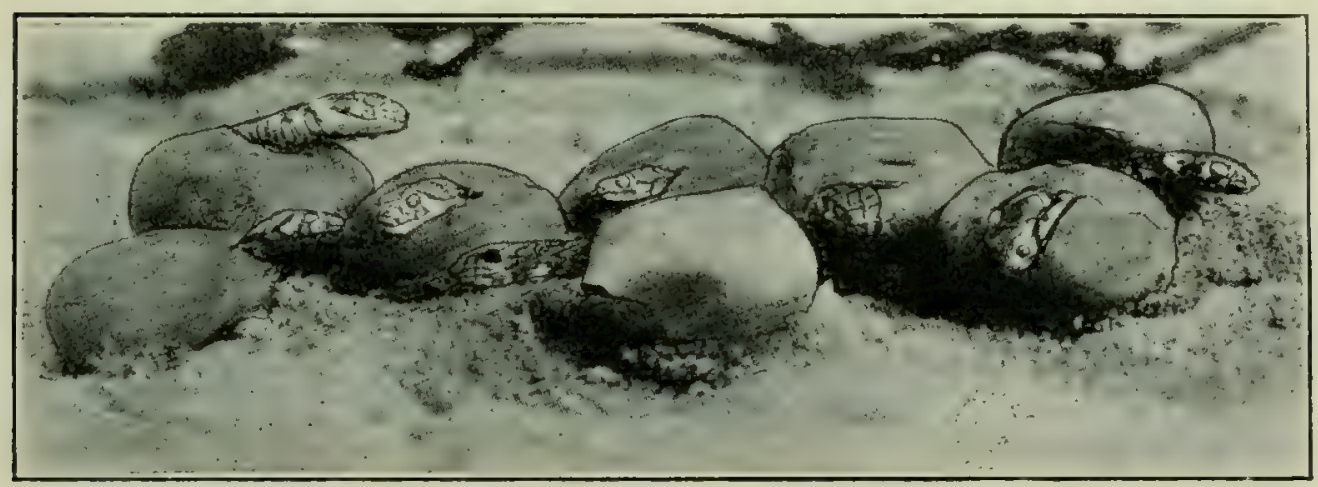

FiG. I 56.-Young snakes emerging from the eggs. They rupture the soft shell with the nose.

All snakes can swim.

During a recent flood in Baaken's River Valley, at Port Elizabeth, a great number of snakes were washed out to sea. The incoming tide cast their dead bodies up on the shore the following day.

The nostrils of Sea Snakes are placed on the top of the snout.

The lung of a Sea Snake extends nearly the whole length of its body.

When on land, Sea Snakes are helpless and blind.

The scales of Sea Snakes are, in shape, just like the wax cells of the honey bee (six-sided). Snakes.

Many cases are on record of people dying after being bitten by Sea

The existence of a sea serpent of monstrous size still remains unproven.

The rattle of a Rattlesnake is a number of hollow horny segments at the end of the tail. These are loosely joined together, and when vibrated make the characteristic rattling sound.

The horns of the Hornsman Adder are upright scales above the eyes. 
The word Sepedon, which is the generic name of the Ringhals Snake, means " Noxious tooth, or a tooth causing putridity."

If the active pair of fangs of a snake be extracted, another pair will take their place in about a month's time, sometimes less or more. days.

If they are naturally shed, the new fangs are ready for action in a few

The American Boa, known as the Anaconda, is stated to attain a length of 36 feet.

Carvings of serpents are found on nearly all the ancient Egyptian sculptures.

In India, carvings and drawings of serpents are to be seen everywhere.

From pre-historic times, the favourite personal adornments, such as rings, bracelets, clasps, etc, have been fashioned after the form of a serpent.

Most savages attribute great virtues to the various portions of a snake's anatomy. Portions are utilized as charms, and as medicine.

The ancient temples of Mexico were beautifully ornamented with carvings of snakes.

Snake worship in India amongst the low-caste Hindoos is still very common. In consequence, they will not kill a serpent.

If a serpent should intrude into a house, the Indian reverently entices it into a vessel and carries it away to the jungle.

In Africa many natives refuse to kill Pythons, as they think such an action would bring many evils upon them.

Indians are great believers in snake stones, spells, sacrifices, and herbs for the cure of snake bite.

In South Africa there are dozens of so-called cures, which are of little or no value.

Many people die, not of the effect of the snake bite, but of the treatment for the cure of same.

One of the South African "cures" is to sjambok the victim to keep him awake.

In classic tribes, ancient doctors were great believers in soups, decoctions, etc., of Vipers. We read of such things as viper wine, viper broth, viper salts, powdered viper, viper oil, etc., prescribed for various human ailments.

Snakes hear chiefly by vibrations of sound conveyed through solid substances.

When travelling along beaten foot-tracks through snake-infested bush or grass by day or night, it is a good plan to carry a jingling stick, and strike the ground with it every few steps. Snakes hearing the noise will crawl out of the way:

Horses, dogs, and most warm-blooded animals seem to possess a power of intuition which warns them of the proximity of a snake, although it may not be visible.

The hiss of a snake will cause alarm in all warm-blooded animals.

I caused a snake in a box to hiss loudly near a cage containing a dozen Cape Baboons and Vervet Monkeys. They instantly showed signs of wild alarm, and set up an unearthly chattering.

Snakes in captivity suffer a great deal from ulcerated mouths. 
They frequently injure themselves through striking their heads against the glass of the cage, when lunging at spectators.

Snakes do not thrive in captivity, unless their places of confinement are more or less similar to their native haunts.

Snakes do not grow a new tail, if theirs should be accidentally cut off. Most lizards, on the contrary, grow new tails.

Pythons in captivity can be kept alive by feeding them once a week on lumps of beef. The beef must be forcibly pushed down the throat of the reptile with a smooth rounded stick. It can then be easily worked down to the stomach with the fingers.

To prevent the Python disgorging the meat, tie a ligature between the meat and the mouth. Keep it on for about half a day. Don't tie it too tightly.

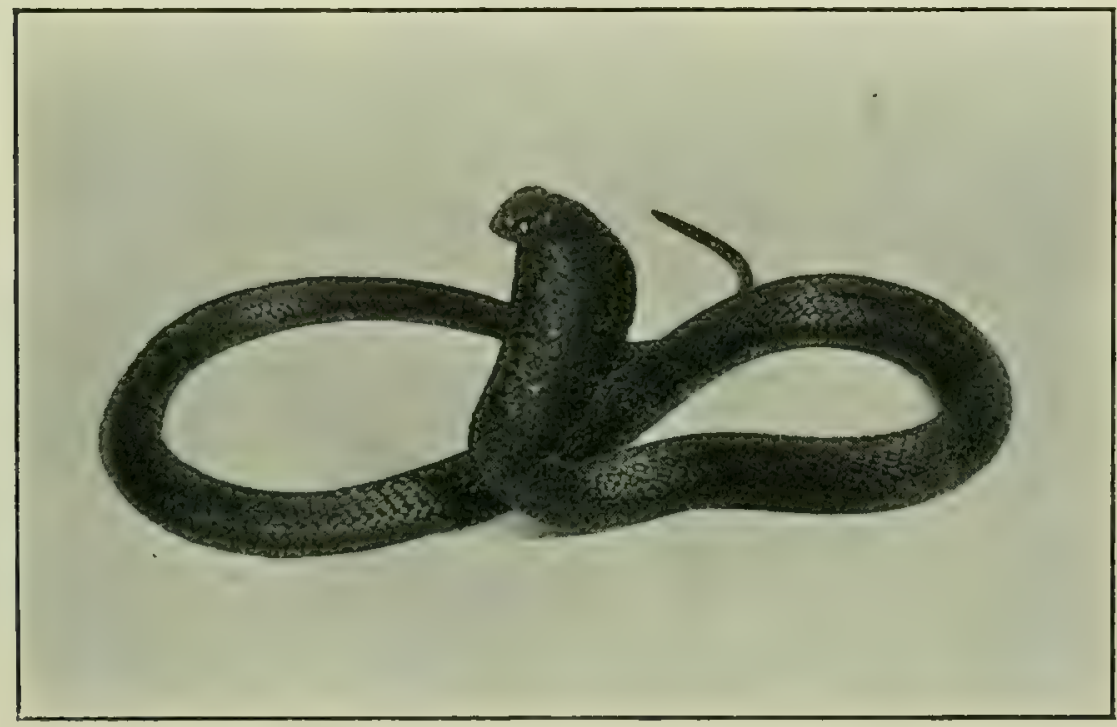

Fic. 157.-A yellow variety of Cape Cobra 6 feet 3 inches in length, in the act of expanding its hood and rearing the anterior part of its body.

Pythons in captivity become very sluggish and allow themselves to be handled without any protest, beyond an occasional hiss.

Pythons have been known to fast for at least two years.

Many of the native tribes of South Africa will devour the flesh of the Python whenever opportunity offers. The flesh is tender, and has a nice flavour when grilled.

The Aglypha snakes are those whose teeth are solid, without any trace of grooving. They are all harmless.

Mole snakes vary in coloration more than any other species of South African snake.

The Dasypeltis snake, or Eier Vreter, is the only snake in the world which has a special apparatus in its backbone for sawing the shells of eggs. This consists of a long row of bony processes tipped with enamel, jutting into the gullet in the neck region. 
Opisthoglypha snakes are those which possess fangs set halfway back in the upper jaw. This division of snakes is all more or less venomous. They are in the transition stage of fang development.

The Boomslang has been proven to be as venomous as the Cape Cobra.

Boomslangs are timid, and retreat into trees or other herbage on the least alarm.

Boomslangs are the typical tree snakes of South Africa.

During November, 1907, Mr. James Williams was bitten by a Boomslang, and nearly died.

During I909, seventy-eight cases of deaths from snake bite were registered in South Africa. This does not include Basutoland, Bechuanaland, and most of the native territories.

The fluid spat out by the Ringhals or Spitting Snake is pure venom.

The fluid will kill just as rapidly if injected subcutaneously as the venom taken from the gland of the snake.

Black and yellow Sea Snakes are often cast up on shore by the tides along the South African coasts. Beware how you handle them. They are highly venomous.

They are bright yellow on the underparts and sides, and black above.

There are four varieties of Cape Cobra. They all belong to the same species. They differ in colour only. In captivity Cobras often fight and kill each other.

The neck ribs of the Cobra are longer than the rest. They form a rough half-circle on each side of the neck, when raised.

The neck skin of a Cobra is loose. When irritated a Cobra elevates the ribs of its neck, forming what we term a hood.

Seven Cobras had a pitched battle in a cage in the Port Elizabeth Museum. They were all bitten and died. Some lingered for two months.

The fangs of the Cobras are not nearly so long or curved as those of the Adders.

Ringhals or Spitting Snakes sometimes feign death when attempts are marle to capture them.

If a Ringhals should spit in your eyes, get them washed immediately with a very weak solution of permanganate of potash. If there is no permanganate at hand, wash well with water, and put oil into the eyes.

The Mamba is the most dreaded of all South African snakes.

Never attack a Mamba in the bush unless you are well armed, and are prepared to shoot it dead. If you only wound it, you will surely be bitten.

Mambas are very plentiful in the bushy parts of Natal, Zululand and Eastern Transvaal.

The Green and the Black Mambas are of the same species. They differ in colour only.

The green variety of the Boomslang is frequently mistaken for a Green Mamba. The Mamba's head is more triangular-shaped than that of the

t Boomslang. Its fangs are right in front, whereas those of the Boomslang are halfway back in the jaw.

There are fourteen kinds or species of the Cobra family, and eleven of the Adder family of snakes in South Africa. 
The Puff Adder hisses more loudly than any other South African snake. It is the typical viper of South Africa.

A snake's heart has three cavities-one ventricle and two auricles.

Snakes are called cold-blooded creatures because the temperature of their bodies is so much lower than that of the mammal class of animals and birds, all of which are what we term warm-blooded.

All reptiles are cold-blooded. They do not suffer pain to the same degree that the warm-blooded animals do.

Snake venom, if swallowed, is harmless, unless there is some abrasion of the mouth and throat, or if the stomach and bowels be inflamed. In

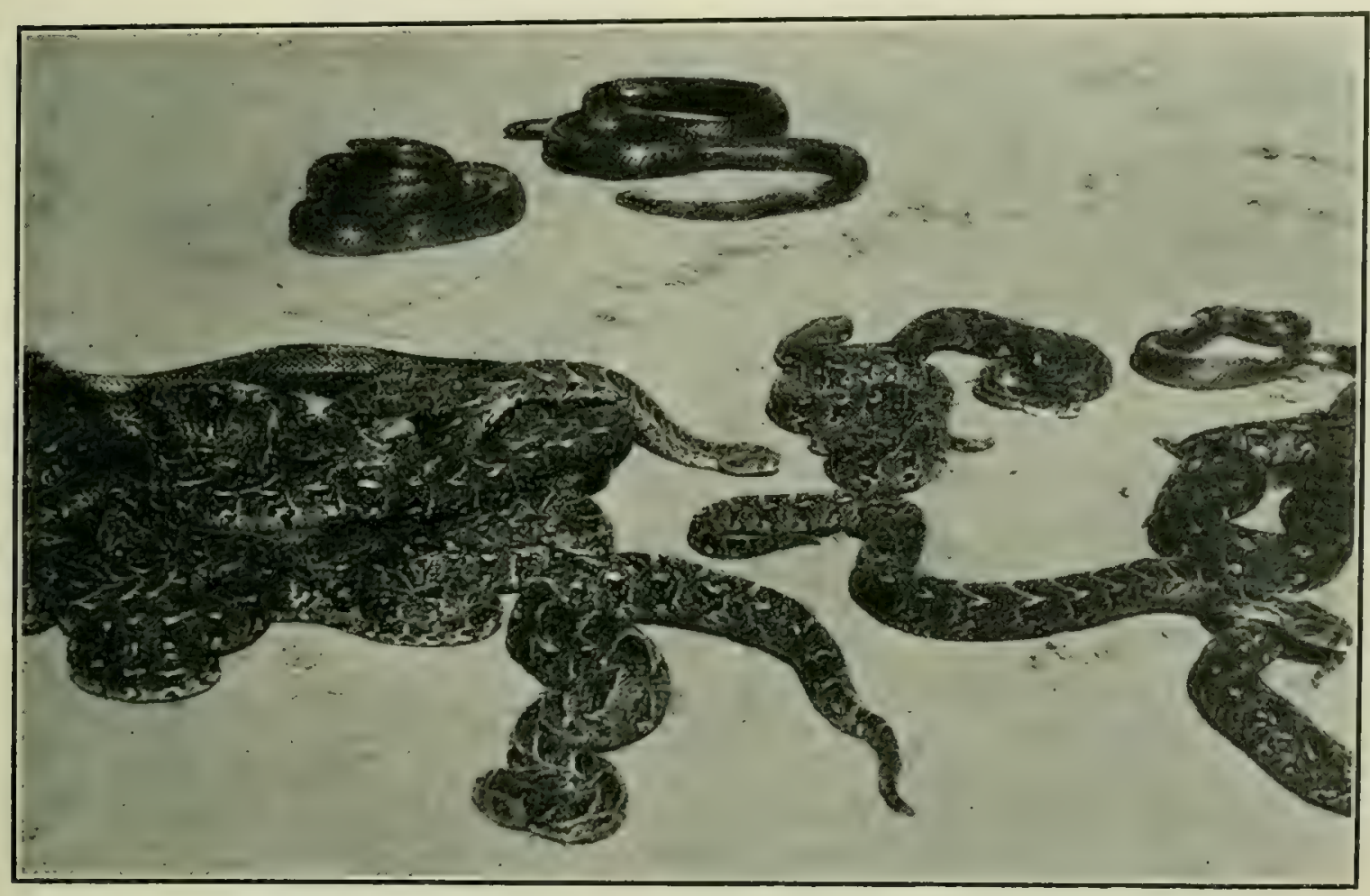

FIG. I58.-A few of the author's Puff Adders and Mole Snakes.

this case it might be absorbed through the broken surfaces direct into the blood.

Snake poison, when swallowed, is digested just as food is.

In case of snake bite instantly scarify the wounds with a penknife or lancet and rub in permanganate of potash crystals. Then apply a ligature above the bitten part to prevent the poisonel blood getting in to the general circulation.

Snakes cannot crawl over perfectly smooth surfaces.

The fangs of snakes are either hollow, or else grooved on their front surface.

If a snake has no grooved or hollow fangs in its mouth, it is one of the harmless kind. 
The Viper Family of snakes have long hollow fangs.

The Cobra Family have grooved fangs, not nearly so long as those of Vipers.

All the Viper and Cobra Family of snakes are venomous.

One of the Viper snakes of South Africa has taken to burrowing in the ground. In consequence, its body has become quite round (cylindrica!). The poison glands of these snakes are situated, one on each side of the head.

These glands manufacture the venom and store it up.

When a snake bites, certain muscles wring the poison glands, causing the venom to run through a narrow channel, and down the hollow or grooved fang.

The Night Adder of South Africa is a remarkable exception to the general rule. Its poison glands extend for about three inches down its back. They lic on each side of the backbone, as seen in the illustration.

Snakes eat rats and mice in great numbers. Rats and mice breed very quickly, and would soon become a great plague to us if their numbers were not kept in check.

The Mole Snake and House Snake are quite harmless. They are both good rat-catchers. They are our friends, and should never be killed.

Some snakes swallow eggs whole. They cannot suck eggs.

The stomach juices dissolve the shell and release the contents.

The Dasypeltis or Egg-eater Snake of South Africa has teeth in his backbone. These are his saw. He swallows an egg, saws the shell, and spits it out.

Snakes have many natural enemies. Mungooses, Meercats, and Muishonds eat them. So do most of the birds of prey.

Most snakes are cannibals. They not only eat those of other species, but of their own too.

Snakes do not chew their food. It is swallowed whole.

Snakes do not cover their prey with saliva before starting to swallow it.

Saliva runs abundantly into the mouth during the swallowing process, and lubricates the prey as it passes down the throat.

When injured or alarmed, a snake will usually disgorge anything it may have swallowed.

Pythons, Mole Snakes, House Snakes, and some other kinds of nonvenomous snakes kill their prey by throwing two or more coils round it, and crushing it to death.

Venomous snakes never constrict their prey. They kill or paralyze it with their venom.

The forked tongue of a snake is not its sting. The tonguc is very sensitive and acts as a feeler, like the tips of your fingers, or a cat's whislers.

Most snakes live upon the ground, although the majority can climb.

Others live almost entirely in trees. They are known as arboreal or Tree Snakes.

Some kinds of snakes live entirely in water. All the Sea Snakes live in the ocean, and feed on fish and other marinc creatures.

The Sea Snakes are all poisonous. They have a flattened oar-like tail for propelling themselves through the water. They breathe air like other snakes. 
Snakes eat many kinds of living creatures, mostly rats, mice, lizards, frogs, toads, and birds.

Snakes are not migratory.

On the approach of winter, snakes crawl away into crevices, holes, under refuse, behind the bark of trees, etc., and lie dormant, more or less, till the springtime. During this time they do not eat or drink.

Snakes love warmth and sunshine. - It is life to them. them.

Snakes strongly dislike the smell of disinfectants. The fumes kill

The oil from the stem of a tobacco pipe, if put into the mouth of a snake, will almost instantly kill it.

One drop of this highly poisonous oil will kill the largest serpent.

Some snakes are quite blind. They burrow in the ground, and look more like worms than snakes. The head and the tail look nearly alike. Some people say they are two-headed snakes.

Most of these burrowing snakes have a small spine on the end of the tail. None of them are venomous.

South African Pythons grow to 25 feet in length. They prefer rocky moist valleys, where there is plenty of water.

A Python can swallow a full-sized Duiker Buck.

A snake's mouth and throat can stretch enormously. The bones of the lower jaw are not joined in front, consequently they can be pushed wide apart. The skin of the mouth and throat stretches like indiarubber.

Pythons will not eat, as a rule, in captivity.

Pythons lay as many as 45 eggs. They are each some $5 \frac{1}{2} \mathrm{oz}$. in weight.

A Python was dug out of an Aard Vark's hole. It was found coiled up around a large batch of eggs right at the bottom of the hole. It was hatching them.

Some snakes kill their prey by constriction. Others by poison. Some, such as the Green Water Snakes, simply swallow their victims alive.

The bones of a snake's head are loose. That means they are not firmly joined together in the rigid manner of those of the higher animals. Snakes' teeth are for grasping or holding their prey.

The teeth are re-curved. They are sharp and pointed.

There are three classes of snakes-the Front-fanged or typical venomous snakes, the Back-fanged snakes which are more or less venomous, and the Solid-toothed snakes, which are harmless. The latter do not possess any grooved teeth or venom glands.

A Boa Constrictor in the London Zoo swallowed her blanket. When it was pulled out it looked like a huge sausage, and was wet and slimy.

Snakes' eyes are protected from injury by a transparent scale in front, which is like a tiny watch-glass in shape.

A Boomslang in the Port Elizabeth Museum swallowed a full-grown Green Water Snake. It was irritated with a stick, whereupon it disgorged its victim, which was none the worse, for, within a minute of being cast up, it caught and swallowed a frog.

On another occasion a Boomslang swallowed another, and was forced to disgorge. It began again and swallowed it a second time, and was again made to disgorge. The victim was as lively as ever, and did not seem at all alarmed. 
In the Port Elizabeth Museum two snakes will often seize a frog. Both start swallowing. When their noses meet, the larger usually engulphs the smaller and swallows him whole, frog and all.

The study of snakes is called Ophiology.

People speak of the "Wisdom of the Serpent." They have no more wisdom than a lizard.

Snakes are animals, inasmuch as they belong to the great Animal Kingdom.

Snakes are classed as Reptilia, of the Order Ophidia.

Snakes can be divided into five groups, viz., Burrowing Snakes, Tree Snakes, Fresh-water Snakes, Sea Snakes, Terrestrial or Ground Snakes.

Snakes hunt for their prey mostly during the daytime, and the early part of the evening.

They also issue forth on warm moonlight nights. On the slightest approach of chilliness of the air they retire to their retreats.

Snakes have been known to live over two years without food.

Young Puff Adders, born in the Port Elizabeth Museum, grew two inches in length and a quarter of an inch in breadth, without food. From the moment they were born, till three months later, they refused all food, yet they grew in length and girth.

As soon as the young of the snakes are born they shift for themselves. Their mothers take no heed of them.

Snakes are very low in intelligence. They have very tiny brains, and their sensibility to pain is very blunt.

If a snake's brain and its heart, or either, be removed, it will live quite a long while.

After severing the head the body of a snake will wriggle, coil and quiver for many hours.

If the nose be irritated, the jaws of the severed head sometimes open, the fangs spring erect, and the mouth closes with a snap.

Snakes can penetrate into the innermost retreats of rats and mice, hence their great value as vermin destroyers.

Learn which are the harmless kinds of snakes, and protect them. They are your friends. If you want to make certain, send them to the author of this book, and he will be pleased to tell you.

Snakes will seldom eat dead food. When very hungry they sometimes do so in captivity.

Snakes nearly always wait till the victim moves before seizing it.

In Bechuanaland, a Cobra was found in a fowl house with five whole hens' eggs inside it. The Cobra was killed, the eggs taken out and set under a hen. They all hatched out into healthy chickens.

Another Cobra was discovered in a hen's nest. It immediately disgorged six eggs entire, there not being a crack in any of them.

Indians sometimes catch Cobras by placing fowls' eggs inside a wire cage in the snakes' haunts. The Cobra enters between the wires, swallows one or more eggs whole, and consequently cannot escape.

The author had a pet English canary. One morning he found a snake coiled up inside the cage, asleep. It had swallowed the bird whole, and could not get through the wire bars of the cage. 
One night he set a wire rat-trap. Next morning a half-grown Blacknecked Cobra was found inside the cage, with a rat in its stomach.

The Mole Snakes and Boomslangs in the Port Elizabeth Museum sometimes swallow pigeons' eggs whole. The shell is dissolved within twentyfour hours or so by the snakes' gastric juices.

The gastric or stomach juices of a snake can digest bones, skin and horn.

Snakes drink by sucking the water into their mouths.

Snakes do not suck eggs. If egg-shells are found with a portion bitten out and the contents gone, probably a Leguan, Meercat or a Mungoose has done it. Snakes cannot bite bits out of egg-shells, or bore holes into them.

The tongue of a snake, when in repose, is withdrawn into a sheath in the lower jaw. The end of the windpipe lies over this sheath.

Snakes cast their skins regularly. It comes off inside out in a complete condition, even to the transparent eye scales.

Pythons often sink themselves in water with the nostrils only above the surface. In this position they lie and watch for animals coming to drink. The victim is seized by the nose when it stoops to drink.

Natural History knowledge in the I8th century was evidently at a low ebb. An author in 1796, in

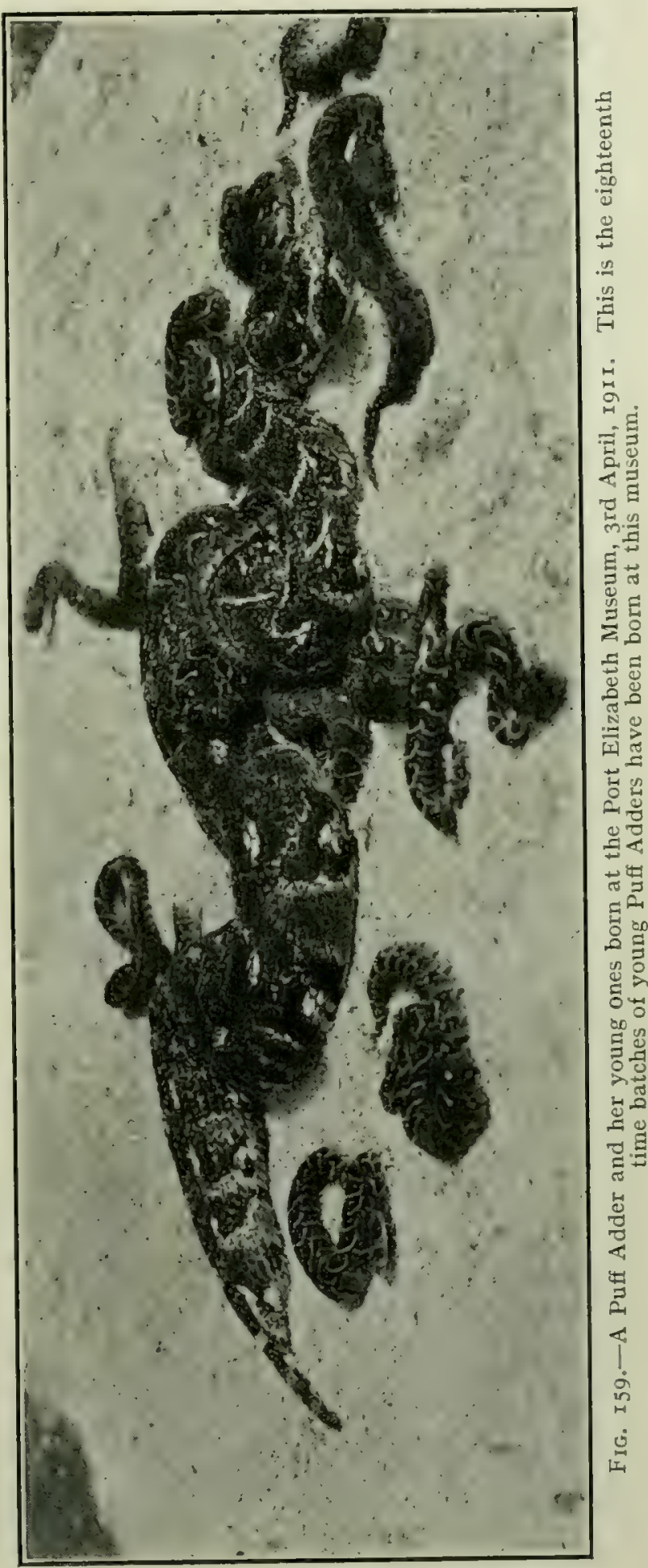
writing about a snake, says: "He hisses like a mountain eagle, and he bellows like a bull." 
Snakes are living barometers. They grow active, lively and strong when the air is warm and the sun shining. In the degree that the air grows cold, they, in that degree, become sluggish.

A snake may be quite stiff, and to all outward appearances dead, but on being warmed it will revive.

The suspension of the vital forces in reptiles during the cold season can be compared to that which vegetation undergoes in winter.

When snakes hibernate, they live upon the fat they have accumulated during the summer. This fat accumulates in the abdomen in little cakes, connected with tissue.

Python fat is in great request among South African natives as a lubricant for rheumatism and pulmonary complaints.

A Python has about 300 sections to its backbone, and I 50 pairs of ribs.

It is not true that Cobras suck cows and goats. They are found in cattle and sheep kraals, drawn thither in search of rats, and the warmth given off by the animals.

A young snake will live four months, sometimes longer, without food. Most of them, however, die within two months after birth, if not fed.

Snakes have strong prehensile or gripping power in their tails. In the Pythons and Tree Snakes it is highly developed.

There is a widespread belief in South Africa that a snake, known as the Hoop Snake, swallows its tail and bowls itself along like a hoop. This is not a fact.

Permanganate of potash is of little or no use unless applied within ten minutes of being bitten.

Permanganate of Potash has no antidotal effect if swallowed.

Don't keep a ligature on for more than half an hour to an hour. If you do, there is grave danger of mortification.

The only absolute antidote for snake bite is a serum which is now being prepared. If you want the genuine stuff, write to the author, who will have it procured for you.

The active principle of practically all the so-called antidotes, except the serum and permanganate of potash, is strychnine and ammonia. These are nerve and heart stimulants only. They do not possess any antidotal power. Some of these so-called antidotes have certain herb extracts in them. All, which I have tested, have been quite worthless.

Don't waste your money on these, and risk loss of life.

Provide yourself with the proper serum, permanganate, lancet and serum syringe, and you are safe.

The Bushmen of old in South Africa used snake poison largely in the poisoning of their arrow-heads.

They first enraged the snake, for in doing so the glands got full, and the venom was more virulent.

To prevent the snake wasting his venom, they held it down by pressing its head against the ground and preventing it opening its mouth.

Cobra venom acts rapidly on the nerve-centres, causing paralysis and rapid death. 


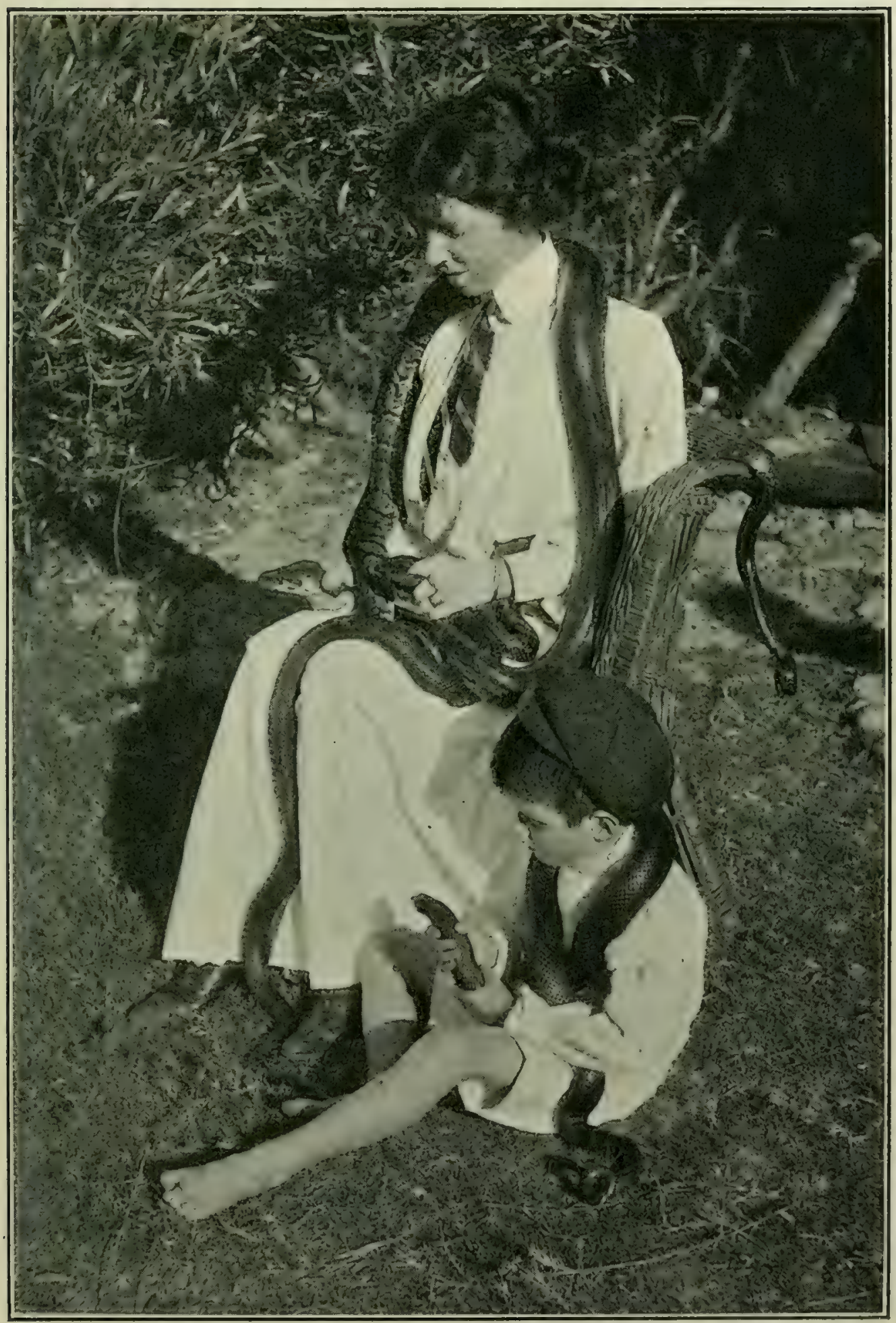

FrG. $160 .-A$ happy family basking in the genial South African sunshine. 
Adder venom acts chiefly on the blood and the walls of its vessels, breaking them up and causing hamorrhage into the tissues.

Adder venom acts much more slowly than Cobra venom.

The venom of every species of snake differs somewhat in its action.

The widest difference is between the Cobra family and the Adder family of snakes.

A serum is now prepared by immunizing horses to the venoms of the different classes of snakes. snake.

It is, therefore, an antidote to the bite of any kind of South African

The mortality in India from snake bite, until lately, has averaged 20,000 a year.

All the popular antidotes in India have been proved to be worthless.

Dosing a man with large quantities of alcohol for snake bite is dangerous; so is ammonia and strychnine.

The mythical Dragon is believed to have had its origin in the Python, of which there are many species inhabiting Asia and Africa.

In a Chinese work entitled "Shan Hai King" dating from 350 A.D., a great snake is referred to which possessed two pairs of wings.

In China and Japan, the mythical Dragon is represented as being more or less snake-like, but in the other parts of the East and the West it differs more or less in shape.

The Greek word " drakon" actually meant a large snake, and is so used by Aristotle and other classical writers.

On a Greek vase is the painting of a great serpent called a Dragon guarding the tree in the garden of the Hesperides on which grew the golden apples, in quest of which, according to Greek legend, the hero Hercules went. The figure represents a large horned serpent coiled round the trunk of a tree on which the golden apples are hanging, while the figures of the Hesperides and Hercules are shown standing near.

According to Bible history it was a great serpent who guarded the forbidden fruit and which tempted Eve to take and cat.

The serpent was worshipped from exceedingly remote times, long before the origin of the Jewish nation.

The ancient Egyptians worshipped a great serpent-god called "Ha-her " or "great Lord of fear and terror." They believed that to him the wicked would be handed over and frightfully tortured.

The much-feared Evil Spirit of the Scandinavian mythology was a great snake.

In Revelation xx., I, 2, it says, "The dragon that old serpent which is the Devil and Satan."

In the East even at the present day the serpent is regarded as being possessed of an evil spirit and used by unseen powers for purposes of vengeance.

Herodotus and Pliny believed in the existence of winged snakes. The belief in winged snakes probably arose from ecls, which are snake-like in shape and possess fins, which would on drawings and carvings take the shape of wings.

In Dutch Guiana the negroes believe that if the leaves of three species of trees are taken, pulverized and applied to the scarified site of the bite, it is a certain cure for snake bite. 
The Cobra (Naia tripudians) is considered to be the most venomous species of snake in India. The Krait (Bungarus caruleus) comes next.

In South Africa the Mamba and the larger species of Cobras are the most venomous species. Their venom is swift and potent in its poisonous action upon the nerve centres.

Dried snake venom looks like light straw-coloured gum arabic. It does not actually crystallize. It assumes the pseudo-crystalline form.

When snake venom decomposes it gives off carbonic anhydride gas, becomes dark brown in colour, and smells disagreeably.

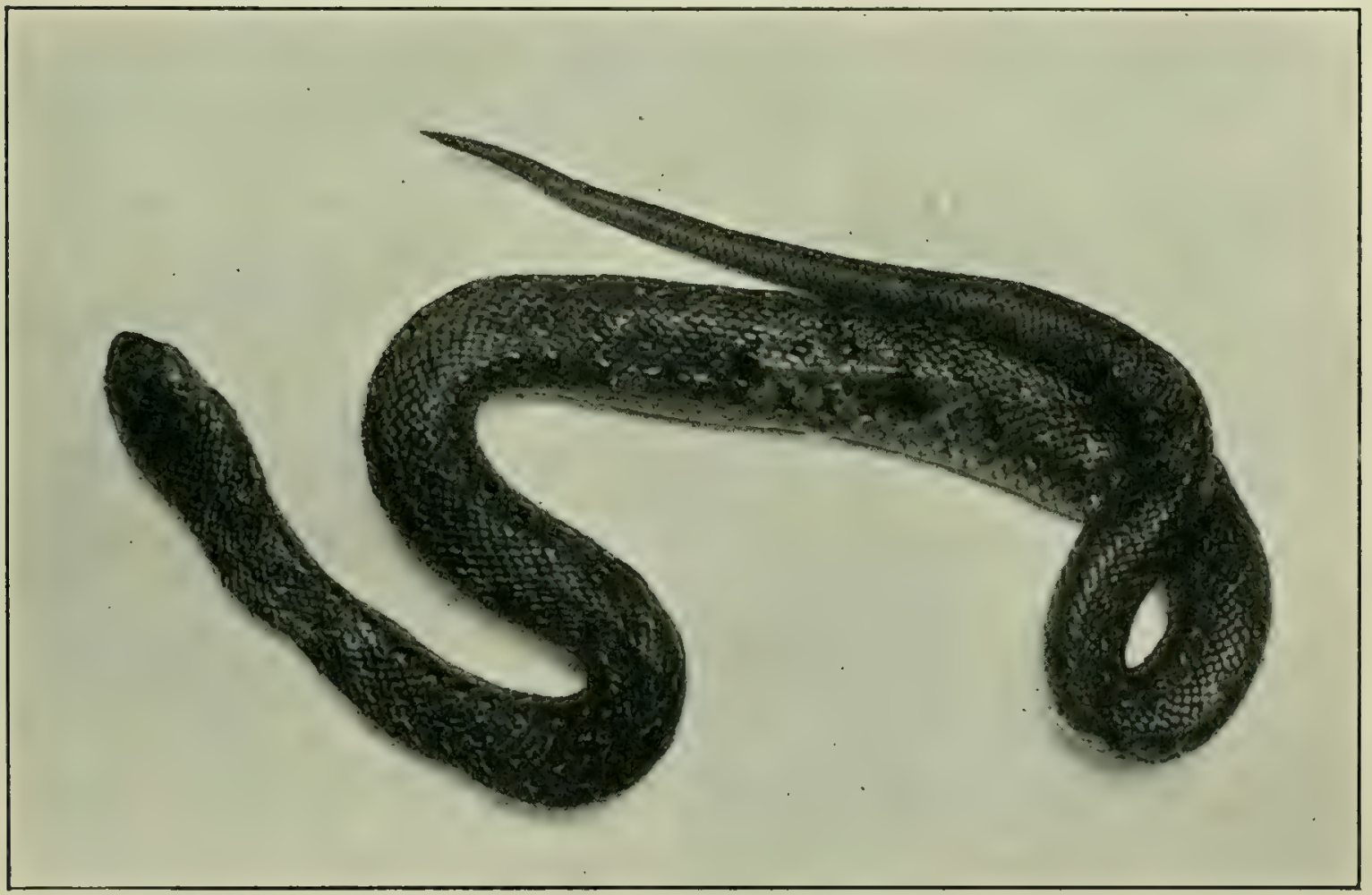

Frg. I6r.-This is a young Mole Snake (Pseudaspis cana). These Snakes are brown with squarish black spots and white dots running in rows the whole length of the body.

Mineral acids when added to snake venom produce a gelatinous sediment.

Snake venom when mixed with pure alcohol throws down a white sediment. Its poisonous properties are, however, not lessened.

Some common symptoms of snake bite in a dog are vomiting, saliva running profusely from the mouth, and a "staring coat."

Half a drop of Cobra venom will kill a man.

An adult cobra can eject ten to fifteen drops of venom at a time. The usual quantity, however, is about six drops.

Dr. Hanna says that an Indian cobra will yield as much as 20 drops of venom. Some give 25 to 28 drops. 
Snakes kept a few months in captivity yield less than one half the venom that they are capable of in the wild condition.

Cobras and Mambas are far more to be dreaded than Adders, because their venom acts so rapidly.

Adder venom being much slower, there are better opportunities of applying remedial measures with success.

Solutions of venom in pure glycerine will keep indefinitely.

In a liquid condition it will keep good a couple of months in a corked bottle. It then decays and loses its poisonous properties.

Cobra venom specially paralyzes the nerve centres of respiration in the top of the spinal cord, known as the.Medulla Oblongata.

Most snake venoms act upon the nerve cells of the central nervous system.

One drop of the venom of a Cape Cobra injected into the hind leg of a dog killed it in one hour five minutes.

Boomslang venom, bulk for bulk, is as powerful as Cobra venom. One drop will kill a large dog or a monkey.

Curare, a South American poison of vegetable origin, like suake venom, has no bad effect if swallowed, but if injected under the skin acts like snake venom.

There are people in South Africa who actually believe that if a man be innoculated with snake venom, no poisonous serpent will ever attempt to bite him. They say the snake knows by instinct he is proof, so they refuse to waste their venom. Snake "instruction "is evidently badly needed.

Snake venom dissolves readily in water. It is usually injected in solution with water when experimenting.

Snake venom may be dried between slips of glass and stored away in a dry place. It will keep fresh for a lifetime.

One of the methods of treating snake bite in India is to sit round the bitten person and chant charms.

For technical details of the anatomy of Snakes, see "Encyclopxdia Britannica," IIth edition, I9I I.

Snakes are not as a rule proof against their own venom, but it usually takes a big dose to ki!l an adult snake.

Some snakes die when bitten by other snakes, or if venom is injected. Others are not affected.

The poison of one snake is not an antidote to the venom of another. If rubbel into the wound it considerably increases the chances of death.

The head of a venomous snake is often dried and pulverized. It is popularly supposed to be a cure for snake bite. It is the very reverse.

Quinine is of no antidotal value as a remedy for snake bite, either injected or applied to the wound.

If a large Cobra bites a dog or other animal, and if the bite be full and complete, enough venom gets into the circulation within two seconds to cause death. Permanganate of potash and ligaturing fail to avert a fatal issue.

An excessively minute quantity of Cobra venom is sufficient to kill a fowl or rabbit. 
ITEMS OF SNAKE KNOWLEDGE.

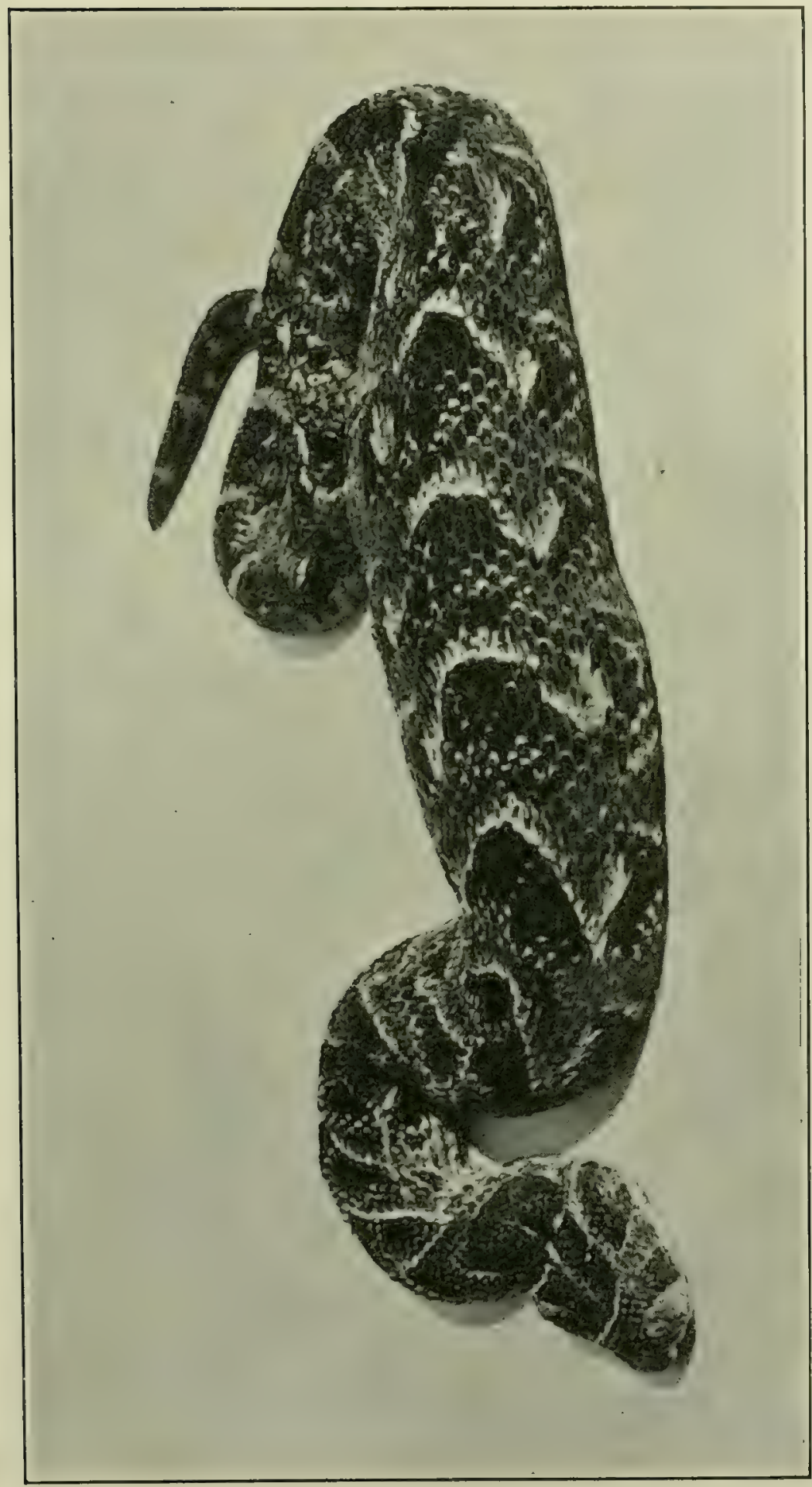

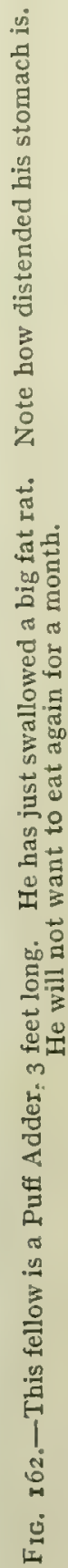


Gadow says, "A bird is known by its feathers, a beast by its hairs, a fish by its fins, but reptiles are neither fish, flesh, nor fowl."

Permanganate of potash, if injected in solution direct into a vein, is attended with grave danger. It will kill all venoms if brought into direct contact with them.

The Bird Snake (Theltornis) is oviparous.

The Cape Wolf Snake (Lycophidium capense) is oviparous. One laid a batch of eggs in the Port Elizabeth Nuseum on 8th December, 1909.

It is untrue that snakes will not pass under geranium bushes. I have often seen them do so. A Puff Adder was actually killed lying asleep under a large geranium bush.

When Mole Snakes shed their skin it comes off in pieces, not in one whole piece. This is owing to their small heads and comparatively large bodies.

I have never known a Python to shed a complete skin. Every one I have kept in captivity shed its skin in pieces. The skin broke up and peeled off in fragments. 


\section{ADDENDA.}

\section{SUPPLEMENTARY SNAKE KNOWLEDGE.}

The information contained in this Supplement was compiled by the author, and the illustrations procured after the previous portion of the book had already gone to press. 

Some Experinents at the Government Veterinary Research Laboratories, Pretoria.

DR. Theiler, the able Director of the Veterinary and Research Departments of the Union of South Africa, has recently started a series of experiments with the object of ascertaining the exact pathological effect of the venom of each species of South African poisonous snake. For this purpose I have supplied him with various venomous snakes. The experiments are in their initial stages; but Dr. Theiler has kindly sent me the following instructive article by his assistant, Mr. W. Horner Andrews.

\section{A Baboon bitten by a Boomslang.}

The Baboon was bitten on the shoulder by a Boomslang at noon on December 29, I9II.

On the following day there was considerable œedematous swelling at the site of the bite, extending down to the elbow. The Baboon was at first fairly active, but later became dull and depressed. By 5 p.m. she was lying down, although still able to stand and walk, but still very depressed.

On the morning of the 3 Ist the Baboon was very poorly, refused food and water, and lay for a long period on one side.

In the evening she was more inclined to eat and drink, but was very weak.

January Ist saw a very decided improvement, although still weak and depressed. After this there was a very rapid recovery.

She was again bitten by a Boomslang at I2.33 p.m. of January 23. The snake bit exceptionally well, seizing a fold of skin over the abdomen, holding on for about four minutes, and worrying it. 
At 4 p.m. there was a distinct swelling at the site of the bite, and this swelling increased in size and extent until the following morning.
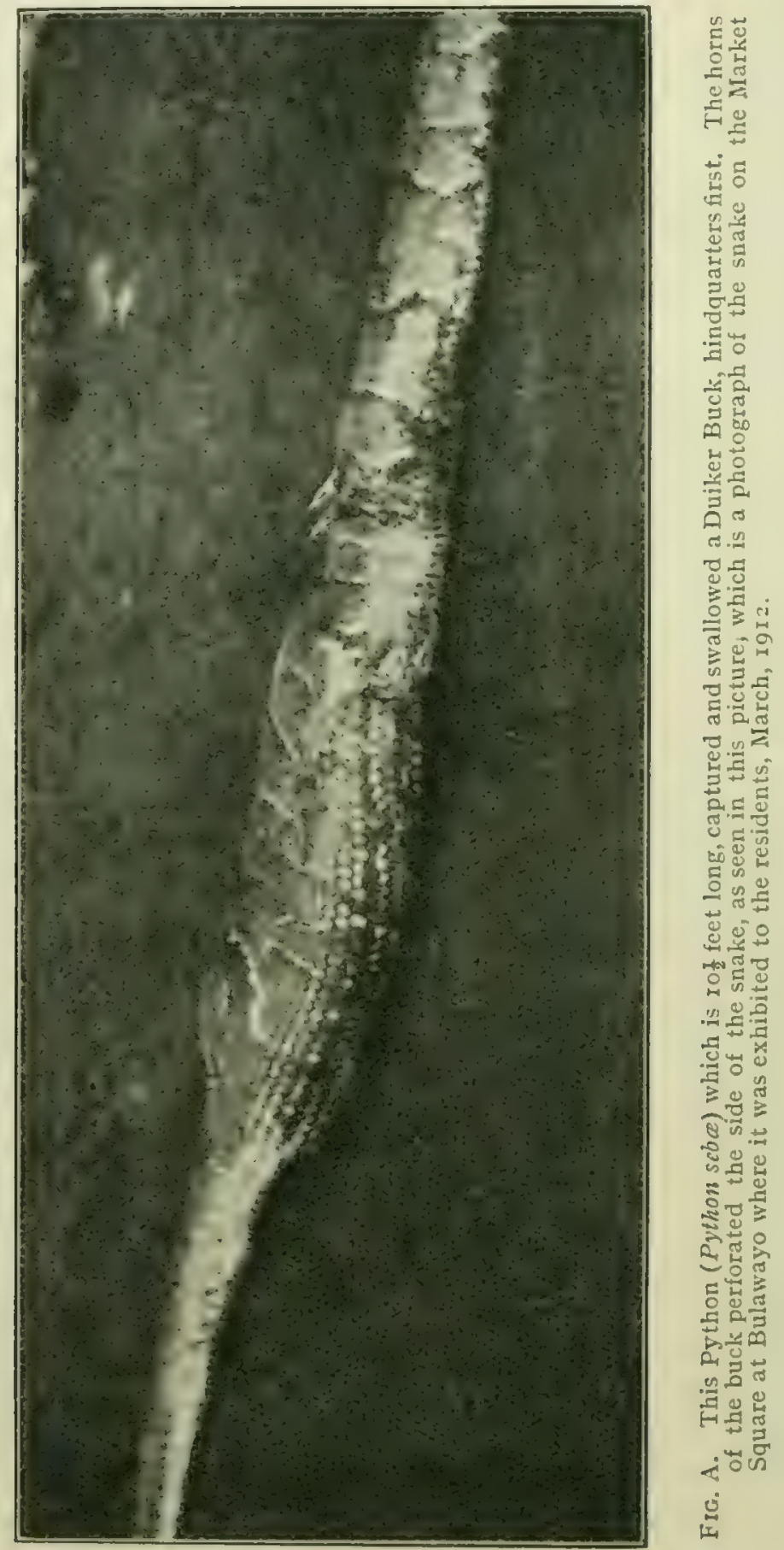

No general symptoms were shown until about 5 p.m. ( $4_{2}^{1}$ hours after the bite), when there was slight dulness. This depression 
increased slowly, but at II p.m. the Baboon was still playing languidly.

The following morning she was lying down, with the eyes closed, and unable to rise or move to any extent, although quite conscious.

At 3 p.m. the animal was very weak, and respiration was slow and stertorous.

Death occurred at 3.20 p.m. (twenty-seven hours after the bite).

Before death the skin showed a large livid area over the abdomen.

In the post-mortem, the most striking points were-

(I) Hæmmorrhagic infiltration occurring subrutaneously in patches, quite remote from the bite.

(2) Hæmmorrhage into the cæcum and colon.

(3) Apparent degenerative changes in the liver (not yet studied histologically).

(4) Excessive anæmic pallor of most parts.

\section{Results of Other Experiments.}

In experiments on the effects of Snake Venom on domesticated animals, undertaken recently at the Veterinary Research Laboratory, Onderstepoort, Pretoria, I have subjected some twenty-five horses, mules, and sheep to the actual bite of Cobras (Naia fluva and nigricollis), Boomslangs, Ringhals, and Puff Adders.

Amongst the animals bitten by each species of snake, there have bcen some showing an acute onset of symptoms, ending rapidly in death, some taking a more chronic course, but with a fatal termination, and others ending in recovery.

In these cases, blood has been taken at intervals, and examined with the following results:-

(I) No appreciable diminution has ever been seen in the number of red corpuscles, as determined by the hæmatocrite.

(2) In no case has any hæmoglobin coloration of the plasma or serum been observed ante-mortem.

(3) In a few cases there has been a marked difference in the coagulability of the blood.

Thus in cases of two sheep dying fairly quickly as a result 
of Boomslang bites, blood taken before death appeared to have lost entirely the power of coagulating, and this was also seen in one case (out of six) of Puff Adder bite. Partial loss of coagulability was seen ante-mortem in one case of Cobra bite in a sheep, and in several cases post-mortem coagulation appeared to be incomplete.

It would appear from our experiments that, in the majority of cases of snake bite in larger animals, no structural alterations in the blood can be observed during life. There may, however, be a diminished coagulative power, and this is seen especially as a result of the bite of a Boomslang.

It will be necessary to confirm and amplify these results by further investigations.

W. Horner ANdrews.

B.

The Venom of the SchaApsteker.

(Another back-fanged Snake.)

The Schaapsteker is one of the back-fanged division of snakes. The fangs are set halfway back in the upper jaw. They are grooved, and like all the back-fanged snakes the Schaapstekers possess poison glands. These glands, however, are not some distance from the fangs nor connected with them by tiny ducts or tubes, as is the case with front-fanged snakes. The glands are situated immediately under the skin. One end of the poison gland comes against a hole in the upper jaw in which the fangs are set, and the venom oozes down through this hole into a mucous sheath which envelopes the fangs. The venom is of greater consistency than that of the typically venomous frontfanged snakes. It collects in this mucous sheath. When the snake bites, in order to get the venom into the wound, it is obliged to take a firm grip and press the fangs strongly into the flesh. The longer it is allowed to grip and worry the flesh, the more venom it will force through the fangs. It is generally believed that the Schaapsteker, as its name implies, is in the habit of biting sheep. The fangs of these snakes are so small that even if a full grip were obtained on a sheep's leg, they, 
except perhaps in a very few instances, would not penetrate the tough skin of the animal. I have tried repeatedly by allowing Schaapstekers to bite the legs of sheep, but in no instance was

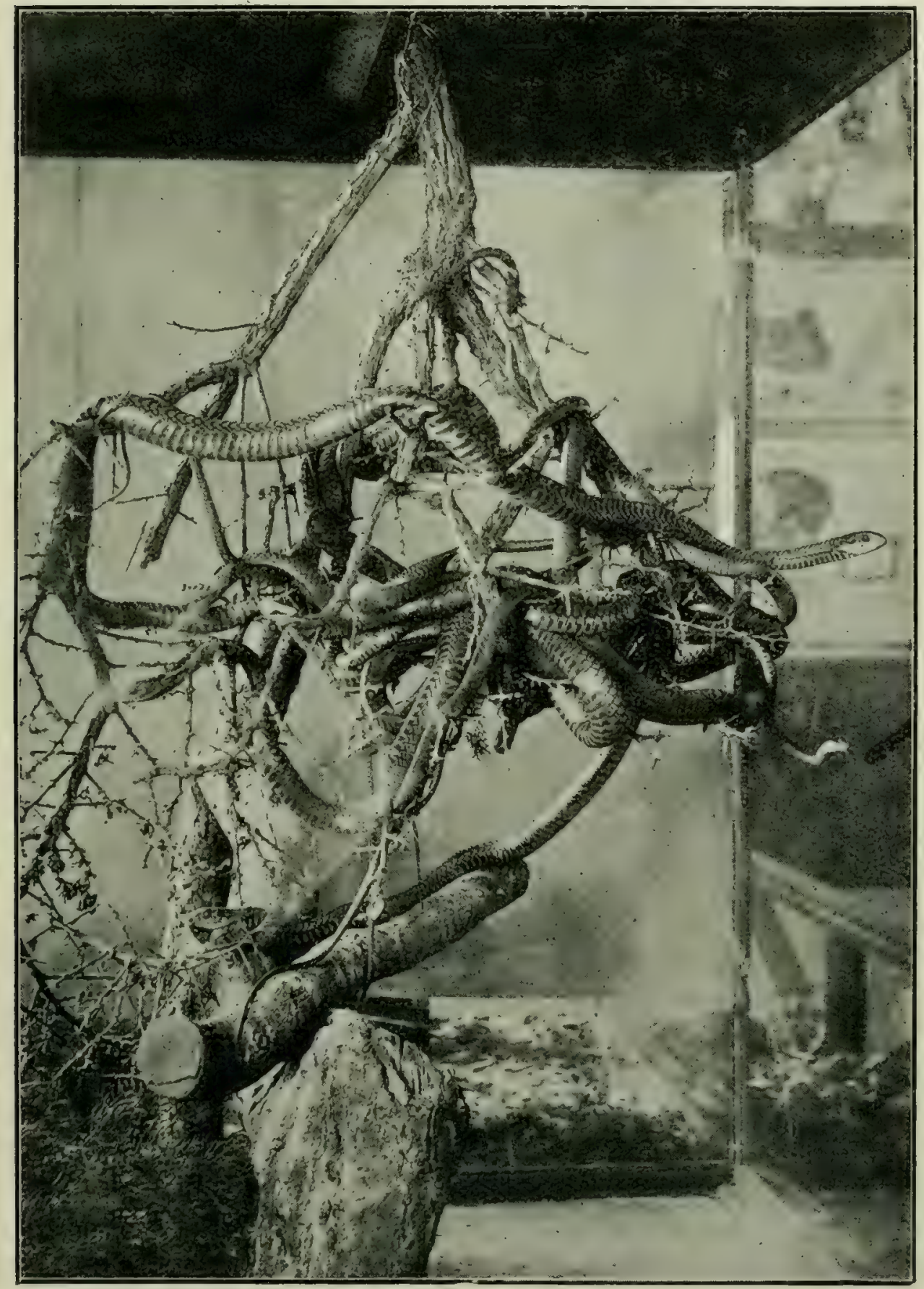

FIG. B.- Some live Boomslangs in one of the snake cages at the Port Elizabeth Museum: These cages are each 4 feet square, with plate glass on the four sides. The door is covered with strong wire gauze, and a strip is inserted in the roof of the cage. This provides sufficient ventilation. A gas apparatus and hot-water pipes supply heat. 
there any appearance of the fangs having penetrated through the skin, nor was there the slightest symptom of poisoning manifested in the animal. Many times I have been bitten on the bare hands by Schaapstekers, but in no case dicl I give the reptile time to get a full grip so as to work its fangs well home. Slight discoloration of the part bitten, and a certain amount of pain in the glands of the armpit supervened. However, in the majority of cases there was not the slightest symptom of poisoning.

\section{Startling Results of Experiments.}

I allowed five newly-captured Schaapstekers (Trimerorhimus rhombeatus) to bite the bared legs of five fowls. Each snake was permitted to take a full grip and hold on for several seconds. Three of the fowls showed no symptoms of poisoning. One became drowsy and died in about six hours. The other moped for a day, but recovered completely. The flesh for an inch around the site of the bite was a light greenish-yellow, and the whole leg was slightly swollen. Taking another batch of fowls, six in number, I caused six different Schaapstekers to bite them on a part of the thigh previously bared. Each snake was allowerl to hold on for several seconds. In two of the fowls it was noticed that immediately under the two punctures made by the fangs slight discoloration occurred, showing that the fangs had really gone through the skin and ruptured some capillary blood-ressels. In both these instances the fowls died. One died in ten minutes, the other in seventeen minutes.

These experiments were repeated until it was clearly proven to me that, should the Schaapsteker succeed in fully penetrating the skin, and should it be able to force a little venom through, its toxic effects were very powerful and rapid. The poison is evidently more or less akin to that of the Cobra, for no hæmorrhage occurred in any part of the body. This shows that the poisonous principle which kills in the Schaapsteker venom is a powerful neurotoxin.

It is a difficult matter to collect venom direct from backfanged snakes. However, I succeeded and discovered that, weight for weight, Schaapsteker and Boomslang venoms were more poisonous than those of the dreaded Cobra or Mamba.

Here we have two species of snakes of the back-fanged 
division which distil a venom of a nature surpassing in its deathproducing power that of the well-known Cobra.

The Schaapstekers experimented with were the Spotted or Rhombic species. (T. rhombeatus). Although some other snakes are termed Schaapstekers, the Spotted or Rhombic species is the typical Schaapsteker of South Africa.

\section{SchaApstekers Comparatively Harmless.}

Although it has been shown that the Schaapsteker has a venom which, in strength, exceeds that of the Cobra, it is not a snake which we need fear overmuch. The fangs are srall, and being set halfway back in the jaw, the reptile is obliged to get a full grip before venom can be ejected. The venom is not driven out forcibly by the violent constriction of the venom glands, as is the case with the front-fanged, typically venomous snakes. The venom is like glycerine in consistency, and the snake is obliged to press the fangs fully home, and at the same time compress the jaws forcibly and worry the flesh before a fatal dose of poison can be worked into the wounds.

A Schaapsteker is incapable of doing harm if it should bite at a man's leg clothed in thick trousers. Even if the sock be of average thickness, the chances of poisoning are remote.

Bare-legged natives, although frequently bitten by Schaapstekers, seldom come to any harm, for the reason that the instant the snake strikes and grips the skin, it is violently kicked off.

James Williams, of Boomslang fame, has many times in my presence been bitten by Schaapstekers, but no symptoms of poisoning supervened. In these instances the snakes merely pecked and inflicted a slight wound with the teeth, but failed to get a strong grip and hold on. However, it must be borne in mind and not forgotten, that if an adult Schaapsteker should obtain a full grip and succeed in driving its fangs through the skin and be allowed to compress its jaws for a moment or two, it is capable of injecting sufficient venom to cause death in a man within six to twelve hours.

Therefore, let all take warning and be careful how they handle these snakes. In fact, every snake of the back-fanged kind should be handled as carefully as those of the typically venomous front-fanged species, such as the Cobra and Puff Adder. 
C.

\section{More about Ringhals-A Crafty Dodge.}

The cunning Ringhals Kapell not only sends out a shower of venom at its enemy to blind him, and thus effect its escape while he is suffering agonies of pain and is staggering about

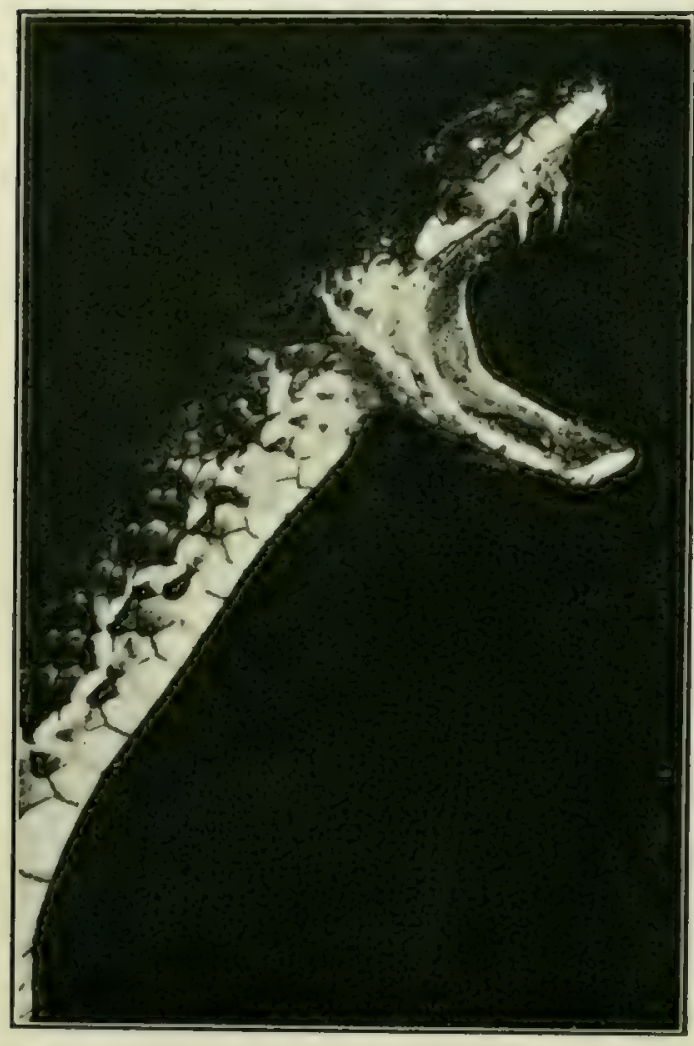

FIG. C. Head of a Spotted or Rhombic Schaapsteker ( $T$. rhombeatus) showing the fangs. These are situated halfway back in the upper jaw under the eyes. (Natural size.) in a dazed and blinded condition, but it actually simulates death. When the Ringhals Kapell realizes that escape is impossible, it frequently pretends to be dead. Its body becomes limp, it turns partly or wholly over on its back, its jaws gape, and to all intents and purposes it is dead. You may turn it over and over with a stick, but not a sign of life will it show. It will lie in the position in which it is thrown. However, this deadly serpent is wide awake all the time. Through its transparent eye scales, its unwinking eyes register every move of the enemy, and should he be unwise enough to approach within striking distance, this apparently dead snake becomes electrified. With a fierce forward thrust, it drives its fangs home with deadly effect. Should the Ringhals Kapell succeed in delivering a full bite, it is capable of injecting eight to ten drops of venom into its victim. A single drop is a fatal dose for a man.

Once I was anxious to get a good photograph of a specially fine Ringhals which we had at the Port Elizabeth Muscum, so, thrusting it into a box, we carried it out to the neighbouring veld. Casting it upon the ground, we got our apparatus ready 
to take a photo when it reared, for we desired its photograph with hood expanded. The reptile would not do anything of the kind. It lay as though dead. Its mouth gaped, and its head and neck were twisted in the attitude of a snake which had recently died. We prodded it with long sticks and turned it over and over, but not a sign of life did it show.

Becoming bolder, my assistant ventured rather near. Then, in a second the snake reared a foot and a half of the anterior part of its body, and the venturesome man received a shower of finely-sprayed venom on his face and coat. Fortunately he had previously donned a pair of curved spectacles, so none got into his eyes. We carefully inspected his face to see if there were any abrasions. He felt rather nervous because he had shaved a few hours previously and his skin was tender in places. A few minutes later I noticed thousands of tiny specks of venom, glistening in the sun, on his blue serge coat.

After this ineffectual attempt to blind its aggressor, the Ringhals glided away, endeavouring to find some place of concealment. Getting annoyed, I prodded it with my stick, whereupon it again reared and, this time, sprayed my face, neck and coat with venom. I too wore spectacles, so no harm was done.

Bitten by a Ringhals. Injecting Normal Salt Solution.

Dr. H. Claude Wright, Medical Superintendent of the Victoria Cottage Hospital, Wynberg, Cape Province, writes me as follows :-

"A railway labourer was admitted to hospital at 2 p.m., having been bitten by a Ringhals at II a.m. He was collapsed, livid, and semi-conscious-almost pulseless, which was very rapid and uncountable. He was approaching death. I administered a large dose of brandy, and immediately transfused him in the left median vein to the extent of three and a half pints of Normal Saline Solution, at the same time opening the median vein in the right arm. At first very little blood flowed out, but as the dynamic pressure asserted itself due to the saline, he bled freely to the extent of a quart by measure, some being lost in the bed. His condition thereupon improved, and, with the addition of plenty of hot boric and brandy, by the night he was much better. His convalescence was uneventful with the 
exception of mortification of the finger which I subsequently amputated. There had been no ligature placed around the finger, so the mortification was not due to strangulation. The finger, on admission, was soaked in strong carbolic solution, and subsequently in strong permanganate of potash. There was evidence that the snake was a Ringhals, and as the man was so near death when admitted, I presume the remedy was successful."

The Normal Saline Solution injected by Dr. Wright is made as follows: 78.75 grs. sodium chloride (common salt) dissolved in 20 ozs. of sterilized water.

D.

\section{A Boomslang Bite.}

Mr. G. W. Pretorius was one day walking among some prickly pear bushes at Uitenhage, when he disturbed a Brown Boomslang in the grass. It struck out at him and gripped the calf of his leg. He endeavoured to kick it off, but failed. Stooping down he seized it by the body, plucked its head away and threw it from him. Although he had ordinary trousers on, the fangs penetrated them and made two punctures in his skin. $\mathrm{He}$ improvised a ligature and applied it. Dr. McPherson, the District Railway doctor, was soon in attendance. He scarified the wound freely and otherwise treated him. Some hours after the infliction of the bite, Pretorius fainted away, and remained insensible for some time.

The ligature was kept on for some days, being slightly loosened at short intervals. The bitten limb swelled considerably, and extensive hæmorrhage occurred in it. Blood slowly oozed from all the mucous surfaces, particularly the nose and mouth. For a month. Pretorius lay in bed in a critical condition. For the first week his stomach rejected all food. For some days water was vomited when swallowed.

For ten days and more, he suffered severely from pains in the bowels. In fact, his symptoms were similar to those described in the case of James Williams, except that the hemorrhage was chiefly confined to the leg which was bitten; also the mucous membranes. This was doubtless due to the ligature which prevented the renom passing into the general circulation in sufficient strength to cause subcutaneous hemorrhage in other parts, as 
was the case with Williams. For two years after recovery,

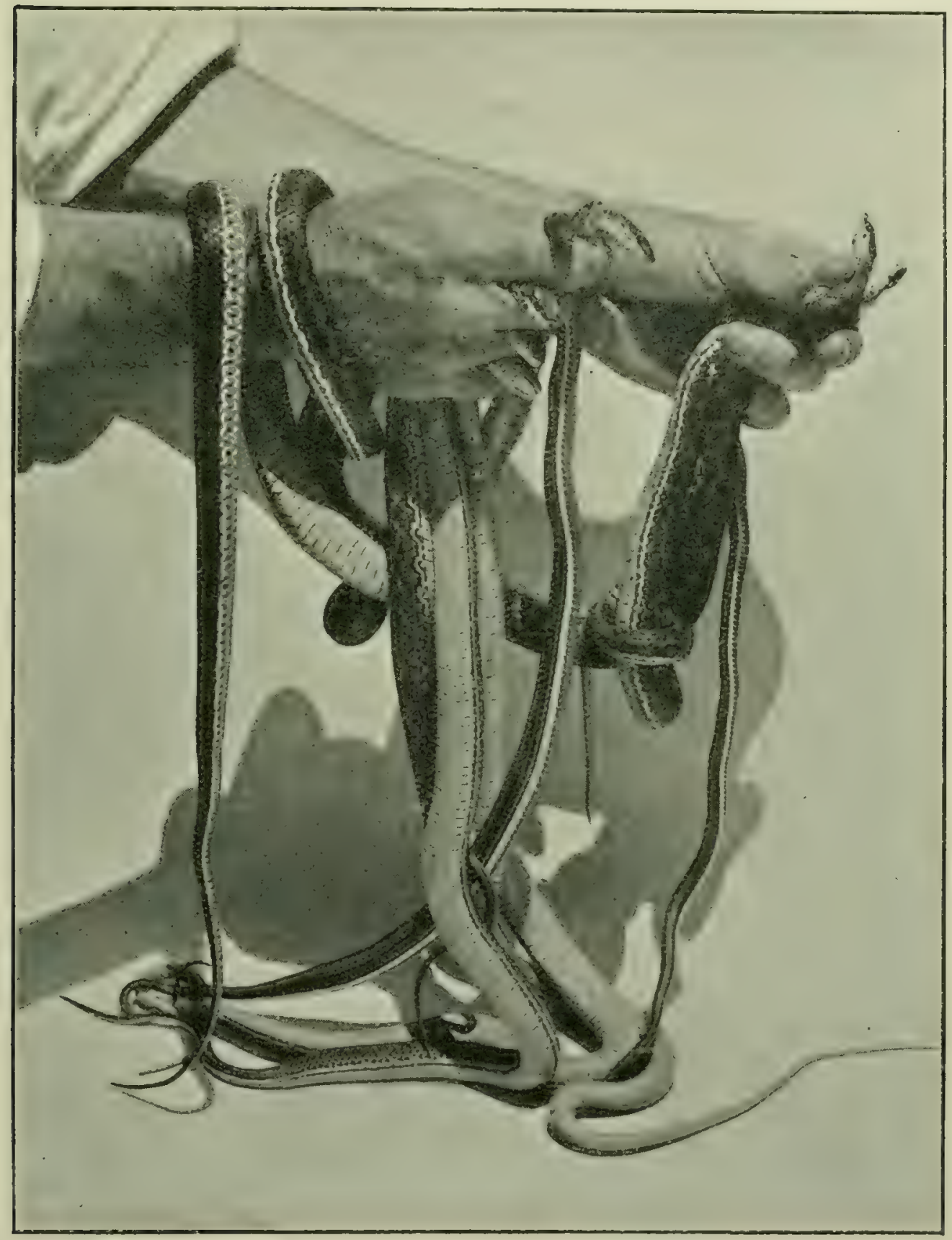

FIG. D.-A few of the author's live Schaapstekers, by the aid of which he demonstrated that their venom, weight for weight, was as potent in its death-dealing properties as that of the cobra.

The two with straight lines down their bodies are commonly known as Crossed Grass Snakes (Psammophis crucifer). The others are Rhombic or Spotted Schaapstekers (Trimero. rhinus thombeatus).

Pretorius suffered from giddiness and mental torpor whenever the weather was unusually warm. To prevent himself falling 
he was obliged to lie down for hours at a time. These symptoms grew less and less severe as time wore on, and have now almost disappeared, although at times when he is out for long in the hot summer sun, he feels faint and dizzy.

Although the snake escaped, there is no doubt about it being a Boomslang, as Pretorius knows a Boomslang as well as I do. He informs me that the snake glided up a dense mass of prickly pears and rapidly slid away out of sight amongst them. This is rather remarkable when it is realized that a hedge of prickly pears is smothered with long, sharp, straight thorns sticking out at all angles.

\section{E.}

\section{The Isolation of Madagascar and Australia.}

There is very strong evidence for believing that Madagascar was, in remote times, joined to the mainland of Africa, and that Australia was a part of Asia. Now, even the study of snakes helps us in coming to such a conclusion, and even suggests the period at which the separation took place.

In Madagascar there are no front-fanged (Proteroglypha) snakes such as the Vipers and Cobras. They are all of the hind-fanged (Opisthoglypha) and solid-toothed (Aglypha) species. This indicates that snakes had not evolved a typical poison apparatus prior to the separation of Madagascar from Africa, otherwise we should have found them there, for Africa is teeming with the front-fanged species of snakes. This fact leads us to conclude that Madagascar was isolated at a very remote period of time, and that the separation of Australia from the mainland of Asia occurred at a more recent period, because we find numbers of species of front-fanged, typically renomous snakes in that country. We thus infer it was isolated after snakes had fully evolved their poison apparatus.

Moreover, in Australia, there are no snakes of the viper (adder) family, although there are plenty of them on the mainland of Asia. This fact would seem to indicate that the viper family of snakes have evolved at a more recent period than the Colubrine group of venomous snakes.

Further, snakes have never been known in New Zealand. 
ISOLATION OF MADAGASCAR AND AUSTRALIA. 493

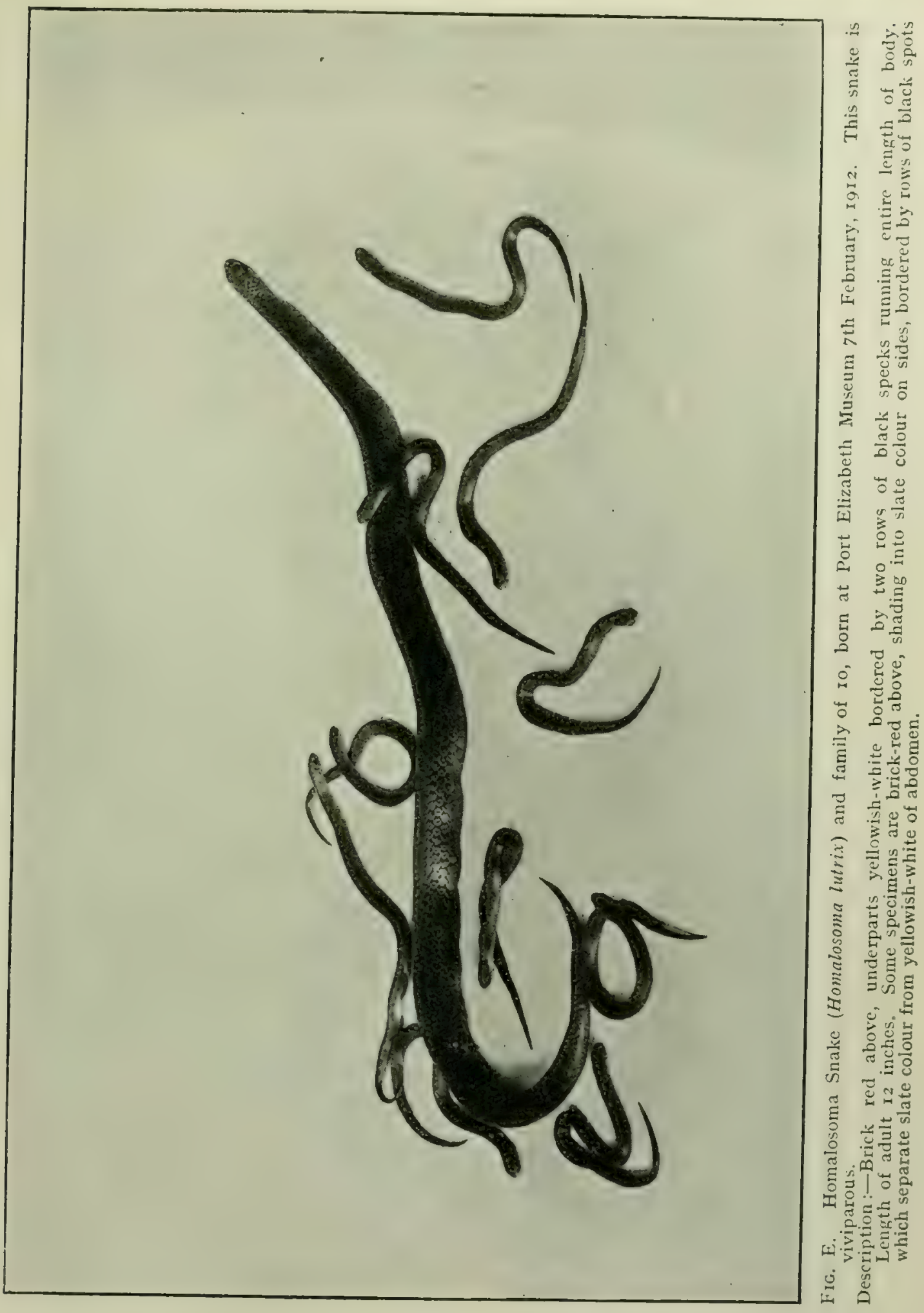


We might reasonably infer from this that New Zealand was isolated prior to the evolution of snakes from lizards or lizard-like creatures. It is reasonable to assume, too, that if New Zealand had been joined to Australia or any other snake-infested territory we should find snakes still living there.

\section{F.}

\section{Potency of Mamba Venom.}

Mr. Hector McKenzie-Shaw, Government Land Surveyor, related to me the details of the sad death of the well-known young farmer referred to in the chapter on the Mamba. He was present when the deceased was bitten by the Mamba, and remained with him till his death. His account is as follows: "We had been out hunting, and on returning to the wagon, which was about a hundred yards distant, my friend trod upon a large Black Mamba which instantly bit him on the front part of the left foot, just above the top of the boot. Without an instant's delay we tied ligatures above and below the punctures, scarified the part and rubbed the wounds full of permanganate of potash crystals. I then put on another ligature above the knee, and yet another at the top of the thigh, tightening them with a stick and screving it round. Arriving at the wagon, I sucked the wound thoroughly and gave him half an ordinary tumbler of brandy, and placing him on a mattress, covered him up with blankets and kindled a large fire at his side to keep him warm. At intervals we gave him doses of brandy. In all, he drank about half a bottle of it. The snake inflicted the bite about three o'clock in the afternoon. For the first hour my friend was somewhat excited, and talkeci and laughed with us. Then he calmed down, and was perfectly normal apparently, and complained of nothing except diarrhoea and an unpleasant twitching of the muscles of the mouth and tongue. Hour after hour went by, and we chatted away beside the checrful fire, planning out many things for the future, never dreaming for one moment that this was the last day for my friend, who seemed none the worse for the bite. A little before 9 p.m. I noticed he was less talkative, and that his eyelids were getting puffy. From this time onward he secmed to be rather tired. Then, 


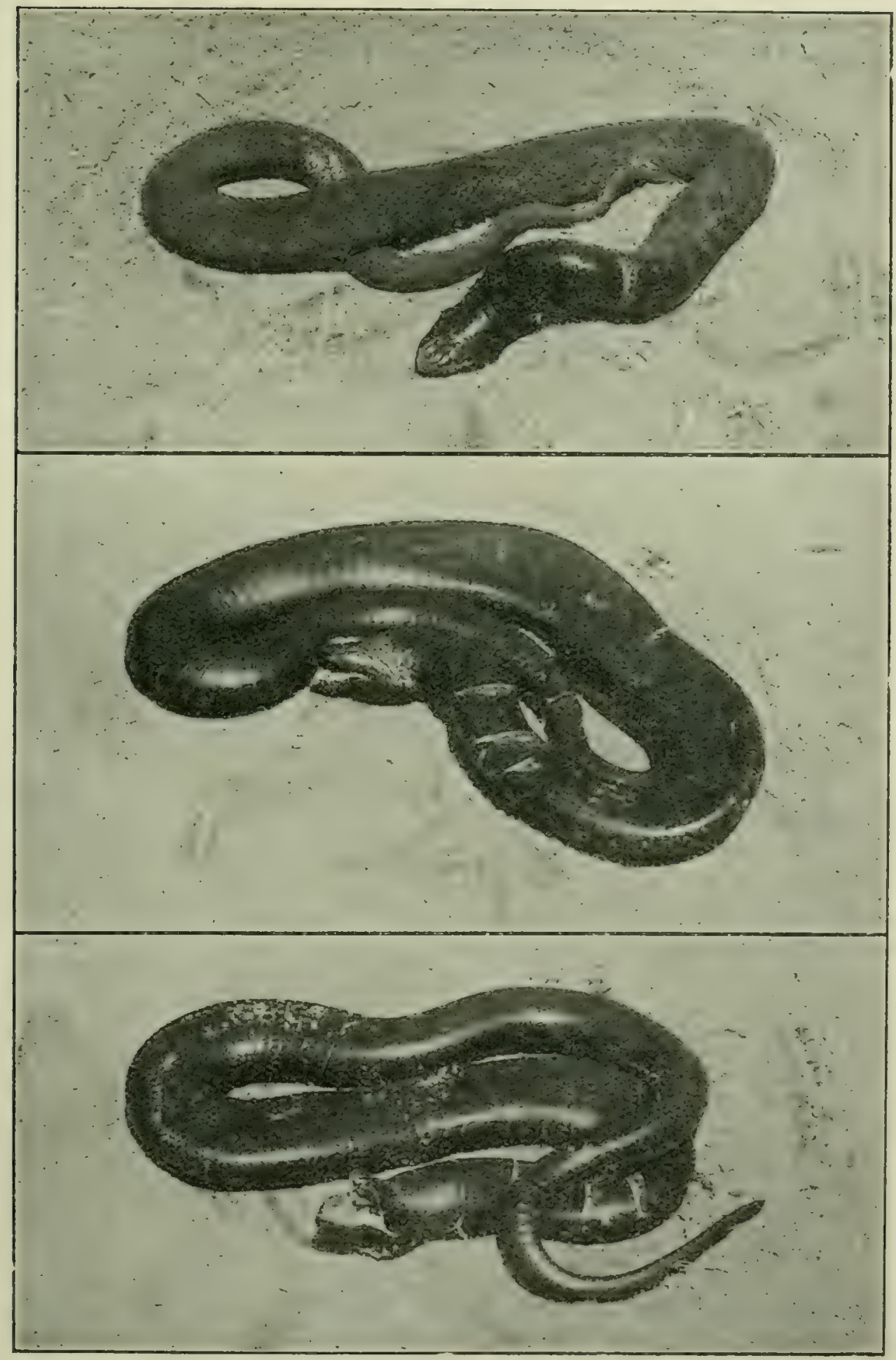

EIG. F.-A Ringhals Cobra shamming death.

Sending three showers of finely-sprayed venom in quick succession at my face, and realizing it had not blinded me as it hoped, it forthwith turned over on its back and pretended to be dead.

The pictures show it in various death-like attitudes. 
at ten p.m. without any warning he clutched his throat desperately and sprang with a bound to his feet, threw his arms out, gripped his throat again, and with a desperate effort tried to speak to me, but as he was uttering my name his breath failed and he collapsed upon the ground, struggled, and was dead in five minutes. All this came upon us with such startling suddenness that we were appalled. In laying him out I noticed that the entire left side of his body was stiff and rigid, while the right side was quite relaxed. He evidently had had a paralytic stroke just before death. On remoring the clothes from the body I noticed an irregular line of dark purple of varying diameter up to two inches, running from the site of the bite up the left side, over the left shoulder, up behind the ear to the base of the skull. There was no swelling or discoloration other than this livid band anywhere about the body, nor was there any hæmorrhage from the mucous surfaces. Diarrhœa was more or less pronounced from the time he was bitten till his death. I mentioned this livid line running from the wound up to the skull to some medical men, but they seemed to be rather sceptical about it, but I assure you it is exactly as I have stated to you.

"My friend was exceptionally strong and muscular. In fact, he was remarkable for his physical strength. He was within two or three days of being twenty-one years of age. He was one of the most fearless and daring of men, but strange to say he had an absolute horror and dread of snakes. About a week before his death he stumbled over a Puff Adder and declared that if he should have another such experience it would be his last, he would clear out of the country, for he could not stand the sight of snakes. Poor fellow, his next experience was indeed his last."

It will be noticed from the above narrative that the permanganate of potash and the ligatures were applied almost instantly after the infliction of the bite. Mr. McKenzic-Shaw says not more than a minute or two could have passed before both operations were completed. The wounds were thoroughly incised, and permanganate rubbed in freely. We must therefore conclude that sufficient venom reached the general circulation within a minute of the infliction of the bite to cause death. It will thus be seen how potent is the venom of the Mamba.

The symptoms in this case indicate that the renom did not 
cause pronounced nerve depression. The actual cause of death was doubtless the paralysis of the lungs, owing to the poisoning of the nerve centre in the medulla oblongata which controls their action.

$$
\text { G. }
$$

\section{ANAPHYLAXIS.}

It has recently been shown by several French scientists (see "L. Anaphylaxie," by Dr. Armand-Delille, and others) that the various antitoxic sera prepared from the serum of horses cannot in all cases be freely injected into animals with impunity. Horse serum injected into animals for the first time, in nearly all cases produced no toxic or poisonous effects, but if an interval of twelve or more days be allowed to elapse before a second injection was made, certain toxic effects were produced. This cansed some alarm, for the reason that various anti-toxic sera are used in the treatment of several diseases, such for instance as diphtheria, cholera, and tetanus. However, after careful study of the experiments by these French scientists, and the statistics of the cases of human beings treated with anti-toxic sera for diphtheria, cholera, tetanus, \&c., in certain large hospitals, and those injected with anti-venene serum for the treatment of snake bite, we may safely conclude there is no real cause for alarm. In the great majority of individuals, the first injection of borse serum is admirably tolerated without reactionary phenomena of any kind, either immediate or late. However, if horse serum is injected a second time, three weeks or more after the first injection, various toxic effects are produced, but which are invariably so slight as not to cause alarm. These toxic effects have been termed "serum sickness." Any form of animal proteid will produce the same symptoms.

Something like 80 per cent. of people re-injected with horse serum show slight toxic symptoms. The usual symptom is a form of urticaria or nettle-rash which is purely local, and invariably arises at the sites of the injections of the serum. Occasionally there is slight fever and pains in the joints. On rare occasions it is found that an individual is extremely sensitive to horse serum, and his body reacts strongly, but such phenomena 
498 THE SNAKES OF SOUTH AFRICA.
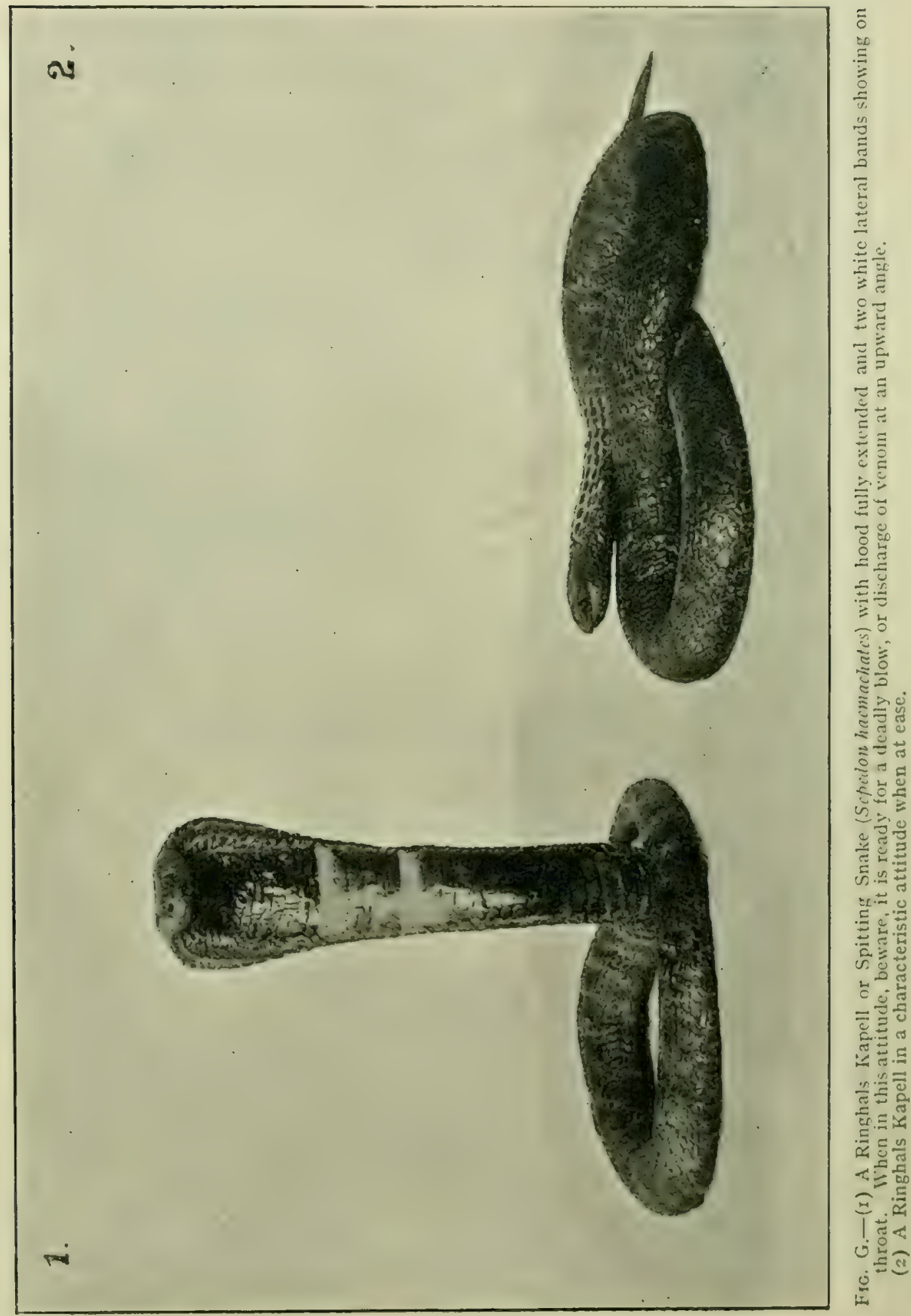
occur in certain individuals with a variety of substances which are quite harmless to the great majority.

Some French scientists have sought to show that horse serum if injected in comparatively large doses is distinctly dangerous. Their theories were based upon experiments with various small animals. However, in the preparation of sera, including that used for the cure of snake venom poisoning, the horse is the favourite animal, consequently horse serum has been used for a considerable number of years by veterinary surgeons and medical men with the most satisfactory results. There is no evidence so far to show that anti-venene serum, if injected in excess, will cause any serious toxic effects. I have recently been in communication with the highest authorities on the subject, who assure me that there is absolutely no danger to life if large doses of it are injected.

I have repeatedly injected animals with very large doses of anti-venene serum. The only toxic symptom was a more or less inflamed appearance about the site of the injection, or a sort of nettle-rash. In most instances there were no toxic effects after the first, or a second injection if it was made within four or five days of the first. If the second one was made two weeks or more after the first, a nettle-rash and sometimes slight fever appeared. It, however, passed off in two or three days.

Occasionally in severe cases of poisoning by snake venom, when the patient is rather far gone before treatment is applied, it is necessary to inject him copiously with anti-venene serum, in order to save his life, and it is as well to know that the serum if injected in excess will not produce any serious toxic effects.

The slight anaphylaxia produced is of no practicai importance. Anti-venene is being used largely in India, and the French possessions in Northern Africa, with the most satisfactory results. When considered necessary, medical practitioners need not hesitate to inject 50 to roo cubic centimetres ( 2 to 4 ounces). However, owing to the possible development of hypersensibility (anaphylaxia) to horse serum, injecting the serum direct into a vein in large doses should not be employed in those cases where horse serum has been injected more than fourteen days before, even if it be two years since the last injection, unless the gravity of the symptoms justify this risk. In severe cases of snake venom poisoning, in my opinion, there should be no hesitation in using serum freely. 
H.

Intravenous versus Subcutaneous Injection of Serum.

It must be borne in mind that serum injected intravenously (direct into a vein) is on an average fifty times greater in its curative effects than if injected subcutaneously (under the skin). This is highly important to remember in the treatment of snake venom poisoning, for the reason that if the serum comes in contact with the venom while it is yet in the blood, it will render it harmless in proportion, of course, to the quantity and quality of the anti-venene serum used. In the case of the Cobras, the venom, after a time, leaves the blood and enters into combination with the nerve cells, notably those composing the nerve centres controlling the movements of the lungs. In the viper (adder) family of snakes, including the Boomslang, which is a Colubrine snake, the venom seriously affects the walls of the capillary blood vessels, causing such changes in the cells as to allow the blood to flow out into the various tissues. Now, it is obvious that if the venom has, previous to the injection of the serum, acted upon nerve cells, and the cells of the blood vessel walls, the serum cannot repair the damage done. All it is capable of doing is to neutralize whatever venom remains in the circulation, and so prevent further mischief. Then, if the damage is not beyond repair, the inherent curative power of the body will build up new cells, absorb and cast out the dead blood, and restore the body to its normal condition. A good all-round plan is to have at least enough anti-venene serum on hand for two full treatments, viz. about fifty cubic centimetres. Then if any one is bitten, inject one full dose of say twenty-five cubic centimetres in two or three places under the skin, and instantly send for a doctor, and then, if he considers the case a grave one requiring more serum, he can inject the second dose, or some of it, direct into a vein. Of course in those cases where it is impossible to obtain the services of a medical man or a veterinary surgeon within a reasonable time, the most capable person in the house should undertake the injection of the serum into a vein in the manner stated previously in this volume, if the symptoms are sufficiently serious to justify this operation.

Residents in snake-infested countries should take a few lessons in injecting serum into veins and under the skin. 
RINGHALS KAPELL OR SPITTING SNAKE 5OI

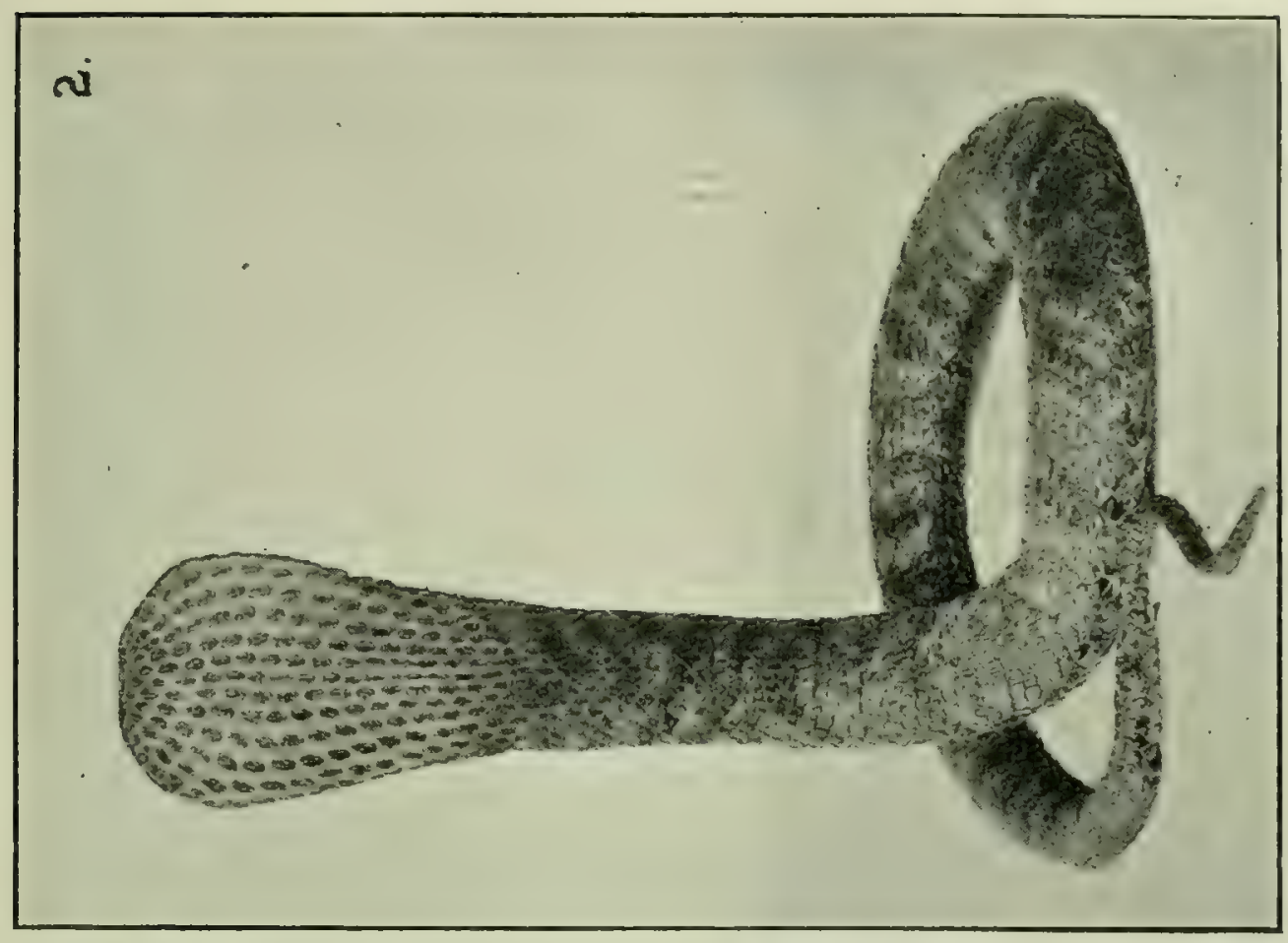

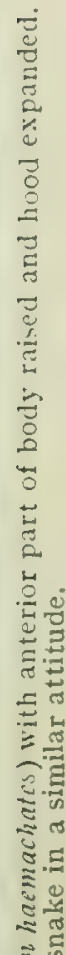

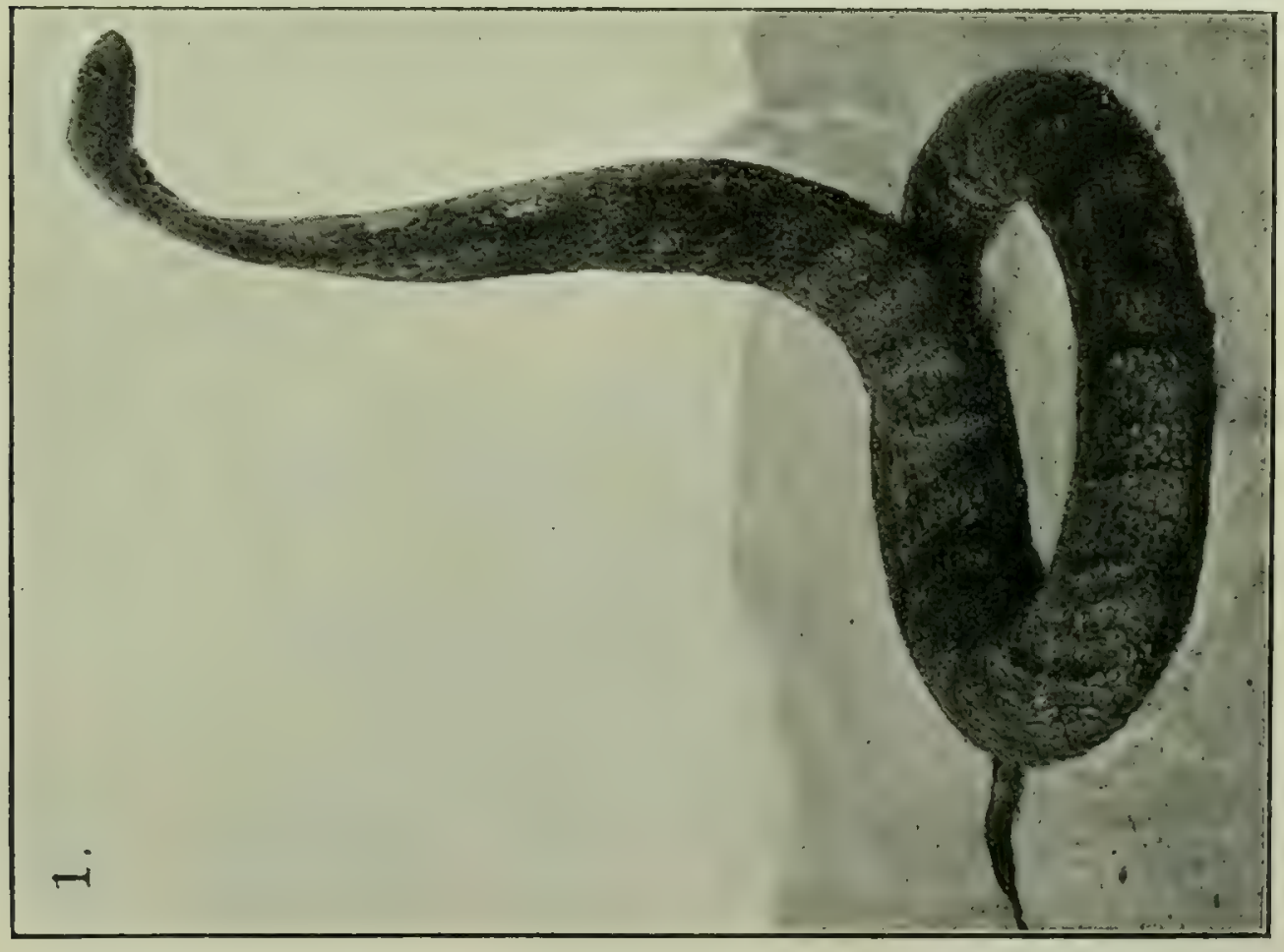

焉


I.

The Saline Solution. An Emergency Measure.

In severe cases of poisoning by the venoms of the Adders and the Boomslang, extensive hæmorrhage occurs. This means that blood oozes out through the dilated walls of the capillary blood vessels into various parts of the body-mostly into the muscular tissue and under the skin. Now, it must be remembered that when the blood thus escapes from the blood vessels it cannot get back again, and very soon dies.

To keep the heart beating vigorously, it is essential that it should be supplied with a sufficiency of fluid to give it something substantial to grip, otherwise it will slow down and eventually stop. In proportion, too, as the heart becomes less energetic, so do the various organs of the body decline in activity and power to generate an anti-toxin, and also to cope with the venom and the dead blood and cast them out of the body.

In these cases death is likely to occur from lack of sufficient fluid in the blood vessels. It is advisable in these instances to inject into the left median vein of the patient, a solution of common salt and sterilized (boiled) water. This solution is known as "Normal Saline" or "Physiological Salt Solution," viz. 78 grammes of common salt (Sodium Chloride) dissolved in 20 ounces of sterilized water. From one to two points of this solution may be injected.

The left median vein is the largest vein in the left forearm, and the right median vein is a similar one in the right forearm.

If extensive hrmorrhage has not taken place, or if the snake which inflicted the bite was one whose venom is a neurotoxin or nerve poison, then the right median vein of the patient should be opened and the blood allowed to flow out freely. At the same time the left median vein should be opened and a pint or two of the saline solution injected. By this means a great deal of the venom is got rid of and its place taken by the salt solution, which keeps the heart beating vigorously until the body is able to manufacture a fresh supply of blood to replace that which has been drained out. Many valuable lives have, in this way, been saved in cases of ordinary hemorrhage, from a severed artery for instance. The principal immediate danger of the loss of 


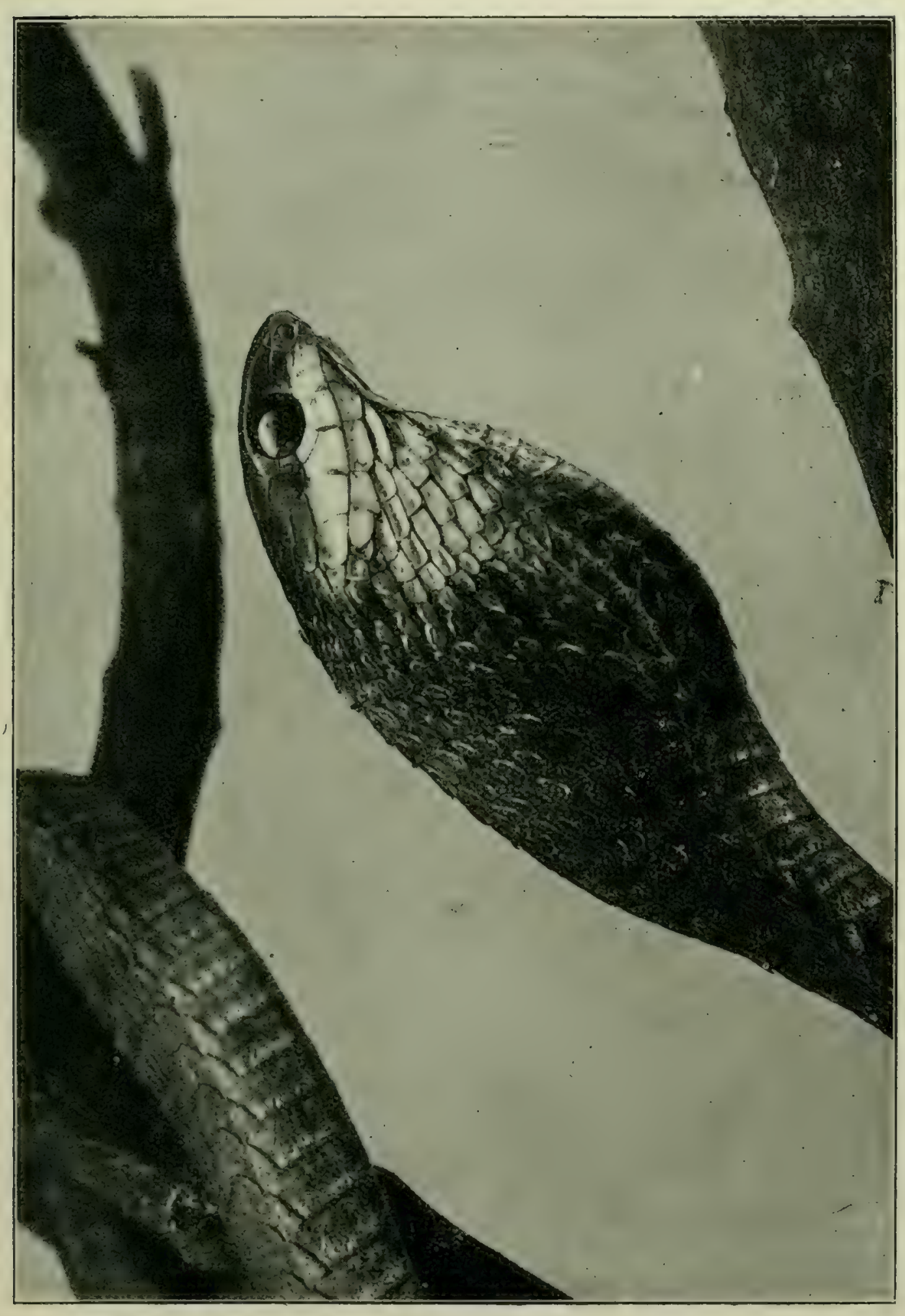

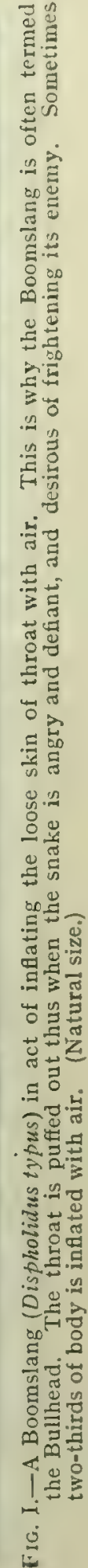


blood is nothing more nor less than the loss of fluid to keep the heart stimulated.

Pure water is never injected, either direct into a vein or under the skin for any purpose, for the reason that it causes pain and irritation. Salt must always be added to it.

When any parts of the body of an animal are required for study, such as nerves or portions of muscles, if they are placed in pure water they soon die, but if immersed in a saline solution they will keep alive for hours, only to die of starvation eventually. For instance, if a snake is killed and the heart is at once taken out and placed in pure water, it will very soon cease to beat, but if put into a saline solution it will continue to beat for a long time-often a whole day.

Thus it will be seen what a valuable aid we have in the saline solution, in the treatment of snake bite, in the absence of antivenene serum.

\section{J.}

Injecting Ammonia for Snake Bite.

The Eastern Pronince Hevald, Port Elizabeth, recently had the following: "Lecturing recently at Durban before the Natal Scientific Society on 'Some Snakes and their Poison,' Dr. Schul/ explained that while alcohol applied externally and internally had heen proved ineffective, and caustic potash injected on the bite also failed to cure, the strongest solution of ammonia diluted to one-half with water had scored unfailing success as poison destroyer. He mentioned three cases of cure by this means, and had no failures to record. A hypodermic syringe and two half-ounce bottles of diluted ammonia, the second a reserve bottle, could be packed up in the space occupied by a match-box."

\section{RESUlT OF EXPERIMENTS ON THIS THEORY.}

Diluting the ammonia, as stated above, I tested the solution on various animals, but it excrted absolutely no curative effect. If an animal was injected with a fatal dose of venom, it alway's died, although the ammonia solution was injected effectively in and around the site of the punctures.

Then, taking three drops of Puff Adder venom, I mixed it 
RESULT OF EXPERIMENTS ON THIS THEORY. 505

with half an ounce of the strongest ammonia, diluted with half an ounce of water. This solution was stirred and allowed to
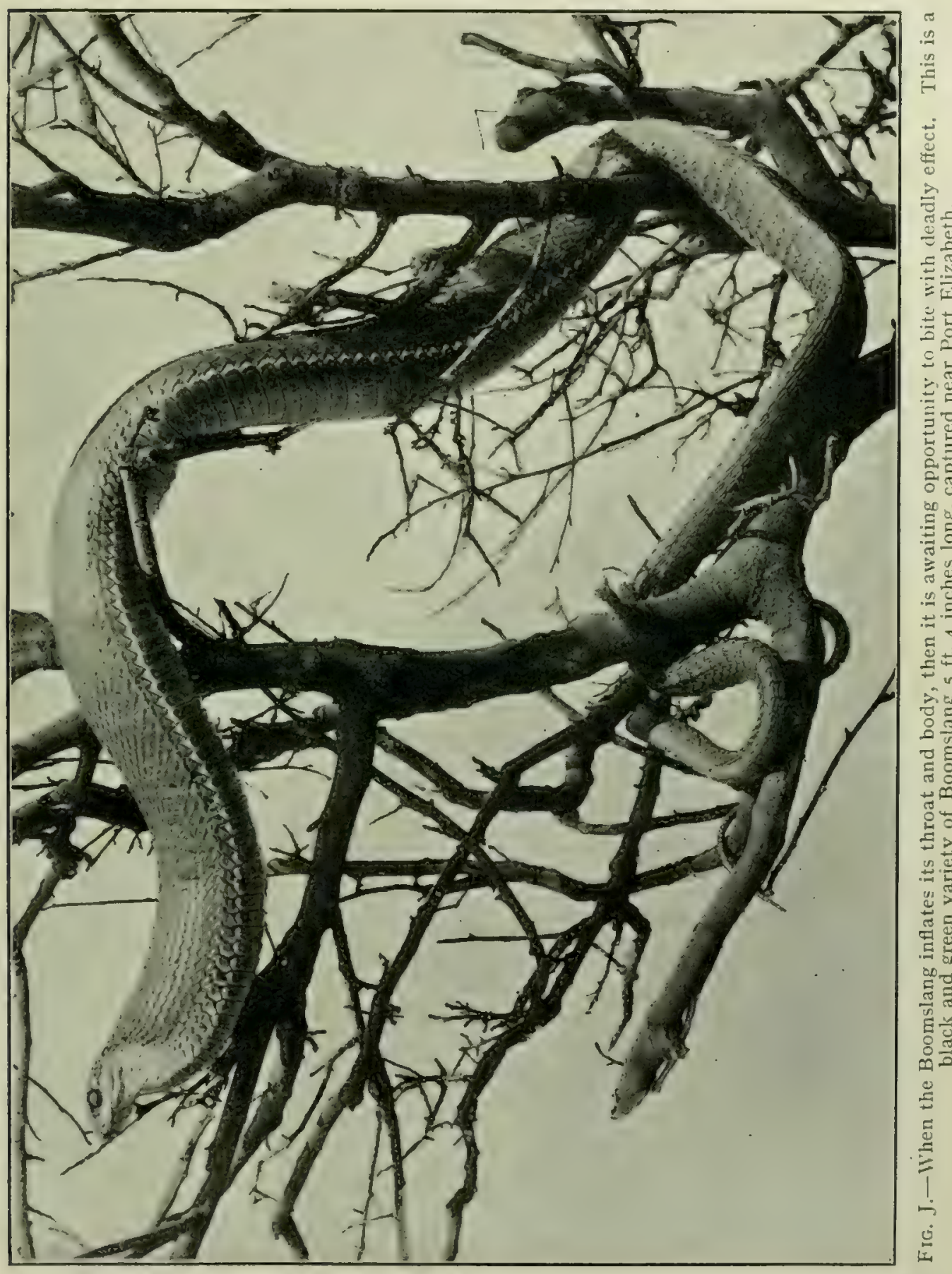

stand fifteen minutes. It was then injected into the muscles of a large fowl. Three drops of Puff Adder venom were at the same time mixed with some pure water and injected into another fowl. 
Both fowls manifested the same symptoms of poisoning and died within five or ten minutes of each other.

Other more or less similar experiments were made, but in all cases the treatment with the ammonia solution did not delay death. The symptoms were the same as those shown by the control animals.

Being desirous of ascertaining if pure ammonia would in any way destroy the poisonous properties of snake venom, I mixed a teaspoonful of the strongest liquid ammonia with three drops of Puff Adder venom and allowed it to stand for half an hour. The solution was then dissolved with one-half water and injected into the muscles of a large cock fowl. The symptoms of poisoning developed in the usual manner, and the fowl died, the ammonia not, apparently, delaying death in the least. From this experiment it was made evident that even the strongest ammonia exerted no venom-destroying power, even when actually mixed in solution with the poison.

K.

\section{Why do Snakes' Fangs Differ in I.ength?}

Why should the Adder family of snakes have long curved fangs, and those of the Cobra family be so comparatively small? This problem vexed my mind. Nature has a fixed and definite purpose in all she does. Those great fangs of the Puff Adder were not evolved without a distinct purpose. True, they enable the reptile to inflict severe mechanical injuries upon the small creatures which are the prey of these snakes. But then, why should not the Cobras have also evolved large recurved fangs, for their prey also consists of the same species of creatures. The viper often grips its prey and holds on till the creature is dead. So also do the Cobras and other venomous Colubrine snakes. At other times they strike and instantly withdraw their fangs, relying upon the venom to paralyze their victim before it can escape out of their reach.

The fangs of a large Cobra are only about a quarter of an inch long, while those of a Puff Adder are three-quarters of an inch in length. When the Cobra delivers a full bite, the venom is shed, mostly on the muscles just under the skin. The Puff $A$ dder, on the contrary, drives its fangs deep down in to the muscular tissue. 


\section{SurPRISING RESUlts of Experiments.}

Collecting a quantity of venom from some Cape Cobras and Ringhals, I carefully measured out doses averaging from half a drop to two drops. A dose was injected deep into the muscular tissue of the thigh of a fowl. A similar dose was injected just under the skin on top of the muscular tissue. This experiment was repeated several times. The poisonous effects were the same in all cases. Death occurred just as rapidly when the venom was injected into the muscles as when it was placed just under the skin.

I carried out a series of similar experiments with the venom of the Puff Adder with surprising results. Several fowls were injecter with half a drop of the venom, mixed with a little water. This was inserted under the skin of the thigh with a hypodermic syringe. The solution spread out over the muscular tissue, and was still further diffused by manipulations with the finger. The fowls in all cases recovered. When one drop of venom was injected, the fowls, with the exception of two small weaklings, fully recovered.

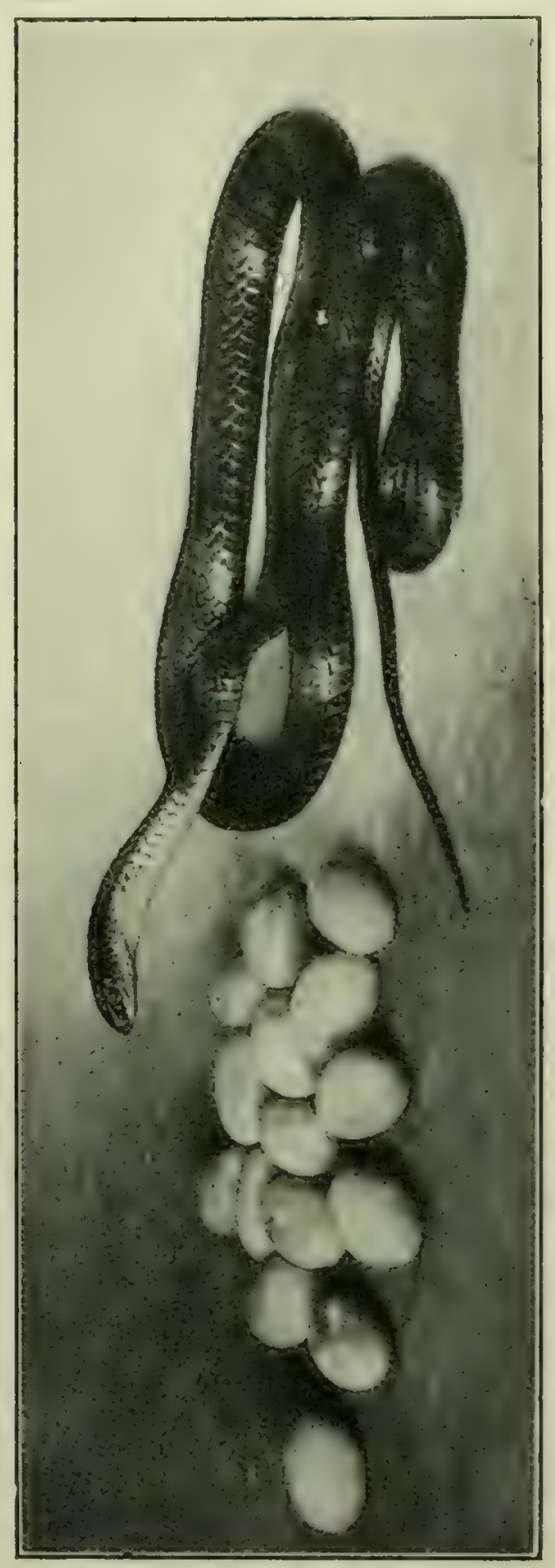

Two drops were then injected into each fowl. All the larger and more vigorous of the fowls recovered. Those which died 
did not mope much. They ate and drank as usual, and were as lively as ever after the first day. Some died in two days, others survived for a week and eventually died. Selecting the most robust fowls I could get, I injected into cach, three drops of Puff Adder venom, as usual under the skin of the thigh, and caused it to spread out by rubbing with a finger. Some of the fowls died after twelve hours. Others lived for two, three to four days and died. An average of one-half of those injected eventually survived.

Taking another lot of healthy fowls, I injected into each, four full drops of Puff Adder venom under the skin of the thigh. Seven died after surviving for periods averaging ten to forty-eight hours. Most of those which died were, during the first twelve hours or so, rather dejected, but afterwards apparently recovered and ate and drank as usual. The injected leg, however, was in every case hot and swollen. Those which died were hens and cockerels. Three large healthy roosters made complete recoveries. After the first day or two they ceased to mope and showed a disposition to fight and quarrel with each other. From day to day the injected leg grew less and less congested. After eight days all swelling had subsided, the temperature was normal, and complete recovery had taken place. No subsequent sloughing occurred at the site of the injection.

\section{Absence of Usual Heliorrhage.}

Now, when a Puff Adder drives its fangs home into its victim, the chief symptom is extensive hremorrhage in the muscle tissues in the vicinity of the part bitten. This hrmorrhage extends up into other parts and frequently affects the various organs of the body. Hæmorrhage also often takes place into the body cavities. In animals I examined which died after being bitten by Puff Adders, the muscles for some distance from the site of the bite presented the appearance of a soft, pulpy, bloody mass, very similar to flesh which had been horribly bruised. It was apparent that extensive hamorrhage had taken place from the capillaries which supplied the muscle fibres with blood. Often the whole limb was in this pulpy, spongy, red condition. After death, when the flesh was incised, the blood ran out copiously.

Strange to say, in all the fowls which died after being injected 
with Puff Adder venom under the skin, the muscles were not affected at all, and there was no hæmorrhage in any of the organs or into the body cavities. The only hæmorrhage which occurred was between the skin and the muscles of the thigh which had been injected. In some cases the hæmorrhage could be traced to the top of the thigh and a little way up the side. Even in those fowls which were injected with four drops of venom, and which subsequently died, there was a total absence of hæmorrhage into the muscles of the injected part, or of other parts of the body. This cannot be attributed to the fowls dying too rapidly, or the full effect of the hæmorrhagin principle of the venom to exert a toxic influence, for the majority survived from twelve hours to three and even four days.

\section{Venom Injected into the Muscles.}

A number of fowls were taken, and into the thigh of each three drops of Puff Adder venom, mixed with a teaspoonful of pure water, was injected deep into the muscular tissue. Some of the fowls died in two hours, and none survived more than four and a half hours. In all cases from the first five minutes after injection till death, the fowls moped, but were not insensible till the last five minutes of life. Several other fowls were injected, each with two drops of venom mixed with a little pure water. The fowls all died within seven hours. Most of them were dead in four hours.

In the post-mortem on those which were injected with three drops of venom, severe hæmorrhage was seen to have taken place into the muscles of the injected leg, as well as up the side and into the body cavities. The muscles of the leg were saturated with blood which had oozed through the walls of the vessels, and presented a soft, pulpy horrible appearance, as is the case when the Puff Adder inflicts a normal bite into the muscles of its victim. In those which were injected with two drops of venom, the hæmorrhage, although extensive, both in the muscular tissue and under the skin, was not so great, owing to the lesser quantity of venom.

\section{CONCLUSIONS.}

These experiments go to show that Puff Adder venom if injected just under the skin, and not into the muscular tissue, is 
comparatively mild in its poisonous effects. Fowls are highly susceptible to snake renom, and succumb easily. It will be seen that several fowls actually recovered in a week's time after four drops of pure fresh venom had been injected into them. The poisonous action appeared to be comparatively slight, for the only hemorrhage was that which occurred in the injected thigh, and this was by no means extensive, and moreover, it was all under the skin, and not in the muscles. Lymph was the principal fluid which accumulated. If those fowls had been larger creatures capable of being properly treated by draining off this lymph and blood, and if antiseptics, fomentations, and other restoratives had been applied, I am assured that many of those which died would have recovered. Nothing at all was done for them. They were simply left in their cages and fed and watered.

Why the venom should behave so very differently when injected under the skin, and when injected deep down into the muscular tissue, I know not. It is probable that this viperine venom when introduced under the skin, is not absorbed so rapidly as when injected into the muscles, and that the vital forces of the body have time to generate anti-toxic substances to cope with it as it enters the general circulation, or that the excretory organs have more time to eliminate it.

In the above-mentioned experiments, the venom was collected from Puff Adders recently captured. The venom was, in every case, used within an hour after being shed by the snake. The manner of collecting the venom was as seen in several illustrations elsewhere.

The subject is an interesting one for scientific men to pursue.

I think I have solved the problem which puzzled me, viz. why a Puff Adder should have such long fangs? It is because the nature of its renom is such that, to have its full poisonous effect, it must be injected deep into the muscular tissues.

\section{L.}

\section{ItEMS OF SNAKE KNOWLEDGE.}

A Ringhals examined on October I6, I9II, which is the spring time in South Africa, had two rows of eggs, thirty in number, the size of peas, lying along each sicle of its backbone. These would 


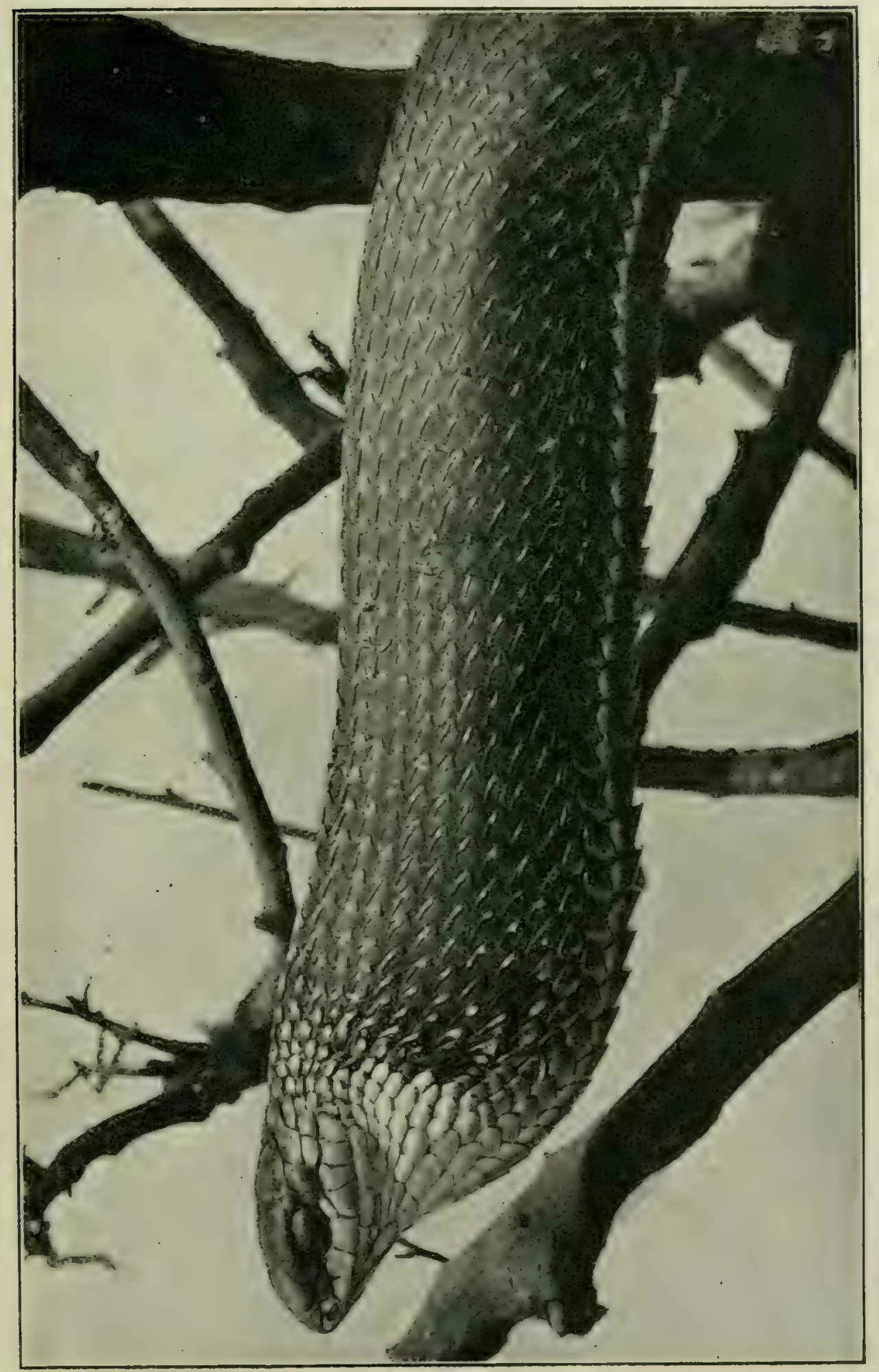

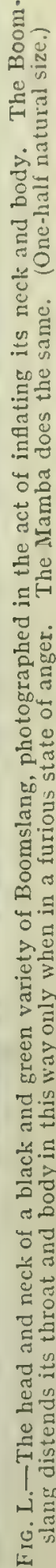


have developed full size and hatched within the body. The young would have been born in the early autumn.

Snakes are often infested with intestinal worms. On several occasions I have removed a score or more of slender wiry-looking worms, three to four inches long, from the stomachs of Puff Adders.

A mother, even if suffering in a slight degree from snake venom poisoning, should not attempt to suckle her infant, else it may die in convulsions. The reason is, that the digestive fluids of an infant have not the power of chemically changing the venom.

Statistics show that the mortality among the people of India in the year I9I0 from bites by snakes amounted to the great total of 22,478 . This was owing to extra heavy rains flooding the jungles and other favourite haunts of the serpents. They were, consequently, driven out upon the open plains and hillsides frequented by mankind. Statistics show that in India, for every one hundred persons bitten by venomous snakes, an average of twenty-five to thirty die. The average time the venom takes to kill is from two to twelve hours.

The dreaded Hamadryad (Naja bungarus) of India has been known to bite a full-grown elephant which, in consequence, died in three hours.

I made sixteen Puff Adders bite the covered top of a wineglass, each snake delivering one full bite. The result was eighty drops of venom, which averages five drops per snake. Two drops is usually a fatal dose for a healthy man. Therefore the sixteen Puff Adders shed sufficient venom to kill forty men. When dried, the venom weighed a little over a gramme, viz. I'II grammes.

There are fewer deaths from snake bite in South Africa than in India, because the population is less dense, not because the snakes are less venomous. As the population increases so will the death rate from snake bite be proportionately great, if the people will persist in pinning their faith to the various popular so-called antidotes.

The Ancient Egyptians worshipped the Cobra (Naja haje), recognizing that it kept the rats from becoming a plague. The snake was allowed to live and breed unchecked in their cornlands. The effigy of this Cobra is engraved on monuments and stones, 
and its embalmed remains have been found. Thus did the Egyptians show their gratitude for services rendered.

In ancient times when Greece was a great power, the priests pretended to cure diseases by allowing serpents to crawl over the patient, by waving them to and tro, and by holding them against the diseased part, meanwhile muttering some formula. Hippocrates, who was born about 460 B.C., and who is commonly styled "the father of medicine," denounced these priests and their methods.

The venom of snakes kept in captivity, and which refuse to eat, is smaller in quantity, but much more poisonous than those recently captured.

Never attempt to feed artificially a snake when it is showing signs of wanting to moult (cast its skin).

In certain districts of South Africa the cattle plague, known as East Coast Fever, has swept off nearly all the cattle. The result of this is, the grass has grown thick and rank, and the herbage has developed unchecked. Snakes, in consequence of the increased protection of luxuriant vegetation, have increased considerably in numbers. 


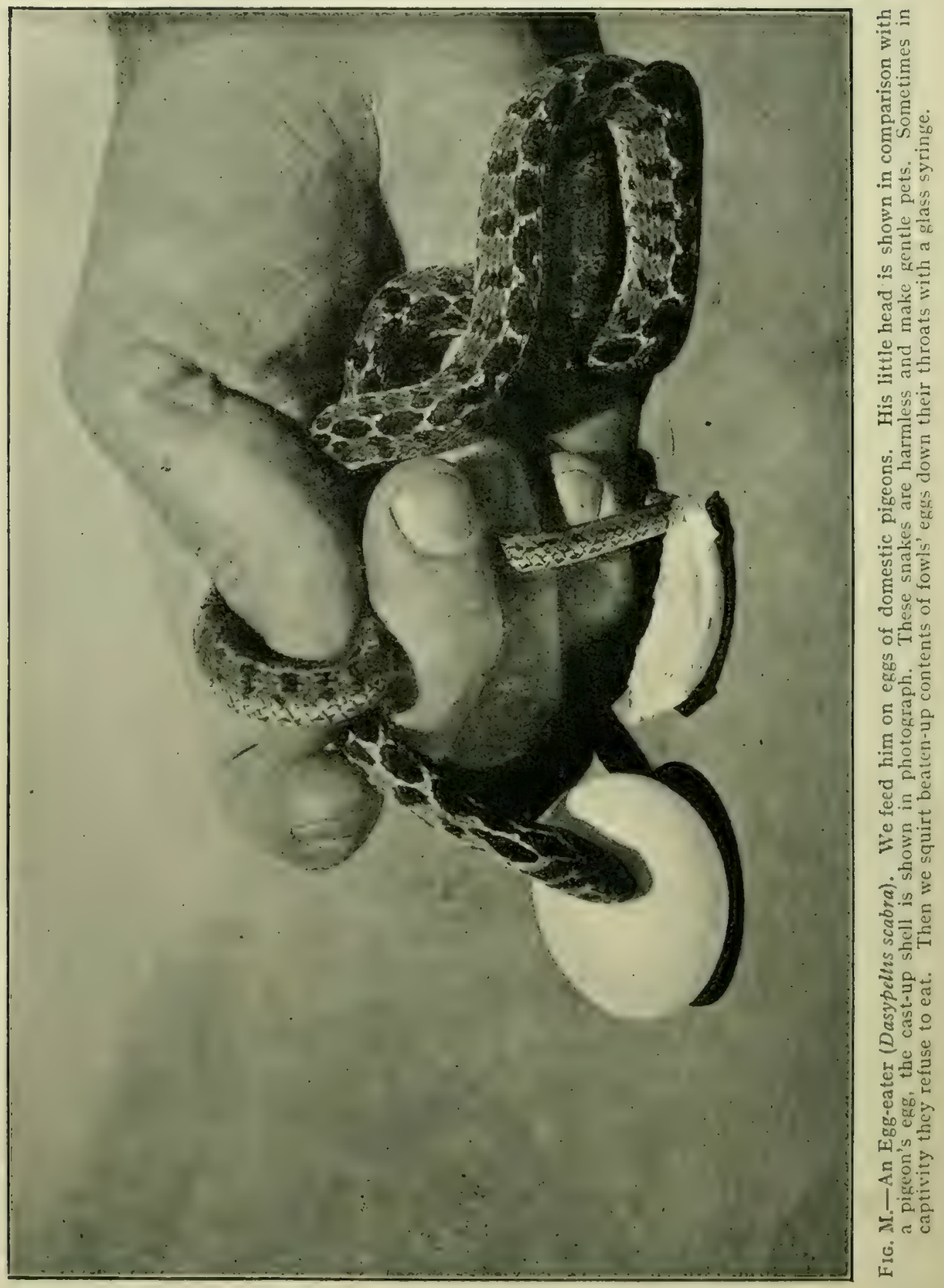


A HERALD OR RED-LIPPED SNAKE.

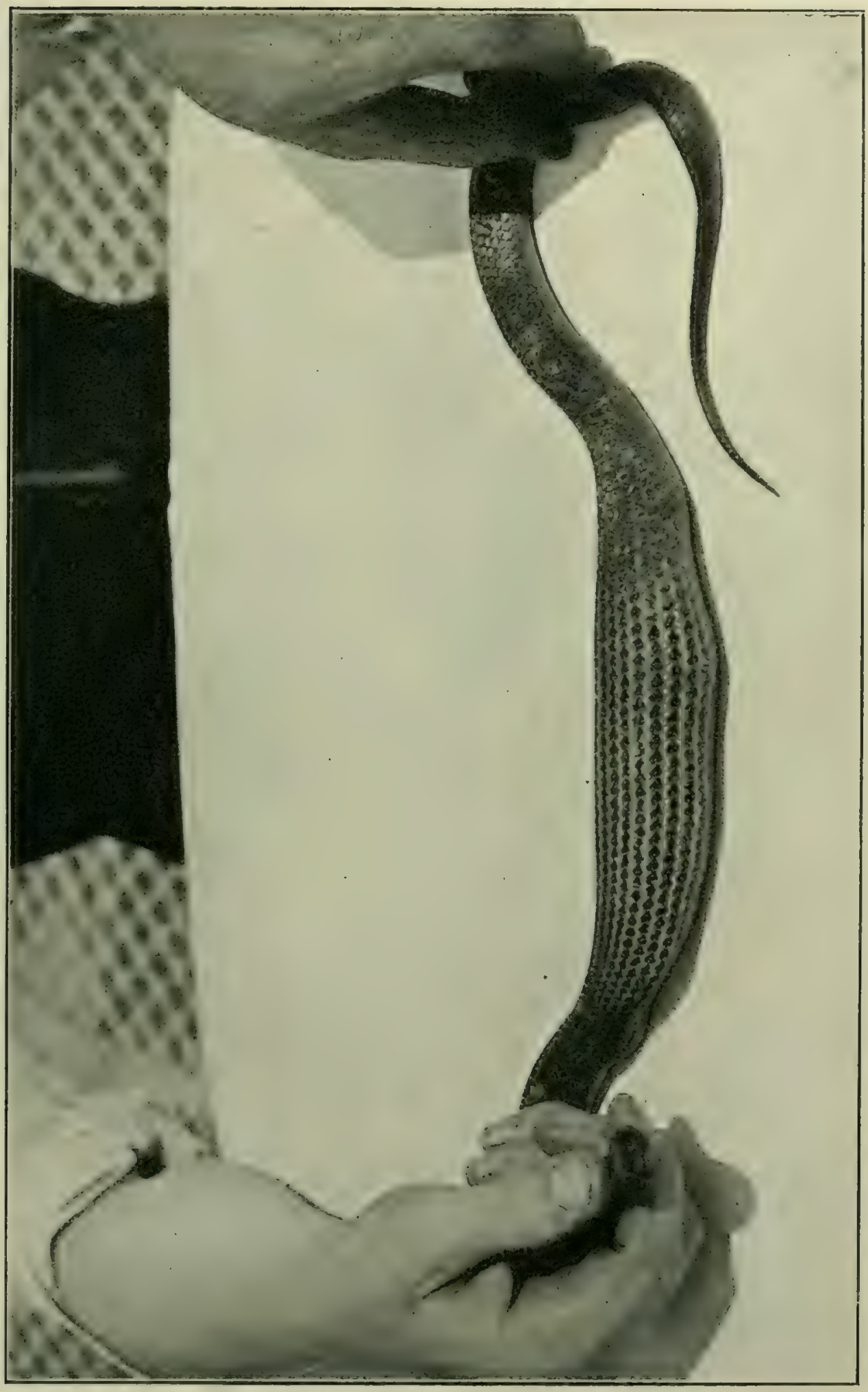

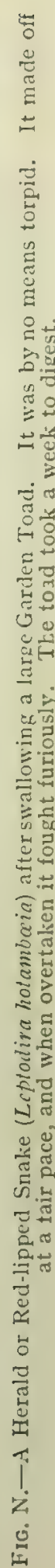




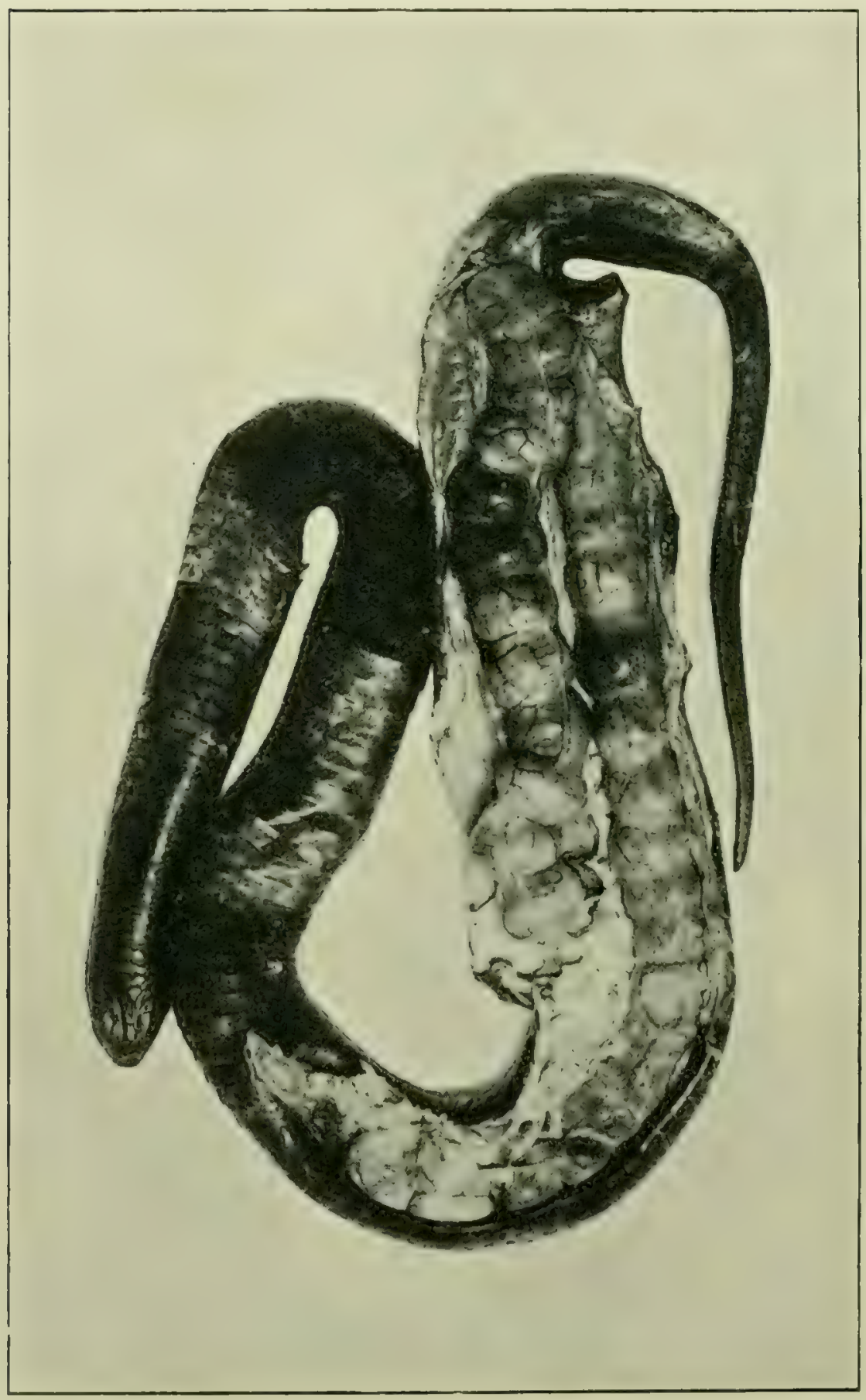

형ํํ

$25=$

है

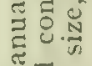

풀ㅋ

일

"द्व

둥

ํㅣㄹ

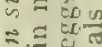

x.

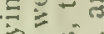

$\therefore$ 政

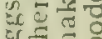

$\therefore=50$

일

c

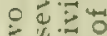

+ हों

ro.

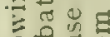

可喝

$\overrightarrow{0}$

要:

0 in

㱐

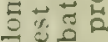

กำ

हैำ

$=$

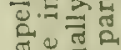

is

तै

है. मे

듬믐

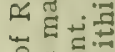

O

돌 ह

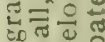

․ㅛㄱㅡ

政

1 등

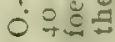

空 


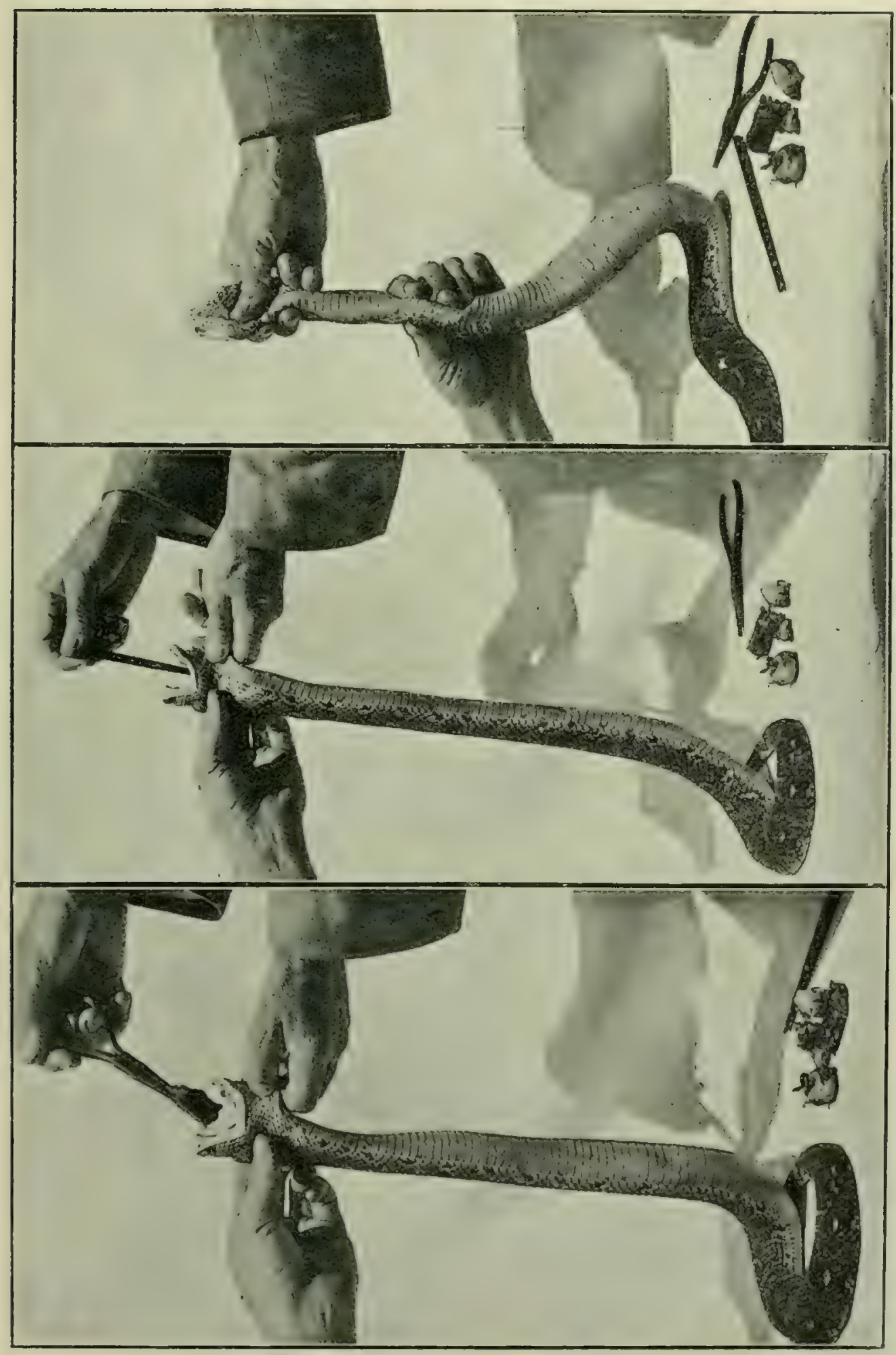

+..

․ㅡㅁ

额政

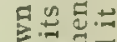

o을

สั

원현

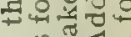

क क

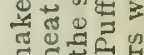

㝕昆证

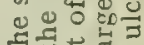

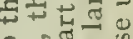

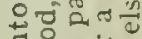

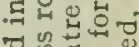

둥

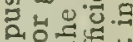

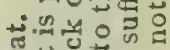

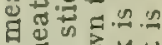

目语密

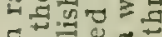

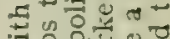

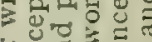

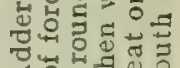

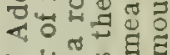

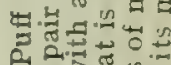

तो

․ㅜㄹ

त्रा:

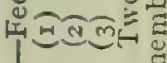

西

垔 


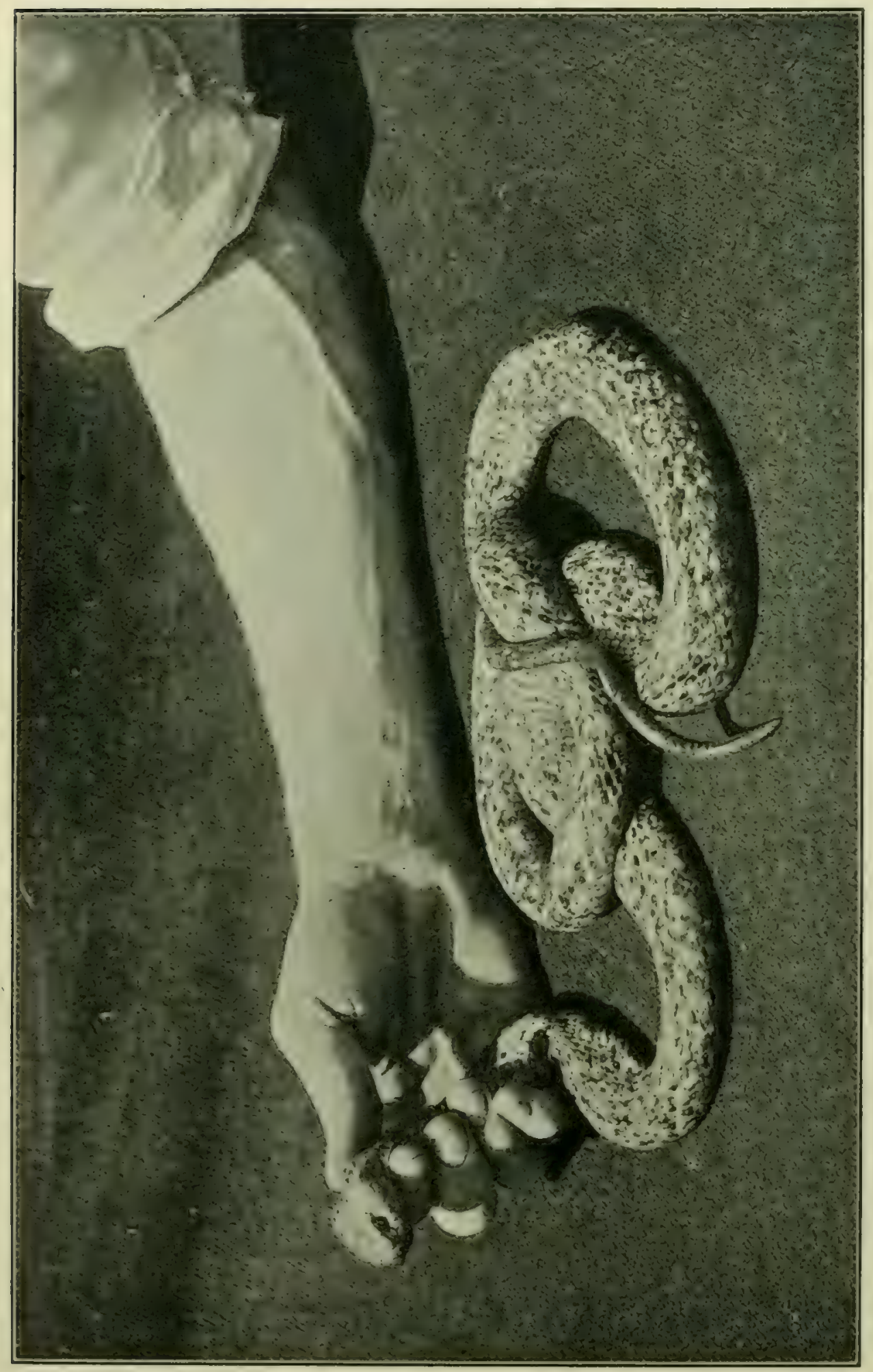

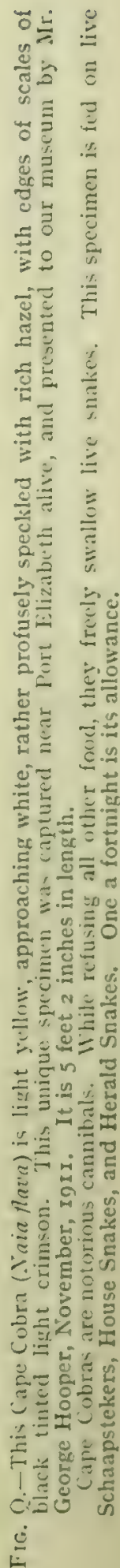




\section{A YOUNG CAPE COBRA.}

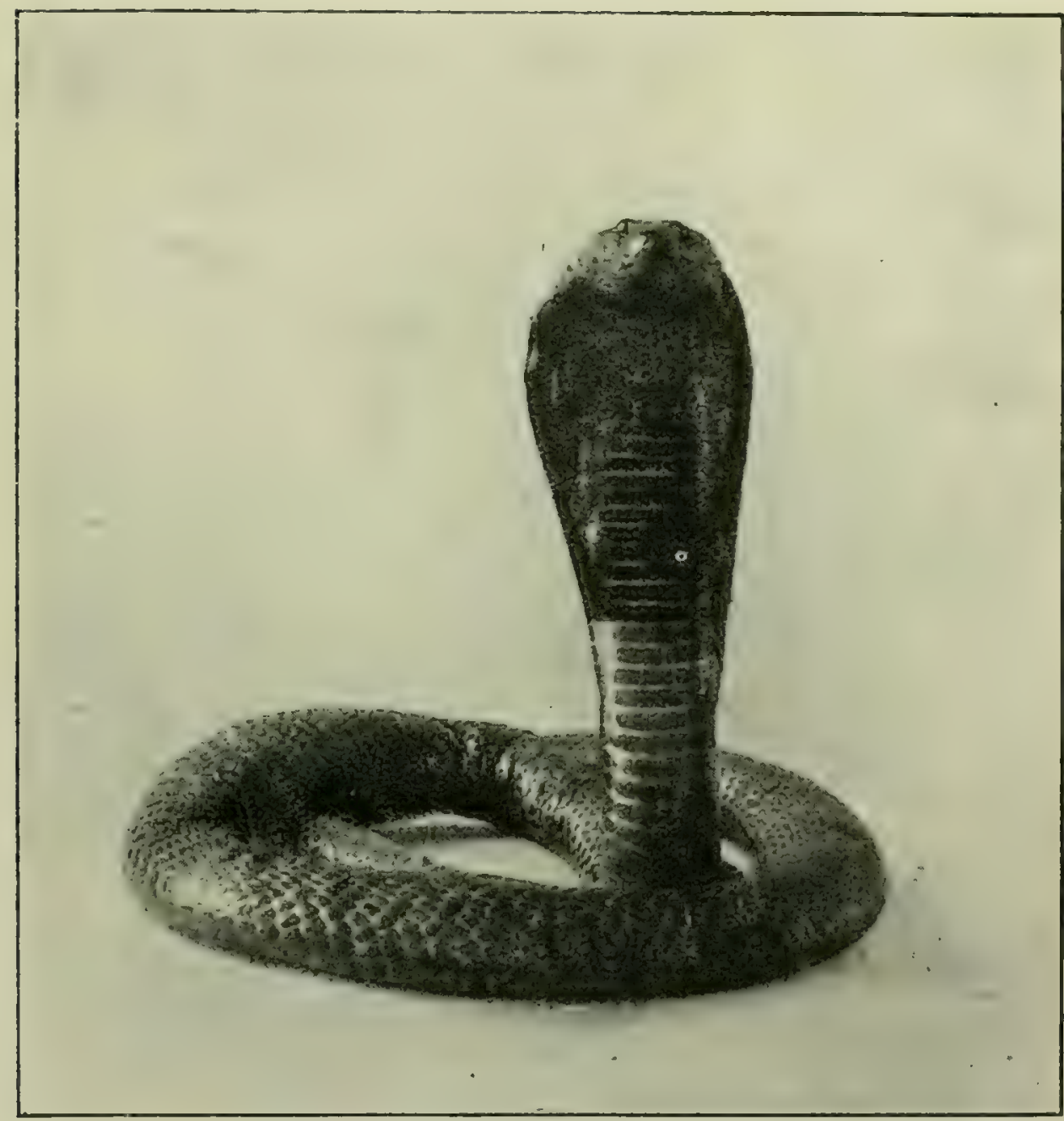

FIG. R.-A young Cape Cobra (Naia Alava) 20 inches in length, with hood expanded, showing the characteristic rich umber-coloured throat patch which disappears when the snake becomes adult. This patch extends right across the throat and hood, and for two inches down the body. The body colour of this snake was gambose yellow. The edges of a number of the scales of the back were tipped with dark hazel colour. 

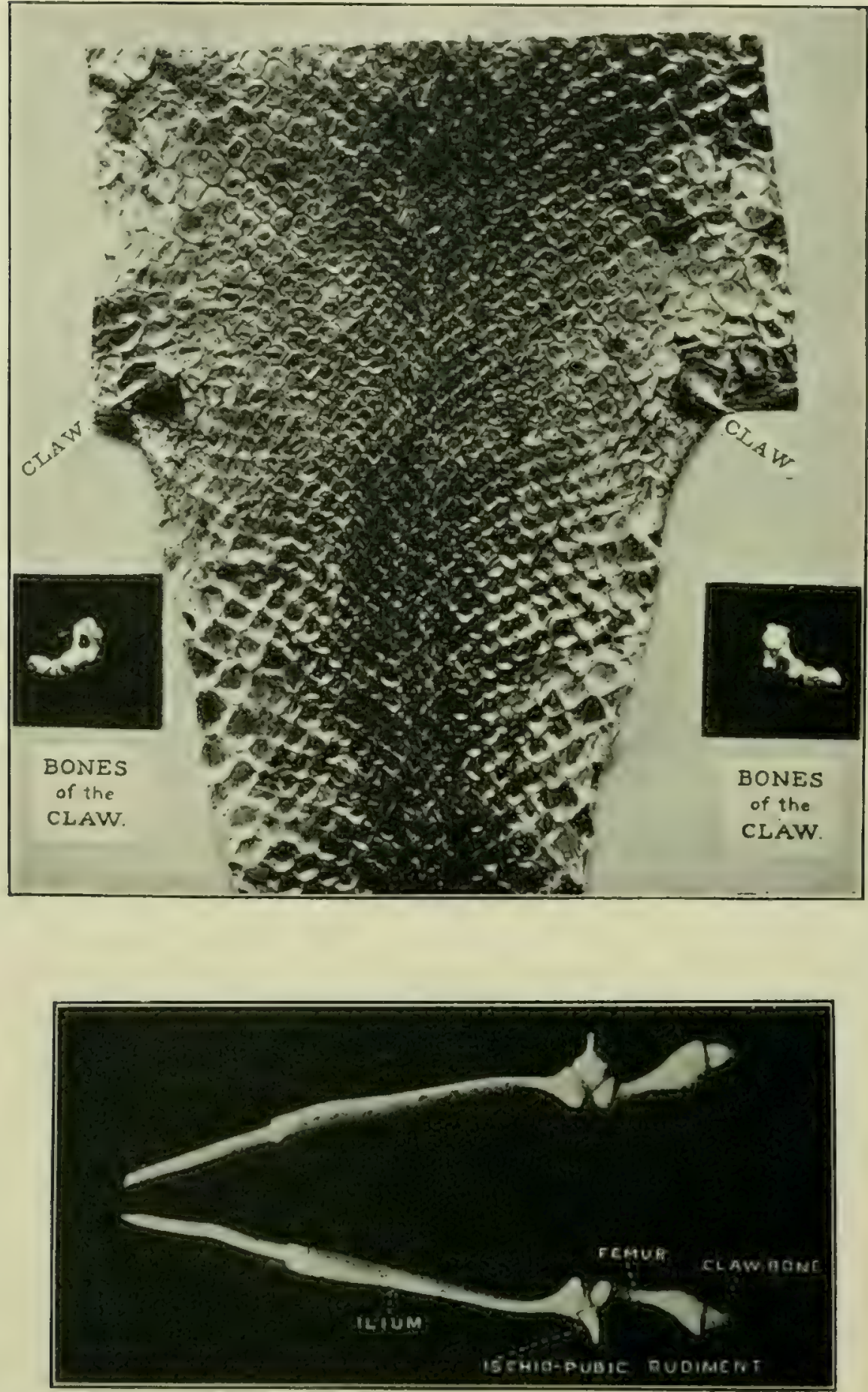

FIG. S.-The remote ancestors of snakes were lizard-like creatures with limbs. This illustration shows the rudimentary hind limbs of the South African Python.

(From an illustration in the British MIscum Guide on Reptiles.) 


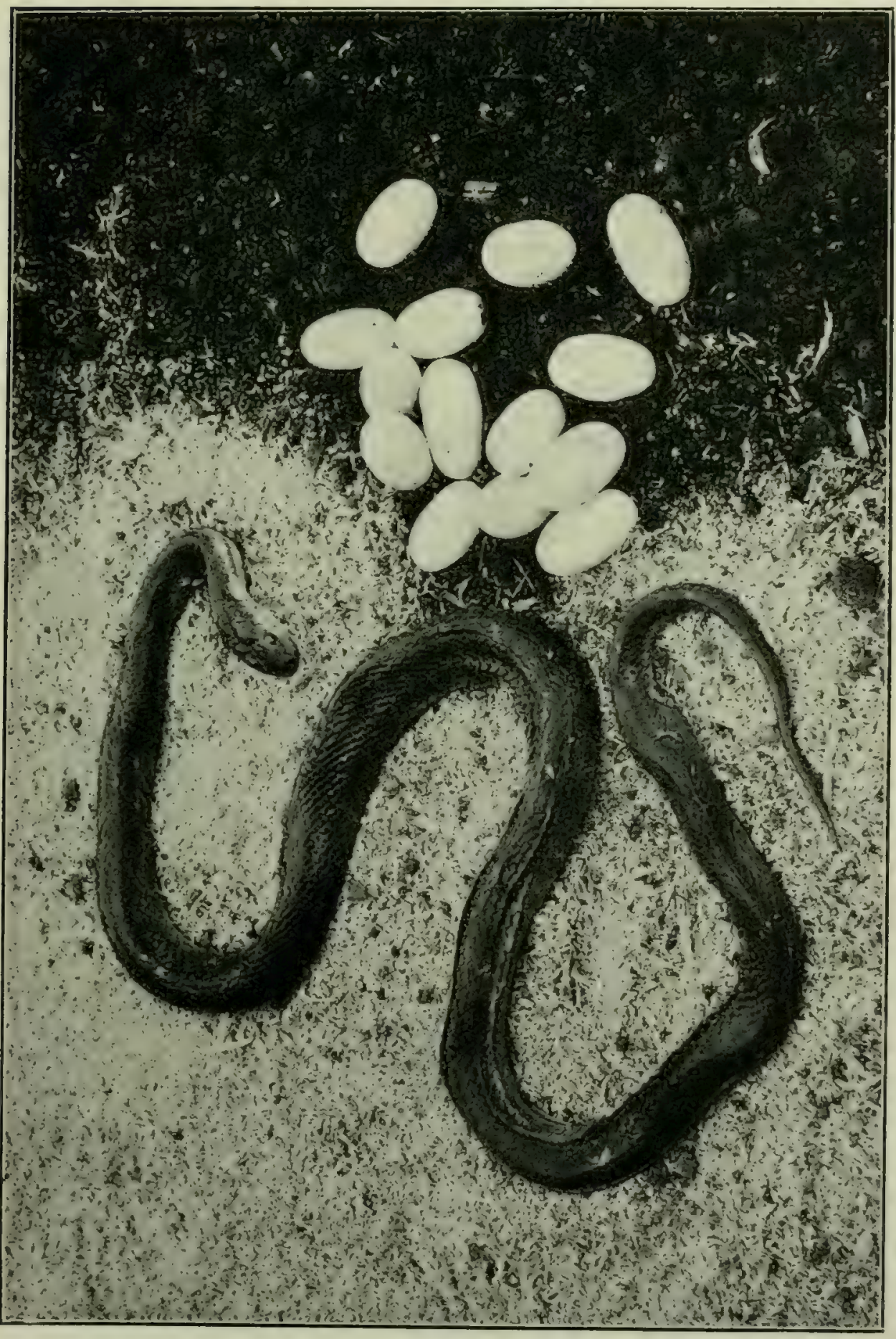




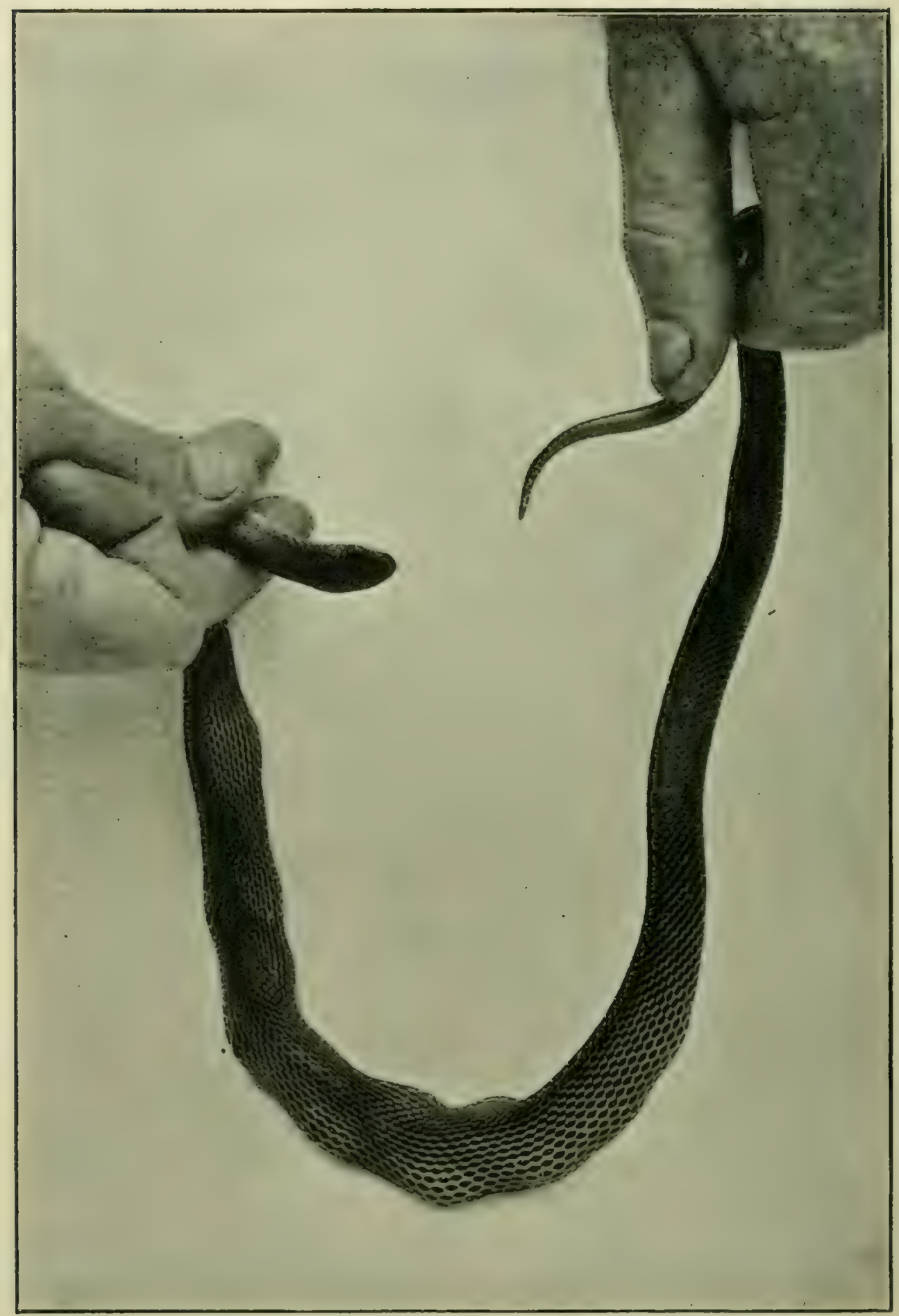

FIG. T (2).-This is an Olive-black House Snake (Boodon in/crnalis) 2 fect I inch long. It deliberatcly attacked a Green Water Snake (Chlorophis matalcusis) 2 fcet 5 inches long. Gripping it by the head it swallowed it completely. This picture shows the Housc Snake with the Water Snake inside it. It was digested completely in eight days. 
A PUFF ADDER.

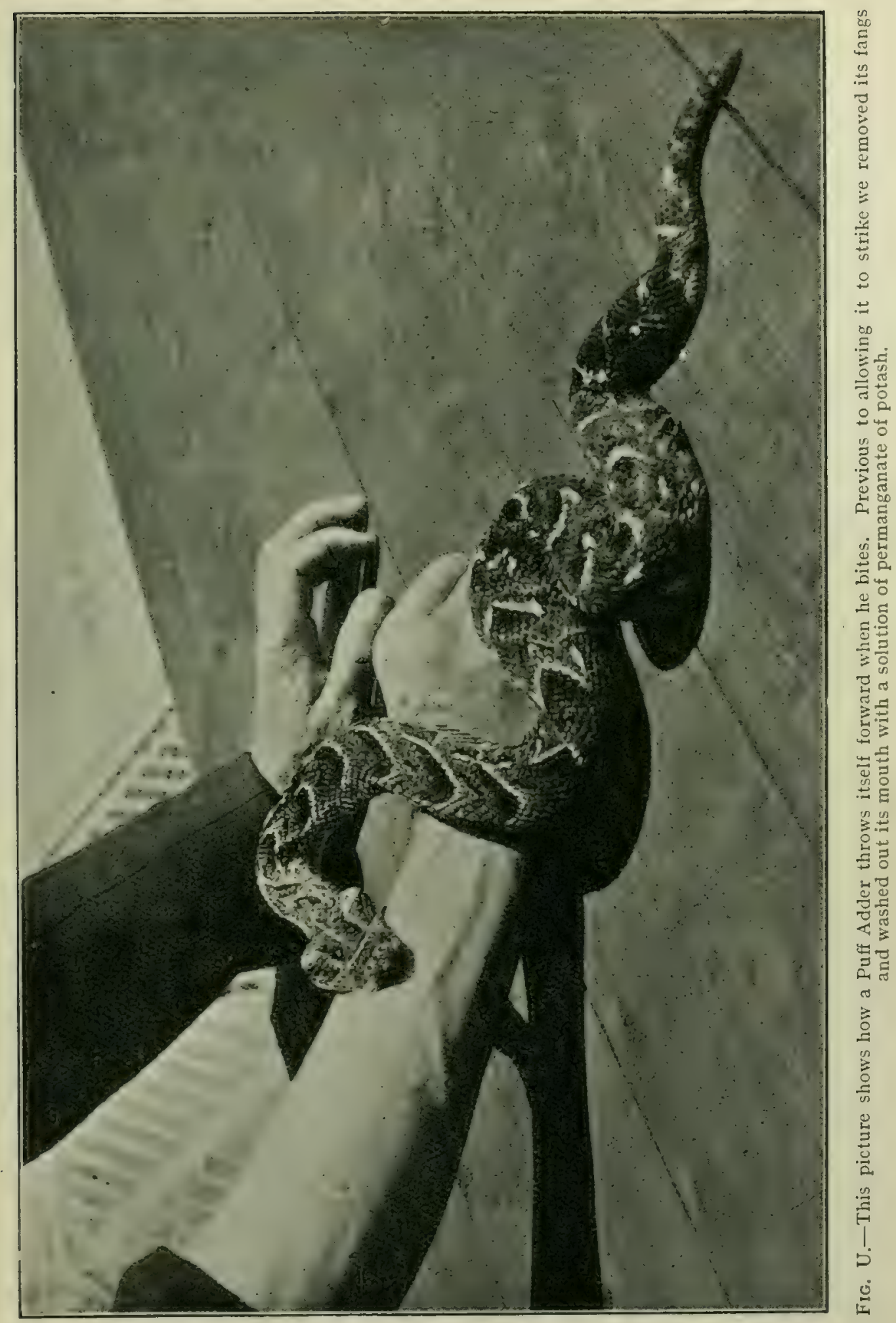




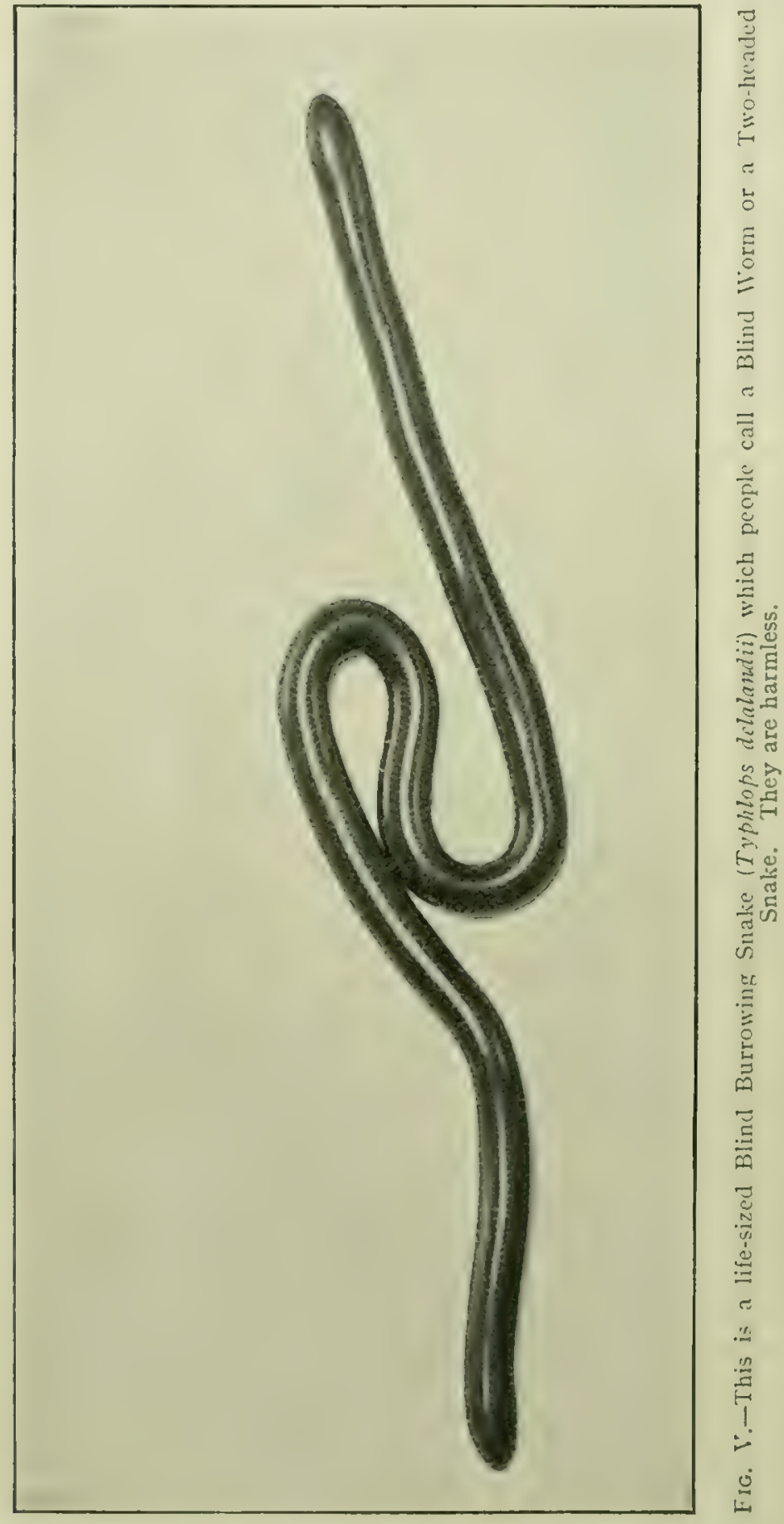


A PUFF ADDER.

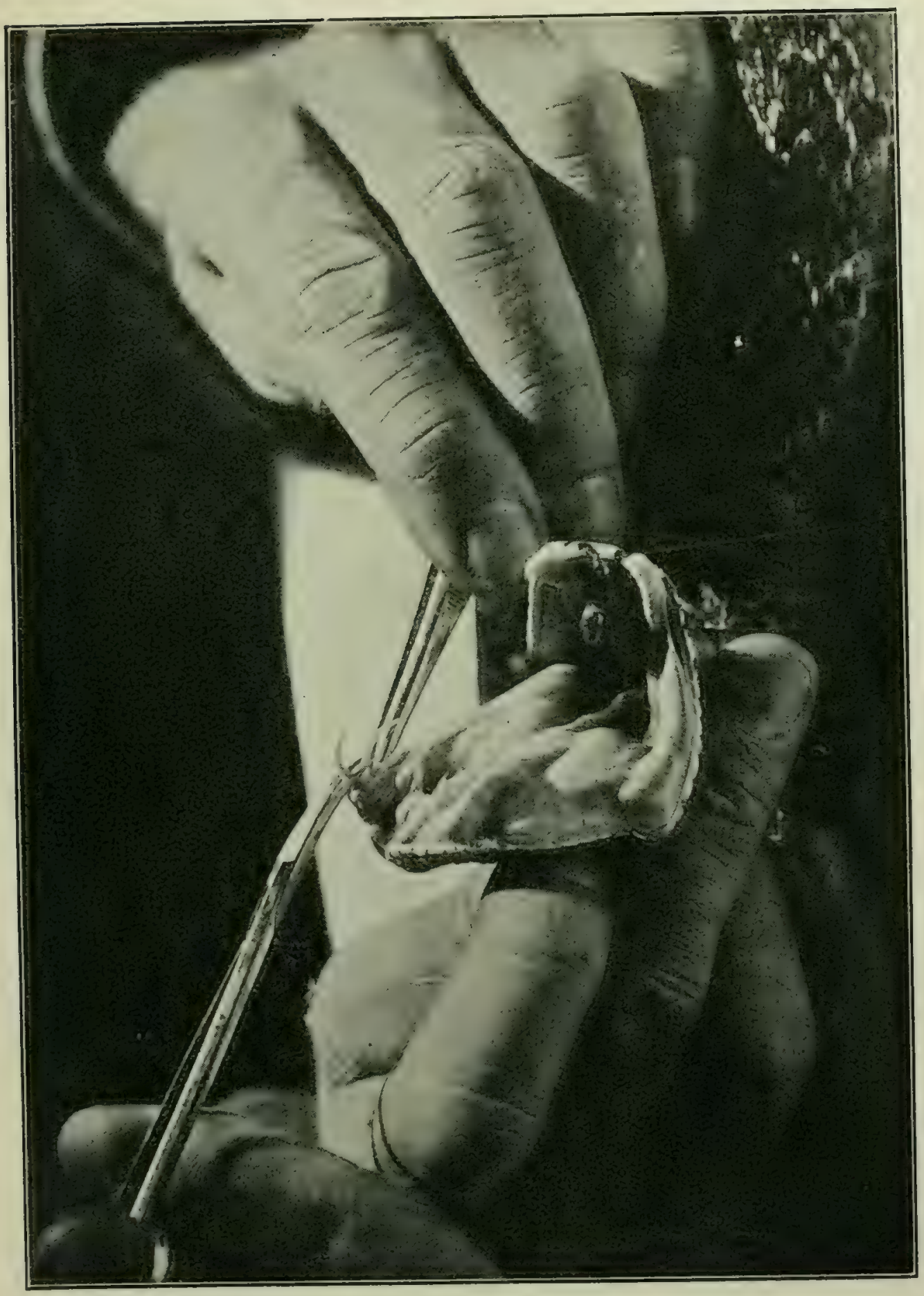

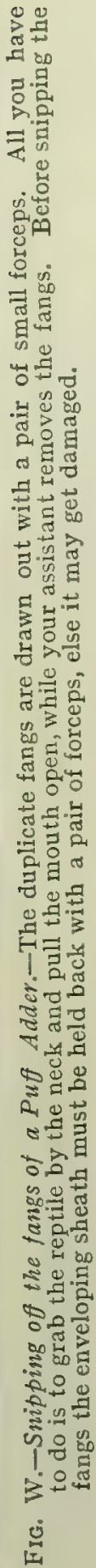


THE SNAKES OF SOUTH AFRICA.
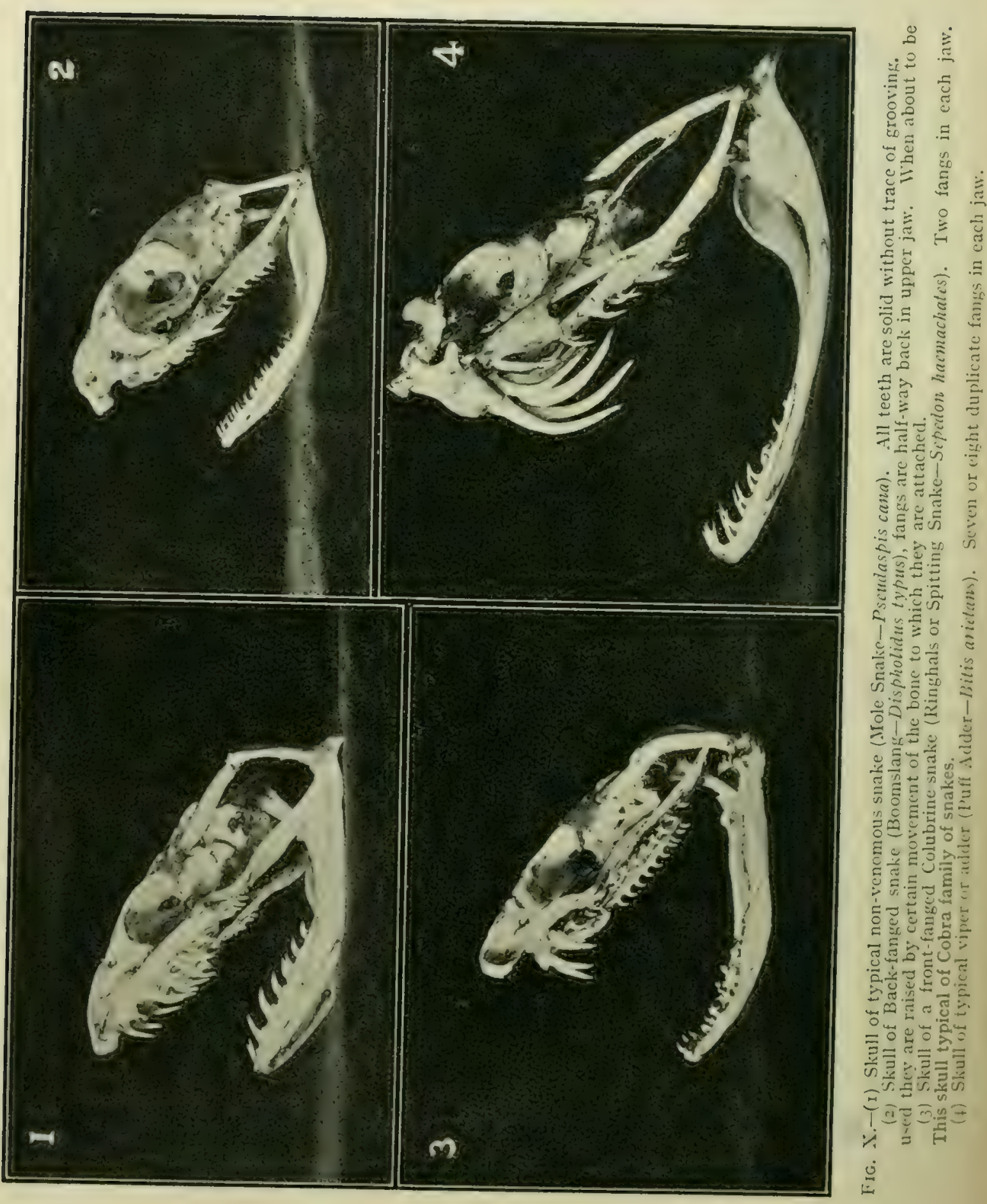


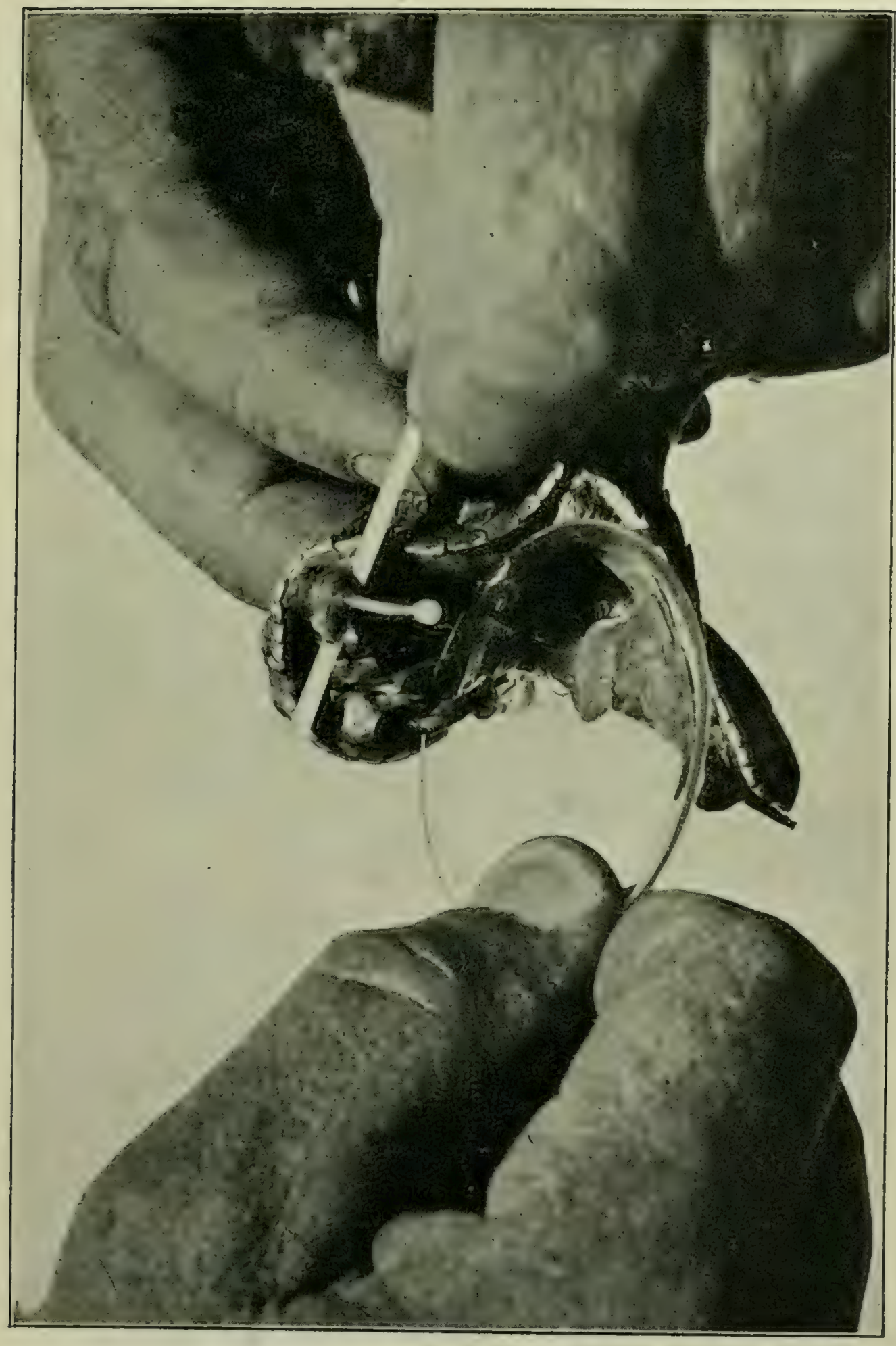

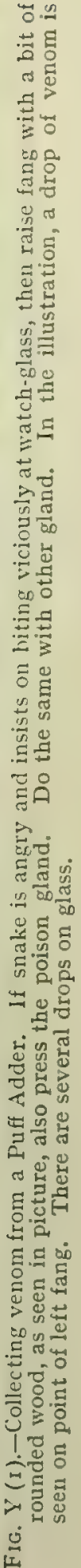



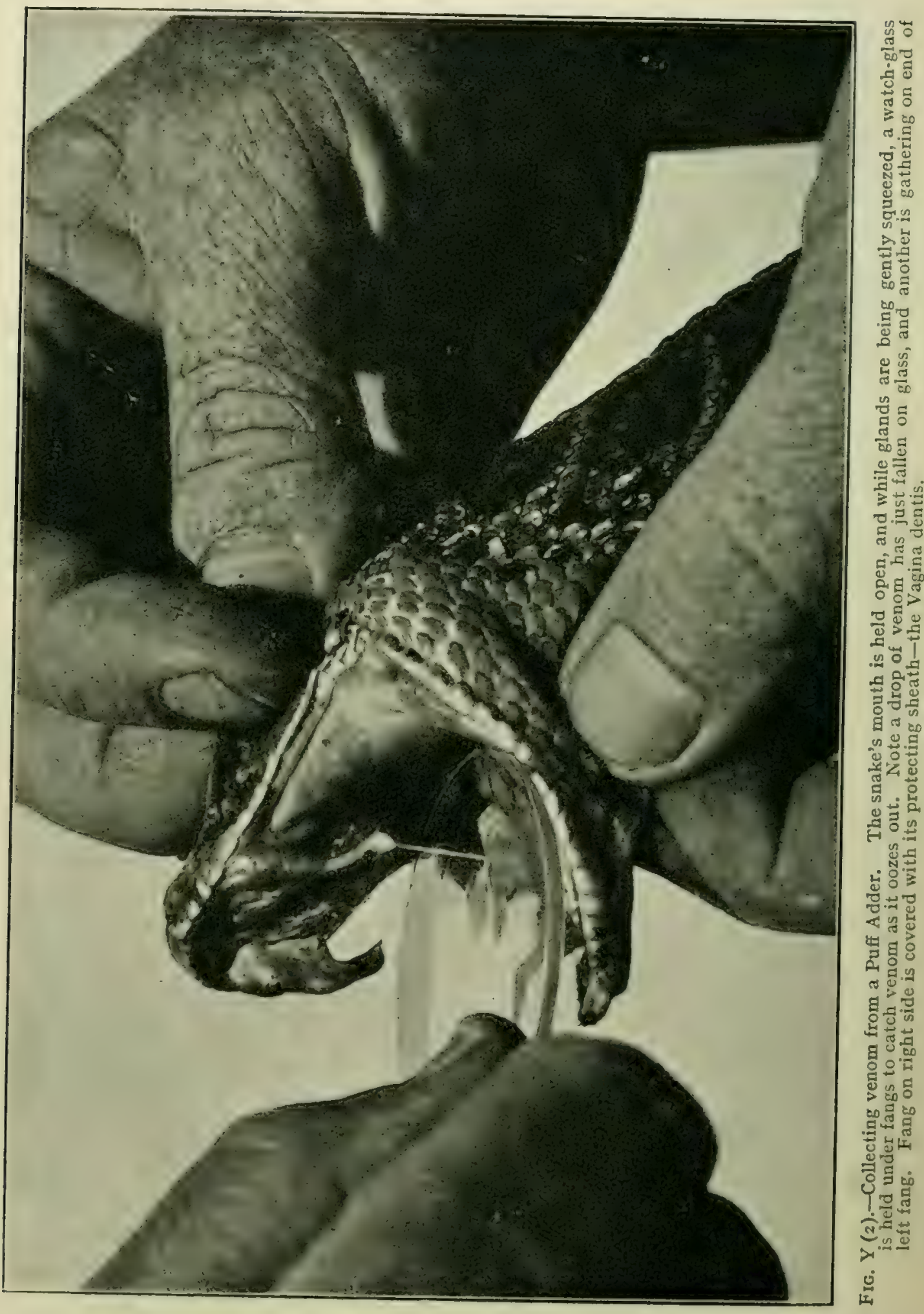


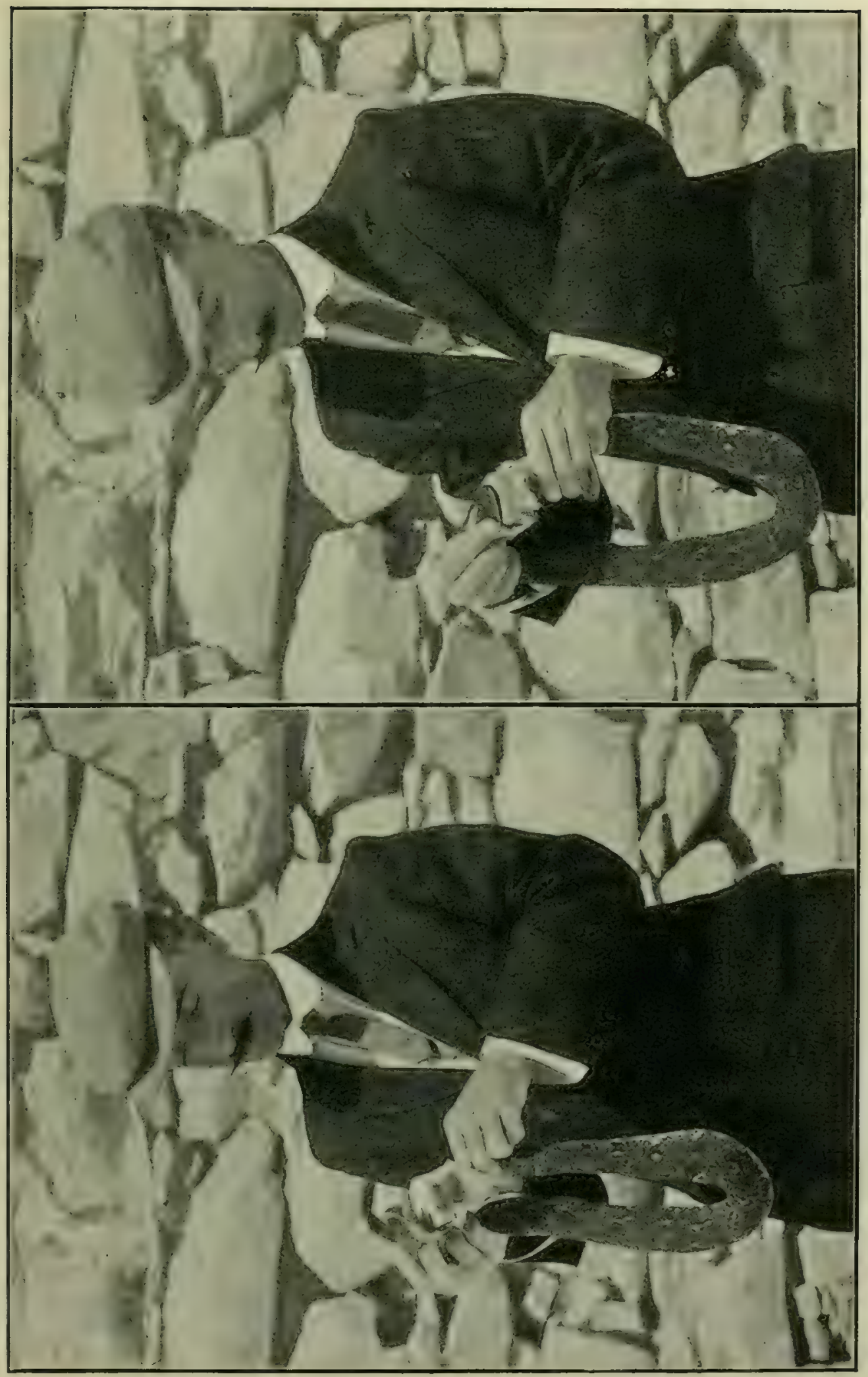

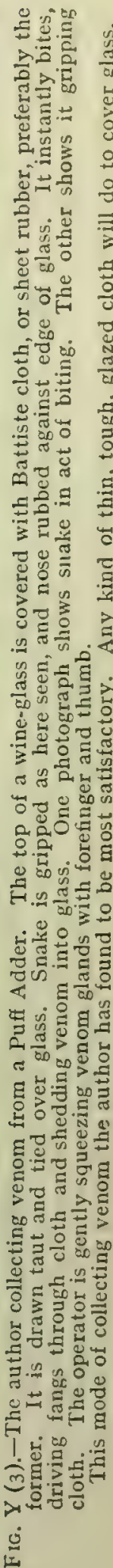




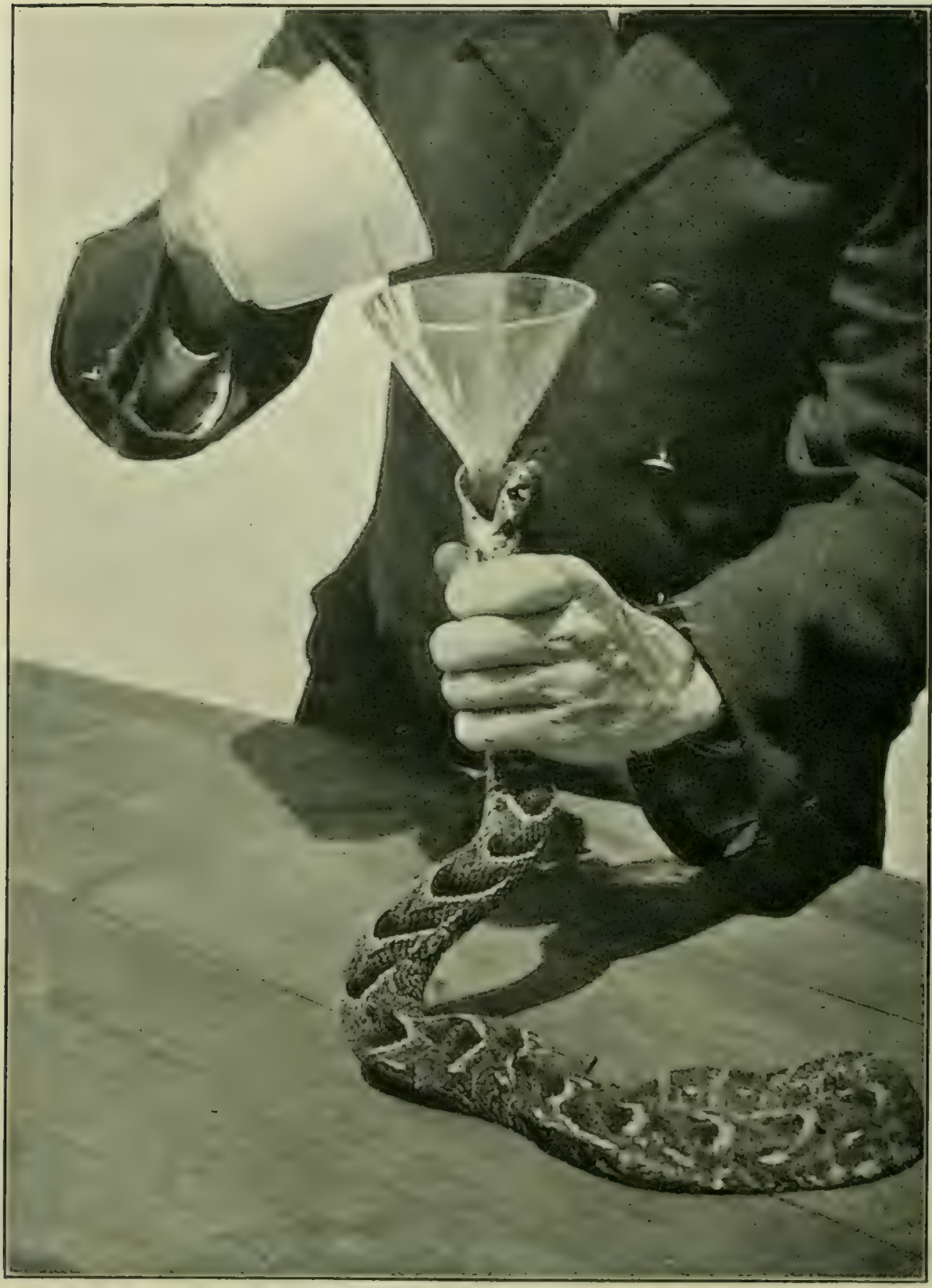

Fic. $Y(4)$. Feeding a Puff Adder. Insert the spout of a glass funnel gently into the gullet of the snake and slowly pour egg flip down his throat. MIcanwhile work the food down to the snake's stomach. Then withdraw the funnel and lay it gently down in a warm, quiet place, and leave it alone for a day or two. 'Two ounces once a week is sufficient for an average snake. 


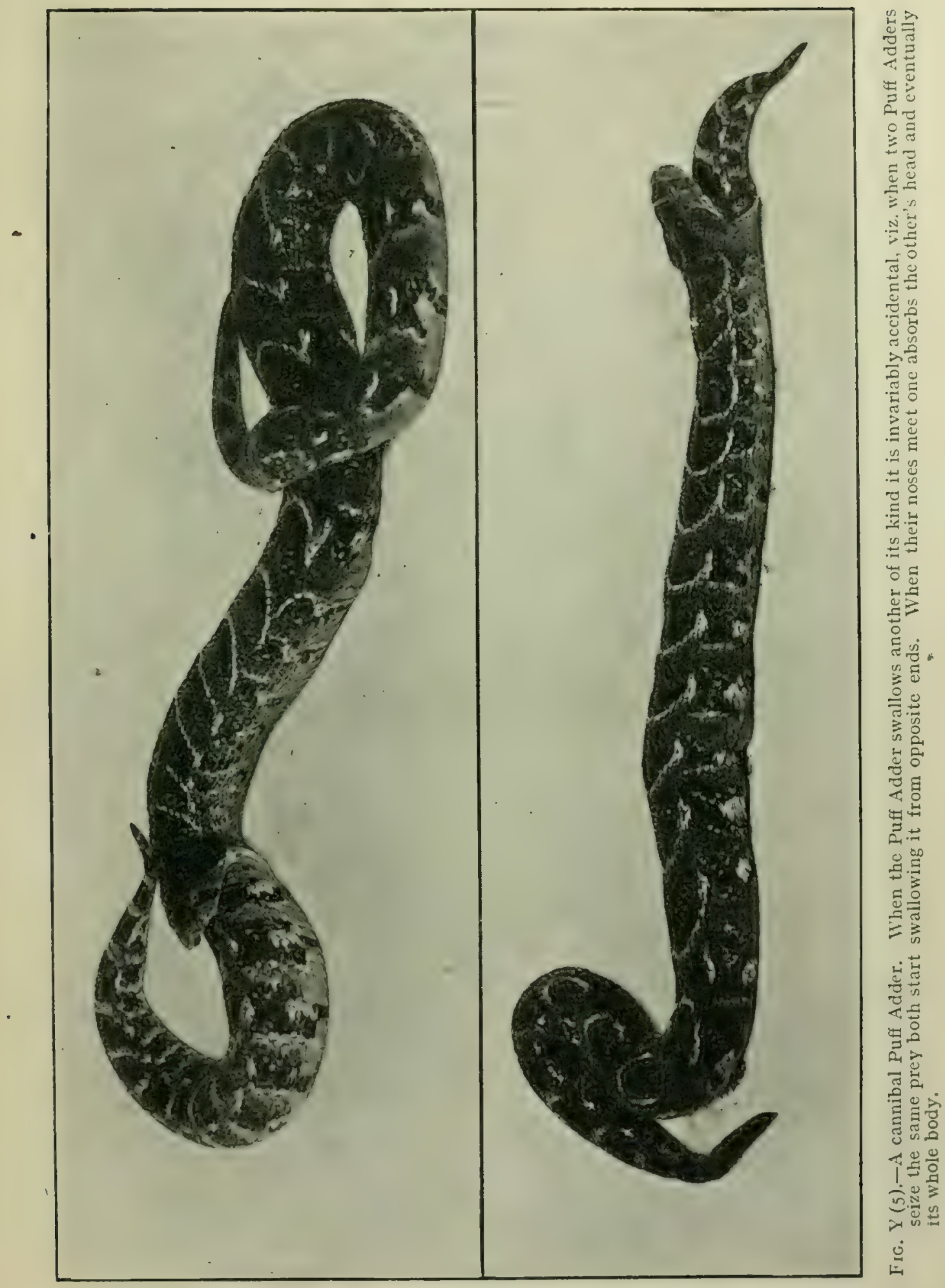




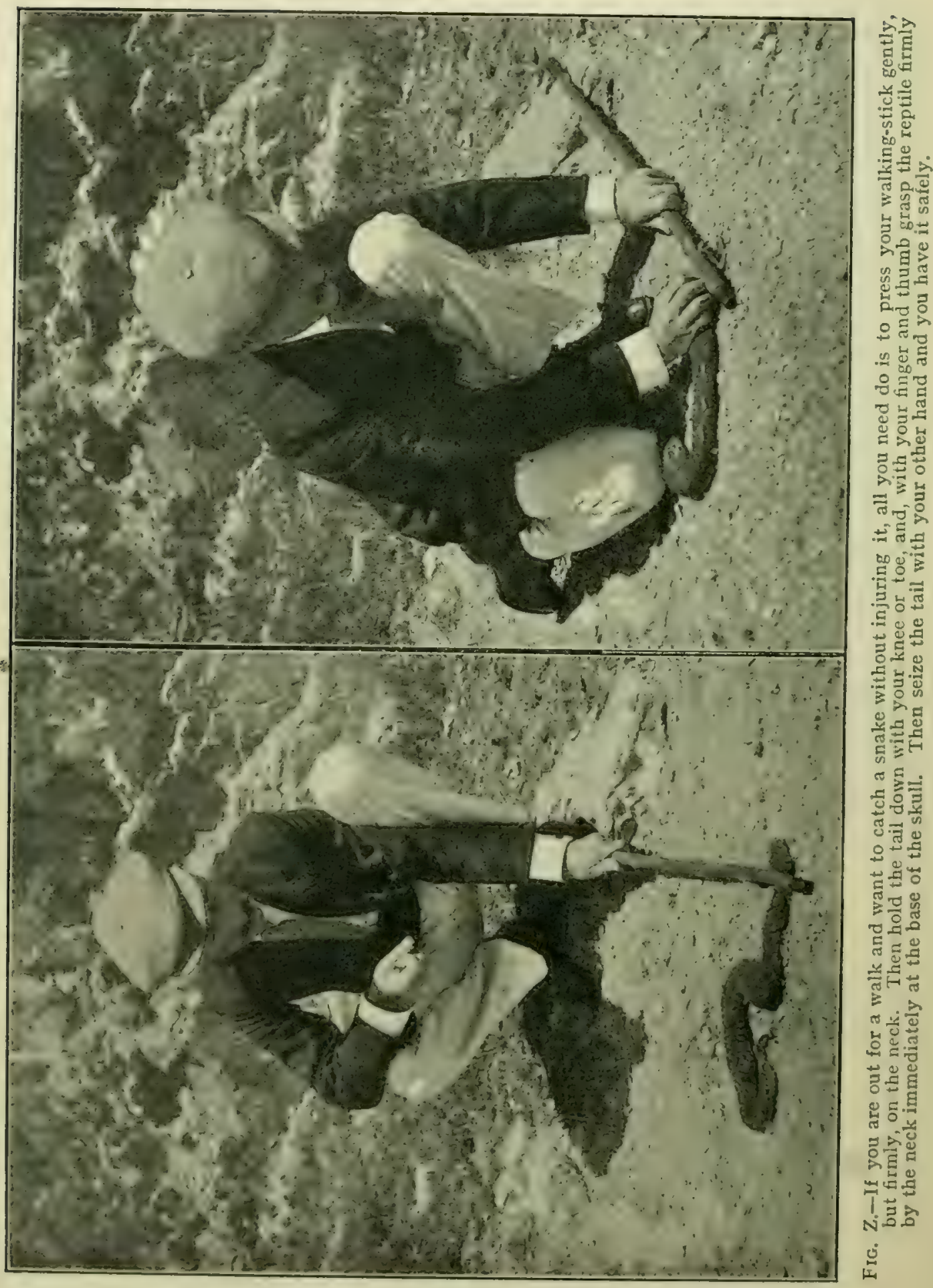




\section{FITZSIMONS}

\section{SNAKE BITE OUTFIT}

IN the interests of the Public, the author has patented an outfit called "FitzSimons' Snake Bite Outfit." His object in doing so is to safeguard the Public against future fraudulent preparations, and to ensure that they will get a complete and thoroughly efficient outfit, together . with a booklet of instructions carefully compiled and illustrated, of so simple a nature that the most inexperienced person may be able to treat cases of snake bite efficaciously.

In patenting this outfit the general Public are effectively guarded against imitations. In obtaining "FitzSimons' Snake Bite Outfit" they may be absolutely certain of getting the genuine Anti-venomous Serum, a Serum Syringe of right calibre, complete First-aid Outfit (specially designed and patented by the author), and an illustrated Booklet of Instructions for the treatment of the bites of every species of venomous snake in all the snake-infested countries of the world.

Wiite for particulars as to price, etc., to-

\section{Messrs. T. MASKEW MILLER}

Educational Publishers and Booksellers,

\section{6, Adderley Street, CAPETOWN, and Church Street, PRETORIA.}

This Firm has been appointed Sole Distributing Agents for the Outfit, and will be pleased to offer special terms to Chemists and Wholesale Dealers. 



\section{INDEX.}

A.

Ablabophis genus, 82

Adaptation of snakes to surroundings, $4 \mathrm{I}$

Adders, 2 I 3

Aglypha snakes, 80

Alcohol for snake bite, 325

Alleged cures for snake bite, 309

Amblyodipsas, 127

American snake catcher, 254

Ammonia cure, 332

Amplorhinus, 120

Anatomy of head of venomous snake, 25

Ancestors of birds, 4-8

Animal ladder of life, I5

Animals, how they are rendered immune, 39I

that eat snakes, 29

Anti-venene serum, 390

Anti-venomous serum, 397 instructions, 424

Aparallactus, I28

Apparently dead, hope of recovery, 432

Artificial respiration methods, 429$43 \mathrm{I}$

Aspidelaps, I65

Atractaspis adder, 220

vipers: habits of, 243

B.

Back-fanged snake, I 8

snakes, list of, II6-

Berg adder, 232 I 28

figure of, 240

another figure of, 242

habits of, 243

Bewitched snakes, 278

Bird that eats snakes, figure of, 339
Bitis, key to the species, 216

Black and yellow sea snake, I 56 fangs of, I 57

Blood, how it is made, 289

we poison it, 299

its circulation, 300

Boodon, 84

Boomslang, a cannibal, I 36

a man bitten, I4I, I 47

another man bitten, I 44

dissected, I 52

effects of being bitten, I 42

experiments, $\mathbf{I} 45$

that bit Williams, ${ }_{43}$

Boomslangs, a handful of, I 54 and their habits, ${ }_{4} 8$ are highly venomous, I $40, I_{4} 6$ just captured, I 49 the fangs of, $I_{4} I$ what naturalists say, I 38

Boulenger's systematic list of African snakes, 439-460

Brain and nervous system, 283

its functions, 284

the seat of intelligence, 285

of a man, 286

cells showing poison, 287

and the spinal cord, 288

Breathing apparatus, 20

Bruin slang, I 70

Brunton's first-aid instruments, 4 I I

Burrowing snakes, $5^{\circ}$

Bush snake, 97

C.

Calamelaps, 127

Cannibal boomslang, 264

cobras, 177 
Cape Cobra, I 70

$$
\text { figure of, } 463
$$

Captive snakes and birds, 260

Capturing a python, 63

Carbolic acid cure, 332

Catching live snakes, 268

Caustics, 33I

Causus, key to the species, 2 I 5

Centipede, 312

Chamætortus, I 20

Changing the skin, I6

Chlorophis, 86

Circulation of blood of snake, 24 the blood, 297

Classification of animal life, I what it means, 2

Climbing powers of snakes, 37

Cobra and meercat, I77

mungoose, 37 mungoose fight, I77

bites children, I 7 I

experiences, $I 72$

hood-expanding apparatus, 176

in a schoolroom, I80

on the watch, I79

poison apparatus, I 76

swallowing puff adder, $17^{8}$

venom symptoms, 367

yellow variety, I73

Cobras, dentition of, I 63

fed with other snakes, I 83

hoods, I74

key to the species, I6 3 synopsis of genera, 162 yellow variety, I 82

Collapse through fear, 394

Collecting snakes, 270 venom from cobra, 37I

Columbrine venom, 366

Constriction, 33

Coral snakes, I95

Cow-milking snakes, 265

Cross-marked snake, 122

Crust of the earth, 9

Curare and snake venom, 434

Cures for snake bite, 309

which kill, 330

\section{D.}

Dasypeltis, 90

Death from cobra bite, I8I

Death-head moth, 3 I 2

Demon adders, 233

Dendraspis, I 69
Desmond FitzSimons and his snakes, 26I

Digestive organs of a man, 290

Dipsademerphinæ, I I 5

synopsis of S. African genera, I 6

Disgorging prey, 36

Dispholidus, I27

Distribution of snakes, I2

Dried snake venom cure, 334

Duels with snakes, 27

E.

Ears of snakes, I 4

Eating, the science of, 294

Egg-breaking mechanism, $\mathrm{IO}_{4}$

Egg-eating snakes, $\mathrm{IO}_{2}$

eater at work, I05

dining, I Io

eater robbing a bird's nest, I08

eaters in captivity, I06

eater's sense of smell, II 2

swallowing process, Io6

Eggs of snakes, I 8

Eier vreter, IO2

Elapechis, I66

Elapinæ, 160

Elixir of life, 295

Enemies of snakes, 26

Evolution of birds, 3 reptiles, 3

Exciting incident, 279

Exercise, 302

Expanding power of snake's jaws, 35

Experiments, 309

with alcohol, 325

with anti-venomous serum, 4 I3

with artificial respiration, 436

with cobras, 378

with Crofts Tincture, 323

with Horniballs Patent Wonderful Extract, 328

with permanganate of potash, 382

with Sebiba or Zibiba, 3I5322

with snake venom, 340

Eyes of snakes, $r_{4}$

F.

Fangs of snakes, 23, 344

for comparison, 36 I

Puff Adders, 349 
Fascination, how it is done, 257 wrong conclusions, 258

Feeding animals on venom, 362 snakes on live animals, 280

Fibrin ferments, 356

File snakes, 96

FitzSimons" first aid instrument, $40 \mathrm{I}$ snake bite outfit, 395

Food converted into blood, 292 of snakes, 38

Formalin for pickling snakes, 274

Fowl Hesh cure for snake bite, 328

Fresh water snakes, 42

Front fanged snakes, I6o

G.

Gall of snake cure, 333

Garter snake, 195 snakes, 169

Geel slang, I 70

Geko lizard, 3I2

Glauconia snakes, 55 skulls of, 56

list of, 57

Grass snakes, I 30

Green water snakes, 92

H.

Habits of snakes, 45

Hæmorrhage into tissues, 369

Hæmorrhagins, 355 and mortification, 370

Hankered after his gall, 65

Harmless snakes, 8I, IO2

key to the species, $82-90$

list of, 82

Health laws, 292

Herald or Red-lipped snake, I34

Heroism of birds, 258

Hibernation of snakes, 43

Hissing, how it is done, 20

History and distribution of snakes, I 2

Homalosoma, 90

Homorelaps, 168

Honey ratel, 324

Hope of recovery for apparently drowned, 430

Horned adder, 2 I 5

figure of, $24^{\circ}$

habits of, 24I

head and neck of, 2 I 8

Horniballs Extract, 328

Horse-hair ropes, 265

House snake, adventure with, 93
House snake, bitten by, 94 swallowing rat, 93

House snakes, 92 pictures of, 95

How to catch live snakes, 25I collect venom, 37 I-373

become immune, 392

Human heart, 296 physiology, 283 pipes that carry air, 298 stomach, 295

Hydrophinæ, I 56

key to the species, $5_{5} 8$

Hydrus platurus, I $58-\mathrm{r} 59$

Hypersensibility, 393

Hypnotism, 262

I.

Identification of snakes, 49

Immunizing animals to snake venom, 39 I

Intestines, 29 I

Ipecachuana cure, 33I

K.

Kafir superstitions, 277

Knots, how to tie them, 405

L.

Lady with armful of snakes, 263

Lamprophis, 83

Lancet and permanganate combined, 4 OI

Legless lizards, 53

Leptodira, 120

Ligaturing the arm, 403

leg, 402

Liquor potassæ, 331

Living self-acting pump, 295

Lycophidium, 84

Lympathics, what they are, 303

that suck up venom, 306

Lymph, what it does, 303

M.

Macrelaps, 128

Mamba, I94
a kafir killed, 205
bit and killed a kafir, 208
distribution of, 2 I 2
do green ones turn black, 202 
Mamba farmer's extraordinary experience, 209

green variety, I99

how a dog protected its owner, 207

how he rushes, 2 I I

killed Mr. Claude Moller, 210

king of S. African snakes, 207

poison apparatus, 205

sleeping, 206

Mambas, black and green, I96 how and why they change colour, I98

their habits, 197

crested, 203-204

inflating body, 204

Meercats and snakes, 30

Methods of injecting serum, 408

Microbe eaters, 301

Microbes of disease, 293

Migration of snakes, 43

Mole snake, 98

and its young, IOI

and boy, 462

young specimen, 475

snakes and how to handle them, 275

and snake venom, 381

are harmless, Ioo

as pets, 275

constricting rats, $\mathrm{IO}_{3}$

heads of, 86

Muishond or Stink Cat, 28

Muishonds fighting snakes, 30

\section{N.}

Naia, 163

Nature's resistance, 369

Nerve cells and snake venom, 288

Nervous collapse, 394

Neurotoxins, 355

Night adder, 215

bit and killed a man 236

Night adder, habits of, 233

head of, 216

laying eggs, 235

venom of, 234

wonderful poison

Night adders, 232 glands of, 237

are oviparous, 239

hatching, I9
O.

Obsession, 278

Olive-brown water snake, 9I

Opisthoglypha, I I 5

Organs of the human body, 29 I

Outfit for treating snake bite, 395

Oviparous adder, 245

snakes, I9

Oxygen, what it does for the blood, 299

\section{P.}

Paralysis of respiratory nerve centres, 429

Paralyzed with fear, 260

Parasites on snakes, 44

Permanganate of potash treatment, 382

tested, 383

Phagosytes devouring microbes, 301

Philothalmus, 87

Poison apparatus, 343

and how it works, 353

fangs, 25

its elimination, 435

of snakes, 359

its effects on other snakes, 378

Poisonous snakes, 342

Poisons, how they are conveyed to the cells of the body, 302

Port Elizabeth snake catcher, $25^{\circ}$

Preserving snakes in spirit, 272

Progression of snakes, 2 I

Prosymna, 88

Proteroglypha, I56, 213

Psammophis, 122

Pseudaspis, 85

Puff adder and batch of young ones, $224,47 \mathrm{I}$

a modern Jonah, 227

dissection of, 219

eaten by red ants, 227

extracting its venom, $373-375$

head, and vagina dentis, $34^{6}$

how it strikes, $228,35^{\circ}$

of South Africa, 220

adder's fangs, 2I3, 22 I

adder swallowing a rat, 36 , $226,232,357$ 


\section{INDEX.}

Puff adder up a Dutchman's trouser leg, 229

adders, deaths by, 230

egg and young, 222

how they kill their prey, 225

how the young are born, 221

in captivity, 223

poison apparatus, 237

the sexes, 229

vary in colour, 229

Python, an adventure, $7 \mathrm{I}$

and buck, 74

and buck-hunting incident, 72

and his boy chum, 462

and his boy friend, 64

and Klip Dassie, 70

and the cock, 72

an exciting adventure, 69

a sensation, 65

constricting a buck, 66

figure and skeleton of, 59

head of, 58

smashing crockery, 77

steak, 79

swallowing a bird, 73

Pythonadipsas, II9

Pythons, 57

and kafir superstitions, 65

Pythons' eggs, 70

artificial feeding, 75

Pythons' fasting powers, 78

legs, 78

in Cape Colony, 79

on a krantz, 67

on the watch, 63

their haunts and diet, 60

R.

Red-lipped or Herald snake, I34

Reptiles living and extinct, Io

Rhachiodontinæ, 90

Rhampiophis, I2I

Ringhals, I 75

experiments with, 378

cobra, 183

and young, 184,193

bespattered glass with venom, I 88

consequences of being bitten, IOI

effect of the venom upon the eyes, I9o
Ringhals, experiments with the venom, I9o

fierce and aggressive, 187

how one was captured, I 85

how they spit, I89

how to hold it, 192

how we photographed him, I 86

Roode-lip slang, I 34

Royal Python of Senegambia, 28 I

\section{S.}

Salivary glands and teeth, 290

Salt-water snakes, 43, I57

Sand snakes, I24

Scarifying, how to do it, $4 \mathrm{O}_{4}$

Schaapsteker, a battle, I 32

Schaapstekers, I30

and eggs, I3 I

Scorpions, 326

Sebiba cure, 3 I 5

Secondary treatment of snake-bite, 426

Sense of smell, 20

Sepedon, I65

Serum, and how to get it, 395

FitzSimons' outfit, 408

how to inject it into arm, 406

into leg, 409

into vein, 419

instructions in brief, 424

its effects, 396

therapeutics, $42 \mathrm{I}$

treatment and its imitations, 399

treatment of animals, 4I3

treatment of snake bite, 390

Shield snake, I95

Shields on snakes' heads, $4^{8}$

Simocephalus, 85

Smelling out a man, 65

Snake blood and gall cure, 336

catcher at work, 25I

charmers, 246 at work, 248

charming explained, 249

eating bird, 339

houses, 47

knowledge in brief, $46 \mathrm{I}$

stones, 336

venom, 352

effect if swallowed, $33^{8}$ 
Snake venom, how it is sucked up, $30_{4}$
how to collect it,
372
its nature and effects,

Snake-killing Tom cat, 3I

Snakes and people, 473

and lizards, I 3

and their mates, 266

can they fascinate their prey, 256

changing their skin, I 6

eating eggs, 32

hatching, 463

how to capture them, 268269

how to collect and preserve them, $27^{\circ}$

how to feed them, 27 I

how to pickle them, 276

how to stuff them, 276

in captivity, 282

in houses, 34

not tenacious of life, 47

sucking eggs, 33

swallowing their prey, 39

their uses, 25

Solenoglypha, 2 I 3

Solid toothed snakes, 80

Special first aid instrument, $40 \mathrm{O}$

Spirits of ancestors in snakes, 279

Spuug slang, I 70

Stockholm tar cure, 328

Strychnine cure, 332

Surroundings of snakes, 43

Symptoms of cobra venom poisoning, 367

Symptoms of viper venom poisoning, 369-370

Systematic list of S. African snakes, $439-460$

\section{'T.}

Tanjore pills, quinine, etc., cure, 333

Tarbophis, I I 9

Teeth of snakes, 22, 344

Thelotornis, I26

Three-cornered snakes, 96

Tongues of snakes, 14,361

Treatment of snake bite, 400 secondary, 426
Trimerorhinus, I2 I

Tropidonotus, 82

Typhlops snakes, 5I heads and tails, 54

list of species, 52

skulls, 5I

\section{V.}

Vagina dentis, 346

Venom, Colubrine, 366

different kinds, 366

effects on non-venomous snakes, 380

effects on other snakes, 377 how it gets in and out of the blood, 307

how it is absorbed, 388

how it is discharged, $34^{8}$

how it poisons the nerve cells, 288

how to destroy it, 305

is digested, 364

its constituents, 355

Viperine, 368

Venomous snakes and their poisons, 342
distribution of,
I $6 \mathrm{I}$
synopsis of genera, 162

Venoms differ in their pathological action, 392

Vinegar cure, 333

Viperidæ, $2 I_{3}$

Vipers, synopsis of genera, $2 I_{4}$ their distribution, 214

Viviparous snakes, 19

W.

What to do if bitten, 400

Whip snake, I24

Why people recover when bitten by snakes, 394

Williams, the snake catcher, 252 with bag of snakes, 255

Williams with captive snakes, 253

\section{Z.}

Zibiba cure, 3 I5

Zwart Ringhals, 185 slang, 98 


\section{INDEX TO ADDENDA.}

A.

Anaphylaxis, 497

Ammonia as an antidote for snake bite, 504

experiments with, 504

B.

Boomslang, bitten by a, 490

E.

Experiments with venoms at Government Research Laboratory, Pretoria, 48 I

surprising results of, $4^{81}$

F.

Fangs of snakes, why they differ, 506

First aid treatment, 500

M.

Mamba, young farmer's fatal bite from Mamba, 494

N.

Normal salt solution, 502

P.

Puff Adder, venom injection under the skin, 507 venom injection into the muscles, 509

Ringhals simulates death, 488

R.

spat in a man's face, 489

bitten by a, 489

bite treated with normal salt solution, 489 
S.

Schaapstekers, venom experiments, 486

highly venomous, 486

startling results of experiments, 486

comparatively harmless, 487

Snakes in Madagascar and Australia, 492

Snake knowledge in brief, 5 Io

Serum sickness, 497

Intravenous versus Subcutaneous injection, 500

Saline solution as an emergency measure, 502

T.

Treatment of snake bite, 502 


\section{INDEX TO ILLUSTRATIONS.}

[N.B.-For list of illustrations in Addenda, see p.xv.]

A.

Animal ladder of life . . . . . . : . . . I5

Animals that eat snakes . . . . . . . . 29

Applying the test to a snake-a kafir superstition . . . 277

Artificial respiration . . . . . . . 430-43I

Atractaspis adder and skulls of . . . . . . 245

B.

Berg adder . . . . . . . . . 232

" • • • • • • . . 242

Bird that eats snakes-Jackal Buzzard . . . . . 339

Brain of man in section . . . . . . . . 285

". showing grey matter . . . . . . 286

" cells . . . . . . . . 287

„, and spinal cord . . . . . . 288

Boomslang-dissection of, showing eggs in situ . . . . I5I

Boomslang swallowing another . . . . . . I37, 263

Boomslangs - a handful of . . . . . . . . I53

Boomslangs-how to hold them . . . . . . . I49

Bronchial tubes . . . . . . . . . 298

Brown House snake . . . . . . . . . 93

Brunton's lancet . . . . . . . . . 4 OI

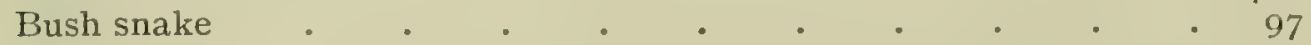

C.

Cannibal Boomslang . . . . . . . . . 263

Cast skin of a snake . . . . . . . . . . 16

Casting its skin-Boomslang in process of . . $\quad . \quad . \quad$ I7

Centipede . . . . . . . 3I2

Chart showing snake distribution . . . . . . I6I

Circulation of the blood . . . . . . . 300

Cobra, Cape species, yellow variety . . . . . I73,465

. 175

- I 75

- 176

," dissection of neck black variety

," swallowing a Puff adder

", Cape species

Collecting venom from Cobra

- $\quad 178$

- 182

- $37 \mathrm{I}$

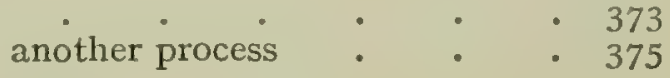


PAGE

Coral snake.$\quad \cdot$ I66, I95

". . head and neck of . . . . . . Ib)

Cross-marked snake (Psammophis) . . . . . . . . 122

D.

Death Head moth . • . . . . . . . 3I2

Dentition and fangs of snakes . . . . . 23, 34t

Diagram showing how venom is absorbed by the blood and lymphatics $3^{\circ} 4$

Digestive apparatus of man . . . . . . 290

E.

Egg-eater snake (Dasypeltis) . . . . . . . 105

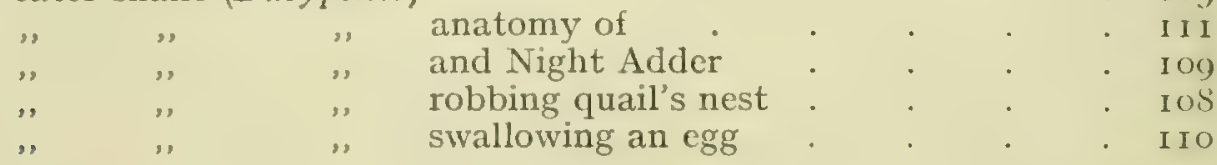

F.

Family group and some tame snakes . . . . . . 473

Family group and their snake pets . . . . . . 275

Fangs and venom glands of snakes . . . . . . . 353

Feeding a snake . . . . . . . . . 27 I

File snake . . . . . . . . . . 97

Flying reptilc-reconstruction of . . . . . . . 7,8

Flying reptiles . • . . . 4

Fossil remains of a lizard-tailed bird in a rock . . . . $\quad 5$

G.

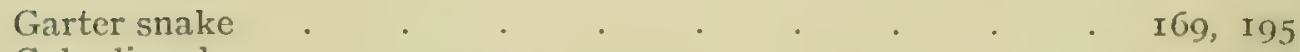

Geko lizard . . . . . . . 3I2

Glass bespattered with Ringhals venom . . . . . I 88

Glauconia snake . . . . . . . . . . 53

Green water snake . . . . . . . . . . . . So

H.

Heart of man

Honey Ratel

Horned adder

House snakes

adders' heads.

How to catch snakes

How venom spreads out under the skin

I.

Ideal landscape of Carboniferous period 
K.

Inots-how to tie them 405

L.

Lady with handful of snakes Legless lizard

Leucosytes

Ligaturing leg

Lungs of man arm.

Lymphatics of the human arm

$$
\begin{array}{rr}
\cdot \quad 262 \\
\cdot \quad 53 \\
401 \\
402,404 \\
403,407 \\
\therefore \quad 298 \\
\cdot \quad 306
\end{array}
$$

M.

Mamba-green variety head and fangs of

Method of progression of a snake .

Microbes and disease

Mole snake-young

, snakes

$$
\begin{array}{lll}
, & \text { snakes } \\
, & \text { " } & \text { and boy } \\
\text { " } & \text { heads of }
\end{array}
$$

N.

Nervous 'system .

Night Adders hatching

", adder

", adders

" adder-dissection of poison glands

,, adders and eggs

Noosing a snake

O.

Olive-brown water snake

Osmosis-to explain how venom passes into the blood

P.

Pet snakes and boy

Phagosytes

Poison apparatus of snake

of Puff Adder, Cape Cobra, and Boomslangs

Psammophis genus of snakes-(cross-marked snakes)

Puff adder-fangs of

$\begin{array}{ll}\text { " } & \text { head of } \\ \text { dissection of } & \text { eggs and young of } \\ \text { ", } & \text { and batch of young } \\ \text { ", } & \text { swallowing a rat } \\ \text { ", how it bites } & \text { how it strikes }\end{array}$


Puff adder-the sexes . . . . . . . 230

" swallowing prey . . . . . . 232

" dissection of poison glands and fangs . . . . 237

collecting venom of
Puff adders and Mole snakes

", adder and her young . . . . . . . . 47 I

" , after swallowing a rat . . . . . . 477

Python-head of . . . . . . . . 58

and its skeleton . . . . . . . . . . 59

, in its native habitat . . . . . OI

". and a boy . . . . . . . . . 64

" constricting a buck . . . . . . . 60

" on a krantz. . . . . . . 07

" about to swallow a Klip Dassie . . . . . . 70

,, swallowing a bird . . . . . . . . 73

" - -feeding one in captivity . . . . . . 70

, Claws and rudimentary legs . . . . . . . 58

, Regius . . . . . . 28

", after swallowing a pig . . . . . . . 329

R.

Relative lengths of Epochs . $\quad$. . . . . . 9

Ringhals cobra $\quad . \quad$. . . . . . . I75

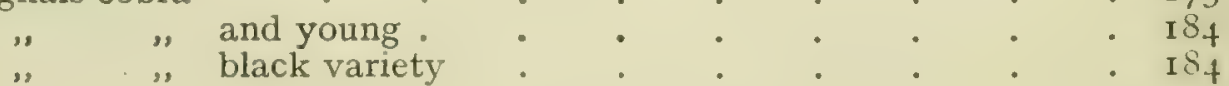

S.

Sand Snake (Psammophis) . . . . . . . . I2t

Schaapstekers . . . . . . . . I 29

Scorpions and eggs . . . . . . . . I 3 I

Sea snake (Hydrus platurus)-head of ${ }^{\circ} \cdot{ }^{\circ} \cdot{ }^{\circ} \cdot{ }^{\circ} \cdot 320$

dentition of $\quad \cdot \quad \cdot \quad \cdot \quad \cdot \quad \cdot \quad$ I 57

figure of . . . . . . . . $\quad$ r 59

Section of human skin, and how venom is driven in skin. . . 388

Serum injection into arm . . . . . . . . 409

" . . . . . . . . . . + t 10

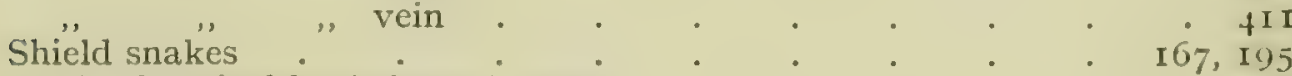

Skull of typical back-fanged snake : . . . . IIS

Skulls of front-fanged snakes . . . . . . . . I03

" of non-venomous and venomous snakes . . . . 344

". of Typhlops snakes . . . . . . . 5 I

", of Glauconia snakes . . . . . . . . $55^{\circ}$

, and dentition of non-venomous snakes . . . . . S I

Snake casting its skin

Snakes' eggs

". in act of swallowing their prey.

"heads for comparison

Snakes-how to hold them.

Snake-like lizard

Snake pets

Stomach of man

Study plate of snakes' heads 
T.

Typhlops Snake (blind burrowing snake) . . . . . 53, 55

PAGE

,

, arrangement of scales

V.

Veins and arteries

Ventrals, anals and sub-caudals of a snake

W.

Water snakes, olive brown . . . . . . . . . . 9 I

Whip snake . . . . . . . . . I24

White corpuscles of the blood . . . . . . 30I

Williams, the snake catcher . . . . . . . 25I

" holding some venomous snakes . . . . . 253

" and the results of a day's collecting . . . . 255

Y.

Young snakes hatching . . . . . . . . . 463 


\section{Interesting African Literature}

Fauna of South Africa. Edited by W. L. Sclater.

Birds-Vols. I, II, III, £4 IOs.; Vol. IV, f2 2s.

Mammals - Two Vols., \&2 2 s.

South African Zoology. A Textbook for the use of Students, Teachers, etc, in South Africa. By DR, J. GilcriRIsT. Illustrated. I0s. 6 d. net.

Causal Geology. By E. L. Schivarz. Illustrated. 9s.

Geology of South Africa. By R. H. HATCH AND DR. CoRstorinine. Illustrated. 25 .

Geology of Cape Colony. By A. W. Roger AND A. DU ToIT. IIs.

The Study of Agricultural Soils of Cape Colony. By DR. C. F. JURITz. $7 s, 6$. net.

Sketches of South African Bird Life. By HAAGNER AND Iry. Illustrated from Photos. 24s.

Stone Implements of South Africa. By J. P. Johnson. Illustrated. Ios.

African Mimetic Buttenflies. "Being descriptions of well-known instances of Mimetic Resemblance." By H. ELTRIngham. With Coloured Plates and Map. £3.

Flona Capensis. "A Systematic Description of Plants of Cape Colony," etc. By W. H. Harvey and O. W. Sonder.

Volumes now ready-I, II, III, $£ 3$ Ios.; IV (Section I), $\delta 33$ s.; IV (Section 2), £I II $s .6 d$ 。; VI, £I IIs. 6d.; VII, £2 $2 s$.

The Orchids of South Africa. By H. BoLus. Illustrated. Two Vols, $£_{2}$ ros. net.

The Naturalist in the Transvaal. By IV. L. DisTANT. Illustrated. $£ I$.

Mineral Industry of Rhodesia. By J. P. Jornson. Ios.

The Monkey Folk of South Africa. By F. W. FitzSmons. $6 s$.

The Native Races of South Africa. By G. IV. STowe. With Illustrations. Edited by Dr. G. M. Theal. £I $5^{\text {s. }}$

Bantu Folk=lore. "Medical and General." By Dr. M. L. Hewat. 6s.

Physical Geography for South African Schools. By ALEX. L. DU TOIT Illustrated. 5 .

We specialise in African Literature, and hold the Largest Stocks in the Sub-Continent of Old and Kare Items dealing with this Conntry.

Any Books not in stock sought after and reported on free of charge.

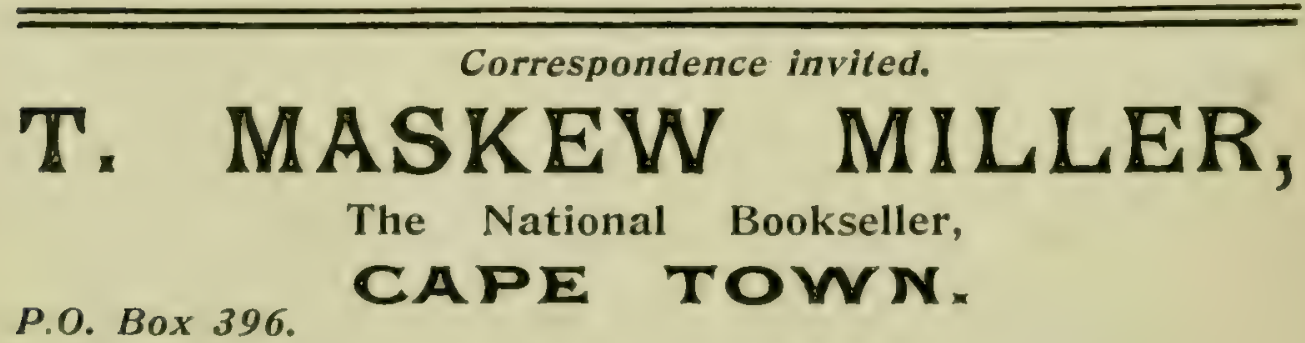






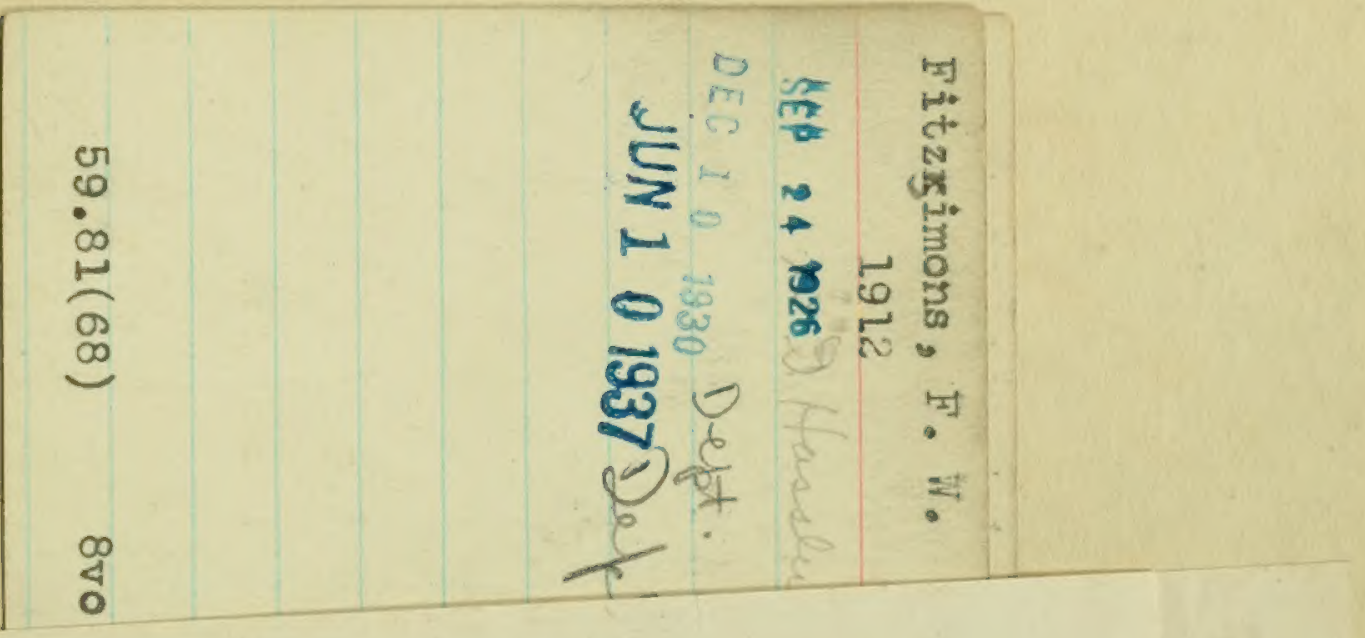


